\title{
Integrated Pest Management
}

Travis Tyrrell Seed Orchard Lorane, Lane County, Oregon

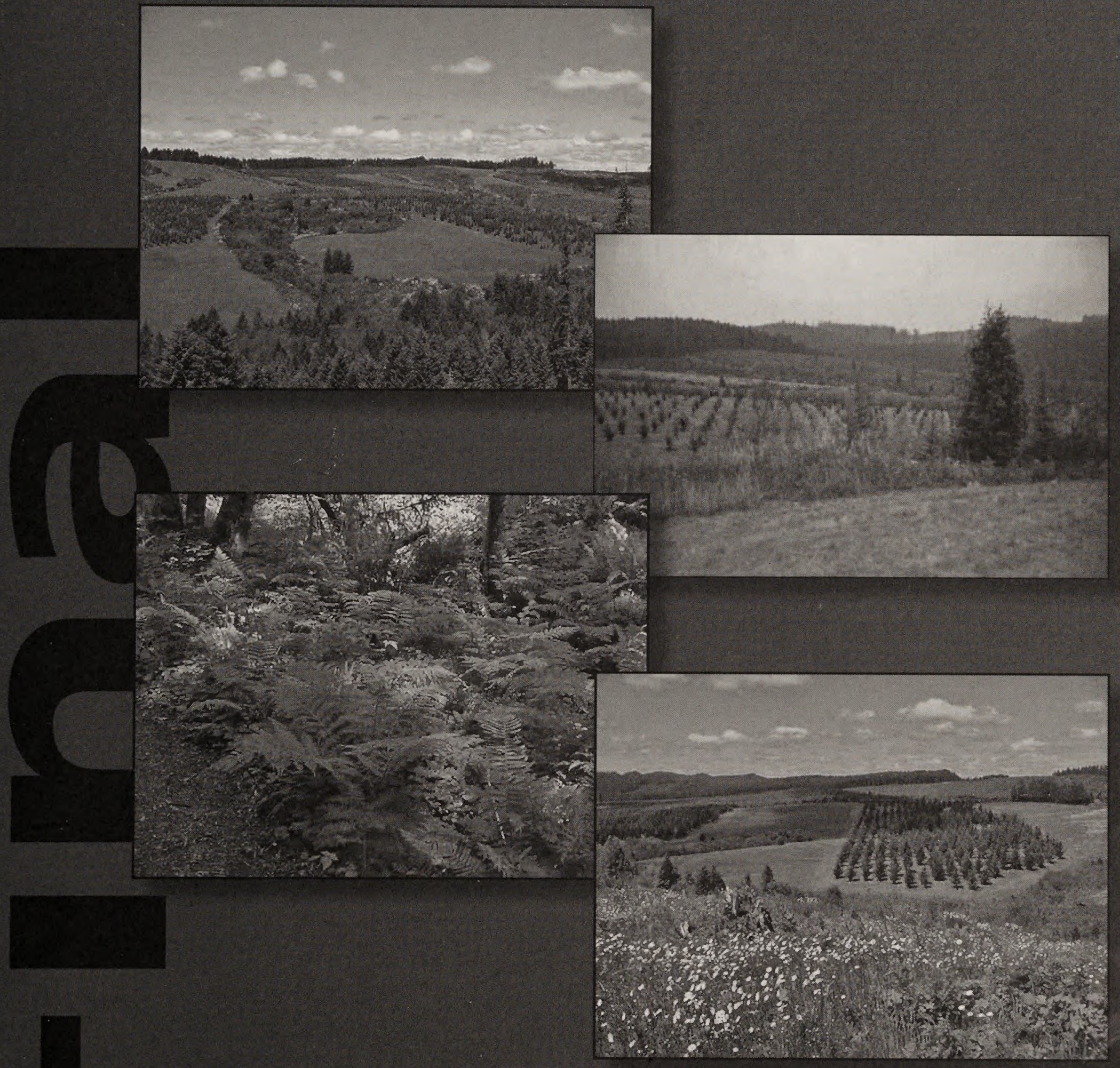


As the Nation's principal conservation agency, the Department of the Interior has responsibility for most of our nationally owned public lands and natural resources. This includes fostering the wisest use of our land and water resources, protecting our fish and wildlife, preserving the environmental and cultural values of our national parks and historical places, and providing for the enjoyment of life through outdoor recreation. The department assesses our energy and mineral resources and works to assure that their development is in the best interest of all our people. The Department also has a major responsibility for American Indian reservation communities and for people who live in Island Territories under U.S. administration.

BLM/OR/WA/PL-04/014+1792

\section{Photographs on Cover:}

Orchard units in Section 9

Orchard units South Umpqua 3 and 4

Vegetation along forest succession interpretive trail

Wells Creek orchard unit 


\title{
United States Department of the Interior
}

\author{
BUREAU OF LAND MANAGEMENT \\ Eugene District Office \\ P.O. Box 10226 \\ Eugene, Oregon 97440-2226
}

IN REPLY REFER TO:

\section{Dear Reader:}

Attached is the final environmental impact statement (EIS) for a proposed integrated pest management (IPM) program at BLM's Travis Tyrrell Seed Orchard, located in Lorane, Oregon, in Lane County. The proposed IPM program will manage the insect, weed, animal, and disease problems at Tyrrell, and maintain healthy, vigorous crop trees and other plants for the production of seed and other vegetative materials, which are used primarily for reforestation and a variety of land management activities. This EIS analyzes the potential impacts of the proposed action and alternatives, and will be used in the development of the IPM program at Tyrrell.

The National Environmental Policy Act requires BLM to assess the potential environmental impacts of the proposed action and alternatives, and to involve the public in its decision-making process. In accordance with Executive Order 12372, Intergovernmental Review of Federal Programs, BLM requested input from other Federal, state, and local agencies and from the public on the Draft EIS, which was published in June 2003, as announced in the Federal Register [68(124):38324] on June 27, 2003. BLM received two verbal comments at the public meetings and three comment letters on the Draft EIS, which are addressed in this Final EIS.

The Environmental Protection Agency (EPA) will publish a notice of the availability of this Final EIS in the Federal Register. Following the 30-day availability period that begins with publication of EPA's Federal Register notice, BLM will issue a Record of Decision (ROD) announcing selection of the alternative to be implemented. Any comments you wish to submit during this 30-day availability period should be mailed, faxed, or e-mailed directly to:

\author{
Mr. Glenn Miller, Manager \\ Tyrrell Seed Orchard \\ P. O. Box 121 (Overnight delivery: 26350 Siuslaw River Road) \\ Lorane, OR 97451 \\ Fax: (541) 683-6597 \\ E-mail: OR_Eugene_TSOEIS@or.blm.gov
}

This forest management decision may be protested under 43 CFR 5003 - Administrative Remedies. In accordance with 43 CFR 5003.2, the decision for this project will not be subject to protest until the notice of availability of the ROD is first published in the newspaper, approximately 30 days after the notice of availability of this Final EIS. Protests of the decision must be filed with this office within 15 days after newspaper publication of the notice of availability of the ROD. If no protest is received by the close of business (4:15 p.m. Pacific Standard Time) on the $15^{\text {th }}$ day, the decision will become final. If a timely protest is received, the decision will be reconsidered in light of the protest and other pertinent information available in accordance with 43 CFR 5003.3.

Sincerely,

Mark Buckbee, Acting District Manager, Eugene District 



\section{Final Environmental Impact Statement: Integrated Pest Management Program BLM Travis Tyrrell Seed Orchard Lorane, Lane County, Oregon}

Agency: Bureau of Land Management

Tyrrell Seed Orchard

P. O. Box 121 (Overnight delivery: 26350 Siuslaw River Road)

Lorane, OR 97451

E-mail: OR_Eugene_TSOEIS@or.blm.gov

Fax: (541) 683-6597

For Further

Information

Contact:

Designation:
Mr. Glenn Miller, Manager

Tyrrell Seed Orchard

P. O. Box 121 (Overnight delivery: 26350 Siuslaw River Road)

Lorane, OR 97451

Telephone: (541) 683-6445

Email: OR_Eugene_TSOEIS@or.blm.gov

Final Environmental Impact Statement (EIS)

\section{Privacy Advisory}

Any comments on this Final EIS are requested by 30 days after the notice of availability is published. In accordance with the Privacy Act, individuals (but not organizations and businesses) may request their name be withheld from public review by stating this request at the beginning of their letter. 


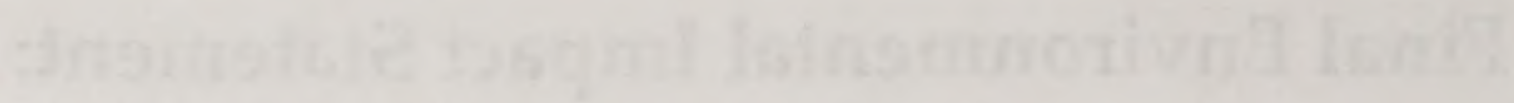

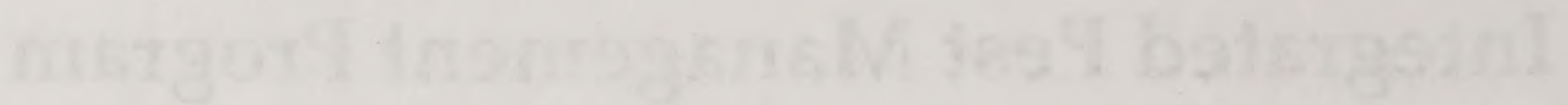

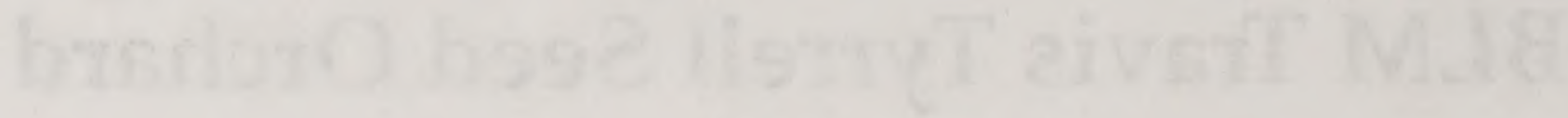

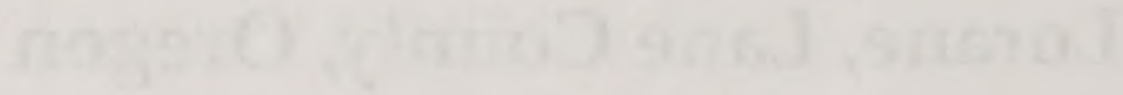


The Bureau of Land Management (BLM) is proposing to implement an integrated pest management (IPM) program at Travis Tyrrell Seed Orchard. In compliance with the National Environmental Policy Act (NEPA) of 1969, BLM has prepared this environmental impact statement (EIS), which assesses four action alternatives and the no action alternative:

- Alternative A-Maximum Production IPM. Pests would be managed using all identified biological, chemical, prescribed fire, cultural, and other pest control methods, including aerial esfenvalerate, Bacillus thuringiensis, and fertilizer application by helicopter.

- Alternative B-IPM with Environmental Protection Emphasis (Proposed Action). Pests would be managed using all of the methods in Alternative A, with limitations designed to protect worker health and safety and the environment. The limitations are based on the conclusions of a recent risk assessment, scoping comments, and recommendations from BLM interdisciplinary team members.

- Alternative C-Ground-Based IPM. This alternative is identical to Alternative B except for the exclusion of helicopter applications.

- Alternative D-Non-Pesticide Pest Management. Pests would be managed using only the non-pesticide biological, prescribed fire, cultural, and other methods listed under Alternative A. No biological or chemical pesticide methods would be permitted.

- Alternative E-No Action: Continuation of Current Management Approach. The current management system uses all non-chemical-pesticide pest control practices at the seed orchard, as well as chemical pesticides on a case-by-case basis. All biological, prescribed fire, cultural, and other methods would be used in accordance with current procedures. When a specific need is identified for a chemical pesticide, the action would be reviewed to determine whether it is encompassed by an existing NEPA document, or whether an environmental assessment or EIS is required.

Alternative $B$, the proposed action, is the preferred alternative of BLM.

Resources analyzed in the EIS include air quality, geology, water, land use, human health and safety, biological resources, noise, cultural resources, and socioeconomics and environmental justice. The EIS also assesses the potential cumulative effects of implementing the IPM program along with other actions occurring concurrently at Tyrrell and in the surrounding area. The recently conducted risk assessment is included in the supporting record for this EIS and summarized in an appendix. 


\section{Changes in Proposed Action from Draft EIS to Final EIS}

- Use of the biological insecticide B.t. was removed from Alternative D, which was renamed "Non-Pesticide Pest Management."

- Imidacloprid, as a capsule implant, was added to the list of potential insecticides.

- The terms and conditions specified by NOAA Fisheries during Endangered Species Act consultation have been added to the list of limitations (Section 2.3.3) that are inherent to Alternative $B$, the proposed action.

- The monitoring plan (Appendix B) has been revised for consistency with the terms and conditions specified by NOAA Fisheries.

- Throughout the EIS, the Endangered Species Act status of Oregon coast coho salmon has been revised from "threatened" to "proposed for listing as threatened", in accordance with changes in the species' status since publication of the Draft EIS; see Section 3.7.3 for background on this change. 


\section{Executive Summary}

The U.S. Bureau of Land Management (BLM) proposes to implement an integrated pest management (IPM) program at the Travis Tyrrell Seed Orchard in Lane County, Oregon. Tyrrell is located within BLM's Eugene District. In accordance with the National Environmental Policy Act (NEPA) of 1969, as amended, which requires Federal agencies to consider environmental consequences in their decision-making process, this environmental impact statement (EIS) identifies potential environmental impacts from each alternative considered. This EIS must be prepared before BLM makes final decisions regarding the selection of an alternative, and be available to inform decision makers and the public of potential environmental consequences of the proposed action or an alternative. Distribution and review of the Draft EIS in June 2003 allowed for public consideration and input concerning the proposed IPM program. After carefully considering comments on the Draft EIS, BLM has made minor changes to the document and is now issuing this Final EIS. After a 30-day availability period for the Final EIS, BLM will publicly state which action will be implemented in a formal document called a Record of Decision (ROD). Subsequent IPM activities will be implemented over the life of the IPM plan (usually 15 to 20 years) in accordance with that decision.

BLM will use the analyses presented in this EIS to decide how to continue operations at Tyrrell in a manner consistent with human health and safety considerations and existing environmental protection laws, while maintaining adequate seed and seedling production. Maintaining adequate production includes the implementation of an IPM approach to manage vegetation, insects, disease, and animal pests at the seed orchard. The ROD to be issued on the basis of this EIS, by the BLM Eugene District Manager, will identify the specific control methods available for use at Tyrrell for controlling insects, disease, vegetation, and animal pests. No further NEPA documentation relating to IPM should be required before pest management projects are undertaken, unless the seed orchard manager proposes a new IPM product or technology that was not analyzed in this EIS.

\section{Purpose and Need for Action}

The purpose of the action is to manage competing and unwanted vegetation, diseases, insects, and animals at Tyrrell. Management of adverse impacts from pests is necessary to allow the seed orchard to produce improved seed for conifer seedling production, preserve valuable individual conifer trees, and produce native species plants and seed (including grass, forb, and brush). This high-quality seed is supplied to BLM and other cooperators for reforestation and restoration projects.

For many years, Tyrrell has managed pests with very limited use of chemicals: lindane was applied from 1989 to 1998 to younger trees to control coneworm (Dioryctria) in Douglas-fir graft unions, bark scores, and partial girdle stimulation cuts. Under projectspecific environmental assessments (EA's), esfenvalerate was used in 2003 (29 acres) and 2005 (58 acres) to control cone and seed insects. Imidacloprid was used in 2004 (60 acres) to control Douglas-fir gall midge. Each use in the orchard has required preparation of a separate NEPA document or the presence of a categorical exclusion. Changes and experience with control methods at the orchard have created the need to re-evaluate the pest management program to ensure that the pest management objectives at Tyrrell continue to be met. In addition, the public demand for efficient use of resources in government, as well as for providing appropriate environmental protection, requires the 
selection and use of the best pest management techniques for efficient and cost-effective orchard operation over the long term. The pest management objectives at Tyrrell include the following:

- Minimize insect damage to orchard trees, cone crops, and native plants.

- Remove noxious weeds and control vegetation that favors animal pests and disease conditions; and reduce growth of vegetation to allow tree establishment and growth, and reduce fire hazard conditions.

- Treat fungal diseases to maintain the health and vigor of the orchard trees used for seed production, and native plant species.

- Minimize animal damage to orchard trees, native plant beds, and orchard equipment and infrastructure.

The need for action is demonstrated by an intensive cone dissection studies done since September 2000, which reported that cone insect pests caused notable damage to the seed crop at Tyrrell (at least 34\%), with higher damage levels projected for future years. The need for action is also demonstrated by the orchard's experience with periodic problems from other insects, disease, weeds, and animals.

\section{Pest Management Methods}

There are many methods available to manage vegetation, insects, disease, and animal pests at Tyrrell. These methods generally fall into the following categories: biological, chemical, prescribed fire, cultural, and other control methods.

The pest management methods that are analyzed under one or more of the alternatives in this EIS are as follows:

\section{Biological Control Methods}

- Vegetation: sheep, cattle, or goats placed in the orchard units to control grass cover crop.

- Insects: bird boxes to attract insect-eating birds, bat boxes to attract insect-eating bats, naturally occurring bacteria such as Bacillus thuringiensis (B.t.), a biological insecticide.

\section{Chemical Pesticide Methods}

- Vegetation: herbicides, including dicamba, glyphosate, hexazinone, picloram, and triclopyr.

- Insects: insecticides, including acephate, chlorpyrifos, diazinon, dimethoate, esfenvalerate, horticultural oil, imidacloprid, permethrin, propargite, and Safer ${ }^{\circledR}$ soap.

- Disease: fungicides, including chlorothalonil, propiconazole, and dazomet (a soil fumigant).

The methods that may be used to apply these chemicals at Tyrrell are aerial (helicopter) for esfenvalerate, fertilizers, and the biological insecticide B.t.; airblast sprayer; highpressure hydraulic sprayer; hydraulic sprayer with hand-held wand; tractor-pulled spray rig with boom; backpack sprayer; capsule implantation; ground pull fertilizer spreader; and hand application. 
Note that not all chemicals would be used in a given year, and some might never be used. However, their analysis in an alternative in this EIS, and subsequent selection of that alternative in the ROD, would give the seed orchard manager the option of using them in the future should a specific need arise. It is also important to note that each chemical application must first be approved by the Tyrrell seed orchard manager. All pesticides would be applied in compliance with all Federal and Oregon state laws, BLM regulations and policies, and manufacturer recommendations.

\section{Prescribed Fire}

- Vegetation: propane-fueled torch for vegetation removal in native plant beds prior to planting, pile burning of cut/cleared vegetation.

- Insects: pile burning of insect-damaged branches and trees, burning insect-damaged cones and cones collected during sanitation operations.

- Disease: pile burning of infected branches and trees.

\section{Cultural Control Methods}

- Vegetation: hand-pulling; non-powered and powered hand tools to cut and clear; tractors with various mowing attachments and gasoline-powered string trimmers for mowing grass and other vegetation; brush-cutting machine mounted on tractor for cutting brush and topping trees; chainsaw for cutting thinned, rogued, or dead/dying orchard trees and brush; pruner, power pruners, and similar equipment for cutting tree limbs and brush; chipping; tilling an unvegetated buffer around native plant beds; organic hot foam weed control; mulch mats to control vegetation around orchard trees; mulch or black plastic to cover and control noxious weeds and other vegetation.

- Insects: pruning, thinning, use of grafting wax or spray seal on tree wounds, sanitation of damaged branches and trees, cone sanitation (clean-picking cones from trees), hand-picking large and noticeable insect pupae.

- Disease: pruning, thinning, cone sanitation, stump grinding, power saws to cut infected or dead trees, physical removal of stump by grinding or pulling.

- Animal pests: trapping of gophers, walking (herding) stray deer and elk toward gate and out of orchard, pruning tree limbs up at the base of the trees, removing unwanted vegetation, mowing cover crop vegetation that provides cover for small mammals, live trapping, fencing to exclude deer and elk from orchard, chicken wire to exclude rabbits from common garden study, $\operatorname{Vexar}^{\mathrm{TM}}$ tubes to protect seedlings from voles.

\section{Other Methods}

- Insects: pheromone bait traps to attract and kill insects.

- Fertilization to promote overall tree health, cone production, and disease resistance.

It is the policy of the Department of Interior, and all of its agencies including BLM, to use chemical pesticides only after considering the alternatives; and to develop, support, and adopt IPM strategies wherever practicable.

The focus of IPM is on long-term prevention or suppression of pests. The integrated approach to pest management incorporates the best-suited biological, chemical, and cultural controls that have minimum impact on the environment and on people. IPM is not pesticide-free management; however, a successful IPM program should result in the most efficient use of pesticides if and when they are needed. 
Research into better and more effective control methods is also an essential part of an IPM program. The seed orchard manager would regularly review the pest management methods available for use, including new and developing technologies, to ensure that the seed orchard utilizes the most effective methods of control while minimizing the potential for any adverse environmental or health impacts.

The focus of this EIS is on activities directly relating to implementing an IPM program at the seed orchard. Other routine management actions - such as establishment and maintenance of orchard units, buffer zone management, and facilities/equipment maintenance - are not directly related to IPM and therefore not evaluated in this EIS.

\section{Alternatives}

BLM identified and evaluated five alternatives to address the need for a pest management program at Tyrrell, as follows:

- Alternative A: Maximum Production IPM

- Alternative B: IPM with Environmental Protection Emphasis (Proposed Action)

- Alternative C: Ground-Based IPM

- Alternative D: Non-Pesticide Pest Management

- Alternative E: No Action-Continue Current Management Approach

Alternative B is BLM's preferred alternative. Each alternative is described in more detail below.

Pest management methods that are common to all alternatives are biological methods, cultural methods, prescribed burning, and other non-pesticide control methods.

Other activities common to all alternatives include orchard management activities unrelated to pest management and protection measures that would be observed under any alternative. Protection measures are a list of "best management practices" intended to ensure the proper and safe application of pesticides at Tyrrell and include worker protection measures as well as public, environmental, and ecological protection measures.

\section{Alternative A-Maximum Production IPM}

Under this alternative, the primary goal is the maximum production of seeds and plants with a very low level of acceptable losses. Tyrrell's seed orchard manager would have all identified biological, chemical, prescribed fire, cultural, and other pest control methods available for use. An effective IPM strategy for all orchard pests would be implemented under this alternative; however, the primary management objective would be to maximize seed production for annual BLM and cooperator seed needs by aggressively controlling cone and seed insects and other limiting factors. The most effective insect control measures would be implemented, to maximize seed yield and reduce damage to the seed crops with low acceptable seed losses, emphasizing production above other less-effective control methods and considerations, with a low threshold for initiating treatment.

\section{Alternative B-IPM with Environmental Protection Emphasis (Proposed Action)}

Under this alternative, the seed orchard manager would have access to the full list of pest management methods identified above; however, chemical use would be restricted by a set of limitations. These limitations address risks predicted by the quantitative risk 
assessment, respond to scoping concerns, consider the results of previous monitoring, and include recommendations made by the interdisciplinary EIS preparation team. The limitations provide additional protection to human health and the environment, and distinguish the details of potential treatments under Alternative B from those under Alternative A. A complete list of limitations is provided in Section 2.3.3.

\section{Alternative C-Ground-Based IPM}

Alternative $C$ would be identical to Alternative B, except that the option for aerial applications of esfenvalerate, B.t., and fertilizer would be eliminated.

\section{Alternative D-Non-Pesticide Pest Management}

Alternative D would allow the seed orchard manager to use only the non-pesticide biological, prescribed fire, cultural, and other methods listed above. No biological or chemical pesticides would be permitted.

\section{Alternative E-No Action: Continue Current Management Approach}

Alternative E would allow continuation of the current management system, which is the use of all non-pesticide control practices at the seed orchard, as well as the use of pesticides on a specific case-by-case basis. All biological, prescribed fire, cultural, and other non-pesticide methods would be used as needed. When a specific need is identified for a pesticide, the action would be reviewed to determine whether it is encompassed by an existing EA or EIS. This could include applications for controlling cone insects or other orchard insect outbreaks, disease infestations, and any vegetation control necessary that is not covered by other BLM vegetation control NEPA documents.

\section{Alternative Considered But Not Further Analyzed}

During the scoping process, one member of the public suggested planting more crop trees than necessary to allow for some loss to pests, which was interpreted as a request to consider no pest management at all. This is not a viable alternative for several reasons. First, this approach could lead to a significant loss of the crop trees in the production units if disease were to occur. Secondly, orchard research has shown that approximately $70 \%$ of the seed crop could be lost if no pest management were practiced. To partially offset the effects of cone and seed insects and decreased tree vigor due to disease, it would be necessary to plant production trees in fields that are currently fallow, as the commentor suggested. This solution would require the seed orchard and their cooperators to accept an estimated 10-year reduction in seed production, which is the time that would be required for the newly planted trees to produce collectable seed. This decrease in production could also result in delays in reforestation projects caused by potential seed shortages, or reduced forest growth resulting from the use of genetically inferior seed from other sources. In addition, a more intensive planting regime on seed orchard grounds, with no pest management of any kind, would allow the orchard lands to become a "reservoir" for insects, disease, noxious weeds, and animal pests that would spread to neighboring public and private lands-effectively, becoming a threat and nuisance to the neighbors, particularly those who cultivate crops of their own.

\section{Affected Environment}

The Tyrrell Seed Orchard is located approximately 15 miles southwest of the city of Eugene, Oregon, near the small community of Lorane and within Lane County. It is 
within the Siuslaw River valley of the Oregon Coast Range province and about 40 miles east of the Pacific Ocean. The town of Cottage Grove is about 12 miles east of the seed orchard. Its geographical location near the Coast Range, between the Pacific Ocean and Cascade Mountains, results in a maritime west coast climate, featuring mild, wet winters and cool, dry summers. Douglas Creek and its tributaries have cut several valleys in the seed orchard. The Siuslaw River flows about 700 feet to the south of the site.

The EIS includes a detailed discussion of the relevant environment at Tyrrell, providing baseline information to allow the evaluation of potential environmental impacts that could result from the proposed action or an alternative action. The human environment includes natural and physical resources and the relationship of people to those resources.

The resources described in the EIS include, in order of presentation, the physical environment (air, geology, and water), followed by land use, human health, biological resources, and the human environment (noise, cultural resources, socioeconomics, and environmental justice). These resources are described in a sufficient level of detail to adequately support the impact analysis.

\section{Environmental Impacts}

Chapter 4 of the EIS details the methods of analysis and assumptions made in evaluating potential impacts to each resource. Approaches included conducting a quantitative human health and ecological (non-target species) risk assessment (summarized in Appendix C), environmental fate and transport modeling, literature review, statistical evaluations, and review of similar actions at other locations. The resource-specific subsections in Chapter 4 describe the methods and present the criteria used for determining whether there are any potential impacts.

The analysis predicted no significant impacts to air quality, geology and soils, land use, noise, cultural resources, and socioeconomics and environmental justice. Human health, biological resources, and surface water (as it relates to aquatic species) are the resources with the greatest potential for impact and should receive the greatest attention in decision-making.

\section{Human Health and Safety}

- There are no significant risks to members of the public from the proposed use of any of the control methods under any of the alternatives. However, an accidental spill to a stream of pesticide under Alternatives A, B, C, and E, or of fertilizer under any alternative, could make surface water unsafe for drinking or fishing.

- Under Alternatives A and $\mathrm{E}$, there is a possibility of health effects for workers from some chemical pesticides. No risks of worker health effects were predicted for pesticide applications under Alternatives B and C. Under Alternatives A, B, C, and E, an accidental spill onto the skin could cause health risks. Under all of the alternatives, there is a possibility of injury from cultural or prescribed fire methods.

- Although runoff or drift to surface water is possible from some applications, the predicted stream concentrations are below levels that would be associated with risks to human health.

\section{Water Quality}

- No significant impacts to groundwater quality were predicted under any alternative.

- Runoff or drift from pesticide or fertilizer applications could enter streams and rivers 
under Alternatives A, B, C, and E, and fertilizers could enter surface water under Alternative $D$. The effects of the estimated stream concentrations on human health and aquatic species are described under those headings. Under Alternatives B and C, limitations would be in place to control the potential for runoff and drift.

- An accidental spill of pesticide concentrate or mix could contaminate groundwater or surface water under Alternatives A, B, C, and E, and a spill of fertilizer could contaminate water under any alternative.

\section{Biological Resources}

- Localized impacts to non-target vegetation are possible from broadcast herbicide applications in areas that are already intensively managed or disturbed. These impacts are not considered significant, as no special status plant species are present.

- There are possible risks to terrestrial wildlife species from some of the proposed pesticides under Alternatives A and E. Maximum scenario fertilizer application could pose a risk to the special status species western bluebird under any alternative. Lethality would be expected for non-target insects in an area treated with insecticide under Alternatives A, B, C, and E. No other significant impacts to terrestrial wildlife were predicted.

- There are possible risks of sublethal effects to special status fish species from pyrethroid insecticides under some maximum (but not typical) conditions under Alternatives A, B, C, and E; and a risk of sublethal and lethal effects from fertilizer under maximum runoff conditions. Limitations included in Alternatives $B$ and $C$ would decrease these risks compared to Alternative A. An accidental spill of pesticide to a stream could cause adverse impacts to aquatic species under Alternatives $\mathrm{A}$, $\mathrm{B}, \mathrm{C}$, and $\mathrm{E}$; and there could be risks from an accidental spill of fertilizer under all alternatives. Although runoff or drift to surface water is possible from some applications of other pesticides and other ingredients, the predicted stream concentrations are below levels that would be associated with risks to aquatic species.

Alternative B is the proposed action, and is BLM's preferred alternative for minimizing long-term impacts to all resources, including human health.

\section{Cumulative Impacts}

According to CEQ regulations at 40 CFR 1508.7, "cumulative impact" is the impact on the environment that results from the incremental impact of the action when added to other past, present, and reasonably foreseeable future actions, regardless of what agency or person undertakes such actions. There are no other major projects proposed in the orchard vicinity that are long-term in nature or would result in significant changes in the physical characteristics of the project area. Another cumulative concern relates to the potential toxic effects of exposure to multiple chemicals. The human health risk assessment addressed cumulative risk to workers and the public from the subset of proposed chemicals that are more likely than others to be used in a given year. No risk was identified for members of the public, but risk was identified for some workers under Alternative A when very conservative assumptions were applied to avoid underestimating the potential impact.

\section{Mitigation Measures}

Based on the results of the quantitative risk assessment, the selection of Alternative A, Maximum Production IPM, could result in adverse impacts to human health and ecological resources. Therefore, CEQ's regulations for implementing NEPA require that potential mitigation measures be identified in this EIS. The identified mitigation 
measures, described in detail in Section 4.12, restrict rates, frequencies, and other use details for acephate, chlorpyrifos, diazinon, dimethoate, dicamba, hexazinone, horticultural oil, propargite, triclopyr, and fertilizers.

A potential mitigation measure is identified for BLM's proposed action: Alternative B, IPM with Environmental Protection Emphasis. To address the potential for sublethal effects to special status fish species from maximum scenario applications of pyrethroid insecticides, these pesticides would only be applied using the application rates and frequencies identified in the typical scenarios in Table 2.2-1. The design of this alternative, including the limitations specified in Section 2.3.3, are expected to address all potential risks identified in this EIS, with the exception of possible maximum scenario risks from fertilizers. These risks are only predicted for conditions in which soils are saturated and then a large storm event follows application, which is a situation with a very low probability of occurrence, representing the upper bound of the risk range estimated in the risk assessment. The identified limitation of requiring soil aeration will reduce, but may not completely avoid, the probability of this scenario occurring. During the ESA conference process, NOAA Fisheries identified additional terms and conditions to provide additional protection to coho salmon. These requirements are listed in Section 2.3.3 of this Final EIS. The terms and conditions in the conference opinion do not become effective until NMFS adopts the conference opinion as a biological opinion, after the listing becomes final. However, BLM will implement the terms and conditions associated with reasonable and prudent measure 1 through 4 to conserve EFH. Alternative $C$ (Ground-Based IPM) also incorporates all of the limitations identified for Alternative B, so only the mitigation measure restricting pyrethroid applications to typical rates was identified for that alternative; this alternative was not included in the ESA consultation process.

The only significant impacts associated with Alternative D, Non-Pesticide Pest Management, are those from maximum scenario fertilization, as described in the preceding paragraph. No additional mitigation is identified for this risk other than as described above.

Mitigation measures for use of chemical pesticides under Alternative E, No Action, would be identified on a project-by-project basis during the specific NEPA assessments.

The ROD that will be published at the conclusion of the EIS process will specify the mitigation measures that will be implemented with the selected alternative. 


\section{Table Of Contents}

Executive Summary $\ldots \ldots \ldots \ldots \ldots \ldots \ldots \ldots \ldots \ldots \ldots \ldots \ldots \ldots \ldots \ldots \ldots \ldots \ldots \ldots$

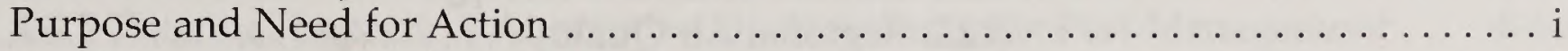

Pest Management Methods .................................... ii

Alternatives. ........................................ iv

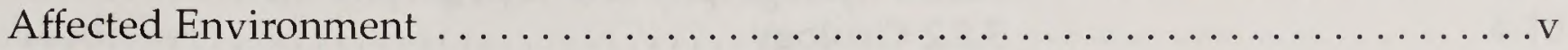

Environmental Impacts $\ldots \ldots \ldots \ldots \ldots \ldots \ldots \ldots \ldots \ldots \ldots \ldots \ldots \ldots \ldots \ldots \ldots \ldots$

\section{Chapter 1}

1.0 Introduction $\ldots \ldots \ldots \ldots \ldots \ldots \ldots \ldots \ldots \ldots \ldots \ldots \ldots \ldots \ldots \ldots \ldots, 1-1$

1.1 Purpose and Need for Action $\ldots \ldots \ldots \ldots \ldots \ldots \ldots \ldots \ldots \ldots \ldots \ldots \ldots \ldots \ldots \ldots, 1-1$

1.1.1 Purpose ........................................... 1-1

1.1 .2 Need for Action $\ldots \ldots \ldots \ldots \ldots \ldots \ldots \ldots \ldots \ldots \ldots \ldots \ldots \ldots \ldots \ldots, 1-2$

1.1.2.1 Insects $\ldots \ldots \ldots \ldots \ldots \ldots \ldots \ldots \ldots \ldots \ldots \ldots \ldots \ldots \ldots \ldots \ldots \ldots \ldots \ldots \ldots \ldots, 2$

1.1.2.2 Disease $\ldots \ldots \ldots \ldots \ldots \ldots \ldots \ldots \ldots \ldots \ldots \ldots \ldots \ldots \ldots \ldots \ldots \ldots, 1-3$

1.1.2.3 Vegetation $\ldots \ldots \ldots \ldots \ldots \ldots \ldots \ldots \ldots \ldots \ldots \ldots \ldots \ldots \ldots \ldots, 1-3$

1.1.2.4 Animal Pests .................................. 1-4

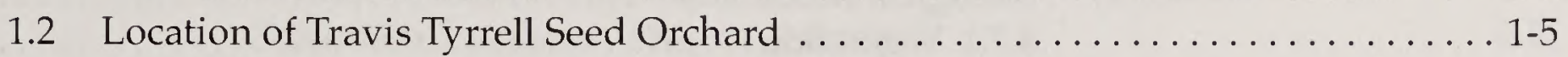

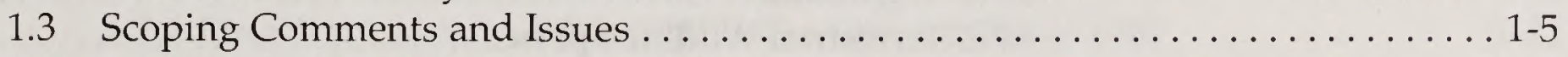

1.4 Relationship to Plans, Policies, and Programs $\ldots \ldots \ldots \ldots \ldots \ldots \ldots \ldots \ldots \ldots \ldots \ldots \ldots \ldots \ldots$

1.4.1 Related BLM Plans, Policies, and Programs .................. 1-7

1.4.2 Relevant Federal, State, and Local Statutes and Guidelines ............ 1-9

1.5 Organization of this EIS $\ldots \ldots \ldots \ldots \ldots \ldots \ldots \ldots \ldots \ldots \ldots \ldots \ldots \ldots \ldots \ldots \ldots \ldots \ldots, 12$

\section{Chapter 2}

2.0 Description of Alternatives, Including Proposed Action $\ldots \ldots \ldots \ldots \ldots \ldots .2-1$

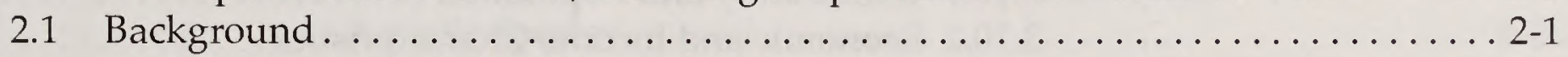

2.1.1 Seed Orchards, Tree Improvement Program, and Genetics ............ 2-1

2.1.2 Ongoing Orchard Activities ........................... 2-2

2.2 Integrated Pest Management in the Travis Tyrrell Seed Orchard ............ 2-5

2.2.1 Integrated Pest Management............................... 2-5

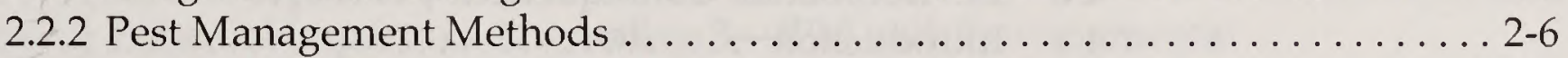

2.2.2.1 Biological Control Methods $\ldots \ldots \ldots \ldots \ldots \ldots \ldots \ldots \ldots \ldots .2-6$

2.2.2.2 Chemical Pesticide Methods $\ldots \ldots \ldots \ldots \ldots \ldots \ldots \ldots \ldots . . .2-8$

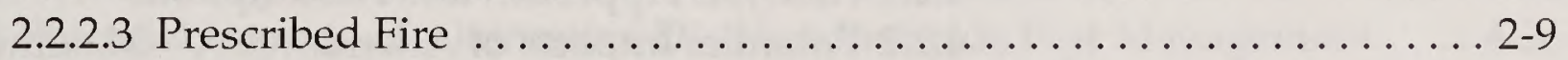

2.2.2.4 Cultural Methods, including Manual and Mechanical Methods ... . 2-9

2.2.2.5 Other Control Methods ................................ 2-11

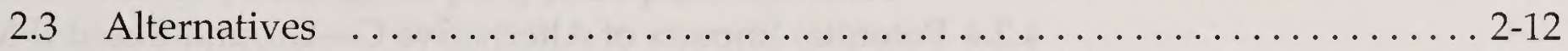

2.3.1 General Description and Features Common to All Alternatives ......... 2-12

2.3.2 Alternative A-Maximum Production IPM …............... 2-15

2.3.3 Alternative B-IPM with Environmental Protection Emphasis

(Proposed Action) ................................. 2-15

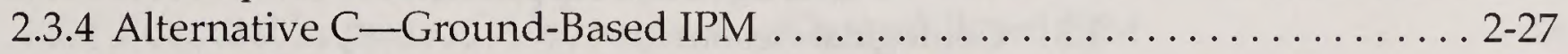

2.3.5 Alternative D—Non-Pesticide Pest Management ............... 2-27

2.3.6 Alternative E-No Action: Continue Current Management Approach . . . . 2-28

2.3.7 Alternative Considered But Not Further Analyzed ................ 2-28

2.4 Approval of New Products and Technologies ..................... 2-28

2.4.1 Identification of New Chemical Products and Technologies .......... 2-29

2.4.2 Assessment of Effectiveness............................ 2-30

2.4.3 Assessment of Hazards and Risks $\ldots \ldots \ldots \ldots \ldots \ldots \ldots \ldots \ldots \ldots . . .2-30$

2.4.4 NEPA Documentation............................... 2-31

2.5 Ongoing and Reasonably Foreseeable Future Actions in Study Area . . . . . . 2-36

2.6 Summary of Environmental Impacts by Alternative ................ 2-36 


\section{Chapter 3}

3.0 Affected Environment ................................... 3-1

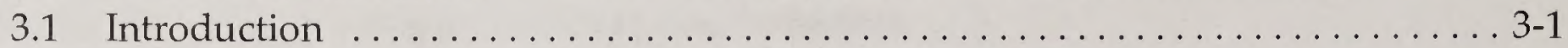

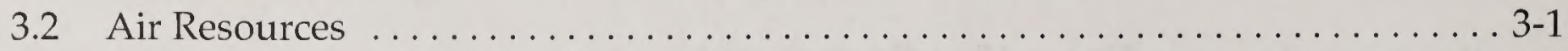

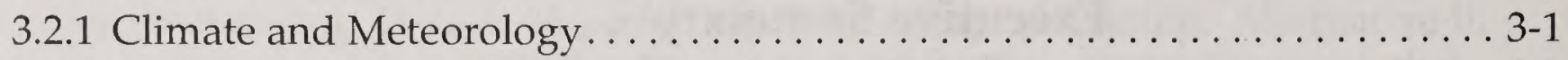

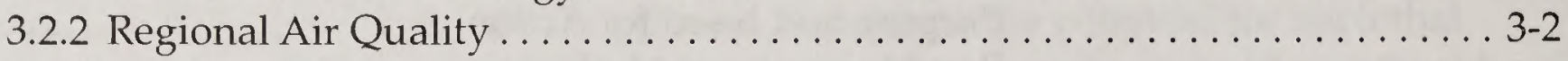

3.3 Geological Resources ............................. 3

3.3.1 Physiography and Topography ................

3.3 .2 Geology ...................................... $3-4$

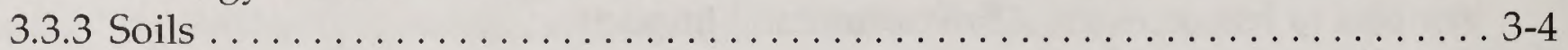

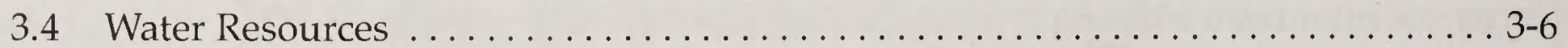

3.4 .1 Groundwater . . . . . . . . . . . . . . .

3.4 .2 Surface Water . . . . . . . . . . . . . . . . . . . . 6

3.4 .3 Floodplains ............................... 3-9

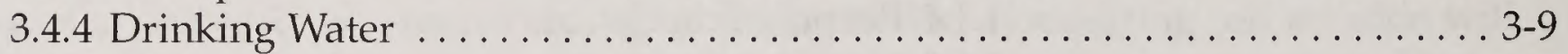

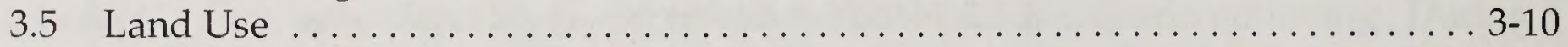

3.6 Human Health. . . . . . . . . . . . . . . . . . . . . . . . . .

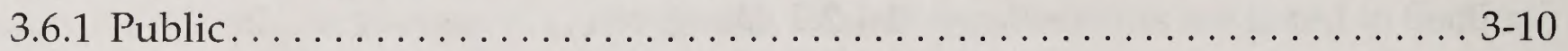

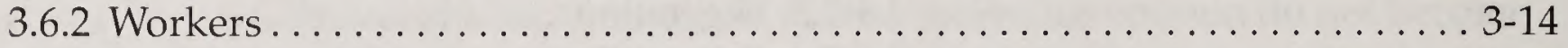

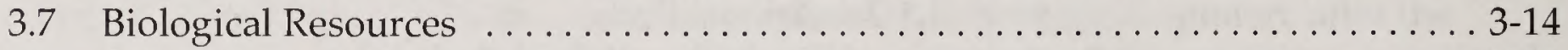

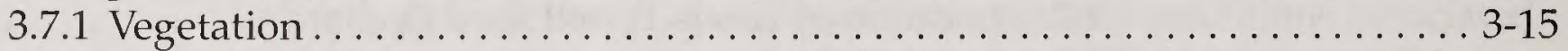

3.7.2 Terrestrial Wildlife Species............................. 3-16

3.7 .3 Aquatic Species .................................... 3-19

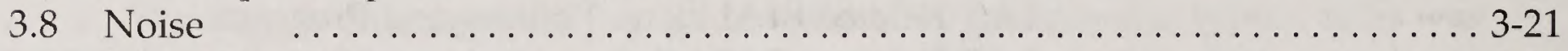

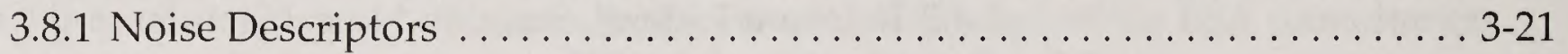

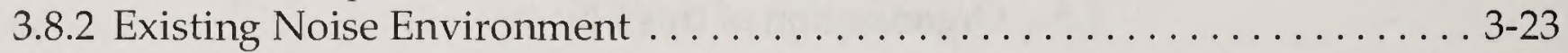

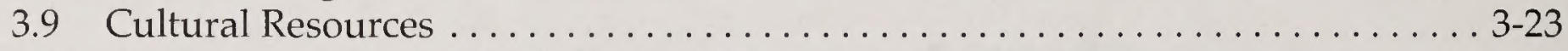

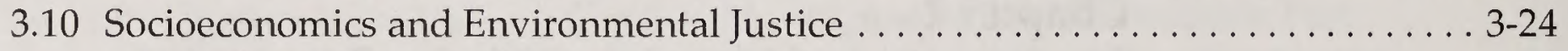

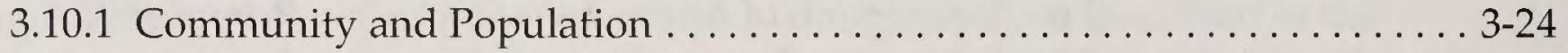

3.10.2 Economic and Income Characteristics . . . . . . . . . . . . . . . . . 3-24

3.10 .3 Environmental Justice. . . . . . . . . . . . . . . . . . . . . . 3-25

\section{Chapter 4}

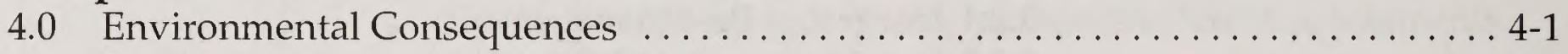

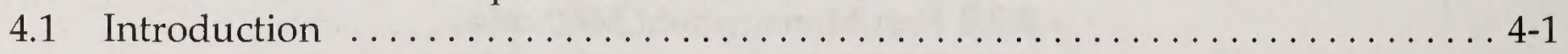

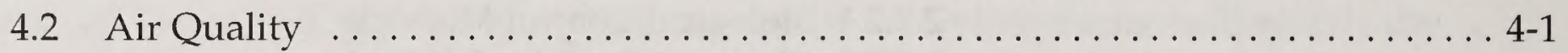

4.2.1 Analysis Approach and Assumptions ................... 4-2

4.2.2 Potential Impacts of Alternative A-Maximum Production IPM . . . . . . . . 4-2

4.2.3 Potential Impacts of Alternative B-IPM with Environmental

Protection Emphasis (Proposed Action) .................. 4-3

4.2.4 Potential Impacts of Alternative C - Ground-Based IPM . . . . . . . . . . . 4-3

4.2.5 Potential Impacts of Alternative D-Non-Pesticide Pest Management ........................... $4-3$

4.2.6 Potential Impacts of Alternative E-No Action: Continue Current Management Approach . .......................... $4-3$

4.3 Geological Resources .............................. 4.3

4.3.1 Analysis Approach and Assumptions . ................. 4-3

4.3.2 Potential Impacts of Alternative A-Maximum Production IPM . . . . . . . . 4 4-3

4.3.3 Potential Impacts of Alternative B-IPM with Environmental Protection Emphasis (Proposed Action) . . . . . . . . . . . . . . . 4-5

4.3.4 Potential Impacts of Alternative C - Ground-Based IPM . . . . . . . . . . . . . 4-6

4.3.5 Potential Impacts of Alternative D-Non-Pesticide Pest Management . . . . . 4-6

4.3.6 Potential Impacts of Alternative E-No Action: Continue Current Management Approach ......................... 4-6

4.4 Water Resources ................................. 4-6

4.4.1 Analysis Approach and Assumptions . ................... 4-6

4.4.2 Potential Impacts of Alternative A-Maximum Production IPM . . . . . . . . 4-7 
4.4.2.1 Groundwater........................... 4

4.4.2.2 Surface Water. . . . . . . . . . . . . . . . . . . . . 4-8

4.4.3 Potential Impacts of Alternative B-IPM with Environmental

Protection Emphasis (Proposed Action) . . . . . . . . . . . . . 4-10

4.4.4 Potential Impacts of Alternative C - Ground-Based IPM . . . . . . . . . . . 4-10

4.4.5 Potential Impacts of Alternative D-Non-Pesticide Pest Management . . . . 4-10

4.4.6 Potential Impacts of Alternative E-No Action: Continue Current

Management Approach . ....................... 4-10

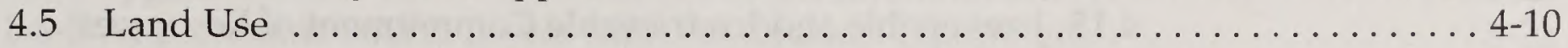

4.5.1 Analysis Approach and Assumptions . . . . . . . . . . . . . . 4 4-11

4.5.2 Potential Impacts of All Alternatives . . . . . . . . . . . . . . . . 4-11

4.6 Human Health and Safety $\ldots \ldots \ldots \ldots \ldots \ldots \ldots \ldots \ldots \ldots \ldots \ldots \ldots \ldots \ldots \ldots \ldots \ldots \ldots \ldots \ldots \ldots . .11$

4.6.1 Analysis Approach and Assumptions .................. . . 4-12

4.6.2 Potential Impacts of Alternative A-Maximum Production IPM . . . . . . . 4-17

4.6.2.1 Biological Control Methods .................... 4-17

4.6.2.2 Chemical Control Methods ..................... 4-17

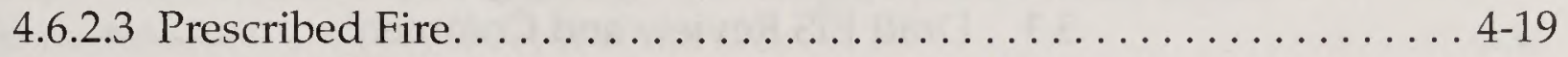

4.6.2.4 Cultural Controls ......................... 4-20

4.6.2.5 Other Control Methods ..................... 4-20

4.6.3 Potential Impacts of Alternative B-IPM with Environmental

Protection Emphasis (Proposed Action) .................. 4-21

4.6.4 Potential Impacts of Alternative $C$-Ground-Based IPM . . . . . . . . . . . 4-22

4.6.5 Potential Impacts of Alternative D-Non-Pesticide Pest Management . . . 4-22

4.6.6 Potential Impacts of Alternative E-No Action: Continue Current

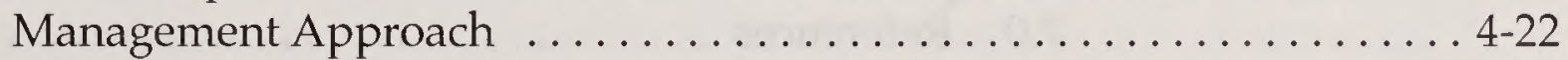

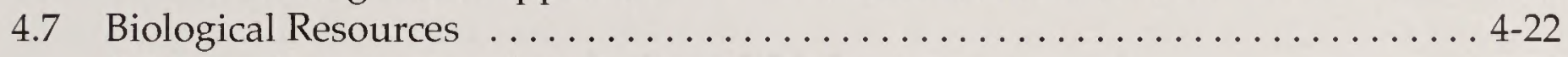

4.7.1 Analysis Approach and Assumptions . ................. 4-23

4.7.1.1 Non-Target Species Risk Assessment ................. . 4-23

4.7.1.2 Risk Analysis for Sublethal Effects to Special Status

Aquatic Species .......................... 4-26

4.7.2 Potential Impacts of Alternative A-Maximum Production IPM . . . . . . . 4-28

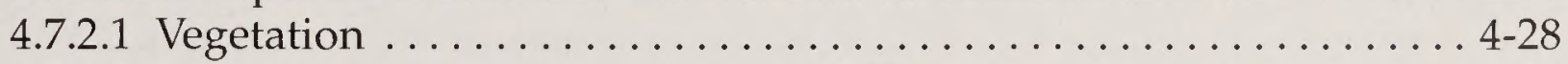

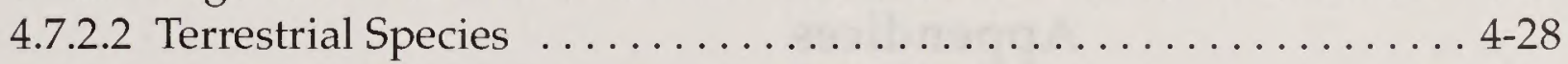

4.7.2.3 Aquatic Species . . . . . . . . . . . . . . . . . . .

4.7.3 Potential Impacts of Alternative B-IPM with Environmental

Protection Emphasis (Proposed Action) ................ . . 44

4.7.4 Potential Impacts of Alternative C - Ground-Based IPM . . . . . . . . . . 4-36

4.7.5 Potential Impacts of Alternative D-Non-Pesticide Pest Management . . . 4 4-36

4.7.6 Potential Impacts of Alternative E-No Action: Continue Current

Management Approach . ...................... 4-36

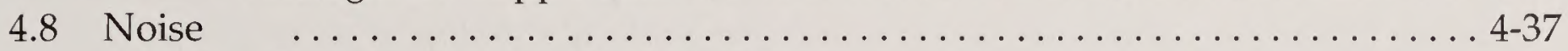

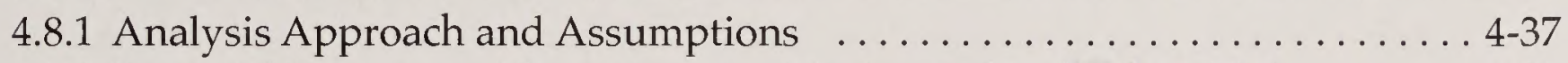

4.8.2 Potential Impacts of Alternative A-Maximum Production IPM . . . . . . 4 4-38

4.8.3 Potential Impacts of Alternative B-IPM with Environmental

Protection Emphasis (Proposed Action) . . . . . . . . . . . . 4 4

4.8.4 Potential Impacts of Alternative C-Ground-Based IPM . . . . . . . . . . 4-38

4.8.5 Potential Impacts of Alternative D-Non-Pesticide Pest Management . . . 4 4-38

4.8.6 Potential Impacts of Alternative E-No Action: Continue Current

Management Approach . ..................... 4-38

4.9 Cultural Resources ............................... $4-39$

4.9.1 Analysis Approach and Assumptions . . . . . . . . . . . . . . . 4-39

4.9.2 Potential Impacts of All Alternatives . . . . . . . . . . . . . . . 4 49

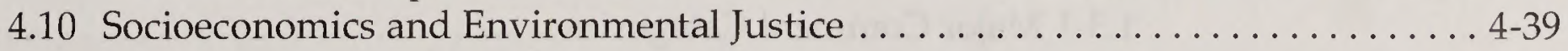

4.10 .1 Analysis Approach and Assumptions . . . . . . . . . . . . . . 4-40

4.10.2 Potential Impacts of Alternative A-Maximum Production IPM . . . . . . 4-40

4.10.3 Potential Impacts of Alternative B-IPM with Environmental

Protection Emphasis (Proposed Action) . . . . . . . . . . . . . 4-40 
Final EIS - Tyrrell Seed Orchard IPM 


\subsection{Introduction}

The U.S. Bureau of Land Management (BLM) proposes to implement an integrated pest management (IPM) program at the Travis Tyrrell Seed Orchard (Tyrrell) in Lane County, Oregon. The orchard is within BLM's Eugene District. The National Environmental Policy Act (NEPA) of 1969, as amended, requires Federal agencies to consider environmental consequences in their decision-making process. The President's Council on Environmental Quality (CEQ) has issued regulations to implement NEPA that include provisions for both the content and procedural aspects of the required environmental analysis (40 Code of Federal Regulations (CFR) 1500 et seq.). The environmental impact analysis process, as governed by the Department of the Interior's Departmental Manual 516, NEPA Compliance, and BLM's Manual H-1790-1, National Environmental Policy Act Handbook, is the mechanism by which BLM ensures its decisions are based on an understanding of potential environmental consequences. The CEQ regulations were used in conjunction with the Departmental and Bureau guidance to determine the appropriate level of environmental analysis for this action, which BLM has determined to be an Environmental Impact Statement (EIS).

Preparation of this EIS must precede final decisions regarding the selection of an alternative, and be available to inform decision makers and the public of potential environmental consequences. A Notice of Intent was originally published in the Federal Register (FR) on March 26, 1999 (64 FR 14747), and announced BLM's intent to prepare one consolidated EIS for all four Oregon seed orchards. A Revised Notice of Intent was published on March 29, 2001 (66 FR 17192) to announce BLM's revised intent to prepare three separate EISs for the four seed orchards, with each EIS being District-specific and the Medford District EIS including both the Sprague and Provolt Seed Orchards. Distribution and review of the Draft EIS in June 2003 allowed for public consideration and input concerning the proposed IPM program, and provided to decision makers and the public the information required to understand the future environmental consequences of the action or an alternative. After carefully considering comments on the Draft EIS, BLM is now issuing a Final EIS. After a 30-day availability period for the Final EIS, BLM will publicly state which action will be implemented in a formal document called a Record of Decision (ROD). Subsequent IPM activities will be implemented over the life of the IPM plan (usually 15 to 20 years) in accordance with that decision. No further NEPA documentation relating to IPM would be required, unless the seed orchard manager proposes to use a new IPM product or technology that was not included in the alternative selected in the ROD. The NEPA review requirements in this situation are discussed in Section 2.4.4.

This introductory chapter identifies the purpose and need for action, provides a general description of the location of the seed orchard, summarizes scoping comments and issues, and discusses the relationship of this document to other plans, policies, and programs. It concludes by describing the organization of the remainder of this EIS.

\subsection{Purpose and Need for Action}

\subsubsection{Purpose}

The purpose of the action is to manage competing and unwanted vegetation, diseases, insects, and animal pests at Tyrrell. Management of adverse impacts from pests is necessary to allow the seed orchard to produce improved seed for conifer seedling production, and preserve valuable individual conifer trees. Management is also necessary to allow the seed orchard to produce native species plants and seed (including 
grass, forb, brush, and other), although this is currently a very small program at Tyrrell. This high-quality seed is supplied to BLM and other cooperators for reforestation and restoration projects.

For many years, Tyrrell has managed pests using an IPM program that included very limited use of chemicals: lindane was applied from 1989 to 1998 to younger trees to control coneworm in Douglas-fir graft unions, bark scores, and partial girdle stimulation cuts. Esfenvalerate was used in 2003 ( 29 acres) and 2005 (58 acres) to control cone and seed insects. Imidacloprid was used in 2004 ( 60 acres) to control Douglas-fir gall midge. Each use has required preparation of a separate NEPA document or presence of a categorical exclusion (CX). Changes and experience with control methods at Tyrrell have created the need to re-evaluate the pest management program to ensure that the pest management objectives at the seed orchard continue to be met. In addition, the public demand for efficient use of resources in government, as well as for providing appropriate environmental protection, requires the selection and use of the best pest management techniques for efficient and cost-effective orchard operation over the long term. The pest management objectives at Tyrrell include the following:

- Minimize insect damage to orchard trees, cone crops, and native plants.

- Remove noxious weeds and control vegetation that favors animal pests and disease conditions; and reduce growth of vegetation to allow tree establishment and growth and reduce fire hazard conditions.

- Treat fungal diseases to maintain the health and vigor of the orchard trees used for seed production and native plant species.

- Minimize animal damage to orchard trees, native plant beds, and orchard equipment and infrastructure.

\subsubsection{Need for Action}

The need for this action is demonstrated by intensive cone dissection studies done since September 2000 under the direction of a U.S. Forest Service entomologist for the Westside Forest Insect and Disease Center. Results from these studies indicate that cone insect pests have caused notable damage to seed crops since 2000 at Tyrrell (as high as $34 \%$ ), with higher damage levels projected for future years. The need for action is also demonstrated by the orchard's experience with periodic problems from insects, disease, weeds, and animals. These pests are described in the following paragraphs. Appendix A contains detailed information on the more common and damaging insects and diseases at Tyrrell.

\subsubsection{Insects}

Douglas-fir cone gall midge (Contarina oregonensis), Douglas-fir cone worm (Dioryctria abietivorella), and Douglas-fir seed chalcid (Megastigmus spermotrophus) have caused substantial cone damage and seed loss to the Douglas-fir cone crops at Tyrrell. In past years, these insects have caused up to a $34 \%$ loss of seed. The Douglas-fir cone moth (Barbara colfaxiana) and seed bug (Leptoglossus occidentalis) have also caused damage and are present in some orchards. The level of damage from insects is expected to increase as the orchard trees become older.

The seed orchard also has other tree species, such as ponderosa pine, western hemlock, and Port-Orford-cedar, that are being managed to produce cones and seed. These orchards will be reaching cone production age in a few years and will likely be susceptible to insect damage. Pest management will become necessary in these orchards if insect populations and cone insect damage prevent the orchard from meeting customer needs. 
Healthy, vigorous trees are able to withstand occasional or limited attacks of foliar, bark, or root insects and recover with little damage. However, cone and seed insects are present in the orchard every year, and are capable of causing seed crop damage. A variety of control measures can generally limit the effects of most insects to minor or acceptable amounts of damage. The exceptions are cone and seed insects, insect population bursts, and very localized small outbreaks of other insects.

Infestations by insects such as aphids, leaf hoppers, bark beetles, sawflies, scales, mites, and defoliating caterpillars are relatively infrequent. There are usually some of these insects present, but they seldom pose any significant threat. However, they have the capacity to cause significant damage should their populations increase to high levels, such as has occurred in other geographic areas.

\subsubsection{Disease}

During orchard development, stumps and roots were removed to a depth of three feet, so there is little potential for root diseases to exist. Although diseases such as Armillaria root rot (Armillaria spp.) and laminated root rot (Phellinus weirii) are present in adjacent stands, there is only a slight chance they would cause significant damage prior to orchard recycling, when stump removal and ripping would occur again.

Foliar diseases have also affected orchard trees in small outbreaks and limited areas. Douglas-fir rust (Melampsora occidentali), Phomopsis canker (Phomopsis lokoyae), and Rhabdocline needle cast (Rhabdocline pseudotsugae) have been found occasionally at Tyrrell. Swiss needlecast (Phaecryptopus gaumanni) is very common in areas of western Oregon having strong coastal weather influence; although small pockets of this disease are found inland as far east as the Cascade mountain range, there is no indication that any trees have been infected at Tyrrell. Sugar pine and western white pine are also susceptible to white pine blister rust, an exotic fungus which affects the stem, branches, and needles. Although pines planted at Tyrrell were selected based on higher blister rust resistance levels, the pathogen is capable of infecting and damaging branches and sometimes whole trees. When the orchard trees are healthy, all of these diseases, except blister rust, cause minor damage such as branch or stem deformation, and loss of vigor and growth. Except for white pine blister rust, these diseases seldom result in mortality.

Most of these diseases become aggressive in stress situations, when trees are lacking sufficient moisture or nutrients, when environmental conditions are severe, or when humans or animals cause damage to trees. Sunscald, high temperatures, frost, prolonged high water table, drought, unusual rainy periods, or other extreme conditions can cause physical injury, weaken a tree, and expose it to diseases. Management and cultural practices in the orchard can reduce the risk of injury and stress, thus reducing the risk of disease.

\subsubsection{Vegetation}

Undesirable vegetation (grasses, forbs, small and large trees, and brush) grows in orchard units and native species beds; along fence lines, ditches, and roads; around developed areas such as structures and parking lots; on fallow lands; and in the buffer zones located between the orchard units.

This vegetation often creates hazards or impediments to normal orchard operations. Undesirable vegetation can also introduce contaminating "weed" seed into pure native plant seed beds, affecting the quality of the source seed being produced.

Unwanted and uncontrolled vegetation provides fuels for potential wildfires. Tyrrell is in a lightly populated rural setting surrounded by both industrial and non-industrial private timberland. The potential for wildfires is highest during the late summer and 
early fall, when fuel moisture levels are very low. The control of vegetation height in the orchard units, fallow open land areas, and borders is essential to reduce the rapid spread of grass fires.

Competition for water, nutrients, and light among the orchard trees, and cover crop vegetation in the orchard units, occurs during the active growing season. Reduction of vegetation increases available soil moisture and nutrients to the trees. The uncontrolled vegetation is also a physical barrier to safe and efficient foot and vehicular travel.

Uncontrolled vegetation also provides protective hiding and nesting cover for rodents and other animals, which cause damage to orchard trees, building foundations, road surfaces, and the surface lands in the orchard units. Rodents chew and eat tree roots and bark, and sometimes eat foliage. Rodents also chew and damage electrical wiring; burrow under concrete foundations, undermining building integrity; and burrow into roadways and throughout orchard units, causing erosion, degradation, and an uneven surface. Any uneven surface, in turn, creates a safety hazard when using high lifts, utility vehicles, or all-terrain vehicles (ATVs). Keeping vegetation low reduces animal cover and increases opportunity for predation on these animals by raptors and carnivores, thereby reducing the damage.

Because the eight-foot tall perimeter fence surrounding the orchard represents a very high capital investment, vegetation has been controlled along these fence lines. If left uncontrolled, this vegetation would ultimately overgrow and affect the structural integrity of this fence and its ability to act as a barrier.

\subsubsection{Animal Pests}

A wide variety of animal habitat exists in and around the seed orchard, including grassand tree-covered orchard units, open grass-covered fallow areas, open woodlots, brushy hedgerows and edge areas, intermittent drainages, culverts, riparian areas, fence lines, and roadsides. These habitats attract a wide variety of animals, which live and feed in the orchard.

The eight miles of eight-foot high woven wire fence material at Tyrrell excludes big game from the orchard. The fences are essential for keeping black-tailed deer and Roosevelt elk away from seedlings.

Rodents such as the western pocket gopher, and a variety of mice and voles, such as the long-tailed vole and deer mouse, all cause damage to young tree roots and lower stems by eating plant tissue. Older trees can be damaged by porcupines, which eat inner bark tissue and girdle the tree stem. Mountain beavers, which clip lateral branches and strip the bark on younger trees, build burrow systems in the moist areas adjacent to drainages of the orchard. Ground squirrels tunnel around the foundations of buildings, in and near roads, and in the orchard lands, creating hazards to facilities and people.

Coyote, gray fox, and black bear are present in the orchard. Except for occasional shallow holes dug around the base of trees, these animals cause little damage.

Although they can cause great amounts of damage and loss to cones, western gray squirrels have not been a problem to date at Tyrrell. The squirrels enter into the orchard from adjacent woodlands to hunt for food.

Some animals causing damage are also predators for other animals that damage orchard crops. For instance, moles, voles, and gophers are hunted by coyote and gray fox. Animals are generally welcome and accepted until populations rise, food preferences shift to orchard crops, or damage becomes unacceptable. 


\subsection{Location of Travis Tyrrell Seed Orchard}

Tyrrell is located approximately 15 miles southwest of the city of Eugene, Oregon, near the small community of Lorane and within Lane County. It lies within the Siuslaw River valley of the Oregon Coast Range province. Figure 1.2-1 shows the seed orchard location.

\subsection{Scoping Comments and Issues}

Numerous scoping-related activities were conducted for this EIS between 1999 and 2002. These are described in BLM's scoping report for Tyrrell (BLM 2002a) and summarized in Section 5.1 of this document. Scoping comments received during this time are described in detail in BLM's public comment summary report for Tyrrell (BLM 2002b), and summarized herein. Thirty public comments were received from 11 responders during the 1999-2002 timeframe. The majority supported the proposed IPM program or had no comments or concerns about BLM's proposal. One commentor was opposed to the use of chemical pesticides. Table 1.3-1 summarizes the number of comments by major category. Note that some commentors had more than one comment. These comments reflect the major issues that require consideration by the decisionmaker in developing the ROD for this EIS.

Comments made during the 2000 site meetings with adjacent or nearby landowners related primarily to information relevant to analyzing impacts to human health and safety (stocking nearby ponds, locations of nearby drinking water supplies, possible objections by neighboring tenants sensitive to pesticides, the logging camp, and organic garden/farm). The majority of landowners consulted had no concerns, objections, or comments about the proposed IPM program, nor did they think the program would adversely affect their water supply. They did ask to be kept informed, however, and several requested copies of future orchard environmental assessments (EAs) and EISs.

Three of the five commentors responding to the July 2002 scoping efforts were orchard cooperators (a fourth cooperator indicated that his comments were personal and not those of his business), who were in favor of the proposed IPM program, including the use of chemical pesticides. One of the cooperators specified that use should be within the EPA label restrictions. The cooperators also requested that the EIS consider the economic effects on the community and cooperative orchard users, particularly from the no action alternative, which could fail to adequately control orchard pests and thereby threaten the future of successful and timely reforestation goals.

The fifth commentor from July 2002 represented herself as well as the Coast Range Guardians and Canaries Who Sing. She expressed concern about the effects of insecticides in particular (specifically esfenvalerate) on soil, tree health, and ecological resources, including plants, wildlife, and coho salmon. She provided copies of two recent court decisions relating to salmon and pesticide use, and to pesticides entering waters of the U.S.

All of the scoping comments received and considered to be within scope are addressed in this EIS. Specific environmental resources of concern identified during scoping and analyzed in Chapter 4 are human health and safety, ecological (including vegetation, terrestrial wildlife, and aquatic species), soils, economics, and water quality. This EIS also addresses potential impacts to other resources that were not identified as concerns during scoping, but required evaluation to determine if any impacts were possible: air quality, land use, noise, and cultural resources. 
Figure 1.2-1: Location of Tyrrell Seed Orchard

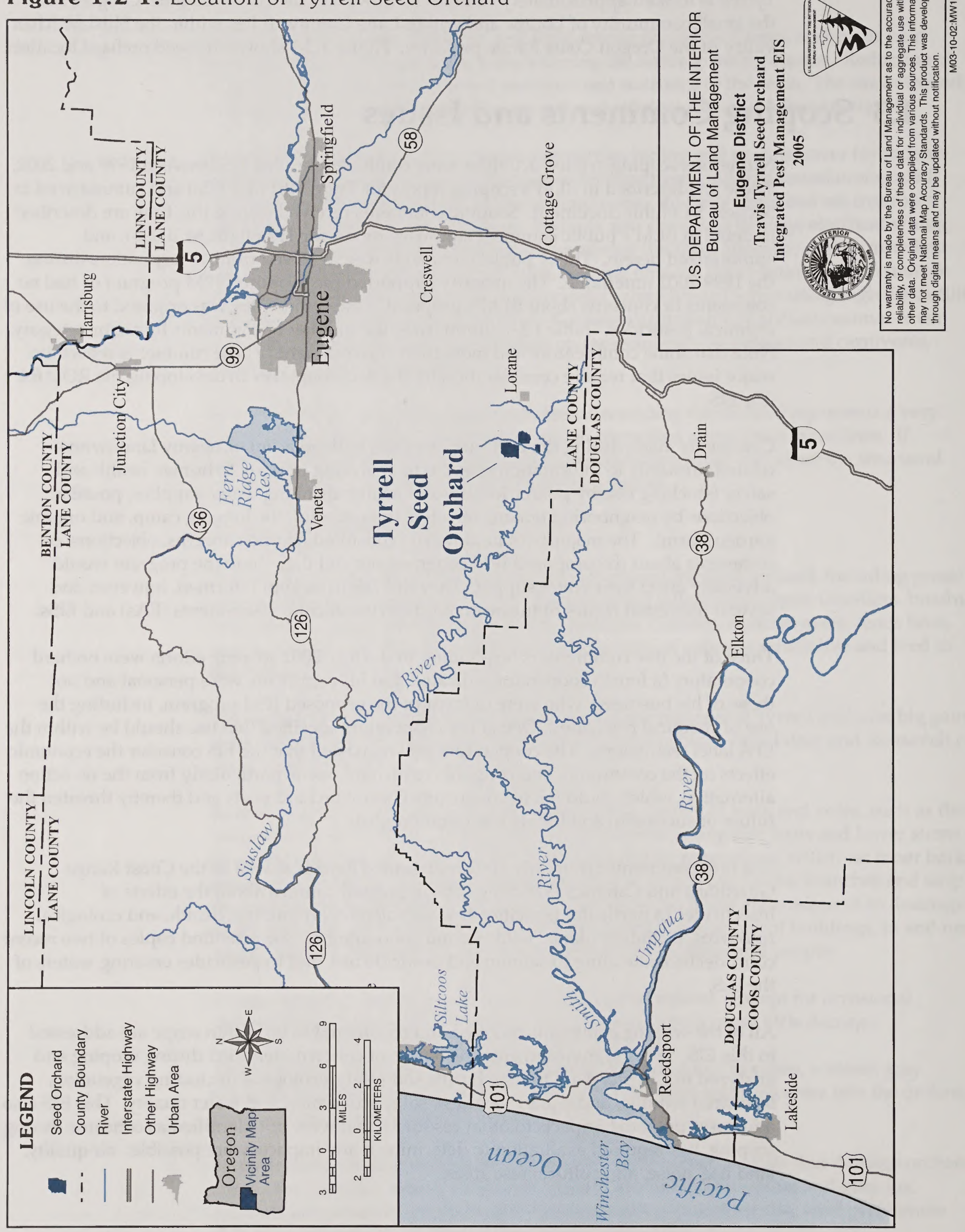


Table 1.3-1. Major Comment Categories

\begin{tabular}{|l|c|}
\hline Comment Category & Number of Comments \\
\hline Alternatives & 6 \\
\hline $\begin{array}{l}\text { Human health and safety impacts (related to drinking } \\
\text { water and fish consumption) }\end{array}$ & 2 \\
\hline Economic impacts & 2 \\
\hline Ecological impacts & 1 \\
\hline Soil impacts & 3 \\
\hline Water quality impacts & 1 \\
\hline General opposition to chemical pesticides & 5 \\
\hline General support for chemical pesticides & 3 \\
\hline No comment/out of scope & 30 \\
\hline Total Comments & 2 \\
\hline
\end{tabular}

\subsection{Relationship to Plans, Policies, and Programs}

\subsubsection{Related BLM Plans, Policies, and Programs}

The Eugene District Resource Management Plant (RMP) (BLM 1995) included the seed orchard within the District Designated Reserve system. These reserves were established for protection of specific resources, flora and fauna, and other values. These seed orchard values included preservation of genetic materials, production of improved seed, and various orchard developments and facilities.

The provisions of the Eugene District RMP found in the resource program sections for Energy and Minerals; Land Tenure Adjustments; Rights-of-Way, Access, and Withdrawals; and the information in Appendices C-Best Management Practices-Roads, and M-Forest Genetics Program, apply to Tyrrell. Except for these specific sections, the objectives and management actions / direction described in the Eugene District RMP are not applicable to Tyrrell.

Tyrrell is administratively withdrawn. Section 204 of the Federal Land Policy and Management Act (FLPMA) of 1976 (43 U.S.C. 1700 et seq.) describes "withdrawal" as "withholding an area of Federal land from settlement, sale, location, or entry, under some or all of the general land laws, for the purpose of limiting activities under those laws in order to maintain other public values in the area or reserving the area for a particular public purpose or program." It was noted as a public land withdrawal in the Eugene District RMP (BLM 1995). Specifically, Public Land Order 6662 withdrew a total of 832.5 acres at the seed orchard from surface entry and mining under the general land laws and mining laws.

BLM's Oregon State Office concluded that this intensively developed, administratively withdrawn site was not intended to meet the standards and guidelines for forest health as generally provided in the Eugene District RMP, which incorporated and superseded 
the Northwest Forest Plan (BLM 2000). In addition, standards and guidelines for various resources, such as Survey and Manage and Protection Buffer Species, while applicable to many administrative withdrawals, are not intended to be applied to intensively developed and used areas, such as Tyrrell (BLM 2000). The orchard is not considered appropriate or available for conversion to a late-successional reserve or any other land use allocation which might directly serve as scarce or important habitat (BLM 2000). BLM's findings distinguish the unique nature of this site from other administrative withdrawals, such as Research Natural Areas, which are designed and designated to be important components of the broad ecosystem management direction under the RMP.

BLM prepared and supplemented an EIS for Port-Orford-cedar management in southwest Oregon (BLM 2004a). Tyrrell will follow all relevant recommendations contained in the ROD for the Port-Orford-cedar management EIS.

BLM prepared and supplemented a programmatic-level EIS for Northwest Area Noxious Weed Control (BLM 1987). The ROD authorized use of specific herbicide formulations to control noxious weeds. The herbicide products contain dicamba, glyphosate, picloram, or 2,4-D as the active ingredient. Noxious weed control projects at Tyrrell using these herbicides would be authorized under this 1987 ROD. Subsequently, BLM prepared an EIS and ROD for the Western Oregon Program for Management of Competing Vegetation (BLM 1992). This ROD selected an IPM approach with a preference for non-herbicide methods, and applies to all BLM-administered land in the Coos Bay, Eugene, Medford, Roseburg, and Salem Districts, and part of the Lakeview District. Actions covered under the 1987 Noxious Weed Control EIS are excepted from this decision.

There is currently an injunction prohibiting BLM from applying herbicides. It has been partially lifted to allow applications for noxious weeds, as covered under the NEPA documents described in the preceding paragraph. Except for these uses, the injunction would have to be lifted (in its entirety or specifically for the seed orchard) before herbicides could be used as described in this EIS.

BLM is undertaking a programmatic EIS for vegetation treatment on public lands administered by the BLM in the western U.S., including Alaska. This programmatic EIS will consolidate, update, and replace analyses contained in existing BLM vegetation treatment EISs, as well as include lands not analyzed in the existing documents. The programmatic EIS is not intended to affect specific Agency management decisions developed under local land-use plans, but will provide a baseline cumulative impact assessment that local BLM offices, including the Eugene District Office, can use as they develop or update each district land use plan/EIS. The public scoping comment period on the programmatic EIS ended March 29, 2002. The programmatic Draft EIS was not published as of the date this seed orchard IPM Final EIS went into publication.

In the absence of this IPM EIS, Tyrrell prepared a project specific EA's for insecticide applications in 2003, 2004, and 2005 at Tyrrell (BLM 2002c, BLM 2003, and BLM 2004b). However, once a decision is issued on the basis of this EIS, such project-specific NEPA documentation should no longer be required at Tyrrell, since the ROD would make available to the seed orchard manager a variety of pest control methods that can be implemented to control specific pests in a manner that best fulfills orchard goals.

BLM's Salem and Medford Districts in western Oregon are developing similar IPM EISs for their three seed orchards concurrently with this one for Tyrrell. Specifically, the Salem District is developing an EIS for the Horning Seed Orchard, and the Medford District is developing a second EIS to cover both the Provolt and Sprague Seed Orchards. Both EISs are being prepared under the same project schedule as this EIS for Tyrrell. 


\subsubsection{Relevant Federal, State, and Local Statutes and Guidelines}

Pest management at Tyrrell would follow all relevant Federal, state, and local laws and regulations. Major legislation relating to this EIS includes the following.

- National Environmental Policy Act of 1969 (42 U.S.C. 4321 et seq.), as amended: requires Federal agencies to prepare an EIS if a proposed action has a potential for significant environmental impacts.

- The Federal Insecticide, Fungicide, and Rodenticide Act (FIFRA) of 1947, as amended (7 U.S.C. 136 et seq.): establishes procedures for the registration, classification, and regulation of all pesticides. The Environmental Protection Agency (EPA) is responsible for implementing FIFRA; primary enforcement responsibilities for use-related violations are assigned to states with approved programs. Before any pesticide may be sold legally, it must be registered by EPA. EPA may classify a pesticide for unrestricted use if it determines that the pesticide is not likely to cause unreasonable adverse effects on applicators or the environment. States may classify pesticides for restricted use (which means they may be applied only by or under the direct supervision of a certified applicator or in accordance with other restrictions), even though EPA may not have done so.

- The Clean Air Act, as amended (42 U.S.C. 1857 et seq.): sets national primary and secondary ambient air quality standards, requires that specific emission increases be evaluated to prevent a significant deterioration in air quality, and provides EPA with authority to set national standards for performance of new stationary sources of air pollutants and standards for emissions of hazardous air pollutants.

- The Clean Water Act (33 U.S.C. 1251-1387) of 1984, as amended: charges EPA with protecting the nation's water resources and wetlands, and controlling the discharge of toxic chemicals. The Act defines water quality standards for priority toxic pollutants, oversees the industrial pre-treatment program, and provides local governments with the authority to control non-industrial discharges of toxics.

- The Safe Drinking Water Act (SDWA) of 1974 (42 U.S.C. 300(f) et seq.): established a national structure for drinking water protection activities. The Act authorized EPA to establish national, enforceable health standards for contaminants in drinking water; provided for public water system compliance through a Federal-state partnership; established public notification to alert customers to water system violations; and set up procedures to protect underground sources of drinking water.

The 1996 amendments to the SDWA required states to develop source water assessment programs (SWAPs) that outline an approach for conducting source water assessments, delineate the boundaries of areas from which public drinking water systems receive drinking water, and identify the origins of regulated and unregulated contaminants. In Oregon, the Oregon Department of Environmental Quality (ODEQ) has state primacy for implementing the SDWA and administers both the SWAP and the underground injection control (UIC) program through this authorization. Through both the SWAP and UIC programs, ODEQ seeks to ensure the protection of groundwater that is used for drinking water. BLM supports ODEQ's efforts by contributing data and information to ODEQ's UIC registry of sites. Among the sites registered under ODEQ's UIC program are Class V injection wells. EPA Region 10 defines Class V injection wells to be systems, structures, or activities that allow for subsurface placement of fluid directly. In most instances, a hole or a trench using piping would qualify if the purpose or intent is for subsurface discharge either through infiltration or injection. Operation and maintenance activities at Tyrrell do 
public lands within its jurisdiction. FLPMA requires BLM to manage public lands and their resources for multiple use, and to develop resource management plans for lands under BLM's jurisdiction.

State and county weed control laws place responsibility for noxious weed control on individual land owners, including the Federal government. Permittees and grantees operating rights-of-way on BLM-administered land are required to comply with Department of the Interior herbicide use regulations. BLM must also coordinate with appropriate state agencies in managing state-listed plant and animal species when a state has formally made such designations.

\subsection{Organization of this EIS}

This document is organized into four main chapters. Background and support information, including a summary of the human health and ecological risk assessment, is provided in the appendices. The Final EIS presents five alternatives for managing pests at Tyrrell, including the no action alternative, and examines the potential environmental impacts of each alternative. Chapter 1, Purpose and Need, identifies the purpose and need for action, provides an introduction to typical pests found at the orchard, and discusses the public issues surrounding pest management and other considerations. Chapter 2, Alternatives, presents and compares the alternatives, with information on how they would be implemented with measures to protect the environment. Chapter 3, Affected Environment, includes a description of the physical, biological, and social setting of the orchard. Chapter 4, Environmental Consequences, addresses changes likely to occur with implementation of any of the alternatives.

In addition to the four main chapters, the document contains these sections: Executive Summary; Table of Contents; Chapter 5-Consultation and Coordination (including scoping process, consultation list and a list of agencies, organizations, and individuals to whom copies of the statement were sent); Chapter 6-List of Preparers; Chapter 7-References; a list of acronyms; a glossary; and an index.

Additional detail and background information is presented in appendices:
A. Seed Orchard Pests
B. Monitoring Plan
C. Risk Assessment Summary
D. Risk Analysis of Sublethal Effects for Special Status Aquatic Species
E. Public Comments on Draft EIS and BLM Responses
F. NOAA Fisheries Conference Opinion Transmittal Letter and Conference Opinion 


\subsection{Description of Alternatives, Including Proposed Action}

\subsection{Background}

\subsubsection{Seed Orchards, Tree Improvement Program, and Genetics}

BLM manages four centralized tree seed orchards in western Oregon: Tyrrell in the Eugene District, Horning in the Salem District, and Provolt and Sprague in the Medford District. Historically, the seed orchards' role was to provide genetically improved Douglas-fir and sugar pine seed and seedlings to the five western Oregon districts and the western Klamath Falls resource area for reforestation and progeny test programs. A major shift in management emphasis in the districts' RMPs sharply decreased the need for seeds for reforestation. Therefore, the seed needed for BLM purposes from the BLM seed orchards was greatly reduced. To allow BLM to cost-effectively manage the seed orchards, an effort has been made to share the seed orchards with other cooperators. Consequently, the seed needs from many of the orchard units have increased because of strong cooperator interest.

\section{Orchard Operations}

There are two types of BLM seed orchards, each serving a different purpose. In breeding and preservation orchards, trees from the same clone/family are planted in tight spacing and located together. The main purpose of these orchards is to breed for advanced generation programs and/or preserve genetic material (clone banks). They do not represent the total genetic variation selected within the breeding zone. This variation is more appropriately preserved in the progeny test sites. In seed production orchards, trees from different clones / families within the same seed zone are planted at wider spacing and are designed to facilitate good mixing of pollen and reduce self-pollination. The main purpose of the seed production orchards is to produce genetically improved seed for reforestation. There are Phase I and Phase II seed production units. The Phase I units have been established with the first generation clonal material, and will be the main source of seed for the current and next decade. Most of the Phase II units are undeveloped and are reserved for advanced generation orchards.

Tyrrell meets the improved conifer seed needs for BLM's Roseburg, Eugene, and part of Coos Bay Districts. A cooperative program was started in 1998 to share improved Douglasfir seed with nine private timber companies and one seed company. There are 297 acres of Douglas-fir seed production units, and the 25 orchard units range from 2 to 17 years of age. Small crops were harvested in 1997 to 1999. The first large crop (1,000 bushels) was harvested in 2000, with collections steadily increasing to 4800 bushels in 2004 .

Although Tyrrell is outside of the tree species' natural range, a six-acre Port-Orford-cedar preservation orchard was begun in 1999 to preserve material with genetic resistance to the Phytophthora fungus. New material is planted as it becomes available.

A Douglas-fir breeding and preservation orchard occupies 40 acres. A Douglas-fir second generation tree breeding program has been ongoing in this orchard since 1993.

An 18-acre multi-species seed production orchard was also established, and includes the following species: western hemlock, Port-Orford-cedar, western redcedar, incense cedar, ponderosa pine, western white pine, grand fir, Sitka spruce, knobcone pine, Jeffrey pine, and shore pine. These species range in age from 2 to 13 years; seed production will not start until sometime in the future. 
A pollen processing facility exists on-site, with more than 800 pollen lots in long-term storage.

Also present is a seed extraction facility, which processes conifer and native grass seed. A native brome common garden study is ongoing.

Figure 2.1-1 depicts the layout of Tyrrell and its seed production and breeding and preservation units. A fenced hazardous materials storage area is located on BLM land in Section 15 outside of the seed on land's fenced perimeter; the herbicide use proposed for vegetation control in this EIS includes potential treatment in this area.

\subsubsection{Ongoing Orchard Activities}

Under all alternatives, routine management actions for orchard establishment and maintenance activities would continue to occur. However, these actions-which include orchard establishment, orchard maintenance, buffer zone management, and facilities/ equipment maintenance-are not directly related to IPM and therefore are not evaluated in this EIS. See also discussion of District RMP in Section 1.4.1.

\section{Orchard Establishment}

Most land clearing at Tyrrell has been completed. Any future site preparation would be very limited and would consist of preparing an area for a new orchard by removing existing stumps, subsoiling, rototilling or disking, leveling, and cover crop seeding. These site preparation activities would also occur as older orchards are recycled; that is, as trees become too large to harvest cones and are replaced with advanced generation orchard material. Approximately 10 acres of orchard are likely to be recycled over the next decade. Thirty more acres would likely be recycled in the following decade.

New orchards would periodically be established in the Phase II fallow areas and in orchards that are being recycled. Individual tree positions in new orchards would be rototilled to prepare the area for planting. Trees would be planted by shovel, tree spade, or power auger, mulched with porous fiber or poly mats to help control competing vegetation and retain soil moisture, shaded with cards or screens to reduce seedling basal heat damage and overall tree stress, and tubed with mesh cylinders or fencing material to prevent animal damage.

Most of the first generation seed orchards are clonal and contain the best parent trees selected from natural forest stands and tested in progeny testing programs. Cuttings would be taken from the best parent trees, based on progeny test results, and grafted onto rootstock in the orchard units. Orchard trees would occasionally be transplanted with various sizes of tree spades. All genetic improvements at Tyrrell are based on selective breeding; Tyrrell is not equipped and has no program for direct genetic manipulation.

In addition to conifer tree seed production orchards, some additional native plant areas may be established for production of native grasses, forbs, and other plant species. At the current time, only a one-acre native grass (bromes) study is in place. Future establishment of native plant areas is not currently planned, but will be considered and is possible in the future. Actions for establishment and maintenance of these native plant areas would not be substantially different from the conifer tree seed production orchards.

\section{Orchard Maintenance}

Orchard trees would be pruned to remove unwanted rootstock vegetation (as graft unions become established), to remove lower limbs to improve access for equipment 
Figure 2.1-1: Layout of Tyrrell Seed Orchard

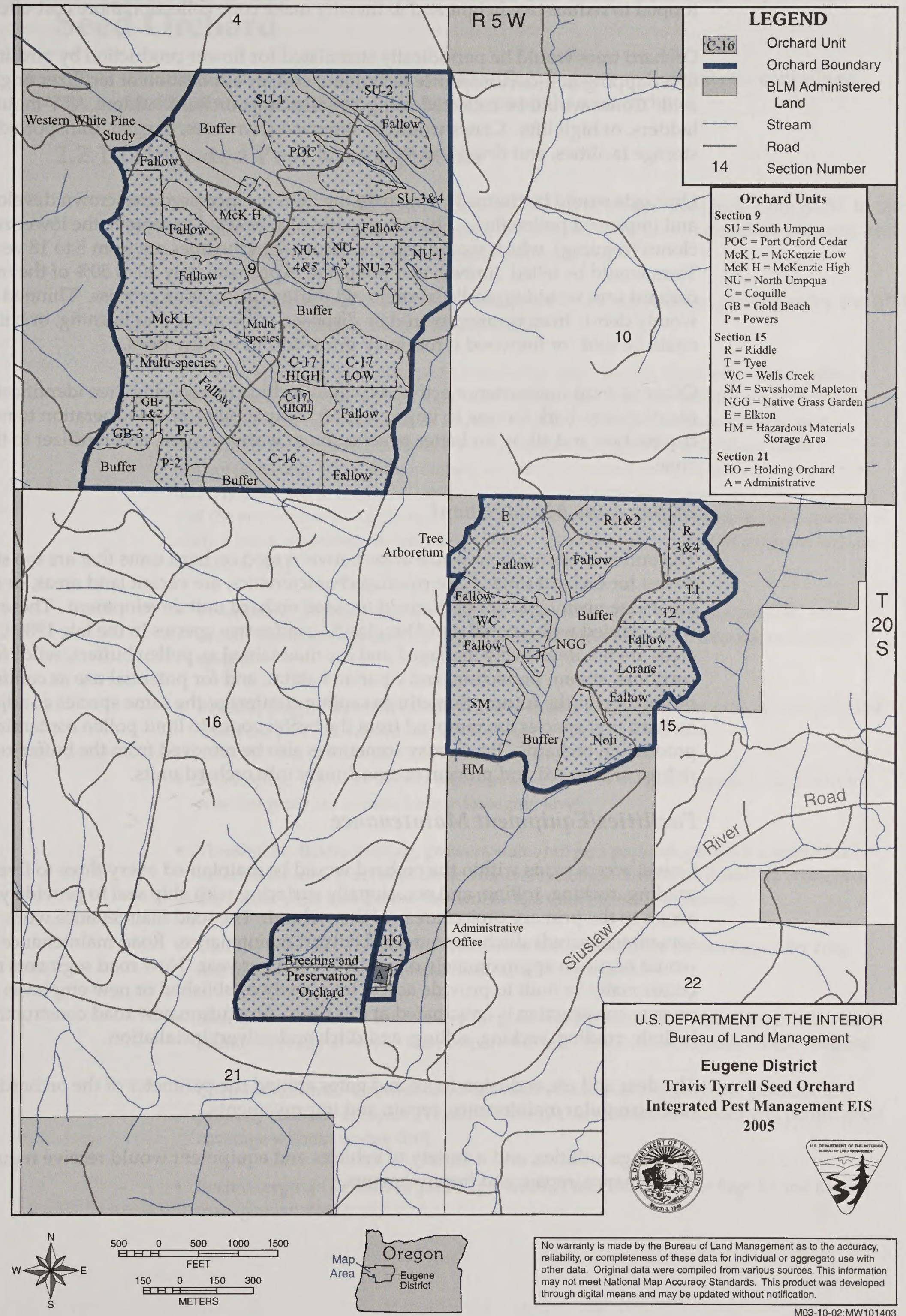


operation, and to thin and shape tree crowns. In addition, some orchard trees would be topped to reduce tree height and to thereby make cone collection more cost-effective.

Orchard trees would be periodically stimulated for flower production by girdling (overlapping half-circumference technique) and/or application of fertilizer or gibberellic acid. Cones would be collected using tree climbing, orchard ladders, ATV-mounted ladders, or high lifts. Cones would be removed from trees, bagged, transported to cone storage facilities, and dried and stored.

Orchards would be thinned to increase the light for increased tree crown development and improved pollen flow. Thinning would also be used to remove the lower ranked clones (roguing), which would usually occur when the trees are from 5 to 18 years old. Trees would be felled, limbed, and removed. Approximately 20 to $50 \%$ of the trees in an orchard unit would typically be removed during the roguing process. Thinned trees and woody debris from pruning would be disposed of by piling and burning, or chipping; or could be sold for firewood if routinely pruned from healthy trees.

Other orchard maintenance activities would include tree staking, tree identification tag maintenance, bark scoring to improve graft compatibility, and soil aeration to reduce soil compaction and allow for better penetration of water, oxygen, and fertilizer to the rooting zone.

\section{Buffer Zone Management}

The buffer zones are non-usable areas between seed orchard units that are too steep or wet for orchard units, have riparian characteristics, are vacant land areas, or are otherwise unsuitable or not planned for seed orchard unit development. These areas were planted with several non-Douglas-fir conifer tree species in the late 1980s. The areas are not intensively managed and are maintained as pollen buffers, wildlife corridors, stream protection, and riparian habitat, and for potential use as conifer seed production in the future. Sometimes sapling conifers of the same species as adjacent orchard unit species are removed from the buffer zones to limit pollen contamination of production orchards. Brush may sometimes also be removed from the buffer zones to reduce fire hazard and prevent encroachment into orchard units.

\section{Facilities/Equipment Maintenance}

Gravel access roads within the orchard would be maintained every three to five years by grading, rocking, rolling, and occasionally surfacing with chip seal to provide year-round access to the primary project areas of the orchard. The road maintenance work would sometimes include ditch cleaning and culvert maintenance. Road maintenance activities would occur on approximately one mile of road per year. New road segments might occasionally be built to provide access into newly established or new emphasis areas, but no new construction is anticipated at this time. Any future new road construction would include grading, rocking, rolling, and ditch and culvert installation.

The deer and elk exclusion fence and gates around the perimeter of the orchards would receive regular maintenance, repair, and improvements.

Buildings, utilities, and a variety of vehicles and equipment would receive regular maintenance, repair, and improvements. 


\subsection{Integrated Pest Management in the Travis Tyrrell Seed Orchard}

This section describes the principles of an IPM program and options for controlling insects, disease, vegetation, and animal pests at the seed orchard.

\subsubsection{Integrated Pest Management}

It is the policy of the Department of Interior, and all of its agencies including BLM, to use chemical pesticides only after considering the alternatives; and to develop, support, and adopt IPM strategies wherever practicable (DOI 1981).

The following description of IPM was condensed from information published by the IPM Institute of North America, Inc. (IPM Inc. 2002).

IPM is an approach to solving pest problems by applying our knowledge about pests to prevent them from damaging crops, harming animals, infesting buildings or otherwise interfering with our livelihood or enjoyment of life. IPM means responding to pest problems with the most effective, least-risk option. Under IPM, actions are taken to control pests only when their numbers are likely to exceed acceptable levels. Any action taken is designed to target the troublesome pest, and limit the impact on other organisms and the environment. Applying pesticides to crops, animals, buildings or landscapes on a routine basis, regardless of need, is not IPM. ... [Components of an IPM program include the following:]

- Forecasting: Weather data is consulted to predict if and when pest outbreaks will occur. Treatments can then be properly timed, preventing crop damage and saving sprays.

- Pest trapping: Traps that are attractive to insects are used so that growers can pinpoint when the pest has arrived and decide whether control is justified.

- Monitoring: Growers inspect representative areas of the fields regularly to determine whether pests are approaching a damaging level.

- Thresholds: Before treating, growers wait until pest populations reach a scientifically determined level that could cause economic damage. Until that threshold is reached, the cost of yield and quality loss will be less than the cost for control.

- Cultural controls: The pest's environment is then disrupted by turning under crop residues, sterilizing greenhouse tools, and harvesting early.

- Biological controls: It is necessary for growers to conserve the many beneficial natural enemies already at work. They import and use additional biologicals where effective.

- Chemical controls: Growers select the most effective and appropriate pesticide and properly calibrate sprayers. They then verify that weather conditions will permit good coverage without undue drift.

- Recordkeeping: Records of pest traps, weather and treatment are kept for use in pest management decisions. 
IPM for seed orchards is the maintenance of seed orchard pests at tolerable levels by the planned use of a variety of preventive, suppressive, or regulatory methods (including no action) that are consistent with orchard management goals. Each pest management activity is the end result of a decision-making process where pest problems and their impact on hosts are considered, and control methods are analyzed for their effectiveness, as well as their impacts on economics, human health, and the environment. Deciding which particular method would be used depends on several factors. Initial questions at the seed orchard might include, "Is it really necessary to control this pest? Can we live with the damage and still have the trees survive and produce suitable amounts of seed?" If the answers are yes and no, respectively, then decisions must be made as to what method(s) of control to use. Figure 2.2-1 graphically displays the steps involved in carrying out an IPM program in BLM seed orchards.

The focus of IPM is on long-term prevention or suppression of pests. The integrated approach to pest management incorporates the best-suited biological, chemical, and cultural controls that have minimum impact on the environment and on people. IPM is not pesticide-free management; however, a successful IPM program should result in the most efficient use of pesticides if and when they are needed.

Research into better and more effective control methods is also an essential part of this program. The seed orchard manager would regularly review the pest management methods available for use, including new and developing technologies, to ensure that the seed orchard utilizes the most effective methods of control while minimizing the potential for any adverse environmental or health impacts.

\subsubsection{Pest Management Methods}

There are many methods available to manage vegetation, insects, disease, and animal pests at Tyrrell. These methods generally fall into the following categories:

- Biological controls, such as bird or bat boxes to attract insect-eaters.

- Chemical herbicides, insecticides, fungicides, and fumigants.

- Prescribed fire to remove vegetation.

- Cultural methods, including all mechanical (tractor mowing) and manual (pruning) methods, sanitation, mulch mats, and fences.

- Other methods, such as pheromone bait traps for monitoring and potentially controlling insects.

The subsections that follow outline each of these pest management methods in more detail.

\subsubsection{Biological Control Methods}

Biological pest control is the deliberate use of natural enemies such as parasites, predators, or disease organisms to reduce pest populations. Three types of biological controls are under consideration to manage insect pests:

- Bird boxes are located throughout the orchard. Birds are seen predating insects throughout the year, though their overall effect has not been quantified. Bat boxes are also used to encourage insect-eating bats.

- Bacillus thuringiensis (B.t.), a biological insecticide, is being considered to help reduce insect damage at the orchard. 
Figure 2.2-1. Seed Orchard IPM Process

Develop annual IPM plan for each pest, including:

- Compile information profile for each pest*

- Identify and analyze available control options

- Select method that best address seed orchard goals**

- Document decision and rationale.

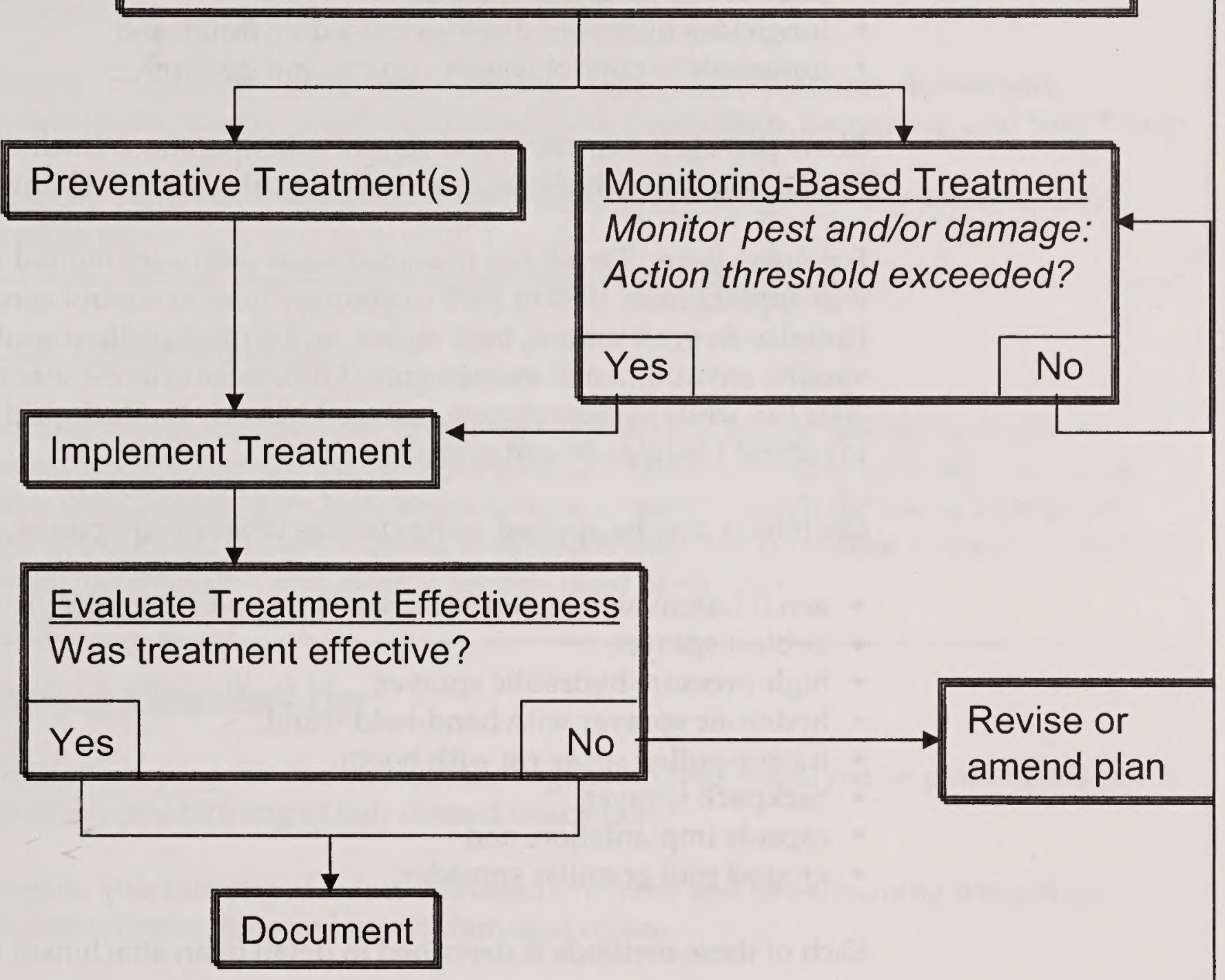

*Profiles will vary in depth and included information based on threat from any particular pes may consist of a group of files, reports, and on-line data sources.

- Grazing using sheep, goats, or cattle could be used to help control undesirable vegetation.

Control of animal pests has been and would continue to be partially accomplished by predators that frequent the orchard, including coyote, fox, cougar, and bobcats. Coyote, as well as red-tailed hawks, are often seen following behind the mowers in search of mice, moles, and voles. Except for occasional digging near the base of trees for bees nests and small mammals, which leave large holes and disturb tree roots, they are of little threat. 


\section{Summary: Biological Control Methods}

- Vegetation: Sheep, goats, or cattle placed in the orchard units to control grasses.

- Insects: bird boxes to attract insect-eating birds, bat boxes to attract bats, B.t.

\subsubsection{Chemical Pesticide Methods}

Four categories of chemical pesticides may be used at Tyrrell:

- herbicides to control weeds,

- insecticides to control insects,

- fungicides to control diseases caused by fungi, and

- fumigants to control weeds, insects, and diseases.

Many private landowners and commercial operations (including those in the vicinity of Tyrrell) rely extensively on chemical pesticides to control unwanted pests.

For many years, Tyrrell has managed pests with very limited use of chemicals: lindane was applied from 1989 to 1998 to younger trees to control coneworm (Dioryctria) in Douglas-fir graft unions, bark scores, and partial girdle stimulation cuts. Under projectspecific environmental assessments (EAs), esfenvalerate was used in 2003 ( 29 acres) and 2005 (58 acres) to control cone and seed insects. Imidacloprid was used in 2004 (60 acres) to control Douglas-fir gall midge..

Chemicals may be applied using various types of equipment. These include:

- aerial (esfenvalerate, fertilizer, and B.t. applications only),

- airblast sprayer,

- high-pressure hydraulic sprayer,

- hydraulic sprayer with hand-held wand,

- tractor-pulled spray rig with boom,

- backpack sprayer,

- capsule implantation, and

- ground pull granular spreader.

Each of these methods is described in detail in an attachment to Appendix C.

Table 2.2-1, provided as an attachment at the end of this chapter, lists the biological and chemical pesticides that are included in the alternatives for pest management at Tyrrell, including formulations, target pests, application methods, areas that could be treated, application rates, application frequency, and months when use could occur. Note that not all chemicals would be used in a given year, and some might never be used. However, their analysis in this EIS gives the seed orchard manager the option of using them in the future should a specific need arise. It is also important to note that each chemical application must first be approved by the Tyrrell seed orchard manager. All pesticides would be applied in compliance with all Federal and Oregon state laws, BLM regulations and policies, the pesticide label, and manufacturer recommendations.

Table 2.2-1 lists pesticides by both active ingredient (a.i.) and trade name. The active ingredient is the pesticidally active chemical contained in the product proposed for use, such as esfenvalerate or glyphosate. The trade name is the name of the formulated product that is currently expected to be used, such as Asana ${ }^{\circledast}$ XL or Roundup ${ }^{\circledR}$. A trade name's formulation is described by a specific composition of active ingredient(s) and other ingredients. The formulation associated with a trade name may change over time. The chemical pesticide methods proposed in this EIS are described fully as the 
active ingredients listed in Table 2.2-1. The trade names provided in the table and the associated \% a.i. are examples, and are current at the time of EIS publication. The trade names illustrate the formulations that may be used, but are not intended to limit the proposed IPM program to exclusive use of those formulations that are named in the table. Other formulations of the listed active ingredients may be substituted, at the same rate of application described in the table. The table presents application rates in terms of a.i. per acre or per tree, and will therefore remain applicable to any trade name or formulation of the listed active ingredients.

\section{Summary: Chemical Pesticide Methods}

- Vegetation: herbicides, including dicamba, glyphosate, hexazinone, picloram, and triclopyr.

- Insects: insecticides, including acephate, chlorpyrifos, diazinon, dimethoate, esfenvalerate, horticultural oil, imidacloprid, permethrin, propargite, and Safer ${ }^{\circledR}$ soap.

- Disease: fungicides, including chlorothalonil, propiconazole, and dazomet (a soil fumigant).

\subsubsection{Prescribed Fire}

Prescribed fire may be used for removing vegetation in native species beds prior to planting, and also for disposing of branches and cones damaged by insects or disease. In the native species beds, high temperatures, created through the use of a propanefueled flame wand, kill any existing herbaceous material, providing a weed-free bed for growing native plants, and quickly remove dead plant litter.

\section{Summary: Prescribed Fire}

- Vegetation: propane-fueled torch for vegetation removal in native plant beds prior to planting, pile burning of cut/cleared vegetation.

- Insects: pile burning of insect-damaged branches and trees, burning cones from sanitation collections and insect-damaged cones.

- Disease: pile burning of infected branches and trees.

\subsubsection{Cultural Methods, Including Manual and Mechanical Methods}

Cultural control refers to the use of methods that make the habitat less suitable for pests or prevents, suppresses, or removes them. Cultural methods include both manual and mechanical control methods.

Cultural methods for vegetation include hand-pulling or using non-powered and powered hand tools and machinery to cut and clear vegetation.

- Orchards are rogued and thinned to allow desirable clones to thrive and produce bountiful crops. Thinning opens up the crowns, allowing additional light to reach the crown surface. Thinning also increases available soil moisture to residual trees.

- Vegetation mats using polypropylene and nylon mesh sheets have been used since orchard development for protecting seedlings from competing vegetation. They are 
placed over bare mineral soil following planting. The matting is typically three or four feet $(\mathrm{ft})$ square and is held in place with metal or plastic pins placed in the corners. The tree protrudes through a slit in the middle of the sheet. Maintenance is minimal and the mats can be left on indefinitely.

- Hand weeding is used to manually remove undesired vegetation from the native grass beds two to three times during the growing season. Hand weeding also takes place several times a year around the office compound.

- Mechanical control methods typically involve the use of machinery to physically cut or remove vegetation. Several mechanical methods are used at Tyrrell, including the use of tractors for mowing. Seed production orchards (20 ft $\times 20 \mathrm{ft}$ spacing) are mowed and cross-mowed using 15 -ft bat-wing rotary mowers. This leaves a 5 -ft unmowed area around the base of each tree. Orchards are typically mowed twice during the summer, in May/June and July/August. Mower heights are set at about four inches to avoid scalping the ground surface, which would open up growing space for what often becomes unwanted vegetation. Close mowing, using a 3 -ft flail mower or a walk-behind rotary mower, is often done around trees in young orchards to cut vegetation that remains following treatment with the large mowers. A 5-ft swath is mowed several times during the growing season along roadsides to control low vegetation. Grading of roadside edges at appropriate times can also be used to control weedy vegetation. Taller, overhanging vegetation is mowed every two to three years using an articulating mower with an $18-\mathrm{ft}$ reach. Fence lines, where accessible, are mowed with 15 - $\mathrm{ft}$ batwing mowers to provide clear access around the orchard perimeter and to create a fire break. Gasoline-powered string trimmers are utilized for cutting tall grass around the office compound.

- Tractor-pulled vacuum is used to remove duff and litter from around the drip line of orchard trees to remove insect habitat.

- Brush in the orchards is generally controlled by mowing. However, hand cutting (using hand shears, loppers, and chain saws) of brush is often done around the base of the tree.

- Tilling is used to physically remove the weedy vegetation at some locations. A 6-ft tiller is used around the native grass beds to maintain an unvegetated buffer. Tilling is usually done in spring and fall.

Pruning is done in western white pine and sugar pine stands to remove lightly infected branches having blister rust. Severely infected trees are removed.

Stump grinding to remove the physical threat of root disease has not yet been used at Tyrrell, but may be done in the future. Tracked excavators have been used on a limited basis to remove stumps from the orchard. To date, neither Armillaria root rot nor laminated root rot has been detected in the orchard. During orchard development, stumps and roots were removed to a depth of three feet, removing much of the potential for root diseases. Although these diseases are present in adjacent stands, the likelihood of them causing significant damage prior to recycling the orchards (at which time the stumps would be removed and ripping would occur again) would be minimal. At present, stumps are cut flush to the ground surface.

For animal pests, particularly for gophers, live trapping and relocation or kill trapping are possible alternatives.

For animal pests such as deer and elk, exclusion fencing has been installed to reduce browsing damage. An eight-foot steel mesh fence surrounds the orchard. It is approximately $7 \frac{1}{2}$ miles in length. The common garden study for brome $(1 / 4$ acre $)$ is enclosed by one-foot tall chicken wire to keep rabbits out of the study area. Vexar ${ }^{\mathrm{TM}}$ tubes, approximately one-foot tall, are placed around newly planted seedlings. These tubes provide a barrier to voles, moles, and rabbits, which can damage the cambium layer of seedlings. 


\section{Summary: Cultural Control Methods}

- Vegetation: hand-pulling; non-powered and powered hand tools to cut and clear; tractors with various mowing attachments and gasoline-powered string trimmers for mowing grass and other vegetation; brush cutting machine mounted on tractor for cutting brush and topping trees; chainsaw for cutting thinned, rogued, or dead/ dying orchard trees and brush; pruner, power pruners, and similar equipment for cutting tree limbs and brush; chipping; tilling an unvegetated buffer around native plant beds; organic hot foam weed control; mulch mats to control vegetation around orchard trees; mulch or black plastic to cover and control noxious weeds and other vegetation.

- Insects: pruning, thinning, use of grafting wax or spray seal on tree wounds, sanitation of damaged branches and trees, hand-picking large and noticeable insect pupae, cone sanitation (clean-picking cones from trees).

- Disease: pruning, thinning, cone sanitation (clean-picking cones from trees), stump grinding, power saws to cut infected or dead trees, physical removal of stump by grinding or pulling.

- Animal pests: trapping of gophers, walking (herding) stray deer and elk toward gate and out of orchard, pruning tree limbs up at the base of the trees, removing unwanted vegetation, mowing cover crop vegetation that provides cover for small mammals, live trapping, fencing to exclude deer and elk from orchard, chicken wire to exclude rabbits from common garden study, Vexar ${ }^{\mathrm{TM}}$ tubes to protect seedlings from voles.

\subsubsection{Other Control Methods}

Pheromone bait traps can attract and kill damaging insects. They are currently used to monitor insect populations. In the future, they may be used for insect control, based on the findings of ongoing studies.

To promote overall tree health, cone production, and disease resistance in the orchards, fertilization and cone stimulation are used. Fertilizer "tea bags" are placed in the bottom of planting holes. These packets are filled with a slow release blend of essential nutrients that provide seedlings with additional health and vigor during their first year. Calcium nitrate is used in specific orchards in March to help stimulate flower production for the following year's cone crop. It is applied by hand around the drip-line of trees at a rate of about 0.7 pounds $(\mathrm{lb})$ of nitrogen per tree. Every one to three years, a general fertilization (by ground or aerial application) is completed to improve the nutrient levels of the trees and grass cover crop. Soils are aerated prior to fertilization. Although mowing is more intense for the first year, the nutrient boost appears to keep the desirable ground cover thriving and invasive species at bay. Fertilizer mixes and rates have been determined by a soil scientist, based on site-specific information for Tyrrell. Application details for fertilizers are included in Table 2.2-1.

\section{Summary: Other Methods}

- Insects: pheromone bait traps.

- Fertilization to promote overall tree health, cone production, and disease resistance. 


\subsection{Alternatives}

\subsubsection{General Description and Features Common to All Alternatives}

Five alternatives based on the pest management approaches described in Section 2.2.2 were identified and evaluated by BLM to address the need for a pest management program at Tyrrell, as follows:

- Alternative A-Maximum Production IPM

- Alternative B-IPM with Environmental Protection Emphasis (Proposed Action)

- Alternative C-Ground-Based IPM

- Alternative D-Non-Pesticide Pest Management

- Alternative E-No Action: Continue Current Management Approach

There are several features common to all alternatives. Pest management methods that are common to all alternatives are non-pesticide biological methods, cultural methods, prescribed burning, and other control methods. Additional activities common to all alternatives include orchard management activities unrelated to pest management (see Section 2.1.2) and protection measures that would be associated with a given pest control method under any alternative in which it is included. These protection measures are described in the following paragraphs.

Protection measures are intended to ensure the proper and safe application of pesticides at Tyrrell. FIFRA requires pesticide manufacturers to register their chemicals with EPA, and list the allowable uses, application rates, and special restrictions on each pesticide's label. The pesticides considered for use at Tyrrell are all registered under FIFRA. Application operations would comply with the label rates, uses, and handling instructions, in accordance with Federal law. In addition, the following procedures would be designed and implemented by Tyrrell, and routinely observed in pesticide applications. If output from the monitoring plan (see Appendix B) indicates that more protection is needed, these protection measures may be altered over the life of this IPM program to provide more (but not less) protection to workers, the public, the environment, and ecological resources:

\section{Worker Protection Measures}

- Pesticide treatments would normally be done under contract by licensed pesticide applicators. BLM would administer the contracts for compliance.

- A Job Hazard Analysis for pesticide applications would be developed, providing a detailed description of the jobs and associated risks involved with pesticide use and application. It would identify requirements for personal safety equipment, training, and certification to perform specific tasks.

- Pesticide applications done by BLM employees would be conducted in compliance with all aspects of EPA's Worker Protection Standard under FIFRA, including protection during applications, restricted entry intervals, personal protective equipment, notification of workers, decontamination supplies, emergency assistance, pesticide safety training and safety posters, and access to labeling and site-specific information. All pesticide applications done by contract would require that the contractor use licensed pesticide applicators.

- All BLM workers directly involved in pesticide applications would be required to participate in a pesticide exposure monitoring program. Testing for cholinesterase inhibition would be conducted on BLM employees applying organophosphates. Also, workers with declared hypersensitivity or who display symptoms of hypersensitivity to pesticides would not be assigned to application projects. 
- Material safety data sheets would be posted at storage facilities and made available to workers. These provide physical and chemical data, fire and reactivity data, specific health hazard information, spill or leak procedures, instructions for worker hygiene, and special precautions.

- Appropriate protective clothing would be worn by all BLM workers. At a minimum, the type and amount of protective clothing listed on the pesticide label would be used.

- For all pesticide application methods (except spot treatments using hand-held application equipment), treated areas would not be re-entered until sprays have dried or until the stated label re-entry period has been met. If permitted by the label, early re-entry would be allowed but protective clothing would be required.

\section{Public, Environmental, and Ecological Protection Measures}

- Prior to pesticide application, Tyrrell would notify downstream water users within one-half mile of the project area, and adjacent landowners who could be affected by accidental drift, water transport from the pesticide application area, or an accidental spill.

- Warning signs would be posted to discourage entry into treated areas treated with pesticides.

- Pesticides would be applied within the parameters of prescribed environmental conditions stated on the label. Factors such as relative humidity, wind speed, and air temperature would be considered to determine the timing of applications to minimize the potential for off-target drift. These weather factors would also be monitored during the spray application.

- Pesticides would not be applied under the following weather and soil conditions unless the product label specifically recommends otherwise. (1) Within 72 hours of predicted precipitation that would result in runoff and measurable increases in streamflow. To predict this, use a combination of precipitation forecasting, antecedent soil moisture conditions and current streamflows. (2) In areas with standing water (unless covered by plastic in isolated areas away from aquatic systems) and saturated soils. (3) In unstable air situations that may affect spray pattern or lead to offsite movement of spray, such as high air temperatures, during temperature inversions. (4) In wind that exceeds 6 miles per hour or blows toward flowing streams.

- When spraying trees within two tree rows from the edge of treatment unit perimeters (for high pressure hydraulic spray equipment), spraying will be done by directing the nozzle towards the center of the treatment unit, minimizing the chance for drift outside the designated treatment areas.

- No spraying would occur if snow or ice covers the target foliage.

- Equipment used for pesticide transport, mixing, and application would be properly maintained to avoid leaking pesticides into water or soil.

- Maintenance and calibration of spray equipment will occur at least annually to ensure proper application rates.

- To prevent contamination from an unlikely spill event, pesticides would be mixed and equipment cleaned in areas protected from the potential for runoff to surface waters or leaching to groundwater.

- To minimize the potential for chemical contamination of runoff to streams, pesticide and fertilizer application would not occur if soils are saturated. Saturation levels would be determined by a soil scientist.

- For prescribed burns: Prescribed burns would be designed to minimize disturbance of riparian ground cover and vegetation, and any other habitat characteristic that could 
be damaging to long-term ecosystem function; if riparian areas are inadvertently damaged during a prescribed burn, would immediately prepare and implement a rehabilitation plan designed to restore riparian ground cover and vegetation; would ensure that all vehicles, including emergency equipment, are not operated, maintained, or stored next to any stream, water body or wetland; would ensure that all vehicles, including emergency equipment, are not fueled within 150 feet of any waterbody; and, appropriate fire suppression equipment would always be at the project site during a prescribed burn.

- Silt catchments barriers, such as bio-bags, will be installed across all ephemeral drainages located adjacent to or inside treatment units during periods when overland flow may occur following pesticide application. The function of these barriers will be to catch organics and sediment leaving the treatment area.

- No chemical pesticides would be applied to road or ditch surfaces that directly controbute to stream channel flow, nor to fencelines within $50 \mathrm{ft}$. on either side of stream channels.

- Soil aeration would be done around the perimeter of orchard units prior to general orchard fertilizer applications, and aerial or airblast pesticide applications.

- Fertilizer will not be applied within 50 feet of any stream, wetland or other waterbody.

- Fertilizer loading (pertaining to application equipment) areas would be located at least 100 feet from perennial streams.

- Fertilizer applications would be timed, to the extent predictable by weather forecasts, to not coincide or closely precede a storm event that could result in substantial runoff.

- If possible, insecticide applications would be done during the early morning or late evening, allowing foliage to dry before pollinators become active.

- Orchard fields would be mowed prior to insecticide applications to remove floral components of the ground cover if significant amounts of flowers are present, and if pollinators are likely be active on the day of the application (as seasonally applicable and practical).

- No special status ${ }^{1}$ plant species are known to occur at Tyrrell. However, if any are discovered, an herbicide-free buffer zone would be implemented for their protection. Alternatively, mechanical control of nearby weeds could be accomplished through mowing.

- The monitoring program, detailed in Appendix B to this EIS, would be implemented as described for IPM activities. This monitoring plan would be modified as necessary to address the differences between the various pesticides and application methods, and to respond to the results of on-going monitoring.

- A pesticide safety plan would be developed to identify project-specific safety procedures. In the unlikely event of a spill, spill containment procedures in the safety plan would be followed.

- No carrier other than water would be used to mix (dilute) the pesticide products for application. In some cases, surfactants or adjuvants may be added to application mixtures of pesticides to improve their effectiveness or minimize handling and application problems. The seed orchard will only use surfactants or adjuvants that do not contain any ingredients on EPA's List 1 or 2, where listing indicates a chemical is of toxicological concern, or is potentially toxic with a high priority for testing (EPA 2000a). If a surfactant or adjuvant that contains any List 1 or 2 ingredients is considered, the risk associated with that chemical would be evaluated before a use determination is made.

${ }^{1}$ Special status species are species which are proposed for listing, officially listed as threatened or endangered, or are candidates for listing as threatened or endangered under the provisions of the Endangered Species Act; those listed by a state in a category such as threatened or endangered implying potential endangerment or extinction; and those designated by each BLM State Director as sensitive. 
- No additional adjuvants would be added to Roundup ${ }^{\circledR}$, including but not limited to 'x-77.'

- When necessary and feasible, BLM would deploy smoke flares in each unit prior to application to provide for pilot recognition of wind speed and direction.

- Smoke flares would be deployed when doing aerial applications beside surface water.

- Aerial pesticide applications would be designed to deliver a median droplet diameter of 200 to 800 microns to reduce drift.

- No more than one application of picloram will be made on an area in any given year to reduce the potential for picloram accumulation in the soil.

\subsubsection{Alternative A-Maximum Production IPM}

Under this alternative, the primary goal is the maximum production of seeds and plants with a very low level of acceptable losses. Tyrrell's seed orchard manager would have all the methods of pest management listed in Section 2.2.2 available for use, including all identified biological, chemical, prescribed fire, cultural, and other pest control methods. An effective IPM strategy for all orchard pests would be used under this alternative, including monitoring pest levels and treating if action thresholds are exceeded. However, the primary management objective, which would be reflected in the annual IPM plan (see Figure 2.2-1), would be to maximize seed production for annual BLM and cooperator seed needs by aggressively controlling cone and seed insects and other limiting factors. The most effective insect control measures would be implemented, to maximize seed yield and reduce damage to the seed crops with low acceptable seed losses, emphasizing production above other less-effective control methods and considerations, with a low threshold for initiating treatment.

\subsubsection{Alternative B-IPM with Environmental Protection Emphasis (Proposed Action)}

Alternative B is BLM's preferred alternative. An effective IPM strategy for all orchard pests would be used under this alternative, including monitoring pest levels and treating if action thresholds are exceeded.

Under this alternative, the seed orchard manager would have access to the full list of pest management methods identified in Alternative A, with the exceptions listed below. These limitations were identified by reviewing the results of the quantitative risk assessment (summarized in Appendix C), considering the scoping comments, and responding to recommendations made by district interdisciplinary team members. This approach would offer control of pests, but might not permit seed production at the levels possible under Alternative A.

These limitations, listed below, address each risk identified during the risk assessment for Alternative A (summarized in Table 4.6-2 for human health and Table 4.7-2 for wildlife and aquatic species). Each quantitative limitation was calculated by varying the application scenario parameters in the model spreadsheet until the risk was lowered to the acceptable level. Parameters that were varied were those that the seed orchard manager can limit when approving the application, such as application rate, frequency, length of time to re-entry, total area or number of trees treated, and distance from area assumed to receive drift in the risk assessment scenario. The resulting risks correspond in each case to the negligible risk levels for human health, terrestrial wildlife, and aquatic species (see Section 4.6.1 for human health risk methodology and Section 4.7.1 for nontarget species risk methodology).

\section{Limitations to protect worker health:}

- An individual applying diazinon using a high-pressure hydraulic sprayer would mix, load, and apply no more than $3.82 \mathrm{lb}$ a.i. total in one day. 
- Dimethoate would be applied to no more than 22 trees in one day at a rate of $0.13 \mathrm{lb}$ a.i. per tree (nor any combination of number of trees and application rate more than $2.86 \mathrm{lb}$ a.i. total applied) by an individual using the high-pressure hydraulic sprayer, and an individual other than the applicator would conduct the mixing/loading activities. If more than one applicator sprayed trees during a single day, different mixer/loaders would prepare each pesticide mixture.

- An individual applying dicamba using a backpack sprayer would apply no more than $0.61 \mathrm{lb}$ a.i. during any given day.

- An individual applying hexazinone using a backpack sprayer would apply no more than $6.5 \mathrm{lb}$ a.i. during any given day.

- Application of chlorpyrifos, diazinon, dimethoate, or propargite to orchard trees would be scheduled so that a minimum of $20,17,27$, and 18 days would elapse, respectively, before routine cone surveying activities occurred in orchard units treated at the typical application rates listed in Table 2.2-1. If the maximum application rates listed in Table 2.2-1 were used, the elapsed time before cone surveying would be 27, 29 , and 32 days for chlorpyrifos, diazinon, and dimethoate, respectively.

\section{Limitations to protect ecological resources:}

- No more than two aerial applications of esfenvalerate would occur during a year, to protect coho salmon in Stream 8 and Douglas Creek from sublethal effects predicted under the maximum scenario of Alternative A.

- Chlorpyrifos would not be applied within 40 feet of either a bird box (unless the bird box is empty and covered with a plastic bag during spraying) or the edge of a managed orchard unit (the distance associated with no drift from the proposed application methods). ${ }^{2}$ Within a 14-day period, it would not be applied to more than 150 trees at a rate of $0.02 \mathrm{lb}$ a.i. per tree (nor combination of number of trees and application rate more than $3 \mathrm{lb}$ a.i. total applied) in any twelve-acre area, ${ }^{3}$ nor to more than 22 trees (at $0.02 \mathrm{lb}$ a.i. per tree) in any one-acre area. ${ }^{4}$

- Diazinon would not be applied within 40 feet of either a bird box (unless the bird box is empty and covered with a plastic bag during spraying) or the edge of a managed orchard unit (the distance associated with no drift from the proposed application methods). ${ }^{5}$ Within an 11-day period, it would not be applied to more than 150 trees at a rate of $0.015 \mathrm{lb}$ a.i. per tree (nor any combination of number of trees and application rate more than $2.25 \mathrm{lb}$ a.i. total applied) in any twelve-acre area, nor to more than 17 trees (at $0.015 \mathrm{lb}$ a.i. per tree) in any one-acre area. ${ }^{6}$

- Dimethoate would not be applied within 40 feet of either a bird box (unless the bird box is empty and covered with a plastic bag during spraying) or the edge of a managed orchard unit (the distance associated with no drift from the proposed application methods). ${ }^{7}$ It would not be applied to more than three trees in any one-acre area. ${ }^{8}$

- When applied using a high-pressure hydraulic sprayer, acephate would not be applied within 40 feet of either a bird box (unless the bird box is empty and covered with a plastic bag during spraying) or the edge of a managed orchard unit (the distance associated with no drift from the proposed application methods). No more than 40 trees per acre would be treated (at $0.01 \mathrm{lb}$ a.i. per tree) in any 16-day period.

- Horticultural oil, triclopyr triethylamine salt, and triclopyr butoxyethyl ester would not be applied at rates greater than 0.03 gallons per tree, $7.2 \mathrm{lb}$ a.i. per acre, or $2.6 \mathrm{lb}$ a.i. per acre, respectively. ${ }^{9}$

\footnotetext{
2 To protect the little willow flycatcher.

To protect the black-capped chickadee.

${ }^{4}$ To protect bird and amphibian species.

${ }^{5}$ To protect special status bird species.

${ }^{6}$ To protect special status bird species

${ }^{7}$ To protect bird and amphibian species.

${ }^{8}$ To protect the western bluebird.

${ }^{9}$ To protect the little willow flycatcher.
} 
- Application of general fertilization at maximum rates $(1,000 \mathrm{lb} /$ acre $)$ would be preceded by soil aeration throughout the unit to encourage downward movement (as opposed to runoff) of fertilizer in the case of an unpredicted large storm event.

- To limit the potential for drift, pesticides would not be applied through aerial, airblast, or high-pressure hydraulic sprayer methods within 200 feet of perennial streams or non-perennial streams that are flowing at the time of application (Table 2.3-1). A 40 -foot buffer would also be applied (when using these methods) on non-perennial streams that are dry at the time of application. These buffers may be adjusted as drift monitoring results are obtained that demonstrate that either an increased or a reduced buffer width is appropriate to prevent chemical introduction into the waterways (buffer widths will not be decreased without additional consultation with NOAAFisheries, if necessary).

- From the edge of the 200 -foot buffer to 40 feet from the flowing streams, pesticide applications would be limited to methods associated with little to no drift (Table 2.3-1).. These methods could include tractor-pulled spray rig with boom, backpack sprayers, hydraulic sprayer with hand-held wand, capsule implantation, or other no-drift technologies. These buffers may be adjusted as drift monitoring results are obtained that demonstrate that either an increased or a reduced buffer width is appropriate to prevent chemical introduction into the waterways (buffer widths will not be decreased without additional consultation with NOAA-Fisheries, if necessary).

- Only cultural methods would be used for control of pests within 40 feet of any perennial or non-perennial streams.

- To help prevent potential impacts to aquatic species associated with a spill, chemical pesticides would not be transported by air over perennial streams.

- The terms and conditions specified by NOAA Fisheries during the ESA consultation process are incorporated as additional limitations into Alternative $\mathrm{B}$, the proposed action, and are presented in full in the next subsection.

Table 2.3-1. Minimum No-Spray Buffers ${ }^{1}$

\begin{tabular}{|c|c|c|}
\hline Chemical & Application Method & Minimum Stream Buffer (ft) \\
\hline B.t. Esfenvalerate & Aerial & 200 \\
\hline Esfenvalerate Permethrin & Airblast sprayer & 200 \\
\hline $\begin{array}{l}\text { Acephate B.t. Chlorothalonil } \\
\text { Chlorpyrifos Diazinon } \\
\text { Dimethoate Esfenvalerate } \\
\text { Horticultural oil Permethrin } \\
\text { Potassium salts of fatty acids } \\
\text { Propargite }\end{array}$ & High-pressure hydraulic sprayer & 200 \\
\hline $\begin{array}{l}\text { Glyphosate Hexazinone } \\
\text { Picloram Propiconazole } \\
\text { Triclopyr }\end{array}$ & Tractor-pulled spray rig with boom & 40 \\
\hline $\begin{array}{l}\text { Acephate B.t. Dicamba } \\
\text { Esfenvalerate Glyphosate } \\
\text { Hexazinone Picloram } \\
\text { Potassium salts of fatty acids } \\
\text { Propiconazole Triclopyr }\end{array}$ & Hydraulic sprayer with handheld wand & 40 \\
\hline $\begin{array}{l}\text { Dicamba Glyphosate } \\
\text { Hexazinone Picloram } \\
\text { Potassium salts of fatty acids } \\
\text { Propiconazole Triclopyr }\end{array}$ & Backpack sprayer & 40 \\
\hline Acephate Imidacloprid & Capsule implantation & 40 \\
\hline Fertilizers & Broadcast spreader & 50 \\
\hline
\end{tabular}

${ }^{1}$ These buffer zones may be adjusted if drift monitoring results are obtained that demonstrate that either a reduced buffer would not introduce chemicals into the waterways or that a wider buffer is required. However, buffer widths will not be decreased without additional consultation with NOAA-Fisheries, if necessary. 
Terms and conditions were specified by NOAA Fisheries during ESA consultation to implement reasonable and prudent measures. These are included in the limitations incorporated into Alternative B, the proposed action, and are provided, verbatim, below.

$\underline{\text { Reasonable and Prudent Measures }}$

Reasonable and Prudent Measures are non-discretionary measures to avoid or minimize take that must be carried out by cooperators for the exemption in section $7(0)(2)$ to apply. The BLM has the continuing duty to regulate the activities covered in this incidental take statement where discretionary Federal involvement or control over the action has been retained or is authorized by law. The protective coverage of section $7(0)(2)$ may lapse if the BLM fails to exercise its discretion to require adherence to terms and conditions of the incidental take statement, or to exercise that discretion as necessary to retain the oversight to ensure compliance with these terms and conditions.

The NMFS believes that the following reasonable and prudent measures are necessary and appropriate to minimize take of listed species resulting from completion of the proposed action.

The BLM shall:

1. Minimize incidental take by ensuring that orchard pests are managed using integrated pest management techniques that use treatment thresholds and minimize the need for pesticide application.

2. Minimize incidental take from pesticide applications by choosing pesticide formulas, timing, place, and manner of pesticide use to minimize the likelihood of delivery to riparian and aquatic systems.

3. Minimize incidental take from fertilizer application by ensuring that fertilizer is applied in a time, place and manner that minimizes the likelihood of delivery to surface and groundwater.

4. Minimize incidental take from aerial applications by implementing practices that preclude and / or limit non-target delivery of chemicals.

5. Ensure completion of a annual comprehensive monitoring and operations reporting program to confirm this Opinion is meeting its objective of minimizing take from permitted activities.

\section{Terms and Conditions}

To be exempt from the prohibitions of section 9 of the ESA, the BLM must comply with the following terms and conditions, which implement the reasonable and prudent measures described above. These terms and conditions are non-discretionary and, in relevant part, apply equally to proposed actions in all categories of activity.

1. To implement Reasonable and Prudent Measure $\# 1$ (integrated pest management) the BLM shall:

a. Treatment thresholds. Ensure that no action to suppress insect pests will be taken unless pest monitoring show that one or more pests have reached a threshold at which losses in seed yield and quality exceed the economic and environmental cost of treatment. No pesticide will be applied on a routine basis, without regard for treatment thresholds based on pest populations.

b. Prescribed burning. When prescribed burning will be used as a pest control, the following conditions will apply.

i. Design the prescribed burn to minimize disturbance of riparian ground cover and vegetation, and any other habitat characteristic that could be damaging to 
long-term ecosystem function.

ii. Ensure that all vehicles, including emergency equipment, are not operated, maintained, or stored next to any stream, water body or wetland. Equipment shall not disturb native riparian vegetation.

iii. Ensure that all vehicles, including emergency equipment, are not fueled within 150 feet of any waterbody.

iv. If riparian areas are inadvertently damaged during a prescribed burn, immediately prepare and implement a rehabilitation plan designed to restore riparian ground cover and vegetation.

v. Appropriate fire suppression equipment shall always be at the project site during a prescribed burn.

c. Each supervisor engaged in IPM activities must be informed of the following requirement:

NOTICE: If a sick, injured or dead specimen of a threatened or endangered species is found, the finder must notify the Vancouver Field Office of NMFS Law Enforcement at 360.418 .4246 . The finder must take care in handling of sick or injured specimens to ensure effective treatment, and in handling dead specimens to preserve biological material in the best possible condition for later analysis of cause of death. The finder also has the responsibility to carry out instructions provided by Law Enforcement to ensure that evidence intrinsic to the specimen is not disturbed unnecessarily.

2. To implement Reasonable and Prudent Measure \#2 (use of pesticides), the BLM shall ensure that:

a. These terms and conditions do not authorize any pesticide use that is inconsistent with the EPA pesticide product label.

b. Pesticides will be mixed and equipment cleaned in areas where spills cannot runoff to surface waters or leach to groundwater, such as a paved and bermed mixing pad capable of containing the volume of any potential spill.

c. Spill Prevention Plan. Prepare and carry out a spill prevention plan to prevent contamination from spill of pesticides and other hazardous materials. The plan will contain the pertinent elements listed below, meet requirements of all applicable laws and regulations, and must be available for inspection on request by NMFS.

i. The name and address of the party(s) responsible for accomplishment of the spill prevention plan.

ii. A description of any regulated pesticide and other hazardous materials that will be used as part of the IPM Plan.

iii. Training and certification for those who will be involved with pesticide transportation, storage, use, disposal, record keeping, monitoring, and emergency response

iv. Practices to prevent spills associated with mixing sites (i.e. containment), critical areas where spills are likely to occur, and environmental restrictions.

v. Spill containment and notification procedures, specific cleanup and disposal instructions for different products, quick response containment and cleanup measures that will be available on the site, proposed methods for disposal of spilled materials.

vi. Identify specific routes of the equipment, load limits for equipment, allowable speeds on the routes, mixing site limits in quantities, chemical types, or spill potential.

d. Choice of pesticide. Choose pesticides and additives as follows.

i. When pesticides are required, the BLM will choose the pesticide that is least toxic to fish while meeting IPM pest control objectives, and accounting for human health concerns.

ii. No carrier other than water will be used to mix (dilute) the pesticide products for application.

iii. No surfactant or adjuvant that contains ingredients included on EPA's List 1 
or 2 for toxicological concern or that has a high priority for testing (EPA 2000a) may be used, unless otherwise approved in writing by NMFS.

iv. Only one application of picloram may be made on an area in any given year to reduce the potential for picloram accumulation in the soil.

v. No additional adjuvants may be added to Roundup, including but not limited to ' $x-77$ '

e. Timing of pesticide application.

i. Prioritize applications for mornings or evenings when pollinators are not active (as seasonally applicable) in accordance with the best overall weather period.

ii. Weather. Pesticides will not be applied under the following weather and soil conditions unless the product label specifically recommends otherwise.

(1) Within 72 hours of predicted precipitation that would result in runoff and measurable increases in streamflow. To predict this, use a combination of precipitation forecasting, antecedent soil moisture conditions and current streamflows. These methods shall be documented and included in the annual monitoring report.

(2) In areas with standing water (unless covered by plastic in isolated areas away from aquatic systems), saturated soils, snow or ice.

(3) In unstable air situations that may affect spray pattern or lead to offsite movement of spray, such as high air temperatures, during temperature inversions.

(4) In wind that exceeds 6 miles per hour or blows toward flowing streams.

f. Areas of pesticide application.

i. Application buffers. Application methods will be restricted by zones as follows. Zone widths refer distances from any non-perennial or perennial stream or water body with flowing water, measured horizontally from, and perpendicular to, the bankfull elevation, the edge of the channel migration zone, or the edge of any associated wetland, whichever is greater.

(1) $\leq 40$ Feet. Cultural methods.

(2) $>40$ Feet. Capsule implantation, backpack prayer, hydraulic sprayer with handheld wand, tractor-pulled spray rig with boom, cultural methods, although hand-held wicks and backpack sprayers may be used to control plants designated as noxious weeds in Oregon, as defined in ORS 603-521200 , that cannot be effectively controlled using cultural methods.

(3) $>\mathbf{2 0 0}$ Feet - All of the above, and high-pressure hydraulic sprayer, airblast sprayer, and aerial applications. Beside non-perennial streams dry during the time of application, a 40 -foot buffer will also be applied (when using these methods).

ii. Do not apply pesticides to road or ditch surfaces that directly contribute to stream channel flow, nor to fence-lines within 50 feet on either side of stream channels.

g. Method of pesticide application.

i. Mow or graze orchard fields before insecticide applications to remove floral components or ground cover that attract pollinators (as seasonally applicable and practicable).

ii. No pesticide may be applied on a routine basis, without regard for treatment thresholds based on pest populations.

3. To implement Reasonable and Prudent Measure \#3 (use of fertilizers), the BLM shall ensure that:

a. Fertilizer will not be applied within 50 feet of any stream, wetland or other waterbody.

b. Fertilizer will be applied at agronomic rates.

c. Fertilizer loading (pertaining to application equipment) areas shall be at least 100 feet from perennial streams. 
4. To implement reasonable and prudent measure \#4 (aerial chemical application), the BLM shall ensure that:

a. Aerial Application CPs. In addition to the drift CPs listed above, the following actions shall be implemented during aerial applications:

i. Smoke flares shall be deployed beside surface water before application to provide for pilot/applicator recognition of wind speed and direction.

5. To implement Reasonable and Prudent Measure \#5 (monitoring and reporting), the BLM shall ensure that:

a. Annual monitoring report. All water quality monitoring information associated with application of the Tyrrell Seed Orchard IPM program shall be compiled, analyzed, documented, and reviewed on a 'water year' basis. This 'water year' shall include all monitoring performed during the October 1 to September 30 period. This information, along with any recommendation for adjustments to protection measures and adjustments to the monitoring plan, shall be contained in an Annual Tyrrell Seed Orchard Monitoring Report. This report shall be available to the public and regulatory agencies on November 15 of each year and be on file at the Tyrrell seed orchard.

i. Project identification.

(1) BLM contact person.

(2) Pesticide project manager

(3) Starting and ending dates for work completed.

ii. IPM documentation.

(1) Description of how treatment was based on weather and pest monitoring.

(2) A description of the biological and cultural pest controls used before pesticides were applied, or the reasons that biological and cultural controls were not used. Note that this provision is applicable to the overall orchard IPM, not individual applications, and shall be documented within the annual monitoring report.

(3) Pesticide use history.

(a) Type of chemical applied

(b) Date of application

(c) Buffers present

(d) Method of pesticide application

(e) Total area treated

(f) Amount of pesticide applied

(g) Precipitation for the three days preceding and following application

(h) Wind direction and speed, relative humidity, air temperature at time of application

(i) Location used for mixing and loading and notes regarding whether any leakage or spills occurred

iii. Effectiveness Monitoring.

(1) Orchard units or treatment areas directly beside open water (within 200 feet) shall require drift cards be placed at a maximum of 100 foot intervals along the edge of Tyrrell's unit before the application (for aerial, airblast and high pressure hydraulic sprayer applications).

(2) If open canopy occurs in the waterway buffer, drift cards shall be selectively placed along the waterway edge to characterize potential intrusion of $\mathrm{drift}$ toward waterways. Any applications shall cease if there is any indication that there is off-target delivery occurring.

\footnotetext{
${ }^{19}$ 'Agronomic rate' means a quantity and timing of total nutrient application that does not exceed the requirements of the crop production and harvest or grazing system, as opposed to a nutrient application rate based on production goals that are difficult to define and variable. Calculation of the agronomic rate should take into account the total nitrogen or phosphorus resources for plant nutrition, and any retention of phosphorus in the soil and losses of nitrogen through denitrification and ammonia volatilization.

ii. Chemicals shall not be transported by air over perennial streams.
} 
(3) Immediately after the application, the cards shall be collected and reviewed to determine if a drift signature is present, the extent of the drift, and the potential for aquatic contamination. A copy of all the cards shall be kept on file at Tyrrell, along with a record of their location and all the compliance monitoring documentation.

vi. Surface Water Monitoring to Detect Drift.

(1) Aerial, airblast, and high-pressure hydraulic sprayer applications of chemicals, water samples shall be collected before and after spray application that include representative "15 minute" and "24hour (composite)" posttreatment water samples.

(2) Section of sampling stations for surface water sampling shall be based on the proximity to application areas and characteristics of nearby surface water.

(3) All data shall be used in conjunction with the spray cards to determine the effectiveness of the full "suite" of protective measures implemented to avoid drift.

(4) Samples shall be analyzed at a state-certified laboratory that has detection limits at the lowest certified detection levels.

(5) Samples shall be collected in accordance with laboratory instructions.

(6) When sites are sampled, additional interpretive data shall be collected for $\mathrm{pH}$, specific conductance, turbidity, suspended sediment, temperature, or other relevant parameters.

(7) Surface water samples are collected within the project area, also collect water samples concurrently where flowing water enters the project area to facilitate a baseline/cumulative concentration analysis.

iii. Surface Runoff.

(1) Effectiveness monitoring of protective measures and limitations in the proposed action shall target those periods of precipitation that could result in field surface runoff and increased streamflow. These periods are most likely to carry the greatest detectible concentrations of chemicals.

(2) Continuous flow recording stations shall be established during runoff events with the intention of providing individual storm concentrations.

(3) The data from recording stations shall be interpreted to be representative of water quality conditions as a result of the effectiveness of implemented protection measures and limitations in the higher-risk seed production areas.

(4) All data shall be used in conjunction with continuous recorded climate data to evaluate the effectiveness of protection measures and limitations in minimizing introduction of pesticides and fertilizers to the aquatic system.

(5) Samples shall be analyzed at a state-certified laboratory that has the lowest certified detection levels.

iv. Cumulative Concentrations Runoff.

(1) Stormflow with the highest potential for chemical presence shall be sampled and, during these flow events, samples shall be composited according to the rise and fall of the hydrograph.

(2) Semi-permeable membrane devices (SPMDs) shall be deployed, to monitor the accumulation of chemicals in waters containing aquatic species.

(3) SPMDs shall be deployed before initial winter storms and spring storm periods after compound application.

(4) Streamflow gauges (USGS and BLM) shall be maintained to provide flow data for deriving concentrations (chemical loading) over the period of time the SPMD is deployed.

(5) Data from the SPMD concentrations shall be used to compare and validate the storm flow concentration monitored during the deployment period.

${ }^{20}$ Temperature shall always be collected, but other parameters collected will depend upon the applicability to the particular 'targeted' chemical.

${ }^{21}$ It is anticipated that most, if not all, sampling locations at Tyrrell will not require 'upstream' sampling, because drainages sampled will originate solely from the orchard boundaries. 
(6) The SPMDs shall be tested for those compounds that were applied and can be sequestered.

v. Monitoring of Best Management Actions. For select sites, monitoring shall be used to validate the water quality modeling predictions presented in the EIS and BA.

(1) Monitoring the stream systems shall identify the effectiveness of protection measures, and to help to gauge the estimates in the RA.

(2) Collection chambers shall be installed in selected areas where there is concern regarding overland flow. During the first overland flow event following select chemical applications, these sites shall be visited, and a water sample taken from the collection chamber. This data shall be used to assess the mobility of chemicals that have been used onsite within the past year.

(3) Concentrations shall be compared with modeled results utilizing field-and climate-specific data to validate RA estimates.

(4) If detectable concentrations are found, stream concentrations shall also be compared to model results using actual application information, fieldspecific data, and continuous climate record. These data shall provide a relationship between previous monitoring results and the management that is planned for the future.

(5) For select sites and once the yearly application period is complete, the climate record collected during that period shall be used to model a predicted concentration using the GLEAMS and MOC models. These concentrations shall be "diluted" using the continuous flow data from the station. The resulting concentrations shall be compared with the actual measured concentrations for each storm event sampled.

vi. Spill Monitoring. In the event of a chemical spill, the volume of spill, proximity to water, and chemical characteristics, such as toxicity and mobility, shall be immediately evaluated to determine if water sampling is desirable and necessary. If the spill occurs in an area that is reasonably certain to deliver to surface waters, either immediately, or on the next precipitation event, sampling shall occur, as appropriate.

(1) Water samples shall be collected in a sufficient number and at surface water and groundwater locations that shall allow characterization of impacts and effective remediation methods. Depending on ODEQ Monitoring Hazardous Substances Remediation Rules (OAR 340-122), monitoring could include surface water, groundwater, air, and soil.

(2) At a minimum, sampling shall be conducted in the streams draining the spill area and the immediate groundwater table. Tyrrell's domestic well shall be sampled if in proximity to spill.

vii. Notification of Discharge. If a surface water discharge occurs, the BLM shall notify NMFS within 10 business days of detection. Notification will include the type, location, and concentration of the discharge.

viii. Implement monitoring at Tyrrell as follows: The concentrations of the following pesticides shall not exceed the following trigger values in flowing water:

${ }^{22}$ For the Rodeo formulation of glyphosate, if additives and their concentrations in tank mixes are identified, along with the total volume and locations of application, are included in the annual monitoring report, no testing of water samples for glyphosate will be required, unless NOAA-Fisheries identifies additives of concern in the future. 


\begin{tabular}{|l|l|c|c|}
\hline Compound & Chemical Family & Low Trigger & High Trigger \\
\hline Chlorpyrifos & Organo-phosphate & 0.15 & 1.5 \\
\hline Dimethoate & & 310 & 3100 \\
\hline Diazinon & & 4.5 & 45 \\
\hline Permethrin & Pyrethroids & 0.4 & 3.5 \\
\hline Esfenvalerate & Organo-sulfite & 0.0005 & 0.045 \\
\hline Propargite & & 5.9 & 59 \\
\hline $\begin{array}{l}\text { Trichloropyridnol (Triclopyr } \\
\text { and chlorpyrifos degradate) } \\
\text { picloram23 }\end{array}$ & Pyridine derivatives & 75 & 750 \\
\hline Chlorothanil & Chlorinated-benzene nitrile & 2.1 & 21 \\
\hline
\end{tabular}

(1) The low trigger and high trigger values may be revisited (and potentially revised) annually to incorporate new data regarding baseline conditions, and newly-published sublethal effects.

(2) The 'low trigger' levels are those estimated flowing water concentrations, which can be surpassed a single time, for a total of one compound, during each of the three annual precipitation and application 'zones' as displayed within the Opinion. Thus, a total of three annual exceedences of the 'low triggers' are allowed, one during each period.

(3) The 'high trigger' values are those concentrations at which acute lethal take may occur in flowing water concentrations at the confluence with listed salmonids. Meeting or exceeding these concentrations would require reinitiation of consultation.

\begin{tabular}{|l|l|l|l|}
\hline \multicolumn{1}{|c|}{ Application Method } & \multicolumn{1}{|c|}{ Compound } & \multicolumn{1}{|c|}{$\begin{array}{c}\text { Surface Water } \\
\text { Drift } \\
\text { Monitoring }\end{array}$} & $\begin{array}{c}\text { Sites for Surface Water Drift } \\
\text { Sampling and sites } \\
\text { for SPMD Placement }\end{array}$ \\
\hline Aerial & Esfenvalerate & $\begin{array}{l}\text { A representative stream }{ }^{24} \text { or } \\
\text { streams will be sampled and } \\
\text { tested for each application }\end{array}$ & $\begin{array}{l}\text { Stream } 8 \text { and stream } 54 \text { will } \\
\text { be monitored at one of four } \\
\text { established sites downstream } \\
\text { from potentially affected } \\
\text { tributaries. Streams 11, 12, 13, } \\
\text { 25 and 17 would be monitored } \\
\text { where they cross the fenced } \\
\text { orchard boundary* }\end{array}$ \\
\hline $\begin{array}{l}\text { Airblast sprayer } \\
\text { Hydraulic sprayer w/ } \\
\text { handheld wand } \\
\text { Backpack Sprayer - } \\
\text { Hand-held wand }\end{array}$ & $\begin{array}{l}\text { Esfenvalerate } \\
\text { Chlorpyrifos } \\
\text { Permethrin } \\
\text { Diazinon } \\
\text { Dimethoate } \\
\text { Propargite } \\
\text { Chlorothalonil }\end{array}$ & $\begin{array}{l}\text { Surface water } \\
\text { sampling and } \\
\text { testing for each } \\
\text { application } \\
\text { within 300 feet } \\
\text { of surface water }\end{array}$ & \\
\hline
\end{tabular}

* Additional upstream sites in section 9 may be added to substituted upstream in specific instances where it is thought that capture of potentially contaminated runoff is more effective.

\footnotetext{
${ }^{23}$ Trichloropyridnol (TCP) is a degradate of both chlorpyrifos, that is classified as moderately toxic to fish. As a moderately toxic, common degradate of two of the pesticides applied, with a half-life ranging from $12-229$ days, TCP poses a risk to listed salmonids greater than or equal to some of the pesticides applied. Therefore, TCP was added to the list of compounds to be monitored. Surface drift monitoring shall occur for the following compounds that are applied using the specific methodologies.

${ }^{24} \mathrm{~A}$ representative stream is any stream beside a spray unit, downwind of a spray unit, or otherwise likely to be affected if drift outside the treatment units occurs.
} 
xiv. Circumstances that would trigger reinitiation

(1) More than one discharge per zone, as defined in this Opinion, between the 'low trigger' and high trigger; values (within any one year). Note that discharges below the low trigger value are not applicable to this total.

(2) A discharge within any one year above the 'high trigger' value.

(3) For compounds with a common mode of action (i.e. pyrethroids and organophosphates), if the sum total of the toxic units is $>0.05$ (equivalent to $1 / 20$ th of the standardized LC50's) it will be counted as a 'low trigger' exceedence. If the sum total of the toxic units is $>0.5$ (equivalent to $1 / 2$ of the standardized LC50's) it will be counted as a 'high trigger' exceedence. This applies only when both detections occur in the same location, and at the same time (the compounds co-occur in the water column). The toxic units for each class, pyrethroids, and organophosphates, will be calculated as outlined within this Opinion. Only one 'low trigger' exceedence will be counted if there is a toxic unit 'low trigger' exceedence and if the same chemical family already contains a 'low trigger' exceedence of an individual compound.

(4) To account for the synergistic action of pyrethroids and organophosphates, as described within this Opinion, an exceedence of a 'low trigger' of both a pyrethroid and an organophosphate (either individually or as a sum total of family toxic units) will be considered the equivalent of exceeding a high trigger. This applies only when both detections occur in the same location, and at the same time (the compounds co-occur in the water column), and includes SPMD data.

(5) Upon any SPMD detection, the data shall be used to provide a 24-hour average waterborne contaminant concentration for the chemicals that were applied and can be sequestered. To reflect the margin of error within the SPMD methodology, a 2-fold safety factor (Huckins 2004) shall be applied to the back calculated 24-hour average concentration (multiply the value by two). The corrected 24 -hour concentration shall then be treated as a discharge within the final monitoring plan and the same circumstances (Table 18) apply for reinitiation.

(6) An annual review of SPMD data collection, data use, and sampling methodology may occur. In the event of a detection, factors leading to the resultant discharge concentration shall be reviewed.

b. Annual Operation Report . The Annual Operation Report will be submitted to NMFS by December 1st, and include the following information (NMFS will review the Annual Operation Report within 30 business days of its receipt):

i. A description and list of pesticide applications conducted over the reporting period.

ii. The results of the previous year monitoring program. If a discharge occurred during the previous year, possible causes of the discharge shall be explored, as well as future mitigation steps to prevent like discharges in the future.

iii. A data review of the pesticides that are proposed for use, or may be used, at Tyrrell in the following year. The review will include:

(1) New scientific data regarding non-target fish species effects or environmental fate.

(2) Changes to EPA-approved labels (ESA-approved and other).

(3) A review of legal findings relevant to the use of compounds.

(4) Any new scientific data will be reviewed and summarized, as stated in the proposed action, considered in terms of effects on orchard operations and compound use. Literature will include peer-reviewed data and other forms of scientific evidence that may be relevant to Pacific salmon and steelhead

${ }^{25}$ Note that the annual operations plan for 2005 only needs to include data specified within letter (e). 
(5) A plan for proposed pesticide applications for the following year, including, to the extent possible, units or acres to be treated, proposed pesticide, application rate and method, dates, and a proposed monitoring plan.

(6) Any proposed changes to the IPM, including new limitations, protection measures, or mitigation measures as part of an adaptive management approach; the use of pesticides in addition to those proposed; or other relevant information.

(7) The annual report shall be sent to:

\section{Director, Oregon State Habitat Office NMFS}

Attn: 2004/00213

525 NE Oregon Street

Portland, OR 97232

c. Submittal of a New BA and Request for Reinitiation. Throughout the implementation of the proposed action(s), the BLM shall assess situations that might trigger a new consultation, including but not limited to:

i. New pesticides are proposed for use at Tyrrell.

ii. A proposal is made to increase application rates.

iii. New toxicity information becomes available that indicates additional possible effects that were not identified in the BA or considered in the original Opinion.

iv. Monitoring results show significant changes in expected results - concurrent with science review.

v. A proposal is made to increase the application acreage.

vi. New information on persistence, delivery or movement of chemicals within Tyrrell and/or new literature.

d. Annual coordination. Meet with NMFS by January 15, each year as necessary, to discuss the annual monitoring report and any action necessary to make the program more effective.

${ }^{26}$ The draft monitoring plan shall include proposed sampling locations, frequencies, and methods in relation to the application plan. The 2005 monitoring plan will also include a map with the proposed SPMD placement site.

\section{How is Alternative B Different from Alternative A?}

Under Alternative B, all of the same pest control methods are available to the seed orchard manager as under Alternative A. However, Alternative B contains specific limitations (see list above) on certain aspects of chemical pesticide and fertilizer use to provide added protection to human health and the environment. Commonly, during the preparation of an EIS, the analysis of impacts occurs wholly during the EIS development process. In the case of the proposed IPM program at Tyrrell, a quantitative risk assessment of the proposed chemical pesticides and fertilizers was completed before development of the EIS alternatives. The assumptions made during this risk assessment correspond to the pesticide application details of Alternative A. The conclusions of this assessment, and the interaction among the interdisciplinary team members during the assessment, directly resulted in developing a new alternative-Alternative B-that addresses all the predicted risks in the risk assessment scenarios, as well as protects resources based on these experts' site-specific knowledge of overall potential chemical transport pathways at the seed orchard. Alternative B, as the proposed action, also includes the terms and conditions identified by NOAA Fisheries during consultation under Section 7 of the ESA. 


\section{What are Limitations, Protection Measures, and Mitigation Measures?}

These three concepts may seem similar, but they have distinct definitions within this EIS:

Limitations are the list of exceptions in Section 2.3.3 that distinguish the details of potential pesticide and fertilizer applications under Alternative B from those under Alternative A. These limitations were designed by the interdisciplinary team preparing this EIS to address predicted risks, respond to scoping concerns, and provide additional environmental protection. Limitations include the terms and conditions specified by NOAA Fisheries during ESA consulation; these requirements are inherent in Alternative $B$, the proposed action.

Protection measures are best management practices (BMPs), including BMPs for water quality protection under the Clean Water $A c t,{ }^{1}$ that would be implemented during any use of chemical pesticides by Tyrrell, regardless of the alternative selected. Protection measures are listed in Section 2.3.1.

Mitigation measures are defined by CEQ (40 CFR 1508.20) as (a) avoiding the impact altogether by not taking a certain action or parts of an action; (b) minimizing impacts by limiting the degree or magnitude of the action and its implementation; (c) rectifying the impact by repairing, rehabilitating, or restoring the affected environment; (d) reducing or eliminating the impact over time by preservation and maintenance operations during the life of the action; or (e) compensating for the impact by replacing or providing substitute resources or environments. Mitigation measures are not specifically included in an alternative, but are additional measures in response to the potential environmental impact(s) that an alternative may have. Potential mitigation measures for the alternatives in this EIS are listed in Section 4.12, and, if needed, would be specifically identified in the ROD to correspond to the selected alternative.

${ }^{1}$ BMPs in relation to water pollution are defined by EPA as "methods that have been determined to be the most effective, practical means of preventing or reducing pollution from non-point sources."

\subsubsection{Alternative C-Ground-Based IPM}

Alternative $C$ would be identical to the proposed action (Alternative B) except that the option to apply esfenvalerate, B.t., and fertilizer aerially, as identified in Table 2.2-1, would be eliminated. Thus, under Alternative $C$, the seed orchard manager would be permitted to use any of the biological, prescribed fire, cultural, ground-based chemical, or other methods included in Alternative B. Esfenvalerate could be applied by an airblast sprayer, a high-pressure hydraulic sprayer, or a hydraulic sprayer with a hand-held wand. B.t. could be applied using a high-pressure hydraulic sprayer or a hydraulic sprayer with a hand-held wand. Fertilizer could be applied with a ground pull fertilizer spreader.

\subsubsection{Alternative D-Non-Pesticide Pest Management}

Alternative D would allow the seed orchard manager to use only the non-pesticide biological, prescribed fire, cultural, and other methods listed under Alternative A. No biological or chemical pesticides would be permitted. 


\subsubsection{Alternative E-No Action: Continue Current Management Approach}

Alternative E would allow continuation of the current management system, which is the use of all non-pesticide pest control practices at the seed orchard, as well as the use of pesticides on a specific case-by-case basis. All non-pesticide biological, prescribed fire, cultural, and other methods would be used in accordance with current procedures. When a specific need is identified for a pesticide, the action would be reviewed to determine whether it is encompassed by an existing NEPA document. For example, weed control projects could be within the scope of the Northwest Area Noxious Weed Control Program EIS and Supplemental EIS, and the EIS for Vegetation Treatment on BLM Lands - Thirteen Western States. Section 1.4.1 provides more information on existing NEPA documents related to pest management. When specific proposed pesticide applications are not within the scope of an existing EA or EIS, another NEPA document would be prepared. This would include applications for cone insect control, control of other orchard insect outbreaks, disease infestations, and any vegetation control necessary that is not covered by other BLM vegetation control NEPA documents. Using this approach, project-specific CXs were documented for lindane use to control coneworms in production orchards from 1989 to 1998. Under project-specific enfironmental assessments (EA's), esfenvalerate was used in 2003 (29 acres) and 2005 (58 acres) to control cone and seed insects. Imidacloprid was used in 2004 (60 acres) to control Douglas-fir gall midge.

\subsubsection{Alternative Considered But Not Further Analyzed}

During the scoping process, one member of the public suggested planting more crop trees than necessary to allow for some loss to pests, which was interpreted as a request to consider no pest management at all. This is not a viable alternative for several reasons. First, this approach could lead to a significant loss of the crop trees in the production units if disease were to occur. Secondly, orchard research has shown that approximately $70 \%$ of the seed crop could be lost if no pest management were practiced (Showalter et al. 1985). To partially offset the effects of cone and seed insects and decreased tree vigor due to disease, it would be necessary to plant production trees in fields that are currently fallow, as the commentor suggested. This solution would require the seed orchard and their cooperators to accept an estimated 10-year reduction in seed production, which is the time that would be required for the newly planted trees to produce collectable seed. This decrease in production could also result in delays in reforestation projects caused by potential seed shortages, or reduced forest growth resulting from the use of genetically inferior seed from other sources. In addition, a more intensive planting regime on seed orchard grounds, with no pest management of any kind, would allow the orchard lands to become a "reservoir" for insects, disease, noxious weeds, and animal pests that would spread to neighboring public and private lands-effectively, becoming a threat and nuisance to the neighbors, particularly those who cultivate crops of their own.

\subsection{Approval of New Products and Technologies}

It is likely that, over the life of the proposed IPM program, BLM seed orchard personnel will become aware of chemicals or non-chemical control methods that are currently available but were not described in this EIS, or that represent new technologies not currently available or practiced. This section describes how BLM would ensure compliance with U.S. laws (including NEPA) and regulations, and evaluate these new approaches for inclusion in the seed orchard's pest management plans, in terms of both their efficacy and their potential environmental impacts. This information applies both to full-scale use as a control method, as well as to field research projects investigating the potential for larger applications.

This approach includes descriptions of how new chemical products or technologies would be examined for consideration by BLM, what data would be relied upon to assess 
a product or technology's effectiveness for use on public lands, what data would be relied upon to conduct human health hazard and risk assessment, and the level of NEPA documentation required to support a decision to use or not use a product or technology.

\subsubsection{Identification of New Chemical Products and Technologies}

The seed orchard manager and employees may become aware of new pest control products and technologies through three general mechanisms: professional networking, technical research and publications, and vendor marketing.

\section{Networking}

Participation in professional networks is the principal method for staying current on new pest control approaches, and yields information on the technical, regulatory, efficacy, and environmental aspects of methods, both those in the development phase and those currently on the market. The primary professional association for BLM seed orchard managers in Oregon is the Northwest Seed Orchard Managers Association (NWSOMA), and particularly its Northwest Pest Management Committee.

The Southwest Oregon Forest Insect and Disease Service Center is a group of U.S. Forest Service pathologists and entomologists that provide forest insect and disease technical assistance, field consultation, modeling, risk assessments, and historical information to Federal resource managers in southwest Oregon. A field service center is located near BLM's Medford District seed orchards at the Forest Service's J. Herbert Stone Nursery in Central Point. Similar services are also available in the Forest Service's regional office in Portland.

Useful information can also be obtained by staying in contact with other non-regional professional networks with similar goals, such as the Southern Seed Orchard Pest Management Subcommittee of the Southern Forest Tree Improvement Committee (part of the North Carolina State University Industry Cooperative Tree Improvement Association). Similarly, the British Columbia Seed Orchard Association, which often has formal interactions and collaborations with NWSOMA, is another professional network focusing on seed orchard management.

\section{Technical Research and Publications}

The U.S. Forest Service conducts extensive research activities that support tree improvement and re-forestation activities. The web page USDA/FS Research Publications (http://216.48.37.142/) provides a search function that indexes Forest Service research publications, by keyword or by research station. ${ }^{10}$ The Forest Service's Reforestation Nurseries and Genetics Resource web page (http:/ / www.rngr.fs.fed.us) includes current information on seed orchard and tree nursery practices and pest management.

The IR-4 Ornamentals Research Program, organized by the state land grant universities and the U.S. Department of Agriculture, assists in collecting data that can be used to add minor crop (including seed orchard tree species) uses to existing chemical and biological pesticide registrations. The program's activities are described in detail at its web site (http:/ / pestdata.ncsu.edu/ir-4/).

The Washington State Commission on Pesticide Registration is a state-funded regional program with a similar mandate (http://wscpr.org/).

${ }^{10}$ This and other Internet citations (uniform resource locators, or URLs) in this EIS were accurate at the time of publication. However, websites change frequently due to changes in data availability or reorganization of information, and the cited URLs may not work in the future. If this occurs, "backing up" to a less specific web address or using an Internet search function may allow retrieval of the information. 


\section{Vendor Marketing}

Vendors of pest control technologies, including chemical company representatives, occasionally contact BLM's seed orchards to introduce new products. These contacts may come in the form of mailed brochures or advertisements, or telephone contacts to request a visit to the seed orchard.

From time to time, members of the public who are interested in various approaches to pest management send information to the seed orchard manager describing these methods. As with pest control methods identified through other avenues, if the seed orchard manager determines that the approach may have some utility for the seed orchard's needs, a product demonstration or additional information may be requested.

\subsubsection{Assessment of Effectiveness}

The seed orchard manager would be the one to judge whether a previously unconsidered pest control product or technology is likely to be effective in meeting the specific seed orchard's pest control needs. The decision would be based on details such as previous use reports at other sites and their outcomes, availability, cost, expected effectiveness compared to any currently used methods, training and personnel requirements, factors that could limit efficacy, and any other relevant factors (including hazards and risks-see Section 2.4 .3 below).

Any new chemical or biological pesticide considered for use by the seed orchard must be registered under FIFRA, which requires product performance data relating to its effectiveness. This requirement was designed "to ensure that pesticide products will control the pests listed on the label and that unnecessary pesticide exposure to the environment will not occur as a result of the use of ineffective products" [ 40 CFR 158.202(i)]. Therefore, any new pesticide registered under FIFRA is expected to be generally effective for the labeled uses. To further assess the potential for site-specific effectiveness prior to an actual application in the seed orchard, the seed orchard manager would investigate its use through professional networks, technical publications, and/or research reports, such as those described in the previous section.

For a pest control technology that is not required to be registered under FIFRA, the avenues of research described in the previous section would be the likely initial means for discovering its advantages and limitations over currently used methods. This could pertain to cultural control practices, tools or equipment, or other means that are not considered pesticides under the purview of FIFRA.

\subsubsection{Assessment of Hazards and Risks}

As stated in the previous section, BLM only uses pesticide products that are registered under FIFRA. Therefore, for any chemical or biological pesticide that may be considered for use in the seed orchard, there would exist a body of EPA-reviewed toxicological, environmental fate, and ecotoxicity data that were submitted by the pesticide manufacturer to support its registration application. These data can be used to conduct a site-specific assessment of the potential human health and ecological risks from the pesticide's use at the seed orchard, including the following components:

- Identification of potential use patterns, including target pest(s), formulation, application method(s), locations to be treated, application rate, and anticipated frequency.

- Review of chemical hazards relevant to human health risk assessment, including systemic and reproductive effects, skin and eye irritation, dermal absorption, allergic 
hypersensitivity, carcinogenicity, neurotoxicity, immunotoxicity, and endocrine disruption.

- Estimation of exposure to workers applying the chemical or re-entering a treated area.

- Environmental fate and transport, including drift, leaching to groundwater, and runoff to surface streams and ponds.

- Estimation of exposure to members of the public.

- Review of available ecotoxicity data, including hazards to mammals, birds, reptiles, amphibians, fish, and aquatic invertebrates.

- Estimation of exposure to terrestrial and aquatic wildlife species.

- Characterization of risk to human health and wildlife.

If the available toxicity or ecotoxicity data are inconclusive, or substantial disagreement occurs among the results of technical studies that could affect the potential risk conclusions for the chemical, BLM could conduct a formal peer review of the available scientific information to develop a consensus as to the endpoint(s) in question. The peer review process would include the following steps, based largely on EPA's peer review process (EPA 2000b):

- BLM would conduct a literature search of studies submitted to EPA, studies published in professional journals, and research projects conducted by other government agencies or universities. The identified literature would be indexed and abstracted.

- A peer review committee would be formed, consisting of reviewers with recognized technical expertise that bears on the subject matter under discussion, who represent a balanced range of technically legitimate points of view, and who do not have any real or perceived bias or conflict of interest. The peer reviewers would be supplied with their charge, the results of the literature review, and a description of the issue at hand.

- The input of each reviewer would be sent to BLM. If the results of the peer review are not consistent at this point, a working session would be convened, in which the peer reviewers would come together to discuss the technical aspects of the questions and attempt to reach a consensus.

The details of the peer review process would be determined by the question to be answered and the nature of the controversy. To the extent they are relevant, the guidelines and processes in EPA's Peer Review Handbook (EPA 2000b) would be followed.

For assessment of the hazards and risks from non-pesticide methods (biological controls, cultural controls, and other methods), BLM would review the potential for impacts to worker health and safety, public health and safety, and special status species and their habitat. Limited-scale field trials could assist in identifying potential hazards from a nonpesticide method under consideration, as well as in determining the effectiveness of any new approach.

\subsubsection{NEPA Documentation}

The potential use of new technologies or products for pest control in the seed orchard would require a review to ensure compliance with NEPA. The review would follow the process outlined in the BLM NEPA Handbook (H-1790-1), Chapter 1 (BLM 1988), and would consist of the basic steps described below and outlined in Figure 2.4-1. 
Figure 2.4-1. NEPA Review of New Products and Technologies.

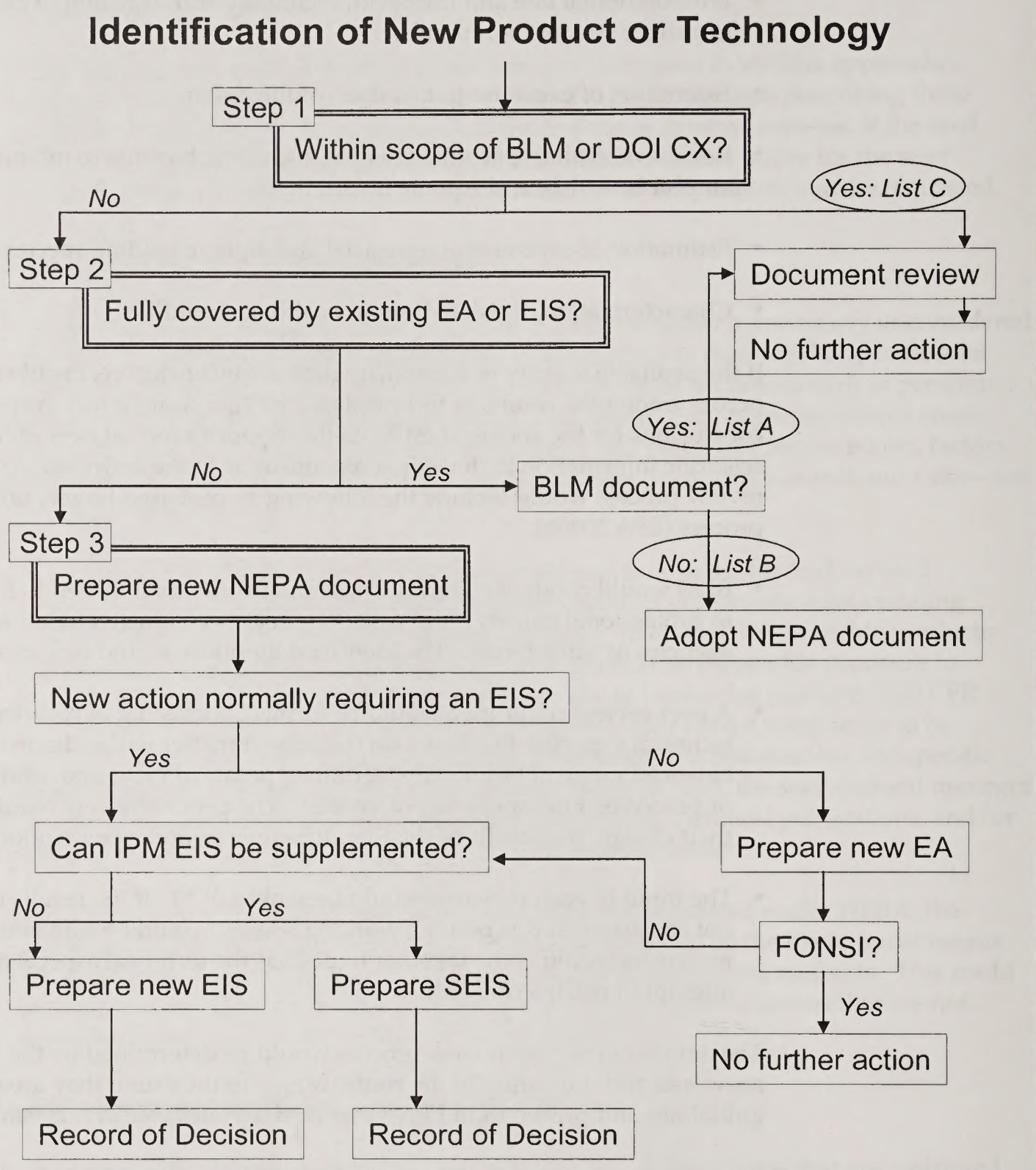

\section{Step 1. Conduct a CX Review}

The first step in this review is to determine whether the new action is within the scope of a Department of Interior or BLM CX (516 DM 2, Appendix 1; and 516 DM 11.5, respectively) (DOI 1980). These two lists constitute List $C$, as identified in Figure 2.4-1. Based on an initial review of this list, there appear to be only two CXs, both within the Forestry areas on the BLM list, that have the potential to cover a new technology or product relating to seed orchard operations (516 DM $11.5 \mathrm{c}$ (1) and (3)):

- Land cultivation and silvicultural activities (excluding herbicides) in forest tree nurseries, seed orchards, and progeny test sites. 
- Seeding or reforestation of timber sales or burn areas where no chaining is done, no pesticides are used, and there is no conversion of timber type or conversion of nonforest to forest land. Specific reforestation activities covered include: seeding and seedling plantings, shading, tubing (browse protection), paper mulching, bud caps, ravel protection, application of non-toxic big game repellant, spot scalping, rodent trapping, fertilization of seed trees, fenced construction around out-planting sites, and collection of pollen, scions and cones.

Therefore, some non-pesticide methods could be within the scope of an existing CX.

The CX review actually involves three steps: (1) ensure conformance with existing land use plan; (2) identify potential $\mathrm{CX}$ - see above; and (3) review the current list of exceptions to CX at 516 DM 2, Appendix 2.

If the new action is within the scope of a CX, and none of the exceptions applies, the CX review would be documented and then no further action would be required. If a $C X$ was not identified or one or more of the exceptions were met, then BLM would proceed to Step 2.

\section{Step 2. Review Existing EAs and EISs}

The following types of existing NEPA documents would be reviewed to determine whether any have fully covered the use of the proposed new product or technology:

\section{BLM NEPA Documents (List A)}

- This seed orchard-specific IPM EIS.

- EISs associated with the District RMP or Plan amendments.

- Programmatic documents such as the EIS for Vegetation Treatments, Watersheds and Wildlife Habitats on Public Lands Administered by the BLM in the Western United States, Including Alaska (currently in preparation).

- Any seed orchard-specific EAs that have been prepared for pest management or operations.

- NEPA documents prepared by other Federal agencies, with BLM as a cooperating agency.

\section{Other Agency NEPA Documents (List B)}

- NEPA documents for which BLM was not listed as a cooperating agency, but for which the scope is relevant to evaluation of the proposed pest management method. Possible source agencies could include the Forest Service, National Park Service, Animal and Plant Health Inspection Service, and the military services.

Generally, existing NEPA documents may be used when: (1) a current proposed action was previously proposed and analyzed (or is part of an earlier proposal that was analyzed); (2) resource conditions and other relevant circumstances have not changed significantly, and there is no significant new information germane to the proposed action; and (3) there is no suggestion by the public of a significant new and appropriate alternative (BLM 2001). 
The review would focus on the following questions to determine whether the existing document(s) satisfy NEPA analysis requirements for the proposed new pest management method (BLM 2001):

- Is the current proposed action substantially the same action (or is a part of an action) as previously analyzed?

- Is the range of alternatives analyzed in the existing NEPA document(s) appropriate with respect to the current proposed action, given current environmental concerns, interests, resource values, and circumstances?

- Is the existing analysis adequate and are the conclusions adequate in light of any new information or circumstances (including, for example, riparian proper functioning condition [PFC] reports; rangeland health standards assessments; Unified Watershed Assessment categorizations; inventory and monitoring data; most recent Fish and Wildlife Service and NOAA Fisheries lists of threatened, endangered, proposed, and candidate species; most recent BLM lists of special status species)? Can you reasonably conclude that all new information and all new circumstances are insignificant with regard to analysis of the proposed action?

- Do the methodology and analytical approach used in the existing NEPA document(s) continue to be appropriate for the current proposed action?

- Are the direct and indirect effects of the current proposed action substantially unchanged from those identified in the existing NEPA document(s)? Does the existing NEPA document sufficiently analyze site-specific impacts related to the current proposed action?

- Can you conclude without additional analysis or information that the cumulative impacts that would result from implementation of the current proposed action are substantially unchanged from those analyzed in the existing NEPA document(s)?

- Are the public involvement and interagency review associated with existing NEPA document(s) adequately [sic] for the current proposed action?

If all the criteria are met and the existing document is a BLM document or one with BLM as a cooperating agency, then the analysis and results would be documented using the Documentation of Land Use Plan Conformance and NEPA Adequacy, described in BLM Instruction Memorandum No. 2001-062 (BLM 2001). Reliance on existing NEPA documents requires the establishment of an administrative record that clearly shows a "hard look" has been taken at whether new circumstances, new information, or environmental impacts not previously anticipated or analyzed warrant new analysis or supplementation of existing analyses, and whether the impact analysis supports the proposed action. The review must be conducted through an interdisciplinary process, and the resulting documentation must adequately address the criteria included in the worksheet contained in BLM (2001). If existing NEPA documentation is found to be adequate, this must be documented on the worksheet, which must also include a signed conclusion statement. Approval of the proposed action requires a Finding of No Significant Impact (FONSI) decision document.

If existing NEPA documentation is found to be adequate, but BLM is not formally a cooperating agency on the document, then BLM would adopt the document to comply with NEPA; adoption would be in accordance with the requirements set forth in 40 CFR 1506.3. If existing NEPA documentation was determined to be inadequate, completion of 
the worksheet is not required and either the proposal would be rejected or BLM would proceed to Step 3.

\section{Step 3. Prepare a New NEPA Document}

This step can be further broken down into two sub-steps: (a) what level of NEPA review is required (EA or EIS); and (b) can portions of an existing document(s) be used in preparation of the new NEPA document?

To determine the level of NEPA review needed, the action should be compared to the actions typically requiring preparation of an EIS (516 DM 11.4). Depending on the outcome, it may be appropriate to tier to, supplement, or incorporate by reference parts or all of existing document(s) as part of the document preparation process:

- Tiering (40 CFR 1508.28) could be used to prepare new more specific or more narrow environmental documents (such as an EA for the proposed activity) without duplicating relevant parts of previously prepared, more general or broader documents (such as the IPM EIS). Tiering is mostly used to avoid unnecessary paperwork. Documents can be tiered only if decisions made in the new document would not change or modify the decision(s) of the more general document.

- Supplementing (40 CFR 1502.9c) is most often used to address alternatives not previously analyzed and may lead to a new decision. In this instance, a supplemental EIS (SEIS) could be prepared to the IPM EIS. Supplemental documents are generally prepared when there is a substantial change in the proposed action that is relevant to environmental concerns; that is, if there are significant new circumstances or facts relevant to environmental concerns and bearing on proposed action or impacts that were not addressed in existing analysis. If the existing IPM EIS is supplemented, the same standard procedural and documentation requirements for EISs are followed (see Chapter 5 of BLM Handbook), except that additional scoping is optional. In addition, the SEIS must identify the EIS being supplemented and explain the relationship to the prior analysis early in the text. Further, the SEIS should identify changes in the proposed project and/or significant new information or changed circumstances that necessitate preparation of the supplement.

- Incorporating by reference (40 CFR 1502.21) is a technique used to avoid redundancies in analysis and to reduce the bulk of a NEPA document. An EA or EIS must identify the documents that are incorporated by reference and indicate where they are available for public review. Relevant portions of the incorporated analysis must be referenced by page number, and summarized in the EA or EIS to the extent necessary to provide the decisionmaker and public with an understanding of significance of the referenced material to the current analysis. The new NEPA document must be able to stand alone.

Preparation of a new EA would follow the procedures outlined in the BLM NEPA Handbook, Chapter 4. Preparation of a new EIS or SEIS would follow the procedures outlined in the BLM NEPA Handbook, Chapter 5 (including, where appropriate, tiering, supplementing, and incorporating by reference, as noted above). The EA process would end in issuance of a FONSI or a determination of the need to prepare an EIS. The EIS process would end with issuance of a ROD. 


\subsection{Ongoing and Reasonably Foreseeable Future Actions in Study Area}

Implementing the proposed action or an alternative at Tyrrell would be concurrent with other actions at the orchard and adjacent lands; these actions could contribute to cumulative impacts to some resources. Otherwise, the orchard plans only routine operations, and expects no construction or other unusual activities that would contribute to cumulative impacts (BLM 2002).

On some properties adjacent to Tyrrell, several companies conduct timber operations, including logging, the use of heavy machinery, and IPM activities. These companies apply chemicals using a variety of methods, including helicopter applications. There are no other activities known to occur on adjacent properties that would contribute to cumulative impacts (BLM 2002).

\subsection{Summary of Environmental Impacts by Alternative}

Areas of potential concern for the proposed action and alternatives were identified based on input from BLM interdisciplinary team members, consultation with Federal and state agencies, scoping comments, and comparisons with similar activities. The potential impacts were evaluated and are described in Chapter 4.

As defined in CEQ's regulations for implementing NEPA, determining whether an environmental impact is "significant" requires consideration of both context and intensity. In the resource-specific subsections of Chapter 4 of this EIS, the criteria used to define each impact's significance are described under the sub-heading "Analysis Approach and Assumptions."

Table 2.6-1 summarizes the environmental impacts for each resource by alternative. Table 2.6-1 is provided as an attachment at the end of this chapter, following Table 2.2-1.

The resource-specific assessments in Chapter 4 are organized according to a logical flow of analysis. Effects on the physical environment (for example, surface water) must be determined before effects on the associated resources (such as aquatic species) can be assessed. This same sequence of resources is maintained in Table 2.6-1. However, scoping concerns would dictate a different priority for considering the results, in which the following five resources are of greater importance than the others for purposes of decisionmaking: human health and safety, water quality, wildlife and aquatic species, socioeconomics, and soils. The analysis predicted no significant impacts in two of these areas: socioeconomics and soils. Comparison of potential impacts among the remaining three resources provides the critical information to be considered by the decisionmaker in preparing the ROD for this EIS:

\section{Human Health and Safety}

- There are no significant risks to members of the public from the proposed use of any of the control methods under any of the alternatives. However, an accidental spill to a stream of pesticide under Alternatives A, B, C, and E, or of fertilizer under any alternative, could make surface water unsafe for drinking or fishing.

- Under Alternatives A and E, there is a possibility of health effects for workers from some chemical pesticides. No risks of worker health effects were predicted for pesticide applications under Alternatives B and C. Under Alternatives A, B, C, and E, an accidental spill onto the skin could cause health risks. Under all of the alternatives, there is a possibility of injury from cultural or prescribed fire methods. 
- Although runoff or drift to surface water is possible from some applications, the predicted stream concentrations are below levels that would be associated with risks to human health.

\section{Water Quality}

- No significant impacts to groundwater quality were predicted under any alternative.

- Runoff or drift from pesticide or fertilizer applications could enter streams and rivers under Alternatives A, B, C, and E, and fertilizers under Alternative D. The effects of the estimated stream concentrations on human health and aquatic species are described under those headings. Under Alternatives B and C, limitations would be in place to control the potential for runoff and drift.

- An accidental spill of pesticide concentrate or mix could contaminate groundwater or surface water under Alternatives A, B, C, and E, and a spill of fertilizer could contaminate water under any alternative.

\section{Biological Resources}

- Localized impacts to non-target vegetation are possible from broadcast herbicide applications in areas that are already intensively managed or disturbed. These impacts are not considered significant, as no special status plant species are present.

- There are possible risks to terrestrial wildlife species from some of the proposed pesticides under Alternatives A and E. Maximum scenario fertilizer application could pose a risk to the special status species western bluebird under any alternative. Lethality would be expected for non-target insects in an area treated with insecticide under Alternatives A, B, C, and E. No other significant impacts to terrestrial wildlife were predicted.

- There are possible risks of sublethal effects to special status fish species from pyrethroid insecticides under some maximum (but not typical) conditions under Alternatives A, B, C, and E; and a risk of sublethal and lethal effects from fertilizer under maximum runoff conditions. Limitations included in Alternatives B and C would decrease these risks compared to Alternative A. An accidental spill of pesticide to a stream would cause adverse impacts to aquatic species under Alternatives A, B, C, and E; and there could be risks from an accidental spill of fertilizer under all alternatives. Although runoff or drift to surface water is possible from some applications of other pesticides and other ingredients, the predicted stream concentrations are below levels that would be associated with risks to aquatic species.

Alternative B, the proposed action, is BLM's preferred alternative for minimizing longterm impacts to all resources, including human health. 


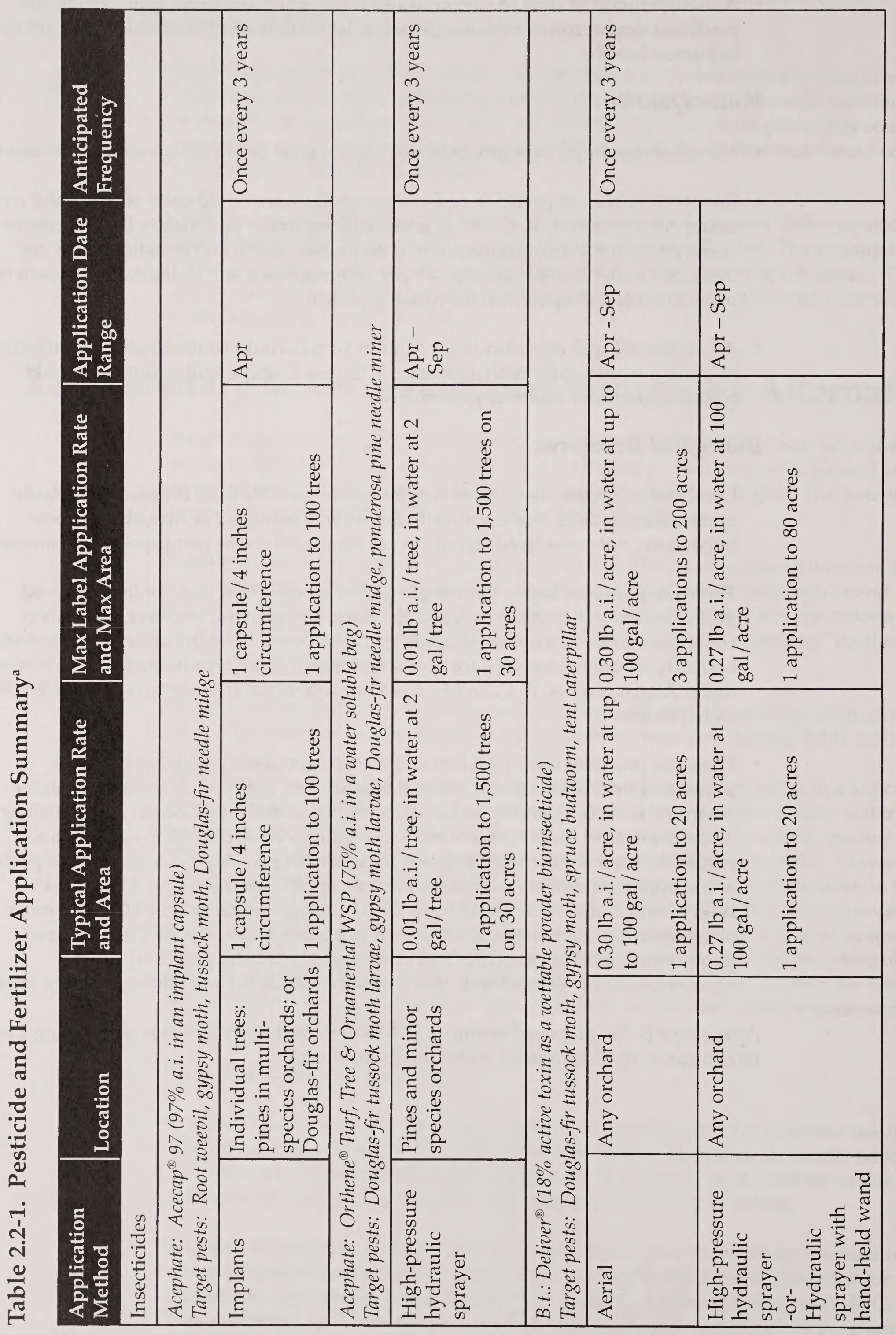




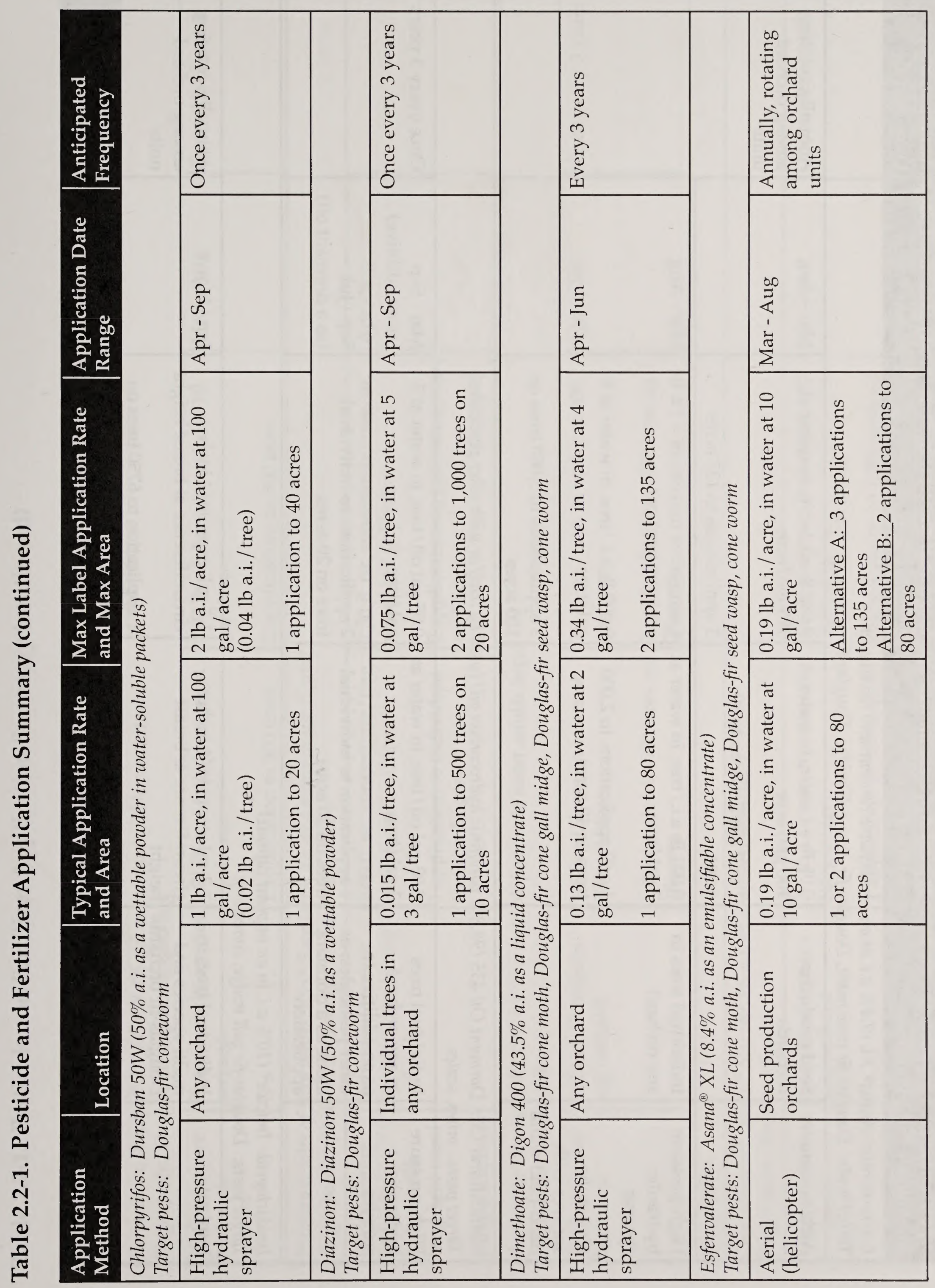




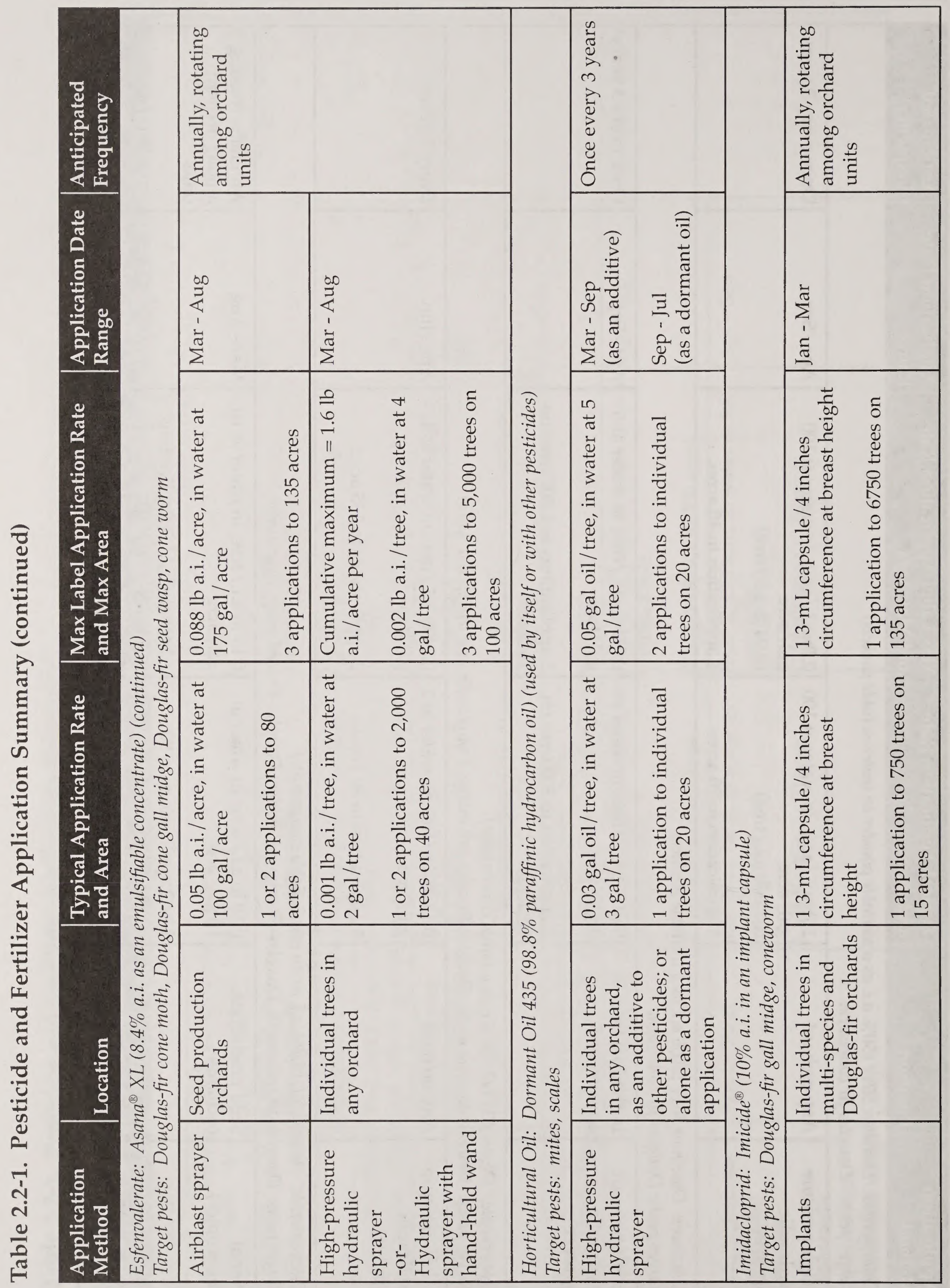









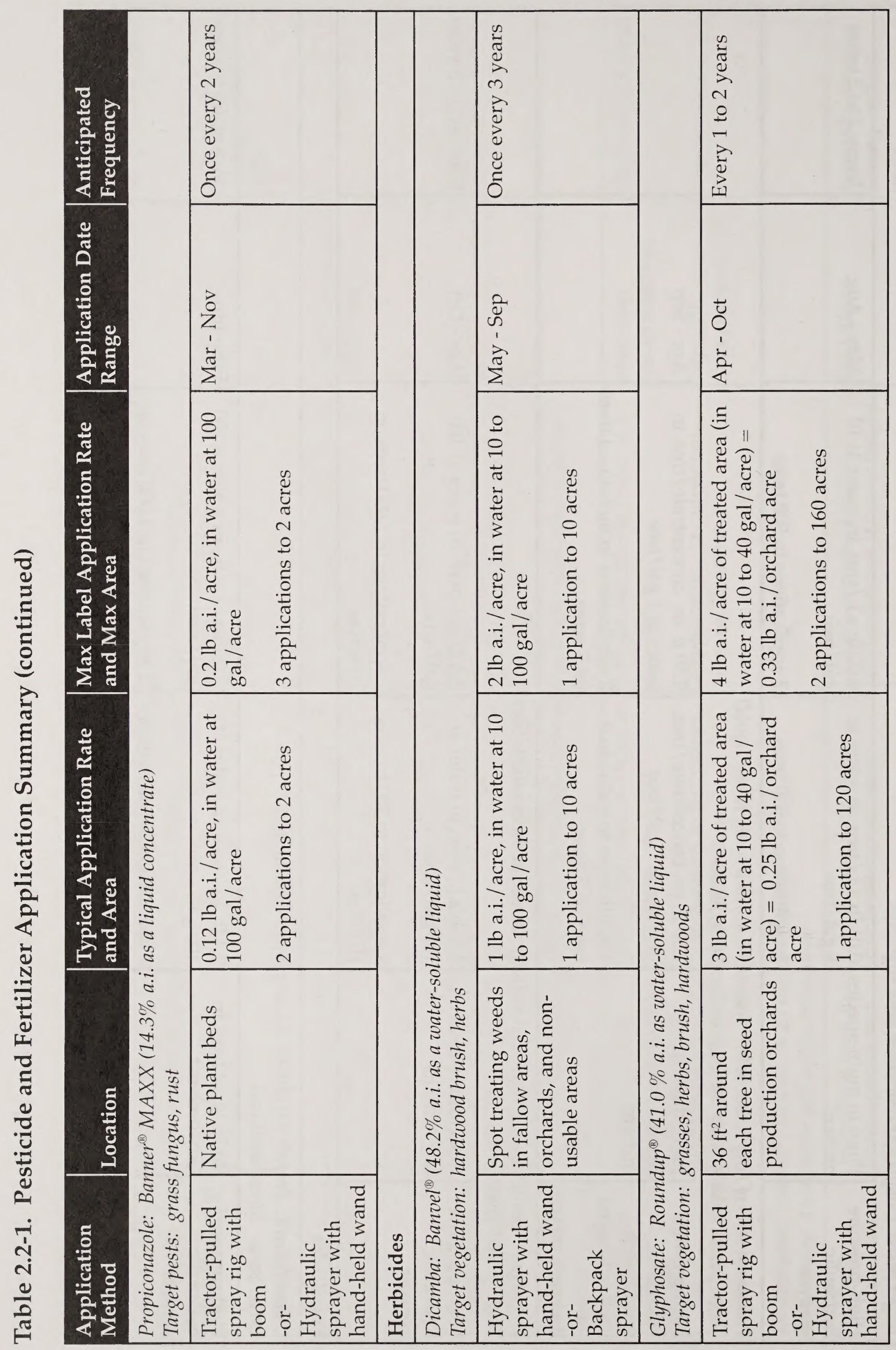




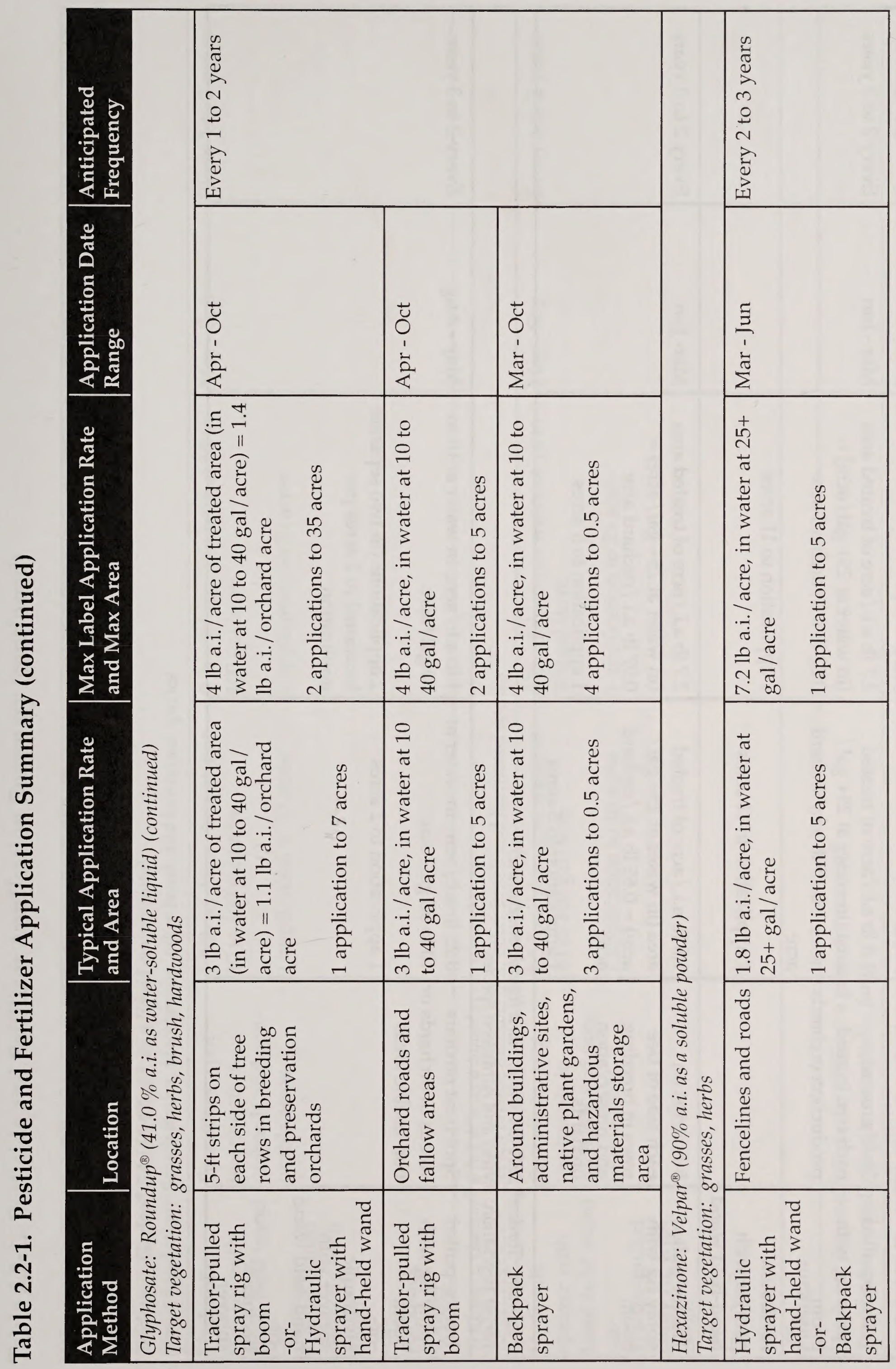




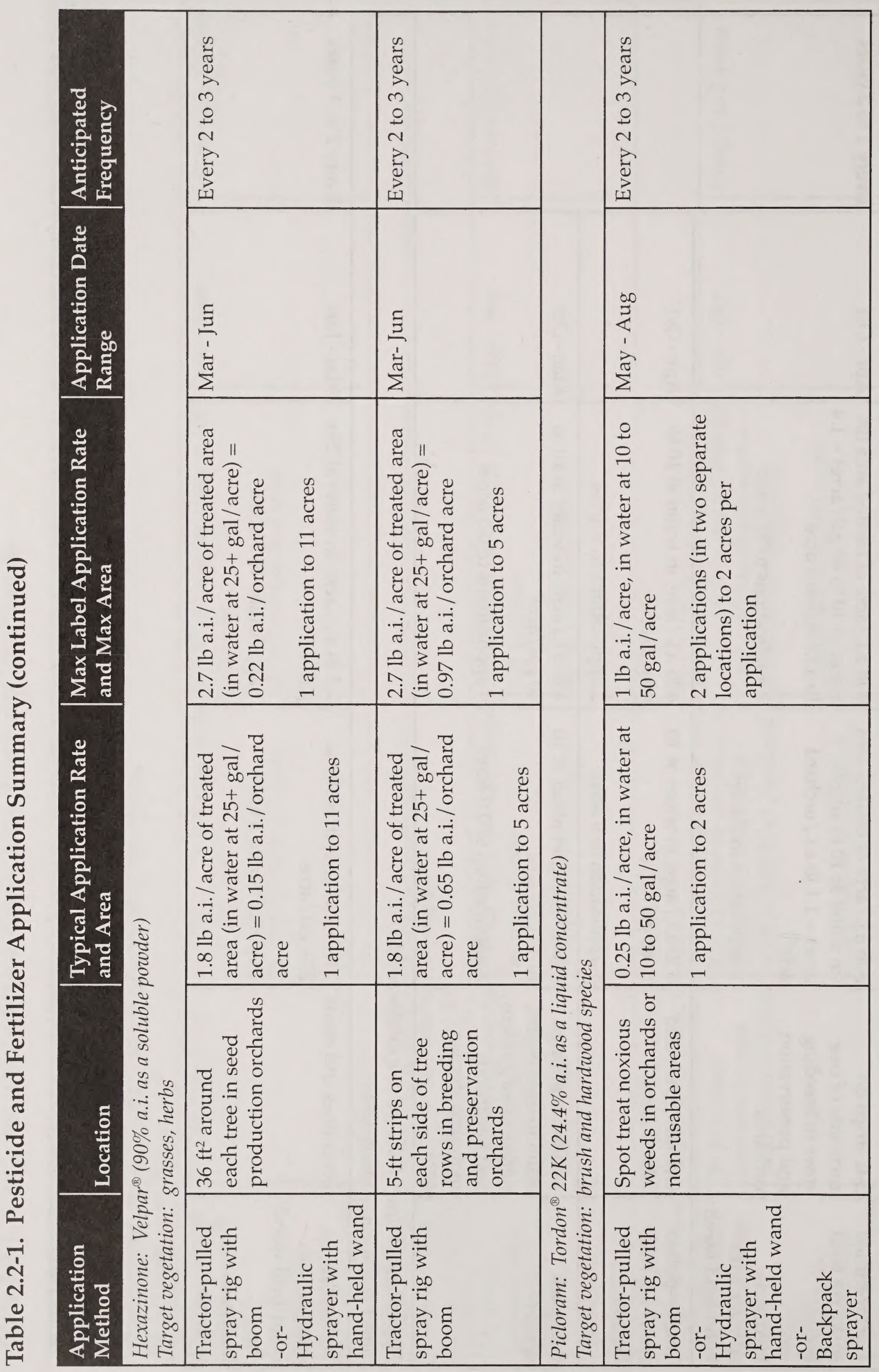




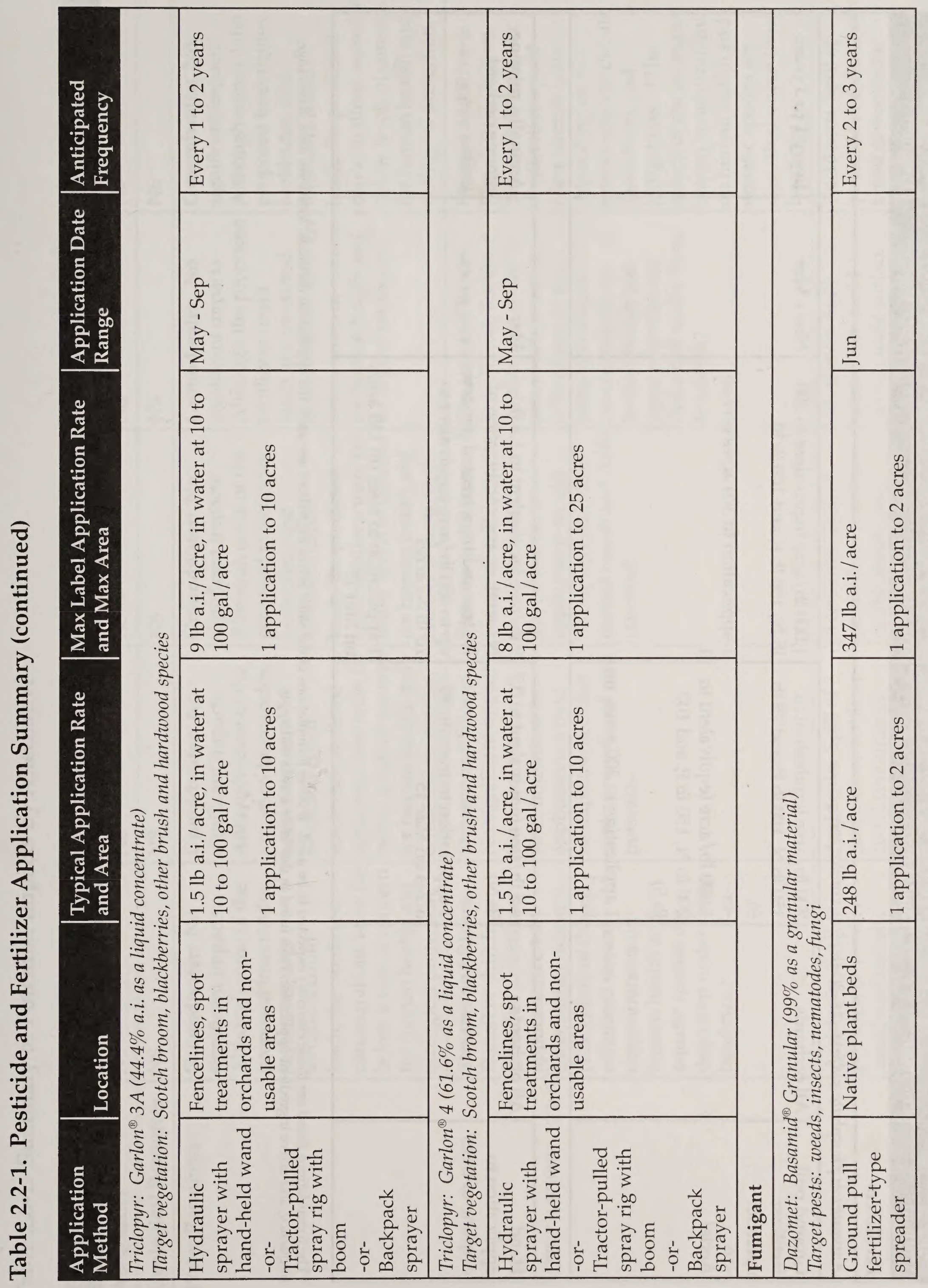




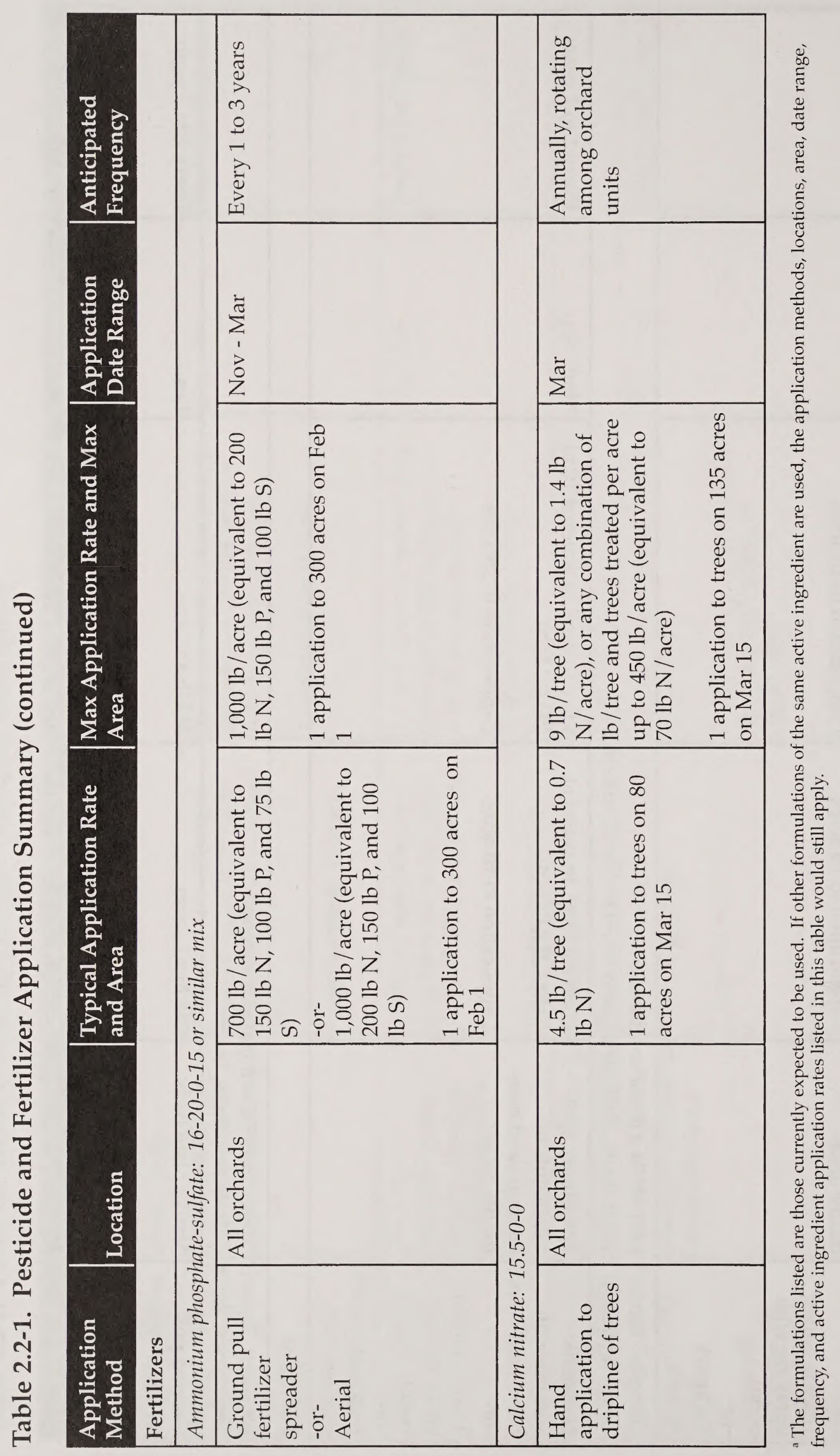




\begin{tabular}{|c|c|c|c|c|c|c|}
\hline 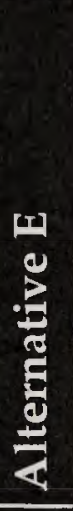 & Z & Z & 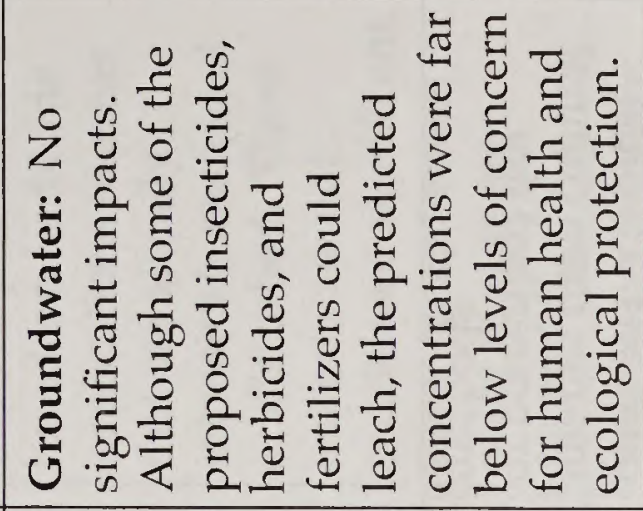 & 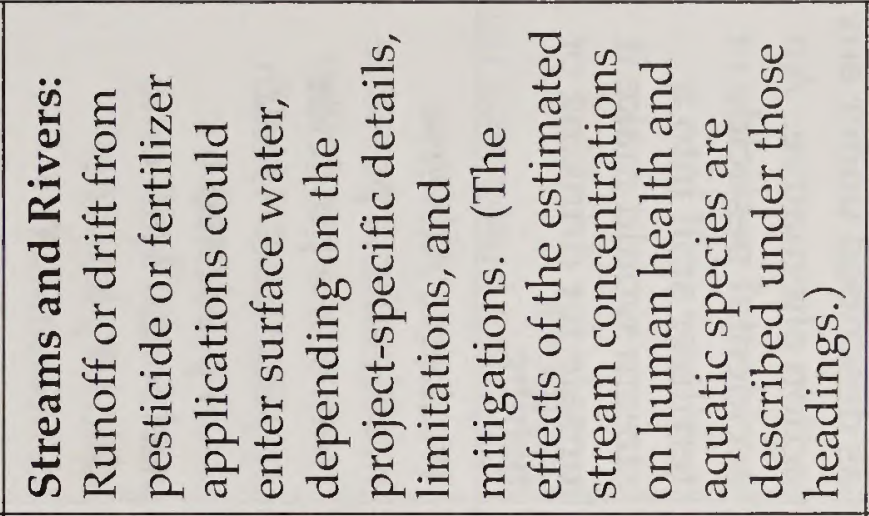 & 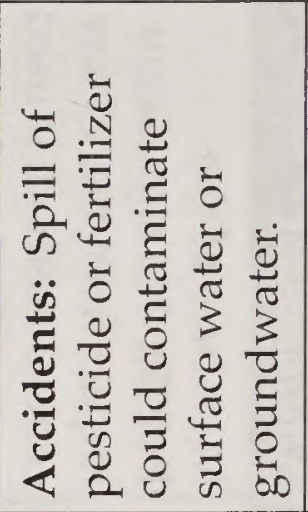 & z \\
\hline $\begin{array}{l}0 \\
\frac{D}{2} \\
\frac{\pi}{0} \\
\frac{0}{0} \\
\frac{0}{2}\end{array}$ & z & Z & 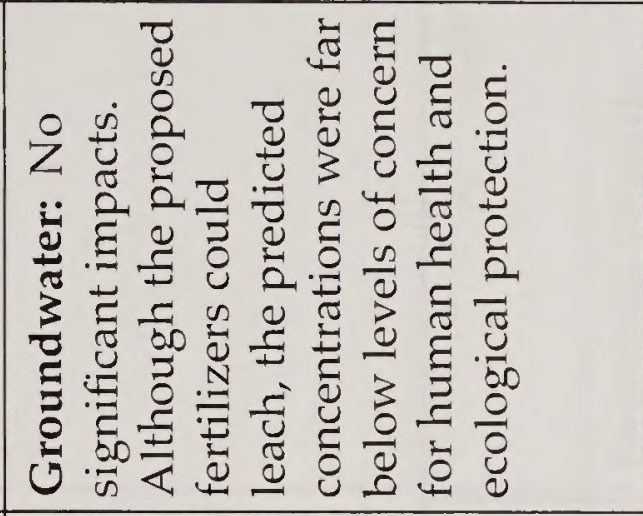 & 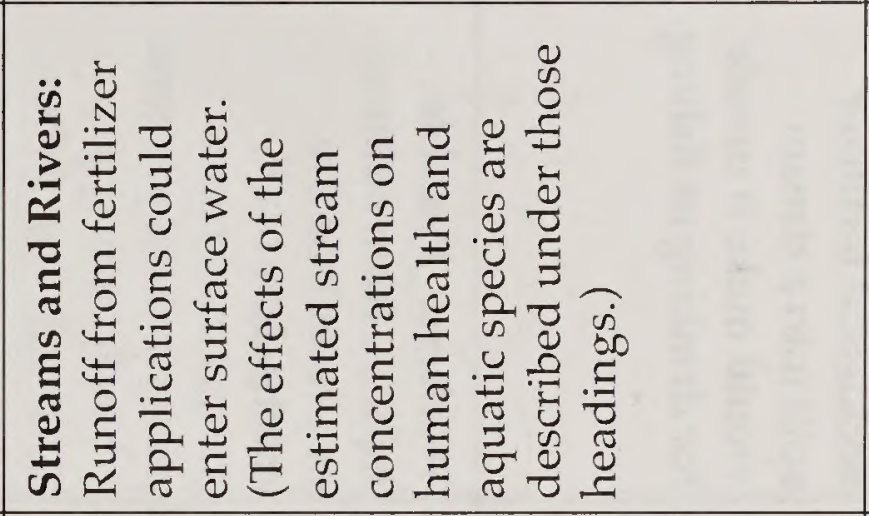 & 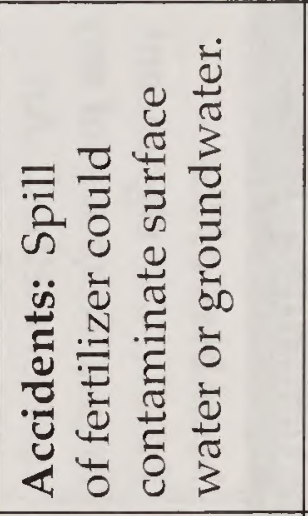 & Z \\
\hline$\frac{U}{\frac{3}{3}}$ & $\bar{Z}$ & 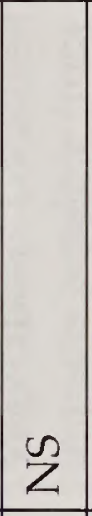 & 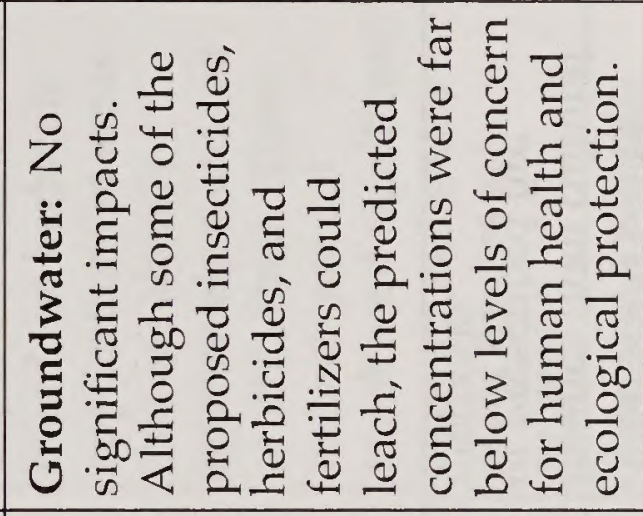 & 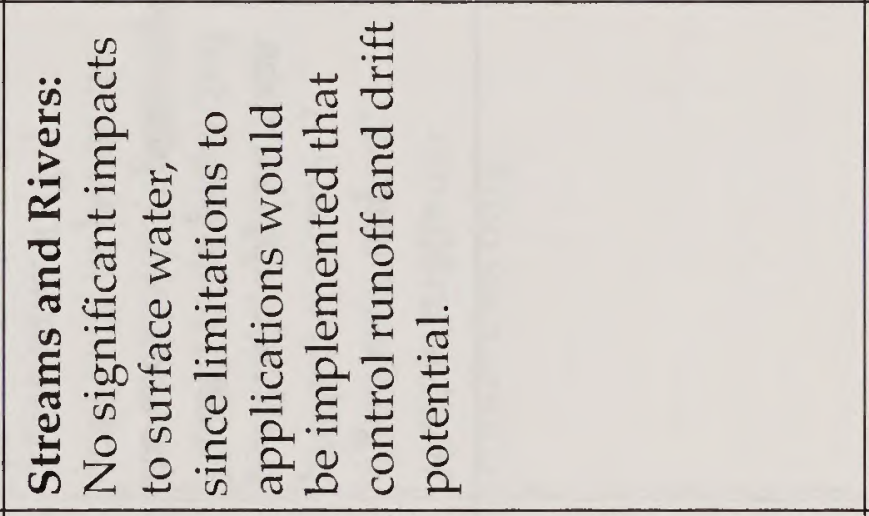 & 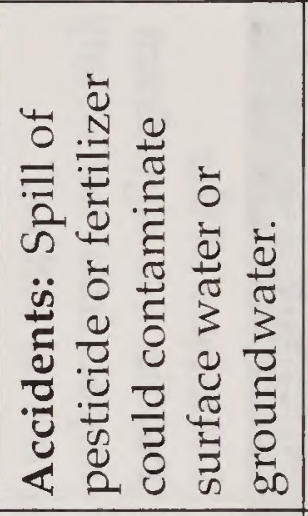 & Z \\
\hline$\frac{\infty}{\frac{0}{3}}$ & Z & Z & 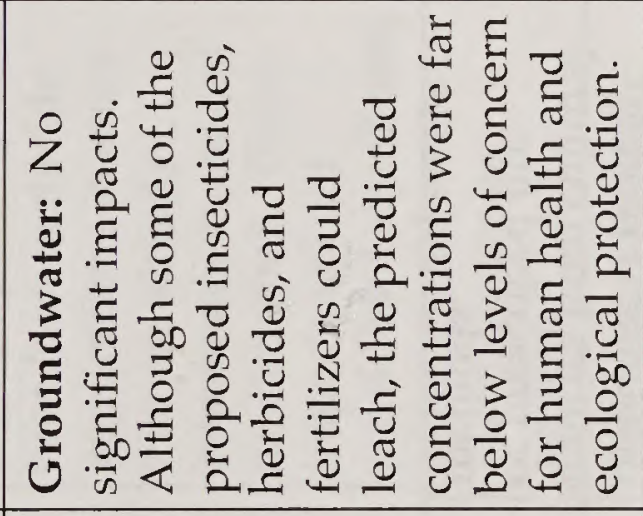 & 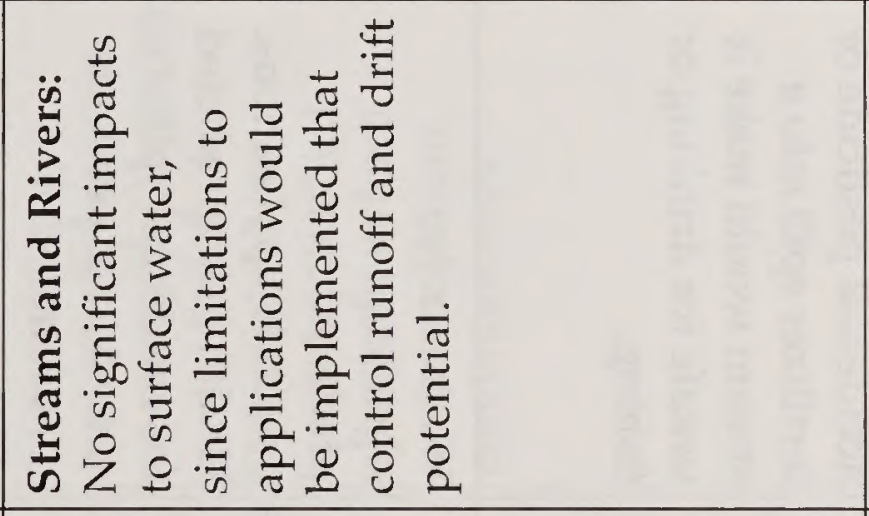 & 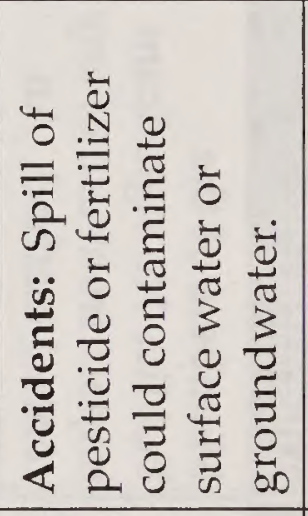 & 兄 \\
\hline 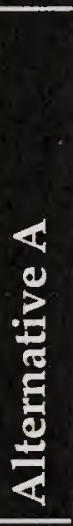 & $\begin{array}{l}* \\
\text { Z } \\
\end{array}$ & $\Sigma^{n}$ & 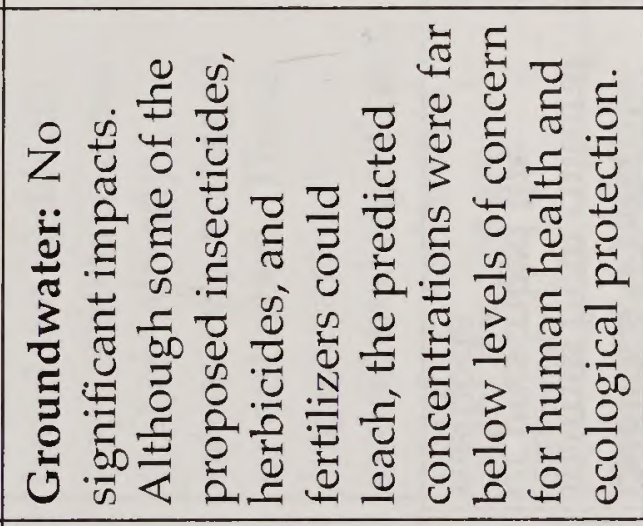 & 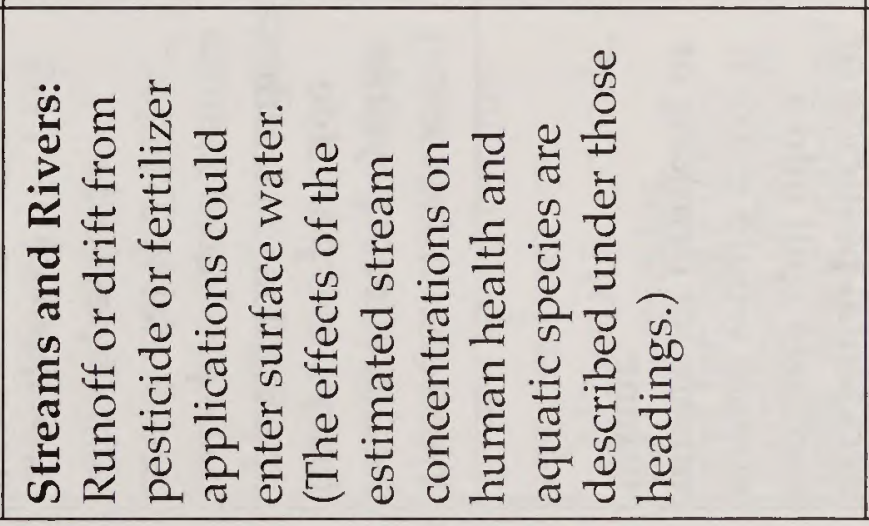 & 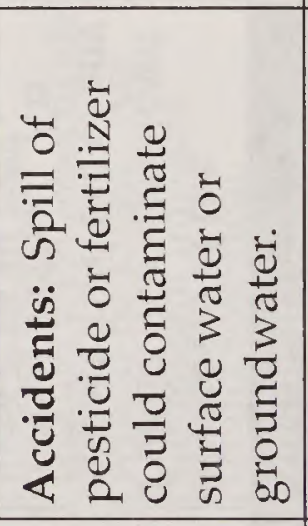 & n \\
\hline 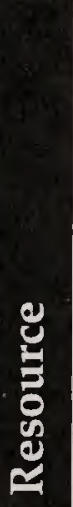 & 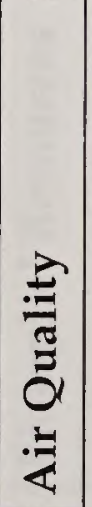 & 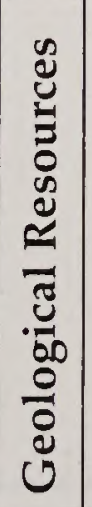 & 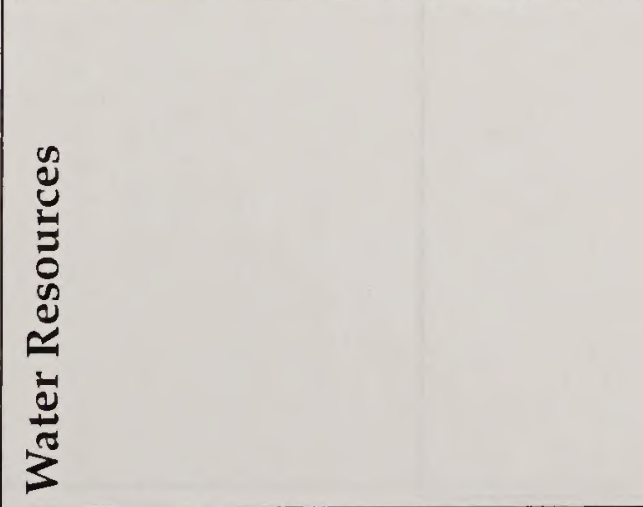 & & & 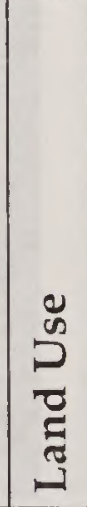 \\
\hline
\end{tabular}




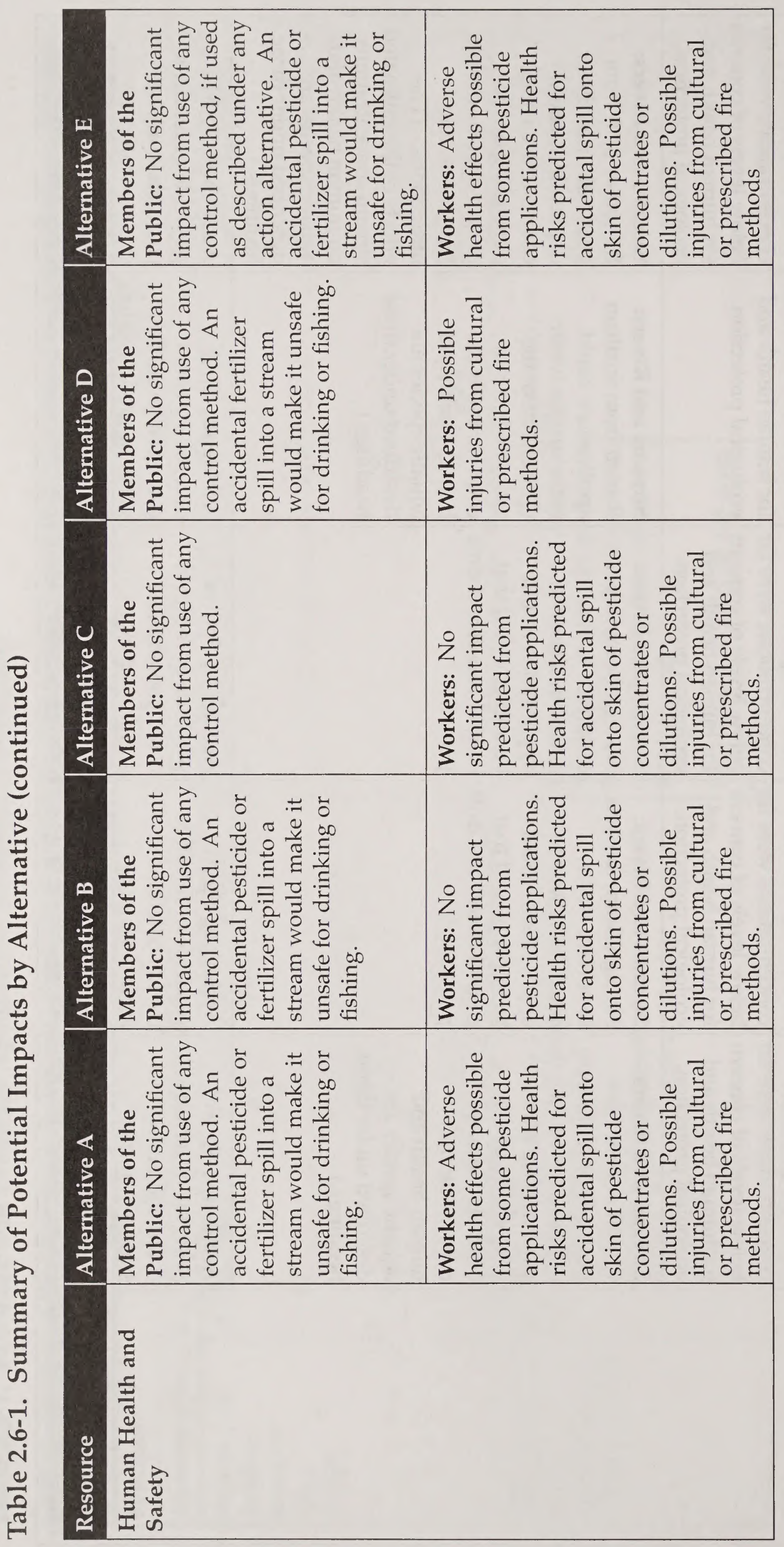

Chapter $2-48$ 


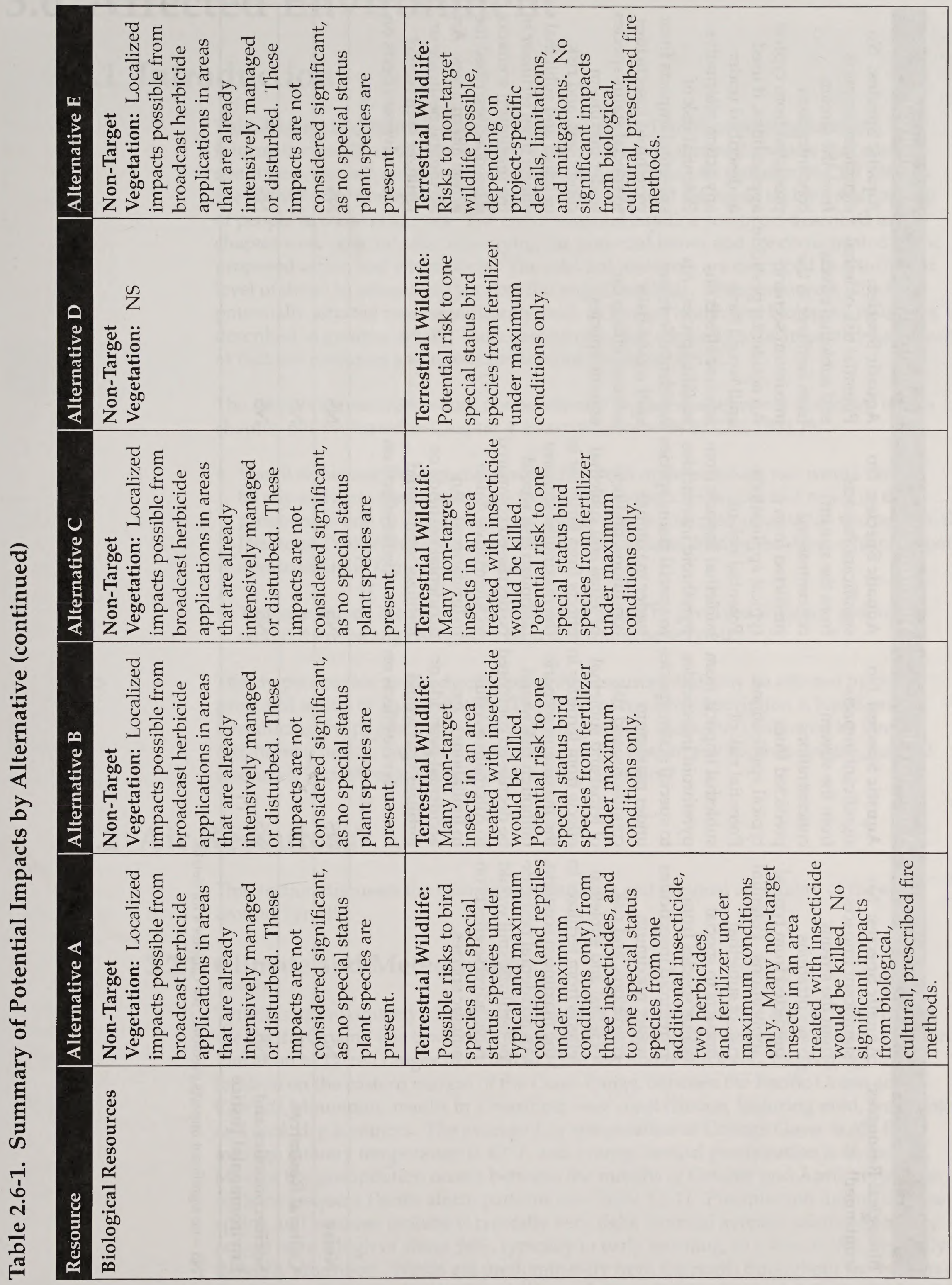




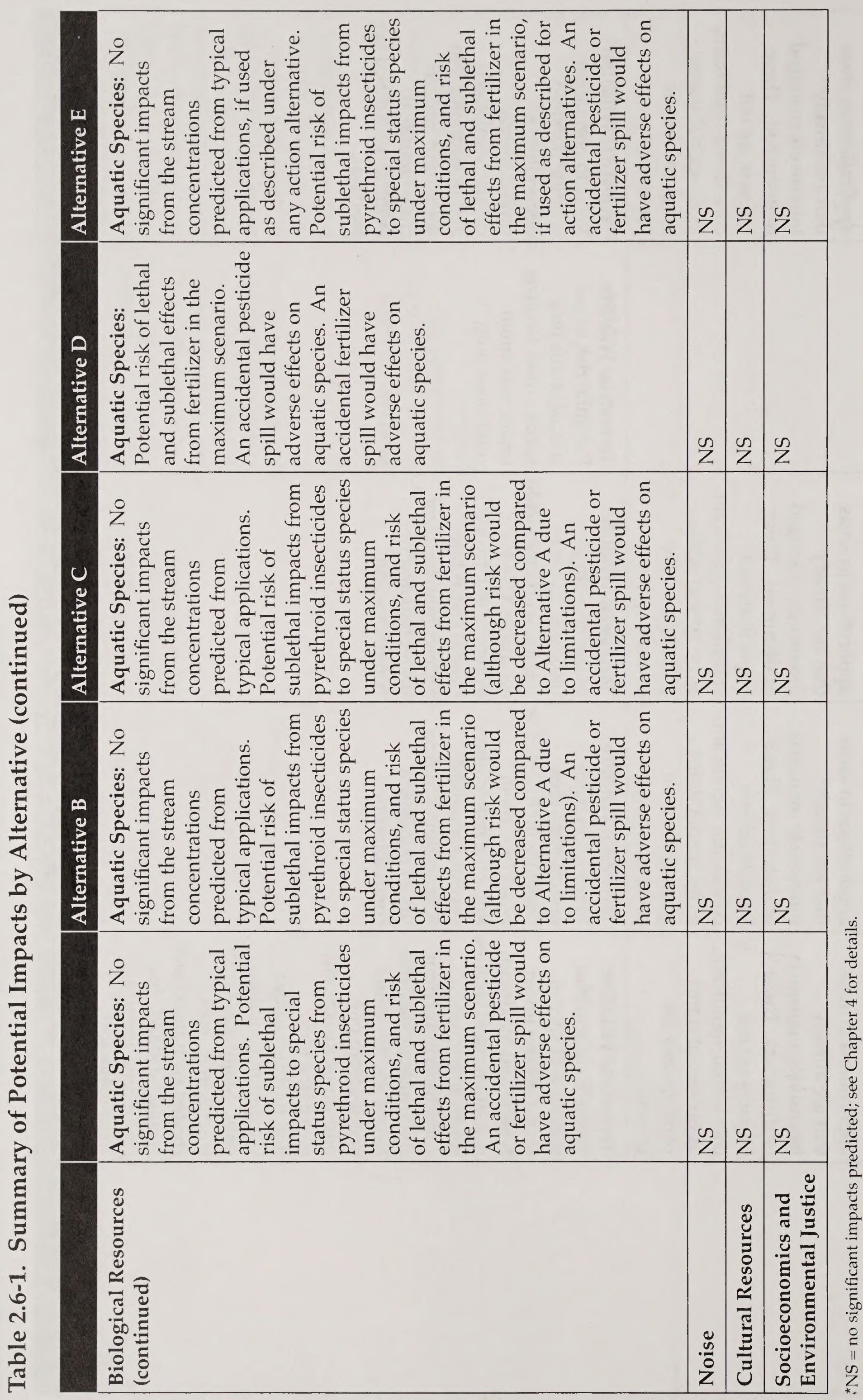




\subsection{Affected Environment}

\subsection{Introduction}

This chapter describes the relevant environment at Tyrrell, providing baseline information to allow the evaluation of potential environmental impacts that could result from the proposed action or an alternative action. As stated in 40 CFR 1508.14, the human environment includes natural and physical resources and the relationship of people to those resources. The environmental baseline resources described in this chapter were selected after identifying the potential issues and concerns related to the proposed action and alternatives. The relevant resources are described in a sufficient level of detail to adequately support the impact analysis. Those resources which are potentially affected most significantly, such as human health and biological resources, are described in greatest detail. Those resources which are likely to be impacted least, such as cultural resources and noise, are described in lesser detail.

The following resources would not be affected and are therefore not described in this chapter, nor evaluated in Chapter 4, in accordance with 40 CFR 1502.15:

- Visual resources: No structures would be built or demolished, nor would there be any activities that would affect visual or aesthetic resources as a result of the proposed action or any alternative. The closest wilderness areas to the orchard are the Diamond Peak Wilderness Area and the Waldo Lake Wilderness Area, which are both approximately 50 miles to the east.

- Transportation: No construction vehicles would be involved with any action, nor would there be any changes to vehicular traffic near Tyrell.

The chapter begins with a discussion of the resources that may be affected by the proposed action or an alternative. The order of resource description is based on introducing the physical environment (air, geology, and water), followed by land use, human health, biological resources, and the human environment (noise, cultural resources, socioeconomics, and environmental justice).

\subsection{Air Resources}

This section discusses the climate, meteorology, and regional air quality of the area around Tyrrell.

\subsubsection{Climate and Meteorology}

Tyrrell is approximately 15 miles southwest of the city of Eugene and 40 miles east of the Pacific Ocean. The town of Cottage Grove is about 12 miles east of the seed orchard. Elevation at Tyrrell ranges from 660 to 1,240 feet above sea level. Its geographical location on the eastern margin of the Coast Range, between the Pacific Ocean and Cascade Mountains, results in a maritime west coast climate, featuring mild, wet winters and cool, dry summers. The average July temperature at Cottage Grove is $65^{\circ} \mathrm{F}$, the average January temperature is $40^{\circ} \mathrm{F}$, and average annual precipitation is 46 inches. Most of the precipitation occurs between the months of October and April, consistent with the frequent Pacific storm patterns (see Table 3.2-1). Precipitation during the late spring and summer months is typically very light. Annual average relative humidity ranges from a high of about $94 \%$, typically in early morning, to a low of $38 \%$, typically in the early afternoon. Winds are predominantly from the north throughout the months of April through September, and from the south from October through March. Table 3.2-2 
Table 3.2-1. Climate Characteristics ${ }^{\mathrm{a}}$

\begin{tabular}{|l|c|c|c|c|c|c|c|c|c|c|c|c|c|}
\hline & \multicolumn{10}{|c|}{ Month } & \\
\hline Characteristic & Jan & Feb & Mar & Apr & May & Jun & Jul & Aug & Sep & Oct & Nov & Dec & Year \\
\hline Mean temperature $\left(^{\circ}\right.$ F) & 40.2 & 43.5 & 46.6 & 50.0 & 54.7 & 59.8 & 64.7 & 64.8 & 60.1 & 52.9 & 45.2 & 40.1 & 51.9 \\
\hline Mean precipitation (in) & 6.51 & 5.40 & 5.20 & 4.00 & 2.81 & 1.53 & 0.60 & 0.92 & 1.48 & 3.22 & 7.27 & 6.96 & 45.90 \\
\hline $\begin{array}{l}\text { Average days with 0.5 } \\
\text { or more inches of rain }\end{array}$ & 4.4 & 3.7 & 3.3 & 2.3 & 1.4 & 0.8 & 0.3 & 0.6 & 0.9 & 2.1 & 5.2 & 4.6 & 29.3 \\
\hline
\end{tabular}

${ }^{2}$ Data are for Cottage Grove for the period of record 1971 - 2000 (Oregon Climate Service 2002a).

Table 3.2-2. Wind Characteristics ${ }^{a}$

\begin{tabular}{|c|c|c|c|c|c|c|c|c|c|c|c|c|}
\hline & \multicolumn{12}{|c|}{ Month } \\
\hline Characteristic & Jan & Feb & Mar & Apr & May & Jun & Jul & Aug & Sep & Oct & Nov & Dec \\
\hline Prevailing direction $^{b}$ & $S$ & $S$ & $S$ & $\mathrm{~N}$ & $\mathrm{~N}$ & $\mathrm{~N}$ & $\mathrm{~N}$ & $\mathrm{~N}$ & $\mathrm{~N}$ & $S$ & $S$ & $\mathrm{~S}$ \\
\hline $\begin{array}{l}\text { Average wind speed } \\
(\mathrm{mph})^{\mathrm{c}}\end{array}$ & 7.8 & 6.6 & 7.4 & 6.8 & 6.7 & 6.6 & 7.4 & 6.5 & 6.3 & 5.4 & 5.7 & 7.0 \\
\hline \multicolumn{13}{|c|}{ Percent occurrence of wind speeds for all directions: } \\
\hline Calm & 10.8 & 18.3 & 11.1 & 13.7 & 14.3 & 14.7 & 13.8 & 16.8 & 19.3 & 24.0 & 23.4 & 16.2 \\
\hline 1-3 mph & 14.5 & 13.4 & 13.1 & 14.4 & 14.5 & 14.3 & 12.1 & 13.7 & 15.2 & 16.7 & 17.2 & 13.0 \\
\hline 4-7 mph & 25.9 & 28.0 & 29.0 & 30.5 & 30.0 & 31.2 & 24.2 & 27.7 & 26.9 & 28.6 & 26.4 & 28.6 \\
\hline 8-12 mph & 29.9 & 27.6 & 32.0 & 28.7 & 29.7 & 28.3 & 35.0 & 32.2 & 27.3 & 23.1 & 23.4 & 27.8 \\
\hline$>12 \mathrm{mph}$ & 18.7 & 12.8 & 14.8 & 12.7 & 11.5 & 11.4 & 14.9 & 9.6 & 11.3 & 7.5 & 9.7 & 14.3 \\
\hline
\end{tabular}

${ }^{a}$ Data are for the Eugene Airport for the period of record 1948 - 1958 (Oregon Climate Service 2002b).

'Highest total percentage per direction observed during month.

cAveraged for all directions observed per month.

presents wind speed data from the Eugene Airport, 17 miles to the north; average wind speeds usually range from 5 to 8 miles per hour year round.

\subsubsection{Regional Air Quality}

The National Ambient Air Quality Standards (NAAQS), established by EPA and adopted by ODEQ, define the maximum allowable concentrations of pollutants that may be reached but not exceeded within a given time period. Primary standards protect public health, and secondary standards protect public welfare, including protection against decreased visibility and damage to animals, crops, vegetation, and buildings. Section 110 of the Clean Air Act requires states to develop air pollution regulations and control strategies to ensure that state air quality meets the NAAQS established by EPA. These ambient standards, established under Section 109 of the Clean Air Act, currently address six criteria pollutants: carbon monoxide $(\mathrm{CO})$, nitrogen dioxide $\left(\mathrm{NO}_{2}\right)$, ozone $\left(\mathrm{O}_{3}\right)$, lead $(\mathrm{Pb})$, particulate matter $(\mathrm{PM})$, and sulfur dioxide $\left(\mathrm{SO}_{2}\right)$. Particulate matter is further regulated by size for particles smaller than 10 microns in diameter $\left(\mathrm{PM}_{10}\right)$. Exceeding the NAAQS concentration is referred to as "nonattainment" of the pollutant standard.

Table 3.2-3 presents the current NAAQS and the Oregon Ambient Air Quality Standards for the six criteria pollutants, along with regional air quality data for 2001, during which time all standards were met.

The Clean Air Act Amendments of 1970 established three Federal air quality control regions (AQCRs) in western Oregon. Tyrrell is located in the Portland Interstate AQCR. 
Table 3.2-3. National and State Ambient Air Quality Standards and Data

\begin{tabular}{|c|c|c|c|c|c|}
\hline \multirow[b]{2}{*}{ Pollutant } & \multirow[b]{2}{*}{ Averaging Time } & \multicolumn{3}{|c|}{ Standard ${ }^{b}$} & \multirow{2}{*}{$\begin{array}{l}2001 \text { Air } \\
\text { Quality Data } \\
\text { (ppm) }^{d}\end{array}$} \\
\hline & & Primary NAAQS & $\begin{array}{l}\text { Secondary } \\
\text { NAAQS }\end{array}$ & $\begin{array}{l}\text { Oregon } \\
\text { AAQS }\end{array}$ & \\
\hline $\mathrm{O}_{3}$ & $\begin{array}{l}1 \mathrm{hr} \\
8 \mathrm{hr}^{\mathrm{c}}\end{array}$ & $\begin{array}{l}0.12 \mathrm{ppm}\left(235 \mu \mathrm{g} / \mathrm{m}^{3}\right) \\
0.08 \mathrm{ppm}\left(157 \mu \mathrm{g} / \mathrm{m}^{3}\right)^{\mathrm{c}}\end{array}$ & - & $0.12 \mathrm{ppm}$ & $\begin{array}{l}0.090 \\
0.076\end{array}$ \\
\hline $\mathrm{CO}$ & $\begin{array}{l}1 \mathrm{hr} \\
8 \mathrm{hr}\end{array}$ & $\begin{array}{l}35 \mathrm{ppm}\left(40 \mathrm{mg} / \mathrm{m}^{3}\right) \\
9 \mathrm{ppm}\left(10 \mathrm{mg} / \mathrm{m}^{3}\right)\end{array}$ & - & $\begin{array}{l}35 \mathrm{ppm} \\
9 \mathrm{ppm}\end{array}$ & $\begin{array}{l}6.1 \\
4.2\end{array}$ \\
\hline $\mathrm{NO}_{2}$ & $\begin{array}{c}\text { Annual arithmetic } \\
\text { mean }\end{array}$ & $0.053 \mathrm{ppm}\left(100 \mu \mathrm{g} / \mathrm{m}^{3}\right)$ & $\begin{array}{c}\text { Same as primary } \\
\text { NAAQS }\end{array}$ & $0.053 \mathrm{ppm}$ & $\mathrm{ND}^{\mathrm{e}}$ \\
\hline $\mathrm{SO}_{2}$ & $\begin{array}{c}3 \mathrm{hr} \\
24 \mathrm{hr} \\
\text { Annual arithmetic } \\
\text { mean } \\
\end{array}$ & $\begin{array}{c}0.50 \mathrm{ppm}\left(1,300 \mu \mathrm{g} / \mathrm{m}^{3}\right) \\
0.14 \mathrm{ppm}\left(365 \mu \mathrm{g} / \mathrm{m}^{3}\right) \\
-\end{array}$ & $\begin{array}{c}- \\
- \\
0.03 \mathrm{ppm}(80 \mu \mathrm{g} / \\
\left.\mathrm{m}^{3}\right)\end{array}$ & $\begin{array}{l}0.50 \mathrm{ppm} \\
0.10 \mathrm{ppm} \\
0.02 \mathrm{ppm}\end{array}$ & $\begin{array}{l}\text { ND } \\
\text { ND } \\
\text { ND }\end{array}$ \\
\hline $\mathrm{PM}_{10}$ & $\begin{array}{c}\text { Annual arithmetic } \\
\text { mean } \\
24 \text { hours }\end{array}$ & $\begin{array}{l}50 \mu \mathrm{g} / \mathrm{m}^{3} \\
150 \mu \mathrm{g} / \mathrm{m}^{3}\end{array}$ & $\begin{array}{c}\text { Same as primary } \\
\text { NAAQS }\end{array}$ & $\begin{array}{l}50 \mu \mathrm{g} / \mathrm{m}^{3} \\
150 \mu \mathrm{g} / \mathrm{m}^{3}\end{array}$ & $\begin{array}{l}17^{\mathrm{f}} \\
42^{\mathrm{f}} \\
\end{array}$ \\
\hline $\mathrm{PM}_{2.5}{ }^{\mathrm{c}}$ & $\begin{array}{c}\text { Annual arithmetic } \\
\text { mean }^{c} \\
24 \text { hours }^{c}\end{array}$ & $\begin{array}{l}15 \mu \mathrm{g} / \mathrm{m}^{3 \mathrm{c}} \\
65 \mu \mathrm{g} / \mathrm{m}^{3 \mathrm{c}} \\
\end{array}$ & $\begin{array}{c}\text { Same as primary } \\
\text { NAAQS }\end{array}$ & - & $\begin{array}{l}9.4 \\
51 \\
\end{array}$ \\
\hline $\mathrm{Pb}$ & Quarterly & $1.5 \mu \mathrm{g} / \mathrm{m}^{3}$ & $\begin{array}{c}\text { Same as primary } \\
\text { NAAQS }\end{array}$ & $1.5 \mu \mathrm{g} / \mathrm{m}^{3}$ & 0.02 \\
\hline
\end{tabular}

${ }^{a} 40$ CFR 50, OAR 340-202, ODEQ 2002.

${ }^{\mathrm{b}} \mathrm{mg} / \mathrm{m} 3$ - milligrams per cubic meter; $\mu \mathrm{g} / \mathrm{m} 3$ - micrograms per cubic meter; ppm - parts per million.

'A 1999 Federal court ruling has blocked implementation of these standards; they are included for information purposes only at this time.

${ }^{\mathrm{d}}$ Maximum reading from 2001 in Eugene.

eND $=$ no data available.

fData are presented for the closer monitoring station at Cottage Grove since they were available.

Air quality throughout most of this area meets Federal standards. However, the EugeneSpringfield Urban Growth Area is currently in nonattainment for $\mathrm{PM}_{10}$. Tyrrell is about 11 miles southwest of this nonattainment area. Additionally, the Eugene-Springfield Air Quality Maintenance Area has been under a maintenance plan for CO since February 1994, because, for a time prior to that, the area was in nonattainment of the NAAQS for CO. Tyrrell is about 11 miles outside of this maintenance area as well. The seed orchard and its vicinity are in attainment for all criteria pollutants; that is, the national primary and secondary standards are met.

\subsection{Geological Resources}

\subsubsection{Physiography and Topography}

Tyrrell is located within the Coast Range Mountains, north of the Siuslaw River on hill slopes. Slopes within the seed orchard are generally to the south and southeast, ranging from 4 to $54 \%$. Elevations range from about 660 feet at the southwest corner of the breeding and preservation orchard to 1,240 feet near the northwest corner of the seed orchard in Section 9. The western edge of Tyrrell in Section 9 is situated along a ridge, with a valley to the east. Douglas Creek and its tributaries have cut several valleys in the 
seed orchard. The Siuslaw River, which flows about 700 feet to the south of the breeding and preservation orchard, has cut a relatively flat valley ranging from several hundred to two thousand feet wide.

\subsubsection{Geology}

The Coast Range Mountains were formed in a series of uplift and depositional events. The seed orchard is situated on slopes which are actively eroding, depositing sediment into the Siuslaw River and its tributaries. The Tyee Formation, consisting of marine sandstone and micaceous carbonaceous siltstone with interbeds of basaltic tuff-breccia (a sedimentary rock composed of large fragments of pre-existing rocks in a matrix of fine grained material) and dacitic tuff (formed from volcanic ash), underlies the soils at Tyrrell (PSU 2002). Soils at the seed orchard formed from these materials and from colluvium eroded from hillsides. Bedrock is at a depth of 20 to 60 inches. Weathered sandstone is generally permeable. Siltstone generally has poor permeability, while tuff and breccia have moderate permeability.

\subsubsection{Soils}

Soil is formed by physical and chemical processes which are determined by parent material (what the soils are derived from), climate, living organisms (plants, animals, and microorganisms), topography, and time. A relatively high amount of organic material is returned to the soil each year from leaves and the annual dieback of vegetation. The topographic position of these soils varies and has resulted in somewhat poorly drained to well-drained soils.

Soil compaction from heavy equipment use at the seed orchard has occurred. Excessive compaction in cultivated soils results in poor internal drainage, the potential for increased runoff, inhibited root development, and decreased yields, especially if other stresses are present. A type of deep tilling, called subsoiling, was used during initial site development to alleviate soil compaction at Tyrrell. Soil aeration is also done periodically to reduce surface soil compaction and increase infiltration.

Three types of soil are present at Tyrrell: Bellpine silty clay loam, Dupee silt loam, and Jory silty clay loam (SCS 1987). The Soil Conservation Service (now the Natural Resources Conservation Service) further categorized the Bellpine series by slope. At Tyrrell, there are Bellpine soils with a slope of 3 to $12 \%$ (Bellpine C), 12 to 20\% (D), 20 to $30 \%$ (E), and 30 to $50 \%$ (F). The cation exchange capacity of each of these soils ranges from 10 to 25 milliequivalents per 100 grams, indicating that they contain smectite clay and a high amount of organic matter, which adsorbs pesticides and fertilizers and retards their movement through the soil. The following paragraphs describe the soils identified on the seed orchard. Soil properties, which vary by depth, are summarized in Table 3.3-1.

Bellpine silty clay loam is a moderately deep well-drained soil found on the foothills and uplands of the seed orchard, and comprises the majority of the area within orchard boundaries. It formed in colluvium and residuum derived from sandstone, siltstone, volcanic tuff, and breccia. Typically, the surface layer is a dark reddish brown silty clay loam about 13 inches thick. The upper 21 inches of the subsoil is brown and dark red silty clay. Weathered tuffaceous sandstone is at a depth of 34 inches and depth to bedrock ranges from 20 to 40 inches. Slopes range from 2 to $50 \%$. The available water holding capacity is 0.13 to 0.21 inches of water per inch of soil. This soil is droughty in the summer. The effective rooting depth is 20 to 40 inches. Runoff is slow to rapid and the hazard of water erosion is slight to high depending on the slope. The hazard of erosion by wind is moderate. The main limitation for tree growth is susceptibility to compaction and slow permeability which can contribute to high hazard of erosion during the wet season. Soil $\mathrm{pH}$ is from 4.5 to 6.0. The majority of seed production and arboretum areas are within Bellpine $C$ and $D$ soils, and are also found on the edges of Bellpine E soils. 
Table 3.3-1. Soils at the Tyrrell Seed Orchard

\begin{tabular}{|c|c|c|c|c|c|c|c|}
\hline Soil Series & $\begin{array}{c}\text { Depth } \\
\text { (in.) }\end{array}$ & $\begin{array}{c}\text { Permeability } \\
\text { (in/hr) }\end{array}$ & $\begin{array}{c}\text { Depth to Water } \\
\text { Table } \\
\text { (ft.) }\end{array}$ & $\begin{array}{c}\text { Runoff } \\
(\%)\end{array}$ & $\begin{array}{c}\text { Organic } \\
\text { Matter } \\
(\%)\end{array}$ & $\begin{array}{l}\text { Clay } \\
(\%)\end{array}$ & $\begin{array}{c}\text { Soil } \\
\text { Sensitivity }^{1}\end{array}$ \\
\hline \multirow[t]{2}{*}{ Bellpine C } & $0-13$ & $0.6-2.0$ & \multirow{2}{*}{$>6$} & \multirow{2}{*}{ slow } & $3-6$ & $27-35$ & \multirow[t]{2}{*}{ low } \\
\hline & $13-34$ & $0.2-0.6$ & & & $1-4$ & $40-55$ & \\
\hline \multirow[t]{2}{*}{ Bellpine D } & $0-13$ & $0.6-2.0$ & \multirow{2}{*}{$>6$} & \multirow{2}{*}{ medium } & $3-6$ & $27-35$ & \multirow[t]{2}{*}{ low } \\
\hline & $13-34$ & $0.2-0.6$ & & & $1-4$ & $40-55$ & \\
\hline \multirow[t]{2}{*}{ Bellpine E } & $0-13$ & $0.6-2.0$ & \multirow{2}{*}{$>6$} & \multirow{2}{*}{ rapid } & $3-6$ & $27-35$ & \multirow[t]{2}{*}{ very low } \\
\hline & $13-34$ & $0.2-0.6$ & & & $1-4$ & $40-55$ & \\
\hline \multirow[t]{2}{*}{ Bellpine F } & $0-13$ & $0.6-2.0$ & \multirow{2}{*}{$>6$} & \multirow{2}{*}{ rapid } & $3-6$ & $27-35$ & \multirow[t]{2}{*}{ very low } \\
\hline & $13-34$ & $0.2-0.6$ & & & $1-4$ & $40-55$ & \\
\hline \multirow[t]{2}{*}{ Dupee } & $0-12$ & $0.6-2.0$ & \multirow{2}{*}{$\begin{array}{c}1.5 \text { - } 3.3 \text { (winter) } \\
>6 \text { (summer) }\end{array}$} & \multirow{2}{*}{$\begin{array}{l}\text { medium } \\
\text { to rapid }\end{array}$} & $2-3$ & $15-27$ & \multirow[t]{2}{*}{ high } \\
\hline & $12-55$ & $0.2-0.6$ & & & $1-2$ & $35-50$ & \\
\hline \multirow[t]{2}{*}{ Jory } & $0-9$ & $0.6-2.0$ & \multirow{2}{*}{$>6$} & \multirow{2}{*}{ slow } & $3-6$ & $27-40$ & \multirow[t]{2}{*}{ very low } \\
\hline & $9-60$ & $0.2-0.6$ & & & $0.5-2$ & $45-60$ & \\
\hline
\end{tabular}

Sources: SCS 1987, OSUES 1998.

${ }^{1}$ The Oregon State University Extension Service developed soil sensitivity ratings for groundwater contamination based on leaching characteristics (permeability, soil depth, depth to groundwater, annual precipitation, and runoff as compared to infiltration) and sorption potential (the amount of organic matter, and the cation exchange capacity) (OSUES 1998).

Dupee silt loam is a deep, somewhat poorly drained soil on drainageways and other depressional areas, and on alluvial fans of foothills. The extent of this soil is limited to parts of the Noti and Lorane seed production orchard units. This soil formed in colluvium primarily derived from sandstone. Typically, the surface layer is very dark grayish brown silt loam about 12 inches thick. The subsoil is dark brown and brown, mottled silty clay loam, silty clay, and clay loam about 39 inches thick. The substratum is variegated clay loam about 4 inches thick and weathered bedrock is found at 55 inches, with the depth to bedrock ranging from 40 to 60 inches. Slopes range from 3 to $20 \%$. The available water holding capacity is 0.16 to 0.23 inches of water per inch of soil. The effective rooting depth is limited by the high water table that is at a depth of 2 to 3 feet from December to March. Runoff is slow to rapid, and the hazard of erosion by water is slight to high, depending on the slope. The hazard of erosion by wind is very slight. The main limitation for tree growth is the high water table; however, this soil can be productive if properly drained. Soil $\mathrm{pH}$ is from 4.5 to 6.0. Most of the Dupee soils are utilized for seed production and native species garden areas.

Jory silty clay loam is a deep, well-drained soil located on the low rolling foothills. This soil formed in colluvium primarily derived from igneous and tuffaceous rock. Typically, the surface layer is dark reddish brown silty clay loam about nine inches thick. The subsoil is dark reddish brown silty clay about 51 inches thick. Slopes range from 2 to $12 \%$. The available water holding capacity is 0.15 to 0.21 inches of water per inch of soil. 
The effective rooting depth is 60 inches or more. Runoff is slow and the hazard of erosion by water is slight. The hazard of erosion by wind is very slight. The main limitation for tree growth is competing vegetation and compaction of the soil. Soil $\mathrm{pH}$ is from 4.5 to 6.5. The Jory soil is limited to a small area between the Elkton Phase II fallow area and the Riddle 1 and 2 seed production orchard units that is not currently planted with orchard trees.

\subsection{Water Resources}

Water is a key resource because it is influenced by, and in turn influences, activities and resources outside the seed orchard. Water also provides habitat for fish and aquatic animals, as well as plants and animals that use streamside and pondside areas. Water entering the seed orchard can be a source of pollutants, bringing in organisms that cause tree diseases or bringing in pesticide residues from an industrial forest-related operation. There is also the potential for water to take pollutants out of the seed orchard.

Tyrrell is located in the Siuslaw River watershed near Lorane, Oregon. The Siuslaw watershed is the subject of a recent assessment conducted by BLM's Eugene District (BLM 2002). The orchard is divided into three primary areas-in Section 9, Section 15, and Section 21-all located within Township 20 South and Range 5 West.

\subsubsection{Groundwater}

There is no site-specific groundwater information available for Tyrrell with respect to flow direction or quality. It does not cross any EPA- or state-designated sole-source aquifers, wellhead protection areas, or groundwater management areas. The direction of deep ground water flow is not known and is assumed to follow surface topography (BLM 2001).

Oregon Water Resources Department well log data indicate that there are four domestic wells within Sections 15 and 21, including one on the orchard itself (OWRD 2002a). The three wells outside the seed orchard have static water levels between 14.8 and 26 feet, while the onsite well has a static water level of 87.5 feet. Depth to "first water" was not noted for the orchard well, but ranged between 19 and 100 feet for the other three wells. Drilled to a depth of 347 feet, the orchard well is the deepest well within the orchard sections and adjacent sections; it has a yield of 2.5 gallons per minute. Figure $3.4-1$ shows the well location within the orchard.

There are more than 30 additional domestic wells in sections adjacent to the seed orchard (OWRD 2002a). Some of the adjacent wells are located in different surface drainage basins or upstream of the orchard. Static water depths range from 0 to 288 feet, with an average static water depth of 39.7 feet; "first water" in the boreholes ranged from 15 feet to 320 feet, with an average of 69 feet.

\subsubsection{Surface Water}

Tyrrell is in the Siuslaw River watershed of the Mid Coast sub-basin. The Siuslaw River watershed covers 104,683 acres (approximately 164 square miles) and is located in Lane and Douglas Counties, southwest of the city of Eugene; it contains the town of Lorane. The watershed lies at the southeastern headwaters of the Siuslaw River Basin, which also includes the Lake Creek, Wildcat Creek, and Wolf Creek watersheds.

Tyrrell is located about 700 feet north of the Siuslaw River, which flows in a westerly direction. Developed areas of Section 9 of the seed orchard drain into Douglas Creek, a tributary of the Siuslaw River. Douglas Creek flows generally to the south through 
Figure 3.4-1: Water Resources at Tyrrell Seed Orchard

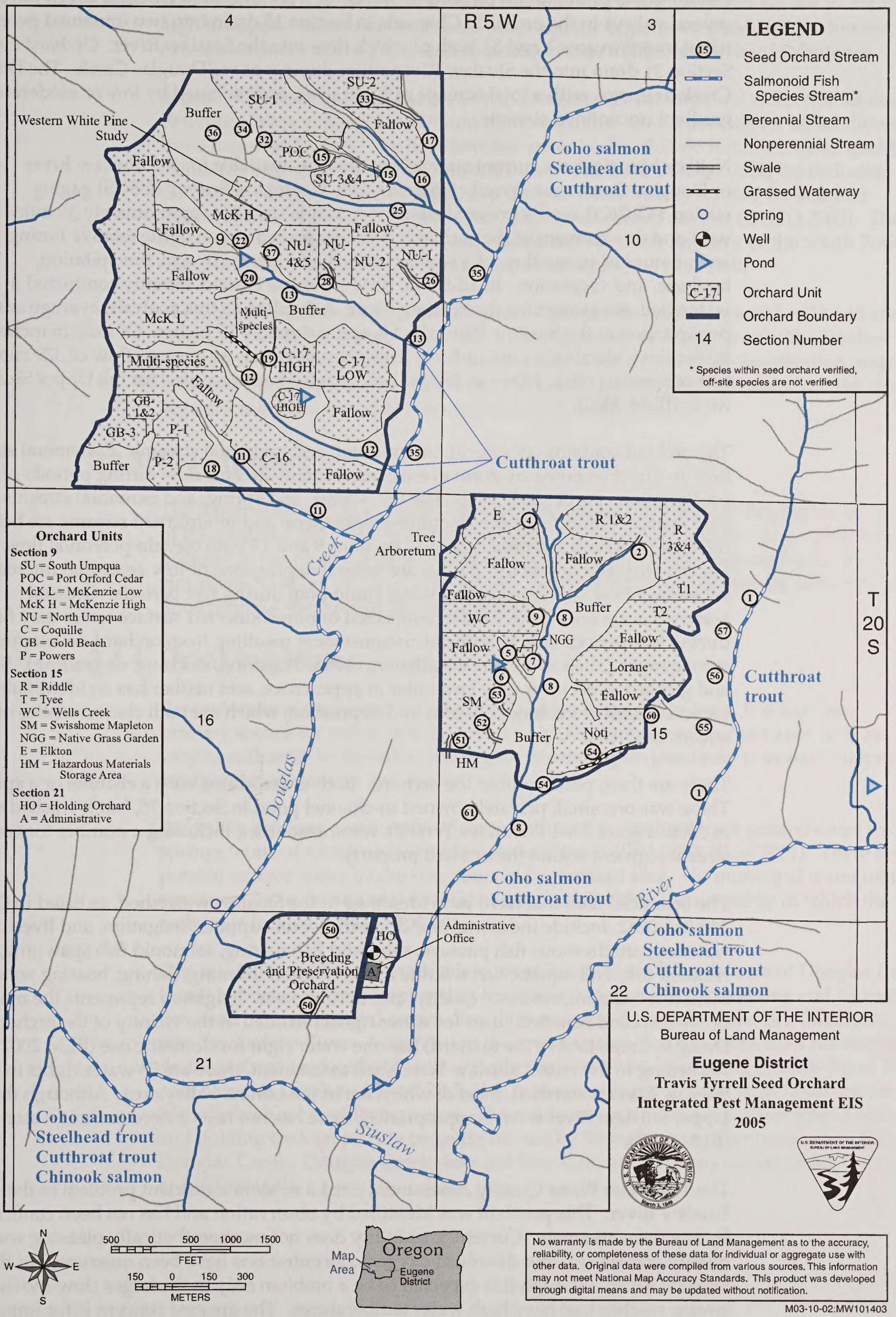


Tyrrell, joining the Siuslaw River about 1,200 feet southwest of the property, below the breeding and preservation orchard in Section 21. Tributaries of Douglas Creek have cut several valleys in the orchard. Channels in Section 15 drain into two unnamed perennial tributaries (Streams 1 and 8), both of which flow into the Siuslaw River. Orchard areas in Section 21 drain into the Siuslaw River either directly or via Douglas Creek. The Douglas Creek drainage, with a total acreage of 3,079 acres, is dominated by low or moderate gradient unconfined streams.

Neither historical nor current streamflow data are available for the Siuslaw River or Douglas Creek near Tyrrell. However, U.S. Geological Survey (USGS) gaging station 14307620, on the lower Siuslaw near Mapleton, OR (approximately 35 miles west and downstream of the orchard), provides an indication of the relative timing and amount of streamflow of a similar watershed in terms of size, precipitation, land use, and vegetation. In addition, BLM's Eugene District recently conducted a watershed assessment for the Siuslaw River. According to this analysis, average annual precipitation in the Siuslaw Watershed is approximately 55 inches. Of this, 26 inches leaves the watershed as streamflow. This amount equals an average flow of 329 cubic feet per second (cfs). Flows as low as $1.42 \mathrm{cfs}$ have been recorded for the Upper Siuslaw River (BLM 2002).

The orchard contains ephemeral, intermittent, and perennial streams. Ephemeral streams flow in direct response to storm events; intermittent streams flow during periods of high precipitation, particularly in the late fall, winter, and spring; and perennial streams flow year round. Throughout this document, ephemeral and intermittent streams are both referred to as non-perennial streams. Sections 9 and 15 both contain perennial flow. For the purposes of this EIS, swales are natural depressions or low areas that intercept subsurface flow or where surface water could pool during wet periods. Grassed waterways are areas where either connected or non-connected surface water may flow during wet periods due to artificial circumstances resulting from orchard development or management (such as culvert installation, orchard clearing, ditching, or grading). Swales and grassed waterways may be similar in appearance, and neither has an identifiable bankfull mark or evidence of scour and deposition, which are both characteristics of stream channels.

There are three ponds within the orchard. Each is associated with a channel or a spring. There was one small privately owned in-channel pond in Section 15, but it washed out in 2000. Figure 3.4-1 illustrates Tyrrell's water resources, including a number for each stream segment within the orchard property.

The beneficial uses that have been identified in the Siuslaw watershed, as listed in OAR 340-041-0242, include industrial and domestic water supplies, irrigation, and livestock watering; anadromous fish passage, salmonid fish rearing, salmonid fish spawning, resident fish, and aquatic life; wildlife and recreation (hunting, fishing, boating water contact recreation); aesthetic quality; and hydropower. Irrigation represents the majority of the recorded beneficial uses for water rights recorded in the vicinity of the orchard. Douglas Creek (above the orchard) has one water right for domestic use (BLM 2002). According to the recent Siuslaw Watershed assessment, there are 58 water rights in the Siuslaw River watershed, most of which are in the Lorane Valley area. Although the Upper Siuslaw River is over-appropriated, there has not been a need to limit water use (BLM 2002).

The 1988 State Water Quality Assessment cited a moderate nutrient problem in the Siuslaw River. This problem was identified by observation and has not been confirmed by any measurements. Currently, turbidity does not meet aesthetically pleasing water quality criteria and low dissolved oxygen concentrations have been measured for the Siuslaw River, although it is expected to be a problem only in the larger slow-moving stream reaches that have high water temperatures. The greatest concern is for impacts 
to fish habitat and other aquatic life. Studies and monitoring reports from adjacent watersheds, such as Wolf Creek, show that summer water temperatures are probably too high to support salmonids and some other aquatic organisms (BLM 2002). However, no excessive temperatures have been recorded to date in the seed orchard tributaries.

Section 303(d) of the Clean Water Act requires states to list impaired water bodies and determine allowable total maximum daily loads that would provide for restoration of those impaired bodies. The list identifies water bodies that do not meet water quality standards necessary to protect beneficial uses. The 2002 ODEQ 303(d) list includes the Siuslaw River from river mile 20 to 105.9 as water quality limited for summer temperatures, and from river mile 5 to 105.9 for dissolved oxygen (ODEQ 2003). The list also includes impaired biological criteria for the lower segment of the South Fork Siuslaw, whose confluence is located two miles upstream of Tyrrell.

There are no outstanding resource waters, national- or state-designated wild and scenic rivers, or public watershed areas near the orchard. Several segments of the Siuslaw River have been studied and determined suitable for recreational classification under the Wild and Scenic Rivers Act. However, no determination has been made, and the closest segment is at least two miles downstream of the orchard.

\subsubsection{Floodplains}

The Siuslaw River flows within 700 feet of the orchard property at the southeast corner of the seed orchard. The river has an extensive 100-year floodplain. Low-lying areas adjacent to the river would be inundated by 100-year flooding, although base flood elevations have not yet been determined. Orchard property lies outside of the 100-year floodplain for the Siuslaw River (FEMA 2002).

\subsubsection{Drinking Water}

Groundwater is the primary source for drinking water in Oregon. It is also the primary source for public drinking water supplies in the seed orchard area. It may vary significantly in elevation and depth, depending on proximity to surface waters, topographic variations, and season.

All public drinking water in the vicinity of Tyrrell is obtained from groundwater wells or springs, none of which are located on Federal lands (EPA 2002, BLM 2001). There are no potable surface water intake structures in the orchard area. No municipal water intake structures occur on any of the water bodies found within the township in which the orchard is located (OWRD 2002b).

One resident who lives along Siuslaw River Road (about 0.2 mile west of Douglas Creek Road) indicated during scoping that her water supply (both for drinking and watering her small organic garden) comes directly from a small side channel creek that flows into the Siuslaw River. A site visit to the area revealed that this creek does not receive drainage from seed orchard land. Another resident who lives along Siuslaw River Road, near Douglas Creek and Road 20-5-21.1, manages a logging camp with 12 cabins, about half of which are usually occupied. The residents obtain drinking water from a spring and holding tank on private property owned by Weyerhaeuser Company, away from Douglas Creek. Douglas Creek does not flow into, nor have any influence on, the spring or holding tank. 


\subsection{Land Use}

Tyrrell is located in Lane County within a rural, generally wooded area. Property in the vicinity of the seed orchard is a mix of rural residential, farmland, vineyards, and forests. Figure 3.5-1 illustrates adjacent land uses. There are four residential, non-industrial private landowners along the southern boundary of Tyrrell: three private residences and one cabin rental complex, all on Siuslaw River Road. The nearest residence is approximately $1 / 4$ mile from an orchard production unit.

Lane County's lands are a microcosm of the state: from rugged glaciated mountains in the east, through a broad valley spreading across the Willamette River in the middle of the county, to a beautiful and rugged coastline along the western edge. Formerly focused on timber and agriculture, Lane County's economy has diversified into a regional center for the financial and technology industries, higher education, government, and tourism, and land use reflects these economic changes. With a moist, temperate climate typical of western Oregon, the agriculture of Lane County is also diverse. Although small woodlots and Christmas trees make up the largest portion of commodity sales, grass seed, nursery stock, vegetables, and livestock all make large contributions (OED 2002, LCO 2002).

Lane County is somewhat less densely settled than the U.S. as a whole, with a population density of 70.9 persons per square mile. $80 \%$ of the county's population is considered urban, which is comparable to Oregon and the remainder of the U.S. (USBC 2002a). Most of its urban population is within the larger "urban areas" rather than smaller communities. ${ }^{1}$ Lane County has a comparable proportion of farm residents to the U.S., but lower than for Oregon as a whole. Table 3.5-1 presents urban and rural characteristics for Lane County, Oregon, and the U.S.

Most of the area surrounding the orchard boundary is private timber land or Federal land. Several private acreages are located south of the breeding and preservation orchard along Siuslaw River Road (which is about 700 feet to the south of the seed orchard). The Cascade and Coast-Westside orchard units are in Section 9, the Coast-Eastside orchard units are in Section 15, and the breeding and preservation orchard is in Section 21. Land to the west of Section 9 is forested. Areas to the north, east, and south of this section are a mixture of forest and cut-over timber land. Much of this land is owned by a private timber company. Land around Section 15 is also a mixture of forest and cut-over timber land. Land around Section 21 is mostly forested, with the exception of a regeneration unit to the north.

Tyrrell encompasses 780 acres, of which 475 acres are in Section 9, 252 acres are in Section 15, and 53 acres are in Section 21. Figure 2.1-1 illustrates land use at the orchard, and Table 3.5-2 shows orchard acreages by type of use.

\subsection{Human Health}

\subsubsection{Public}

Tyrrell is located in a rural area with little nearby development and few close neighbors. Aerial photographs were examined to determine approximate distances to nearby residences (BLM 2000). There are no residences adjacent to the Section 9 orchard parcel.

\footnotetext{
"The U.S. Bureau of the Census divides "densely settled territory" into urbanized areas and urbanized clusters. "Densely settled territory" is defined as a cluster of one or more block groups or census blocks, each with a population density of at least 1,000 people per square mile, or the surrounding block groups and census blocks, with a population density of at least 500 people per square mile. Urban areas contain 50,000 or more people, while urban clusters contain between 2,500 and 50,000 people (USBC 2002b).
} 
Figure 3.5-1: Adjacent Land Use

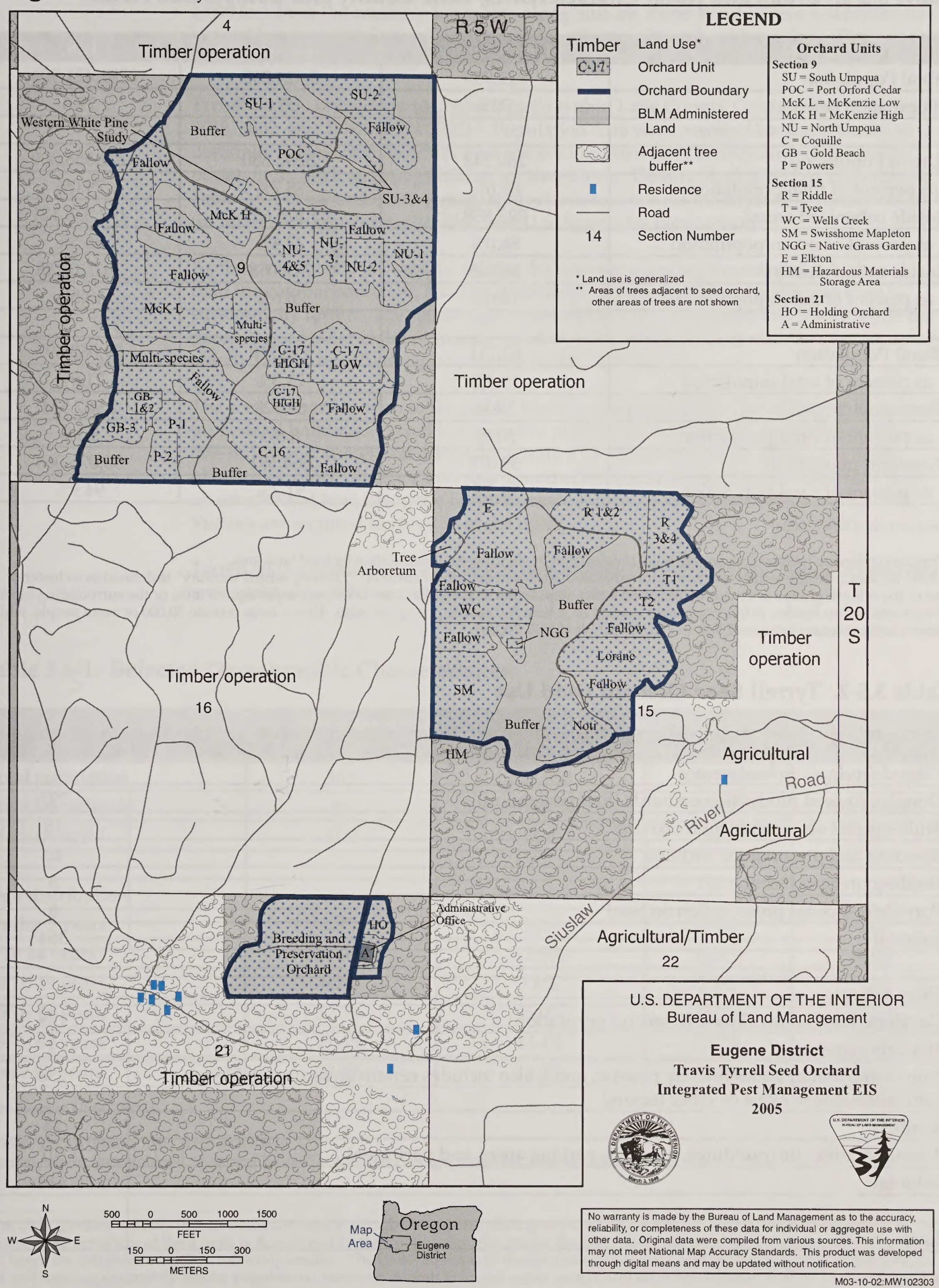


Table 3.5-1. Urban and Rural Characteristics, Lane County and Comparison Areas

\begin{tabular}{|l|c|c|c|}
\hline & Lane County & Oregon & U.S. \\
\hline Total Population & 322,959 & $3,421,399$ & $281,421,906$ \\
\hline Population density & 70.9 & 35.6 & 79.6 \\
\hline & & & $222,358,309$ \\
\hline Urban Population & 260,248 & $2,692,680$ & $79.0 \%$ \\
\hline as percent of total population & $80.6 \%$ & $78.7 \%$ & $192,338,121$ \\
\hline Inside urbanized areas ${ }^{2}$ & 223,858 & $1,975,622$ & $86.5 \%$ \\
\hline as percent of urban population & $86.0 \%$ & $73.4 \%$ & $30,020,188$ \\
\hline Inside urban clusters ${ }^{2}$ & 36,390 & 717,058 & $13.5 \%$ \\
\hline as percent of urban population & $14.0 \%$ & $26.6 \%$ & $59,063,597$ \\
\hline & & & $21.0 \%$ \\
\hline Rural Population & 62,711 & 728,719 & $2,987,531$ \\
\hline as percent of total population & $19.4 \%$ & $21.3 \%$ & $5.1 \%$ \\
\hline Farm population & 3,636 & 64,128 & $56,076,066$ \\
\hline as percent of rural population & $5.8 \%$ & $8.8 \%$ & $94.9 \%$ \\
\hline Nonfarm population & 59,075 & 664,591 & $91.2 \%$ \\
\hline as percent of rural population & $94.2 \%$ & & \\
\hline
\end{tabular}

Data source: USBC 2002a.

${ }^{1}$ Population density (persons per square mile) is calculated by dividing total population by total land area.

2USBC divides "densely settled territory" into urbanized areas and urbanized clusters. "Densely settled territory" is defined as a cluster of one or more block groups or census blocks, each with a population density of at least 1,000 people per square mile, or the surrounding block groups and census blocks, with a population density of at least 500 people per square mile. Urban areas contain 50,000 or more people, while urban clusters contain between 2,500 and 50,000 people (USBC 2002b).

\section{Table 3.5-2. Tyrrell Seed Orchard Land Use}

\section{Description}

\section{Acres}

Planted developed orchard acreage

Douglas-fir seed production orchards (first generation)

Multi-species seed production orchard

Breeding and preservation orchard

Holding orchard (Section 21)

Port-Orford-cedar preservation orchard

Subtotal

Other acreage

Developed but fallow (Phase II, second generation)

Tree arboretum

Non-usable buffer zones (mostly riparian areas; also includes certain areas unsuitable for cultivation due to slope or other factors)

Roads

Administrative site (buildings, grounds, parking areas, and park area)

Subtotal

Subtotal 
Only one residence was identified near the Section 15 orchard parcel, at approximately 1,000 feet from the southern boundary along Siuslaw River Road. Three residences are located between 800 feet and 1,000 feet of the Section 21 orchard boundary. Figure 3.5-1 illustrates the surrounding land uses.

Tyrrell and its immediate surroundings lie within Lane County Census Tract 800 (Blocks 2018, 2082, and 2084) (ESRI 2002). ${ }^{2}$ Population data were assessed for these blocks to determine population numbers near the seed orchard and identify any sensitive subpopulations, such as young children or the elderly. Census Block 2084 has no residents. Table 3.6-1 shows relevant demographic characteristics for the remaining census blocks (in total), along with county, state, and U.S. figures for comparison.

As the table shows, the median age for the area surrounding the orchard is higher than the comparison areas, and the percentage of young children (under age five) is substantially lower. The percentage of teens (aged 15-19) is somewhat lower, while the percentage of older children (aged 5 to 14) is substantially higher, and the percentage of elderly (above age 65) is slightly higher (USBC 2002a).

The seed orchard is open to the public Monday through Friday from 8:00 to 4:30, except for Federal holidays. Tyrrell has an active public outreach program, which includes a one-mile forest succession interpretive trail, a tree arboretum with 40 species, native plant areas, office displays, and year-round educational tours. The typical visitor is on an educational tour, using the forest succession trail, or visiting an educational display. Visitors are required to check in at the office.

Tyrrell allows collection of a variety of forest products by the general public. Permittees are restricted to collection during normal business hours.

Table 3.6-1. Selected Demographic Characteristics

\begin{tabular}{|l|c|c|c|c|} 
& $\begin{array}{c}\text { Total for } \\
\text { Adjacent Blocks }\end{array}$ & Lane County & Oregon & U.S. \\
\hline Total population & 163 & 322,959 & $3,421,399$ & $281,421,906$ \\
\hline Total households & 63 & 130,453 & $1,333,723$ & $105,480,101$ \\
\hline Median age & 41.0 & 36.6 & 36.3 & 35.3 \\
\hline & & & & \\
\hline Age distribution & & & & $6.8 \%$ \\
\hline Under 5 years & $1.8 \%$ & $5.8 \%$ & $6.5 \%$ & $14.6 \%$ \\
\hline 5 To 14 years & $17.8 \%$ & $12.9 \%$ & $13.9 \%$ & $7.2 \%$ \\
\hline 15 To 19 years & $6.7 \%$ & $7.6 \%$ & $7.1 \%$ & $37.0 \%$ \\
\hline 20 To 44 years & $32.5 \%$ & $36.0 \%$ & $35.9 \%$ & $22.0 \%$ \\
\hline 45 To 64 years & $27.6 \%$ & $24.4 \%$ & $23.7 \%$ & $12.4 \%$ \\
\hline Over 65 years & $13.5 \%$ & $13.3 \%$ & $12.8 \%$ & \\
\hline
\end{tabular}

Data source: USBC 2002a.

${ }^{1}$ Census Tract 8 (Blocks 2018, 2082, and 2084)

${ }^{2}$ Median age for the combined "Adjacent Blocks" is estimated using a weighted average technique.

${ }^{2}$ The USBC divides counties into census tracts, which are subdivided into block groups, which are further subdivided into census blocks. The relative geographic size of these units is determined by their population; the greater the population, the more subdivisions each unit will have, and hence the subdivisions will be relatively smaller. The USBC attempts to divide a county in such a manner that sub-units within a larger unit will have approximately similar populations; however, migration in and out of an area will affect this balance over time and can result in "empty" census blocks. 


\subsubsection{Workers}

Tyrrell has five full-time workers. Full-time employees work 40 hours per week yearround; workers may follow flex-time schedules to complete 40 hours of less than five days withing a given period. The length of employment at the seed orchard for Tyrrell's employees ranges from 3 to 17 years.

\subsection{Biological Resources}

The following sections describe the vegetation, terrestrial wildlife, and aquatic species found at and near Tyrrell. In addition to the abundant or common species observed, several species present or potentially present at Tyrrell have a special status under Federal or state laws or recommendations. These species include five birds, one amphibian, five bats, and one fish, as listed in Table 3.7-1.

The Federal ESA applies to all actions on all lands, whether they are undertaken by Federal agencies, state agencies, commercial entities, or private individuals. Species of concern are designated by the Oregon state office of FWS. These species receive no legal protection. Many species of concern are former Category 2 species that were candidates for listing under the ESA until 1996. Category 2 candidate species were those species for which information indicated that a proposal to list the species as endangered or threatened was possibly appropriate, but sufficient data on biological vulnerability and threats were not available to support proposed rules.

The Oregon Threatened and Endangered Species Act applies only to actions of state agencies on state-owned or leased lands, and therefore its regulatory scope does not extend to the proposed activities at the seed orchard. However, these species are evaluated as special status species in this EIS. The Oregon Department of Fish and Wildlife also maintains a "watchlist" of sensitive species that might qualify for state listing in the future. These

Table 3.7-1. Special Status Species At or Near Tyrrell

\begin{tabular}{|l|l|l|}
\hline Species & Federal Status & State Status \\
\hline Bald eagle (Haliaeetus leucocephalus) & Threatened & Threatened \\
\hline Northern spotted owl (Strix occidentalis caurina) & Threatened & Threatened \\
\hline Coho salmon (Oncorhynchus kisutch) & Proposed for listing as threatened & Sensitive-critical \\
\hline $\begin{array}{l}\text { Pacific western big-eared bat (Corynorhinus } \\
\text { townsendii townsendii) }\end{array}$ & Species of concern (FWS) & Sensitive-critical \\
\hline Fringed myotis (Myotis thysanodes) & Species of concern (FWS) & Sensitive-vulnerable \\
\hline Little willow flycatcher (Empidonax traillii adastus) & Species of concern (FWS) & Sensitive-vulnerable \\
\hline Northern red-legged frog (Rana aurora aurora) & Species of concern (FWS) & Sensitive-vulnerable \\
\hline Long-eared myotis (Myotis evotis) & Species of concern (FWS) & Sensitive-undetermined \\
\hline Long-legged myotis (Myotis volans) & Species of concern (FWS) & Sensitive-undetermined \\
\hline Yuma myotis (Myotis yumanensis) & Species of concern (FWS) & -- \\
\hline Purple martin (Progne subis) & -- & Sensitive-critical \\
\hline Western bluebird (Sialia mexicana) & -- & Sensitive-vulnerable \\
\hline
\end{tabular}


species may be designated as critical, vulnerable, peripheral or naturally rare, or of undetermined status.

BLM has three designations that may be applied to particular species. "Bureau Sensitive" species include species that could easily become endangered or extinct in a state, and are not listed, proposed, or candidate species under state or Federal laws, but are eligible. "Bureau Assessment" species are plant or animal species that are not presently eligible for official Federal or state status but are of concern. "Bureau Tracking" species act as an early warning for species which may become of concern in the future; BLM districts are encouraged to collect information on these species, but they are not considered special status species for management purposes. The State of Oregon has state-listed species, and these are on the BLM special status species list, as "State Listed."

Special status species are described within the appropriate sub-section below.

\subsubsection{Vegetation}

In August 1999, a plant and vegetation survey was conducted at Tyrrell. A total of 287 species was documented for Tyrrell as a whole. Five noxious weed species were found: Canada thistle, bull thistle, Scotch broom, Klamath weed, and stinking willie. No special status or rare plants were found. Below are descriptions of the five vegetation units and areas found at Tyrrell.

\section{Orchard Units}

Orchard units include those areas from which the trees were harvested to prepare the area for use as a seed orchard. After logging, the orchard areas were cleared of all vegetation to a depth of 18 inches, and then ripped and leveled as final site preparation. Improved Douglas-fir seed is the predominant crop grown in the orchard units. Two types of orchards are managed at Tyrrell: breeding and preservation orchards and seed production orchards. They are surrounded by tall fencing to protect the trees from deer and elk damage. The understory is dominated largely by non-native grasses such as fescues, orchardgrass, and velvet grass that were planted as a cover crop.

\section{Fallow Areas}

The fallow areas at Tyrrell consist of non-native, open grasslands adjacent to the orchard units within the fence perimeter. These areas are currently unplanted units that will be used in the future for additional orchards. The same non-native grass species found in the orchard units are found here. These fallow areas lack a developed forb component.

\section{Fenceline Areas}

A deer/elk fence surrounds the orchard units at Tyrrell. The fenceline is mowed or brushed at different times during the year to keep vegetation low and help control weeds. Young Douglas-fir plantations largely dominate the areas outside the fenceline that border private property. Where BLM land is present outside the fenceline, vegetation varies from young ponderosa pine plantation areas to remnant old-growth / mixed age forest. Many native species occur along the fenceline areas. Some of the more common herbaceous species include birdfoot deervetch, spreadfruit goldenbanner, fireweed, western pearly everlasting, and roughleaf aster, along with such shrubs as salal, Oregon grape, oceanspray, vine maple, buckbrush, snowberry, and others. Exotic plants such as Scotch broom, blackberry, thistle, tansy, and goat weed are present along the fenceline at different locations in varying densities. South of the office buildings, the fence runs through a stand of approximately 45- to 50-year-old Douglas-fir, with a mostly 
closed canopy. Typical plants here include common whipplea, woodsorrel, wild ginger, calamint, Columbian lily, bedstraw, and others.

\section{Buffer Zone Areas (Shrubby/Young Woodland)}

Orchards were not developed in these areas because of topography. Most of these areas have riparian characteristics and have been reforested with species that will not contaminate the Douglas-fir pollen flow. This shrubby/young woodland classification contains young stands of sugar pine, western white pine, Pacific silver fir, noble fir, giant sequoia, Jeffrey pine, and Port-Orford-cedar. These trees are seldom or never found in surrounding native forests on the Eugene BLM District. Other areas have been planted with grand fir, western hemlock, ponderosa pine, and western redcedar. Vegetation in this classification is typically very dense. Exotic plants such as Scotch broom and blackberry are sometimes found along the edges of the shrubby/young woodland areas; however, these rarely penetrate into the interior of these stands. Occasionally, stands of native grasses such as Columbia brome and blue wildrye can be found in more protected edge areas.

\section{Buffer Zone Areas (Wetland/Riparian)}

The most diverse marsh area at Tyrrell is found near the main road in Section 9. Typical plants here include floating pondweed, narrowleaf bur-reed, American eelgrass, twoheaded water-starwort, tapertip rush, common rush, swordleaf rush, pointed rush, tinker's penny, and muskflower. Other smaller impoundments below and in the Section 15 stream corridor are similar but have lower diversity with fewer aquatic and wetland species. Some of these areas and other smaller boggy areas at Tyrrell are dominated by cattails or dense stands of panicled bulrush and fowl mannagrass. Reed canary grass and blackberry are common along the stream bottoms. Many areas along the creek bottoms and side draws are overgrown with impenetrable thickets of brush and large woody debris.

\subsubsection{Terrestrial Wildlife Species}

Wildlife species that occupy the Tyrrell Seed Orchard during all or part of their life cycle are those adapted to early successional environments and are tolerant of disturbance. However, the proximity of older, more complex habitats adjacent to the orchard also influences the number and kind of wildlife that use it. The adjacent habitats consist of mid- to late-successional forests, commercial clearcuts, and forested riparian habitat.

As a result of Tyrrell's managed condition, the vegetative communities are simple in composition and structure. Much of the vertical structure is absent from the communities within the orchard boundary and the grassland species composition is primarily nonnative and reduced in number. The most complex habitat within the fenced perimeter is the uncultivated draws (buffer zones) between orchard units. These sites have been cleared of most of the trees and have grown back into dense shrubby tangles. Interspersed with the orchard units, these patches serve as hiding and nesting cover for many birds and mammals that use the orchard units for foraging habitat. The orchard units supply excellent open hunting perch sites, an abundance of vulnerable insects, good small mammal populations, and good grass seed production to attract foraging animals.

Five habitats, other than orchard units with trees, were identified in Sections 9, 15, and 21 within seed orchard jurisdiction. These habitats generally correspond to the five vegetation units or areas discussed in Section 3.7.1.

The eight-foot high welded wire perimeter fence surrounding the orchard units serves as a partial to complete barrier for many wildlife species. Deer and elk are excluded from the orchard and only occasional sightings of black bear and mountain lion have 
been reported within. Habitats outside the orchard fence are managed Douglas-fir forest stands in various age classes, ranging from seedling to late successional ( $>80$ years old).

\section{Orchard Units}

About 364 acres of the orchard currently support cultivated conifers. Improved Douglasfir trees are grown on all but about 20 acres, where mixed conifer species are raised. This habitat is very simple and consists of evenly spaced conifers less than 15 years old with an understory of non-native grasses such as fescues, orchardgrass, and velvet grass. This understory is kept simple by management practices such as mowing, tilling, and weeding.

A few wildlife species subsist within the orchard unit boundaries. Most of these species are small mammals including long-tailed vole, western pocket gopher, and California ground squirrel, but also include grassland birds such as western meadowlarks and vesper sparrows. Several species use the orchard units for foraging, some of the most common of which are western bluebird, white-crowned sparrow, violet-green swallow, yellow-rumped warbler, American goldfinch, great-horned owl, and red-tailed hawk.

\section{Douglas-fir Forest}

The older Douglas-fir forest habitat existing within Sections 9 and 15 is outside of the perimeter fence. Douglas-fir stands are located in the south and east sides of Section 15 (139 acres) and the west side of Section 9 (133 acres). These stands are second growth timber around 50 years old, except for about 47 acres of older trees ( $>80$ years old) in Section 9. These older stands are more diverse than the younger ones and support several tree species other than Douglas-fir (western redcedar, incense cedar, western hemlock, and Pacific yew). This diversity creates a greater complexity of habitats for a variety of wildlife. These species tend to be relatively specific to the use of these older habitats and are not often found within the seed orchard itself.

\section{Fallow Areas (Grasslands)}

There are approximately 139 acres of non-native open grasslands adjacent to the orchard units within the fence perimeter. These areas are unplanted units that will be used in Phase II of the orchard implementation process. Currently the same non-native grass mix that is underneath the seed trees is planted on these acres. Some species that use grassland habitats use these sites; however the lack of a well-developed forb component and the limited number of grass species also limits the number of wildlife species that exploit this habitat. Species that do take advantage of these areas include savannah sparrow, western meadowlark, vesper sparrow, long-tailed vole, western pocket gopher, and California ground squirrel.

\section{Woody/Riparian Areas}

Most of this type of habitat ( 36 acres) occurs outside of the orchard fence and is located in the southeastern corner of Section 9. This is the part of Douglas Creek that flows through this section and consists of larger, older, second-growth conifer trees intermingled with hardwoods. It is structurally consistent with habitat that can support species that require shaded coniferous riparian conditions. The smaller slivers of woody riparian habitat within the fenced perimeter have only remnant or small trees along the drainage channels. These areas were cleared during the construction of the orchard and are primarily occupied by shrubs. They do not resemble the same habitat as the more mature patches along Douglas Creek. 


\section{Buffer Zone Areas (Shrubby/Young Woodland)}

The drainage courses within the orchard perimeter were not developed for orchard units. They are buffer zone areas of shrubby riparian vegetation. They were cleared of forested cover and allowed to revegetate with shrubs and small trees such as vine maple, Himalayan blackberry, evergreen blackberry, scotch broom, and salal. These areas were also re-forested, as described in Section 3.7.1. This is a dense, often impenetrable area that supports a variety of smaller wildlife species. Many species of insectivorous birds were observed perching within the shrubby riparian patches and "hawking" insects over the orchard units. These "non-usable" areas bisect both production orchard sections and make up about $32 \%$ of the land base ( 250 acres) inside the fenced perimeter.

\section{Buffer Zone Areas (Wetland/Riparian)}

There are a few places within the fence perimeter where road construction has crossed a drainage and the culvert has created a small pond upstream. These three sites of ponded water total about 0.8 acre. They hold water most of the time as evidenced by the obligate wetland plant species, such as cattail, growing around them. The sites are suitable as breeding pools for amphibians. Rough-skinned newt males in breeding condition were observed in one pool. Aquatic invertebrates are also present in these sites.

\section{Special Status Terrestrial Wildlife Species}

\section{Bald Eagle}

The bald eagle (Haliaeetus leucocephalus) is a Federally and state-listed threatened species that may occur near Tyrrell. It usually frequents aquatic ecosystems, subsisting largely on fish, but also consumes birds and carrion. The bald eagle requires large trees or cliffs for nesting. In western Oregon, nests are constructed in large dominant trees about onequarter the length from the top, and are usually in the line of sight of a major water body.

The bald eagle was first listed under the ESA as endangered in 1978. It was downlisted to threatened in 1995. In 1999, a proposed rule was published to de-list the species completely, based on a finding that the species has recovered as a result of protections initiated under the ESA and a reduction of persistent organochlorine chemicals such as DDT in the environment. No final action has been taken by FWS on the 1999 proposal.

There are no bald eagle nests documented within the area of Tyrrell. There is some possibility that bald eagle activity could occur along the Siuslaw River; however, the seed orchard itself does not provide bald eagle habitat.

\section{Northern Spotted Ow1}

The northern spotted owl (Strix occidentalis caurina) is a Federally and state-listed threatened species that may occur near Tyrrell. They require old-growth forest habitats for nesting and foraging. Favored prey is the northern flying squirrel. These birds nest in trees large enough to provide a cavity or platform that can hold a nest and young. In the Coast Range, Douglas-fir reach this size at about 80 years old. Also at this age, forested stands begin to develop snags and coarse woody debris that provide suitable habitat for the owls' prey species.

The northern spotted owl was listed as threatened throughout its entire range (California, Oregon, Washington, British Columbia) in 1990, due to extensive loss of habitat in oldgrowth and late-successional forests.

Suitable habitat for the northern spotted owl exists within the late successional forest remnants located in the southwest quarter of Section 15 as well as in Section 11 northeast 
of Section 15, and Section 14 just east of Section 15. There is no suitable habitat for spotted owls within the fenced perimeter of the orchard. The nearest northern spotted owl nest site is $2 \frac{1}{2}$ miles from the seed orchard (BLM 2003).

\section{Other Special Status Species}

The long-eared myotis (Myotis evotis), fringed myotis (Myotis thysanodes), long-legged myotis (Myotis volans), Yuma myotis (Myotis yumanensis), and Pacific western big-eared bat (Corynorhinus townsendii townsendii, formerly Plecotus townsendii) are FWS species of concern that all occur within the Coast Range and are likely residents in or near Tyrrell. All are found in Douglas-fir forests and rely heavily on snags or older trees for roosting and/or raising young. These bat species feed on insects and are attracted to areas such as water bodies that support high insect densities. It is likely that the seed orchard is used as a foraging site. All except the Yuma myotis are also state-listed sensitive species.

The little willow flycatcher (Empidonax traillii adastus) frequents shrub fields and shrubby riparian habitats. It has been documented using the shrubby riparian sites within the fence perimeter and appears to be a common summer resident at the seed orchard. This flycatcher is a FWS species of concern and is also state-listed as sensitive. The purple martin (Progne subis) is a state-listed sensitive species. This species requires cavities for nesting and open areas for foraging. Less than 200 pairs have been documented as breeding in Oregon, but they could potentially occur at the seed orchard. The western bluebird (Sialia mexicana) is a state-listed sensitive species. It is common at Tyrrell, using the nest boxes available along the perimeter fence. The orchard units are used heavily as foraging sites, and the birds are often observed perched on orchard trees while hunting.

The northern red-legged frog (Rana aurora aurora) is a FWS species of concern that was documented within the Siuslaw watershed in 1996, and frogs meeting their description were sighted just downstream of the seed orchard. It is also possible that these frogs reside within Tyrrell's fenced perimeter. This frog is also on the Oregon state list of sensitive species.

\subsubsection{Aquatic Species}

Douglas Creek and several other streams near and within the seed orchard support fish species. The Siuslaw River is located downstream from the seed orchard and also supports numerous fish species. Area fish species are separated into two main categories: coldwater anadromous species and coldwater resident species. The majority of coldwater species play an important role in recreational, commercial, and Native American fisheries.

Coldwater anadromous fish species in the vicinity of the seed orchard include coho salmon (also a special status species, see below), chinook salmon, and winter steelhead, all of which are found in the Siuslaw River downstream from the seed orchard. Coho salmon and winter steelhead are also found in Douglas Creek, and coho salmon are present in Stream 8 below the seed orchard.

Cutthroat trout is an important coldwater resident species in the seed orchard area, and is present in the Siuslaw River, Douglas Creek, Stream 8 below the seed orchard, and Streams 1, 11, 12, and 13 (below seed orchard for all). Other coldwater fish present in the Siuslaw River and Douglas Creek include the resident species sculpin, coarse scale sucker, dace, redside shiner, and the western brook lamprey; and the anadromous species Pacific lamprey. Sculpin are also present in Stream 1 below the seed orchard. 
Fish or fish habitat that has been observed within the orchard are identified below; stream numbers correspond to those presented in Figure 3.4-1:

- Stream 11, unnamed tributary to Douglas Creek near south boundary of Section 9: cutthroat trout and lamprey.

- Stream 12, tributary to Douglas Creek near southeast corner of Section 9: cutthroat trout.

- Stream 13, tributary to Douglas Creek between North Umpqua and Coquille units: habitat for cutthroat trout and sculpin.

- Stream 25, tributary to Douglas Creek below South Umpqua units and north of North Umpqua unit: sculpin.

- Stream 8, tributary to Siuslaw River in Section 15: sculpin.

Fish habitat in Douglas Creek has been observed near and downstream from Tyrrell, and includes pools, riffles, glides, and a few rapids. Slopes and stream gradients in Douglas Creek and other tributaries are mostly moderate, with little canyon development or channel incisions. Streams have been buffered with vegetation in the seed orchard, although upper parts of some minor draws have only brush and ground cover at and near the channels. Wide stream buffers were observed in the orchard to contain mainly brush and hardwoods, with relatively few small conifers.

Most of the basin is managed for forest products, and Douglas Creek, in particular, has been highly impacted by past logging practices. Stream temperatures may be elevated in the Douglas Creek drainage due to the high percent of streams exposed to direct sunlight. Streamside shading is the most likely limiting water quality for fish habitat. According to $\mathrm{BLM}, 31 \%$ of the stream system has adequate shading and $33 \%$ of the riparian area is in good condition (BLM 2002).

Macroinvertebrates at streams in the general area include crayfish, aquatic snails, mayflies, stoneflies, caddisflies, water striders, dragonflies, and mosquitoes.

NOAA Fisheries has designated EFH for Pacific salmon, including chinook and coho. NOAA Fisheries designated EFH to comply with the provisions of the Magnuson-Stevens Fishery Conservation and Management Act, as amended by the Sustainable Fisheries Act of 1996. Amendment 14 to the Pacific Coast Salmon Plan identifies the Siuslaw hydrologic unit as freshwater EFH for both chinook and coho salmon (Pacific Fishery Management Council 1999). Similarly, the BLM 2002 assessment indicated that six miles of stream within the Douglas Creek drainage area have inherently good coho spawning and rearing habitat. Chinook salmon habitat is found in the Siuslaw River downstream of the orchard; although they have been reported at the mouth of Douglas Creek, their presence this far up the Siuslaw River is unconfirmed. Coho salmon are present downstream of the seed orchard in Stream 8, Douglas Creek, and the Siuslaw River.

\section{Special Status Aquatic Species}

\section{Coho Salmon}

Naturally spawned Oregon Coast populations of coho salmon (Oncorhynchus kisutch) are proposed for Federal listing as a threatened species and are a state-listed sensitive species. Members of this evolutionarily significant unit of coho salmon spawn in coastal streams from the Columbia River to Cape Blanco. Coho salmon are anadromous fish, meaning they migrate from the ocean to spawn in fresh water. Peak coho spawning is in mid-December, but may occur from November through January in the Siuslaw River. After the adults reproduce, they die. The eggs incubate in gravel nests in freshwater rivers for 60 to 90 days, depending on temperature, then hatch as the larval stage called alevins, who depend on food stored in a yolk sac. After the yolk sac is absorbed, juvenile salmon emerge from the gravel nest as fry (young juveniles) and live in fresh water for up to 15 months, after which they migrate to the ocean as smolts in the spring. Out- 
migration of smolts begins in February, but peaks in the latter part of March, extending into May; timing is influenced by fish size, temperature, stream flows, and phases of the moon. Typically, they will spend two years in the ocean before returning to spawn in the river where they were hatched.

Oregon Coast coho salmon were listed as threatened under the ESA on August 10, 1998 (63 FR 42587), due to habitat degradation, water diversions, harvest, and artificial propagation. In September 2001, in the case Alsea Valley Alliance v. Evans, a U.S. District Court struck down the listing of Oregon Coast coho salmon and remanded the listing decision to NOAA Fisheries for further consideration. Although this decision was appealed (and temporarily stayed during appeal), the appeal was dismissed by the Ninth Circuit and the Oregon Coast coho listing was invalidated as of June 15, 2004. NOAA Fisheries completed a new review of the biological status of Oregon Coast coho salmon-applying their new policy for considering hatchery stocks when making listing decisions-and proposed to list Oregon Coast coho salmon as a threatened species on June 14, 2004 (69 FR 33102). NOAA Fisheries must make a final decision on the proposed listing by June 14, 2005.

Coho salmon have been identified in the Siuslaw River tributary in Section 15 (Stream 8), and are known to be present in Douglas Creek and the Siuslaw River downstream of Tyrrell drainages.

\subsection{Noise}

Noise is defined as any unwanted sound that interferes with normal activities or in some way reduces the quality of the environment. Ambient noise levels vary greatly in magnitude and character from one location to another, depending on the normal activities conducted in the area. In general, noise levels around Tyrrell result primarily from traffic and agricultural and timber operations.

\subsubsection{Noise Descriptors}

Community response to noise is not based on a single event, but on a series of events over the day. Factors that have been found to affect the subjective assessment of the daily noise environment include the noise levels of individual events, the number of events per day, and the time of day at which the events occur. Most environmental descriptors of noise are based on these three factors, although they may differ considerably in the manner in which the factors are taken into account. Two types of noise measures are used to describe impacts on an existing environment. These include the decibel and the equivalent sound level. These measures and their application to noise environments are discussed below.

A decibel $(\mathrm{dB})$ is the physical unit commonly used to describe sound levels. Sound measurement is further refined by using an "A-weighted" decibel (dBA) scale that emphasizes the audio frequency response curve audible to the human ear. Thus, the dBA measurement more closely describes how a person perceives sound. For example, typical noise levels include a quiet urban nighttime (40 dBA), an air conditioner operating 100 feet away ( $55 \mathrm{dBA}$ ), and a heavy truck moving 50 feet away ( $85 \mathrm{dBA}$ ). Table 3.8-1 shows noise levels for various human activities.

Typical noise at the orchard generated by trucks, tractors, mowers, and other power equipment is described over an eight-hour time period, using the equivalent sound level $\left(\mathrm{L}_{\mathrm{eq}}\right) . \mathrm{L}_{\mathrm{eq}}$ is calculated using the dBA levels of noise events averaged over time, taking into account the usage factor (the proportion of time that a maximum level of noise is generated) of various types of equipment. Table 3.8-2 provides approximate sound levels for a typical mix of orchard equipment, estimated with $\mathrm{L}_{\mathrm{eq}}$. 


\section{Table 3.8-1. Typical Decibel Levels Encountered in the Environment}

\begin{tabular}{|c|c|c|}
\hline $\begin{array}{l}\text { Sound Level } \\
\text { (dBA) }\end{array}$ & Source of Noise & Subjective Impression \\
\hline 10 & -- & threshold of hearing \\
\hline 20 & rustling leaves & \\
\hline 30 & quiet bedroom & \\
\hline 35 & soft whisper at $5 \mathrm{ft}$; typical library & \\
\hline 40 & $\begin{array}{l}\text { quiet urban setting (nighttime); normal level in } \\
\text { home }\end{array}$ & threshold of quiet \\
\hline 50 & light traffic at $100 \mathrm{ft}$; quiet urban setting (daytime) & \\
\hline 55 & -- & $\begin{array}{l}\text { desirable limit for outdoor residential } \\
\text { area use }\end{array}$ \\
\hline 65 & automobile at $100 \mathrm{ft}$ & acceptable level for residential land use \\
\hline 70 & pickup truck at $50 \mathrm{ft}$; Freight train at $100 \mathrm{ft}$ & threshold of moderately loud \\
\hline 80 & tractor at $50 \mathrm{ft}$; power saw at $50 \mathrm{ft}$ & most residents annoyed \\
\hline 85 & $\begin{array}{l}\text { heavy truck at } 50 \mathrm{ft} \text {; helicopter flyover at } 30 \mathrm{ft} \\
\text { altitude at } 600 \mathrm{ft} \text { distance }\end{array}$ & $\begin{array}{l}\text { threshold of hearing damage for } \\
\text { prolonged exposure }\end{array}$ \\
\hline 95 & freight train at $50 \mathrm{ft}$; large lawn mower & \\
\hline 100 & heavy diesel equipment at $25 \mathrm{ft}$; chainsaw & threshold of very loud \\
\hline 120 & jet plane taking off at $200 \mathrm{ft}$ & threshold of pain \\
\hline 135 & civil defense siren at $100 \mathrm{ft}$ & threshold of extremely loud \\
\hline
\end{tabular}

Sources: 14 CFR 36.805, Cavanaugh 1998, Suter 1991, U.S. Army 1976, EPA 1974

\section{Table 3.8-2. Approximate Sound Levels (dBA) of Orchard Equipment}

\begin{tabular}{|l|c|c|c|c|c|c|c|}
\hline \multirow{2}{*}{ Equipment } & \multicolumn{5}{|c|}{ Sound Levels (dBA) at Various Distances (ft) } \\
\cline { 3 - 8 } & Averaging Time & $\mathbf{5 0}$ & $\mathbf{1 0 0}$ & $\mathbf{2 0 0}$ & $\mathbf{4 0 0}$ & $\mathbf{8 0 0}$ & $\mathbf{1 , 6 0 0}$ \\
\hline Chain saw & 8 hours & 101 & 95 & 89 & 83 & 77 & 71 \\
\hline Mower & 8 hours & 90 & 84 & 78 & 72 & 66 & 60 \\
\hline Tractor & 8 hours & 79 & 73 & 67 & 61 & 55 & 49 \\
\hline Power saw & 8 hours & 73 & 67 & 61 & 55 & 49 & 43 \\
\hline Pickup truck & 8 hours & 66 & 60 & 54 & 48 & 42 & 36 \\
\hline Composite & 8 hours & 75 & 69 & 63 & 57 & 51 & 45 \\
\hline Composite & 24 hours & 78 & 72 & 66 & 60 & 54 & 48 \\
\hline
\end{tabular}

aNoise attenuation of $6 \mathrm{dBA}$ for each doubling of distance assumes flat terrain with no trees or buildings. Trees and buildings would increase the attenuation, reducing noise levels at various distances. Assumes a background noise level of $45 \mathrm{dBA}$ for a typical rural (farm) area (Cavanaugh 1998).

Sources: U.S. Army 1976, Cavanaugh 1998, Cunniff 1977. 
Helicopter sound levels have been estimated for a helicopter 30 feet off the ground, with an averaging time of eight hours; the estimated noise levels are 85, 79, 73, and $67 \mathrm{dBA}$ at 600, 1,200, 2,400, and 4,800 feet, respectively (U.S. Army 1976, Cavanaugh 1998, Cunniff 1977). This estimate also assumes a background noise level of $45 \mathrm{dBA}$ for a typical rural area (Cavanaugh 1998).

Noise generated near the ground generally attenuates $6 \mathrm{~dB}$ for each doubling of distance from a noise source; trees and terrain can further increase attenuation. Noise generated above ground level (above $50 \mathrm{ft}$ ) generally attenuates about $2 \mathrm{~dB}$ for every doubling of distance. Attenuation of outdoor noise sources is complex, influenced by atmospheric conditions (wind speed and direction, relative humidity, and cloud cover), topography (flat terrain versus hills and mountains), tree cover, and other barriers such as buildings.

\subsubsection{Existing Noise Environment}

Tyrrell is located in an area of timber operations and forest on foothills and low mountains southwest of the Willamette Valley. Typical ambient noise levels for the mix of land use would average around $45 \mathrm{dBA}$.

About four residences are within $1 / 4$ mile of the seed orchard. There are buffers of trees between the orchard and all but one of these residences.

Noise at the orchard is generated by trucks, tractors, and power equipment used for daily operations. Typically, a mix of equipment would intermittently generate around $75 \mathrm{dBA}$ at a distance of 50 feet, averaged over an eight-hour period. Not including the effects of terrain and trees, these estimated noise levels would be expected to attenuate to $69 \mathrm{dBA}$ at 100 feet and to $45 \mathrm{dBA}$ at 1,600 feet (see Table 3.8-2).

Several small airports and landing strips are located in the vicinity of Tyrrell. The closest one is about 12 miles east of the seed orchard. Various aircraft contribute intermittent noise to the noise environment in the vicinity of the orchard.

\subsection{Cultural Resources}

The portion of the Siuslaw River Valley where Tyrrell is located was used by native peoples. A prehistoric archaeological site is located at Siuslaw Falls, approximately seven miles downstream. There are also numerous anecdotal accounts of prehistoric archaeological sites around the town of Lorane, approximately three miles east of the seed orchard.

Euro-American settlement around Lorane began in the 1850s. By the early 1870 s, most of the small flats along the Siuslaw River were homesteaded as far west as Siuslaw Falls. Subsistence agriculture, augmented by hunting and fishing, was employed by most of these early homesteaders and continued to be the focus of those living west of Lorane into the twentieth century. During the early twentieth century, logging and lumbering became important components of the upper Siuslaw River Valley economy. These industries remain staples of the region's economy today.

Post-disturbance cultural resource surveys were conducted when the seed orchard property east of Douglas Creek was cleared between 1983 and 1985. A single bifacially worked fragment was discovered during the course of these surveys. 


\subsection{Socioeconomics and Environmental Justice}

Socioeconomic resources are described in this section using employment, income, and demographic measures. Economic and demographic elements are key factors influencing changes in demand for goods and services within a local economy. Because there are no personnel changes associated with the proposed action or alternatives, the local housing market, schools, community services, and infrastructure will not be discussed in this document.

Tyrrell is located southwest of the city of Eugene, Oregon, near the rural unincorporated community of Lorane. The nearest small town is Cottage Grove. The seed orchard lies within Lane County, which is defined as the region of influence (ROI) for this analysis. Lane County also constitutes the one-county Eugene-Springfield Metropolitan Statistical Area. $^{3}$

\subsubsection{Community and Population}

Lane County is a large county in area, containing both the cities of Eugene and Springfield and the mostly rural area surrounding those cities. Approximately $60 \%$ of the county's population of 323,271 resides in Eugene and Springfield, 12\% in small municipalities, and nearly $28 \%$ in unincorporated areas (OED 2002). The area immediately adjacent to the seed orchard is rural in character, as discussed in Section 3.5.

Lane County is the fourth-most populous county in Oregon, representing over 9\% of Oregon's population of 3,429,399. The county's population increased by $14 \%$ during the 1990 s. During the 1980s, however, regional economic downturns early in the decade led to a population increase of only 3\% (USBC 2002a, USBC 2002c, OED 2002).

The state population grew by $21 \%$ between 1990 and 2000 , but had increased by only $8 \%$ during the 1980s. The population of Cottage Grove in 2000 was 8,445 (USBC 2002a).

\subsubsection{Economic and Income Characteristics}

Lane County had a labor force of 188,965 in 2000, a 21\% increase over 1990 employment, which in turn had increased by $18 \%$ between 1980 and 1990. The county's employment represents about $9 \%$ of the state's total. As of 2000, Lane County had a fairly diversified economy, with nearly one-third of employment in the services sector, about $22 \%$ in wholesale and retail trade, and $14 \%$ in manufacturing. The financial, insurance, and real estate sector and construction were the other major non-governmental employment sectors, accounting for $7 \%$ and $6 \%$ of jobs, respectively. Government provided $14 \%$ of all county jobs, with local government accounting for $56 \%$ of the government jobs. Federal civilian employment constitutes nearly $8 \%$ of government jobs and $1 \%$ of all jobs in Lane County. Farm employment provides $1.7 \%$ of employment, nearly the same proportion of employment for the U.S. The agricultural services, forestry, and fisheries sector provides $1.8 \%$ of county employment, about $1 \frac{1 / 2}{2}$ times the proportion of that sector's employment for the U.S. as a whole (BEA 2002).

In July 2002, unemployment in Lane County was $6.4 \%$, compared to $7 \%$ for Oregon and $6 \%$ for the U.S. The average 2001 unemployment rate was $6.8 \%$ for Lane County, $6.3 \%$ for Oregon, and $4.8 \%$ for the U.S. as a whole (OED 2002, OLMIS 2002).

Total personal income (TPI) for 2000 in Lane County was $\$ 8$ billion. Per capita income (PCI), which is calculated by dividing an area's TPI by its total population, is used to

\footnotetext{
${ }^{3}$ A metropolitan statistical area is a region having a high degree of economic interdependence, with geographically integrated labor, retail, and
} housing markets. Such regions generally consist of a central city or several cities and the surrounding communities or counties. 
compare income across regions. The $2000 \mathrm{PCI}$ in Lane County was $\$ 25,584$, which was $87 \%$ of the U.S. PCI of $\$ 29,469$, and $93 \%$ of Oregon's PCI of $\$ 27,660$ (BEA 2002).

Tyrrell has an annual budget of $\$ 500,000$, approximately two-thirds of which is spent for payroll for its 5 full-time employees. The seed orchard spends about $\$ 80,000$ annually on contracted work. The orchard's seed crop in Fiscal Year 2001 had an estimated value of $\$ 400,000$, and this value will undoubtedly increase with much larger cone crops expected in coming years. Approximately $\$ 60,000$ is spent annually for various types of pest control.

\title{
3.10.3 Environmental Justice
}

Executive Order (EO) 12898, Federal Actions to Address Environmental Justice in Minority Populations and Low-Income Populations, was signed by the President on February 19, 1994. Environmental justice has been defined by EPA's Office of Environmental Justice as follows (EPA 1998):

\begin{abstract}
The fair treatment and meaningful involvement of all people regardless of race, color, national origin, or income with respect to the development, implementation, and enforcement of environmental laws, regulations, and policies. Fair treatment means that no group of people, including racial, ethnic, or socioeconomic group should bear a disproportionate share of the negative environmental consequences resulting from industrial, municipal, and commercial operations or the execution of Federal, state, local, and tribal programs and policies.
\end{abstract}

The environmental justice EO requires that each Federal agency identify and address, as appropriate, disproportionately high and adverse human health or environmental effects of its programs, policies, and activities on minority and low-income populations. Environmental justice also takes into consideration EO 13045, Protection of Children from Environmental Health Risks and Safety Risks, which was signed by the President on April 21, 1997. This EO requires that each Federal agency identify and address, as appropriate, disproportionately high and adverse human health or environmental effects of its programs, policies, and activities on children, who are more at risk because of developing body systems, comparatively higher consumption-to-weight ratios, behaviors that may expose them to more risks and hazards than adults, and less ability than adults to protect themselves from harm.

The environmental justice ROI is Lane County, the same as for socioeconomic resources. To evaluate these potential effects, this section describes the minority and low-income characteristics of the ROI, based on data from the 2000 Census of Population and Housing. Demographic data regarding children are presented in Table 3.6-1.

The terms "low-income" and "minority" are defined according to guidance published by CEQ in 1997 and adopted by EPA. Under this guidance, "low-income" is defined as persons below the poverty level. The poverty threshold, which is a function of family size and is adjusted over time to account for inflation, was designated by the Federal government as $\$ 17,524$ for a family of one adult and three children in 2000 . "Minority" means persons designated in census data as Black (African-American), not of Hispanic origin; American Indian, Eskimo, or Aleut (Native American); Asian or Pacific Islander; or of Hispanic origin (CEQ 1997). According to the USBC definition, the Hispanic origin designation is separate from the ethnic (racial) designation, as people who identify their origin as Spanish, Hispanic, or Latino may be of any race (USBC 2001). Minority populations should be identified for environmental justice consideration where the minority population of the affected area exceeds $50 \%$ of the total population or is "meaningfully greater" than the minority population percentage in the general 
Table 3.10-1. Ethnic Characteristics of Adjacent Census Blocks and Comparison Areas

\begin{tabular}{|l|c|c|c|c|c|c|c|c|}
\hline \multirow{2}{*}{ Characteristic } & \multicolumn{2}{|c|}{$\begin{array}{c}\text { Adjacent Census } \\
\text { Blocks }^{1}\end{array}$} & \multicolumn{2}{|c|}{ Lane County } & \multicolumn{2}{c|}{ Oregon } & \multicolumn{2}{c|}{ U.S. } \\
\cline { 2 - 9 } & Number & $\%$ & Number & $\%$ & Number & $\%$ & Number & $\%$ \\
\hline Total population & 163 & 100 & 322,959 & 100 & $3,421,399$ & 100 & $281,421,906$ & 100 \\
\hline One race & 161 & 98.8 & 312,237 & 96.7 & $3,316,654$ & 96.9 & $274,595,678$ & 97.6 \\
\hline White & 159 & 97.5 & 292,728 & 90.6 & $2,961,623$ & 86.6 & $211,460,626$ & 75.1 \\
\hline Black & 0 & 0.0 & 2,506 & 0.8 & 55,662 & 1.6 & $34,658,190$ & 12.3 \\
\hline Native American & & 1.2 & 3,642 & 1.1 & 45,211 & 1.3 & $2,475,956$ & 0.9 \\
\hline Asian & & 0.0 & 6,470 & 2.0 & 101,350 & 3.0 & $10,242,998$ & 3.6 \\
\hline $\begin{array}{c}\text { Native } \\
\text { Hawaiian } / \mathrm{PI}^{3}\end{array}$ & & & & & & & & \\
\hline Other & & 0.0 & 599 & 0.2 & 7,976 & 0.2 & 398,835 & 0.1 \\
\hline Two or more races & 4 & 0.0 & 6,292 & 1.9 & 144,832 & 4.2 & $15,359,073$ & 5.5 \\
\hline Hispanic & & 1.2 & 10,722 & 3.3 & 104,745 & 3.1 & $6,826,228$ & 2.4 \\
\hline
\end{tabular}

Source: USBC 2002a.

${ }^{1}$ Census Tract 8 (Blocks 2018, 2082, and 2084).

2"Black" = Black or African American; "Native American" = Native American or Alaska Native; "Native Hawaiian/PI" = Native Hawaiian/ Other Pacific Islander; "Other" = Some other race.

${ }^{3}$ The 2000 Census separated the Asian and Native Hawaiian/Other Pacific Islander categories; they were previously combined under one category and are addressed as such in the CEQ and EPA Guidance.

"The 1997 CEQ Guidance did not address the new census categories "other" and "two or more races" for this analysis; those categories are also considered as minorities.

population of the assessment area (CEQ 1997). Table 3.10-1 presents ethnic data for census blocks containing and adjacent to Tyrrell and for Lane County and comparison areas.

According to the 2000 census, the area surrounding Tyrrell is overwhelmingly white and non-Hispanic, with only 6 persons (less than $2 \%$ ) in non-white ethnic categories. Only one Hispanic person was counted in the adjacent census blocks, representing less than $1 \%$ of the adjacent population.

The 2000 census found that $14.4 \%$ of Lane County's population was below the poverty threshold, while $11.6 \%$ of the population of Oregon and $11.3 \%$ of the U.S. population fall into this category (USBC 2002a). Data on poverty status are not yet available at the census block level, but data for the block group containing the census blocks adjacent to the seed orchard indicate that $9.7 \%$ of the block group's population fall below the poverty threshold, reflecting a lower rate of poverty than for the county as a whole (USBC 2002d).

There are few residences near the boundaries of Tyrrell, and no disproportionate numbers of low-income or minority individuals are found there. The 2000 census found that the census blocks adjacent to Tyrrell contained 3 young children (under 5 years) and 29 older children (aged 5 to 14) (USBC 2002a). Section 3.6 contains more detail on the age distribution of the adjacent population. 


\subsection{Environmental Consequences}

Chapter 3 introduced and described the resources that could be affected by implementing the proposed action or an alternative; Chapter 4 assesses the potential impacts. As defined in 40 CFR 1508.14, the human environment includes natural and physical resources, and the relationship of people with those resources. Accordingly, this analysis has focused on identifying types of impacts and estimating their potential significance. Table 2.6-1 in Chapter 2 summarizes the potential environmental consequences of the proposed action and alternatives.

\subsection{Introduction}

This chapter is organized by resource, with information presented in the same sequence as in Chapter 3, providing a logical flow for analysis of potential environmental impacts. Section 2.6 identifies the specific resources that generated concern during scoping and EIS planning, and are therefore highlighted for the decisionmaker in that chapter.

Each resource-specific subsection provides (1) a summary of the potential impacts of implementing the proposed action or an alternative; (2) the analysis methods and criteria for determining significance, as defined in 40 CFR 1508.27; and (3) a discussion of the potential impacts of the proposed action and each alternative. The chapter concludes with an evaluation of cumulative impacts, a discussion of mitigation measures, a discussion of unavoidable adverse impacts, an evaluation of the relationships between short-term uses of the environment versus long-term productivity; and a summary of irreversible and irretrievable commitments of resources.

The concept of "significance" used in this assessment considers both the context and the intensity or severity of the impact, as defined by 40 CFR 1508.27. The criteria used to characterize impacts are introduced at the beginning of each resource section. Significant impacts are effects that are most substantial and should receive the greatest attention in decision-making. Impacts described as minimal are identifiable and may be present, but the intensity or severity is below any threshold of concern, based on the criteria described in the specific resource discussion. Insignificant impacts result in little or no effect to the environment and cannot be easily detected; such impacts may also be referred to as negligible. If a resource would not be affected by a proposed activity, a conclusion of no impact was stated.

\section{Impacts Common to All Alternatives}

Under all alternatives, management actions not directly related to IPM, described in Section 2.1.2, would continue. These activities include administrative actions, such as facilities and equipment maintenance, which are comparable to the administrative actions described in the Eugene District RMP (ROD-Administrative Actions). Orchard establishment and maintenance and buffer zone management are comparable to the silvicultural and harvest practices described for management of young stands described in the Eugene District RMP/Final EIS. The impacts of these actions at Tyrrell would be similar to the impacts described in Chapter 4 of the Final EIS for the Eugene District RMP.

\subsection{Air Quality}

There would be insignificant impacts on air quality at and around Tyrrell from vehicle emissions, from prescribed burns, and temporary very localized drift from pesticide applications. The seed orchard is located in an attainment area for all criteria pollutants, and emissions from proposed activities would not affect the Eugene-Springfield Urban 
Growth Area, which is 11 miles from Tyrrell and is in non-attainment for $\mathrm{PM}_{10}$. Air quality impacts under any alternative would be insignificant. The no action alternative would not change existing air quality at the seed orchard.

\subsubsection{Analysis Approach and Assumptions}

The analysis was based on a review of existing air quality in the region, information on Tyrrell's air emission sources, projections of emissions from the proposed IPM implementation, a review of Federal regulations, and the use of air emission factors from EPA. Current emissions were estimated using the latest available information on the types of equipment used at the seed orchard.

The significance of air quality impacts is based on Federal, state, or local regulations or standards. A significant impact would be a violation of standards, or an exposure of sensitive receptors to excessive quantities of fugitive dust or smoke. A short-term impact that did not exceed standards would not be significant. A reduction in baseline emissions would improve air quality. No standards have been established for aerial concentrations of pesticides.

\subsubsection{Potential Impacts of Alternative A-Maximum Production IPM}

Small increases in equipment use, and occasional helicopter flights, would minimally increase mobile source emissions. The number of vehicles and the amount of equipment would not substantially differ from existing usage at the orchard. Emissions generated from these activities would be slight, would not exceed ambient air quality standards, and would not be significant. Helicopter flights are anticipated only once or twice a year, and their emissions would be negligible. Manual or mechanical IPM methods could produce small, localized amounts of fugitive dust, but impacts would be insignificant.

One IPM method proposed for use at Tyrrell is prescribed fire, which would generate particulate matter, volatile organic compounds, nitrogen oxides, and CO. To minimize the effects of these emissions, Tyrrell would comply with local smoke management restrictions, which coordinate burns within a region to reduce cumulative impacts. To further reduce impacts, Tyrrell would also manage the timing, vegetation type, size of burned area, fuel arrangements and moisture, ignition techniques, and patterns of prescribed burns, while taking into account weather conditions. Prescribed fire at Tyrrell is used only infrequently, on small native plant plots and occasionally to burn diseased branches and trees, cut or cleared vegetation, insect damaged branches and trees, and cones not harvested for seed production (see Section 2.2.2.3). Air quality impacts would be insignificant. Impacts to human health from prescribed fire are discussed in Section 4.6.2.3.

Aerial, ground vehicle, and hand methods of pesticide applications could result in spray drift and volatilized chemicals. The recently conducted risk assessment (summarized in Appendix C) found soil deposition of pesticides no further than 300 feet from the orchard boundary. Options for reducing drift include using spray equipment designed to produce 200 - to $800-\mu \mathrm{m}$-diameter particles, since particles of $100 \mu \mathrm{m}$ or less are more likely to drift farther. Additionally, spraying would be prohibited when the wind speed exceeds 6 miles per hour or is blowing toward a sensitive receptor or a nearby residence, or during an inversion. With the use of protection measures, which are an inherent part of all alternatives and are described in Section 2.3.1, impacts to air quality would be insignificant.

No other activities associated with this alternative would affect air quality. 


\subsubsection{Potential Impacts of Alternative B-IPM with Environmental Protection Emphasis (Proposed Action)}

Under the proposed action, the more restricted application procedures (see Section 2.3.3) would further reduce the risk of pesticide drift to neighboring land parcels. Impacts from mechanical and manual methods, and from prescribed fire, would be the same as those described under Alternative A. Impacts to air quality would be insignificant.

\subsubsection{Potential Impacts of Alternative C-Ground-Based IPM}

Under Alternative $C$, impacts would be similar to those described under Alternative

B. Impacts to air quality would be insignificant. Although it is often assumed to be otherwise, aerial application of pesticides can be associated with decreased drift compared to some ground-based methods. The risk assessment predicted that aerial pesticide application, conducted as proposed by the seed orchard, would be associated with less drift potential than ground-based airblast sprayer application. Therefore, the potential risk of drift from application of esfenvalerate or B.t., while still below the threshold of significance for air quality impacts, would be slightly increased compared to Alternative B. Risks from biological, cultural, and prescribed fire methods would the same as for Alternative B.

\subsubsection{Potential Impacts of Alternative D-Non-Pesticide Pest Management}

Under Alternative D, no biological or chemical pesticides would be used, so there would be no possibility of pesticide drift. Impacts from mechanical and manual methods, and from prescribed fire, would be similar to those described under Alternatives A, B, and C. Impacts to air quality would be insignificant.

\subsubsection{Alternative E-No Action: Continue Current Management Approach}

Under Alternative E, the current insignificant air quality impacts would continue. Before BLM undertook a pesticide application, an EA would be prepared to determine potential impacts of that application. That EA would include an assessment of air quality impacts.

\subsection{Geological Resources}

No significant impacts to geological resources or soil are expected from the proposed action or alternatives.

\subsubsection{Analysis Approach and Assumptions}

Potential impacts were assessed by evaluating current conditions at the orchard (including geology, topography, soil types and properties, and hydrology) and components of the various alternatives to predict conditions occurring after implementation of these alternatives.

\subsubsection{Potential Impacts of Alternative A-Maximum Production IPM}

Impacts from pesticides and fertilizers applied to specified areas at Tyrrell could be either impacts to the soils directly, or impacts where soils provide a pathway of potential contamination to another medium, such as water. Impacts to soils could occur through 
chemical changes to the soil, or physical changes (primarily contributions to existing soil compaction from heavy machinery). Chemicals could leach through the soil into the groundwater or run off to adjacent streams. Impacts where soil provides a pathway to another medium are evaluated in the respective sections of this chapter that address the affected resources (such as water quality or human health). Section 3.0 of the risk assessment report provides a detailed description of the potential for chemical transport through and on the soil, which can result in leaching or runoff of pesticides and fertilizers, leading to impacts on other resources.

\section{Sediment Delivery Potential}

Vegetative buffers between the stream and seed production orchards, consisting of mature hardwoods, conifers, and understory, surround all of the perennial streams at Tyrrell. Most of these buffers are more than 50 feet in width. These buffers would be maintained, with only spot treatments for noxious weeds; therefore, no increase in sediment delivery potential due to de-vegetation is expected from any of the control methods:

\section{Impacts from Chemical Pesticides and Fertilizers}

Impacts from the application of pesticides and fertilizers to soil can be divided into two groups - those occurring from chemicals which are highly mobile in soils and have a high water solubility, and impacts from chemicals with a low mobility in soil (high adsorption rate) and are only slightly soluble in water. Six of the pesticides proposed for application at Tyrrell are highly mobile in soil - acephate, dimethoate, dicamba, hexazinone, picloram, and triclopyr. The risk assessment predicted that, with the exception of acephate and dicamba, these chemicals would leach to the groundwater. The risk assessment also predicted that diazinon (moderately mobile in soil) would leach to the groundwater. The depth to bedrock varies from 20 to 40 inches in the Bellpine soils, to 40 to 60 inches in the Dupee soils, and 60 inches or more in the Jory soils. The root zone extends to the bedrock in the Bellpine soils; any leaching past this zone would reach the underlying bedrock. The rooting zone in the Dupee soils extends to the water table. Some of these chemicals could potentially leach through the Dupee soils to the water table. The application of the pesticides would not use a sufficient amount of water to move chemicals past the surface of the soil. (At a rate of 50 to 150 gallons per acre of water mixed with the chemical, this would be equivalent to about 0.02 to 0.05 inches of water applied to the area.) Any applied pesticides would likely remain near the surface and begin degrading, until subsequent rainfall would move any remaining residues into the soil horizon. Mobile pesticides leaching through the soil column would not persist in the soil or bedrock, but would disperse and degrade to lower concentrations. Any impacts to geologic layers below the soils would be insignificant.

The remaining chemicals proposed for application have a low mobility in soil due to a higher rate of adsorption. These chemicals would likely remain near the surface of the soil and degrade over time. Most degradation occurs by microbial metabolism. Other methods of degradation include hydrolysis (the splitting of a molecule by the addition of the elements of water), photolysis (degradation by radiant energy), and chemical degradation. Except for two herbicides (hexazinone and picloram) with soil half-lives in the five to six month range, the soil half-life of most of these chemicals is less than three months. The fate and transport modeling conducted for the risk assessment (Section 3.0 of the risk assessment report) indicated that negligible accumulation was expected.

Impacts to the soils from the application of fertilizers would be insignificant. Nitrate and other components of the fertilizers remaining in the soil would be absorbed by plants over time. 
Use of vehicles to apply pesticides or fertilizers could also contribute to existing soil compaction, although current practices to minimize compaction from ongoing orchard activities have proven effective and would continue. These include soil aeration and dry season operation to the extent possible.

\section{Impacts from Biological Controls}

Impacts from control methods using sheep, cattle, or goats to graze areas to control unwanted vegetation would be insignificant. Negligible amounts of compaction or erosion could occur, but would not substantially impact soils.

\section{Impacts from Prescribed Fire}

Prescribed fire would be utilized in small areas to remove unwanted vegetation in native plant beds, and to burn cut or cleared vegetation, insect-damaged branches and trees, insect-damaged cones, cones not collected for seed use, branches and trees affected by disease, and dead trees. The prescribed fires are anticipated to remove much of the vegetation and organic layers on top of the soils. This would increase potential runoff and the potential for soil erosion in these localized areas. The amount of vegetation and debris left after the fires depends on the intensity and duration of the fire. A low- to medium-intensity prescribed fire would generally not burn much of the organic layer of the soil. Fuels in the orchard are not heavy enough to create a high-severity burn. Most of the vegetation is well adapted to fire and would recover quickly, limiting the amount of potential erosion. Other impacts to the soil include reduced porosity of the soil from fine ash particles clogging the pore spaces of the soil and, depending on the intensity of the fire, a physical or chemical crust near the upper surface of the soil. With low- to medium-intensity fires in limited areas, the short-term impacts to soils would not be significant. Erosion would be more likely to occur in areas of steeper slopes, but litter and debris remaining after the prescribed fire would somewhat reduce potential erosion. The dense root system of existing plant communities would also limit soil erosion. Areas burned would not be sufficiently large to generate substantial erosion. Any erosion occurring would not likely be transported more than a few feet and would not cause siltation of streams.

\section{Impacts from Cultural Controls}

The use of heavy machinery during mowing would contribute to existing soil compaction. The degree of compaction would depend on soil moisture conditions and the number of passes with the equipment. All of the soils at Tyrrell are vulnerable to compaction when the soil is wet. Compaction of soil inhibits drainage, increases runoff potential, and affects root development and yields. Current practices to minimize compaction from ongoing orchard activities have proven effective and would continue.

\subsubsection{Potential Impacts of Alternative B-IPM with Environmental Protection Emphasis (Proposed Action)}

Impacts on soil and geologic resources from this alternative would not be significantly different than under Alternative A. Limitations on pesticide use could decrease the potential for impacts to soil chemistry from pesticide residues retained in the soil horizon. Impacts to soils from biological controls and prescribed fires would be the same as under Alternative A. Impacts to geological resources and soils occurring from implementation of Alternative B would be insignificant. 


\subsubsection{Potential Impacts of Alternative C-Ground-Based IPM}

Impacts to soils from this alternative would be similar to those described under Alternative B, with one exception. There would be a slightly higher potential for soil compaction due to a greater likelihood of using heavy vehicles to apply pesticides or fertilizers to a given orchard unit.

\subsubsection{Potential Impacts of Alternative D-Non-Pesticide Pest Management}

Impacts to soil chemistry from pesticide residues would not be an issue under this alternative. As under Alternative A, impacts to the soils from the application of fertilizers would be insignificant. Depending on the frequency and timing of mechanical, hand, and cultural methods of controlling pests, soil compaction would probably be somewhat greater compared to Alternatives $\mathrm{A}, \mathrm{B}$, or $\mathrm{C}$.

\subsubsection{Potential Impacts of Alternative E-No Action: Continue Current Management Approach}

Use of non-pesticide methods would continue under this alternative, with no projected change in impacts from biological, cultural, or prescribed fire control methods. Potential soil impacts from chemical methods of control would be reviewed on a case-by-case basis if pesticide chemicals were proposed for use.

\subsection{Water Resources}

The primary water resource concern relating to the proposed IPM activities at Tyrrell is how pest control methods, particularly the use of pesticides, would affect the surface water and groundwater from chemical transport and storage, as well as the resulting potential effects on downstream water users (primarily drinking water) and aquatic ecosystems.

Potential effects to water resources of most pesticide and fertilizer use are expected to be minimal to negligible, based on the conclusions of the risk assessment (summarized in Appendix C). Protection measures, limitations, and mitigation measures are expected to minimize the potential water quality impact from runoff and spills. These measures are listed in Sections 2.3.1, 2.3.3, and 4.12, respectively. All of the alternatives include monitoring the use and effectiveness of these measures, and adjusting application procedures based on monitoring results.

The risk assessment estimated pesticide and fertilizer concentrations in the surface water and groundwater; see Tables C-1 to C-3 in Appendix C. The potential impacts of surface water and groundwater contamination to human health, such as from the ingestion of drinking water or contaminated fish, are addressed in Section 4.6 (Human Health and Safety). Potential impacts to the aquatic ecosystem, including special status species, are addressed in Section 4.7 (Biological Resources). Because drainage patterns and natural topography of the orchard and surrounding area would not be affected by the proposed IPM activities, there would be no adverse impacts to floodplains. Therefore, floodplains are not discussed further in this section.

\subsubsection{Analysis Approach and Assumptions}

The major public scoping concern regarding water quality is the potential for pesticide contamination. Computerized fate and transport modeling was conducted to estimate 
concentrations of pesticides in the surface water and groundwater. The Groundwater Loading Effects of Agricultural Management System (GLEAMS) model, which models pesticide behavior in soils and water, was used to characterize the leaching and runoff behavior of the pesticides. This model used the best available data for orchard soil, watershed, and pesticide-use characteristics. Section 3.2.1 of the risk assessment report provides a detailed description of the model, input parameters, and assumptions. In summary, there are four major components to GLEAMS: hydrology, erosion, nutrients, and pesticides. Factors considered include:

- Soil organic matter content and $\mathrm{pH}$;

- Soil porosity and water retention characteristics;

- Pesticide decomposition rates and tendencies to be adsorbed;

- Pesticide solubility and vapor pressure;

- Pesticide application rates, methods, and timing;

- Surface and subsurface hydrological characteristics; and

- Local precipitation, irrigation, and climatic conditions.

To further distinguish the typical and maximum scenarios beyond any application rate and frequency differences listed in Table 2.2-1, the results of GLEAMS were handled as follows: In the typical scenarios, the mean of the 10 highest runoff concentrations over the modeling period was selected for use in the risk assessment. In the maximum scenarios, the single highest runoff concentration was used in the risk assessment.

The GLEAMS model predicted the volume and chemical concentrations of runoff as it leaves the area that was treated. Therefore, an additional modeling step was required to estimate the runoff amounts and chemical concentrations that entered surface water after the runoff traversed untreated areas. Tyrrell seed orchard units generally have significant areas of untreated field edges and well-vegetated buffers between treated acreage and receiving streams (more than 50 feet). These untreated intervening areas (collectively termed "buffer zones") play a major role in reducing the amount of chemicals that actually reach streams.

To account for the attenuating affect of the buffer zones, the USGS Method of Characteristics model was used to estimate concentrations in groundwater, each onsite stream, the main tributary from Section 15 into the Siuslaw River, for Douglas Creek, and for the Siuslaw River at the first point downstream of all orchard drainages. These values are presented in Table C-1 of Appendix C to this EIS, and can be considered to represent 24-hour average concentrations. For ground water, the GLEAMS simulations calculated estimates of the mass per unit area of each chemical leaching below the rooting zone. Estimated groundwater concentrations are presented in Table C-2 in Appendix C.

Finally, the Exposure Analysis Modeling System (EXAMS) model was used to predict downstream concentrations in the Siuslaw River if an accidental spill of pesticide concentrate or tank mix were to occur. Five potential spill sites were considered in the risk assessment.

\subsubsection{Potential Impacts of Alternative A-Maximum Production IPM}

\subsubsection{Groundwater}

Chemical contamination of groundwater would depend on the extent to which pesticides and fertilizers may leach through the soils into the groundwater and the depth of the water table. The extent of leaching would, in turn, depend on the physical properties of the soils affected (permeability, organic matter, percent clay, depth of soil horizons, and properties of geological materials underlying the soils) and the chemical properties of 
the pesticide or fertilizer (primarily its water solubility and partition coefficient - ratio of chemical absorbed to the soil to the amount in soil solution).

In the typical and maximum scenarios (see Section 4.6.1 for descriptions of scenarios), only five pesticides or other ingredients were seen to leach below the rooting zone: diazinon, dimethoate, hexazinone, picloram, and triclopyr triethylamine salt. Even in the maximum scenarios, the estimated groundwater concentrations at Tyrrell are below levels that would be associated with any risks to human health (see Table 6-1 of the risk assessment report), and movement of groundwater away from the orchard units would lead to even lower concentrations, due to dispersion, adsorption, and degradation. Therefore, impacts to groundwater would be negligible.

The risk assessment predicted that nitrate from the application of ammonium phosphatesulfate and calcium nitrate fertilizers would leach to the groundwater. Estimated concentrations in the groundwater were about $0.5 \mathrm{mg} / \mathrm{L}$ nitrate from ammonium phosphate-sulfate applied at $700 \mathrm{lb} /$ acre, and $0.2 \mathrm{mg} / \mathrm{L}$ nitrate from calcium nitrate applied at $4.5 \mathrm{lb} /$ tree. Impacts to the groundwater would be negligible, however, particularly given reduced concentrations in groundwater as it moves offsite away from the orchard units and becomes further diluted. No human health risks were associated with these concentrations for exposure through drinking water (see Section 4.6 and Appendix C).

Impacts to groundwater (specifically, drinking water) from an accidental spill of a container of pesticide concentrate or fertilizer at the mixing area are addressed in Section 4.6.

All of the alternatives would include an on-site water quality monitoring program. Groundwater from nearby orchard domestic wells would be monitored in the event of a spill to identify any groundwater contamination and the resulting pesticide concentration(s). Detailed information on the proposed Water Quality Monitoring Plan for Tyrrell is found in Appendix B.

Biological and cultural control methods, such as mechanical methods, include no activities that would adversely affect groundwater. B.t., a biological insecticide, is a naturally occurring soil bacteria. Applications of B.t. formulations do not increase natural levels of B.t. in soil. B.t. spores and crystals persist for a relatively short time. Like all soil microbes, B.t. does not percolate through the soil and its presence is confined to the top 10 inches of soil. Thus no groundwater contamination concerns are present (EPA 1998a).

\subsubsection{Surface Water}

Surface water contamination could potentially occur from the use of chemical pesticides or fertilizers and, to a lesser extent, from implementing biological and cultural IPM methods and prescribed fire. Each of these is discussed below. Potential impacts from pesticide and fertilizer use were analyzed for both normal applications and accidental spills.

\section{Impacts from Pesticide and Fertilizer Application}

Surface water contamination could occur from runoff (overland flow) of pesticides or fertilizers after application. This occurrence would depend largely on the characteristics of the soil, including the amount of vegetation present, the slope of the affected area, and the chemical applied. For example, if a chemical adsorbs well to the soil, it will tend to stay in the soil and be broken down in place. A chemical that does not adsorb to the soil could be washed away with irrigation or rainwater, and is more likely to be a potential contaminant. In general, the risk assessment modeling (described in the 
previous section) predicted some low surface runoff losses of pesticides and fertilizers at the orchard (see Table C-1 in Appendix C). The buffer zones between treated acreage and streams significantly reduce the amount of chemicals that actually reach stream water.

The risk assessment predicted the highest concentration in the maximum scenario of about $1 \mathrm{mg} / \mathrm{L}$ of nitrate (from fertilizer) in onsite streams, with far lower concentrations of pesticides predicted to reach surface water. No significant change in the potential for sediment delivery to surface water is expected as a result of vegetation control using chemical herbicides.

Measures would be taken to ensure that no off-target drift occurs during pesticide application, including drift to surface water. Spray nozzles are specifically designed to minimize drift. Buffer strips around streams and restrictions on spraying based on wind speed also would reduce the chance of drift reaching sensitive areas, such as streams. Equipment washing would be conducted in areas protected from the potential to run off to surface water or leach to groundwater. Section 2.3.1 lists the protection measures inherent in the proposed action and all alternatives.

As mentioned previously, Tyrrell proposes to conduct water quality monitoring both during and after some proposed pesticide applications to check for contamination and ensure protection; see Appendix B. The proposed plan encompasses the following components: implementation monitoring to document that protective measures have actually been implemented; effectiveness monitoring to document how well these measures have performed in avoiding the introduction of pesticides to the surface and groundwater systems; validation monitoring which would use the effectiveness data to validate the water quality modeling; and compliance monitoring, to document domestic water quality and pesticide fate in terms of irrigation effluent.

"If coho salmon are listed, BLM will meet the specific requirements that NOAA Fisheries established in the conference opinion for monitoring exposure and potential impacts to a listed species. The monitoring plan as currently established provides for comprehensive and thorough monitoring of potential impacts to all aquatic species."

\section{Impacts from Accidental Chemical Spill}

Chemical pesticide contamination of surface water could occur in the case of an accidental spill during pesticide transport or application.

The EXAMS modeling predicted that maximum residues from spills into the larger perennial streams would reach the Siuslaw River within an hour. Spills into smaller tributaries, especially in Section 15 which drains into the Siuslaw River through a small pond, would take 15 hours or longer to reach maximum concentrations in the river. In the event of an accident or spill, members of the public and workers may be exposed to greater amounts of a pesticide than from normal applications. These risks are discussed in Section 4.6.

\section{Impacts from Biological and Cultural Methods}

Potential effects to surface water resources from biological methods, such as livestock grazing and B.t. in field runoff, would be minimal. B.t., even if it reached the streams, is not known as an aquatic bacterium and is not expected to proliferate in aquatic habitats. It is also considered very non-toxic, especially when it is used in only terrestrial applications.

Potential effects to water resources from cultural methods, such as sedimentation, also would be minimal. While soil-disturbing operations and/or soil compaction caused by the use of heavy machinery can lead to increased runoff and stream sedimentation, very little sediment, or bacteria in the case of biological methods, is likely to reach the orchard's onsite streams due to the extensive buffers of untreated vegetation. During periods of heavy rain, there is some potential for sediment or bacteria residues to be released into the local streams; however, concentrations are expected to be minimal. 


\section{Impacts from Prescribed Fire}

Potential effects to water resources from prescribed fire would be minimal. Fire can remove the top vegetation and organic layers of soils, which could increase the potential for runoff and soil erosion (particularly in areas of steeper slope). However, any erosion would not likely be transported more than a few feet and is not expected to cause siltation of streams. Litter and debris remaining after the prescribed fire would serve to reduce potential erosion, as would the dense root system of existing plant communities. Finally, the burn areas would not be sufficiently large or contiguous to generate substantial erosion.

\subsubsection{Potential Impacts of Alternative B-IPM with Environmental Protection Emphasis (Proposed Action)}

Impacts to surface water and groundwater would be the same under the proposed action as in Alternative A for biological and cultural control methods. Impacts to water resources from pesticide and fertilizer application would be less than those identified in Alternative A because limitations incorporated into project design would control the potential for runoff or drift (see Section 2.3.3).

\subsubsection{Potential Impacts of Alternative C-Ground-Based IPM}

Impacts from this alternative would be similar to those described under Alternative B, except there is actually greater potential for drift from some broadcast ground methods, such as an airblast sprayer, than from aerial application. However, the potential impacts to water resources from a slight increase in drift are still expected to be negligible.

\subsubsection{Potential Impacts of Alternative D-Non-Pesticide Pest Management}

Under this alternative, potential runoff and leaching of pesticides to water would not be a concern since no pesticides would be applied. Fertilizers could be present in runoff, with the same impacts as under Alternative A. Overall impacts would be less than compared to Alternatives A, B, or C. Greater reliance on cultural and non-pesticide biological methods may result in slightly greater potential for runoff and sedimentation in streams. However, impacts would be negligible due to the extensive buffers of untreated vegetation.

\subsubsection{Potential Impacts of Alternative E-No Action: Continue Current Management Approach}

Use of non-pesticide methods would continue under this alternative, with no projected change in impacts. Any potential use of pesticide methods of control would require a separate EA each time a specific use was proposed. Impacts would be similar to Alternatives A or B (depending on project-specific details), although perhaps less since potentially fewer chemicals or mix of chemicals would likely be applied in the orchard on an annual basis, given the schedule limitations (demands) of preparing EAs on a case-bycase basis.

\subsection{Land Use}

Land use impacts are related to changes in the productive use of land as the result of an action. Insignificant impacts on land use are projected for the proposed action and all alternatives. 


\subsubsection{Analysis Approach and Assumptions}

The most recent information about surrounding land uses-including aerial photos, census data, and scoping comments-was used to determine current land uses and evaluate potential impacts. A significant impact to land use would be a permanent or long-term (several years) change in how a parcel could be used. Neither the proposed action nor any alternative includes activities that would change existing land use at the seed orchard or neighboring parcels directly. The potential for indirect impacts, from off-site transport of chemicals, was evaluated by reviewing the conclusions of the risk assessment (summarized in Appendix C).

\subsubsection{Potential Impacts of All Alternatives}

No direct land use impacts are predicted under any alternative.

The risk assessment predicted negligible pesticide drift to neighboring land parcels (shown in Figure 3.5-1) under Alternative A (Maximum Production IPM), which emphasizes aggressive pest management and has the highest potential for use of pesticide chemicals. The potential for indirect land use impacts from pesticide transport to neighboring land units is even smaller for Alternatives B, C, E, and D, with the probability for impact decreasing successively under each alternative. Alternative B (IPM with Environmental Protection Emphasis, the proposed action), includes limitations (see Section 2.3.3) that would reduce the potential for offsite pesticide transport to neighboring land parcels, below the levels predicted for Alternative A. Under Alternative C (Ground-Based IPM), impacts on land use would be similar to those predicted for Alternative B, since drift and runoff can occur from ground-based as well as from aerial applications. Under Alternative $\mathrm{E}$ (No Action), the current practice of preparing a NEPA document prior to pesticide use would continue. Any potential impacts to land use from pest management under this alternative would be identified in each project-specific NEPA document. It is likely that potential impacts would be insignificant, similar to those from Alternatives A, B, or C, depending on the details of the pesticide application. Finally, under Alternative D (Non-Pesticide Pest Management), no biological or chemical pesticides would be used, so there would be no possibility of pesticide transport to nearby land parcels.

While the probability of pesticide drift contaminating adjacent parcels is extremely low, unforeseen weather conditions, coupled with a failure to quickly respond to adverse conditions by ceasing aerial or airblast sprayer applications, could increase the possibility of such an impact. However, even in this situation, the overall impact on land use would be insignificant to landowners surrounding the orchard and to others in the region under any alternative.

Biological, cultural, and prescribed fire control methods under all alternatives would have insignificant land use impacts at Tyrrell or to neighboring parcels.

\subsection{Human Health and Safety}

Human health impacts as a result of any of the pest control methods could include chemical toxicity as a result of exposure to chemical pesticides, injury during use of cultural methods, and injury or smoke exposure during use of prescribed fire. No health impacts were identified for biological control methods or fertilizers. A quantitative human health risk assessment evaluated the potential effects to members of the public and seed orchard workers from using chemical pesticides and fertilizers under Alternative A. No risks to members of the public were predicted for non-accident exposures, but some pesticides (chlorpyrifos, diazinon, dimethoate, propiconazole, 
dicamba, and hexazinone) were predicted to present risks to some workers in certain situations. In response to these identified risks, Alternative B was designed, which incorporates limitations on chemical pesticide use that reduce these estimated workers risks to negligible levels. These limitations are also incorporated into Alternative C. Alternative D does not include the use of pesticides, and Alternative E would result in less frequent pesticide application.

No risks are predicted for members of the public from non-accident exposure to chemical pesticides under any of the alternatives. Under Alternatives A, B, C, and E, an accidental spill into a stream could result in surface water that would be unsafe for drinking or fishing. There are potential risks to workers from six of the proposed pesticides under Alternative $\mathrm{A}$, and no predicted risks to workers from pesticides under Alternatives $\mathrm{B}$, C, D, and E. Potential impacts on human health due to injury, heat, fire, and smoke are possible under all the alternatives, but the most likely of these impacts are temporary (muscle strain, eye and throat irritation due to smoke). These risks are slightly increased under Alternative E (no action), since less use would be made of pesticides, and increase further under Alternative D, since these methods would take the place of all pesticide use.

\subsubsection{Analysis Approach and Assumptions}

Risks from biological, cultural, and prescribed fire methods were evaluated qualitatively, based on potential types of injuries or health effects associated with the specific method, and the frequency of such injuries or effects at Tyrrell in the past.

To assess risks from use of chemical pesticides and fertilizers proposed under Alternative A, a quantitative risk assessment was conducted that estimated the risks to members of the public and workers as a result of using the proposed pesticides and fertilizers at Tyrrell. The supporting record for this EIS contains the full risk assessment; a summary is provided in Appendix C, including tables summarizing the modeling predictions for surface and groundwater concentrations and drift deposition. The human health risk assessment methodology is summarized briefly in the following paragraphs. Detailed information on inputs, methods, assumptions, and outputs can be found in Sections 4.0, 5.0 , and 6.0 of the risk assessment report.

Computerized fate and transport modeling was conducted to estimate concentrations of pesticides and fertilizers in environmental media at the point of exposure. Section 4.4.1 describes the water modeling used to estimate concentrations in groundwater, on-site streams, Douglas Creek, and the Siuslaw River. AgDRIFT was used to estimate off-target pesticide drift from aerial applications, airblast applications, and applications using a tractor-pulled spray rig with a boom. Field studies reported in the published literature provided the basis for estimates of drift from other ground-based pesticide application methods. Section 3.0 of the risk assessment report provides details of the models, their inputs, and the results obtained.

The risk assessment employed the three principal analytical elements that the National Research Council (1983) described and EPA $(1989,2000$ a) affirmed as necessary for characterizing the potential adverse health effects of human exposures to existing or introduced hazards in the environment: hazard assessment, exposure assessment, and risk characterization. 
The risk assessment addresses risks from fertilizers and 16 pesticide active ingredients ${ }^{1}$, as well as "other" ingredients in the pesticide formulations, formerly termed "inert" ingredients. ${ }^{2}$

\section{Human Health Hazard Assessment}

Hazard assessment requires gathering information to determine the toxic properties of each chemical and its dose-response relationship. Human hazard levels are derived primarily from the results of laboratory studies on animals. Toxic effects were divided into two categories, with different analytical approaches used: noncarcinogenic effects (for example, toxicity to the liver or nervous system) and carcinogenicity. The goal of the hazard assessment is to identify acceptable doses for noncarcinogens, and identify the cancer potency of potential carcinogens.

For noncarcinogenic effects, it is generally assumed that there is a threshold level, and that doses lower than this threshold can be tolerated with little potential for adverse health effects. EPA has determined threshold doses for many chemicals; these are referred to as reference doses (RfDs). The oral RfD is an estimate of the highest possible daily oral dose of a chemical that will pose no appreciable risk of deleterious effects to a human during his or her lifetime. The uncertainty of the estimate usually spans about one order of magnitude. RfDs are expressed in units of milligrams of chemical per kilogram of body weight per day $(\mathrm{mg} / \mathrm{kg} /$ day).

Data on carcinogenic potential were reviewed for each chemical. Acephate, permethrin, and propargite are considered possible human carcinogens; and chlorothalonil and hexachlorobenzene (a contaminant in picloram) are considered to be probable human carcinogens. For these compounds, cancer slope factors that have been calculated by EPA or other appropriate sources are used in this risk assessment. The cancer slope factor of a chemical represents the probability that a $1-\mathrm{mg} / \mathrm{kg} /$ day chronic dose will result in formation of a tumor, and is expressed as a probability, in units of "per $\mathrm{mg} / \mathrm{kg} /$ day" or $(\mathrm{mg} / \mathrm{kg} / \text { day })^{-1}$.

The RfDs and cancer slope factors used in this risk assessment are summarized in Table 4.6-1.

\section{Human Health Exposure Assessment}

Exposure assessment involves estimating doses to persons potentially exposed to the pesticides or fertilizers. In the exposure assessment, dose estimates were made for typical, maximum, and accidental exposures. These exposures are defined as follows:

- Typical: For this risk assessment, the word "typical" refers to a level of exposure within a scenario, and does not indicate whether the scenario itself is likely to occur. Typical exposure reflects the average dose an individual may receive if all exposure conditions are met. Typical exposure assumptions include the application rate usually used at the seed orchard, usual number of applications per year, the average of the ten highest values for chemical concentrations predicted to be present in runoff over a 10year period of annual typical applications, and other similar assumptions.

- Maximum: Maximum exposure defines the upper bound of credible doses that an individual may receive if all exposure conditions are met. Maximum exposure assumptions include the maximum application rate according to the label, maximum

\footnotetext{
${ }^{1}$ The biological insecticide B.t. and Safer ${ }^{\circledR}$ Insecticidal Soap were not included in the quantitative risk assessment. Potential environmental impacts are evaluated separately for these two control methods. See specific discussion at the end of Section 4.6.1.

${ }^{2}$ The risk assessment evaluated the formulations that are expected to be used. It is possible that other formulations of the same active ingredients may be substituted at times. The risks from other formulations containing the same active ingredients would be similar to the risks predicted in the risk assessment.
} 


\section{Table 4.6-1. Toxicity Endpoints}

\begin{tabular}{|c|c|c|c|}
\hline Chemical & RfD (mg/kg/day) & $\begin{array}{c}\text { Dermal Absorption } \\
(\%)\end{array}$ & $\begin{array}{l}\text { Cancer Slope Factor } \\
\text { (per mg/kg/day) }\end{array}$ \\
\hline Acephate & 0.004 & $0.4(1-h r)$ & 0.0087 \\
\hline Chlorothalonil & 0.015 & 0.15 & 0.00766 \\
\hline Chlorpyrifos & 0.0003 & $1.78(4-h r)$ & $\mathrm{NA}^{\mathrm{a}}$ \\
\hline $\begin{array}{l}\text { Dazomet } \\
\text { Formaldehyde } \\
\text { MITC } \\
\text { Monomethylamine } \\
\text { Carbon disulfide }\end{array}$ & $\begin{array}{c}0.016 \\
0.020^{\mathrm{b}} \\
0.00365^{\mathrm{b}} \\
6.4^{\mathrm{b}} \\
0.7^{\mathrm{b}} \\
\end{array}$ & $\begin{array}{l}10 \\
\text { NA } \\
\text { NA } \\
\text { NA } \\
\text { NA } \\
\end{array}$ & $\begin{array}{c}\text { NA } \\
0.000013 \text { per } \mu \mathrm{g} / \mathrm{m}^{3} \\
\text { NA } \\
\text { NA } \\
\text { NA } \\
\end{array}$ \\
\hline Diazinon & 0.0002 & 2 & NA \\
\hline Dicamba & 0.045 & 10 & NA \\
\hline Dimethoate & 0.0005 & 11 & NA \\
\hline Esfenvalerate & 0.02 & $3(8-h r)$ & NA \\
\hline Glyphosate & 2 & $1.42(24-h r)$ & NA \\
\hline Hexazinone & 0.05 & 1 & NA \\
\hline Horticultural oil & 1 & 1 & NA \\
\hline Permethrin & 0.05 & 1.7 & 0.016 \\
\hline $\begin{array}{l}\text { Picloram } \\
\text { Hexachlorobenzene }\end{array}$ & $\begin{array}{r}0.2 \\
\text { NA } \\
\end{array}$ & $\begin{array}{l}0.2 \\
23 \\
\end{array}$ & $\begin{array}{l}\text { NA } \\
1.7 \\
\end{array}$ \\
\hline Propargite & 0.04 & 14.5 (8-hr) & 0.201 \\
\hline Propiconazole & 0.013 & 40 (10-hr) & NA \\
\hline Triclopyr & 0.5 & 1.65 (8-hr) & NA \\
\hline $\begin{array}{l}\text { Inert Ingredients } \\
\text { Cyclohexanone } \\
\text { Ethylbenzene } \\
\text { Light aromatic solvent } \\
\text { naphtha } \\
\text { Xylene }\end{array}$ & $\begin{array}{c}5 \\
0.1 \\
0.02 \\
2\end{array}$ & $\begin{array}{cl} & 10 \\
3.4 & (4-\mathrm{hr}) \\
10 \\
3.9 & (4-\mathrm{hr})\end{array}$ & $\begin{array}{l}\text { NA } \\
\text { NA } \\
\text { NA } \\
\text { NA }\end{array}$ \\
\hline Nitrate & 1.6 & NA & NA \\
\hline
\end{tabular}

a $\mathrm{NA}=$ Not applicable

${ }^{b}$ Inhalation $\mathrm{RfC}$, units are $\mathrm{mg} / \mathrm{m} 3$

number of applications per year, the highest chemical concentration predicted to be present in runoff over a 10-year period of annual maximum applications, and other similar assumptions.

- Accidental: The possibility of error exists with all human activities. Therefore, it is possible that during seed orchard operations, accidents could expose individuals to unusually high levels of pesticides or fertilizers. To examine these potential health effects, several accident scenarios were evaluated for health effects to members of the public and workers.

It is important to note that these exposure scenarios estimate risks from clearly defined types of exposure. If all the assumptions in an exposure scenario are not met, the dose would differ from that estimated here, or may not occur at all. 
For members of the public, the exposure scenarios analyzed in this risk assessment consist of the following:

- Ingestion of groundwater.

- Ingestion of water from Douglas Creek near the logging camp on Siuslaw River Road (not a known source of drinking water).

- Ingestion of fish from Siuslaw River downstream of orchard drainages.

- Ingestion of deer hunted near grounds.

- Dermal exposure during recreational hiking on orchard grounds to residues on vegetation from drift of insecticides or fungicides, or from direct application of herbicides.

- Dermal exposure to residues on dogs following recreational use of site.

The categories of workers evaluated in this risk assessment for occupational exposure to pesticides are as follows:

- Helicopter pilot.

- Helicopter mixer/loader.

- Airblast sprayer mixer/loader/applicator.

- High-pressure hydraulic sprayer mixer/loader/applicator.

- Hydraulic sprayer with hand-held wand mixer/loader/applicator.

- Tractor-pulled spray rig with boom mixer/loader/applicator.

- Backpack sprayer mixer/loader/applicator.

- Ground pull spreader loader/applicator.

- Hand fertilizer applicator.

- Cone surveyor.

- Fumigant irrigator.

Several accidental exposure scenarios were also evaluated:

- Ingestion of fish and water downstream of a spill of concentrate.

- Ingestion of fish and water downstream of a spill of tank mix.

- Spill of pesticide concentrate onto worker's skin.

- Spill of pesticide mixture onto worker's skin.

- Spray of worker with tank mix of pesticide.

\section{Human Health Risk Characterization}

Characterizing risk that results from different levels of exposure illustrates a principal tenet of risk assessment, set down by Paracelsus in the $16^{\text {th }}$ century:

All substances are poisons; there is none which is not a poison. The right dose differentiates a poison from a remedy.

Toxicity is a chemical-specific property that does not vary based on the exposure situation; it is determined by a substance's ability to cause effects at certain doses. That is why the exposure analysis is required, to determine whether any exposures will occur at the levels associated with those effects: even a highly toxic chemical can be "safe" at very low levels of exposure, while a relatively nontoxic chemical can cause effects if the exposure is sufficiently high. 
In this risk assessment, the potential noncarcinogenic risks were evaluated by comparing the representative doses (estimated in the exposure assessment) with the RfDs (identified in the hazard assessment). All the RfDs used in this risk analysis take into account multiple exposures over several years and represent acceptable dose levels. The comparison of dose to RfD consists of a simple ratio, called the hazard index:

$$
\text { Hazard Index }=\text { Estimated Dose }(m g / k g / \text { day }) \div R f D(m g / k g / \text { day })
$$

If the estimated dose does not exceed the RfD, the hazard index will be one or less, indicating the dose is within the range generally considered to pose no adverse effects to humans.

A dose estimate that exceeds the RfD, although not necessarily leading to the conclusion that there will be toxic effects, clearly indicates a potential risk for adverse health effects. Risk is presumed to exist if the hazard index is greater than one. However, comparing one-time or once-a-year doses (such as those experienced by the public or in an accident) to RfDs derived from long-term studies with daily dosing tends to exaggerate the risk from those infrequent events.

To estimate cancer risk, the dose is averaged over a lifetime (75 years), and multiplied by the chemical's cancer slope factor. The resulting cancer probability is compared to a benchmark value of one in one million, a value commonly accepted in the scientific community as representing a cancer risk that would result in a negligible addition to the background cancer risk of approximately one in four in the U.S.

\section{Analysis of B.t., Imidacloprid, and Safer ${ }^{\circledR}$ Insecticidal Soap}

B.t. is a rod-shaped bacterium that produces a protein (a delta endotoxin) that is toxic to insects. B.t. is a naturally occurring microorganism that is found in the soil. According to EPA, no known mammalian health effects have been demonstrated in any infectivity / pathogenicity study (EPA 1998a). Some strains of B.t. have the potential to produce various toxins that may exhibit toxic symptoms in mammals; however, the manufacturing process includes monitoring to prevent these toxins from appearing in products. In terms of risks to seed orchard application or re-entry workers, EPA stated that "the potential for eye, dermal, and inhalation exposure to mixers, loaders and applicators does exist. The label for Bacillus thuningiensis based products may recommend wearing gloves, goggles, and a dust mask or equivalent pulmonary tract covering. However, because of a lack of mammalian toxicity, the risk from occupational exposure is minimal." Seed orchard personnel would follow all label guidelines and recommendations to minimize occupational exposure, as with all other pesticides proposed for use in the IPM program. In terms of risk to members of the public, anyone contacting soil is likely to have been dermally exposed to naturally occurring B.t. (EPA 1998a). The mechanism of its pesticidal action is unique to the gut membrane of insects, with no equivalent or similar mechanism in humans or other mammals. Its 50 -year use history in agricultural and community pest (mosquito, gypsy moth, other) control projects with no known adverse effects in members of the public (EPA 1998a) also supports the conclusion that there would be no significant impacts from seed orchard use.

Imidacloprid is a chloronicotinyl insecticide. It is proposed for use only in the form of capsules implants, which apply insecticide directly into a tree. Movement of imidacloprid is restricted to the vascular system of the tree; therefore, there is no potential for exposure to members of the public following application. Applicator exposure is highly unlikely due to the capsulized form of the product, but could occur in the accidental situation in which a capsule breaks open and a worker is dermally exposed to the contents. The label for conifer seed tree use of Imicide ${ }^{\circledast}$ states that the 3-mL size capsules would be used; each contains $332.1 \mathrm{mg}$ a.i. (Mauget 2003). Assuming that 25\% 
of the spilled amount remained on the skin, and using a dermal absorption factor of $7.2 \%$ (EPA 2003), a dose to a $71.8-\mathrm{kg}$ adult would be $0.083 \mathrm{mg} / \mathrm{kg}$. Comparing this to an acute RfD (appropriate for one-time accidental exposures) of $0.14 \mathrm{mg} / \mathrm{kg}$ (EPA 2003), the resulting hazard index is 0.60 , indicating no risk to workers from this accident scenario. Imicide has demonstrated no evidence of carcinogenicity in studies in rats and mice (EPA 2003).

Safer ${ }^{\circledast}$ Insecticidal Soap contains potassium salts of fatty acids. Fatty acids are naturally occurring compounds. The safety of this class of compounds is exemplified by the fact that they are permitted for direct addition to food for human consumption by the U.S. Food and Drug Administration (21 CFR 172.863). They exhibit low acute toxicity by the oral route of exposure, but can be irritating to the skin or eyes (EPA 1992).

No significant health effects are expected for either workers or members of the public from seed orchard use of B.t., imidacloprid, or Safer ${ }^{\circledR}$ Insecticidal Soap.

\section{Adjuvants and Surfactants}

In some cases, surfactants or adjuvants may be added to formulated pesticide products to improve their effectiveness or minimize handling and application problems. The seed orchard will only use surfactants or adjuvants that do not contain any ingredients on EPA's List 1 or 2, where listing indicates a chemical is of toxicological concern, or is potentially toxic with a high priority for testing (EPA 2000b). If a surfactant or adjuvant that contains any List 1 or 2 ingredients is considered, the risk associated with that chemical would be evaluated before a use determination is made.

\subsubsection{Potential Impacts of Alternative A-Maximum Production IPM}

\subsubsection{Biological Control Methods}

No significant impacts on human health are expected from the use of biological controls, including the use of the biological insecticide B.t., livestock grazing to remove grass from orchard units, and the use of bird and bat boxes to attract insect-eaters.

\subsubsection{Chemical Control Methods}

The assumptions used in the risk assessment regarding application rates, frequency, and areas potentially treated correspond to the details of Alternative A. Hazard indices and cancer risks for each chemical and scenario are presented in tables in Section 6.0 of the risk assessment report. The chemicals and scenarios for which risks were identified are summarized in the following paragraphs and in Table 4.6-2.

\section{Members of the Public}

For members of the public, hazard indices were less than one for all typical and maximum exposure scenarios, and cancer risks were all less than $1 \times 10^{-6}$ ( 1 in 1 million), ranging up to $7.90 \times 10^{-10}$ (7.9 in 10 billion). Therefore, no significant risks are predicted for members of the public. 


\section{Table 4.6-2. Summary of Scenarios with Predicted Human Health Risks Under Alternative A}

\begin{tabular}{|c|c|c|}
\hline Chemical & Scenario & Risk \\
\hline \multicolumn{3}{|c|}{ Risks to Members of the Public } \\
\hline None & None & None \\
\hline \multicolumn{3}{|c|}{ Risks to Workers } \\
\hline Chlorpyrifos & Cone surveyor & $\begin{array}{r}\text { Hazard index }=3.37 \text { (typical) } \\
\text { and } 12.8 \text { (maximum) }\end{array}$ \\
\hline \multirow[t]{2}{*}{ Diazinon } & $\begin{array}{l}\text { High-pressure hydraulic sprayer mixer/ } \\
\text { loader/applicator }\end{array}$ & Hazard index $=3.89$ (maximum) \\
\hline & Cone surveyor & $\begin{array}{r}\text { Hazard index }=3.41 \text { (typical) } \\
\text { and } 39.9 \text { (maximum) }\end{array}$ \\
\hline \multirow[t]{2}{*}{ Dimethoate } & $\begin{array}{l}\text { High-pressure hydraulic sprayer mixer/ } \\
\text { loader/applicator }\end{array}$ & $\begin{array}{r}\text { Hazard index }=9.28 \text { (typical) } \\
\text { and } 38.8 \text { (maximum) } \\
\end{array}$ \\
\hline & Cone surveyor & $\begin{array}{r}\text { Hazard index }=42.2 \text { (typical) } \\
\text { and } 289 \text { (maximum) } \\
\end{array}$ \\
\hline Propargite & Cone surveyor & Cancer risk $=1.69 \times 10^{-6}$ (maximum) \\
\hline Dicamba & Backpack sprayer & $\begin{array}{r}\text { Hazard index }=1.64 \text { (typical) } \\
\text { and } 6.57 \text { (maximum) }\end{array}$ \\
\hline Hexazinone & Backpack sprayer & Hazard index $=2.66$ (maximum) \\
\hline
\end{tabular}

\section{Workers}

For typical scenarios, all worker hazard indices are less than one, with the following exceptions:

- A high-pressure hydraulic sprayer mixer/loader/applicator applying dimethoate,

- A backpack sprayer applying dicamba, and

- A cone surveyor encountering residues of chlorpyrifos, diazinon, or dimethoate.

In the maximum scenarios, the hazard indices exceed one for the following workers:

- A high-pressure hydraulic sprayer mixer/loader/applicator applying diazinon or dimethoate;

- A backpack sprayer applying dicamba or hexazinone; and

- A cone surveyor encountering residues of chlorpyrifos, diazinon, or dimethoate.

The estimated cancer risk to cone surveyors encountering propargite residues is 1.69 in one million, slightly exceeding the standard point of departure of one in one million. All other cancer risks to workers were less than one in one million.

\section{Accidents}

For a spill of a container of chemical concentrate from Siuslaw River Road into Douglas Creek, risks to the public from drinking water and eating fish from the Siuslaw River are predicted for chlorpyrifos, diazinon, dimethoate, esfenvalerate, permethrin, chlorothalonil, propiconazole, and dazomet. All cancer risks are less than one in one million. 
For a spill of a container of chemical concentrate from Road 20-5-16 where the road crosses Stream 8 at the southern boundary of the seed orchard in Section 15, risks to the public from drinking water and eating fish from the Siuslaw River are predicted for diazinon, dimethoate, permethrin, and chlorothalonil. All cancer risks are less than one in one million.

For a spill of a container of chemical concentrate from the road that crosses Stream 13 in Section 9, risks to the public from drinking water and eating fish from the Siuslaw River are predicted for chlorpyrifos, diazinon, dimethoate, esfenvalerate, permethrin, chlorothalonil, and dazomet. All cancer risks are less than 1 in 1 million.

For a spill of an application tankload of mixed pesticide from Siuslaw River Road into Douglas Creek, risks to the public from drinking water and eating fish from the Siuslaw River are predicted for chlorpyrifos, diazinon, dimethoate, esfenvalerate, permethrin, propargite, chlorothalonil, and dazomet. The cancer risk to children from propargite is estimated to be 1.85 in one million.

For a spill of an application tankload of mixed pesticide from the remaining three accident scenarios (from Road 20-5-16 into a tributary to the Siuslaw River in the south end of Section 15, from an orchard road in Section 9 into a tributary to Douglas Creek, and from an orchard road in the north end of Section 15 into a tributary to the Siuslaw River), risks to the public from drinking water and eating fish from the Siuslaw River are predicted for diazinon, dimethoate, chlorothalonil, and dazomet. All cancer risks are less than one in one million.

In the accident scenario in which a worker spills liquid pesticide concentrate on the skin, hazard indices exceed one for the acephate, dimethoate, esfenvalerate, permethrin, chlorothalonil, propiconazole, and dicamba formulations. Estimated cancer risks were all less than one in one million.

In the accident scenario in which a worker spills tank-mixed diluted pesticide on the skin, hazard indices are greater than one for chlorpyrifos, diazinon, dimethoate, and dicamba. All estimated cancer risks are less than one in one million.

Hazard indices for the accident scenario in which a worker was directly sprayed exceed one for chlorpyrifos, diazinon, and dimethoate. Estimated cancer risks are all less than one in one million.

\subsubsection{Prescribed Fire}

Potential impacts on human health from prescribed burning as a vegetation control measure were evaluated in the Final EIS for Vegetation Management in 13 Western States (BLM 1991). Possible effects are summarized as follows:

\section{Risks from Fire}

Prescribed burning presents various hazards to ground crews, who could possibly receive injuries ranging from minor burns to severe burns that may result in permanent tissue damage. However, standard safety procedures, protective gear, and training are integrated into every prescribed burn plan and are expected to reduce or eliminate most hazards. If a burn escapes and causes a wildfire, members of the public in adjacent areas may be endangered, and the potential is higher for severe worker injuries (both for orchard workers and firefighters responding to the incident). 


\section{Risks from Smoke}

Substances that may be found in wood smoke include particulate matter, carbon dioxide, nitrogen oxides, aldehydes, and ketones. The proportion of each varies widely, depending on factors such as moisture content in the vegetation and the temperature of the fire.

Particulate matter is a result of incomplete fuel combustion. Fine particulate matter, with a diameter less than $2.5 \mu \mathrm{m}$, has a greater ability than do larger particles to avoid the body's defense mechanisms and reach the lungs. Carbon dioxide, nitrogen oxides, and other gaseous compounds of smoke generally decompose or diffuse into the atmosphere relatively quickly. However, some may attach to particulate matter and remain more concentrated and protected from decomposition. For example, aldehydes, which inhibit the removal of foreign material from the respiratory tract, may be adsorbed onto the surface of particles. Polynuclear aromatic hydrocarbons (PAHs) are of significant toxicological concern in evaluating the health effects of wood smoke. The PAHs in wood smoke contain at least five carcinogenic chemicals: benzo(a)pyrene, benzo(c)phenanthrene, perylene, benzo(g,h,i)perylene, and the benzofluoranthenes.

Exposures to the carcinogenic and possibly carcinogenic PAHs in wood smoke from burning vegetation were estimated for exposures to prescribed burns by BLM (1991). Estimated cancer risks were not expected to exceed the benchmark of 1 in 1 million for any member of the public or worker, even in extreme cases. Because smoke from prescribed fires would affect local air quality for a short time, sensitive individuals may experience eye, throat, or lung irritation from these exposures. Possible effects on workers with closer exposure may include eye irritation, coughing, and shortness of breath.

The effects (if any) on an individual from a prescribed fire or pile burn can vary greatly, and would depend on the size of the burn, the atmospheric conditions at the time of the burn, and the proximity of the individual.

\subsubsection{Cultural Controls}

Cultural controls include manual and mechanical methods of vegetation control, involving manual labor, and the use of hand tools and machinery. Examples of hand tools include hoes, rakes, and various types of pruners and cutters. Machinery includes tractors, mowers, chainsaws, gasoline-powered string trimmers, and other equipment. Impacts on safety and health could include falls, sprains, and other accidental injuries; cuts caused by tools; injuries from accidental contact with equipment or its attachments (blades, mowers, plows); and the possible initiation or aggravation of chronic health problems such as tendon or ligament damage or arthritis. There is some risk to workers of falling or being hit by limbs or tree trunks when pruning orchard trees. When temperatures are high, workers may experience fatigue, heat exhaustion, or heat stroke. Individuals who are sensitive to irritants present in some materials (sawdust, mulch, irritating plant hairs, and spines), or who are severely allergic to insect bites or stings, may experience moderate to severe health effects if exposed to these irritants in the course of conducting cultural pest management activities. No risks to members of the public are expected from cultural control methods.

\subsubsection{Other Control Methods}

No risks to human health are expected from the use of pheromone bait traps or from potential public exposure to nitrates following fertilizer application, as modeled in the risk assessment (see Chapter 4.0 of the risk assessment report). 
For an accidental spill of an application truckload of fertilizer from Siuslaw River Road into Douglas Creek, risks to the public are predicted for nitrate, under the extremely conservative assumption that all nitrogen from the ammonium phosphate-sulfate fertilizer was present as nitrate. For a spill of fertilizer from the remaining three accident scenario sites (Road 20-5-16 into a tributary to the Siuslaw River in the south end of Section 15, from an orchard road in Section 9 into a tributary to Douglas Creek, and from an orchard road in the north end of Section 15 into a tributary to the Siuslaw River), no risks to the public were predicted.

\subsubsection{Potential Impacts of Alternative B-IPM with Environmental Protection Emphasis (Proposed Action)}

Alternative B was designed in response to the results of the quantitative risk assessment, by incorporating limitations to specifically address any non-accident risks under Alternative A (which are summarized in Table 4.6-2). The risks from Alternative A (from Table 4.6-2) and the corresponding limitations that address the risks (from Section 2.3.3)

Table 4.6-3. Risk-Responsive Limitations to Protect Human Health Under Alternative B

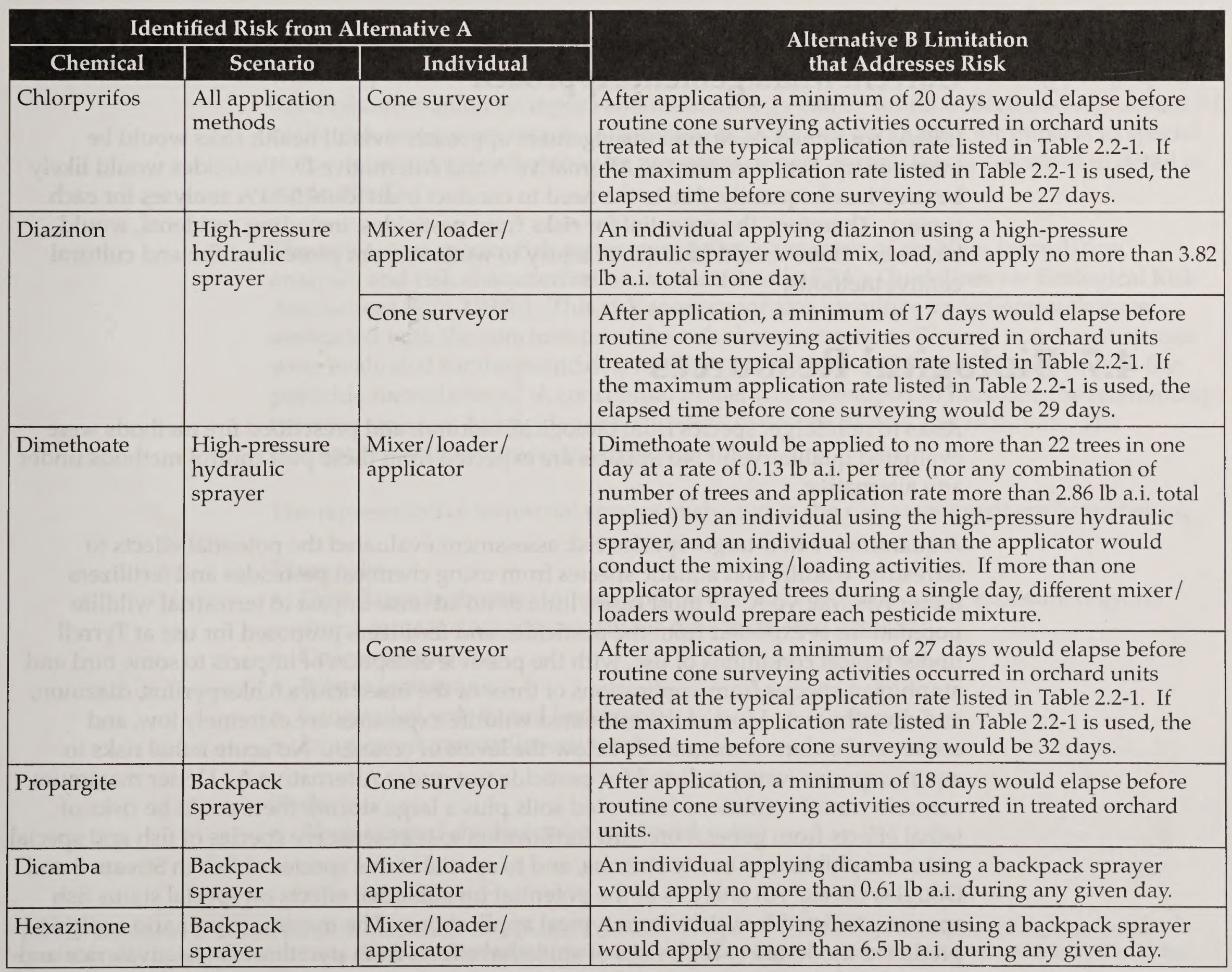


are correlated in Table 4.6-3. With these risk-responsive limitations as part of Alternative $B$, no adverse effects to human health are expected from the use of chemical pesticides under this alternative, except if an accident were to occur. The risks from accidents are the same as those identified under Alternative A. Risks from biological, prescribed fire, cultural methods, and other methods of pest control are the same as under Alternative A.

\subsubsection{Potential Impacts of Alternative C-Ground-Based IPM}

Since no risks are predicted for workers or members of the public from aerial applications, the omission of that method from the alternative does not change the risks. The risks from Alternative $\mathrm{C}$ would be the same as from Alternative $\mathrm{B}$ : no risks to members of the public or workers from pesticides except in the case of accidents. Risks from biological, prescribed fire, cultural methods, and other methods of pest control are the same as under Alternatives A and B.

\subsubsection{Potential Impacts of Alternative D-Non-Pesticide Pest Management}

Under Alternative D, the chance for injury would exist for workers from prescribed fire and cultural control methods. There would be no risks from pesticides since they would not be used. No risks to human health are predicted from the proposed fertilizer applications

\subsubsection{Potential Impacts of Alternative E-No Action: Continue Current Management Approach}

If BLM continued its current management approach, overall health risks would be intermediate between those of Alternative A and Alternative D. Pesticides would likely be used less frequently, due to the need to conduct individual NEPA analyses for each project. Therefore, the potential for risks from pesticides, including accidents, would be lower. There would be a risk of injury to workers from prescribed fire and cultural control methods.

\subsection{Biological Resources}

Risks to non-target species from biological, cultural, and prescribed fire methods were evaluated qualitatively. No impacts are expected from these pest control methods under any alternative.

A quantitative non-target species risk assessment evaluated the potential effects to terrestrial wildlife and aquatic species from using chemical pesticides and fertilizers under Alternative A. In most cases, little or no adverse impact to terrestrial wildlife populations is expected from the pesticides and fertilizers proposed for use at Tyrrell under typical conditions of use, with the possible exception of impacts to some bird and amphibian species from applications of three of the insecticides (chlorpyrifos, diazinon, and dimethoate). Most of the estimated wildlife exposures are extremely low, and are several orders of magnitude below the levels of concern. No acute lethal risks to aquatic species were predicted for pesticide use under Alternative A. Under maximum scenario runoff conditions (saturated soils plus a large storm), there could be risks of lethal effects from general orchard fertilization to non-sensitive species of fish and special status amphibians in onsite streams, and to special status species of fish in Stream 8 and Douglas Creek. An analysis of the potential for sublethal effects on special status fish species predicted low risks from typical applications. The maximum scenario analysis predicted moderate to high risks of sublethal effects from pyrethroids (esfenvalerate and permethrin) to special status species in Stream 8 and Douglas Creek, and moderate risks from general orchard fertilization to special status fish in Stream 8. 
In response to the risks identified for Alternative A, Alternative B was designed, which incorporates limitations on chemical pesticide use that reduce the estimated terrestrial species risks to negligible levels. These limitations are also incorporated into Alternative C. Alternative $\mathrm{D}$ does not include the use of pesticides, and Alternative E would result in less frequent pesticide application. Therefore, the only identified risks from Alternatives $\mathrm{B}$ and $\mathrm{C}$ are for potential moderate sublethal impacts from pyrethroids to special status aquatic species; and decreased, yet still possible, risks from general orchard fertilization under maximum scenario runoff conditions. Risks from Alternative D would be negligible, while risks from Alternative $\mathrm{E}$ would continue to be identified and evaluated on a project-by-project basis.

Under Alternatives A, B, C, and E, an accidental chemical spill into a stream could result in surface water concentrations that would be harmful to both terrestrial wildlife and aquatic species.

\subsubsection{Analysis Approach and Assumptions}

Risks from biological, prescribed fire, and cultural methods of pest control were evaluated qualitatively, based on the types of impacts possible.

\subsubsection{Non-Target Species Risk Assessment}

A quantitative non-target species risk assessment was conducted to evaluate the potential effects of the proposed chemical pesticides and fertilizers on terrestrial and aquatic wildlife species. The methodology is summarized briefly in the following paragraphs; detailed information on inputs and methodology can be found in Sections 7.0, 8.0, and 9.0 of the risk assessment report. Additional analysis was conducted for impacts to special status aquatic species that may be present at or near Tyrrell; this is described in detail in Appendix D.

The non-target species risk assessment follows the steps of problem formulation, analysis, and risk characterization, as described in EPA's Guidelines for Ecological Risk Assessment (EPA 1998b). This risk assessment also identifies uncertainties that are associated with the conclusions of the risk characterization. Risks to non-target species were evaluated for the pesticides, fertilizers, and List 1 or 2 "other" ingredients in the pesticide formulations. ${ }^{3}$ A conceptual model was developed to illustrate the relationships between stressors (pesticides or fertilizers), exposure routes, and receptors. The conceptual model is presented in Figure 4.7-1.

The representative terrestrial species evaluated in the risk assessment are listed below.

\section{Mammals:}

- Deer (large herbivore) (offsite drift residue and drinking water exposure only; no direct contact since fence excludes deer from seed orchard)

- Coyote (carnivore)

- Bobcat (carnivore)

- Long-tailed vole (small herbivore)

- Long-eared myotis (insectivore)

Birds:

- Black-capped chickadee (conifer seed-eater)

\footnotetext{
${ }^{3}$ The risk assessment evaluated the formulations that are expected to be used. It is possible that other formulations of the same active ingredients may be substituted at times. The risks from other formulations containing the same active ingredients would be similar to the risks predicted in the risk assessment.
} 


\section{Figure 4.7-1. Conceptual Model}

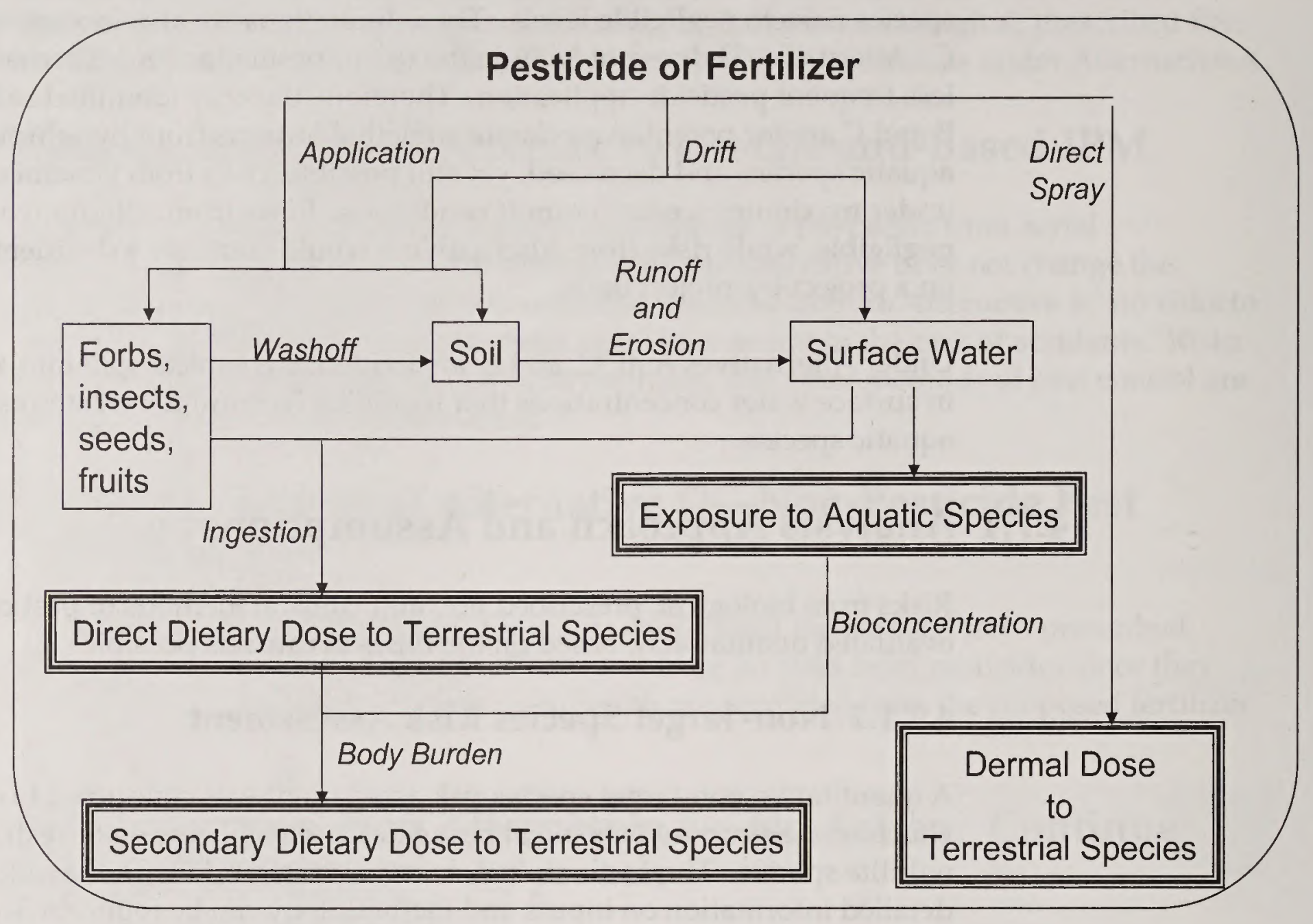

- Western bluebird (insectivore)

- Mallard duck (water fowl)

- Red-tailed hawk (raptor)

- Song sparrow (seed-eater)

Reptiles/amphibians:

- Rough-skinned newt

- Northwestern gartersnake

These particular wildlife species were selected because they represent the majority of the species present, or the seed orchard has suitable habitat and is within their range (e.g., selection of black-capped chickadee as conifer seed-eater), and because they represent several types of coverage: a range of phylogenetic classes, body sizes, foraging habitat, and diets for which parameters are generally available. In addition, several special status terrestrial species were evaluated for potential risk:

- The bald eagle and spotted owl are Federally listed threatened species that may occur near Tyrrell.

- Other Federal species of concern (formerly Category 2 species) that could be present include the northern red-legged frog, little willow flycatcher, long-eared myotis, fringed myotis, long-legged myotis, Yuma myotis, and Pacific western big-eared bat. Risks to the fringed myotis and long-legged myotis are assumed to be essentially the same as those estimated for the Yuma myotis and long-eared myotis, due to similarity of size and diet. Therefore, separate risk estimations were not made.

- BLM special status species likely to be present include the purple martin and western bluebird. 
Risks were also estimated for aquatic species for which ecotoxicity data are available: rainbow trout as a representative coldwater fish species, and the water flea Daphnia magna as a representative aquatic invertebrate. In addition, two special status species known to be present were evaluated:

- Oregon Coast coho salmon are proposed for Federal listing as a threatened species. They have been identified in the Siuslaw River tributary in Section 15 (Stream 8), and are known to be present in Douglas Creek and the Siuslaw River downstream of Tyrrell drainages.

- Aquatic stages of the northern red-legged frog were also assessed, since this is a Federal species of concern.

Stressor-response profiles were prepared for each pesticide, other ingredient, and fertilizer proposed for use at Tyrrell. These profiles addressed ecotoxicity to both terrestrial and aquatic species, with the goal of identifying endpoints relevant to the types of exposure and methodology used in the assessment. The focus of this research was to identify the following toxicity endpoints:

- Median lethal dose $\left(\mathrm{LD}_{50}\right)$ - the amount of a substance that will kill $50 \%$ of a group of laboratory animals after one dose. It is usually expressed in milligrams of the chemical per kilogram of body weight $(\mathrm{mg} / \mathrm{kg})$.

- Median lethal concentration $\left(\mathrm{LC}_{50}\right)$-the concentration in water of a substance that will kill $50 \%$ of the test animals (aquatic species) after they are exposed for a specified amount of time, often 24,48 , or 96 hours. It is usually expressed in milligrams of chemical per liter of water $(\mathrm{mg} / \mathrm{L})$.

- Maximum acceptable toxicant concentration (MATC) - the geometric mean of the noobserved-effect concentration and the lowest-observed-effect concentration, representing a concentration in water that is expected to be tolerated by the test species.

The stressor-response profiles for all chemicals are presented in Section 8.3 of the risk assessment report.

Exposures to non-target species were modeled for both typical and maximum scenarios, as in the human health risk analysis summarized in Section 4.6. The results of computerized fate and transport modeling were used to estimate concentrations of chemicals at points of exposure for non-target species, and are included in Tables C-1 to C-3 in Appendix C. Details of the methods and models can be found in Sections 3.0 and 8.0 of the risk assessment report.

The risk assessment principle that "the dose makes the poison," discussed in Section 4.6.1 under "Human Health Risk Characterization," also applies to risk characterization for wildlife and aquatic species. Both chemical-specific toxicity and estimated levels of exposure must be considered before risk can be predicted.

By comparing the exposure profile data (estimated dose or water concentration) to the stressor-response profile data $\left(\mathrm{LD}_{50} \mathrm{~s}, \mathrm{LC}_{50} \mathrm{~s}, \mathrm{MATCs}\right)$, an estimate of the possibility of adverse effects can be made. The levels of concern are determined following the quotient methodology used by EPA's Office of Pesticide Programs. The quotient is the ratio of the exposure level to the hazard level. For acute exposures, the levels of concern at which a quotient is concluded to reflect risk to non-target species are as follows:

- Terrestrial species (general): 0.5 , where dose equals one-half the $\mathrm{LD}_{50}$.

- Terrestrial species (special status): 0.1 , where dose equals one-tenth the $\mathrm{LD}_{50}$. 
- Aquatic species (general): 0.5 , where water concentration equals one-half the $\mathrm{LC}_{50}$.

- Aquatic species (special status): 0.05 , where water concentration equals one-twentieth the $\mathrm{LC}_{50}$.

Due to the high level of concern for protecting threatened salmonids in the watershed, the predicted water concentrations are also compared to the MATC for a chemical, if available. Any exposures to aquatic species would occur as a limited-duration "pulse" concentration in these flowing streams, and would not be a continuous exposure.

\section{Analysis of Risks from B.t., Imidacloprid, and Safer ${ }^{\circledR}$ Soap}

These three products were added to the proposed IPM program after the quantitative risk assessment was completed, and therefore have been evaluated separately from the other proposed pesticides. The potential for non-target species impacts from these pesticides is described in Section 4.7.2.2 and 4.7.2.3 for terrestrial and aquatic species, respectively.

\section{Adjuvants and Surfactants}

In some cases, surfactants or adjuvants may be added to formulated pesticide products to improve their effectiveness or minimize handling and application problems. The seed orchard will only use surfactants or adjuvants that do not contain any ingredients on EPA's List 1 or 2, where listing indicates a chemical is of toxicological concern, or is potentially toxic with a high priority for testing (EPA 2000b). If a surfactant or adjuvant that contains any List 1 or 2 ingredients is considered, the risk associated with that chemical would be evaluated before a use determination is made.

\subsubsection{Risk Analysis for Sublethal Effects to Special Status Aquatic Species}

The non-target species risk assessment (summarized in Appendix C) evaluated the potential for effects on fish from pesticides or fertilizers in surface runoff or from drift during application. For each chemical, the risk assessment identified the $\mathrm{LC}_{50}$ for the most sensitive coldwater species for which data were available. Risks were estimated for all aquatic species using this approach. However, additional analysis was determined to be necessary for special status species, since chemical exposures may adversely affect vulnerable populations by impacts other than the death of individuals, such as by interfering with migration or reproduction. These are termed "sublethal effects." This analysis is presented in detail in Appendix D, and summarized in the following paragraphs.

Along with impacts to general aquatic species, risks to two special status species known to be present near Tyrrell-coho salmon and northern red-legged frog tadpole-were estimated in the non-target species risk assessment.

The sublethal effects evaluated in this risk analysis for special status aquatic species are those that are relevant to biological requirements of the animal: in this case, rearing and migratory effects, and reproductive endpoints (NOAA 2002). Survival is also included in this analysis.

The assessment endpoints used to characterize potential effects reflect measures of the animal's health that can be functionally related to survival, rearing and migratory behavior, or reproductive success (NOAA 2002). Since relatively few scientific studies have examined sublethal effects of pesticides on fish physiology or behavior, the selection of assessment endpoints is limited. In the absence of data specific to the identified species of concern, data from biologically and genetically similar surrogate 
species were used. Comparative toxicology has demonstrated that various species of scaled fish generally have equivalent sensitivity (within an order of magnitude) to other species tested under the same conditions. Dwyer et al. (1995) and Beyers et al. (1994), among others, have shown that endangered and threatened fish tested to date are similarly sensitive to a variety of pesticides and other chemicals as their nonendangered counterparts. Very few studies have investigated the effects of pesticides specific to the lamprey, so comparative toxicity with fish species from available literature is made cautiously. In some cases, in the absence of sublethal effects data on a specific chemical for appropriate fish species, information was evaluated for pesticides which are chemically similar and share a common mechanism of toxicity.

For the purpose of broadening and strengthening the best available science for this evaluation, the proposed-use chemicals were analyzed by chemical groups. The insecticides and acaricides are divided by chemical classes (biologicals, organophosphates, organosulfites, and pyrethroids), reflecting a common mechanism of toxicity for each class. The herbicides, fungicides and fumigant, other ("inert") ingredients, fertilizers, and "other pesticides" (not inclusive within any other group classification) were evaluated wholly by their respective groups. In each case, the lowest toxicity result (indicating greatest toxicity) was used in the analysis of risks, so that this categorization approach would not sacrifice a protective analysis.

Appendix D provides details of the sublethal effects literature and analysis of risk values. Table 4.7-1 summarizes the lowest (most sensitive) toxicity values identified during this process. These data points are not intended to be definitive of all possible adverse effects at all life-stages related to survival, migration, or reproduction, but are intended to be conservative, representative estimates.

Risks of sublethal effects to special status species were determined by comparing the stream concentrations estimated in the risk assessment and the toxicity data endpoints summarized in Table 4.7-1. A concentration-effects ratio was determined, defined as the estimated chemical concentration in surface waters over the effect concentration. Risks to survival, migratory, and reproductive endpoints were predicted as follows:

- low if the concentration-effects ratio was 0.1 or below,

- moderate if the ratio was 0.1 to 1.0 , and

- high if the ratio was 1.0 or greater.

Table 4.7-1. Summary of Special Status Species Toxicity Data

\begin{tabular}{|l|c|c|c|}
\hline \multirow{2}{*}{ Pesticide } & \multicolumn{2}{|c|}{ Effect Concentration (mg/L) } \\
\cline { 2 - 4 } & Survival & Migration & Reproduction \\
\hline Biological insecticides & 75 & NA & NA \\
\hline Organophosphates & 0.001 & 0.01 & 0.0003 \\
\hline Organosulfites & 0.008 & NA & 0.028 \\
\hline Pyrethroids & 0.000025 & 0.0001 & 0.000004 \\
\hline Herbicides & 0.033 & 0.046 & 2.0 \\
\hline Fungicides/fumigants & 0.0049 & NA & NA \\
\hline Other pesticides & 100 & NA & 8.0 \\
\hline Other ingredients & 0.32 & 0.1 & NA \\
\hline Fertilizers: & 2.0 & NA & NA \\
nitrogen \\
phosphate \\
calcium nitrate
\end{tabular}

NA $=$ No data available. 
For example, if the stream concentration of a given chemical is estimated to be $0.003 \mathrm{mg} /$ $\mathrm{L}$, and the concentration of that chemical which affects reproduction is $0.006 \mathrm{mg} / \mathrm{L}$, then the concentration-effect ratio would be 0.5 - a moderate risk to the fish.

\subsubsection{Potential Impacts of Alternative A-Maximum Production IPM}

\subsubsection{Vegetation}

Biological, cultural, and prescribed fire methods of pest control are not expected to present any adverse impacts to non-target vegetation.

Although the proposed herbicides are variously toxic to plants with which they come into contact, there should be no undesired impacts if properly applied. No special status plant species have been identified on-site at the seed orchard. Broadcast applications of herbicides are only proposed for intensively managed or disturbed areas such as along roads and fences, within orchard units, or around facilities, while spot applications would be used to control weed species in less disturbed areas. Only directed spot applications of herbicides are proposed within the riparian zones. Insecticides, fungicides, and fertilizers are only proposed for use in cultivated areas (seed orchard blocks and native species beds), so no direct contact with plant species in other areas is expected.

Aquatic plants may be present in streams and ponds that receive runoff from treated areas. A literature review was conducted to identify the levels at which any of the proposed chemicals may pose a hazard to aquatic plants (see Section 9.2.4 in the risk assessment report). For many chemicals, tests in algae were the only available data, and are expected to provide a sensitive endpoint for hazards to aquatic plants. For each chemical, the estimated water concentrations were compared to the levels of concern. None of the predicted concentrations in onsite streams, Douglas Creek, or the Siuslaw River exceed the effects criteria equivalent to $50 \%$ of the values reported in the literature summarized in the preceding paragraphs. Therefore, no adverse effects to aquatic plants are expected under typical or maximum conditions of pesticide or fertilizer application at Tyrrell.

\subsubsection{Terrestrial Species}

\section{Risks to General Terrestrial Species}

No risks to terrestrial wildlife are predicted for biological or cultural controls. Risks to wildlife from prescribed fire were evaluated in detail in BLM (1991); this evaluation is summarized below:

Many different wildlife (vertebrate) responses to fire have been reported. Fire effects on wildlife vary with (1) animal species complex, (2) mosaic of habitat types, (3) size and shape of fire-created mosaic, (4) fire intensity, (5) fire duration, (6) fire frequency, (7) fire location, (8) fire shape, (9) fire extent, (10) season of burn, (11) rate of vegetation recovery, (12) species that recover, (13) change in vegetation structure, (14) fuels, (15) sites, and (16) soils...

In general, fire affects wildlife by direct killing, alteration of immediate postfire environments, and postfire successional influences on habitat.... Direct killing of vertebrates by prescribed burning is rare.... For those species that cannot flee a burn, the most exposed habitat sites are dry exposed slopes, hollow logs with a lot of exposed wood, burrows less than five inches deep, lower branches of trees and shrubs, and poorly insulated underground/ground nesting areas.... Effects of prescribed 
burning on ground cover depends on fire severity: low severity fire on wet sites would remove less cover than high severity fires on dry sites. Escaped prescribed burns may accidentally destroy riparian habitats and impact aquatic resources, causing losses of wildlife through exposure, total loss of habitat, and increased sedimentation of the aquatic habitat caused by unchecked overland flow and destabilized stream channels.

Fire mainly affects wildlife through habitat alteration.... Fire may have a positive effect on wildlife habitats by creating habitat diversity, by re-creating lost or degraded habitats for indigenous species, and by allowing for the re-introduction of extirpated species when habitat degradation was significant to their [local] extinction. Immediate postfire conditions raise light penetration and temperatures on and immediately above and below soil surfaces and can reduce soil moisture.... Burning of cover and destruction of trees, shrubs, and forage modify habitat structure.... The loss of small ground cover and charring of larger branches and logs (with diameters greater than 3 inches) can negatively affect small animals and birds. Early, vigorous vegetation growth immediately after a fire alters feeding and nesting behaviors... Postfire plant and animal succession effects creating seral and climax mosaics in habitat cannot be generalized in their effects on wildlife.... Negative impacts can be lessened if the period of treatment avoids the bird nesting season and other critical seasons when loss of cover would be critical to wildlife; for example, during critical reproductive periods and prior to severe winter weather conditions.

Because the seed orchard is an intensively managed site, and only limited areas would potentially be treated with prescribed burning, negligible impacts to wildlife are expected from vegetation control using prescribed fire.

Risks to terrestrial wildlife from pesticide and fertilizer use under Alternative A are summarized in Table 4.7-2.

Similar to the negligible risks to humans, minimal to no risks are predicted for nontarget mammals from the biological insecticide B.t. Avian studies demonstrated that B.t. was practically nontoxic to mallard ducks and bobwhite quail after five days of oral dosing at up to 2,900 mg/ kg/day, indicating negligible toxicity to bird species (EPA 1998a). No impacts to terrestrial animals are expected from the use of B.t.

The insecticide imidacloprid, which was not previously analyzed, is proposed for use only in the form of the Imicide ${ }^{\circledR}$ product, a capsule implanted directly into a tree. No exposure to terrestrial species would occur. In terms of risks to mammalian wildlife, it is also instructive to note that the active ingredient imidacloprid is the same as that found in the Advantage ${ }^{\circledR}$ dog and cat flea control products, which are applied directly to the skin of animals at a recommended dose rate and frequency of $10 \mathrm{mg} / \mathrm{kg}$ body weight once per month.

Little to no terrestrial species risk from seed orchard use of Safer ${ }^{\circledR}$ Insecticidal Soap is indicated by the active ingredient's short half-life (less than one day), natural occurrence of the degradation products (fatty acids), and low toxicity (oral $\mathrm{LD}_{50}$ of $74,000 \mathrm{mg} / \mathrm{kg}$ for the fatty acid oleic acid, and five-day $\mathrm{LC}_{50}>5,000 \mathrm{ppm}$ in food for mallard ducks and bobwhite quail) (EPA 1992).

Risks are predicted from chlorpyrifos and diazinon for the black-capped chickadee (typical and maximum scenarios), and song sparrow and northwestern gartersnake (maximum scenario only).

Dimethoate was estimated to present risks to the mallard duck and song sparrow in the typical scenario, and to the mallard duck, red-tailed hawk, song sparrow, rough-skinned newt, and northwestern gartersnake in the maximum scenario. 


\section{Table 4.7-2. Summary of Scenarios with Predicted Non-Target Species Risks Under Alternative A}

\section{Chemical}

Scenario

Species

Risk*

Risks to General Terrestrial Wildlife

\begin{tabular}{|c|c|c|c|}
\hline \multirow[t]{3}{*}{ Chlorpyrifos } & \multirow[t]{3}{*}{ High-pressure hydraulic sprayer } & Black-capped chickadee & $\begin{array}{l}Q=1.84 \text { (typical) } \\
\text { and } 7.59 \text { (maximum) }\end{array}$ \\
\hline & & Song sparrow & $Q=0.657$ (maximum) \\
\hline & & Northwestern gartersnake & $Q=0.573$ (maximum) \\
\hline \multirow[t]{4}{*}{ Diazinon } & \multirow[t]{4}{*}{ High-pressure hydraulic sprayer } & Black-capped chickadee & $\begin{array}{l}\mathrm{Q}=2.02 \text { (typical) } \\
\text { and } 25.1 \text { (maximum) }\end{array}$ \\
\hline & & Mallard duck & $\mathrm{Q}=0.612$ (maximum) \\
\hline & & Song sparrow & $Q=1.68$ (maximum) \\
\hline & & Northwestern gartersnake & $\mathrm{Q}=2.06$ (maximum) \\
\hline \multirow[t]{5}{*}{ Dimethoate } & \multirow[t]{5}{*}{ High-pressure hydraulic sprayer } & Mallard duck & $\begin{array}{l}Q=1.52 \text { (typical) } \\
\text { and } 9.51 \text { (maximum) }\end{array}$ \\
\hline & & Song sparrow & $\begin{array}{l}Q=1.65 \text { (typical) } \\
\text { and } 10.4 \text { (maximum) }\end{array}$ \\
\hline & & Red-tailed hawk & $\mathrm{Q}=0.512$ (maximum) \\
\hline & & Rough-skinned newt & $\mathrm{Q}=2.57$ (maximum) \\
\hline & & Northwestern gartersnake & $\mathrm{Q}=5.15$ (maximum) \\
\hline \multicolumn{4}{|c|}{ Risks to Special Status Terrestrial Species } \\
\hline Acephate & High-pressure hydraulic sprayer & Little willow flycatcher & $Q=0.124$ (maximum) \\
\hline \multirow[t]{3}{*}{ Chlorpyrifos } & \multirow[t]{3}{*}{ High-pressure hydraulic sprayer } & Western bluebird & $\begin{array}{l}Q=0.223 \text { (typical) } \\
\text { and } 1.07 \text { (maximum) }\end{array}$ \\
\hline & & Little willow flycatcher & $\begin{array}{l}Q=1.71 \text { (typical) } \\
\text { and } 7.03 \text { (maximum) }\end{array}$ \\
\hline & & Purple martin & $\mathrm{Q}=0.143$ (maximum) \\
\hline \multirow[t]{5}{*}{ Diazinon } & \multirow[t]{5}{*}{ High-pressure hydraulic sprayer } & Western bluebird & $\begin{array}{l}Q=0.294 \text { (typical) } \\
\text { and } 3.58 \text { (maximum) }\end{array}$ \\
\hline & & Little willow flycatcher & $\begin{array}{l}\mathrm{Q}=2.25 \text { (typical) } \\
\text { and } 23.2 \text { (maximum) }\end{array}$ \\
\hline & & Bald eagle & $\mathrm{Q}=0.125$ (maximum) \\
\hline & & Spotted owl & $\mathrm{Q}=0.233$ (maximum) \\
\hline & & Purple martin & $\mathrm{Q}=0.521$ (maximum) \\
\hline \multirow[t]{9}{*}{ Dimethoate } & \multirow[t]{9}{*}{ High-pressure hydraulic sprayer } & Western bluebird & $\begin{array}{l}Q=1.52 \text { (typical) } \\
\text { and } 9.51 \text { (maximum) }\end{array}$ \\
\hline & & Little willow flycatcher & $\begin{array}{l}\mathrm{Q}=11.6 \text { (typical) } \\
\text { and } 62.5 \text { (maximum) }\end{array}$ \\
\hline & & Northern red-legged frog & $\begin{array}{l}\mathrm{Q}=0.875 \text { (typical) } \\
\text { and } 4.33 \text { (maximum) }\end{array}$ \\
\hline & & Long-eared myotis & $\mathrm{Q}=0.144$ (maximum) \\
\hline & & Yuma myotis & $\mathrm{Q}=0.153$ (maximum) \\
\hline & & $\begin{array}{l}\text { Pacific western big-eared } \\
\text { bat }\end{array}$ & $Q=0.124($ maximum $)$ \\
\hline & & Bald eagle & $\mathrm{Q}=0.308$ (maximum) \\
\hline & & Spotted owl & $\mathrm{Q}=0.581$ (maximum) \\
\hline & & Purple martin & $\mathrm{Q}=1.36$ (maximum) \\
\hline
\end{tabular}


Table 4.7-2. Summary of Scenarios with Predicted Non-Target Species Risks Under Alternative A (continued)

\begin{tabular}{|l|l|l|l|}
\hline Chemical & Scenario & Species & Risk $^{*}$ \\
\hline Horticultural oil & High-pressure hydraulic sprayer & Little willow flycatcher & $\mathrm{Q}=0.157$ (maximum) \\
\hline $\begin{array}{l}\text { Triclopyr } \\
\text { triethylamine salt }\end{array}$ & $\begin{array}{l}\text { Hydraulic sprayer with hand-held } \\
\text { wand }\end{array}$ & Little willow flycatcher & $\mathrm{Q}=0.124$ (maximum) \\
\cline { 2 - 4 } & Tractor-pulled spray rig with boom & Little willow flycatcher & $\mathrm{Q}=0.124$ (maximum) \\
\cline { 2 - 4 } & Backpack sprayer & Little willow flycatcher & $\mathrm{Q}=0.124$ (maximum) \\
\hline \multirow{2}{*}{$\begin{array}{l}\text { Triclopyr } \\
\text { butoxyethyl ester }\end{array}$} & $\begin{array}{l}\text { Hydraulic sprayer with hand-held } \\
\text { wand }\end{array}$ & Little willow flycatcher & $\mathrm{Q}=0.295$ (maximum) \\
\cline { 2 - 4 } & Tractor-pulled spray rig with boom & Little willow flycatcher & $\mathrm{Q}=0.295$ (maximum) \\
\cline { 2 - 4 } & Backpack sprayer & Little willow flycatcher & $\mathrm{Q}=0.295$ (maximum) \\
\hline Risks to General Aquatic Wildlife & & $\begin{array}{l}\text { Rainbow trout in onsite } \\
\text { streams }\end{array}$ & $\mathrm{Q}=0.646$ (maximum) \\
\hline $\begin{array}{l}\text { Ammonium } \\
\text { phosphate-sulfate }\end{array}$ & General fertilization & & \\
\hline
\end{tabular}

Risks to Special Status Aquatic Species

\begin{tabular}{|l|l|l|l|}
\hline $\begin{array}{l}\text { Ammonium } \\
\text { phosphate-sulfate }\end{array}$ & General fertilization & $\begin{array}{l}\text { Northern red-legged frog } \\
\text { tadpole in onsite streams }\end{array}$ & $\mathrm{Q}=0.192$ (maximum) \\
\cline { 3 - 4 } & \begin{tabular}{ll} 
Coho salmon in Stream 8 \\
\cline { 3 - 4 }
\end{tabular} & $\begin{array}{l}\text { Coho salmon in Douglas } \\
\text { Creek }\end{array}$ & $\mathrm{Q}=0.362$ (maximum) \\
\hline
\end{tabular}

*Risks are predicted for general terrestrial species if $Q>0.5$; for special status terrestrial species if $Q>0.1$; for general aquatic species if $Q>$ 0.5 , and for special status aquatic species if $Q>0.05$.

In most cases, little or no adverse impact to terrestrial wildlife populations is expected from the pesticides and fertilizers proposed for use at Tyrrell under typical conditions of use, with the possible exception of impacts to some bird species from applications of three of the insecticides (chlorpyrifos, diazinon, and dimethoate). Most of the estimated doses are extremely low, with risk quotients several orders of magnitude below the levels of concern. A margin for error is provided by the methodology applied, which uses reasonable assumptions that tend toward overstating potential exposures to wildlife, in the absence of site-specific data on potential exposure patterns. In addition, the chemicals have relatively short half-lives and are not expected to remain in the environment for significant periods of time: two herbicides (hexazinone and picloram) have soil half-lives in the five to six month range, while the rest of the pesticides' soil and foliar half-lives are less than three months.

Although some terrestrial insects onsite may be affected by the insecticide applications, and may constitute a portion of the dose to insectivorous species, populations of beneficial insects as a whole are not expected to suffer adverse impacts because the proposed seed orchard applications are localized. Although honeybees and other pollinators are generally susceptible to insecticides, including the biological insecticide B.t., the protection measures that are part of all alternatives include practices to minimize potential exposures; see Section 2.3.1. If an insecticide temporarily reduces the population of non-target insects in and around the orchards, the food supply for nesting insectivorous birds would also decline. They would have to forage elsewhere until the insect population at the orchard has recovered. Because of the limited areas that would be treated and the availability of adjacent untreated lands to support non-target insect populations, this would not be expected to result in any reduction in vigor or productivity in these bird species. 
It appears that insecticide applications may have adverse impacts on local earthworm populations (see discussion in Section 9.2.1 of the risk assessment report). However, any possible impacts are expected to be reversible, given that these chemicals are not persistent in the soil and that limited areas would be treated only on an as-needed basis in any growing season, allowing for re-population from adjacent untreated areas.

\section{Risks to Special Status Terrestrial Species}

Risks are predicted to the little willow flycatcher from acephate or horticultural oil used as a foliar spray, and all triclopyr applications, in the maximum scenarios.

Risks are predicted from chlorpyrifos for the western bluebird and little willow flycatcher in the typical scenario, and to the purple martin, western bluebird, and little willow flycatcher in the maximum scenario.

Diazinon was estimated to present risks to the western bluebird and little willow flycatcher in the typical scenario, and to the bald eagle, spotted owl, purple martin, western bluebird, and little willow flycatcher in the maximum scenario.

Dimethoate is associated with risk for the western bluebird, little willow flycatcher, and northern red-legged frog in the typical scenario, and for all special status terrestrial species in the maximum scenario.

The western bluebird was predicted to have a risk from fertilizer applications of ammonium phosphate-sulfate in the maximum scenario.

In summary, typical conditions of application using the insecticides chlorpyrifos, diazinon, or dimethoate may present risks to some special status terrestrial species.

\section{Risks from Accidents}

Risks are predicted for all terrestrial species except the deer, coyote, and bobcat in the accident scenario in which an animal ingests an acephate implant capsule.

\subsubsection{Aquatic Species}

Since biological, cultural, and prescribed fire methods are expected to have no significant impacts to surface water (as discussed in Section 4.4.2.2), no impacts to aquatic species would occur from the use of those methods.

\section{Risks to General Aquatic Species}

With the exception of ammonia from ammonium phosphate-sulfate in the maximum scenario, no risks were predicted for coldwater fish species (represented by rainbow trout) in onsite streams, Douglas Creek, Stream 8, or the Siuslaw River. No risks were predicted for aquatic invertebrates from any pesticides or fertilizers in the quantitative risk assessment.

Laboratory toxicity studies and field observations indicate that B.t. would not have any adverse effect on fish species (EPA 1998a). However, moderate toxicity to the water flea Daphnia magna (EPA 1998a) indicates that some impacts to aquatic invertebrates could be possible if the biological insecticide entered surface water. Such impacts would be expected to be localized and temporary, since the bacterium does not proliferate in aquatic habitats. Buffer zones and other standard protection measures (see Chapter 2) would minimize the potential for any surface water contamination. 
The insecticide imidacloprid, which was not previously analyzed, is proposed for use only in the form of a capsule implanted directly into a tree. Movement of imidacloprid is restricted to the vascular system of the tree. The potential for imidacloprid to enter air, soil, or water is negligible when using capsules. Although imidacloprid residues have been found in leaves and needles following capsule application, vegetation buffers, which are a minimum of 40 feet between potentially treated trees and live water, would be expected to intercept needles or leaves that may fall from treated trees. (Observation of fallen needles within orchard units indicates that needles generally fall close to the drip line of trees and are held within the dense grass cover crop once they become wet.) With a 96-hour $\mathrm{LC}_{50}$ of $211 \mathrm{mg} / \mathrm{L}$ reported for rainbow trout and a 48-hour $\mathrm{LC}_{50}$ of 85 $\mathrm{mg} / \mathrm{L}$ reported for the water flea Daphnia magna, toxicity to aquatic species is expected to be low (Extoxnet 2003). Therefore, in the unlikely process by which any residues could be moved by needle drop $\rightarrow$ weathering $\rightarrow$ runoff $\rightarrow$ downstream transport, the resulting concentrations would be expected to be many orders of magnitude below those associated with any type of effect on aquatic species.

Soap salts such as potassium salts of fatty acids, the active ingredient in Safer ${ }^{\circledR}$ Insecticidal Soap, are only slightly toxic to fish, but are highly toxic to aquatic invertebrates (EPA 1992). However, they are not applied directly to water in the proposed seed orchard IPM program, nor in any other labeled uses of this product. Their quick (less than one day) degradation and low-impact application methods (spraying individual trees in managed orchard units) would be associated with little opportunity for transport to surface water, and thus they would pose little risk to aquatic species.

\section{Risks to Special Status Aquatic Species}

\section{Risk of Lethal Effects}

In the lethality effects evaluation contained in the risk assessment (summarized in Appendix C), no risks to coho salmon in Stream 8 and Douglas Creek or to northern red-legged frog tadpoles in onsite streams were predicted under typical scenario assumptions. Coho salmon in Douglas Creek and Stream 8 were predicted to be at risk from ammonia under maximum scenario runoff conditions (saturated soils plus a large storm) for application of fertilizer. Tadpoles of the northern red-legged frog in onsite streams were also predicted to be at risk from ammonia in runoff from fertilizer in the maximum scenario.

\section{Risk of Sublethal Effects}

The risk analysis of sublethal effects to special status aquatic species is presented in Appendix D and summarized in the following paragraphs.

For all of the proposed insecticides, including the biological insecticide B.t., it is conceivable there could be a localized loss of part of the insect food source for fish species due to drift or runoff to streams. However, any chemical presence and associated decrease in non-target aquatic insect populations would be temporary and localized; insects would be expected to quickly re-populate from upstream areas. Therefore, no indirect effects to fish from loss of insect food sources are expected. Additionally, no adverse effects were predicted for aquatic invertebrates in the general aquatic species analysis, so no impacts to food sources for special status fish are expected.

Typical and maximum applications of B.t., organophosphates, and organosulfites are expected to present low risks to special status aquatic species in all surface waters for the sublethal effects evaluated (survival, migration, and reproduction). 
For pyrethroids, risks to special status species of these sublethal effects from typical applications are low in all surface waters. For maximum scenario applications of pyrethroid insecticides, potential risks to the survival endpoints evaluated are low in Douglas Creek and the Siuslaw River, and moderate in Stream 8. The potential risks from maximum scenario pyrethroid applications to migration endpoints are low in all surface waters. Risks from maximum scenario pyrethroid applications to reproductive endpoints are low in the Siuslaw River, moderate in Douglas Creek, and high in Stream 8.

Typical and maximum applications of all herbicides, fungicides and fumigant, other pesticides, and other ("inert") ingredients are expected to have low risk in all streams for all sublethal effects evaluated.

Typical applications of fertilizer are associated with low risk in all streams for the biological end points evaluated. Under maximum scenario runoff conditions, general orchard fertilization is predicted to pose low risk in all surface waters, except for a moderate risk of ammonium or nitrate toxicity in Stream 8.

Spawning of salmonid species such as steelhead and cutthroat may result in their eggs and larvae being present in gravel in streams at times when insecticide spraying is more likely to occur. In drawing conclusions about the potential for risk, both the lethal and sublethal effects analyses utilized the most sensitive toxicity data points (including data for the most sensitive life stage), and assumed that fish species would be present at the time of pesticide application.

\section{Risks from Accidental Spills}

Aquatic species are at risk of lethal effects from spills of concentrate containing chlorpyrifos, diazinon, dimethoate, esfenvalerate, horticultural oil, permethrin, propargite, chlorothalonil, glyphosate, triclopyr butoxyethyl ester, and dazomet; and from ammonium phosphate-sulfate fertilizer. They are at risk of lethal effects from tank mix spills containing chlorpyrifos, diazinon, dimethoate, esfenvalerate, permethrin, propargite, chlorothalonil, glyphosate, picloram, triclopyr, and dazomet; and from an application truckload of ammonium phosphate-sulfate fertilizer. All species in Douglas Creek would be at risk of lethal effects from an aerial spill of esfenvalerate into one of its tributaries. The details of the modeled accidental spills are presented in Section 3.2.5 of the risk assessment report.

\subsubsection{Potential Impacts of Alternative B-IPM with Environmental Protection Emphasis (Proposed Action)}

Alternative B was designed in response to the results of the quantitative risk assessment, by incorporating limitations to specifically address any risks from applications under Alternative A (which are summarized in Table 4.7-2). The risks from Alternative A (from Table 4.7-2) and the corresponding limitations that address the risks (from Section 2.3.3) are correlated in Table 4.7-3. With these risk-responsive limitations as an integral part of Alternative B, no adverse effects to terrestrial wildlife or to aquatic species, including special status fish species, are expected from the use of chemical pesticides under this alternative. The western bluebird was predicted to have a risk from fertilizer applications of ammonium phosphate-sulfate in the maximum scenario.

No lethal or sublethal risks for aquatic species were identified from pesticides in typical use conditions, nor lethal risks in maximum conditions, under Alternative $A$; therefore, no limitations to pesticide application for aquatic species protection are listed in Table 4.7-3, which presents only those limitations that specifically respond to risks identified under Alternative A. However, Alternative B does include limitations that would provide additional protection to aquatic species by limiting the potential for drift or 
Table 4.7-3. Risk-Responsive Limitations to Protect Ecological Resources Under Alternative B

\begin{tabular}{|c|c|c|c|}
\hline \multicolumn{3}{|c|}{ Identified Risk from Alternative A } & \multirow{2}{*}{$\begin{array}{l}\text { Alternative B Limitation } \\
\text { that Addresses Risk }\end{array}$} \\
\hline Chemical & Scenario & Species & \\
\hline Acephate & $\begin{array}{l}\text { High- } \\
\text { pressure } \\
\text { hydraulic } \\
\text { sprayer }\end{array}$ & Little willow flycatcher & $\begin{array}{l}\text { Would not be applied within } 40 \text { feet of either a bird } \\
\text { box (unless the bird box is empty and covered with a } \\
\text { plastic bag during spraying) or the edge of a managed } \\
\text { orchard unit (the distance associated with no drift } \\
\text { from the proposed application methods). No more } \\
\text { than } 40 \text { trees per acre would be treated (at } 0.01 \mathrm{lb} \text { a.i. } \\
\text { per tree) in any 16-day period. }\end{array}$ \\
\hline Chlorpyrifos & $\begin{array}{l}\text { High- } \\
\text { pressure } \\
\text { hydraulic } \\
\text { sprayer }\end{array}$ & $\begin{array}{l}\text { Seed-eating birds, reptiles, } \\
\text { western bluebird, little willow } \\
\text { flycatcher, purple martin }\end{array}$ & $\begin{array}{l}\text { Would not be applied within } 40 \text { feet of either a bird } \\
\text { box (unless the bird box is empty and covered with a } \\
\text { plastic bag during spraying) or the edge of a managed } \\
\text { orchard unit (the distance associated with no drift } \\
\text { from the proposed application methods). Within } \\
\text { a } 14 \text {-day period, it would not be applied to more } \\
\text { than } 150 \text { trees at a rate of } 0.02 \mathrm{lb} \text { a.i. per tree (nor } \\
\text { combination of number of trees and application rate } \\
\text { more than } 3 \mathrm{lb} \text { a.i. total applied) in any twelve-acre } \\
\text { area, nor to more than } 22 \text { trees (at } 0.02 \mathrm{lb} \text { a.i. per tree) } \\
\text { in any one-acre area. }\end{array}$ \\
\hline Diazinon & $\begin{array}{l}\text { High- } \\
\text { pressure } \\
\text { hydraulic } \\
\text { sprayer }\end{array}$ & $\begin{array}{l}\text { Seed-eating birds, water fowl, } \\
\text { reptiles, western bluebird, little } \\
\text { willow flycatcher, bald eagle, } \\
\text { spotted owl, purple martin }\end{array}$ & $\begin{array}{l}\text { Would not be applied within } 40 \text { feet of either a bird } \\
\text { box (unless the bird box is empty and covered with a } \\
\text { plastic bag during spraying) or the edge of a managed } \\
\text { orchard unit (the distance associated with no drift } \\
\text { from the proposed application methods). Within an } \\
11 \text {-day period, it would not be applied to more than } \\
150 \text { trees at a rate of } 0.015 \mathrm{lb} \text { a.i. per tree (nor any } \\
\text { combination of number of trees and application rate } \\
\text { more than } 2.25 \mathrm{lb} \text { a.i. total applied) in any twelve-acre } \\
\text { area, nor to more than } 17 \text { trees (at } 0.015 \mathrm{lb} \text { a.i. per tree) } \\
\text { in any one-acre area. }\end{array}$ \\
\hline Horticultural oil & $\begin{array}{l}\text { High- } \\
\text { pressure } \\
\text { hydraulic } \\
\text { sprayer }\end{array}$ & Little willow flycatcher & $\begin{array}{l}\text { Would not be applied at rate greater than } 0.03 \text { gallons } \\
\text { per tree. }\end{array}$ \\
\hline $\begin{array}{l}\text { Triclopyr } \\
\text { triethylamine salt }\end{array}$ & All methods & Little willow flycatcher & $\begin{array}{l}\text { Would not be applied at rate greater than } 7.2 \mathrm{lb} \text { a.i. per } \\
\text { acre. }\end{array}$ \\
\hline $\begin{array}{l}\text { Triclopyr } \\
\text { butoxyethyl ester }\end{array}$ & All methods & Little willow flycatcher & $\begin{array}{l}\text { Would not be applied at rate greater than } 2.6 \mathrm{lb} \text { a.i. per } \\
\text { acre. }\end{array}$ \\
\hline Fertilizer & All methods & $\begin{array}{l}\text { General fish species and northern } \\
\text { red-legged frog tadpoles in onsite } \\
\text { streams, coho salmon in Stream } 8 \\
\text { and Douglas Creek. }\end{array}$ & $\begin{array}{l}\text { Application of general fertilization at maximum rates } \\
\text { ( } 1,000 \mathrm{lb} / \text { acre) would be preceded by soil aeration } \\
\text { to encourage downward movement (as opposed to } \\
\text { runoff) of fertilizer in the case of an unpredicted large } \\
\text { storm event. }\end{array}$ \\
\hline
\end{tabular}


runoff to surface water, based on the input of interdisciplinary team members; see Section 2.3.3. Under maximum scenario runoff conditions, there may still be risks from fertilizers to general fish species and special status amphibians in onsite streams, and to coho salmon in Stream 8 and Douglas Creek. However, these risks would be decreased compared to Alternative A by requiring that soils be aerated prior to fertilizer use if the maximum applications rate was planned, to encourage downward movement of precipitation (instead of runoff). Additionally, a maximum of two (instead of three) aerial esfenvalerate applications would be possible in any year, which is expected to decrease the sublethal risk prediction for reproductive effects to coho salmon in Stream 8 from the "high" to the "moderate" or "low" range.

BLM's Biological Assessment concluded that it is unlikely that surface waters utilized by Oregon Coast coho salmon would be contaminated at levels high enough to result in either lethal or sublethal effects, and therefore implementation of the proposed IPM alternative may affect, but is not likely to adversely affect, Oregon Coast coho salmon. NOAA Fisheries responded with a conference opinion concluding that the proposed action is not likely to jeopardize the continued existence of Oregon Coast coho salmon; the opinion specified reasonable and prudent measures, with associated terms and conditions, to further protect the species. The terms and conditions in the conference opinion do not become effective until NMFS adopts the conference opinion as a biological opinion, after the listing becomes final. However, BLM will implement the terms and conditions associated with reasonable and prudent measures 1 through 4 to conserve EFH. See Section 2.3.3 for additional details

Should an accidental spill to surface water occur, the risks from that accident would be the same as those identified under Alternative A.

Risks from biological, prescribed fire, and cultural methods of pest control are the same as under Alternative A.

\subsubsection{Potential Impacts of Alternative C-Ground-Based IPM}

Since no risks are predicted under Alternative B for terrestrial or aquatic wildlife species that are specific to aerial application, the omission of that method from the alternative does not change the risks. The risks from Alternative $C$ would be the same as from Alternative B: no risks to terrestrial or aquatic wildlife, including special status species, from chemical pesticides except in the case of accidents; risks to the western bluebird under maximum scenario assumptions for fertilizer applications; and possible risks to aquatic species from fertilizers under maximum scenario runoff conditions. Risks from biological, prescribed fire, and cultural methods of pest control are the same as under Alternative A.

\subsubsection{Potential Impacts of Alternative D-Non-Pesticide Pest Management}

Under Alternative D, there would be no risks from pesticides since they would not be used. The western bluebird was predicted to have a risk from fertilizer applications of ammonium phosphate-sulfate in the maximum scenario. As discussed under Alternative A, no risks to non-target species from biological, cultural, or prescribed fire control methods would be expected from their use in a IPM program at Tyrrell.

\subsubsection{Potential Impacts of Alternative E-No Action: Continue Current Management Approach}

If BLM continued its current management approach, risks would be intermediate between Alternative A and Alternative D. Pesticides would likely be used less frequently, due to the need to conduct individual NEPA analyses for each project. Therefore, the potential for risks from pesticides, including accidents, would be lower. Risks from biological, prescribed fire, and cultural methods of pest control would be higher than 
under Alternatives A, B, or C, due to their increased use compared to those alternatives. Risks from fertilizers would be the same as described under Alternative A.

\subsection{Noise}

The proposed action or an alternative could produce occasional short-term impacts on the noise environment, but the impacts would not be significant. Alternatives A and $\mathrm{B}$ would include occasional helicopter noise from aerial applications; however, the impacts would not be significant since these applications would only occur a few days per year. Ground equipment noise associated with any pest management alternative would not significantly influence the noise environment, because the noise generated would be intermittent and would occur during daytime hours, would be attenuated by the equipment's distance from noise receptors, and would be indistinguishable from the use of the same or similar equipment for non-pest management activities. Under the no action alternative, noise levels would be unchanged.

\subsubsection{Analysis Approach and Assumptions}

The analysis of noise impacts involved assessing the estimated noise levels from the proposed action and alternatives, comparing them with ambient noise levels, and identifying the presence of any sensitive receptors near the seed orchard. Maps of the Tyrrell vicinity were used to determine the locations of possible sensitive receptors.

Noise perception and annoyance to the public depend on the intensity of the sound (measured in $\mathrm{dB}$ ), the frequency of the sound (high or low pitch), and the duration of the noise (steady, intermittent, or impulsive (sudden)). For single noise events, an increase of $3 \mathrm{~dB}$ is perceived by most people as barely louder. An increase of $6 \mathrm{~dB}$ is perceived as noticeably louder, and an increase of $10 \mathrm{~dB}$ is perceived as twice as loud (Cavanaugh 1998).

Aircraft noise is usually perceived as louder because of its frequency. Sudden impulsive sounds are also perceived as louder (FAA 1985). Helicopters generate a distinct noise which is a mixture of noise from many sources: engine, aerodynamics, main rotor, tail rotor and interaction of the vortices created by the two rotors. Blade slap is typically annoying, but it is not present in some maneuvers, speeds, and rotor configurations (HDOT 1994). A helicopter flying overhead at an altitude of 30 feet produces $85 \mathrm{~dB}$ at a distance of 600 feet.

There are two basic considerations for protecting the community from increased noise from short-term sources. To protect human health, noise levels must not exceed limits identified with potential loss of hearing. An $L_{\text {eq }}$ of $73 \mathrm{~dB}$ sustained over 8 hours for 250 days or more per year can cause hearing loss to a general population over a prolonged time period (about 40 years) (EPA 1974). The other consideration for protecting the public is noise interference with activity, or annoyance. This depends upon the setting in which the increased noise takes place, for both indoor and outdoor activities. Thresholds for various uses vary from $45 \mathrm{~L}_{\mathrm{eq}}$ (averaged over 24 hours) within residences and other locations based on a quiet use, to $70 \mathrm{~L}_{\mathrm{eq}}$ (averaged over 24 hours) for outdoor exposure in recreational areas (EPA 1974). Communities that typically experience higher noise levels tolerate higher increases in noise (typically $5 \mathrm{~dB}$ more without complaints).

The impact on the noise environment is related to the magnitude of the noise levels and the proximity of noise-sensitive receptors to the noise source. Increasing the $\mathrm{L}_{\mathrm{eq}}$ (averaged over 24 hours) to $73 \mathrm{~dB}$ or above for one year or more could be a significant impact, as this could potentially cause hearing loss in a portion of the general public. If noise levels increased, but affected noise-sensitive receptors to a level below $73 \mathrm{~L}_{\text {eq }}$, the impact would not be significant. A decrease in noise levels would be a beneficial impact. 


\subsubsection{Potential Impacts of Alternative A-Maximum Production IPM}

Normal background noise levels average about $45 \mathrm{dBA}$ at Tyrrell and in the surrounding area. The ground-based IPM activities associated with Alternative A (tractors and other equipment) would negligibly increase noise levels at Tyrrell for short periods, and the type of noise impact would be similar to the current noise environment at Tyrrell. As noted in Table 3.8-2, at 1,600 feet away from the noise source, composite noise would attenuate to the area's ambient noise level.

Alternative A also includes aerial insecticide and fertilization applications. Tyrrell would use helicopters for insecticide applications at most six times per year (potentially three esfenvalerate applications and three B.t. applications) during normal working hours, and the duration of each application would not exceed a few hours. Aerial fertilization would be conducted over a two-day period for about six hours each day. This occasional helicopter use, which would be similar to that on adjacent privately-owned timber lands, would increase noise levels in and around the orchard during the operations and could produce short-term annoyance among nearby residents, but impacts would be insignificant. Livestock on neighboring lands could experience minor startle effects during helicopter operations, but impacts to livestock would also be insignificant because of the infrequency and short duration of helicopter events.

There are no sensitive receptors within 1,000 feet of the seed orchard. There would be no significant noise impacts.

\subsubsection{Potential Impacts of Alternative B-IPM with Environmental Protection Emphasis (Proposed Action)}

Under Alternative B, which includes both ground-based and aerial applications, impacts would be essentially the same type as under Alternative A, but could be slightly less if equipment use were reduced. Noise impacts would be insignificant.

\subsubsection{Potential Impacts of Alternative C-Ground-Based IPM}

Under Alternative $C$, only ground-based applications would be used for pesticide and fertilizer applications. Noise impacts for ground equipment would be the same as under Alternative B. Noise impacts would be insignificant.

\subsubsection{Potential Impacts of Alternative D-Non-Pesticide Pest Management}

Under Alternative D, no pesticides would be used, and noise impacts could be similar to or less than the impacts under Alternative $C$, depending on the types of mechanical control used. The only helicopter noise would be from potential aerial application of fertilizers. Noise impacts would be insignificant.

\subsubsection{Potential Impacts of Alternative E-No Action: Continue Current Management Approach}

Under Alternative E, the current insignificant noise impacts would continue. Before BLM applied any pesticides, including by helicopter, an EA would be prepared to determine potential impacts of that application, and would include an assessment of potential noise impacts to the area, if appropriate. 


\subsection{Cultural Resources}

Cultural resources are limited, nonrenewable resources whose values may easily be diminished by physical disturbances. There are no important cultural resources at Tyrrell, where the grounds have been disturbed by orchard operations over the years. The proposed action and alternatives include no construction or excavation activities that could disturb any undiscovered cultural resources either on or adjacent to the orchard. There would be no impacts to cultural resources from any alternative.

\subsubsection{Analysis Approach and Assumptions}

To determine potential impacts, the analysis focused on the types of activities that would occur, the location where they would occur, and the significance of the resource in that location. NEPA documents and past archaeological and historic resources surveys were reviewed. BLM and the State Historic Preservation Office (SHPO) were consulted for the latest information concerning cultural resources on the seed orchard.

The criteria used to determine the significance of impacts on cultural resources includes the effects on eligibility for the National Register of Historic Places (NRHP), future research potential, or suitability for religious or traditional uses. An impact could be significant if it resulted in the physical alteration, destruction, or loss of a resource listed or eligible for listing in the NRHP. An adverse impact could not be significant if only slight portions of the resource were affected or if the value of the resource was not important. The impact of the action could be beneficial if it protected or reconstructed the resource.

\subsubsection{Potential Impacts of All Actions}

As noted in Section 3.9, a single bifacially worked fragment was discovered during a 1983 cultural resource survey. This artifact has been recorded and requires no further action. No other important cultural resources have been identified at Tyrrell, where the grounds have been disturbed by orchard operations over the years. There are no nearby Native American religious sites. Neither the proposed action nor any alternative includes construction or excavation activities that could disturb any undiscovered cultural resources either on or adjacent to the orchard. There would be no impacts to cultural resources from any alternative.

In the unlikely event that archaeological materials were encountered during project activities, work in that location would cease until the artifacts were evaluated by a qualified archaeologist, and the BLM had consulted with the Oregon SHPO if applicable.

\subsection{Socioeconomics and Environmental Justice}

Socioeconomic impacts are generally related to changes in an area's population, number of jobs, employment structure, or income. No population or employment impacts are projected for the proposed action or any alternative at Tyrrell. However, income in the ROI could be affected by changes in the land's productivity or value, or in the marketability of its products. There are three possible factors that would lead to economic impacts: offsite pesticide transport to a neighboring land parcel used for organic farming; decreased production on and adjacent to the seed orchard if pest control methods are not successful; and pest infestation on and adjacent to the seed orchard if pest control methods are not successful. The potential for impacts to the organic farm is negligible, with the probability for impact slightly higher under Alternative A. Decreased production is least likely under Alternative A, and increases successively with Alternatives B and C having a similar effect, and Alternative D 
having the greatest potential for this impact. Economic loss from uncontrolled pest infestation is most likely under Alternative D, and is unlikely under Alternatives A, B, or $C$. Overall, socioeconomic and environmental justice impacts would be insignificant under Alternatives A, B, C, or D. Similarly, under Alternative E (no action), the current insignificant impacts would be unchanged.

\subsubsection{Analysis Approach and Assumptions}

Measures used for impact analysis include population, employment, and income. The analysis used population data from the USBC, and employment and income data from the U.S. Bureau of Economic Analysis and the Oregon Employment Department. To predict impacts to socioeconomic resources in a given ROI, significance criteria were determined by analyzing long-term fluctuation in elements such as population, employment, and income within that ROI. This approach allows an ROI-specific determination of the appropriate levels, or thresholds, beyond which changes in an element would noticeably affect individuals and communities. The analysis compares each element's actual yearly change to the predicted amount of change, which, in turn, is based on the average annual change that has occurred over the long-term period used as a basis for the analysis (1980-2000). The annual deviations between actual change and predicted (average) change are the basis for determining a threshold of significance for each element. Regions are assumed to have a greater capacity for positive changegrowth-than for negative change; therefore, the negative income threshold is decreased by one-third to avoid understating impacts from actions that may result in a decline in income. Based on this methodology, a significant adverse impact for this ROI (Lane County) would be a decline of more than $7 \%$ in projected income as a result of an action assessed in this EIS. An increase in income would be considered beneficial. Since no employment or population changes are anticipated, no significance criteria were defined for those measures.

There are no disproportionate populations of low-income or minority persons, or children, in the areas surrounding Tyrrell. Therefore, no environmental justice impacts would occur under any alternative considered in this EIS.

\subsubsection{Potential Impacts of Alternative A-Maximum Production IPM}

Under Alternative A, the risk assessment predicted negligible contamination to neighboring land parcels (see Figure 3.5-1.) While the probability of pesticide drift contaminating adjacent parcels is extremely low, unforeseen weather conditions coupled with a failure to quickly respond to adverse conditions by ceasing the application could increase the possibility of such an impact. Economic impacts to individual parcels adjacent to Tyrrell would be insignificant, and the overall economic impacts of inadvertent contamination would be insignificant to the ROI.

Economic losses due to increases in insects or disease, or to pest infestation, are very unlikely. Impacts would be insignificant.

\subsubsection{Potential Impacts of Alternative B-IPM with Environmental Protection Emphasis (Proposed Action)}

Under the proposed action, the more controlled application procedures (see Section 2.3.3) would further reduce the risk of offsite pesticide transport to neighboring land parcels. The potential economic impacts to neighboring landowners from pesticide drift would be as described under Alternative A, but the likelihood for such impacts would be reduced. Production losses due to increases in insects or disease, or to pest infestation, are very unlikely. Impacts to income would be insignificant. 


\subsubsection{Potential Impacts of Alternative C-Ground-Based IPM}

Under Alternative C, socioeconomic impacts would be similar to those predicted for Alternative B. Although it is a common perception that aerial spraying has the greatest potential for off-site drift, the risk assessment modeling concluded that a ground-based method (airblast sprayer) had more potential for drift deposition at the distance to the organic farm, given the specific wind direction. The potential risk of economic loss from contaminating nearby land parcels would be negligible. The likelihood of production losses due to increases in insects or disease, or to pest infestation, is similar to Alternative B. Impacts to income would be insignificant.

\subsubsection{Potential Impacts of Alternative D-Non-Pesticide Pest Management}

Under Alternative D, no pesticides would be used, so there would be no possibility of pesticide transport to nearby land parcels. However, reduced production and / or pest infestation could result if non-pesticide pest control methods were not successful, resulting in economic losses. If the pest infestation were to spread from the seed orchard to neighboring land parcels whose crops were susceptible to those pests, those landowners would also suffer an economic loss. Although there could be localized economic losses, the overall impact to the ROI would be insignificant.

\subsubsection{Potential Impacts of Alternative E-No Action: Continue Current Management Approach}

Under Alternative E, the current insignificant economic impacts would continue. Before BLM undertook a pesticide application, an EA would be prepared to determine potential impacts of that application. The EA would include an assessment of the potential to contaminate neighboring land parcels and the consequent economic impacts.

\subsection{Cumulative Impacts}

According to CEQ regulations at 40 CFR 1508.7, "cumulative impact" is the impact on the environment that results from the incremental impact of the action when added to other past, present, and reasonably foreseeable future actions, regardless of what agency (Federal or non-Federal) or person undertakes such actions. Cumulative impacts can result from individually minor but collectively significant actions taking place over a period of time.

In terms of pesticide or fertilizer application on adjacent lands and in the watershed, private timber company operations and private individuals in the vicinity of the orchard may conduct treatments with many of the same chemicals as BLM proposes to use. Also, other pesticides and fertilizers may be used in agriculture, forestry, or industrial applications that might create an overall chemical burden in the orchard area. While the chemicals used in the proposed IPM program at Tyrrell are not expected to have an impact on water quality, streams that may receive some pesticide or fertilizer drift or runoff from the orchard also may be receiving drift or runoff of chemicals from other locations, and this cumulative burden may place the aquatic ecosystems at risk. However, significant adverse cumulative effects are not anticipated, since most of the surrounding land use is timber, with a small amount in agriculture (see Figure 3.5-1), and agriculture typically uses more pesticides than are used for timber. Timber operation pesticide use is mostly herbicides, not insecticides or fungicides. The herbicides are usually used only during the establishment phase of reforestation. Most of the timberlands surrounding Tyrrell have been recently harvested, and tree establishment has been completed on a majority of the acres. So there will be only small amounts of 
herbicides used in the coming years. Small landowners and upstream agriculture may use minimal amounts of insecticides and fungicides. Timber and agriculture lands may use some fertilizers as well.

The human health risk assessment addressed cumulative risk to members of the public and workers from all of the pesticides and fertilizers as proposed for use under Alternative A, and from the subset of pesticides that are more likely than others to be used in a given year. Since no data exist indicating synergistic toxicity among the pesticides proposed for use at Tyrrell, cumulative human health risks were estimated assuming additive toxicity. No risks to members of the public were predicted from these aggregated exposures. For workers, the highest cumulative exposure could occur if one employee was involved in all pesticide applications, with the exception of aerial applications, which are always conducted by a contractor. In this case, a risk of health effects is predicted, as the cumulative dose exceeds the acceptable level by a factor of 62.5 for noncarcinogenic effects, and the cumulative cancer risk is 1.96 in one million, which is slightly greater than the generally accepted level of one in one million. It is important to note that this cumulative risk scenario includes the unlikely case in which all pesticides that target every pest problem are called for during the season. The highest contributor to the cumulative hazard index is dimethoate, and the main contributor to the cancer risk is propargite. For the subset of pesticides more likely to be used, the aggregated worker risk exceeds the acceptable level by less than $10 \%$, which would be within the bounds of uncertainty in this type of analysis; and estimated cancer risk is far below the significance threshold. Actual cumulative risk values are likely to be less than the results estimated in this conservative analysis for the following reasons:

- It is highly unlikely that one individual would be exposed to every chemical in all of the scenarios evaluated in the risk assessment;

- Several pesticides are proposed for use as alternatives for certain groups of target pests or weeds, and if one were selected for use in a given season, the alternatives would not also be used;

- To avoid underestimating risk, where multiple application methods are possible for a proposed pesticide treatment scenario, the method with the highest associated risk was included in the cumulative assessment; and

- The temporal spacing of the potential chemical applications would correspond to a timeline in which some exposure routes were no longer active due to dissipation and degradation, prior to application of other chemicals.

\subsection{Mitigation Measures}

\section{Alternative A.}

Based on the results of the quantitative risk assessment, the selection of Alternative A, Maximum Production IPM, could result in environmental impacts to human health and biological resources. Therefore, $\mathrm{CEQ}^{\prime}$ s regulations for implementing NEPA require that potential mitigation measures be identified in this EIS. The following measures have been identified to mitigate the risks predicted for Alternative A:

- An individual applying diazinon using a high-pressure hydraulic sprayer would mix, load, and apply no more than $3.82 \mathrm{lb}$ a.i. total in one day.

- Dimethoate would be applied to no more than 22 trees in one day at a rate of $0.13 \mathrm{lb}$ a.i. per tree (nor any combination of number of trees and application rate more than $2.86 \mathrm{lb}$ a.i. total applied) by an individual using the high-pressure hydraulic sprayer, and an individual other than the applicator would conduct the mixing / loading 
activities. If more than one applicator sprayed trees during a single day, different mixer/loaders would prepare each pesticide mixture.

- An individual applying dicamba using a backpack sprayer would apply no more than $0.61 \mathrm{lb}$ a.i. during any given day.

- An individual applying hexazinone using a backpack sprayer would apply no more than $6.5 \mathrm{lb}$ a.i. during any given day.

- Application of chlorpyrifos, diazinon, dimethoate, or propargite to orchard trees would be scheduled so that a minimum of $20,17,27$, and 18 days would elapse, respectively, before routine cone surveying activities occurred in orchard units treated at the typical application rates listed in Table 2.2-1. If the maximum application rates listed in Table 2.2-1 were used, the elapsed time before cone surveying would be 27, 29 , and 32 days for chlorpyrifos, diazinon, and dimethoate, respectively.

- Chlorpyrifos would not be applied within 40 feet of either a bird box (unless the bird box is empty and covered with a plastic bag during spraying) or the edge of a managed orchard unit (the distance associated with no drift from the proposed application methods). Within a 14-day period, it would not be applied to more than 150 trees at a rate of $0.02 \mathrm{lb}$ a.i. per tree (nor combination of number of trees and application rate more than $3 \mathrm{lb}$ a.i. total applied) in any twelve-acre area, nor to more than 22 trees (at $0.02 \mathrm{lb}$ a.i. per tree) in any one-acre area.

- Diazinon would not be applied within 40 feet of either a bird box (unless the bird box is empty and covered with a plastic bag during spraying) or the edge of a managed orchard unit (the distance associated with no drift from the proposed application methods). Within an 11-day period, it would not be applied to more than 150 trees at a rate of $0.015 \mathrm{lb}$ a.i. per tree (nor any combination of number of trees and application rate more than $2.25 \mathrm{lb}$ a.i. total applied) in any twelve-acre area, nor to more than 17 trees (at $0.015 \mathrm{lb}$ a.i. per tree) in any one-acre area.

- Dimethoate would not be applied within 40 feet of either a bird box (unless the bird box is empty and covered with a plastic bag during spraying) or the edge of a managed orchard unit (the distance associated with no drift from the proposed application methods). It would not be applied to more than three trees in any one-acre area.

- When applied using a high-pressure hydraulic sprayer, acephate would not be applied within 40 feet of either a bird box (unless the bird box is empty and covered with a plastic bag during spraying) or the edge of a managed orchard unit (the distance associated with no drift from the proposed application methods). No more than 40 trees per acre would be treated (at $0.01 \mathrm{lb}$ a.i. per tree) in any 16-day period.

- Horticultural oil, triclopyr triethylamine salt, and triclopyr butoxyethyl ester would not be applied at rates greater than 0.03 gallons per tree, $7.2 \mathrm{lb}$ a.i. per acre, or $2.6 \mathrm{lb}$ a.i. per acre, respectively.

- Application of general fertilization at maximum rates (1,000 lb/acre) would be preceded by soil aeration to encourage downward movement (as opposed to runoff) of fertilizer in the case of an unpredicted large storm event.

\section{Alternatives $B$ and $C$.}

A potential mitigation measure is identified for BLM's proposed action: Alternative B, IPM with Environmental Protection Emphasis. To address the potential for sublethal effects to special status fish species from maximum scenario applications of pyrethroid insecticides, these pesticides would only be applied using the application rates 
and frequencies identified in the typical scenarios in Table 2.2-1. The design of this alternative, including the limitations specified in Section 2.3.3, are expected to address all potential risks identified in this EIS, with the exception of possible maximum scenario risks from fertilizers. These risks are only predicted for conditions in which soils are saturated and then a large storm event follows application, which is a situation with a very low probability of occurrence, representing the upper bound of the risk range estimated in the risk assessment. The identified limitation of requiring soil aeration will reduce, but may not completely avoid, the probability of this scenario occurring. During the ESA conference process, NOAA Fisheries identified additional terms and conditions to provide additional protection to coho salmon. The terms and conditions in the conference opinion do not become effective until NMFS adopts the conference opinion as a biological opinion, after the listing becomes final. However, BLM will implement the terms and conditions associated with reasonable and prudent measures 1 through 4 to conserve EFH. These requirements are listed in Section 2.3.3 of this Final EIS. Alternative $C$ (Ground-Based IPM) also incorporates all of the limitations identified for Alternative $\mathrm{B}$, so only the mitigation measure restricting pyrethroid applications to typical rates was identified for that alternative; this alternative was not included in the ESA conference process.

\section{Alternative D.}

The only significant impacts associated with Alternative D, Non-Pesticide Pest Management, are those from maximum scenario fertilization, as described in the preceding paragraph. No additional mitigation is identified for this risk other than as described above.

\section{Alternative E.}

Mitigation measures for use of pesticides under Alternative E, No Action, would be identified on a project-by-project basis during the specific NEPA assessments.

The ROD that will be published at the conclusion of the EIS process will specify the mitigation measures that will be implemented with the selected alternative.

\subsection{Unavoidable Adverse Impacts}

Any alternative would result in adverse environmental effects that cannot be avoided. Protection measures, limitations, and mitigation measures developed in this EIS are intended to reduce the extent and duration of these effects. However, adverse effects cannot be completely avoided. There are two areas under Alternative A where potential risk was identified from the use of some pesticides and fertilizers in certain situations: human health (workers) and ecological resources (wildlife/aquatics). Specifically, the human health risk assessment predicted some worker risk from the use of chlorpyrifos, diazinon, dimethoate, propiconazole, dicamba, and hexazinone in certain situations. In response to these identified risks, however, Alternative B was developed to limit chemical pesticide use such that these estimated worker and ecological risks would be reduced to negligible levels.

The ecological assessment predicted that the use of B.t. as a biological insecticide could impact populations of non-target beneficial insects in areas immediately adjacent to any treated orchard units. In addition, the use of pesticides could adversely impact bird species from application of chlorpyrifos, diazinon, and dimethoate, although most of the wildlife exposures are very low.

Under maximum application assumptions, risks from fertilizer are possible for fish and special status tadpole species in onsite streams, and to special status fish species in Douglas Creek and the main tributary to the Siuslaw River from Section 15 (Stream 8). An analysis of the potential for sublethal effects on special status fish species identified potential risks to reproductive endpoints from typical and maximum applications of pyrethroids, and from maximum applications of fungicides. Potential risks to migratory endpoints were also identified for pyrethroid applications under maximum scenario 
conditions. Survival endpoints were associated with potential risks from pyrethroids, fungicides, and ammonium and calcium nitrate fertilizers in maximum scenarios. As described previously, Alternative $B$ was designed in response to the risks identified for Alternative A, to limit chemical use and thereby reduce the estimated ecological risks to negligible levels.

There is also potential for additional adverse effects beyond those identified above. However, these also are expected to be negligible given the implementation of protection measures and limitations identified in this EIS. These include:

- Short-term reduction in air quality from dust and engine emissions resulting from IPM activities (power tools and mechanical equipment that burn fossil fuels, prescribed burning, and volatile and drift fraction of pesticides used in chemical methods);

- Temporary increase in fire hazard from waste material (dry vegetation) left on ground after treatment;

- Localized changes in terrestrial wildlife habitat;

- Temporary health effects from prescribed burning (eye, throat, lung irritation); and

- Localized lethal impacts to non-target insects from insecticide use, and to non-target plants from herbicide use.

The potential for adverse effects varies with each alternative and is discussed in greater detail in earlier sections of this chapter. Adherence to protection measures (and, for Alternatives B and C, limitations) would minimize the potential for any adverse environmental effects.

\subsection{Relationship Between Short-Term Uses Versus Long-Term Productivity}

Short-Term uses are generally those that determine the present quality of life for the public, including BLM orchard employees. The short-term use of the orchard is to produce improved seed for conifer seedling production, preserve individual valuable conifer trees, and produce native species plants and plant species seed. This highquality seed is supplied to BLM and other cooperators for reforestation and restoration projects. Long-term productivity refers to the capacity of the soils to support sound ecosystems that produce resources such as forage, wildlife, water, and timber. Long-term productivity for a seed orchard refers to the capabilities of the seed orchard to support production that will continue to sustain adequate quantities of high quality seed. The proposed pest management program is designed to protect and enhance the long-term productivity of the orchard, as well as contribute to the short-term uses.

The cultural and biological pest control methods associated with short-term uses have no known long-term adverse effects on productivity. The pesticides examined in this EIS also should have no adverse effect on long-term productivity because most dissipate in the environment relatively quickly and would not change the productivity of the natural environment.

\subsection{Irreversible and Irretrievable Commitment of Resources}

Implementation of the proposed IPM program at Tyrrell would result in the commitments of various natural resources and man-made resources. Some of these commitments of resources are irretrievable by virtue of duration of commitment or cost. 
In other cases, commitments of resources are irreversible since the resource is consumed during IPM implementation.

\subsubsection{Irretrievable Effects}

\section{Orchard Seed Production}

An irretrievable effect on resources is the loss of seed production opportunities. Seed production would vary between alternatives, as would the costs associated with accomplishing environmentally sound pest management. The commitment of time and dollars are irretrievable when production is lost. However, they are not irreversible, since production levels can be reversed by changing orchard pest management strategies in the future.

Seed loss, primarily to insects and disease, would occur under all alternatives, but would have the potential to be highest under Alternative D (Non-Pesticide Pest Management).

\section{Cost Efficiency}

Lost efficiencies associated with not using an optimum mix of pest control methods would be irretrievable. Since Alternative A has the most flexibility for using all pest management methods, it should be the most cost-efficient.

\subsubsection{Irreversible Effects}

The principal irreversible commitment of resources associated with the proposed IPM methods is the use of fossil fuels from the operation of heavy equipment or power tools associated with mechanical methods or the equipment used in application of pesticides and fertilizers. Pest management approaches selected, the mix of which can vary widely even within a single alternative, would determine the level of fossil fuel consumption. For example, hand applications of pesticides and manual vegetation control methods would consume no fossil fuel during the treatment, while mowers or a tractor-mounted sprayer would. 


\subsection{Consultation and Coordination}

Public involvement and interagency / intergovernmental coordination and consultation are recognized as an essential element in the development of an EIS. Public participation has been encouraged and solicited since the original "Notice of Intent to Prepare an EIS" was published in March 1999, and will continue through completion of the Final EIS. A scoping plan was developed in June 2002 when BLM initiated contractor support to complete the IPM EIS (BLM 2002). Agencies and interest groups with special expertise or concerns related to pest management have been notified of the project and advised of the need to coordinate information and provide input. Technical and scientific information available from a variety of sources has been reviewed and considered during the scoping process

\subsection{Scoping Process}

Table 5.1-1 outlines a chronology of BLM's public outreach for the EIS scoping - starting March 26, 1999, when the first Notice of Intent was published in the Federal Register, through July 26, 2002, the official end of the public scoping period for the Draft EIS.

\section{Table 5.1-1. Chronology of Scoping Activities}

\begin{tabular}{|l|l|}
\hline Date & Action \\
\hline $3 / 26 / 99$ & $\begin{array}{l}\text { Notice of Intent published in Federal Register (one EIS for all four BLM western Oregon seed } \\
\text { orchards) }\end{array}$ \\
\hline $4 / 7 / 99$ & Request for comments published in Illinois Valley News in Cave Junction, OR \\
\hline $5 / 99$ & Open house announcement and fact sheet mailed \\
\hline $6 / 8 / 99$ & Open house at Tyrrell Seed Orchard (one couple attended) \\
\hline $3 / 29 / 01$ & $\begin{array}{l}\text { Revised Notice of Intent in Federal Register (indicating decision to prepare three district-specific } \\
\text { EISs) }\end{array}$ \\
\hline $11 / 15-21 / 01$ & $\begin{array}{l}\text { Orchard staff visited adjacent landowners (six) to obtain information on water use and identify } \\
\text { any concerns }\end{array}$ \\
\hline $7 / 1 / 02$ & $\begin{array}{l}\text { Mailing to interested public advising of additional scoping and revised EIS schedule } \\
\text { (approximately 70 on mailing list) }\end{array}$ \\
\hline $7 / 1 / 02$ & $\begin{array}{l}\text { Mailing to interested agencies advising of additional scoping and revised EIS schedule (15 on } \\
\text { mailing list) }\end{array}$ \\
\hline $7 / 5 / 02$ & Second public scoping period beings \\
\hline $7 / 7 / 02$ & Public notice in local newspaper, Eugene Register Guard \\
\hline $7 / 10 / 02$ & Public notice in local newspaper, Cottage Grove Sentinel \\
\hline $7 / 11 / 02$ & Public notice in local newspaper, West Lane News \\
\hline $7 / 9 / 02$ & Article in The Community Shopper (from West Lane News) \\
\hline $7 / 15 / 02$ & $\begin{array}{l}\text { Channel } 9 \text { TV (KEZI) in Eugene interviews seed orchard manager and airs short TV news story } \\
\text { about EIS and pest management program }\end{array}$ \\
\hline $7 / 26 / 02$ & Second public scoping period ends \\
\hline
\end{tabular}




\subsection{Persons, Groups, and Agencies Consulted}

BLM actively solicited scoping comments from the interested members of the general public, including adjacent and nearby landowners and other public citizens, public interest groups, industry and business, members of the media, libraries, and schools; and requested input from state and Federal officials (including tribal representatives), and Federal, state, and local environmental resource agencies. These persons and groups are identified in more detail in Section 5.3.

Numerous members of the public, representing nearby landowners, orchard cooperators, and public interest groups, have commented to date. However, no agencies commented during scoping other than the NOAA Fisheries (Dan Tonnes), who at the invitation of BLM, conducted a site visit of the orchard on October 28, 2002, to meet with BLM orchard staff, and identify and discuss potential areas of concern for special status aquatic species. Conference with NOAA Fisheries under Section 7 of the ESA was completed with issuance of a conference opinion by NOAA on February 9, 2005; see information summarized in Section 1.4.2. Finally, BLM contractors consulted with the EPA Office of Pesticide Programs and with manufacturers of pesticide products during performance of the risk assessment to request relevant information. Specifically, EPA provided agency-prepared documents that summarize technical studies relevant to the FIFRA registration of the pesticides and the current status of "other" ("inert") ingredients. Pesticide manufacturers provided material safety data sheets and product labels, as well as information on "other" ingredients.

\subsection{Draft EIS Review and Comment}

A detailed report of the public review and comment process on the Draft EIS is provided as Appendix E to this Final EIS. BLM received very few comments on the Draft EIS. Two verbal comments were received during the public meetings and three written comments were received during the public comment period. The commentor at the first session was an individual who identified himself as a volunteer at Tyrrell, a BLM retiree, and a nearby landowner. The commentors at the second session were a couple who live near the orchard. Written comments were received from two Federal agencies and an individual representing herself and two organizations. Of the five commentors, one supported the selection of Alternative B (IPM with Environmental Protection Emphasisthe proposed action and preferred alternative), and one recommended that Alternative $D$ (Non-Chemical Pest Management $t^{1}$ ) be selected. Three commentors did not express any preference for a selected alternative, and one of those limited comments to suggestions for changes to the details of Alternative B to further protect threatened salmonid species. A summary of the comments received is provided in Table 5.3-1. The comments and detailed responses are provided in Appendix E.

\subsection{List Of Agencies, Organizations, and Persons to Whom Copies of the Statement are Sent}

The current mailing list includes 90 names, 74 of which are members of the general public, including adjacent and nearby landowners and other public citizens, public interest groups, industry and business, members of the media, libraries, and schools, and state and Federal officials (including tribal representatives); and 16 of which represent Federal, state, and local environmental resource agencies. A breakdown of the state, Federal, and local environmental resource agencies, tribal contacts, and public interest groups is provided. 
Table 5.3-1. Summary of Public Comments on Draft EIS

\begin{tabular}{|c|c|c|c|}
\hline $\begin{array}{l}\text { Tracking } \\
\text { Number }\end{array}$ & Commentor & Format and Date & Focus \\
\hline T1 & $\begin{array}{l}\text { Albert Goins } \\
\text { Volunteer at Tyrrell Seed Orchard, BLM retiree, } \\
\text { and landowner } \\
\text { Lorane, OR }\end{array}$ & $\begin{array}{l}\text { Tyrrell Public } \\
\text { Meeting } \\
7 / 16 / 03\end{array}$ & $\begin{array}{l}\text { Requested information } \\
\text { on monitoring conducted } \\
\text { for the spring } 2003 \\
\text { esfenvalerate spray } \\
\text { project }\end{array}$ \\
\hline $\mathrm{T} 2$ & $\begin{array}{l}\text { Mary Seereiter } \\
\text { Neighbor of seed orchard } \\
\text { Lorane, OR }\end{array}$ & $\begin{array}{l}\text { Tyrrell Public } \\
\text { Meeting } \\
7 / 16 / 03\end{array}$ & $\begin{array}{l}\text { Dislike for chemicals in } \\
\text { general; asked questions } \\
\text { about the details of the } \\
\text { risk assessment and } \\
\text { impact analysis. Support } \\
\text { for the research activities } \\
\text { at Tyrrell. }\end{array}$ \\
\hline T3 & $\begin{array}{l}\text { Michael P. Tehan } \\
\text { National Marine Fisheries Service (NOAA } \\
\text { Fisheries) } \\
\text { National Oceanic and Atmospheric } \\
\text { Administration } \\
\text { Portland, OR }\end{array}$ & $\begin{array}{l}\text { Letter dated } \\
8 / 13 / 03 \text {, received } \\
8 / 20 / 03\end{array}$ & $\begin{array}{l}\text { Suggestions for } \\
\text { additional analysis, } \\
\text { monitoring, and } \\
\text { protection measures for } \\
\text { anadromous fish species }\end{array}$ \\
\hline $\mathrm{T} 4$ & $\begin{array}{l}\text { Judith Leckrone Lee } \\
\text { Manager, Geographic Unit } \\
\text { Region 10, U.S. Environmental Protection Agency } \\
\text { Seattle, WA }\end{array}$ & $\begin{array}{l}\text { Faxed letter dated } \\
9 / 10 / 03 \text {, received } \\
9 / 10 / 03\end{array}$ & $\begin{array}{l}\text { Support for Alternative } \\
\text { B, pesticide safety, IPM } \\
\text { for specific diseases, } \\
\text { additional technologies, } \\
\text { Port-Orford-Cedar } \\
\text { management, pesticides } \\
\text { listed in a recent Western } \\
\text { District Court decision }\end{array}$ \\
\hline T5 & $\begin{array}{l}\text { Jan Wroncy } \\
\text { Individually and representing Coast Range } \\
\text { Guardians and Canaries Who Sing } \\
\text { Eugene, OR }\end{array}$ & $\begin{array}{l}\text { Letter dated } 8 / 25 / \\
03 \text {, faxed } 8 / 27 / 03\end{array}$ & $\begin{array}{l}\text { Support for Alternative } \\
\text { D, opposition to } \\
\text { use of pesticides, } \\
\text { request to exclude B.t. } \\
\text { from Alternative D, } \\
\text { statement that impacts } \\
\text { from pesticides are } \\
\text { underestimated and } \\
\text { would affect salmon, } \\
\text { recommended no use } \\
\text { of fertilizers to decrease } \\
\text { need for pesticides }\end{array}$ \\
\hline
\end{tabular}

Agency List (16)

Lane County Land Management

Lane County - County Owned Lands Department

Oregon Department of Agriculture

Oregon Department of Environmental Quality

Oregon Department of Fish and Wildlife

Oregon Department of Forestry (2)

Oregon Department of Land Conservation and Development

Oregon Department of Water Resources

Deputy State Historic Preservation Officer

National Marine Fisheries Service (2) 
U.S. Department of Agriculture, APHIS Wildlife Services

U.S. Environmental Protection Agency

U.S. Fish and Wildlife Service

U.S. Forest Service, Willamette National Forest

\section{Public Interest Groups (22)}

1000 Friends of Oregon

Associated Oregon Loggers, Inc.

Canaries Who Sing

Coast Range Guardians

Kalapooya Sacred Circle Alliance

Native Plant Society of Oregon

Northwest Coalition for Alternatives to Pesticides

Oregon Farm Bureau Federation

Oregon Forest Resources Institute

Oregon Natural Resources Council

Oregon Public Broadcasting

Oregon Trout

Oregon Water Trust

Oregon Wildlife Federation

Oregonians for Food and Shelter

Pacific Rivers Council

Portland Audubon Society

Sierra Club - Many Rivers Group

Society of American Foresters

The Nature Conservancy

The Oregonian

Wildlife Management Institute

\section{Government Officials (6)}

Confederated Tribes of Coos, Lower Umpqua \& Siuslaw Indians Rep. Cedrick Hayden

Rep. Peter De Fazio

Sen. Gordon H. Smith

Sen. Ron Wyden

Sen. Tony Corcoran 


\subsection{List of Preparers}

\section{BLM Staff (Tyrrell Seed Orchard, District Offices, Oregon State Office)}

\begin{tabular}{|c|c|c|c|}
\hline Name & Primary Responsibility & Discipline & Related Professional Experience \\
\hline Jeannette Griese & $\begin{array}{l}\text { Contracting officer's } \\
\text { representative } \\
\text { State coordinator }\end{array}$ & Forestry & 14 years BLM forester/silviculturist \\
\hline Michael Crawford & $\begin{array}{l}\text { Alternate contracting } \\
\text { officer's representative } \\
\text { Eugene District ID team }\end{array}$ & Orchardist & $\begin{array}{l}6 \text { years Oregon State University } \\
\text { forester/ research assistant } \\
8 \text { years Forest Service forester/ } \\
\text { silviculturist } \\
6 \text { years BLM forester/orchardist }\end{array}$ \\
\hline $\begin{array}{l}\text { Neil Armantrout, } \\
\text { Ph.D }\end{array}$ & $\begin{array}{l}\text { Eugene District fisheries } \\
\text { specialist }\end{array}$ & Fisheries & $\begin{array}{l}30 \text { years BLM, State of Washington, } \\
\text { universities, and other governmental } \\
\text { agencies }\end{array}$ \\
\hline Mary D'Aversa & $\begin{array}{l}\text { Eugene District } \\
\text { hydrology specialist }\end{array}$ & Hydrology & $\begin{array}{l}10 \text { years hydrology, soils, and riparian } \\
\text { experience }\end{array}$ \\
\hline Rudy Wiedenbeck & $\begin{array}{l}\text { Eugene District soils } \\
\text { specialist }\end{array}$ & Soils & $\begin{array}{l}14 \text { years Forest Service soil scientist/ } \\
\text { forestry technician } \\
5 \text { years BLM soil scientist } \\
7 \text { years forestry contractor }\end{array}$ \\
\hline Carla Alford & $\begin{array}{l}\text { Eugene District wildlife } \\
\text { specialist }\end{array}$ & Wildlife biology & 13 years BLM wildlife biologist \\
\hline Nancy Brian & $\begin{array}{l}\text { Coos Bay District botany } \\
\text { specialist }\end{array}$ & Botany & $\begin{array}{l}2 \text { years BLM botanist } \\
8 \text { years National Park Service botanist } \\
3 \text { years Bureau of Reclamation botanist } \\
1 \text { year U.S. Geological Survey } \\
\text { hydrologist }\end{array}$ \\
\hline Gary Wilkinson & $\begin{array}{l}\text { Eugene District } \\
\text { geographic information } \\
\text { specialist }\end{array}$ & GIS & $\begin{array}{l}13 \text { years BLM district forester } \\
12 \text { years BLM GIS specialist }\end{array}$ \\
\hline Richard Hardt & $\begin{array}{l}\text { Eugene District NEPA } \\
\text { coordinator }\end{array}$ & NEPA & 8 years BLM NEPA / forest ecologist \\
\hline $\begin{array}{l}\text { Leslie Frewing- } \\
\text { Runyon }\end{array}$ & $\begin{array}{l}\text { Oregon State Office } \\
\text { NEPA }\end{array}$ & $\begin{array}{l}\text { Planning and } \\
\text { economics }\end{array}$ & $\begin{array}{l}14 \text { years BLM regional economist / } \\
\text { planner }\end{array}$ \\
\hline Glenn Miller & $\begin{array}{l}\text { Alternate contracting } \\
\text { officer's representative } \\
\text { Eugene District ID team } \\
\text { lead }\end{array}$ & $\begin{array}{l}\text { Seed orchard } \\
\text { manager }\end{array}$ & $\begin{array}{l}9 \text { years BLM district forester } \\
10 \text { years BLM orchardist } \\
7 \text { years BLM seed orchard manager }\end{array}$ \\
\hline
\end{tabular}




\section{Contract Staff (LABAT-ANDERSON INCORPORATED and Subcontractors)}

\begin{tabular}{|c|c|c|c|}
\hline Name & Primary Responsibility & Discipline & Related Professional Experience \\
\hline $\begin{array}{l}\text { Christine } \\
\text { Modovsky }\end{array}$ & $\begin{array}{l}\text { Project manager } \\
\text { Alternatives } \\
\text { Human health } \\
\text { Ecological impacts } \\
\text { Risk assessment } \\
\end{array}$ & $\begin{array}{l}\text { Environmental } \\
\text { chemistry and risk } \\
\text { assessment }\end{array}$ & $\begin{array}{l}15 \text { years risk assessment and NEPA } \\
\text { analysis/ compliance (LABAT, EPA, } \\
\text { Dept. of Interior) }\end{array}$ \\
\hline Kristin Sutherlin & $\begin{array}{l}\text { Deputy project manager } \\
\text { Socioeconomics and } \\
\text { environmental justice } \\
\text { Land use } \\
\text { Noise } \\
\text { Public involvement } \\
\end{array}$ & $\begin{array}{l}\text { Planning and } \\
\text { economics }\end{array}$ & $\begin{array}{l}16 \text { years socioeconomics and NEPA } \\
\text { analysis/ compliance (LABAT, USDA } \\
\text { APHIS, University of Maryland) }\end{array}$ \\
\hline Susan Smillie & \begin{tabular}{|l|} 
NEPA compliance \\
Public involvement \\
Water resources \\
\end{tabular} & $\begin{array}{l}\text { Environmental } \\
\text { engineering and } \\
\text { biology }\end{array}$ & $\begin{array}{l}22 \text { years NEPA analysis/compliance and } \\
\text { impact assessment (LABAT, Morrison- } \\
\text { Knudsen, Battelle) }\end{array}$ \\
\hline Randy McCart & \begin{tabular}{|l|} 
Soils \\
GIS mapping \\
Air quality \\
\end{tabular} & Geography & $\begin{array}{l}14 \text { years NEPA compliance and impact } \\
\text { assessment (LABAT) }\end{array}$ \\
\hline John Weeks & $\begin{array}{l}\text { Environmental fate } \\
\text { modeling } \\
\text { Risk assessment }\end{array}$ & $\begin{array}{l}\text { Forestry, biostatistics, } \\
\text { biology, and } \\
\text { toxicology }\end{array}$ & $\begin{array}{l}23 \text { years fate and transport modeling, risk } \\
\text { assessment (SC Johnson, LABAT, Ketron, } \\
\text { Environmental Research Associates, } \\
\text { Forest Service) }\end{array}$ \\
\hline $\begin{array}{l}\text { Dr. Jason } \\
\text { Sandahl }\end{array}$ & Aquatic species impacts & Aquatic toxicology & $\begin{array}{l}12 \text { years pesticide management and } \\
\text { impacts, science research and education, } \\
\text { forestry (Oregon State University, Forest } \\
\text { Service, Peace Corps) }\end{array}$ \\
\hline Dr. William Liss & Aquatic species impacts & Salmonid ecology & $\begin{array}{l}26 \text { years science research and education } \\
\text { (Oregon State University) }\end{array}$ \\
\hline Dr. Jesse Ford & Impact assessment & Ecology & $\begin{array}{l}23 \text { years science research and education } \\
\text { (Oregon State University, University } \\
\text { of Alaska, NCASI, Cornell University, } \\
\text { North Shore Consultants, University of } \\
\text { Minnesota, Minnesota DNR) }\end{array}$ \\
\hline Jody Nelson & $\begin{array}{l}\text { Vegetation impacts } \\
\text { IPM methods }\end{array}$ & Botany & $\begin{array}{l}12 \text { years ecological impact assessment, } \\
\text { science education (LABAT, Denver } \\
\text { Botanic Gardens, University of Northern } \\
\text { Colorado) }\end{array}$ \\
\hline Karin Keifer & Terrestrial wildlife & $\begin{array}{l}\text { Biology and animal } \\
\text { behavior }\end{array}$ & $\begin{array}{l}4 \text { years ecological impact assessment, } \\
\text { research, animal husbandry (LABAT, } \\
\text { Sevilleta National Wildlife Refuge, Dallas } \\
\text { Zoo, Tantra National Park -Slovakia, } \\
\text { Franklin and Marshall College) }\end{array}$ \\
\hline Quinn Damgaard & $\begin{array}{l}\text { General research and } \\
\text { support } \\
\text { Cultural resources } \\
\text { Aquatic species }\end{array}$ & Biology & $\begin{array}{l}2 \text { years technical writing, lab analysis, } \\
\text { vegetation management, public outreach } \\
\text { (LABAT, Midwest Laboratories, } \\
\text { Pottawattamie County Conservation } \\
\text { Board) }\end{array}$ \\
\hline Dean Converse & $\begin{array}{l}\text { General research and } \\
\text { support } \\
\text { Air quality }\end{array}$ & $\begin{array}{l}\text { Geography and } \\
\text { environmental studies }\end{array}$ & $\begin{array}{l}3 \text { years air quality, environmental analysis } \\
\text { (LABAT, Nebraska DEQ) }\end{array}$ \\
\hline
\end{tabular}




\subsection{References}

Certain information cited below was obtained from Internet sites maintained by government agencies or other reliable sources. The Internet citations (uniform resource locators, or URLS) were accurate at the time the data were collected. However, websites change frequently due to changes in data availability or reorganization of information, and the cited URLs may not work in the future. If this occurs, "backing up" to a less specific web address may allow retrieval of the information. For further assistance in locating references cited in this document, please contact the seed orchard manager at the Bureau of Land Management.

\section{Chapter 1}

64 FR 14747. Seed orchard pest management programs at the Walter H. Horning, Charles A. Sprague, Travis Tyrrell, and Provolt Seed Orchards, on lands administered by the Bureau of Land Management, Clackamas, Josephine, Lane, and Jackson Counties, OR. U.S. Bureau of Land Management.

66 FR 17192. Oregon seed orchard; environmental impact statements, notice of intent. U.S. Bureau of Land Management.

BLM. See U.S. Bureau of Land Management.

League of Wilderness Defenders et al. v. Harv Forsgren and U.S. Forest Service. November 4, 2002. Opinion from the U.S. Circuit Court for the Ninth District. No. 01-35729. Seattle, WA.

ODA. See Oregon Department of Agriculture.

ODEQ. See Oregon Department of Environmental Quality.

ODF. See Oregon Department of Forestry.

Oregon Department of Agriculture. 2003. Oregon nurseries declared free of sudden oak death. October 1, 2003. http:// oda.state.or.us/information/news/2003/031001sod.pdf

Oregon Department of Environmental Quality. 1999. Department of Environmental Quality Class V underground injection control (UIC) BMPs. Policy \& Program Development Section, Water Quality Division. Portland, OR.

Oregon Department of Forestry. 2003. Thanks for asking about....Sudden oak death. http:/ / www.odf.state.or.us/DIVISIONS/resource_policy/public_affairs/publications / thanksforasking/TFA-SuddenOakDeath.pdf

U.S. Bureau of Land Management. 1987. Supplement to the Northwest Area Noxious Weed Control Program final environmental impact statement. Oregon State Office. Portland, OR.

U.S. Bureau of Land Management. 1992. Western Oregon program-Management of competing vegetation: Final record of decision. Oregon State Office. Portland, OR.

U.S. Bureau of Land Management. 1995. Eugene Resource Management Plan (RMP) and Record of Decision (ROD), Eugene District. Eugene District Office. Eugene, OR. 
U.S. Bureau of Land Management. 2000. EMS transmission: Plan consistency review of administrative withdrawals for seed orchards. From Deputy State Director, Resource Planning, Use and Protection to District Manager, Salem. February 4, 2000. Oregon State Office. Portland, OR.

U.S. Bureau of Land Management. 2002a. Scoping report: Integrated pest management environmental impact statement, Tyrrell Seed Orchard. Prepared by LABATANDERSON INCORPORATED under Contract HAD021001 for BLM Oregon State Office. Portland, OR.

U.S. Bureau of Land Management. 2002b. Public comment summary: Integrated pest management environmental impact statement, Tyrrell Seed Orchard. Prepared by LABAT-ANDERSON INCORPORATED under Contract HAD021001 for BLM Oregon State Office. Portland, OR.

U.S. Bureau of Land Management. 2002c. Tyrrell Seed Orchard insect control: Environmental assessment. EA No. OR-02-15. Eugene District. Eugene, OR.

U.S. Bureau of Land Management. 2003. Tyrrell Seed Orchard insect control: Environmental assessment. EA No. OR-03-018. Eugene District. Eugene, OR.

U.S. Bureau of Land Management. 2004a. Management of Port-Orford-Cedar in Southwest Oregon, Final Supplemental Environmental Impact Statement.

U.S. Bureau of Land Management. 2004b. Tyrrell Seed Orchard insect control: Environmental assessment. EA No. OR-04-017. Eugene District. Eugene, OR.

USDA. See U.S. Department of Agriculture.

U.S. Department of Agriculture. 2003. Sudden oak death: Protecting America's woodlands from a new and deadly pathogen (draft). U.S. Forest Service, State and Private Forestry. Arlington, VA.

U.S. Department of Agriculture. 2004. Emergency Federal order restricting movement of nursery stock from California, Oregon, and Washington nurseries. December 21, 2004. Plant Protection and Quarantine, Animal and Plant Health Inspection Service. Washington, DC.

U.S. Environmental Protection Agency. 2003. Memorandum: Interpretive statement and guidance addressing effect on Ninth Circuit decision in League of Wilderness Defenders v. Forsgren on application of pesticides and fire retardants. September 3, 2003. Robert E. Fabricant, General Counsel. Washington, DC.

Washington Toxics Coalition et al. v. Environmental Protection Agency and Christine Todd Whitman, Administrator. July 2, 2002. Opinion from the U.S. District Court, Western District of Washington at Seattle. Case No. C01-132C. Seattle, WA.

\section{Chapter 2}

40 CFR 158.202(i). Data requirements for registration: Product performance. U.S. Environmental Protection Agency. Washington, DC.

40 CFR 1502.9c. Environmental impact statement: Draft, final, and supplemental statements. Council on Environmental Quality. Washington, DC.

40 CFR 1502.21. Environmental impact statement: Incorporation by reference. Council 
40 CFR 1508.20. Terminology and index: Mitigation. Council on Environmental Quality. Washington, DC.

40 CFR 1508.28. Terminology and index: Tiering. Council on Environmental Quality. Washington, DC.

BLM. See U.S. Bureau of Land Management.

DOI. See U.S. Department of the Interior.

EPA. See U.S. Environmental Protection Agency.

IPM Inc. See IPM Institute of North America, Inc.

IPM Institute of North America, Inc. 2002. Frequently asked questions: What is integrated pest management (IPM)? Madison, WI. http://www.ipminstitute.org/ipm_f aq.htm\#IntegratedPestManagment

Schowalter, T.D., M.I. Haverty, and T.W. Koerber. 1985. Cone and seed insects in Douglas-fir, Pseudotsuga menziesii (Mirb.) Franco, seed orchards in the western United States: Distribution and relative impact. The Canadian Entomologist 117(10):1223-1230.

U.S. Bureau of Land Management. 1988. H-17901-1 - National Environmental Policy Act Handbook. http://www.blm.gov/nhp/ efoia/wo/handbook/h1790-1.html

U.S. Bureau of Land Management. 2001. BLM Instruction Memorandum No. 2001-062: Documentation of land use plan conformance and National Environmental Policy Act (NEPA) adequacy. Renewable Resources and Planning. Washington, DC.

U.S. Bureau of Land Management. 2002. Personal communication: Glenn Miller. Tyrrell Seed Orchard. Lorane, OR.

U.S. Department of the Interior. 1980. 516 DM 1: Departmental manual-National Environmental Policy Act of 1969. Office of Environmental Policy and Compliance. http: / / elips.doi.gov/ elips/release/3506.htm

U.S. Department of the Interior. 1981. 517 DM 1: Departmental manual-Pesticide use policy. Office of Environmental Policy and Compliance. http:/ / elips.doi.gov/elips/ release / 2336.htm

U.S. Environmental Protection Agency. 2000a. Lists of other (inert) pesticide ingredients. Office of Pesticide Programs. Washington, DC. http://www.epa.gov/opprd001/inerts/ lists.html

U.S. Environmental Protection Agency. 2000b. Peer review handbook, 2nd ed. EPA 100-B-00-001. Science Policy Council. Washington, DC. http://www.epa.gov/osp/spc/ prhandbk.pdf

\section{Chapter 3}

14 CFR 36.805. Federal aviation regulations. Part 36: Noise standards; Subpart H: Helicopters, noise limits. Federal Aviation Administration. Washington, DC.

40 CFR 50. National primary and secondary ambient air quality standards. U.S. EPA Office of Air and Radiation. Washington, DC. 
40 CFR 1502.15. Environmental impact statement: Affected environment. Council on Environmental Quality. Washington, DC.

40 CFR 1508.14. Terminology and index: Human environment. Council on Environmental Quality. Washington, DC.

63 FR 42587. 1998. Endangered and threatened species; threatened status for the Oregon Coast evolutionarily significant unit of coho salmon. August 10, 1998. National Marine Fisheries Service, National Oceanic and Atmospheric Administration, Department of Commerce. Federal Register 63(153):42587-42591.

69 FR 33102. 2004. Endangered and threatened species: Proposed listing determinations for 27 ESUs of west coast salmonids; proposed rule. June 14, 2004. National Marine Fisheries Service, National Oceanic and Atmospheric Administration, Department of Commerce. Federal Register 69(113):33102-33179.

BEA. See U.S. Bureau of Economic Analysis.

BLM. See U.S. Bureau of Land Management.

Cavanaugh, W.J., and G.C. Tocci. 1998. Environmental Noise. University of Southern California Institute of Public Affairs. Los Angeles.

CEQ. See Council on Environmental Quality.

Council on Environmental Quality. 1997. Environmental justice: Guidance under the National Environmental Policy Act. Executive Office of the President. Washington, DC.

Cunniff, P.F. 1977. Environmental Noise Pollution. John Wiley and Sons. New York.

Environmental Systems Research Institute, Inc. 2002. Census 2000 topologically integrated geographic encoding and referencing system (TIGER)/Line® data. County subdivisions (census tracts, block groups, and blocks). http:/ / arcdata.esri.com/data/ tiger2000/tiger_download.cfm

EPA. See U.S. Environmental Protection Agency.

ESRI. See Environmental Systems Research Institute, Inc.

Federal Emergency Management Agency. 2002. FEMA's Multi-hazard mapping initiative (in partnership with National Oceanic and Atmospheric Administration). Hazardmap query at http://www.hazardmaps.gov/atlas.php.

FEMA. See Federal Emergency Management Agency.

LCO. See Lane County, Oregon.

Lane County, Oregon. 2002. Official web site. http://www.co.lane.or.us/

National Marine Fisheries Service. 2002. Coho salmon: Oregon Coast ESU.

National Oceanic and Atmospheric Administration, Department of Commerce. www.nwr.noaa.gov/1salmon/salmesa/ cohoorc.htm

NMFS. See National Marine Fisheries Service.

OAR 340-041-0242. Mid Coast Basin: Beneficial water uses to be protected. Department of Environmental Quality. Portland, OR. 
OAR 340-202-0020. Ambient air quality standards and PSD increments. Department of Environmental Quality. Portland, OR.

ODEQ. See Oregon Department of Environmental Quality.

OED. See Oregon Employment Department.

OLMIS. See Oregon Labor Market Information System.

Oregon Climate Service. 2002a. Monthly means and extremes: Cottage Grove 1 S, OR. http:/ / www.ocs.orst.edu/pub_ftp/climate_data/mme2/mme1897.html

Oregon Climate Service. 2002b. Wind: Percentage frequency by directions, in selected speed increments by months; Eugene Airport, OR; 1948-1958. http://www.ocs.orst.edu/ pub_ftp/climate_data/wind/eugene.html.

Oregon Department of Environmental Quality. 2002. 2001 Oregon air quality data summaries. Air Quality Division. Portland, OR. http://www.deq.state.or.us/aq/ forms / 2001AnnRpt/2001AnnRpt_all.pdf

Oregon Department of Environmental Quality. 2003. Final 2002 303(d) database. Portland, OR. http://www.deq.state.or.us/wq/WQLData/SearchChoice02.htm

Oregon Employment Department. 2002. Regional economic profile, Region 5, Lane County. http:/ / qualityinfo.org/olmisj

Oregon Labor Market Information System. 2002. Unemployment rates. http:// www.qualityinfo.org/olmisj/AllRates

Oregon State University Extension Service. 1998. Determination of soil sensitivity ratings for the Oregon Water Quality Decision Aid. Publication EM 8708. http:// wwwagcomm.ads.orst.edu/AgComWebFile/EdMat/EM8708.pdf

Oregon Water Resources Department. 2002a. Well log report for Township 20 South, Range 5 West, Section 9, 15, 21 and adjacent sections, Lane County. Groundwater Resource Information Distribution (GRID) Query. http:// www.wrd.state.or.us / groundwater/index.shtml

Oregon Water Resources Department. 2002b. Water rights information system query. http:/ / www.wrd.state.or.us

OSUES. See Oregon State University Extension Service.

OWRD. See Oregon Water Resources Department.

Pacific Fishery Management Council. 1999. Amendment 14 to the Pacific Coast Salmon Plan. Appendix A - Identification and description of essential fish habitat, adverse impacts, and recommended conservation measures for salmon. Portland, OR. http: / / www.pcouncil.org

PSU. See Portland State University.

Portland State University. 2002. Interactive geologic map of Oregon. http:// nwdata.geol.pdx.edu/OR-Geology /

SCS. See Soil Conservation Service. 
Soil Conservation Service (now Natural Resources Conservation Service). 1987. Soil survey of Lane County, Oregon. U.S. Department of Agriculture. http:/ / www.or.nrcs.usda.gov/soil/reports_pdf/oregon/lane.pdf

Suter, A.H. 1991. Noise and its effects: A report presented to the Administrative Conference of the United States. Washington, DC.

U.S. Army. 1976. Construction site noise specification and control. Interim report N-33. Construction Engineering Research Laboratory. Champaign, Illinois.

USBC. See U.S. Bureau of the Census.

U.S. Bureau of Economic Analysis. 2002. Employment and labor force data. http:// www.bea.gov/bea/regional/reis.

U.S. Bureau of Land Management. 2000. Aerial photography of Tyrrell Seed Orchard and vicinity.

U.S. Bureau of Land Management. 2001. Environmental Assessment No. EA-01-05: Travis Tyrrell Seed Orchard Insect Control. Eugene District Office. Eugene, OR.

U.S. Bureau of Land Management. 2002. A watershed assessment for the Siuslaw Basin. Eugene District Office. Eugene, OR. http:/ / www.edo.or.blm.gov/planning/watershed_ analysis/ siuslaw/ contents.htm

U.S. Bureau of Land Management. 2003. Personal communication with C. Alford, March 5, 2003. Eugene District Office. Eugene, OR.

U.S. Bureau of the Census. 2001. Census 2000 brief: Overview of race and Hispanic origin. C2KBR/01-1. http:// www.census.gov/prod/2001pubs/c2kbr01-1.pdf

U.S. Bureau of the Census. 2002a. 2000 census of population and housing, summary file 1, 100-percent data. American FactFinder. http:/ / factfinder.census.gov/ servlet/ BasicFactsServlet

U.S. Bureau of the Census. 2002b. 2000 census of population and housing, summary file 3, technical documentation. SF3/04 (RV). American FactFinder. http:/ / factfinder.census.gov/servlet/BasicFactsServlet

U.S. Bureau of the Census. 2002c. 1990 census of population and housing; USA counties 1998. http:/ / govinfo.library.orst.edu/php/commerce/state/state.php

U.S. Bureau of the Census. 2002d. 2000 census of population and housing, summary file 3, sample data. American FactFinder. http:/ / factfinder.census.gov/servlet/ BasicFactsServlet

U.S. Environmental Protection Agency. 1974. Information on levels of environmental noise requisite to protect public health and welfare with an adequate margin of safety. 550/9-74-004. Washington, D.C.

U.S. Environmental Protection Agency. 1998. Final guidance for incorporating environmental justice concerns in EPA's NEPA compliance analyses. Prepared by SAIC under contract to EPA's Office of Federal Activities. Washington, DC.

U.S. Environmental Protection Agency. 2002. Local drinking water information: Oregon drinking water. http:/ / www.epa.gov/safewater/dwinfo/or.htm 


\section{Chapter 4}

21 CFR 172.863. Food additives permitted for direct addition to food for human consumption-Multipurpose additives: Salts of fatty acids. U.S. Food and Drug Administration, Department of Health and Human Services. Washington, DC.

40 CFR 1508.7. Terminology and index: Cumulative impact. Council on Environmental Quality. Washington, DC.

40 CFR 1508.14. Terminology and index: Human environment. Council on Environmental Quality. Washington, DC.

40 CFR 1508.27. Terminology and index: Significantly. Council on Environmental Quality. Washington, DC.

Beyers, D.W., J.J. Keefe, and C.A. Carlson. 1994. Toxicity of carbaryl and malathion to two federally listed endangered fishes, as estimated by regression and Anova. Environmental Toxicology and Chemistry 13:101-107.

BLM. See U.S. Bureau of Land Management

Cavanaugh, W.J., and G.C. Tocci. 1998. Environmental Noise. University of Southern California Institute of Public Affairs. Los Angeles.

Dwyer, F.J., L.C. Sappington, D.R. Buckler, and S.B. Jones. 1995. Use of surrogate species in assessing contaminant risk to endangered and threatened species. Draft final report submitted to Foster L. Mayer, Project Officer, Gulf Breeze Environment Research Laboratory, EPA. U.S. EPA Project Number DW14935115-01-0.

EPA. See U.S. Environmental Protection Agency.

Extoxnet. 2003. Bacillus thuringiensis. Pesticide Information Profiles. Extension Toxicology Network (database of pesticide information profiles). http://ace.orst.edu/ info/extoxnet

FAA. See Federal Aviation Administration

Federal Aviation Administration. 1985. Aviation noise effects. ADA-154319. http:// www.nonoise.org/library/ane/ane.htm

Hawaii Department of Transportation. 1994. Effects Of helicopter noise on rural residents away from airports and heliports. http:/ / www.eng.hawaii.edu/ panos/ heli.htm

HDOT. See Hawaii Department of Transportation

J.J. Mauget Co. 2003. Label: Imicide ${ }^{\circledR}$ systemic insecticide in ready to use capsules for use in conifer seed orchards. Arcadia, CA.

Mauget. See J.J. Mauget Co.

National Oceanic and Atmospheric Administration. 2002. Pesticides and Pacific salmon: Technical guidance for NOAA Fisheries section 7 pesticide consultations (draft). Environmental Conservation Division. Seattle, WA. 
National Research Council. 1983. Risk Assessment in the Federal Government: Managing the Process. National Academy Press. Washington, DC.

NOAA. See National Oceanic and Atmospheric Administration.

NRC. See National Research Council.

U.S. Bureau of Land Management. 1991. Final environmental impact statement: Vegetation Treatment on BLM Lands in 13 Western States. BLM-WY-EIS-91-022-4320. Cheyenne, WY.

U.S. Environmental Protection Agency. 1974. Information on levels of environmental noise requisite to protect public health and welfare with an adequate margin of safety. 550/9-74-004. Washington, D.C.

U.S. Environmental Protection Agency. 1989. Risk assessment guidance for SuperfundVolume 1: Human health evaluation manual (part A). Interim final. EPA/540/1-89/002. Office of Emergency and Remedial Response. Washington, DC.

U.S. Environmental Protection Agency. 1992. Reregistration eligibility document (RED): Soap salts. Office of Prevention, Pesticides, and Toxic Substances. Washington, DC.

U.S. Environmental Protection Agency. 1998a. Reregistration eligibility decision (RED: Bacillus thuringiensis. EPA 738-R-98-004. Office of Pesticide Programs. Washington, DC.

U.S. Environmental Protection Agency. 1998b. Guidelines for ecological risk assessment. Risk Assessment Forum. Washington, DC.

U.S. Environmental Protection Agency. 2000a. Risk characterization handbook. EPA 100-B-00-002. Science Policy Council. Washington, DC.

U.S. Environmental Protection Agency. 2000b. Lists of other (inert) pesticide ingredients. Office of Pesticide Programs. Washington, DC. http:/ / www.epa.gov/opprd001 / inerts/ lists.html

U.S. Environmental Protection Agency. 2003. Imidacloprid; pesticide tolerances for emergency exemptions. October 29, 2003. Federal Register 68(209):61624-61634.

\section{Chapter 5}

U.S. Bureau of Land Management. 2002. Scoping plan: Integrated pest management environmental impact statement, Tyrrell Seed Orchard. Prepared by LABATANDERSON INCORPORATED under Contract HAD021001 for BLM Oregon State Office. Portland, OR. 


\section{Acronyms and Abbreviations}

${ }^{\circ} \mathrm{F}$

$\mu \mathrm{g} / \mathrm{m}^{3}$

$\mu \mathrm{m}$

a.i.

AQCR

ATV

BLM

BMP

B.t.

CEQ

CFR

cfs

$\mathrm{CO}$

CX

$\mathrm{dB}$

$\mathrm{dBA}$

EA

EFH

EIS

EO

EPA

ESA

ESU

EXAMS

FIFRA

FLPMA

FONSI

$\mathrm{ft}$

FWS

gal

GLEAMS

IPM

$\mathrm{kg}$

$\mathrm{lb}$

$\mathrm{LC}_{50}$

$\mathrm{LD}_{50}$

$\mathrm{L}_{\text {eq }}$

MATC

$\mathrm{mg}$

$\mathrm{mg} / \mathrm{L}$

$\mathrm{mg} / \mathrm{m}^{3}$ degrees Fahrenheit

micrograms per cubic meter

micometer, micron

active ingredient

air quality control region

all-terrain vehicle

Bureau of Land Management

best management practice

Bacillus thuringiensis

Council on Environmental Quality

Code of Federal Regulations

cubic feet per second

carbon monoxide

categorical exclusion (under NEPA)

decibel

"A-weighted" decibel

environmental assessment

essential fish habitat

environmental impact statement

Executive Order

U.S. Environmental Protection Agency

Endangered Species Act

evolutionarily significant unit

Exposure Analysis Modeling System

Federal Insecticide, Fungicide, and Rodenticide Act

Federal Land Policy and Management Act

finding of no significant impact

foot or feet

U.S. Fish and Wildlife Service

gallon

Groundwater Loading Effects of Agricultural Management Systems

integrated pest management

kilogram

pound(s)

median lethal concentration

median lethal dose

equivalent sound level

maximum acceptable toxicant concentration

milligram

milligrams per liter

milligrams per cubic meter 
NA

NAAQS

NEPA

NMFS

NOAA

$\mathrm{NO}_{2}$

NPDES

NRHP

NWSOMA

$\mathrm{O}_{3}$

ODEQ

PAH

$\mathrm{Pb}$

PCI

PM

$\mathrm{PM}_{2.5}$

$\mathrm{PM}_{10}$

ppm

Q

RfD

RMP

ROD

ROI

SDWA

SEIS

SHPO

$\mathrm{SO}_{2}$

SWAP

TPI

UIC

URL

USGS not applicable / not available

National Ambient Air Quality Standards

National Environmental Policy Act

National Marine Fisheries Service

National Oceanic and Atmospheric Administration nitrogen dioxide

National Pollutant Discharge Elimination System

National Register of Historic Places

Northwest Seed Orchard Managers Association

ozone

Oregon Department of Environmental Quality

polynuclear aromatic hydrocarbon

lead

per capita income

particulate matter

particulate matter less than 2.5 microns in diameter particulate matter less than 10 microns in diameter parts per million

quotient

reference dose

resource management plan

record of decision

region of influence

Safe Drinking Water Act

supplemental environmental impact statement

State Historic Preservation Officer

sulfur dioxide

source water assessment program

total personal income

underground injection control

uniform resource locator (web site address)

U.S. Geological Survey 
Note: All definitions are specific to their use in this environmental impact statement. Additional terms specific to the recently conducted risk assessment are found in Section 10 of the risk assessment report.

Acaricide. An insecticide that specifically targets mites and ticks.

Active ingredient. The pesticidally active chemical contained in a pesticide product.

Acute. Single-dose toxicity study. May also refer to adverse effects that exhibit a short and relatively severe course.

Adsorption. Adhesion of substances to the surfaces of solids or liquids; technically, the attraction of ions of compounds to the surfaces of solids or liquids.

Anadromous. Fish that are born in fresh water, migrate to the ocean to grow into adults, and then return to fresh water to spawn.

Analysis. The second step of an ecological risk assessment, which examines the two primary components of risk-exposure and effects-and the relationships between each other and ecosystem characteristics.

Biological control. The use of natural enemies to attack a target plant, insect, or animal pest.

Boom. A tubular metal device that conducts a pesticide or fertilizer mixture from a tank to a series of spray nozzles. A boom may be mounted beneath an aircraft or behind a vehicle.

Broadcast application. The applying of pesticide or fertilizer over an entire area or field rather than only to rows, beds, or individual plants.

Buffer (strip or zone). A zone left untreated with pesticide or fertilizer (at the outer edge of a treated area or along streams) as protection against the effects of treatment.

Cancer slope factor. Represents the probability that a 1-mg/ $\mathrm{kg} /$ day chronic dose of a chemical will result in formation of a tumor. Expressed as a probability, in units of "per $\mathrm{mg} / \mathrm{kg} /$ day" $^{\prime \prime}$ or $(\mathrm{mg} / \mathrm{kg} / \text { day })^{-1}$.

Canopy. The uppermost level of a forest community, usually formed by the tallest trees.

Carcinogen. A substance producing or inciting cancer.

Categorical exclusion. A category of actions that do not individually or cumulatively have significant effects on the human environment and for which neither an environmental assessment nor an environmental impact statement is required.

Cation exchange capacity. The capacity of a soil to adsorb cations (positively charged ions), expressed in milliequivalents per 100 grams of soil.

Chemical degradation. The breakdown of a chemical substance into simpler components through chemical reactions.

Chemigation. The injection of pesticides and fertilizers through irrigation systems. 
Chronic. Long-term, usually lifetime or near lifetime in duration.

Clonal orchard. A production unit consisting of plants that are genetically identical to the parent plant; they are produced asexually, e.g., from cuttings or suckers.

Control. Reduction of a pest problem to a point where it is below an acceptable threshold.

Critical habitat. (1) Specific areas within the habitat occupied by a species at the time it is listed under the Endangered Species Act where there are physical or biological features (i) essential to the conservation of the species and (ii) that may require special management considerations or protection, and (2) specific areas outside the habitat occupied by the species at the time it is listed upon the determination by the Secretary of the Interior that such areas are essential for the conservation of the species.

Cultural resources. Remains of human activity, occupation, or endeavor, reflected in districts, sites, structures, building, objects, artifacts, ruins, works of art, architecture, and natural features that were of importance in past human events. Cultural resources consist of (1) physical remains, (2) areas where significant human events occurred, even though evidence of the events no longer remains, and (3) the environment immediately surrounding the actual resource.

Cumulative impact. The impact on the environment which results from the incremental impact of the action when added to other past, present, and reasonably foreseeable future actions regardless of what agency (Federal or non-Federal) or person undertakes such other actions. Cumulative impacts can result from individually minor but collectively significant actions taking place over a period of time

Dose. The amount of chemical entering the body.

Drift. The movement of airborne particles by air motion (wind) away from an intended target area.

Endangered species. Plant or animal species that are in danger of extinction throughout all or a significant part of their range.

Environmental assessment. A systematic environmental analysis of site-specific activities used to determine whether such activities would significantly affect the human environment, and whether an environmental impact statement is required.

Environmental impact statement. An analytical document developed for use by decisionmakers to weigh the environmental consequences of a potential action.

Ephemeral stream. A stream that flows only in direct response to precipitation and whose channel is at all times above the water table.

Exotic plants. Plants that are not native to the region in which they occur.

Exposure assessment. The second step in human health risk assessment, involving estimation of doses from various scenarios and routes of exposure.

Fertilizer. Any of a large number of natural or synthetic materials, including manure and nitrogen, phosphorus, and potassium compounds, spread on or worked into the soil to increase its fertility. General fertilization refers to application of fertilizer to entire orchard units, in contrast to calcium nitrate application to specific trees for cone stimulation. 
Forb. A low-growing herbaceous plant that is not a grass, sedge, or rush.

Formulation. A specific composition of pesticide active ingredient(s) and other ingredients, comprising a pesticide product.

Girdling. A physical cutting or disruption of the cambial sap flow within a tree.

GLEAMS. Groundwater Loading Effects of Agricultural Management Systems, a computer-based model for predicting the fate and transport of agricultural pesticides and fertilizers.

Ground cover. Grasses or other plants that keep soil from being blown or washed away.

Habitat. The environment in which an organism occurs.

Half-life. The time required for a chemical to degrade to $50 \%$ of its original concentration.

Hazard assessment. The first step in human health risk assessment, in which each chemical's toxic properties and dose-response relationship are identified.

Hazard index. An indicator of risk to human health, representing the ratio of the estimated dose to the reference dose. A hazard index of 1 or less usually indicates negligible risk to human health.

Infiltration. The downward or lateral entry of water into the soil.

Integrated pest management. Use of several techniques (for example, burning, grazing and mechanical, manual, or chemical methods) as one system to control pests where they are unwanted. IPM means responding to pest problems with the most effective, least-risk option. Under IPM, actions are taken to control pests only when their numbers are likely to exceed acceptable levels and to limit the impact on other organisms and the environment.

Intermittent stream. A stream that flows only at certain times of the year when it receives water from winter rain or melting snow.

$\mathrm{LC}_{50}$. The concentration of a chemical in water at which 50 percent of test animals were killed. It is usually used in testing of fish or other aquatic animals.

$\mathbf{L D}_{50}$. The dosage of toxicant (expressed in milligrams of toxicant per kilogram of animal body weight) required to kill 50 percent of the animals in a test population.

Leaching. The movement of chemicals through soil by water.

Lowest-observed-effect concentration. The lowest chemical concentration in water at which adverse effects are observed in an aquatic toxicity study.

Maximum acceptable toxicant concentration. The geometric mean of a no-observableeffect concentration and a lowest-observed-effect concentration.

Mean. The average of a set of values.

Median. The middle value in a ranked distribution.

$\mathrm{mg} / \mathrm{kg}$. Milligrams per kilogram, usually indicating a dose level in terms of milligrams intake of a substance per kilogram of body weight. 
$\mathrm{mg} / \mathrm{kg} /$ day. Milligrams per kilogram per day, usually indicating a daily dose level in terms of milligrams intake of a substance per kilogram of body weight per day.

$\mathrm{mg} / \mathrm{L}$. Milligrams per liter, usually indicating a concentration of a substance in water.

No-observed-effect concentration. The highest water concentration at which no adverse effects are observed in an aquatic toxicity study.

Noxious weed. According to the Federal Noxious Weed Act (FL 93-629), a weed that causes disease or has other adverse effects on man or his environment and therefore is detrimental to the agriculture and commerce of the United States and to the public health.

Perennial stream. A stream that flows continuously year round.

Pesticide. Any substance or mixture of substances intended for controlling insects, rodents, fungi, weeds, or other plants and animals that are considered pests.

Phytophagous. An organism that feeds on plants, particularly an insect that feeds on shrubs or trees.

Prescribed burning (prescribed fire). The scientific, intentional burning of wildland fuels in either their natural or modified states under conditions to allow the fire to continue to a predetermined area and to produce the intensity of heat and rate of spread needed to meet certain objectives.

Problem formulation. The first step in an ecological risk assessment, in which the purpose of the assessment is provided, the problem is defined, and a plan for analyzing and characterizing risk is determined.

Raptors. Birds of prey, such as owls, hawks, or eagles.

Receptor. An ecological entity that is exposed to a stressor.

Reference dose. An estimate of the highest possible daily dose of a chemical that will pose no appreciable risk of deleterious effects to a human during his or her lifetime.

Riparian. Pertaining to or located along a stream bank or other water bodies, such as ponds, lakes, reservoirs, or marshes.

Risk characterization. The third step in both human health and ecological risk assessment, in which estimated doses are compared to a chemical's toxic properties to predict the potential for adverse effects under the given conditions of exposure.

Risk. The probability that a substance will produce harm under specified conditions.

Rogue. To systematically cull individual trees and/or families considered no longer desirable within the seed orchard population. Roguing is used to increase genetic gain potential in an orchard. Theoretically, the more intensive the roguing, the greater the genetic improvement.

Runoff. The part of the precipitation in a drainage area that is discharged from the area in stream channels, including surface runoff, ground water runoff, and seepage.

Scoping. The process by which significant issues relating to a proposal are identified for environmental analysis. Scoping includes eliciting public comment on the proposal, evaluating concerns, and developing alternatives for consideration. 
Soil compaction. The compression of the soil profile from surface pressure, resulting in reduced air space, lower water-holding capacity, and decreased plant root penetrability.

Sorption. The process of taking up or holding by either absorption or adsorption.

Special status species. Species which are proposed for listing, officially listed as threatened or endangered, or are candidates for listing as threatened or endangered under the provisions of the Endangered Species Act; those listed by a state in a category such as threatened or endangered implying potential endangerment or extinction; and those designated by each BLM State Director as sensitive.

Spot treatment. Applying pesticide to a selected individual area (as opposed to broadcast application).

Stressor. Any physical, chemical, or biological entity that can induce an adverse response.

Threatened species. A plant or animal species that is not in danger of extinction but is likely to become so within the foreseeable future throughout all or a significant portion of its range.

Trade name. The commercial name of a pesticide product.

Water table. The upper limit of the part of the soil or underlying rock material that is wholly saturated with water.

Weed. A plant out of place or growing where not desired. 
Final EIS - Tyrrell Seed Orchard IPM

Glossary -6 


\section{Index}

\section{Term}

Acephate Accident

Administrative withdrawal

Aerial

AgDRIFT

Airblast sprayer

Air quality

Alternatives

Alternative A: maximum production IPM

Alternative B: IPM with environmental protection emphasis

Alternative C: ground-based IPM

Alternative D: non-chemical pest management

Alternative E: no action

Considered but not further analyzed

Ammonia

Animal pests

Aquatic species

Backpack sprayer

Bat boxes

Bird boxes

Biological control

Black-capped chickadee

Breeding and preservation

B.t. (Bacillus thuringiensis)

Buffer

Burning. See prescribed fire

Calcium nitrate

Capsule implantation

Chemical pesticides. See also pesticides

Chinook salmon

Chlorothalonil

Chlorpyrifos

Clean Air Act

Clean Water Act

Climate and meteorology

Coho salmon

Cooperators

Cultural control

Cultural resources

Cumulative impacts

Cutthroat trout

Dazomet

Dicamba

Diazinon

Dimethoate

Disease

Drift

Drinking water

Ecological risk assessment

\section{Section}

2.2.2.2, 2.3.3, 4.7.3, App C, App D

4.4.2.4, 4.6.1, 4.6.2.2, 4.7.2.3

\section{4 .1}

2.2.2.2, 2.3.3, 4.7.3, App C

4.6.1, App C

2.2.2.2, App C

$3.2,4.2$

2.3

2.3.2

2.3 .3

2.3.4

2.3 .5

2.3.6

2.3.7

4.7.2.3, App C, App D

1.1.2.4

3.7.3, 4.7.1.2, 4.7.2.3, App C, App D

2.2.2.2, 2.3.3, 4.6.1, 4.6.3, App C

2.2.2.1

2.2.2.1, 4.7.3

2.2.2.1, 2.3, Chap 4

2.3.3, 3.7.2, 4.7.2.2, 4.7.3, App C

$2.2 .1,2.2 .2 .4$

2.2.2.1, 2.3, 4.6.1, App D

2.1.2, 2,3,1, 4.4, 4.6.1, App C

2.1.3, 2.3.3, 4.7.3, App C, App D

2.2.2.2, App C

2.2.2.2, 2.3.3, Chap 4, App C, App D

3.7.3, 4.7.2.3, App C, App D

2.2.2.2, App C, App D

2.2.2.2, 2.3.3, 4.6.3, App C, App D

$1.4 .2,3.2 .2$

$1.4 .2,3.4 .2$

3.2.1

3.7.3, 4.7.2.3, App C, App D

2.1.1

2.2.2.4, 2.3, Chap 4

$3.9,4.9$

4.11

3.7.3, 4.7.2.3, App C, App D

2.2.2.2, App C, App D

2.2.2.2, 4.6.3, App C, App D

2.2.2.2, 2.3.3, 4.6.3, App C, App D

2.2.2.2, 2.3.3, 4.6.3, App C, App D

1.1.2.2, App A

2.3.1, 2.3.3, 4.6, 4.7, App C

3.4.4, 4.6. App C 
Economic and income characteristics

3.10 .2

Employment

3.10 .2

Endangered Species Act

Environmental justice

Esfenvalerate

Essential fish habitat

EXAMS

Exposure assessment

Federal Insecticide, Fungicide, and Rodenticide Act

Federal Land Policy and Management Act

Fertilizers

Fish and Wildlife Coordination Act

Fisheries. See aquatic species

Floodplains

Fumigant

Fungicide

Geological resources

Geology. See geological resources

GLEAMS

Glyphosate

Granular spreader

Ground-based IPM

Groundwater

Hazard assessment

Hazard index

Herbicide

Hexazinone

High-pressure hydraulic sprayer

Horticultural oil

Human health

Hydraulic sprayer with hand-held wand

Impacts

Alternative A: maximum production IPM

Alternative B: IPM with environmental protection emphasis

Alternative C: ground-based IPM

Alternative D: non-chemical pest management

Alternative E: no-action

Insecticide

Insect pests

Integrated pest management (IPM)

IPM with environmental protection emphasis

Irreversible and irretrievable commitment of resources

Land use

League of Wilderness

Limitations

Little willow flycatcher
1.4.2, 3.7

3.10.3, 4.10.7

2.2.2.2, App C, App D

1.4.2, 3.7, 4.7

4.4.1, App C

4.6.1, App C

1.4.2, 2.4, App C

1.4.1, 1.4.2

2.2.2.5, Chap 4, App C, App D

1.4 .2

3.4.3, 4.4

2.2.2.2, App C, App D

2.2.2.2, App C, App D

$3.3,4.3$

4.4.1, App C

2.2.2.2, 2.3.3, App C, App D

2.2.2.2, 4.6.1, App C

2.3.4

3.4.1, 4.4.2.1

4.6.1, App C

4.6.1, App C

2.2.2.2, App C, App D

2.2.2.2, 4.6.3, App C, App D

2.2.2.2, 4.6.1, App C

2.2.2.2, 2.3.3, 4.7.3, App C, App D

3.6, 4.6, App C

2.2.2.2, 4.6.1, App C

2.6, 4.0, App C, App D

2.6, 4.2.2, 4.3.2, 4.4.2, 4.5.2,

4.6.2, 4.7.2, 4.8.2, 4.9.2, 4.10.2

2.6, 4.2.3, 4.3.3, 4.4.3, 4.5.2,

4.6.3, 4.7.3, 4.8.3, 4.9.2, 4.10.3

2.6, 4.2.4, 4.3.4, 4.4.4, 4.5.2,

4.6.4, 4.7.4, 4.8.4, 4.9.2, 4.10.4

2.6, 4.2.5, 4.3.5, 4.4.5, 4.5.2,

$4.6 .5,4.7 .5,4.8 .5,4.9 .2,4.10 .5$

2.6, 4.2.6, 4.3.6, 4.4.6, 4.5.2,

4.6.6, 4.7.6, 4.8.6, 4.9.2, 4.10.6

2.2.2.2, App C, App D

1.1.2.1, App A

2.2

2.3 .3

4.15

$3.5,4.5$

1.4 .2

2.3.3

2.3.3, 3.7.2, 4.7.2.2, 4.7.3, App C

Index -2 
Magnuson-Stevens Fisheries Conservation \& Management Act Manual control

Maximum application scenario

Maximum production IPM

Mechanical control

Migratory Bird Treaty Act

Mitigation measures

Monitoring

Mowing

Mulching

Mulch mats

National Environmental Policy Act

National pollutant discharge elimination system

New products and technologies

Nitrate

No action alternative

Non-chemical pest management

Noise

Northwest Area Noxious Weed Control EIS

Northwest Forest Plan

Ongoing and reasonably foreseeable future actions in study area

Orchard activities not included in analysis

Organic farm

Organophosphates

Organosulfites

Other (inert) ingredients

Other pest control methods

Pacific lamprey

Permethrin

Pest control methods

Pest management methods. See pest control methods

Pesticides.

Pests

Physiography. See geological resources

Picloram

Preferred alternative

Prescribed fire

Propargite

Propiconazole

Proposed action

Protection measures

Public

Public land orders

Purpose and need

Pyrethroids

Record of decision

Regional air quality

Resource management plan

Risk assessment

Risk characterization

Safe Drinking Water Act

Safer ${ }^{\circledR}$ Soap
$1.4 .2,3.7 .3$

2.2.2.4

4.6.1

2.3.2

2.2.2.4

1.4.2

2.3.3, 4.12

2.3.3, 4.4, 4.6.3, 4.7.3, Аpp B

2.2.2.4

2.2.2.4

2.2.2.4

$1.0,1.4 .2$

1.4 .2

2.4

2.1.3, 4.4.2, App C, App D

2.3.6

2.3 .5

$3.8,4.8$

1.4 .1

1.4.1

\section{5}

2.1.2

$1.3,3.5,4.10$

App D

App D

4.6.1, 4.7.1, App C, App D

2.2.2.5, App D

3.7.3, 4.7.2.3, App C, App D

2.2.2.2, App C, App D

2.2.2, App C, App D

2.2.2.2, Chap 4, App C, App D

1.1.2, App A

2.2.2.2, App C, App D

2.3.3

2.2.2.3, Chap 4

2.2.2.2, App C, App D

2.2.2.2, App C, App D

2.3.3

2.3.1, 2.3.3

2.6, 3.6, 3.10.1, 4.6.2.2, App C

1.4.1

1.1

App C, App D

$1.0,2.6,4.12$

3.2.2

$1.4 .1,4.1$

4.6, 4.7, App C

4.6.1, App C

1.4 .2

2.2.2.2, 4.6.1.4, App C, App D 
Scoping

Short-term uses vs. long term productivity

Sikes Act

Socioeconomics

Soils

Special status species

Steelhead

Stump grinding

Surface water

Survey and manage and protection buffer species

Sustainable Fisheries Act

Synergistic

Terrestrial wildlife

Threatened, endangered, and sensitive species.

See special status species

Tilling

Topography. See geological resources

Toxicity

Tractor-pulled spray rig with boom

Treatment methods. See pest control methods

Triclopyr

Typical application scenario

Unavoidable adverse impacts

Uncertainties

Vegetation

Washington Toxics Coalition

Water resources

Western bluebird

Western Oregon Program for Mgmt. of Competing Vegetation EIS

Wildlife. See terrestrial wildlife

Workers
1.3, Chap 5

4.14

1.4 .2

$2.6,3.10,4.10$

$2.6,3.3,4.3,4.4 .1$

2.6, 3.7.2, 3.7.3, 4.7.1.2, 4.7.2.1, 4.7.2.2, 4.7.2.3, App C, App D

3.7.3, 4.7.1.2, 4.7.2.3, App C, App D

2.2.2.4

2.6, 3.4.2, 4.4.2.2, 4.7, App C

1.4.1

1.4.2, 3.7.3

4.11

3.7.2, 2.3.3, 2.6, 4.7.2.2, App C

$2.1 .2,2.2 .2 .4$

4.6, 4.7, App C, App D

2.2.2.2, 4.6.1

2.2.2.2, 2.3.3, 4.7.3, App C, App D 4.6.1, App C

4.13

App C

1.1.2.3, 2.6, 3.7.1, 4.7.2.1

4.7 .2

$3.4,4.4$

2.3.3, 3.7.2, 4.7.2.2, 4.7.3, App C 1.4 .1

2.3.1, 3.6.2, 4.6.2.2, App C

Index -4 


\section{Appendix A: Seed Orchard Pests}

This appendix provides detailed information on the more common and damaging insects and diseases at the Tyrrell Seed Orchard; information on weeds and animal pests is provided in Chapter 1. It is not intended to be a complete guide to orchard insects and diseases in the Pacific Northwest Region.

\section{Insects}

\section{Cone gall midge (Contarinia oregonensis)}

Adults are flies, 3-4 mm in length, which emerge in early spring. The females lay eggs near the base of the cone scale in newly opened flowers. When the egg hatches, the larva tunnels into the young cone scale and forms a gall. When the mature cones become wet in the fall, the larvae drop to the litter and pupate. Cocoons are spun in the litter, and overwintering occurs in prepupal and pupal stages. Seeds may be fused to the scale when only a few larvae are present or completely destroyed when numbers are large. This insect can be a major destroyer of Douglas-fir seeds; severe infestations can destroy all seeds in the cone.

\section{Fir coneworm (Dioryctria abietivorella)}

As a group, coneworms are one of the most important North American lepidopterous cone pests. Life cycles and preferred hosts vary between species of coneworms. White fir, Douglas-fir, ponderosa pine, and sugar pine cones may be attacked. The adults are moderate-sized, drab-colored moths with mouth parts that are somewhat snout-like. Larvae can bore into the cambium of the trunk, branches, and shoots or into fresh green cones. The larva feeds voraciously, tunneling indiscriminately through the scales and seeds. One larva can destroy an entire cone. A heavy infestation can destroy $100 \%$ of a Douglas-fir cone (and seed) crop.

\section{Cone moth (Barbara colfaxiana)}

Adult cone moths are grayish brown in color with forewings transversely banded with gray, silver, and brown. The moth emerges in spring and the female lays eggs on the cone bract. The larva feeds first in scale tissue, but soon moves to the central seedproducing portion of the cone, where it mainly feeds on seeds. By the end of July, they pupate in a tough pitch-coated cocoon in the center of the cone. Feeding tunnels around the cone axis sharply reduce seed production. External evidence of damage differs depending on cone size. This insect is one of the major pests of Douglas-fir cones. One larva may destroy up to $60 \%$ of the seeds in a cone. Pupae may remain in diapause for one to three years in the old cones after they have fallen from the trees.

\section{Western conifer seed bug (Leptoglossus occidentalis)}

The broad flat tibia of the hind legs characterizes the western conifer seed bug, also called the leaf-footed bug. It feeds upon and damages the seed of Douglas-fir, sugar pine, and ponderosa pine. The adults are 15 to $18 \mathrm{~mm}$ long, and are reddish brown to dark gray with dense whitish pubescence. The seed bug overwinters in the adult stage and emerges in May or June; there is one generation per year. The eggs are deposited in rows on the needles from June until mid-August. Seed bug nymphs feed in the ovules and can cause conelet abortion. Later nymphal instars and adults feed on seeds. No external damage is visible on the cones. Both adult and nymph stages insert their long proboscises into cones to suck juices from the seeds, while the bug remains on outside of cone. Feeding by this insect lowers the quality of the seed crop, and heavy feeding can cause up to $40 \%$ loss in Douglas-fir seed crops. 


\section{Seed chalcid (Megastigmus spp.)}

The species of this genus include pests of a wide range of conifers. All species are highly specialized in their method of attack and feeding habits. Several species are found attacking Douglas-fir and true fir; however, only one species is known to attack pine $(M$. albifrons). The adults are small antlike wasps, which may be black to brown, or yellowish in color. The females are larger (about $4.0 \mathrm{~mm}$ long) with a long curved ovipositor. Eggs are deposited into immature seeds. Larvae feed only on seed contents, each one destroying a single seed. After devouring the contents, it remains within the seed coat. There is no external evidence of damage on the seeds until the adult emerges, after which a clearly defined emergence hole is evident. Larvae remain over winter in the seeds, either in the cone or in the litter under the trees in the orchard. It pupates in the spring.

\section{Bark beetles and wood borers}

A variety of small, dark-colored, winged beetles bore into standing green trees or downed slash material, or lay eggs on the bark surface of standing green trees or dead and downed trees. These damaging forest insects are ubiquitous throughout the forest, are specific to host trees, and maintain fairly consistent populations during normal conditions, but increase significantly during stressful events or conditions. Under normal circumstances, vigorous, healthy trees have unique capabilities to resist beetle attack. However, under adverse conditions such as disease infection, heat and drought damage, mechanical damage, high water tables, nutrient deficiencies, or a variety of other stressrelated tree conditions, the insect populations increase and infest weak trees, as well as healthy nearby trees.

An adult insect generally emerges in spring from a tree infested the previous year and flies to a susceptible green tree, where it excavates an egg gallery in the fresh phloem tissue. When the eggs hatch, the larvae bore away from the egg gallery and construct a mine that gradually increases in length and width. The pattern of adult and larval mines is distinctive for each insect species. The larvae pupate in the wood and overwinter as pupae or adults. Some species produce more than one generation in a year.

The trees are killed by fungi introduced into the tree by beetles feeding and boring in the phloem tissue, and the fungi expanding into the xylem tissue, obstructing the transport of water to the tree crown. The beetle galleries themselves also can become so numerous that the tree is girdled by insect activity.

\section{Disease}

\section{Armillaria root rot (Armillaria spp.)}

Armillaria root disease is the most common and most widely distributed forest root disease in Oregon and Washington. It is often found affecting trees that have been weakened by other agents, particularly drought or poorly drained soils. Symptoms of Armillaria root disease include thin and/or chlorotic foliage; distress cone crops; abundant resin flow, or leaching of brown liquid at tree bases; a yellow-stringy root and butt rot; and tree mortality. Crown and root collar symptoms occur on only $15-20 \%$ of the living infected trees with disease centers; infection in the remaining trees is virtually undetectable. Virtually all trees and other woody species in Oregon and Washington can be damaged by Armillaria root disease. It can locally be very severe in southwestern Oregon. In general, white fir is the most susceptible. Mortality caused by the disease is most common in Douglas-fir plantations between the ages of 10 and 25. Tree death after age 25 is uncommon unless the trees are stressed. The disease in Douglas-fir is often associated with poor planting technique, use of planting stock that is not adapted to a particular site, wounding, inadequate drainage, or soil compaction. Affected trees can be windthrown but tend to die standing. Tree death by the disease will often increase one to two years after severe droughts or nearly complete defoliation by insects. Spread of the disease from infected stumps or trees to adjacent healthy trees occurs mainly by mycelia 
growing across root contacts and, to a lesser extent, by rhyzomorphs that form after a stump or large root system has been colonized. Once a root is infected, the fungus can spread distally and proximally within it.

\section{Laminated root rot (Phellinus weirii)}

Laminated root rot is caused by the fungus Phellinus weirii. It is the most damaging root disease in the Pacific Northwest, estimated to cause annual losses of 32 million cubic feet of wood in western Oregon and Washington. Douglas-fir, mountain hemlock, white fir, and grand fir are especially susceptible; pines and cedars are considered to be tolerant or resistant and are seldom infected and killed. Crown symptoms of affected trees include retarded leader growth; short, sparse, and chlorotic faded foliage; and distress cone crops. Crown symptoms are usually not seen until at least half of the host root system is affected. Only about half the infected trees in a disease center will have crown symptoms. Laminated root rot extensively decays roots of highly susceptible host trees and either causes windthrow or kills the trees by destroying their ability to take up water and nutrients. Infected saplings and small poles usually die standing; larger trees are more likely to be windthrown. Infected trees may suffer growth loss for several years prior to death. Laminated root rot often predisposes highly susceptible hosts to bark beetle. Spreading of the disease is all by mycelia on or within the roots. The fungus can persist from tree generation to generation in infested areas and can be considered a disease of the site. It can survive up to 50 years in large roots and stumps of dead or cut trees, and can infect trees that become established nearby by growing across root contacts. This disease is found mostly in forested areas with a site history of its occurrence, and likely not to be found in non-forest conditions.

\section{Phomopsis canker (Phomopsis lokoyae)}

Infection of two-year-old stem tissue occurs early in the second growing season, resulting in a canker at the base of the new growth, which girdles the stem. The part of the shoot above the canker is killed. The disease appears periodically in the Pacific Northwest, typically 1 or 2 years after droughts. It is associated with prolonged periods of warm weather during budburst. Douglas-fir is most susceptible to this pest.

\section{Rhabdocline needlecast (Rhabdocline pseudotsugae)}

Rhabdocline needlecast is occasionally common, but seldom damaging in Douglas-fir stands. Yellow and purple blotches appear on infected needles in the fall and following spring. Needles drop one year after infection. Purplish-pink fruit bodies break through the undersides of one-year-old needles in May to June, exposing orange-brown spores. Spores released from them are windborne and require considerable moisture to germinate. Only the current season's needles are susceptible. There is considerable variation in the susceptibility of Douglas-fir to this disease. In general, coastal Douglasfir is less susceptible than the inter-mountain variety, and local seed source stock is less susceptible than offsite stock. However, trees within any stand show different levels of infection (many are immune). Disease is most common on trees 5-30 years old.

\section{Swiss needlecast (Phaeocryptopus gaumanni).}

This disease is very common in western Oregon and Washington. Damage is seldom serious in forest stands, but is probably the most important disease in Christmas tree plantations. Only Douglas-fir is attacked. Infected needles are killed and shed. Growth loss may result on severely infected trees. It has become an increasingly important concern as a threat to Douglas-fir in the Oregon Coast Range and western Cascades. For the past several years, Swiss needlecast has been especially damaging in stands within 30 miles of the Oregon coast north from Coos Bay. Affected trees exhibit yellowing and browning of infected previous year's needles in spring shortly after current needles emerge. One-and two-year-old needles are lost in summer, with needle loss beginning in the bottom of the crown and progressing upward. Severely infected trees may have only current season's needles in the fall. The disease cycle begins in spring when spores are released from fruiting bodies on older diseased needles. Spores are carried on air 
currents to newly emerged needles. When adequate moisture is present, the spores germinate and the fungus penetrates the needle. Needles are only susceptible for a few weeks after emergence. The fungus ramifies through the needles and, eventually, the fruiting bodies form in the stomata in the fall and winter and mature in the spring.

\section{Douglas-fir rust (Melampsora occidentalis)}

Native Melampsora rusts attack a wide variety of conifer hosts that belong to a number of different genera, including Douglas-fir (one of the primary hosts). Melampsora rusts attack the foliage of young primary hosts, most severely in the regeneration and sapling stages. The infected needles are killed and, in years of severe infections, all current year's foliage may be eliminated, resulting in growth reduction. Occasionally, cone scales are attacked, but no damage to seed occurs as happens with cone rusts. All foliage rusts cause yellow to orange discoloration or spots on the foliage of their hosts. For M. medusae and M. occidentalis, host alternation appears to be obligatory; that is, the presence and proximity of both poplars and conifers is necessary for the rust's survival. Basidiospores from secondary hosts infect the new foliage of the primary hosts in spring, and aecia begin to appear on the primary hosts approximately two weeks after infection. The aeciospores infect the secondary hosts during the summer, and uredinia begin to appear on them approximately two weeks after infection. Uredeniospores spread and intensify the rust on its secondary hosts. Toward fall, telia, instead of uredinia develop on the secondary hosts. They overwinter in a state of dormancy in dead leaves on the ground and germinate the following spring, at a time when young shoots of the primary hosts begin to break forth from their buds.

\section{White pine blister rust (Cronartium ribicola)}

White pine blister rust is caused by an obligate parasite that attacks sugar, white bark, and western white pines and several species of Ribes. The fungus needs the two alternate hosts to survive, spending part of its life on 5-needled pines and part on Ribes. Infection of pines results in cankers on branches and main stems, branch mortality, top kill, and tree mortality.

Spores (aeciospores) produced by the fungus in the spring on pine bole or branch cankers are wind-disseminated to Ribes where they infect the leaves. Spores (urediospores) produce orange pustules on the underside of the leaves that infect other Ribes throughout the summer, resulting in an intensification of the rust. A telial spore stage forms on Ribes leaves in the fall. Teliospores germinate in place to produce spores (sporidia), which are wind-disseminated to pines and infect current year needles. Following infection, the fungus grows from the needle into the branch and forms a canker. After two or three years, spores are produced on the cankers and are spread to Ribes to continue the cycle. Although blister rust may spread hundreds of miles from pines to Ribes, its spread back to pines is usually limited to a few hundred feet.

Environmental conditions are critical for successful infection and limit the disease in most years. Moisture and low temperatures must coincide with spore dispersal. 


\section{References}

Hunt, R.S. 1978. Melampsora Foliage Rusts in British Columbia. Forestry Canada, Forest Insect and Disease Survey, Forest Pest Leaflet No. 49.4 p. [as cited in Canadian Forest Service website: http:/ / www.pfc.cfs.nrcan.gc.ca/ diseases/hforest/pests/melfrust_ e.html]

USDA Forest Service. Online catalog of western forest insects and diseases. http: //www.fs.fed.us/r6/nr/fid/wid.shtml (insects) http://www.fs.fed.us/r6/nr/fid/ pubsweb/rootdiseases.shtml (root diseases)

http:/ / www.fs.fed.us/r6/rogue/swofidsc/ pineblister/ pineblister.html (white pine blister rust)

http:/ / www.psw.fs.fed.us/ifg/WPBR/wpbr.html (white pine blister rust)

USDA Forest Service. Nursery diseases of western conifers. Forest Service Insect and Disease Leaflet 157. http:/ / www.na.fs.fed.us/spfo/bpubs/fidls/disease_west/ nur_ diseases.htm

USDA Forest Service. 1991. Forest Service nursery pest management: Draft EIS. Eastern Region. Milwaukee, WI.

USDA Forest Service. 1991. Nursery pest management: Draft environmental impact statement. Rocky Mountain Region. Lakewood, CO.

USDA Forest Service. 1996. Humboldt Nursery pest management: Final environmental impact statement. Pacific Southwest Region. Vallejo, CA.

USDA Forest Service. 1997. Pest management for Foresthill Forest Genetics Center. Environmental Assessment. Pacific Southwest Region. Foresthill, CA. 
Final EIS - Tyrrell Seed Orchard IPM

$A-6$ 


\section{Appendix B: Monitoring Plan}

Note: This monitoring plan would be modified as necessary to address the differences between the various pesticides and application methods, and to respond to the results of on-going monitoring. If coho salmon are listed, BLM will meet the specific requirements that NOAA Fisheries established in the conference opinion for monitoring exposure and potential impacts to a listed species. The monitoring plan as currently established provides for comprehensive and thorough monitoring of potential impacts to all aquatic species.

The goals of the Tyrrell monitoring plan are as follows:

- Ensure water quality and other resources are protected during and after IPM applications.

- Ensure that target pests are identified and managed effectively (using IPM methods) to protect orchard trees, cone and seed crops, and facilities from damage.

- Ensure human health of BLM employees.

\section{B.1 Water Quality Monitoring}

\section{B.1.1 Background}

Agencies and the public are concerned that pesticide and fertilizer application at Tyrrell may enter streams and ground water, contributing to concentrations which exceed those known to impact human and aquatic life. Special status salmonid species occur in direct proximity to actively managed orchard units.

The risk characterization sections in the Human Health and Non-Target Species Risk Assessment of Pesticides and Fertilizers Proposed for Use at Travis Tyrrell Seed Orchard indicate the use of pesticides and fertilizers poses minimal threat to water quality with two possible exceptions: (1) pyrethroid insecticide residues in runoff under the maximum application scenario: and (2) ammonium phosphate-sulfate runoff under the maximum fertilizer application scenario.

This plan provides general direction for water quality monitoring whenever a pesticide or fertilizer covered under the environmental impact statement is proposed for use. The plan covers four types of monitoring: implementation monitoring, effectiveness monitoring, validation monitoring, and compliance monitoring. The implementation monitoring is intended to document the protective measures (best management practices, or BMPs) and limitations that are actually implemented. The effectiveness component documents how well these measures performed in avoiding introduction of chemicals to the aquatic and groundwater system. The effectiveness data would also be used to further validate that water quality modeling conducted for the Human Health and Non-Target Species Risk Assessment was conservative for orchard units. Compliance monitoring would be used to document domestic water quality and chemical fate in the case of an accidental spill.

Tyrrell is fortunate to be the beneficiary of monitoring activities conducted by the Horning Seed Orchard and the experience of an April 2003 pyrethroid application at Tyrrell. Water quality monitoring of an aerial esfenvalerate application at Horning during the spring of 2001 documented that introduction of drift is possible despite implementation of standard protective measures. Monitoring of a similar spray project in 2002 documented control of drift through implementation of additional streamspecific protective measures. During both periods of monitoring, surface runoff from the orchard units was found to be an insignificant pathway for esfenvalerate transport, as almost all actual and potential rainfall infiltrates the soil surface. No concentrations of 
esfenvalerate were recorded in streamflow samples during peak storm flow periods. This monitoring indicates that risk assessment estimates of chemical concentrations in surface runoff are very conservative and significantly over-estimate the potential for runoff and concentrations of exposure. The predicted model values have inherent uncertainty in terms of pesticide movement through subsurface pathways of preferential flow. During the April 2003 esfenvalerate application at Tyrrell, drift was limited to less than 50 feet with one drift card hit 30 feet away from the spray boundary. Runoff monitoring is still in progress.

Protective measures and limitations in the EIS proposed action are expected to minimize the potential water quality impacts from drift, runoff, and spills. Monitoring the protective measures and limitations, documenting impacts, and adjusting practices based on this knowledge are part of the EIS design features.

\section{B.1.2 Overall Objective}

The overall objective of the water quality monitoring program at Tyrrell is to document the impacts of IPM actions on water quality and to use this information to continue or modify the protective measures needed to meet the requirements for a healthy aquatic ecosystem. A full assessment of protective measures used in the orchard requires monitoring both groundwater and surface water. Documentation would focus on the following monitoring questions that have been formulated based on public concerns and prior monitoring results.

\section{B.1.3 Specific Monitoring Questions}

1. Does drift of pesticides occur?

Method: Monitor all aerial, airblast, and high-pressure hydraulic sprayer applications to ensure compliance with protective measures and to document application rates, environmental conditions, and the actual occurrence of drift.

2. Does application of pesticides or fertilizers result in measurable concentrations in the streams associated with the treated fields?

Method: Conduct effectiveness monitoring to ensure that the implemented protective measures were effective in preventing drift, surface runoff, and subsurface runoff from entering surface water.

3. If a spill occurs, what is the potential for surface water and groundwater contamination and what are the resulting concentrations in the associated stream and groundwater area?

Method: Depending on the type and amount of chemical, conduct surface water, groundwater, air, and soil monitoring to comply with the ODEQ Monitoring Hazardous Substances Remediation Rules (OAR 340-122). At a minimum, sample downslope streams and the immediate groundwater table if present. Conduct sampling of orchard domestic well if in proximity to spill.

4. What are the cumulative effects of the most toxic pesticides included in the IPM program?

Method: Conduct fall / winter monitoring of select streams for analysis of select chemicals applied during the previous season.

The overall strategies to address these questions and apply these methods are provided in the following sections. 


\section{B.1.4 Monitoring Strategies}

Implementing protective measures and analyzing monitoring data of all types depends heavily on quality climate information. Informed decisions involving pesticide or fertilizer application rely on access to on-site weather data. Maintenance of the existing seed orchard climate station would continue providing real-time climate data including air temperature, precipitation, wind speed, wind direction, and relative humidity. These data would provide documentation of compliance and information to predict runoff patterns for effectiveness and validation monitoring.

\section{B.1.4.1 Implementation Monitoring}

All pesticide and fertilizer applications would be documented by the orchard manager or designated representative. Items to be documented include type of chemical applied, date of application, method of application, area treated, amount applied, precipitation for the three days preceding and following application, location used for mixing and loading, wind direction and speed for aerial or airblast applications, relative humidity, air temperature, and notes regarding whether any leakage or spills occurred. A list of all protection measures and limitations for each unit applied would be provided in an Annual Tyrrell Seed Orchard Monitoring Report.

\section{B.1.4.2 Effectiveness Monitoring}

\section{Drift}

\section{Drift Card Monitoring}

All orchard units adjacent to flowing streams and planned for aerial, airblast, highpressure hydraulic sprayer applications, and select hand-held spray applications of chemicals would have spray cards placed such that drift from the application can be captured and characterized. Where the application unit is in direct proximity to a flowing stream, cards would be placed at a maximum of 200 -foot intervals along the edge of the unit prior to the application. Where open canopy occurs in the stream buffer, drift cards would be selectively placed to characterize potential intrusion of drift toward channels. Immediately after the application, the cards would be collected and reviewed to determine if a drift signature is present, the extent of the drift, and the potential for aquatic contamination. A copy of all the cards would be kept on file at Tyrrell along with a record of their location and all the compliance monitoring documentation.

\section{Surface Water Monitoring}

Water samples would be taken in streams before and during the 24 hours after spray application, dependant on the type of chemical, the distance from water and the application method. The time of collection would be based on the time of concentration measurements in the flowing channels associated with the treatment areas. Selection of sampling stations for surface water sampling would be based on the proximity to application areas. For aerial spray treatments, samples would also be collected above and below helicopter corridors in cases where the helicopter crosses a stream to access orchard spray units.

All data would be used in conjunction with the spray cards to determine the effectiveness of the full suite of protective measures and limitations implemented to avoid drift. Samples would be analyzed at a state-certified laboratory that has detection limits of 0.02 parts per billion (ppb) for most of the potential pesticides. Samples would be collected in accordance with laboratory instructions. When sites are sampled, additional interpretive data, such as $\mathrm{pH}$, specific conductance, turbidity, temperature, or suspended sediment 
may also be collected. At the discretion of the fish biologist, stream reaches may be visually inspected after application.

\section{Runoff}

\section{Surface Runoff}

Pesticide and fertilizer fate modeling from the risk assessment indicates that field runoff events within the first six months after spray application have the highest probability for carrying detectible concentrations of chemicals. One study (Rashin and Graber 1993) determined that runoff events within the first 72 hours of application were the most important in terms of increases in detectible chemical concentrations. Effectiveness monitoring of protection measures in the proposed action would target those periods of precipitation that could result in field surface runoff and increased stream flow. These periods are most likely to carry the greatest detectible concentrations of pesticides or fertilizers.

Previous rates of surface runoff and predicted concentrations at the Horning Seed Orchard have been shown to be significantly lower than the literature and model predictions for the soils and climate at the orchard (BLM 2002). Under this plan, similar investigations would be conducted at Tyrrell.

Perennially flowing Streams 8, 11, 12, 13, and 25 would be equipped with continuous flow recording devices. Flow-weighted water and sediment samples would be collected with the intention of providing individual storm concentrations. Other sampling designs would be employed if and where appropriate. Operation of these stations would target streams affected by application. The data from these stations would be used to characterize runoff response and to represent water quality conditions as a result of the effectiveness of implemented protective measures and limitations in the higher-risk seed production orchards.

Semi-permeable membrane devices (SPMDs) may be used in lieu of flow-weighted sampling, particularly when there are concerns about sublethal concentrations below the laboratory detection limit. SPMDs could be used to "accumulate" pesticides to detect levels that would otherwise be undetectable by traditional water sampling. In response to public and regulatory concerns, SPMDs are in use in this capacity at Tyrrell with respect to an April 2003 pyrethroid application. Details regarding SPMDs are provided in the Cumulative Effects Runoff discussion below.

Stream 54 is an important perennial and non-perennial stream. Depending on the type of and location of application, it would either be monitored individually, like Streams 8, 11, 12,13 , and 25; or a site on Stream 8 would be used to characterize potential runoff from both Streams 8 and 54 .

All data would be used in conjunction with continuous recorded climate data to assess the effectiveness of protection measures and limitations in minimizing introduction of pesticides and fertilizers to the aquatic system. Samples would be analyzed at a state-certified laboratory that has detection limits of $0.02 \mathrm{ppb}$ for most of the potential pesticides. Samples would be collected in accordance with laboratory instructions.

\section{Cumulative Effects Runoff}

In 2001, Horning Seed Orchard monitoring did not address the potential for nondetectible chemical concentrations, which over a cumulative period could reach sublethal levels affecting beneficial uses. Horning 2002 monitoring and Tyrrell 2003 monitoring was adapted to address sublethal levels. There is also concern over the transitory 
nature of concentrations in the stormflow period and questions on whether sampling is accounting for concentration which may be present. Manpower, budget, and logistics all demand that only flows with the highest potential for chemical presence be sampled. During these flow events, samples are often combined according to the rise and fall of the hydrograph, which in turn can inadvertently diminish concentrations.

In an effort to address these issues and answer the cumulative effects question, SPMDs would be deployed, as appropriate, in Streams 8, 11, 12, 13, and 25 to monitor the accumulation of pesticides in reaches containing aquatic species. The SPMD is an instream "accumulator" which allows calculation of an average chemical concentration during the period of deployment. For this reason, the SPMDs would only be deployed during the initial winter storm and spring storm periods after pesticide application.

Streamflow measurement sites in Streams 8, 11, 12, 13, and 25 would provide flow data for deriving concentrations (chemical loading) over the period of time the SPMD is deployed. Operation of these stations and associated SPMD units would target streams affected by application. Data from the SPMD concentrations would be used to compare and validate the storm flow concentration monitored during the deployment period. Since previous monitoring at the Horning Seed Orchard documented no detection of esfenvalerate at $0.02 \mathrm{ppb}$ for all storm flow monitoring, the SPMD would serve as a better indicator of a "low concentration" presence of the pesticide and provide documentation of beneficial use exposure over time.

Stream 54 is an important perennial and non-perennial stream. Depending on the type and location of application, it would either be monitored individually, like Streams 8, 11, 12,13 , and 25; or the site on Stream 8 would be used to characterize potential runoff from both Streams 8 and 54 .

\section{B.1.4.3 Validation Monitoring}

Validation monitoring is intended to verify the water quality modeling predictions presented in the EIS. Concentrations well below those that would cause sublethal effects to fish were predicted for Stream 8 and Douglas Creek. Stream 8 and the "affected" tributaries (Streams 11, 12, 13, and 25) of Douglas Creek would be monitored to determine the effectiveness of protective measures, and to help validate the conservative estimates in the risk assessment.

Collection chambers would be installed in areas where there are concerns regarding overland flow. During the first overland flow event following select pesticide applications, a water sample would be taken from the collection chamber. Once the first surface runoff event is captured and results become available, the need to sample later runoff events would be determined based on concentrations detected. In the short term, these data would be used to assess the mobility of chemicals of high aquatic toxicity. Concentrations would be compared with previously modeled predictions used to develop the protective measures in the EIS.

Additional validation utilizing field- and climate-specific data to validate risk assessment estimates would occur in selected cases, such as higher risk application areas, where validation findings could lead to improved protection measures, or if unusual weather conditions prevailed. Detectible stream concentrations gathered from Streams 8, 11, 12 , 13 , and 25 would be compared to model results using actual application information, field-specific data, and continuous climate record. These data would provide relationships between previous monitoring results and management that is planned for the future. Once the yearly application period is complete, the climate record collected during that period may be used to model a predicted concentration using the GLEAMS and MOC models. These concentrations would be "diluted" using the continuous flow 
data from the station. The resulting concentrations would be compared with the actual measured detectible concentrations for each storm event sampled.

\section{B.1.4.4 Compliance Monitoring}

In the event of a chemical spill, the volume of spill, proximity to water, and chemical characteristics such as toxicity and mobility would be evaluated to determine if water sampling is desirable and necessary. If so, water samples may be collected in a sufficient number and at surface water and groundwater locations that would allow characterization of impacts and effective remediation methods. Depending on ODEQ Monitoring Hazardous Substances Remediation Rules (OAR 340-122), monitoring could include surface water, groundwater, air, and soil. At a minimum, sampling would be conducted in the streams draining the spill area and the immediate groundwater table, if present. If in proximity to the spill, the orchard domestic well would be sampled.

\section{B.1.5 Annual Reporting}

All water quality monitoring information associated with the Tyrrell Seed Orchard IPM program would be compiled, analyzed, and documented on a "water year" basis. This "water year" would include all monitoring performed during the October 1 to September 30 period (for example, October 1, 2003 to September 30, 2004). This information, along with any recommendation for adjustments to BMPs (protective measures) and the monitoring plan, would be contained in an Annual Tyrrell Seed Orchard Monitoring Report. This report would be made available to the public and regulatory agencies on November 15 of each year and would be on file at the Tyrrell Orchard. BLM will request that NOAA's review of this plan be complete by January 15 of the following year. This schedule should provide for timely inclusion of monitoring results in the Annual Operating Report, inclusion of the full period of runoff during the fall / winter period, and planning for the upcoming budget year.

\section{B.1.6 Responsibility}

Specific aspects of implementing this plan would be determined by the Eugene District hydrologist in coordination with the seed orchard manager, tailoring the site-specific monitoring needs to the chemicals actually applied, the level of use, the risk of entering water, and the toxicity. The district hydrologist would be responsible for formalizing the water sampling plans with the orchard manager, selecting sample locations and times, analyzing sample results, reporting annual water monitoring results, presenting results to regulatory agencies, and submitting an annual budget.

Responsibility for maintaining all sampling sites, collecting all water samples, QA/QC, transferring samples to the laboratory as appropriate, coordination with the analysis lab, and providing data for analysis would be coordinated by the seed orchard manager and district hydrologist and assigned to appropriate personnel.

\section{B.2 Pest Monitoring}

Monitoring of pests (insects, diseases, vegetation, unwanted animals) is an integral and ongoing component of the orchard integrated pest management program. A wide variety of monitoring tools are used to detect and report the incidence and severity of pest activity and damage to orchard resources and facilities.

Knowledge of potential pests, recognition of damage symptoms, past damage in the orchard or surrounding lands, analysis of the damage in relation to objectives, and other factors help to determine the best way to manage pests as part of an IPM program. Field 
observations and pest identification methods, along with specific pest and damage survey techniques, are used to detect the presence of pests and the severity of damage. Annual assessments of cone and seed insect populations and damage are used to predict potential crop damage and the need for pest control. Other insect, disease, vegetation (noxious weeds and competing vegetation), and animal pests are routinely surveyed throughout the orchard during normal orchard activities and projects and during periodic orchard tree inventories.

Pest and damage survey data are collected, summarized, and evaluated to determine if control measures are needed and the most effective methods of control. The primary focus of pest management in the orchard is the protection of cone and seed crops. A variety of methods are currently used to determine the presence of cone-damaging insects at Tyrrell.

Monitoring for the seed chalcid has taken place at Tyrrell since 1998 using a sampling technique developed by U.S. Forest Service entomologists. Sticky traps are monitored for chalcid in the spring between the time when the first cones turn pendant until ten days after all cones are pendant. Results from this monitoring give an approximate estimate of seed chalcid populations and anticipated chalcid damage.

Monitoring for the cone gall midge has been done using two techniques: pheromone traps and ground traps. Pheromones lure the males to a sticky trap, from which information is gathered on emergence and potential damage. The procedure is still under development by entomologists at the University of British Columbia, with the goal of developing strong correlations between trap counts and insect damage. Ground traps have also been used to determine the timing of cone gall midge emergence from the duff and litter layer, but this method does not predict potential damage.

Cone dissection research, under the direction of Beth Wilhite, a U.S. Forest Service entomologist, is ongoing each fall following cone collection. Cones are manually dissected and seed is examined under a microscope and through $\mathrm{x}$-rays to determine the degree of damage caused by each of the cone insects. The results of this process are compared with those from the spring monitoring traps, field observations, and actual seed yields.

In the future, pest monitoring plans would be modified and expanded to incorporate new research and include new pests. To help with this effort, forest health (insect and disease) specialists are contacted as necessary to assist in pest identification and assessment and to obtain IPM recommendations. For other IPM work, noxious weed specialists, botanists, wildlife biologists, fish biologists, and silviculturists may be contacted for expertise in identification of pests or control methods. Also, seed orchard staff members receive periodic training to build a knowledge base for recognition of orchard pests and damage symptoms.

\section{B.3 Human Health Monitoring}

All BLM employees involved in pesticide application programs at Tyrrell would be required to participate in a monitoring program. Monitoring would ensure that all of the worker protection measures and limitations to protect worker health are implemented.

Documentation would include such things as names and application duties of involved individuals, chemical(s) used, dates of application, acreage and location of treatment areas, use of protective clothing and equipment, duration of exposure, and method of application. 
Baseline medical evaluations would be conducted on BLM employees for the use of cholinesterase-inhibiting pesticides. The Government would not conduct medical or personal monitoring of contractors involved with pesticide application.

\section{References}

BLM. See U.S. Bureau of Land Management.

OAR 340-122. Hazardous Substance Remedial Action Rules. Oregon Department of Environmental Quality.

ODF. See Oregon Department of Forestry.

Oregon Department of Forestry. 1997. Forest chemical monitoring program. November 1997. Salem, OR.

Rashin, E., and C. Graber. 1993. Effectiveness of best management practices for aerial application of forest pesticides. TFW-WQ1-93-001. State of Washington Timber, Fish and Wildlife. Olympia, WA.

U.S. Bureau of Land Management. 2002. Horning Seed Orchard Esfenvalerate Spray 2002, Water Quality Monitoring Report for Salem District. C.A. Novak and K.A. Appleman. Salem, OR. 


\section{Appendix C: Risk Assessment Summary}

\section{C.1 Risks to Human Health}

A quantitative risk assessment was conducted to estimate the risks to members of the public and workers as a result of using the proposed pesticides and fertilizers at Tyrrell Seed Orchard, as described under Alternative A, Maximum Seed Production. The application details are listed in Table 2.2-1 in Chapter 2 of this EIS, and the proposed application methods are described in an attachment to this appendix. The supporting record for this EIS contains the full risk assessment. The methodology and results of the human health risk assessment are summarized in the following paragraphs. Detailed information on inputs, methodology, assumptions, and outputs can be found in Sections $4.0,5.0$, and 6.0 of the risk assessment report.

Computerized fate and transport modeling was conducted to estimate concentrations of pesticides in environmental media at the point of exposure. The Groundwater Loading Effects of Agricultural Management Systems (GLEAMS) model was used to characterize the leaching and runoff behavior of the pesticides. Published studies and the Method of Characteristics model were used to represent attenuation of pesticides in runoff through buffer zones, and to estimate concentrations in groundwater, on-site streams, Douglas Creek, and the Siuslaw River. AgDRIFT was used to estimate off-target pesticide drift from aerial applications, airblast applications, and applications using a tractor-pulled spray rig with a boom. Field studies reported in the published literature provided the basis for estimates of drift from other ground-based pesticide application methods. The Exposure Analysis Modeling System model was used to predict downstream concentrations following accidental spills of pesticide concentrate or tank mixes. Section 3.0 of the risk assessment report provides an overview of the models, their inputs, and the results obtained. The estimated surface water and groundwater concentrations due to runoff or leaching are presented in Tables C-1 and C-2, respectively, and the estimated drift deposition results are presented in Table C-3.

To assess the risk of human health effects from using pesticides and fertilizers at Tyrrell, it was necessary to estimate the human exposures that could occur as a result of the proposed applications and associated activities, and to estimate the probability and extent of adverse health effects that could occur as a result of those exposures. This risk assessment employs the three principal analytical elements that the National Research Council (1983) described and EPA $(1989,2000$ a) affirmed as necessary for characterizing the potential adverse health effects of human exposures to existing or introduced hazards in the environment: hazard assessment, exposure assessment, and risk characterization.

The risk assessment addresses risks from fertilizers and the 16 pesticide active ingredients, as well as "other" ingredients in the pesticide formulations, formerly termed "inert" ingredients. EPA (2000b) has classified these other ingredients into four categories, based on the degree of toxicity posed by the chemical, as follows:

- List 1: Inerts of toxicological concern.

- List 2: Potentially toxic inerts, with high priority for testing

- List 3: Inerts of unknown toxicity

- List 4: Inerts of minimal concern

To include consideration of potential risks from these chemicals, any "other" ingredients in the proposed pesticide formulations that appear on either List 1 or List 2 are included 


\section{Table C-1. Estimated Surface Water Concentrations from Runoff and Erosion (mg/L)}

\begin{tabular}{|c|c|c|c|c|c|c|c|}
\hline \multirow[b]{2}{*}{ Chemical } & \multirow[b]{2}{*}{ App Method* } & \multicolumn{3}{|c|}{ Onsite Stream Segments } & \multicolumn{3}{|c|}{ Main Sec. 15 Tributary to Siuslaw River ("Segment 8") } \\
\hline & & Тур & & Max & Typ & & Max \\
\hline Acephate & HPHS & $-0-$ & & $-0-$ & $-0-$ & 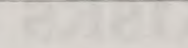 & $-0-$ \\
\hline Chlorpyrifos & HPHS & $3.12 \mathrm{E}-007$ & & $1.43 \mathrm{E}-005$ & $-0-$ & & $2.26 \mathrm{E}-006$ \\
\hline Diazinon & HPHS & $1.83 \mathrm{E}-008$ & & $2.78 \mathrm{E}-005$ & $-0-$ & & $4.54 \mathrm{E}-006$ \\
\hline Dimethoate & HPHS & $-0-$ & & $-0-$ & -0 & & $-0-$ \\
\hline Cyclohexanone & & $-0-$ & & $-0-$ & $-0-$ & 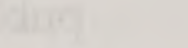 & $-0-$ \\
\hline \multirow[t]{2}{*}{ Petroleum distillate } & & $4.23 \mathrm{E}-007$ & & $6.54 \mathrm{E}-005$ & $1.70 \mathrm{E}-007$ & & $1.98 \mathrm{E}-005$ \\
\hline & & 1 app & 2 apps & & $1 a p p$ & 2 apps & \\
\hline Esfenvalerate (both sections) & Aerial & $2.06 \mathrm{E}-007$ & $5.25 \mathrm{E}-007$ & $1.92 \mathrm{E}-005$ & $8.02 \mathrm{E}-008$ & $2.05 \mathrm{E}-007$ & $5.65 \mathrm{E}-006$ \\
\hline Ethylbenzene & (both sections) & $3.53 \mathrm{E}-009$ & $3.55 \mathrm{E}-008$ & $4.00 \mathrm{E}-006$ & 4.13E-010 & $6.39 \mathrm{E}-009$ & $1.37 \mathrm{E}-006$ \\
\hline Xylene & & $-0-$ & -0 & -0 & $-0-$ & $-0-$ & $-0-$ \\
\hline Esfenvalerate & Aerial & $1.49 \mathrm{E}-007$ & $3.81 \mathrm{E}-007$ & & $1.49 \mathrm{E}-007$ & $3.81 \mathrm{E}-007$ & \\
\hline Ethylbenzene & (Section 15) & $7.66 \mathrm{E}-010$ & $1.19 \mathrm{E}-008$ & 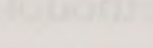 & $7.66 \mathrm{E}-010$ & $1.19 \mathrm{E}-008$ & \\
\hline Xylene & & $-0-$ & -0 & 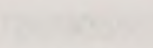 & -0 & $-0-$ & \\
\hline Esfenvalerate (both sections) & Airblast & $5.41 \mathrm{E}-008$ & $1.38 \mathrm{E}-007$ & $8.60 \mathrm{E}-006$ & $2.11 \mathrm{E}-008$ & $5.36 \mathrm{E}-008$ & $2.54 \mathrm{E}-006$ \\
\hline Ethylbenzene & (both sections) & $-0-$ & $1.26 \mathrm{E}-008$ & $1.74 \mathrm{E}-006$ & $-0-$ & $9.41 \mathrm{E}-010$ & $5.93 \mathrm{E}-007$ \\
\hline Xylene & & $-0-$ & $-0-$ & $-0-$ & $-0-$ & $-0-$ & $-0-$ \\
\hline Esfenvalerate & Airblast & $3.91 \mathrm{E}-008$ & $9.97 \mathrm{E}-008$ & & $3.91 \mathrm{E}-008$ & $9.97 \mathrm{E}-008$ & t \\
\hline Ethylbenzene & (Section 15) & $-0-$ & $1.75 \mathrm{E}-009$ & & $-0-$ & $1.75 \mathrm{E}-009$ & \\
\hline Xylene & & $-0-$ & $-0-$ & & $-0-$ & $-0-$ & \\
\hline Esfenvalerate (both sections) & HPHS \& HHW & $2.03 \mathrm{E}-008$ & $5.13 \mathrm{E}-008$ & $5.97 \mathrm{E}-006$ & $1.31 \mathrm{E}-008$ & 3.34E-008 & 3.03E-006 \\
\hline Ethylbenzene & (both sections) & $-0-$ & $5.56 \mathrm{E}-010$ & $1.15 \mathrm{E}-006$ & $-0-$ & $5.16 \mathrm{E}-010$ & $6.23 \mathrm{E}-007$ \\
\hline Xylene & & $-0-$ & $-0-$ & $-0-$ & $-0-$ & -0 & $-0-$ \\
\hline Esfenvalerate & HPHS \& HHW & $3.91 \mathrm{E}-008$ & $9.97 \mathrm{E}-008$ & & $3.91 \mathrm{E}-008$ & $9.97 \mathrm{E}-008$ & \\
\hline Ethylbenzene & (Section 15) & $-0-$ & $1.40 \mathrm{E}-009$ & & $-0-$ & $1.40 \mathrm{E}-009$ & \\
\hline Xylene & & $-0-$ & $-0-$ & & $-0-$ & $-0-$ & \\
\hline Horticultural Oil & HPHS & $2.89 \mathrm{E}-006$ & & $1.21 \mathrm{E}-004$ & $-0-$ & 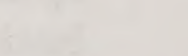 & $1.97 \mathrm{E}-005$ \\
\hline Permethrin & HPHS & $1.81 \mathrm{E}-008$ & & $1.46 \mathrm{E}-006$ & $-0-$ & & $-0-$ \\
\hline Ethylbenzene & & $-0-$ & & $2.14 \mathrm{E}-006$ & $-0-$ & & $-0-$ \\
\hline Light aromatic solvent naphtha & & $7.09 \mathrm{E}-007$ & & 4.13E-005 & $-0-$ & fit & $-0-$ \\
\hline Xylene & & $-0-$ & & $-0-$ & $-0-$ & $\sqrt{1}=$ & $-0-$ \\
\hline Propargite & HPHS & $2.47 \mathrm{E}-007$ & & $1.37 \mathrm{E}-005$ & $-0-$ & & $2.10 \mathrm{E}-006$ \\
\hline Chlorothalonil & HPHS & $2.46 \mathrm{E}-007$ & & $3.49 \mathrm{E}-005$ & $-0-$ & & $5.70 \mathrm{E}-006$ \\
\hline Propiconazole & Ground & $2.19 \mathrm{E}-006$ & & $2.34 \mathrm{E}-006$ & 2.19E-008 & & $2.34 \mathrm{E}-006$ \\
\hline Dicamba & Ground & $-0-$ & a & $-0-$ & $-0-$ & 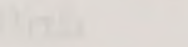 & $-0-$ \\
\hline Glyphosate & Ground-circles & $2.38 \mathrm{E}-007$ & & $1.26 \mathrm{E}-005$ & $1.04 \mathrm{E}-007$ & & $5.09 \mathrm{E}-006$ \\
\hline Glyphosate & Ground-strips & $4.43 \mathrm{E}-007$ & & $7.61 \mathrm{E}-005$ & $-0-$ & & $-0-$ \\
\hline Hexazinone & Ground-circles & $-0-$ & & $6.83 \mathrm{E}-007$ & $-0-$ & & $2.63 \mathrm{E}-007$ \\
\hline Hexazinone & Ground-strips & $-0-$ & & $3.82 \mathrm{E}-006$ & $-0-$ & $\sqrt{12}+x_{1}$ & $-0-$ \\
\hline Picloram & Ground & $-0-$ & & $7.23 \mathrm{E}-009$ & $-0-$ & & 7.23E-009 \\
\hline Hexachlorobenzene & & -0 & & $7.23 \mathrm{E}-013$ & -0 & & 7.23E-013 \\
\hline Triclopyr triethylamine salt & Ground & $-0-$ & & $9.27 \mathrm{E}-009$ & $-0-$ & & $3.89 \mathrm{E}-009$ \\
\hline Triclopyr butoxyethyl ester & Ground & $6.69 \mathrm{E}-007$ & & $2.99 \mathrm{E}-005$ & $2.69 \mathrm{E}-007$ & 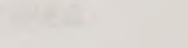 & $1.27 \mathrm{E}-005$ \\
\hline Dazomet & Spreader & $-0-$ & (1) & $-0-$ & $-0-$ & $=4 x_{1}$ & $-0-$ \\
\hline & & $700 \mathrm{lb} / \mathrm{acre}$ & 1,000 lb/acre & & $700 \mathrm{lb} / \mathrm{acre}$ & $1,000 \mathrm{lb} / \mathrm{acre}$ & \\
\hline Ammonium Phosphate-Sulfate & Spreader & & & & & & \\
\hline Nitrogen (as N) & & $2.42 \mathrm{E}-002$ & $4.75 \mathrm{E}-002$ & $1.13 \mathrm{E}+000$ & $1.26 \mathrm{E}-002$ & $2.42 \mathrm{E}-002$ & $6.31 \mathrm{E}-001$ \\
\hline Phosphorus (as P2O5) & & $9.33 \mathrm{E}-003$ & $1.44 \mathrm{E}-002$ & $3.14 \mathrm{E}-002$ & $9.42 \mathrm{E}-004$ & $1.45 \mathrm{E}-003$ & $1.77 \mathrm{E}-002$ \\
\hline Calcium Nitrate (as N) & Hand & $1.74 \mathrm{E}-002$ & & $2.07 \mathrm{E}-002$ & $8.86 \mathrm{E}-003$ & & $1.17 \mathrm{E}-002$ \\
\hline
\end{tabular}


Table C-1. Estimated Surface Water Concentrations from Runoff and Erosion (mg/L) (cont.)

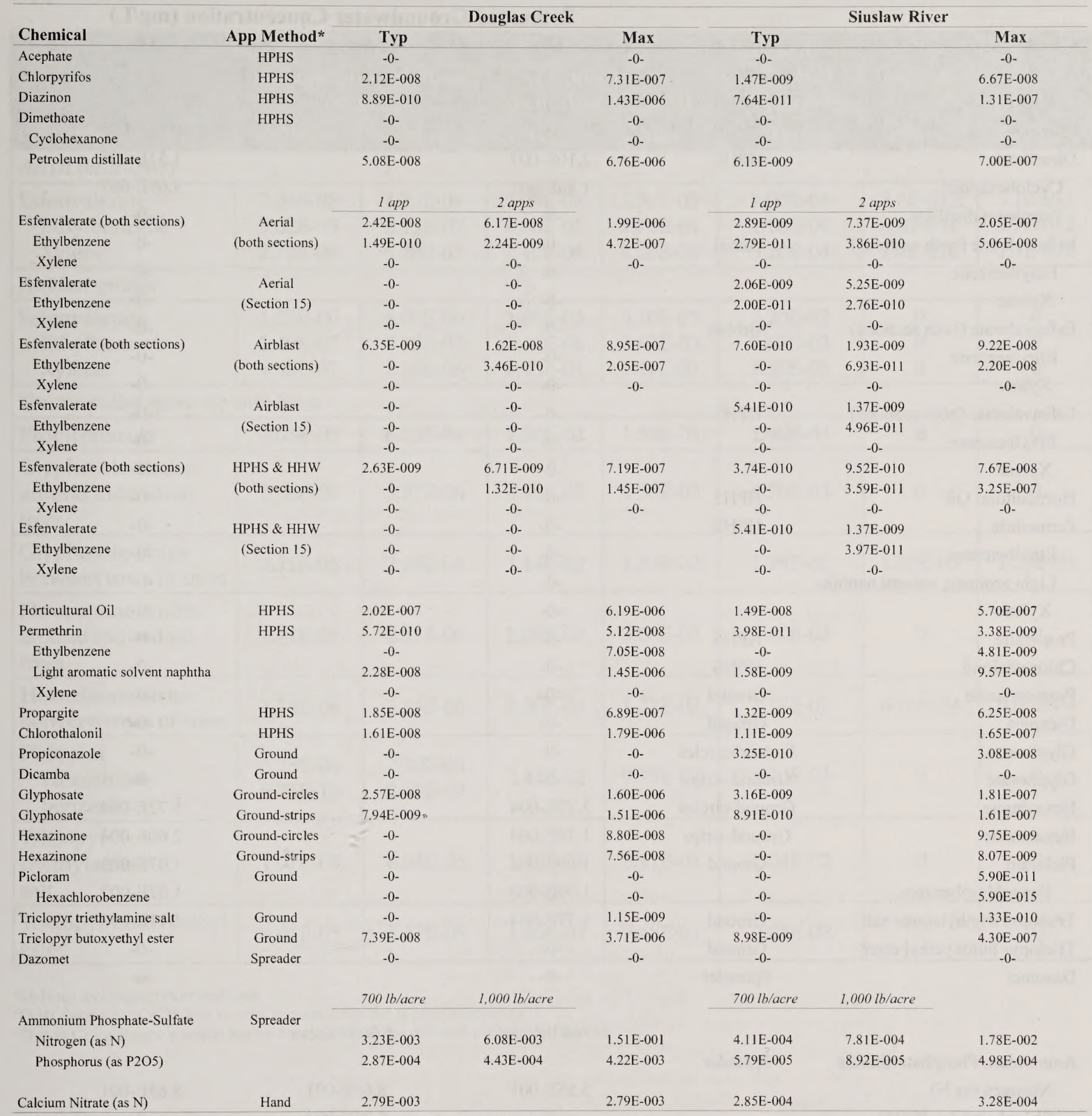

*HPHS = high-pressure hydraulic sprayer; $\mathrm{HHW}=$ hydraulic sprayer with hand-held wand

Note: $1 \mathrm{mg} / \mathrm{L}=1$ part per million $(\mathrm{ppm})=0.001$ parts per billion $(\mathrm{ppb})$ 


\section{Table C-2. Estimated Groundwater Concentrations (mg/L)}

\begin{tabular}{|c|c|c|c|c|}
\hline \multirow[b]{2}{*}{ Chemical } & \multirow[b]{2}{*}{ Method } & \multicolumn{3}{|c|}{ Estimated Groundwater Concentration (mg/L) } \\
\hline & & Typ & & Max \\
\hline Acephate & HPHS & $-0-$ & 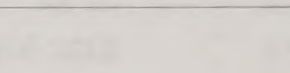 & $-0-$ \\
\hline Chlorpyrifos & HPHS & $-0-$ & $\sqrt{1}$ & $-0-$ \\
\hline Diazinon & HPHS & $-0-$ & & $9.84 \mathrm{E}-009$ \\
\hline Dimethoate & HPHS & $2.10 \mathrm{E}-007$ & 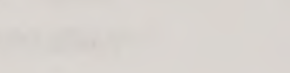 & $1.51 \mathrm{E}-005$ \\
\hline Cyclohexanone & & $1.36 \mathrm{E}-007$ & & $3.69 \mathrm{E}-007$ \\
\hline Petroleum distillate & & $-0-$ & & $-0-$ \\
\hline Esfenvalerate (both sections) & Aerial & $-0-$ & $\sqrt{3}$ & $-0-$ \\
\hline Ethylbenzene & & $-0-$ & & $-0-$ \\
\hline Xylene & & $-0-$ & & $-0-$ \\
\hline Esfenvalerate (both sections) & Airblast & $-0-$ & & $-0-$ \\
\hline Ethylbenzene & & $-0-$ & 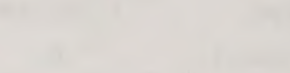 & $-0-$ \\
\hline Xylene & 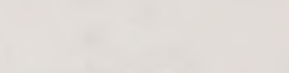 & $-0-$ & 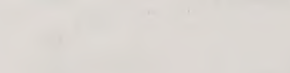 & $-0-$ \\
\hline Esfenvalerate (both sections) & HPHS & $-0-$ & & $-0-$ \\
\hline Ethylbenzene & 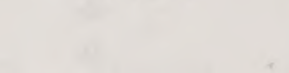 & $-0-$ & & $-0-$ \\
\hline Xylene & & $-0-$ & 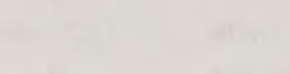 & $-0-$ \\
\hline Horticultural Oil & HPHS & $-0-$ & 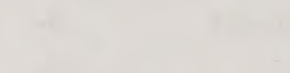 & $-0-$ \\
\hline Permethrin & HPHS & $-0-$ & 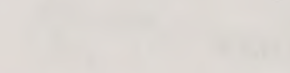 & $-0-$ \\
\hline Ethylbenzene & & $-0-$ & 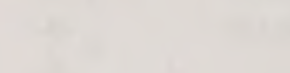 & $-0-$ \\
\hline Light aromatic solvent naphtha & & $-0-$ & & $-0-$ \\
\hline Xylene & 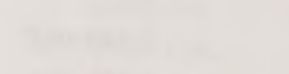 & $-0-$ & 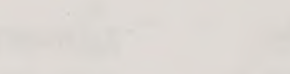 & $-0-$ \\
\hline Propargite & HPHS & $-0-$ & & $-0-$ \\
\hline Chlorothalonil & HPHS & $-0-$ & - & $-0-$ \\
\hline Propiconazole & Ground & $-0-$ & 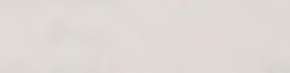 & $-0-$ \\
\hline Dicamba & Ground & $-0-$ & 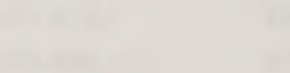 & $-0-$ \\
\hline Glyphosate & Ground-circles & $-0-$ & 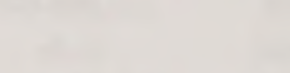 & $-0-$ \\
\hline Glyphosate & Ground-strips & $-0-$ & rat & $-0-$ \\
\hline Hexazinone & Ground-circles & $3.82 \mathrm{E}-004$ & $\sqrt{3}$ & $5.72 \mathrm{E}-004$ \\
\hline Hexazinone & Ground-strips & $1.74 \mathrm{E}-004$ & $\sqrt{3}$ & $2.60 \mathrm{E}-004$ \\
\hline Picloram & Ground & $1.09 \mathrm{E}-004$ & 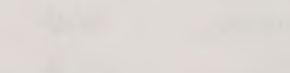 & $1.07 \mathrm{E}-003$ \\
\hline Hexachlorobenzene & 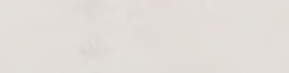 & $1.09 \mathrm{E}-008$ & 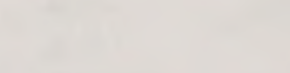 & $1.07 \mathrm{E}-007$ \\
\hline Triclopyr triethylamine salt & Ground & $1.77 \mathrm{E}-004$ & 1 & $1.11 \mathrm{E}-003$ \\
\hline Triclopyr butoxyethyl ester & Ground & -0 & 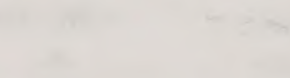 & $-0-$ \\
\hline Dazomet & Spreader & $-0-$ & & $-0-$ \\
\hline & & $700 \mathrm{lb} / \mathrm{acre}$ & 1,000 lb/acre & \\
\hline Ammonium Phosphate-Sulfate & Spreader & & & \\
\hline Nitrogen (as N) & & $5.55 \mathrm{E}-001$ & $8.68 \mathrm{E}-001$ & $8.68 \mathrm{E}-001$ \\
\hline Phosphorus (as P2O5) & & $-0-$ & $5.25 \mathrm{E}-003$ & $-0-$ \\
\hline Calcium Nitrate (as N) & Hand & $2.25 \mathrm{E}-001$ & & 7.94E-001 \\
\hline
\end{tabular}

Note: $1 \mathrm{mg} / \mathrm{L}=1$ part per million $(\mathrm{ppm})=0.001$ parts per billion $(\mathrm{ppb})$ 
Table C-3. Estimated Drift Deposition from Aerial, Airblast Sprayer, and Boom Applications

\begin{tabular}{|c|c|c|c|c|c|c|c|}
\hline \multirow[b]{2}{*}{ Pesticide } & \multicolumn{2}{|c|}{$\begin{array}{c}\text { Stream Concentration } \\
(\mathrm{mg} / \mathrm{L})^{\mathrm{a}}\end{array}$} & \multicolumn{2}{|c|}{$\begin{array}{c}\text { Deposition at } \\
\text { Fenceline (lb/acre) }\end{array}$} & \multirow{2}{*}{$\begin{array}{c}\begin{array}{c}\text { Deposition } \\
\text { at } 25 \text { Feet } \\
\text { (lb/acre) }\end{array} \\
\text { Typ }^{b} \\
\end{array}$} & \multicolumn{2}{|c|}{$\begin{array}{c}\text { Deposition at House } \\
\text { (lb/acre) }\end{array}$} \\
\hline & Typ & Max & Typ & Max & & Typ & $\operatorname{Max}$ \\
\hline \multicolumn{8}{|l|}{ Aerial (helicopter) } \\
\hline Esfenvalerate & $7.58 \mathrm{E}-08$ & $1.79 \mathrm{E}-06$ & $4.00 \mathrm{E}-04$ & 2.30E-03 & $9.00 \mathrm{E}-04$ & $5.0 \mathrm{E}-010$ & $3.1 \mathrm{E}-011$ \\
\hline Ethylbenzene & $9.02 \mathrm{E}-09$ & $2.13 \mathrm{E}-07$ & $4.80 \mathrm{E}-05$ & $2.70 \mathrm{E}-04$ & $1.10 \mathrm{E}-04$ & $6.0 \mathrm{E}-011$ & 3.7E-012 \\
\hline Xylene & $2.70 \mathrm{E}-08$ & $6.38 \mathrm{E}-07$ & $1.40 \mathrm{E}-04$ & 8.20E-04 & $3.20 \mathrm{E}-04$ & $1.8 \mathrm{E}-010$ & $1.1 \mathrm{E}-011$ \\
\hline \multicolumn{8}{|l|}{ Airblast sprayer } \\
\hline Esfenvalerate & $1.25 \mathrm{E}-06$ & $6.04 \mathrm{E}-06$ & $1.80 \mathrm{E}-03$ & $3.10 \mathrm{E}-03$ & $2.20 \mathrm{E}-02$ & 0 & 0 \\
\hline Ethylbenzene & $1.49 \mathrm{E}-07$ & $7.18 \mathrm{E}-07$ & $2.14 \mathrm{E}-04$ & $3.69 \mathrm{E}-03$ & $2.62 \mathrm{E}-03$ & 0 & 0 \\
\hline Xylene & $4.48 \mathrm{E}-07$ & $2.16 \mathrm{E}-06$ & $6.43 \mathrm{E}-04$ & $1.11 \mathrm{E}-03$ & $7.85 \mathrm{E}-03$ & 0 & 0 \\
\hline \multicolumn{8}{|c|}{ Tractor-pulled spray rig with boom } \\
\hline Propiconazole & $1.03 \mathrm{E}-05$ & 6.73E-04 & $1.30 \mathrm{E}-03$ & $1.30 \mathrm{E}-03$ & $1.90 \mathrm{E}-03$ & 0 & 0 \\
\hline $\begin{array}{l}\text { Glyphosate-circles } \\
\text { around individual } \\
\text { trees }\end{array}$ & $2.86 \mathrm{E}-06$ & 3.77E-06 & $3.40 \mathrm{E}-03$ & $4.50 \mathrm{E}-03$ & $4.70 \mathrm{E}-03$ & 0 & 0 \\
\hline $\begin{array}{l}\text { Glyphosate-strips } \\
\text { between rows of trees }\end{array}$ & $2.11 \mathrm{E}-06$ & $2.68 \mathrm{E}-06$ & $1.44 \mathrm{E}-02$ & $1.83 \mathrm{E}-02$ & $1.99 \mathrm{E}-02$ & $1.00 \mathrm{E}-03$ & $1.20 \mathrm{E}-03$ \\
\hline $\begin{array}{l}\text { Hexazinone-circles } \\
\text { around individual } \\
\text { trees }\end{array}$ & $1.71 \mathrm{E}-06$ & $2.51 \mathrm{E}-06$ & $2.00 \mathrm{E}-03$ & $3.00 \mathrm{E}-03$ & $2.80 \mathrm{E}-03$ & 0 & 0 \\
\hline $\begin{array}{l}\text { Hexazinone-strips } \\
\text { between rows of trees }\end{array}$ & $1.24 \mathrm{E}-06$ & $1.86 \mathrm{E}-06$ & $8.50 \mathrm{E}-03$ & $1.27 \mathrm{E}-02$ & 1.17E-02 & $6.00 \mathrm{E}-04$ & $9.00 \mathrm{E}-04$ \\
\hline $\begin{array}{l}\text { Picloram } \\
\text { Hexachloro- } \\
\text { benzene }\end{array}$ & $\begin{array}{l}5.75 \mathrm{E}-06 \\
5.75 \mathrm{E}-10\end{array}$ & $\begin{array}{l}2.30 \mathrm{E}-05 \\
2.30 \mathrm{E}-09\end{array}$ & $2.44 \mathrm{E}-02$ & $9.75 \mathrm{E}-02$ & $4.20 \mathrm{E}-03$ & 0 & 0 \\
\hline $\begin{array}{l}\text { Triclopyr } \\
\text { triethylamine } \\
\text { salt }\end{array}$ & $1.01 \mathrm{E}-05$ & $6.04 \mathrm{E}-05$ & $1.40 \mathrm{E}-01$ & $8.41 \mathrm{E}-01$ & $2.04 \mathrm{E}-02$ & 0 & 0 \\
\hline $\begin{array}{l}\text { Triclopyr butoxyethyl } \\
\text { ester }\end{array}$ & $1.01 \mathrm{E}-05$ & $5.37 \mathrm{E}-05$ & $1.40 \mathrm{E}-01$ & 7.48E-01 & $2.04 \mathrm{E}-02$ & 0 & 0 \\
\hline
\end{tabular}

a24-hour average concentrations.

${ }^{b}$ Drift deposition at 25 feet is only required for the typical scenarios.

'This is Craig Royce's rental house located SE of the orchard units in Section 15. 
in this quantitative risk assessment, along with the active ingredient in the formulation. Accordingly, the following "other" ingredients are included in the human health (and non-target species) risk assessments:

- Cyclohexanone: present in Digon ${ }^{\circledast} 400$ formulation of dimethoate.

- Ethylbenzene: present in the Asana ${ }^{\circledR}$ XL formulation of esfenvalerate and the Pounce ${ }^{\circledR}$ 3.2 EC formulation of permethrin.

- Light aromatic solvent naphtha: present in the Pounce ${ }^{\circledR} 3.2 \mathrm{EC}$ formulation of permethrin.

- Petroleum distillates: present in the Digon ${ }^{\circledR} 400$ formulation of dimethoate.

- Xylene: present in the Asana ${ }^{\circledR}$ XL formulation of esfenvalerate and the Pounce ${ }^{\circledR} 3.2$ EC formulation of permethrin.

\section{C.1.1 Human Health Hazard Assessment}

\section{Methodology and Data Summary}

Hazard assessment requires gathering information to determine the toxic properties of each chemical and its dose-response relationship. Human hazard levels are derived primarily from the results of laboratory studies on animals. The goal of the hazard assessment is to identify acceptable doses for noncarcinogens, and identify the cancer potency of potential carcinogens.

For noncarcinogenic effects, it is generally assumed that there is a threshold level, and that doses lower than this threshold can be tolerated with little potential for adverse health effects. EPA has determined threshold doses for many chemicals; these are referred to as reference doses (RfDs). The oral RfD is an estimate of the highest possible daily oral dose of a chemical that will pose no appreciable risk of deleterious effects to a human during his or her lifetime. The uncertainty of the estimate usually spans about one order of magnitude.

EPA selects the RfD using the lowest no-observed-effect level (NOEL) from the species and study most relevant to humans. (The NOEL is the dose in a toxicity study at which there is no statistically or biologically significant increase in the frequency or severity of an adverse effect in individuals in an exposed group, when compared with individuals in an appropriate control group.) In the absence of data from the most clearly relevant species, a study using the most sensitive species (the species that exhibited the lowest NOEL) is selected for use in RfD determination. This NOEL is divided by an uncertainty factor (usually 100) consisting of a factor of 10 to allow for the variation of response within the human population and a factor of 10 to allow for extrapolation to humans. Additional uncertainty factors may be applied to account for extrapolation from a shorter term study, overall inadequacy of data, or failure to determine a no-effect level. RfDs are expressed in units of $(\mathrm{mg} / \mathrm{kg} / \text { day })^{-1}$.

In many cases, exposures to the chemicals proposed for use at Tyrrell will not occur every day for a person's lifetime, but over a shorter duration. EPA's Risk Assessment Guidance for Superfund (EPA 1989) discusses the use of subchronic RfDs when exposures may range from two weeks to seven years in duration, instead of an individual's entire lifetime. These subchronic RfDs are not used in the assessment of risks from seed orchard chemicals, for the following reasons: 
- The seed orchard pesticide and fertilizer use programs are anticipated to be in effect for more than seven years, exceeding the upper time limit for exposure in EPA's discussion of appropriate use of subchronic RfDs. It is safe to assume that length of employment and length of residence may make the exposure scenarios applicable to an individual worker or nearby resident for longer than a seven-year period.

- EPA (2000c) stated that subchronic RfDs should not be used to evaluate risks to children, as they may not be sufficiently protective. Children are a subset of the general public whose risks are assessed in the analysis.

Additionally, the use of chronic RfDs provides a more conservative estimate of the dose-response relationship in all cases, decreasing the likelihood of underestimating any potential risks to any worker or member of the public.

Data on carcinogenic potential were reviewed for each chemical. Acephate, permethrin, and propargite are considered possible human carcinogens; and chlorothalonil and hexachlorobenzene (a contaminant in picloram) are considered to be probable human carcinogens. For these compounds, cancer slope factors that have been calculated by EPA or other appropriate sources are used in this risk assessment. The cancer slope factor of a chemical represents the probability that a $1-\mathrm{mg} / \mathrm{kg} /$ day chronic dose will result in formation of a tumor, and is expressed as a probability, in units of "per $\mathrm{mg} / \mathrm{kg} / \mathrm{day}$ " or (mg/kg/day)-1.

The RfDs and cancer slope factors used in this risk assessment are summarized in Table 4.6-1 in Chapter 4 of this EIS.

\section{Data Availability and Quality}

A consistent level of information on all data points researched was not available for all of the chemicals evaluated in this risk assessment. For the endpoints evaluated in this quantitative risk assessment, there are no data gaps in the information available for acephate, chlorothalonil, chlorpyrifos, diazinon, dimethoate, esfenvalerate, glyphosate, permethrin, picloram, propargite, and propiconazole. However, the following data gaps were identified and addressed as described:

- No dermal absorption data were available for dazomet, so a value of $10 \%$ was assumed. Inhalation exposure to dazomet's hydrolysis products is expected to be the route with the highest potential for exposure to humans from this pesticide, so this assumption is not likely to significantly affect the conclusions of the risk assessment.

- No studies of dermal absorption were available for dicamba. USDA (1984) recommended a value of $10 \%$ as a conservative assumption. This value is used in the risk assessment.

- Hexazinone's carcinogenic potential is unknown, with equivocal results from one study in mice and negative results from a study in rats. Cancer risks are not quantified for this pesticide.

- Conclusive information was not available on triclopyr's potential for carcinogenicity. Therefore, no judgment was made as to whether it is potentially carcinogenic, and no quantitative cancer risk analysis was conducted.

- No dermal absorption factor was identified for cyclohexanone. A value of $10 \%$ was selected for use in the risk assessment. Carcinogenicity findings for cyclohexanone were inconclusive. No quantitative analysis of the compound's cancer risk is conducted. 
- Inhalation studies of ethylbenzene in rats and mice resulted in some tumors in the high-exposure groups, although EPA lists it as not classifiable as to human carcinogenicity. No cancer risk assessment is conducted for this chemical.

- Although naphthalene (an example of the "other" ingredient light aromatic solvent naphtha) is considered a possible human carcinogen, the available data do not allow calculation of a cancer slope factor; therefore, no quantitative estimate of cancer risk from light aromatic solvent naphtha compounds is made. No dermal absorption data were available, so a default value of $10 \%$ was selected for use in the risk assessment.

- For xylene, one negative and one equivocal carcinogenicity study were reported, and dermal studies have indicated a potential for xylene to be a promoter or co-carcinogen for skin cancer. Due to the lack of conclusive information, no judgment was made in this risk assessment as to whether xylene is potentially carcinogenic, and no quantitative cancer risk analysis was conducted for it.

- No dermal absorption data were available for the fertilizers. A value of $1 \%$ was used in the risk assessment.

\section{C.1.2 Human Health Exposure Assessment}

Exposure assessment involves estimating doses to persons potentially exposed to the pesticides or fertilizers. In the exposure assessment, dose estimates were made for typical, maximum, and accidental exposures. These exposures are defined as follows:

- Typical: For this risk assessment, the word "typical" refers to a level of exposure within a scenario, and does not indicate whether the scenario itself is likely to occur. Typical exposure reflects the average dose an individual may receive if all exposure conditions are met. Typical exposure assumptions include the application rate usually used at the seed orchard, usual number of applications per year, the average of the ten highest values for chemical concentrations predicted to be present in runoff over a 10 year period of annual typical applications, and other similar assumptions.

- Maximum: Maximum exposure defines the upper bound of credible doses that an individual may receive if all exposure conditions are met. Maximum exposure assumptions include the maximum application rate according to the label, maximum number of applications per year, the highest chemical concentration predicted to be present in runoff over a 10-year period of annual maximum applications, and other similar assumptions.

- Accidental: The possibility of error exists with all human activities. Therefore, it is possible that during seed orchard operations, accidents could expose individuals to unusually high levels of pesticides or fertilizers. To examine these potential health effects, several accident scenarios were evaluated for health effects to members of the public and workers.

It is important to note that these exposure scenarios estimate risks from clearly defined types of exposure. If all the assumptions in an exposure scenario are not met, the dose will differ from that estimated here, or may not occur at all.

For members of the public, the exposure scenarios analyzed in this risk assessment consist of the following:

- Ingestion of groundwater.

- Ingestion of water from Douglas Creek near the logging camp on Siuslaw River Road (not a known source of drinking water). 
- Ingestion of fish from Siuslaw River downstream of orchard drainages.

- Ingestion of deer hunted near grounds.

- Dermal exposure to insecticide/fungicide drift residues on vegetation, or herbicide treatment residues on vegetation, during recreational hiking on orchard grounds.

- Dermal exposure to residues on dogs following recreational use of site.

The categories of workers evaluated in this risk assessment for occupational exposure to pesticides are as follows:

- Helicopter pilot.

- Helicopter mixer/loader.

- Airblast sprayer mixer/loader/applicator.

- High-pressure hydraulic sprayer mixer/loader/applicator.

- Hydraulic sprayer with hand-held wand mixer/loader/applicator.

- Tractor-pulled spray rig with boom mixer/loader/applicator.

- Backpack sprayer mixer/loader/applicator.

- Ground pull spreader loader/applicator.

- Hand fertilizer applicator.

- Cone surveyor.

- Fumigant irrigator.

Several accidental exposure scenarios were also evaluated:

- Ingestion of fish and water downstream of a spill of concentrate.

- Ingestion of fish and water downstream of a spill of tank mix.

- Spill of pesticide concentrate onto worker's skin.

- Spill of pesticide mixture onto worker's skin.

- Spray of worker with tank mix of pesticide.

\section{C.1.3 Human Health Risk Characterization}

\section{Methodology}

Risk characterization requires comparing the hazard information with the dose estimates to predict the potential for health effects to individuals under the conditions of exposure. The risk characterization also identifies uncertainties (such as data gaps where scientific studies are unavailable) that may affect the magnitude of the estimated risks.

In this risk assessment, the potential noncarcinogenic risks were evaluated by comparing the representative doses (estimated in the exposure assessment) with the RfDs (identified in the hazard assessment). All the RfDs used in this risk analysis take into account multiple exposures over several years and represent acceptable dose levels. The comparison of dose to RfD consists of a simple ratio, called the hazard index:

$$
\text { Hazard Index }=\text { Estimated Dose }(m g / \mathrm{kg} / \text { day }) \div R f D(m g / k g / \text { day })
$$

If the estimated dose does not exceed the RfD, the hazard index will be one or less, indicating a negligible risk of noncarcinogenic human health effects. It is important to note two characteristics of the hazard index: (1) the greater the value of the hazard above one, the greater the level of concern; but (2) the level of concern does not increase linearly as the hazard index increases, because RfDs do not have equal accuracy or precision and are not based on the same severity of toxic effects. Thus, the interpretation of the potential toxic response associated with a particular hazard index can range widely depending on the chemical (EPA 1989). 
A dose estimate that exceeds the RfD, although not necessarily leading to the conclusion that there will be toxic effects, clearly indicates a potential risk for adverse health effects. Risk is presumed to exist if the hazard index is greater than one. However, comparing one-time or once-a-year doses (such as those experienced by the public or in an accident) to RfDs derived from long-term studies with daily dosing tends to exaggerate the risk from those infrequent events.

For workers and the public, hazard indices were computed for each chemical, application, and scenario for typical, maximum, and accident situations. For pesticide formulations containing ingredients on EPA's List 1 or 2 of "other" ingredients, the hazard indices for each component of the formulation are added together, to indicate the total risk to the exposed individual from that pesticide.

If the hazard index exceeds one, the risk may require mitigation, depending on the circumstances of exposure. For workers, this may mean reducing the quantity of pesticide to which the worker is exposed or increasing the level of protective clothing. For members of the public, it may mean decreasing the application rate or using measures to reduce the potential for runoff to reach streams. In some cases, the simple mitigation procedures will not reduce exposures (and thereby decrease the hazard index) to an acceptable level. In these cases, the seed orchard manager may consider use of a different pesticide or use a non-pesticide method to meet management goals.

To estimate cancer risk, the dose is averaged over a lifetime (75 years), and multiplied by the chemical's cancer slope factor. The resulting cancer probability is compared to a benchmark value of one in one million, a value commonly accepted in the scientific community as representing a cancer risk that would result in a negligible addition to the background cancer risk of approximately one in four in the U.S.

\section{Risk Summary}

Hazard indices and cancer risks for each chemical and scenario are presented in tables in Section 6.0 of the risk assessment report. The chemicals and scenarios for which risks were identified are summarized in the following paragraphs and in Table 4.6-2 in Chapter 4 of this EIS.

\section{Members of the Public}

For members of the public, hazard indices were less than one for all typical and maximum exposure scenarios, and cancer risks were all less than $1 \times 10^{-6}$ ( 1 in 1 million), ranging up to $7.90 \times 10^{-10}$ (7.9 in 10 billion).

\section{Workers}

For typical scenarios, worker hazard indices are less than one, with the following exceptions:

- A high-pressure hydraulic sprayer mixer/loader/applicator applying dimethoate,

- A backpack sprayer applying dicamba, and

- A cone surveyor encountering residues of chlorpyrifos, diazinon, or dimethoate.

In the maximum scenarios, the hazard indices exceed one for the following workers:

- A high-pressure hydraulic sprayer mixer/loader/applicator applying diazinon or dimethoate; 
- A backpack sprayer applying dicamba or hexazinone; and

- A cone surveyor encountering residues of chlorpyrifos, diazinon, or dimethoate.

The estimated cancer risk to cone surveyors encountering propargite residues is 1.69 in one million, slightly exceeding the standard point of departure of one in one million. All other cancer risks to workers were less than one in one million.

\section{$\underline{\text { Risk Management Approaches }}$}

If applications of these pesticides were prescribed, risks to mixer/loader/applicators could be mitigated by decreasing the application rate, using water soluble bags (if available), spreading the work over a longer time period, increasing the use of personal protective equipment, and dividing the work between two or more workers. Risks to cone surveyors could be mitigated by increasing the time period between applications and cone surveying to allow additional degradation, decreasing the application rate, increasing the use of personal protective equipment, and dividing the work between two or more workers.

\section{$\underline{\text { Accidents }}$}

For spill of a container of chemical concentrate from Siuslaw River Road into Douglas Creek, risks to the public from drinking water and eating fish from the Siuslaw River are predicted for chlorpyrifos, diazinon, dimethoate, esfenvalerate, permethrin, chlorothalonil, propiconazole, and dazomet. All cancer risks are less than one in one million.

For spill of a container of chemical concentrate from Road 20-5-16 into a tributary to the Siuslaw River, risks to the public from drinking water and eating fish from the Siuslaw River are predicted for diazinon, dimethoate, permethrin, and chlorothalonil. All cancer risks are less than one in one million.

For spill of a container of chemical concentrate from the Section 9 road that crosses Segment 13, risks to the public from drinking water and eating fish from the Siuslaw River are predicted for chlorpyrifos, diazinon, dimethoate, esfenvalerate, permethrin, chlorothalonil, and dazomet. All cancer risks are less than 1 in 1 million.

For spill of an application tankload of mixed pesticide or fertilizer from Siuslaw River Road into Douglas Creek, risks to the public from drinking water and eating fish from the Siuslaw River are predicted for chlorpyrifos, diazinon, dimethoate, esfenvalerate, permethrin, propargite, chlorothalonil, dazomet, and nitrate (under the extremely conservative assumption that all nitrogen from the ammonium phosphate-sulfate fertilizer was present as nitrate). In addition, the cancer risk to children from propargite is estimated to be 1.85 in one million.

For spill of an application tankload of mixed pesticide or fertilizer from the remaining three accident scenarios ( from Road 20-5-16 into a tributary to the Siuslaw River in the south end of Section 15, from an orchard road in Section 9 into a tributary to Douglas Creek, and from an orchard road in the north end of Section 15 into a tributary to the Siuslaw River), risks to the public from drinking water and eating fish from the Siuslaw River are predicted for diazinon, dimethoate, chlorothalonil, and dazomet. All cancer risks are less than one in one million.

In the scenario in which a worker spills liquid pesticide concentrate on the skin, hazard indices exceed one for the acephate, dimethoate, esfenvalerate, permethrin, chlorothalonil, propiconazole, and dicamba formulations. Estimated cancer risks were all less than one in one million. 
In the scenario in which a worker spills tank-mixed diluted pesticide on the skin, hazard indices are greater than one for chlorpyrifos, diazinon, dimethoate, and dicamba. All estimated cancer risks are less than one in one million.

Hazard indices for the accident scenario in which a worker was directly sprayed exceed one for chlorpyrifos, diazinon, and dimethoate. Estimated cancer risks are all less than one in one million.

\section{Cumulative Human Health Risks}

No data indicating synergistic toxicity exists among the proposed chemicals were identified. Therefore, cumulative human health risks were estimated assuming additive toxicity.

For members of the public, risks were aggregated from all routes of exposure for each chemical, as estimated for the typical scenarios. These chemical-specific aggregated risks were then added together to provide an upper bound estimate of the cumulative risk for adults and children. Actual cumulative risk values are likely to be far less than the results estimated in this assessment, since (1) it is highly unlikely that one individual would be exposed to every chemical in all of the scenarios evaluated in the risk assessment; (2) several pesticides are proposed for use as alternatives for certain groups of target pests or weeds, and if one was selected for use in a given season, the alternatives would not also be used; (3) where multiple application methods are possible for a proposed pesticide treatment scenario, the method with the highest associated risk was included in the cumulative assessment; and (4) the temporal spacing of the potential chemical applications would correspond to a timeline in which some exposure routes were no longer active due to dissipation and degradation, prior to application of other chemicals. The upper bound cumulative risk estimates are as follows:

- Cumulative hazard indices are 0.327 and 0.553 for adult and child members of the public, respectively. These values do not exceed the reference value of 1 , at which noncarcinogenic hazard indices are concluded to represent a risk.

- Cumulative cancer risks are $8.60 \times 10-10$ (8.60 in 10 billion) and $1.54 \times 10-9$ (1.54 in one billion) for adult and child members of the public, respectively. Neither value exceeds the cancer risk criterion of one in one million.

For workers, the highest cumulative exposure could occur if one employee was involved in all pesticide applications, with the exception of aerial applications, which are always conducted by a contractor. In this case, the cumulative hazard index for workers is 62.5 , and the cumulative cancer risk is 1.96 in one million. It is important to note that this cumulative risk scenario includes the unlikely case in which all pesticides that target every pest problem are called for during the season. The highest contributor to the cumulative hazard index is dimethoate (51.5). The estimated cumulative cancer risk to workers is $1.96 \times 10^{-6}$. The main contributor to this risk is propargite, which is associated with a $1.85 \times 10^{-6}$ cancer risk for an individual conducting both application and cone surveying activities.

\section{Uncertainties}

The risks summarized in this assessment are not probabilistic estimates of risk, but are conditional estimates. That is, these risks are likely only if all exposure scenario assumptions that were described are met. In addition, the methodology applied to 
estimating risks is not definitive, since uncertainty in the final risk estimates is introduced in almost every step of the assessment. Some of the primary areas of uncertainty are as follows:

- The accuracy of the RfDs in approximating doses to humans that pose negligible risk of health effects, without either under- or overestimating these doses: the RfDs are derived from tests in laboratory animals. Extrapolating the results of animal tests to human health hazards has an inherent level of uncertainty associated with it.

- The use of the conservative approach, recommended by EPA, that chronic toxicity data be used in estimating risks from occasional (or, at most, subchronic) exposures to the chemicals proposed for use at the seed orchard.

- The cancer slope factors, in providing a good approximation of the chemical's carcinogenic potency in humans: updated guidelines for estimating cancer risks are in progress that may provide a different approach to estimating cancer risks for some of the chemicals evaluated in this report (see discussion in Section 6.2.2 of the risk assessment report). However, reassessment of the carcinogenic mechanism and application of an appropriate strategy for cancer risk assessment for any one chemical may be years away. This analysis uses the cancer risk approach currently used by EPA for estimating the cancer potency of each chemical.

- The equations and studies on which the dose estimations are based: Many monitoring studies have been conducted since the 1970s that measure exposures to pesticides in a range of situations. This risk assessment relies on those that (1) are most relevant to the types of applications at the seed orchard, (2) incorporated sound methodology to provide a degree of confidence in the reported results, and (3) monitored, correlated, and reported a sufficient number of parameters to allow extrapolation to other situations.

All together, it is likely that the uncertainty in the risk estimates predicted in this assessment spans at least an order of magnitude. For example, for a hazard index estimated to be 0.0035 , the true value is likely to be within the range of 0.035 to 0.00035 , as a result of the uncertainties described here.

\section{C.2 Risks To Non-Target Species}

A quantitative non-target species risk assessment was conducted to evaluate the potential effects of the proposed chemical pesticides and fertilizers on terrestrial and aquatic wildlife species. The methodology and results are summarized in the following paragraphs; detailed information on inputs, methodology, assumptions, and outputs can be found in Sections 7.0, 8.0, and 9.0 of the risk assessment report.

The results of computerized fate and transport modeling were used to estimate concentrations of chemicals at points of exposure for non-target species, just as described in the summary of the human health risk assessment. Details of the methods and models can be found in Section 3.0 of the risk assessment report. Estimated surface water concentrations from runoff and drift are presented in Tables C-1 and C-3.

The non-target species risk assessment follows the steps of problem formulation, analysis, and risk characterization, as described in EPA's Guidelines for Ecological Risk Assessment (EPA 1998). This risk assessment also identifies uncertainties that are associated with the conclusions of the risk characterization. Risks to non-target species were evaluated for the fertilizers, pesticides, and List 1 or 2 "other" ingredients in the pesticide formulations. 


\section{C.2.1 Problem Formulation}

In problem formulation, the purpose of the assessment is provided, the problem is defined, and a plan for analyzing and characterizing risk is determined. The potential stressors (in this case, pesticides and fertilizers), the ecological effects expected or observed, the receptors, and ecosystem(s) potentially affected are identified and characterized. Using this information, the three products of problem formulation are developed: (1) assessment endpoints that adequately reflect management goals and the ecosystem they represent, (2) conceptual models that describe key relationships between a stressor and assessment endpoint, and (3) an analysis plan that includes the design of the assessment, data needs, measures that will be use to evaluate risk hypotheses, and methods for conducting the analysis phase of the assessment.

The ecological effects that may be associated with the chemical pesticides and fertilizers are those associated with direct toxicity to non-target species that encounter the chemical. Permanent or persistent exposures through environmental pathways are not expected, since the half-lives of these chemicals are on the order of one month or less. Control of certain pests and vegetation in and of itself is not expected to affect the area's wildlife, since the seed orchard is a managed area, and has been managed for tree species preservation and seed production for 16 years.

The receptors in this non-target species risk assessment were selected to represent the range of species present at or near Tyrrell, along with specific evaluation of special status species that may inhabit or visit the site. These receptors include mammals, birds, reptiles, amphibians, fish, and aquatic vertebrates for which quantitative risk estimates can be made.

Assessment endpoints are selected based on three criteria: ecological relevance, susceptibility to stressors, and relevance to management goals (EPA 1998). For special status species, the assessment endpoint selected is individual survival, growth, and reproduction. For general species present at the seed orchard, the assessment endpoint selected is the survival of populations.

A conceptual model was developed to illustrate the relationships between stressors, exposure routes, and receptors. The conceptual model is presented in Figure 4.7-1 in Chapter 4 of this EIS.

Based on the conceptual model, an analysis plan was developed with the following components:

- Selection of typical and maximum exposure scenarios to evaluate risks to terrestrial and aquatic wildlife species;

- Identification of representative terrestrial and aquatic species and their characteristics, illustrating the various types of exposure that wildlife species may have to chemicals used at the seed orchard;

- Estimation of environmental exposures in terms of dose $(\mathrm{mg} / \mathrm{kg})$ for terrestrial species or concentration $(\mathrm{mg} / \mathrm{L})$ for aquatic species;

- Research and summary of the toxic properties of each pesticide, "other" ingredient, and fertilizer to wildlife species, to identify endpoints, including median lethal doses (LD50s), median lethal concentrations (LC50s), and maximum acceptable toxicant concentrations (MATCs); and

- Comparison of the doses and concentrations identified in the exposure characterization to the toxic properties identified in the effects characterization, using 
the guidelines specified by EPA's Office of Pesticide Programs for interpreting risk estimates to general wildlife and to special status species.

\section{C.2.2 Analysis}

Analysis is a process that examines the two primary components of risk-exposure and effects-and the relationships between each other and ecosystem characteristics. The assessment endpoints and conceptual models developed during problem formulation provide the focus and structure for the analysis. Exposure characterization describes potential or actual contact or co-occurrence of stressors with receptors, to produce a summary exposure profile that identifies the receptor, describes the exposure pathway, and describes the intensity and extent of contact or co-occurrence. Ecological effects characterization consists of evaluating ecological effects (e.g., ecotoxicity) data on the stressor of interest, as related to the assessment endpoints and the conceptual models, and preparing a stressor-response profile.

The terrestrial species exposure scenarios postulate that a variety of terrestrial wildlife species use the Tyrrell Seed Orchard at various times. The scenarios further postulate that these terrestrial species may be exposed to any applied pesticides or fertilizers through ingestion of contaminated food and water and, in the maximum scenario, direct dermal spray as a result of being in an area while a treatment is occurring.

The list of representative terrestrial species is as follows:

Mammals

- Deer (large herbivore) (offsite drift residue and drinking water exposure only; no direct contact since fence excludes deer from seed orchard)

- Coyote (carnivore)

- Bobcat (carnivore)

- Long-tailed vole (small herbivore)

- Long-eared myotis (insectivore)

Birds

- Black-capped chickadee (conifer seed-eater)

- Western bluebird (insectivore)

- Mallard duck (water fowl)

- Red-tailed hawk (raptor)

- Song sparrow (seed-eater)

Reptiles/Amphibians

- Rough-skinned newt

- Northwestern gartersnake

These particular wildlife species were selected because they represent the majority of the species present, or the seed orchard has suitable habitat and is within their range (e.g., selection of black-capped chickadee as conifer seed-eater), and because they represent several types of coverage: a range of phylogenetic classes, body sizes, foraging habitat, and diets for which parameters are generally available. In addition, several special status terrestrial species were evaluated for potential risk:

- The bald eagle and spotted owl are Federally listed threatened species that may occur near the Tyrrell Seed Orchard.

- Other special status species that could be present include the northern red-legged frog, little willow flycatcher, long-eared myotis, fringed myotis, long-legged myotis, Yuma myotis, and Pacific western big-eared bat. Risks to the fringed myotis and long-legged 
myotis are assumed to be essentially the same as those estimated for the Yuma myotis and long-eared myotis, due to similarity of size and diet. Therefore, separate risk estimations were not made.

- BLM special status species likely to be present include the purple martin and western bluebird.

For each species, characteristics were identified that were used in estimating doses of pesticides, other ingredients, and fertilizers. These characteristics include body weight, surface area, water intake, dietary intake, composition of diet, and home range/foraging area.

Risks were also estimated for aquatic species for which ecotoxicity data are available: rainbow trout as a representative coldwater fish species, and the water flea Daphnia magna as a representative aquatic invertebrate. In addition, two special status aquatic species known to be present were evaluated:

- Coho salmon are proposed for Federal listing as a threatened species, and have been identified in the Siuslaw River tributary in Section 15 (stream 8), and are known to be present in Douglas Creek and the Siuslaw River downstream of Tyrrell drainages.

- Aquatic stages of the northern red-legged frog were also assessed, since this is statelisted sensitive species.

Stressor-response profiles were prepared for each pesticide, "other" ingredient, and fertilizer proposed for use at Tyrrell. These profiles addressed ecotoxicity to both terrestrial and aquatic species, with the goal of identifying endpoints relevant to the types of exposure and methodology used in the assessment. The focus of this research was to identify $\mathrm{LD}_{50} \mathrm{~S}, \mathrm{LC}_{50} \mathrm{~s}$, and MATCs. The stressor-response profiles for all chemicals are presented in Section 8.3 of the risk assessment report.

\section{C.2.3 Risk Characterization}

Risk characterization uses the results of the analysis phase to develop an estimate of the risks to ecological entities, describes the significance and likelihood of any predicted adverse effects, and identifies uncertainties, assumptions, and qualifiers in the risk assessment.

By comparing the exposure profile data (estimated dose or water concentration) to the stressor-response profile data $\left(\mathrm{LD}_{50} \mathrm{~s}, \mathrm{LC}_{50} \mathrm{~s}, \mathrm{MATCs}\right)$, an estimate of the possibility of adverse effects can be made. The levels of concern are determined following the quotient methodology used by EPA's Office of Pesticide Programs. The quotient is the ratio of the exposure level to the hazard level. For acute exposures, the levels of concern at which a quotient is concluded to reflect risk to non-target species are as follows:

- Terrestrial species (general): 0.5 , where dose equals one-half the $\mathrm{LD}_{50^{\circ}}$

- Terrestrial species (special status): 0.1 , where dose equals one-tenth the $\mathrm{LD}_{50}$.

- Aquatic species (general): 0.5 , where water concentration equals one-half the $\mathrm{LC}_{50}$.

- Aquatic species (special status): 0.05, where water concentration equals one-twentieth the $\mathrm{LC}_{50}$.

Due to the high level of concern for protecting threatened salmonids in the watershed, the predicted water concentrations are also compared to the MATC for a chemical, if available. 
Quotients for each chemical and scenario are presented in tables in Section 9.0 of the risk assessment report. The chemicals and scenarios for which risks were identified are summarized in the following paragraphs and in Table 4.7-2 in Chapter 4 of this EIS.

\section{Risks to Terrestrial Wildlife}

\section{$\underline{\text { Risks to General Terrestrial Species }}$}

Risks are predicted for all terrestrial species except the deer and coyote in the maximum scenario in which an animal ingests an acephate implant capsule.

Risks are predicted from chlorpyrifos and diazinon for the black-capped chickadee (typical and maximum scenarios), and song sparrow and northwestern gartersnake (maximum scenario only).

Dimethoate was estimated to present risks to the mallard duck and song sparrow in the typical scenario, and to the mallard duck, red-tailed hawk, song sparrow, rough-skinned newt, and northwestern gartersnake in the maximum scenario.

In most cases, little or no adverse impact to terrestrial wildlife populations is expected from the pesticides and fertilizers proposed for use at Tyrrell under typical conditions of use, with the possible exception of impacts to some bird species from applications of three of the insecticides (chlorpyrifos, diazinon, and dimethoate). Most of the estimated doses are extremely low, with risk quotients several orders of magnitude below the levels of concern. A margin for error is provided by the methodology applied, which uses reasonable assumptions that tend toward overstating potential exposures to wildlife, in the absence of site-specific data on potential exposure patterns. In addition, all of the chemicals have relatively short half-lives and are not expected to remain in the environment for significant periods of time.

Although some terrestrial insects onsite may be affected by the insecticide applications, and may constitute a portion of the dose to insectivorous species, populations of beneficial insects as a whole are not expected to suffer adverse impacts because the proposed seed orchard applications are localized. Although honeybees and other pollinators are generally susceptible to insecticides, the standard operating procedures at Tyrrell include practices to mitigate potential exposures.

It appears that insecticide applications may have adverse impacts on local earthworm populations (see discussion in Section 9.2.1 of the risk assessment report). However, any possible impacts are expected to be reversible, given that these chemicals are not persistent in the soil and that limited areas would be treated only on an as-needed basis in any growing season, allowing for re-population from adjacent untreated areas.

\section{Risks to Special Status Terrestrial Species}

Risks are predicted to the little willow flycatcher from acephate or horticultural oil used as a foliar spray, and all triclopyr applications, in the maximum scenarios.

Risks are predicted from chlorpyrifos for the western bluebird and little willow flycatcher in the typical scenario, and to the purple martin, western bluebird, and little willow flycatcher in the maximum scenario.

Diazinon was estimated to present risks to the western bluebird and little willow flycatcher in the typical scenario, and to the bald eagle, spotted owl, purple martin, western bluebird, and little willow flycatcher in the maximum scenario. 
Dimethoate is associated with risk for the western bluebird, little willow flycatcher, and northern red-legged frog in the typical scenario, and for all special status terrestrial species in the maximum scenario.

The western bluebird was predicted to have a risk from fertilizer applications of ammonium phosphate-sulfate in the maximum scenario.

In summary, typical conditions of application using the insecticides chlorpyrifos, diazinon, or dimethoate may present risks to some special status terrestrial species.

\section{$\underline{\text { Risks to Terrestrial Plants }}$}

The proposed herbicides will be variously toxic to any plants with which they come into contact. However, no special status plant species have been identified on site at the seed orchard. Broadcast applications of herbicides are only proposed for intensively managed or disturbed areas such as the orchard blocks and roads, while spot applications will be used to control weed species in less disturbed areas, such as along fencelines. No herbicide treatments are proposed within the riparian buffer areas. Insecticides, fungicides, the fumigant dazomet, and fertilizers are only proposed for use in cultivated areas (seed orchard blocks and native grass beds), so no direct contact with plant species in other areas is expected.

\section{Risks to Aquatic Species}

\section{$\underline{\text { Risks to General Aquatic Species }}$}

With the exception of ammonia from ammonium-phosphate sulfate in the maximum scenario, no risks were predicted for coldwater fish species (represented by rainbow trout) in onsite stream segments, Douglas Creek, or the Siuslaw River. No risks were predicted for aquatic invertebrates from any pesticides or fertilizers.

\section{Risks to Special Status Aquatic Species}

No risks to coho salmon in Stream 8 or Douglas Creek, or to northern red-legged frog tadpoles in onsite streams, were predicted under typical scenario assumptions.

Coho salmon in Douglas Creek and its main tributary draining Section 15 ("Segment $\left.8^{\prime \prime}\right)$ were predicted to be at risk from maximum scenario ammonia runoff concentrations from ammonium phosphate-sulfate fertilizer.

Tadpoles of the northern red-legged frog in onsite stream segments were predicted to be at risk from ammonia in runoff from ammonium phosphate-sulfate fertilizer in the maximum scenario.

\section{$\underline{\text { Risks from Accidents }}$}

Risks are predicted for all terrestrial species except the deer, coyote, and bobcat in the accident scenario in which an animal ingests an acephate implant capsule.

Aquatic species are at risk from spills of concentrate containing chlorpyrifos, diazinon, dimethoate, esfenvalerate, horticultural oil, permethrin, propargite, chlorothalonil, glyphosate, triclopyr butoxyethyl ester, dazomet, and ammonium phosphate-sulfate. They are at risk from tank mix spills containing chlorpyrifos, diazinon, dimethoate, esfenvalerate, permethrin, propargite, chlorothalonil, glyphosate, picloram, triclopyr, dazomet, and ammonium phosphate-sulfate. All species in Douglas Creek would be at risk from an aerial spill of esfenvalerate into one of its tributaries. 


\section{$\underline{\text { Risks to Aquatic Plants }}$}

Aquatic plants may be present in streams and ponds that receive runoff from treated areas. A literature review was conducted to identify the levels at which any of the proposed chemicals may pose a hazard to aquatic plants (see Section 9.2.4 in the risk assessment report). For many chemicals, tests in algae were the only available data, and are expected to provide a sensitive endpoint for hazards to aquatic plants. For each chemical, the estimated water concentrations were compared to the levels of concern. None of the predicted concentrations in onsite stream segments, Douglas Creek, or the Siuslaw River exceed the effects criteria equivalent to $50 \%$ of the values reported in the literature reviewed. Therefore, no adverse effects to aquatic plants are expected under typical or maximum conditions of pesticide or fertilizer application at Tyrrell Seed Orchard.

\section{Risk Management Approaches}

If applications of these pesticides were prescribed, risks to wildlife species could be mitigated by measures such as decreasing the application rate, decreasing the area treated, decreasing the number of applications, and increasing the distance to streams from treated areas. Field surveys could also be used to determine whether some special status species that were evaluated are actually present on the seed orchard grounds, in on-site streams, or in downstream drainages.

\section{$\underline{\text { Uncertainties }}$}

The risks summarized in this assessment are not probabilistic estimates of risk, but are conditional estimates. That is, these risks are likely only if all exposure scenario assumptions that were described are met. In addition, the methodology applied to estimating risks is not definitive, since uncertainty in the final risk estimates is introduced in almost every step of the assessment. Some of the primary areas of uncertainty are as follows:

- The information on each terrestrial species' range, diet, and other characteristics, compared to the characteristics it exhibits at the specific time of year when any particular application may be made.

- The $\mathrm{LD}_{50} \mathrm{~s}$ and $\mathrm{LC}_{50} \mathrm{~s}$ selected for use in the risk assessment, which are often drawn from data on species related to the species of interest, and not from tests on the species of interest itself.

- The necessity of using model-defined inputs and site-characterizing assumptions to depict the seed orchard and management activities for conducting the runoff, drift, and accidental spill modeling; as well as the accuracy of the models themselves, which provide an estimate of the impacts that could occur for purposes of prospective program evaluation, mitigation design, and alternative comparison, but are not able to be as accurate as data obtained from actual monitoring. 


\section{References Cited}

EPA. See U.S. Environmental Protection Agency.

National Research Council. 1983. Risk Assessment in the Federal Government: Managing the Process. National Academy Press. Washington, DC.

NRC. See National Research Council.

U.S. Environmental Protection Agency. 1989. Risk assessment guidance for SuperfundVolume 1: Human health evaluation manual (part A). Interim final. EPA/540/1-89/002. Office of Emergency and Remedial Response. Washington, DC.

U.S. Environmental Protection Agency. 1998. Guidelines for ecological risk assessment. Risk Assessment Forum. Washington, DC.

U.S. Environmental Protection Agency. 2000a. Risk characterization handbook. EPA 100-B-00-002. Science Policy Council. Washington, DC.

U.S. Environmental Protection Agency. 2000b. Lists of other (inert) pesticide ingredients. Office of Pesticide Programs. Washington, DC. http://www.epa.gov/opprd001/inerts/ lists.html

U.S. Environmental Protection Agency. 2000c. Region 4 human health risk assessment bulletins-Supplement to RAGS. Waste Management Division. Atlanta, GA. www.epa.gov/ region04/waste/ oftecser/healtbul.htm

USDA. See U.S. Department of Agriculture.

U.S. Department of Agriculture. 1984. Pesticide background statements, Volume I: Herbicides. Agriculture Handbook Number 633. U.S. Forest Service. Washington, DC. 


\section{Attachment Proposed Application Methods}

Pesticides may be applied using several methods. For some pesticides, different combinations of pesticide and application method are being proposed, to give the seed orchard flexibility in addressing the specific management needs that may occur, including:

- aerial, using helicopter

- airblast sprayer

- high-pressure hydraulic sprayer

- hydraulic sprayer with hand-held wand

- tractor-pulled spray rig with boom

- backpack sprayer

- capsule implantation

- ground pull fertilizer spreader

- hand application

Each method is described briefly in the following paragraphs.

\section{Aerial Application}

A helicopter is equipped with a pesticide tank for aerial application of liquid mixtures. The size and type of helicopter may vary; however, a standard representation of its application equipment will be used in the risk assessment, based on a potential contractor's current equipment. Aerial methods may be used to apply the insecticides esfenvalerate or B.t. to seed production orchards, or to apply fertilizers.

\section{Airblast Sprayer}

An airblast sprayer is pulled behind a tractor or a truck. An airblast sprayer uses fans or blowers to propel spray mixtures into dense foliage or the tops of trees. The nozzles of an airblast sprayer are positioned in the air stream to break up spray droplets and propel them into the tree tops. At Tyrrell, an airblast sprayer may be used to apply the insecticide esfenvalerate to orchard units.

\section{High-Pressure Hydraulic Sprayer}

A high-pressure hydraulic sprayer consists of a powered pump and tank carried by truck or tractor, and hand-held nozzle for dispersing the solution upward into the tree. This type of sprayer could be used to treat individual mature trees with the insecticides acephate, chlorpyrifos, diazinon, dimethoate, esfenvalerate, permethrin, horticultural oil, or propargite, or with the fungicide chlorothalonil.

\section{Hydraulic Sprayer with Hand-Held Wand}

A spray tank is mounted on a truck, tractor, or all-terrain vehicle, and may be used to treat young trees; and to apply herbicides around trees in orchard units, along fencelines, and as a spot treatment in fallow fields, non-useable areas, and administrative areas. The sprayer may be operated by one worker, who drives and stops to spray; or by two workers, with one driving and the other spraying. This method may be used to apply the insecticide esfenvalerate; the fungicide propiconazole to native grass beds; or the herbicides glyphosate, triclopyr, hexazinone, picloram, or dicamba. 


\section{Tractor-Pulled Spray Rig with Boom}

This method may be used to apply herbicides for control of weeds in orchard units, in roadways, or in fallow areas. Equipment consists of a hydraulic spray tank pulled by a tractor or heavy-duty pickup truck, with a spray boom attached to the tank to release the herbicide. At Tyrrell, this method may be used to apply the herbicides glyphosate, hexazinone, picloram, or triclopyr; or the fungicide propiconazole to native grass beds.

\section{Backpack Sprayer}

A backpack sprayer consists of a plastic tank that is strapped to the applicator's back. A hand-operated hydraulic pump forces the liquid from the tank through a nozzle in a hand-held wand. At Tyrrell, a backpack sprayer could be used to apply the herbicides dicamba, glyphosate, hexazinone, picloram, or triclopyr for spot treatment of unwanted vegetation in orchard units, fallow areas, non-useable areas, and along fencelines.

\section{Capsule Implantation}

The insecticide acephate may be implanted into individual trees for long-term control of insect pests in the form of a capsule. One small hole is drilled into a tree for every 4 inches of its circumference, and a capsule is inserted.

\section{Ground Pull Fertilizer Spreader}

Fertilizers or the granular fumigant dazomet may be distributed over the ground using a spreader pulled by a truck or tractor. After application of the fumigant dazomet, the granules would be incorporated to a depth of four to eight inches, depending on targets to be controlled (e.g., annual weeds, specific soil-borne pathogens).

\section{Hand Application}

The fertilizer calcium nitrate may be hand-applied, using a scoop or small hand-crank spreader, to the dripline of trees to stimulate flower production. 


\section{Appendix D: Risk Analysis of Sublethal Effects for Special Status Aquatic Species}

\section{D.1 Methodology}

In the non-target species risk assessment (summarized in Appendix C), it was postulated that species of fish may be exposed to pesticides or fertilizers through contaminated surface runoff or from drift during application. For each chemical, acute lethality data were evaluated for a representative species, the rainbow trout. Based on this information, mortality risks were also evaluated for a special status fish species known to be present at or near Tyrrell: coho salmon.

In the quantitative aquatic species risk assessment, if data were available for sublethal or long-term toxic effects, a maximum acceptable toxicant concentration (MATC) was determined. The MATC is the geometric mean of a no-observable-effect concentration (NOEC) and a lowest-observed-effect concentration (LOEC). This further analysis of risks to special status aquatic species expands upon the MATC approach by estimating risks that are relevant to the biological requirements of the animal: in this case, survival, rearing and migration, and reproductive endpoints.

The assessment endpoints used to characterize potential sublethal effects reflect measures of the animal's health that can be functionally related to survival, migratory, or reproductive success (Washington State Pesticide/ESA Task Force 2001). The attributes of the assessment endpoints are termed assessment measures, which are defined by a quantifiable measure (EPA 1998a). For example, reduced swimming speed (quantifiable measure) can increase susceptibility to predation (assessment measure) which can ultimately threaten survival (assessment endpoint). Since $1 / 20^{\text {th }}$ of the acute lethality $\left(\mathrm{LC}_{50}\right)$ value has been presumed to be protective of sublethal effects in threatened and endangered fish species (EPA 1986, EPA 1999a), it has been included here as a "sublethal survival" endpoint.

Since relatively few scientific studies have examined sublethal effects of pesticides on fish physiology or behavior, the selection of assessment end points is limited by available scientific and commercial literature. In the absence of data specific to the identified species of concern, data from biologically and genetically similar surrogate species are used. Comparative toxicology has demonstrated that various species of scaled fish generally have equivalent sensitivity (within an order of magnitude) to other species tested under the same conditions. Dwyer et al. (1995) and Beyers et al. (1994) have shown that some species of threatened and endangered fish are similarly sensitive to some classes of pesticides and other chemicals as their non-endangered counterparts. In some cases, in the absence of pesticide-specific data for a fish species, data for pesticides that are chemically similar and share a common mechanism of toxicity were substituted.

For the purpose of broadening and strengthening the best available science for this evaluation, the proposed-use chemicals are analyzed by chemical groups. The insecticides and acaricides are divided by chemical classes (biologicals, organophosphates, organosulfates, and pyrethroids), reflecting the common mechanism of action for each class. The herbicides and fungicides/fumigants are evaluated as groups, based on the most sensitive toxicity findings. Pesticides that do not fit in specific categories are grouped as "other pesticides". The other pesticides, "other" (formerly "inert") ingredients, and fertilizers are evaluated within their respective groups. In each case, the lowest toxicity result (indicating greatest toxicity) was used in the analysis of risks, so that this categorization approach would not sacrifice a protective analysis. 


\section{D.2 Literature Review of Toxicity Data}

\section{D.2.1 Insecticides and Acaricides}

\section{Biological}

This group includes the insecticide Bacillus thuringiensis (B.t.).

The mode of action for B.t. is a disruption of the digestive tract. After an insect ingests a crystal of B.t., the biopesticide dissolves in the alkaline gut. The toxin that is released binds to the lining of the midgut membrane, creating pores and upsetting ion balance. A similar mechanism of toxicity is assumed for fish.

Table D-1 lists relevant assessment endpoints and effect concentrations of B.t. to fish species as identified from the literature.

B.t. is practically nontoxic to aquatic vertebrate species, and only one identified study has investigated sublethal effects relevant to the assessment endpoints and measures for the essential biological requirements of special status fish species. Field observations of populations of brook trout, common white suckers, and smallmouth bass found no adverse effects to populations one month after an aerial application of the B.t. HD-1 formulation (Abbott Laboratories 1982).

B.t. israelensis was tested for possible impacts on non-target invertebrates. Its use over a three-year period did not disturb the prey base of fish. No negative impacts were observed on invertebrate predators (Plecoptera, Odonata, Megaloptera, Trichoptera,

Table D-1. Effects of Bacillus thuringiensis on Fish Species

\section{Assessment Endpoints} Assessment Measures

\section{Species}

\section{$\operatorname{LOEC}^{a}(\mathrm{mg} / \mathrm{L})$}

Reference

\begin{tabular}{|c|c|c|c|c|c|}
\hline mortality & $1 / 20 \mathrm{LC}_{50}{ }^{\mathrm{b}}$ & $\begin{array}{l}\text { rainbow } \\
\text { trout }\end{array}$ & HD-1 & $>112$ & Abbott Laboratories 1982 \\
\hline mortality & $1 / 20 \mathrm{LC}_{50}{ }^{\mathrm{b}}$ & bluegill & HD-1 & $>200$ & Abbott Laboratories 1982 \\
\hline mortality & $1 / 20 \mathrm{LC}_{50}{ }^{\mathrm{b}}$ & European eel & HD-1 & $\begin{array}{l}200 \text { - } 400 \text { times } \\
\text { field rates }\end{array}$ & Abbott Laboratories 1982 \\
\hline mortality & $1 / 20 \mathrm{LC}_{50}{ }^{\mathrm{b}}$ & trout & israelensis & $75-100$ & Merritt 1999 \\
\hline \multicolumn{6}{|l|}{ Migration } \\
\hline \multicolumn{6}{|l|}{$\mathrm{NA}^{\mathrm{c}}$} \\
\hline \multicolumn{6}{|c|}{ Reproduction } \\
\hline Success & $\begin{array}{l}\text { population } \\
\text { (number) }\end{array}$ & brook trout & HD-1 & $\begin{array}{l}\text { typical aerial } \\
\text { application }\end{array}$ & Abbott Laboratories 1982 \\
\hline
\end{tabular}

a Lowest-observed-effect concentration. Shaded values are used in the final risk evaluation.

${ }^{b}$ Adjusted 24-hour value.

NA = Not available.

$\mathrm{D}-2$ 
Diptera) or grazers (Trichoptera, Ephemeroptera). Predators often consumed more B.t.-contaminated (dead) black fly larvae than live larvae with no adverse effects. Detritivores (mainly mayflies) consumed large amounts of B.t.-contaminated black fly larvae, resulting in increased body mass and shorter developmental times. Some Diptera species were sensitive to high doses of B.t. israelensis (>100 times the normal field dose) (Merritt 1999).

B.t. is moderately persistent in soils, with a half-life of about 4 months (Extoxnet 1996). In soils with a $\mathrm{pH}$ below 5.1, B.t. is rapidly inactivated. It does not tend to move, or leach, with groundwater. After $48 \mathrm{hrs}$, B.t. begins to inactivate in water, gradually settling out or adhering to suspended organic matter.

\section{Organophosphates}

This group includes the insecticides acephate, chlorpyrifos, diazinon, and dimethoate.

Organophosphate insecticides are highly toxic to fish. The primary mechanism of this toxicity is generally well understood, with inhibition of acetylcholinesterase (AChE) being the critical target. The function of AChE is to hydrolyze the neurotransmitter acetylcholine at synaptic junctions, terminating nervous stimulation. Inhibition of AChE is followed by an accumulation of acetylcholine, resulting in a continuous stimulation at cholinergic and muscarinic receptors. Relationships between AChE inhibition and biological function for fish have been investigated and include alterations in growth, reproduction, maturation, swimming, hyperactivity, and feeding. Organophosphate insecticides can target $\mathrm{AChE}$ located in the central and peripheral nervous system, and in the neuro-muscular junctions. Inhibition of $\mathrm{AChE}$ at these regions can affect behavioral processes, sensory systems, and swimming ability in fish.

Table D-2 lists relevant assessment endpoints and effect concentrations of acephate, chlorpyrifos, diazinon and dimethoate and other relevant organophosphates to salmonid species and the European eel.

Scholz et al. (2000) exposed juvenile chinook salmon to concentrations of diazinon ranging from 0.0001 to $0.010 \mathrm{mg} / \mathrm{L}$ for two hours and then allowed them to recover for one hour. After exposures, anti-predator behaviors were observed when skin extracts from juvenile salmon were added to the trial tanks. At concentrations of 0.001 and 0.010 $\mathrm{mg} / \mathrm{L}$, the fish failed to respond to the olfactory cue. Rainbow trout showed altered swimming patterns when exposed to diazinon for 24 to 96 hours, at concentrations ranging from 0.25 to $1.0 \mathrm{mg} / \mathrm{L}$ (Brewer et al. 2001).

The European eel, when exposed to diazinon or chlorpyrifos, exhibited signs of restlessness, erratic swimming, convulsions and difficulty in respiration at acutely toxic concentrations of 0.16 and $1.29 \mathrm{mg} / \mathrm{L}$, respectively, after 24 hours (Ferrando et al. 1991). When rainbow trout were exposed to $0.01 \mathrm{mg} / \mathrm{L}$ methyl parathion for 96 hours, swimming activity decreased and the fish were more vulnerable to predation by bass. Of control fish, $84 \%$ survived predation, as opposed to $57 \%$ of the exposed fish (Little et al. 1990). 
Table D-2. Effects of Organophosphates on Fish Species

\begin{tabular}{|c|c|c|c|c|c|}
\hline $\begin{array}{l}\text { Assessment } \\
\text { Endpoints }\end{array}$ & $\begin{array}{l}\text { Assessment } \\
\text { Measures }\end{array}$ & Species & Chemical & $\begin{array}{l}\mathrm{LOEC}^{\mathrm{a}} \\
\text { (mg/L) }\end{array}$ & Reference \\
\hline \multicolumn{6}{|l|}{ Survival } \\
\hline mortality & $1 / 20 \mathrm{LC}_{50}^{\mathrm{b}}$ & $\begin{array}{l}\text { rainbow trout } \\
\text { cutthroat trout } \\
\text { brook trout }\end{array}$ & acephate & $\begin{aligned} & 44.8 \\
> & 20.0 \\
> & 20.0\end{aligned}$ & EPA 1984 \\
\hline mortality & $1 / 20 \mathrm{LC}_{50}^{\mathrm{b}}$ & $\begin{array}{l}\text { rainbow trout } \\
\text { cutthroat trout } \\
\text { lake trout }\end{array}$ & chlorpyrifos & $\begin{array}{l}0.006 \\
0.003 \\
0.020 \\
\end{array}$ & EPA 2000a \\
\hline mortality & $1 / 20 \mathrm{LC}_{50}{ }^{\mathrm{b}}$ & $\begin{array}{l}\text { rainbow trout } \\
\text { cutthroat trout } \\
\text { lake trout }\end{array}$ & diazinon & $\begin{array}{c}0.018 \\
0.34 \\
0.12 \\
\end{array}$ & $\begin{array}{l}\text { Johnson and Finley } \\
1980\end{array}$ \\
\hline mortality & $1 / 20 \mathrm{LC}_{50}^{\mathrm{b}}$ & brook trout & diazinon & 0.15 & $\begin{array}{l}\text { Allison and } \\
\text { Hermanutz } 1977\end{array}$ \\
\hline mortality & $1 / 20 \mathrm{LC}_{50}{ }^{\mathrm{b}}$ & European eel & diazinon & 0.008 & Sancho et al. 1992 \\
\hline mortality & $1 / 20 \mathrm{LC}_{50}{ }^{\mathrm{b}}$ & European eel & chlorpyrifos & 0.065 & Ferrando et al. 1991 \\
\hline mortality & $1 / 20 \mathrm{LC}_{50}{ }^{\mathrm{b}}$ & rainbow trout & dimethoate & 1.24 & EPA 1999b \\
\hline predation & $\begin{array}{l}\text { olfactory anti-predatory } \\
\text { response (food strikes, } \\
\text { activity) }\end{array}$ & chinook salmon & diazinon & 0.001 & Scholz et al. 2000 \\
\hline predation & $\begin{array}{l}\text { swimming (distance, } \\
\text { speed, turning rate, } \\
\text { tortuosity of path) }\end{array}$ & rainbow trout & diazinon & 0.250 & Brewer et al. 2001 \\
\hline predation & $\begin{array}{l}\text { survival (predation by } \\
\text { Large mouth bass) }\end{array}$ & rainbow trout & $\begin{array}{l}\text { methyl } \\
\text { parathion }^{c}\end{array}$ & 0.01 & Little et al. 1990 \\
\hline predation & $\begin{array}{l}\text { swimming (erratic } \\
\text { pattern) }\end{array}$ & European eel & diazinon & 0.16 & Ferrando et al. 1991 \\
\hline predation & $\begin{array}{l}\text { swimming (erratic } \\
\text { pattern) }\end{array}$ & European eel & chlorpyrifos & 1.29 & Ferrando et al. 1991 \\
\hline growth & foraging (prey ingestion) & Atlantic salmon & fenitrothion ${ }^{c}$ & 0.006 & $\begin{array}{l}\text { Morgan and } \\
\text { Kiceniuk } 1991 \\
\end{array}$ \\
\hline \multicolumn{6}{|l|}{ Migration } \\
\hline $\begin{array}{l}\text { upstream } \\
\text { return }\end{array}$ & $\begin{array}{l}\text { homing (number } \\
\text { returning to hatchery) }\end{array}$ & chinook salmon & diazinon & 0.010 & Scholz et al. 2000 \\
\hline rearing & $\begin{array}{l}\text { Territory defense } \\
\text { (location) }\end{array}$ & Atlantic salmon & fenitrothion ${ }^{c}$ & 0.1 & Symons 1973 \\
\hline rearing & $\begin{array}{l}\text { territory defense } \\
\text { (agonistic behaviors) }\end{array}$ & coho salmon & fenitrothion ${ }^{c}$ & 0.1 & $\begin{array}{l}\text { Bull and McInerney } \\
1974\end{array}$ \\
\hline
\end{tabular}

\section{Reproduction}

\begin{tabular}{|l|l|l|l|l|l|}
\hline mating & $\begin{array}{l}\text { detection of mate } \\
\text { (electrophysiology) }\end{array}$ & Atlantic salmon & diazinon & 0.001 & $\begin{array}{l}\text { Moore and Waring } \\
1996\end{array}$ \\
\hline physiology & $\begin{array}{l}\text { biological stimulation } \\
\text { (hormone production, } \\
\text { expressible milt) }\end{array}$ & Atlantic salmon & diazinon & 0.0003 & $\begin{array}{l}\text { Moore and Waring } \\
1996\end{array}$ \\
\hline
\end{tabular}

a Lowest-observed-effect-concentration. Shaded values are used in the final risk evaluation.

${ }^{b}$ Adjusted 24-hour value.

' Not proposed for use in seed orchard by BLM; data used for assessment purposes only.

$\mathrm{D}-4$ 
Foraging behaviors were tested in Atlantic salmon exposed to fenitrothion for two 24hour periods separated by seven days. At concentrations of 0.006 and $0.21 \mathrm{mg} / \mathrm{L}$, the reaction distance of the salmon to respond to prey decreased significantly (Morgan and Kiceniuk 1991).

Exposure of juvenile Atlantic salmon to $0.1 \mathrm{mg} / \mathrm{L}$ fenitrothion for 15 to 16 hours caused a $20 \%$ decrease in the number of fish that were able to maintain and hold territories six days following treatments (Symons 1973). The territories were not reclaimed for approximately two to three weeks. Some severely affected fish swam stiffly and ceased feeding, but recovery to these effects was evident within 48 hours after returning to clean water. Coho salmon showed very similar behavioral changes over the same concentration range (Bull and McInerney 1974). When adult chinook salmon were treated with $0.010 \mathrm{mg} / \mathrm{L}$ diazinon and re-released downstream of their native hatchery, the number of returns was significantly lower than unexposed control fish.

Following a direct perfusion-exposure of diazinon directly over the olfactory epithelium, adult male Atlantic salmon showed inhibited olfactory stimulation in response to a female reproductive pheromone (Moore and Waring 1996). Concentrations of diazinon affecting olfactory sensitivity ranged from 0.001 to $0.02 \mathrm{mg} / \mathrm{L}$. The same study found that diazinon exposures of 0.0003 to $0.045 \mathrm{mg} / \mathrm{L}$ reduced the production of reproductive hormones and viable sperm in the males when presented with the female priming pheromone.

Environmental factors may also influence organophosphate toxicity to aquatic species, altering effect estimates to the fish (Table D-3). A number of studies tested environmental effects on the toxicity of chlorpyrifos and azinphos-methyl to salmonids. Parameters included temperature, $\mathrm{pH}$, water hardness, fish size, and static versus flow-through exposures. In general, acute toxicity of chlorpyrifos and azinphos-methyl were found to increase with temperature, $\mathrm{pH}$, and body size of the fish. Increasing hardness tended to reduce the toxicity of chlorpyrifos, and static exposure tests produced lower lethality values than those from flow-through tests.

\section{Table D-3. Environmental Factors Influencing Organophosphate Toxicity to Fish}

\begin{tabular}{|c|c|c|c|c|}
\hline $\begin{array}{l}\text { Environmental } \\
\text { Factor }\end{array}$ & $\begin{array}{l}\text { Assessment } \\
\text { Measures }\end{array}$ & Species & Chemical & Reference \\
\hline temperature & 24-hr $\operatorname{LC}_{50}\left(2,7,13^{\circ} \mathrm{C}\right)$ & rainbow trout & chlorpyrifos & Macek et al. 1969 \\
\hline temperature & 96-hr $\mathrm{LC}_{50}\left(2,7,13^{\circ} \mathrm{C}\right)$ & rainbow trout & chlorpyrifos & Macek et al. 1969 \\
\hline temperature & 24-hr $\operatorname{LC}_{50}\left(2,7,13^{\circ} \mathrm{C}\right)$ & rainbow trout & azinphos-methyl ${ }^{\text {a }}$ & Macek et al. 1969 \\
\hline temperature & $96-\mathrm{hr} \mathrm{LC} \mathrm{LC}_{50}\left(2,7,13^{\circ} \mathrm{C}\right)$ & rainbow trout & azinphos-methyla & Macek et al. 1969 \\
\hline temperature & 96-hr $\mathrm{LC}_{50}\left(2,7,13,18^{\circ} \mathrm{C}\right)$ & rainbow trout & chlorpyrifos & EPA 2000a \\
\hline $\mathrm{pH}$ & 96-hr LC ${ }_{50}(7.5,9.0)$ & cutthroat trout & chlorpyrifos & EPA 2000a \\
\hline hardness & $\begin{array}{l}96-\mathrm{hr} \mathrm{LC}_{50}(44,162 \mathrm{mg} / \mathrm{L} \\
\left.\mathrm{CaCO}_{3}\right)\end{array}$ & lake trout & chlorpyrifos & EPA 2000a \\
\hline exposure system & 96-hr LC $_{50}$ (static, flow through) & lake trout & chlorpyrifos & EPA 2000a \\
\hline body weight & 96-hr LC ${ }_{50}(0.32 .9 \mathrm{~g})$ & lake trout & chlorpyrifos & EPA 2000a \\
\hline
\end{tabular}

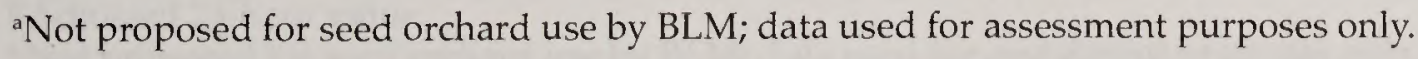




\section{Organosulfites}

This group includes the acaricide propargite.

EPA lists propargite as a probable human carcinogen, meaning there is a possibility of causing cancer in animals as well. Propargite is highly toxic to fish.

Table D-4 lists relevant assessment endpoints and effect concentrations of propargite to fish species as identified from the literature.

A chronic test in fathead minnows showed that propargite affected growth and survival at a concentration of $0.028 \mathrm{mg} / \mathrm{L}$; the NOEC was $0.016 \mathrm{mg} / \mathrm{L}$ (EPA 2000b). Acute mortality data for the catfish are used in the risk evaluation for the survival endpoint, since this was the most sensitive endpoint identified.

For reproductive parameters, a chronic test in fathead minnows showed that propargite affected growth, survival, and day to hatch at a concentration of $0.028 \mathrm{mg} / \mathrm{L}$; the NOEC was $0.016 \mathrm{mg} / \mathrm{L}$ (EPA 2000b).

No data are currently available for migratory effects endpoints or environmental influences on toxicity.

\section{Pyrethroids}

The pyrethroid insecticide group includes esfenvalerate and permethrin.

Pyrethroids are highly toxic to fish, generally with acute $\mathrm{LC}_{50}$ values for salmonids near or below $0.001 \mathrm{mg} / \mathrm{L}$. The mode of action for pyrethroids is the blocking of neural voltage-activated sodium/calcium channels, producing common symptoms of toxicity for the various synthetic compounds. The sensitivity of fish to pyrethroids, compared to other vertebrates, has been explained, in part, by the fishes' inability to metabolize and excrete the toxins (Haya 1989). A comparative study between steelhead trout and coho salmon showed that both species were similarly sensitive across the five pyrethroids

Table D-4. Effects of Organosulfites on Fish Species

\begin{tabular}{|c|c|c|c|c|c|}
\hline $\begin{array}{l}\text { Assessment } \\
\text { Endpoints }\end{array}$ & $\begin{array}{l}\text { Assessment } \\
\text { Measures }\end{array}$ & Species & Chemical & $\begin{array}{l}\mathrm{LOEC}^{\mathrm{a}} \\
(\mathrm{mg} / \mathrm{L})\end{array}$ & Reference \\
\hline \multicolumn{6}{|l|}{ Survival } \\
\hline mortality & $1 / 20 \mathrm{LC}_{50}$ (adjusted 24-hr) ${ }^{\mathrm{b}}$ & rainbow trout & propargite & 0.024 & EPA 2000b \\
\hline mortality & 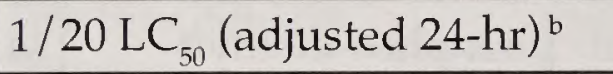 & bluegill & propargite & 0.034 & Uniroyal 1998 \\
\hline mortality & $1 / 20$ LC $_{50}$ (adjusted $\left.24-h r\right)^{b}$ & minnow & propargite & 0.012 & Uniroyal 1998 \\
\hline mortality & 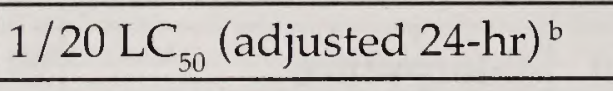 & catfish & propargite & 0.008 & Uniroyal 1998 \\
\hline growth & size (length, weight) & fathead minnow & propargite & 0.028 & EPA 2000b \\
\hline \multicolumn{6}{|l|}{ Migration } \\
\hline \multicolumn{6}{|l|}{$\mathrm{NA}^{\mathrm{c}}$} \\
\hline \multicolumn{6}{|l|}{ Reproduction } \\
\hline success & day to hatch (mean number) & fathead minnow & propargite & 0.028 & EPA 2000b \\
\hline
\end{tabular}

a Lowest-observed-effect-concentration. Shaded values are used in the final risk evaluation.

${ }^{\text {b }}$ Adjusted 24-hour value.

$\mathrm{NA}=$ Not available.

$\mathrm{D}-6$ 
tested (Mauck and Olson 1976). Thus, incorporating data from pyrethroids of similar toxicity across similar fish species should provide adequate estimates where salmonid data gaps are present.

Table D-5 lists relevant assessment endpoints and effect concentrations of esfenvalerate, permethrin, and other pyrethroids to fish species as identified from the literature. Note that the active isomer of fenvalerate is esfenvalerate.

Table D-5. Effects of Pyrethroids on Fish Species

\begin{tabular}{|c|c|c|c|c|c|}
\hline $\begin{array}{l}\text { Assessment } \\
\text { Endpoints }\end{array}$ & $\begin{array}{l}\text { Assessment } \\
\text { Measures }\end{array}$ & Species & Chemical & $\begin{array}{l}\mathrm{LOEC}^{\mathrm{a}} \\
(\mathrm{mg} / \mathrm{L})\end{array}$ & Reference \\
\hline \multicolumn{6}{|l|}{ Survival } \\
\hline mortality & 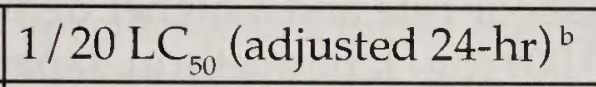 & rainbow trout & esfenvalerate & 0.001 & Du Pont 1999 \\
\hline mortality & 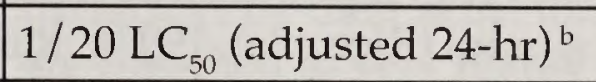 & steelhead trout & fenvalerate & 0.00035 & Curtis et al. 1985 \\
\hline mortality & $1 / 20 \mathrm{LC}_{50}(\text { adjusted } 24-\mathrm{hr})^{\mathrm{b}}$ & rainbow trout & permethrin & 0.0043 & $\begin{array}{l}\text { Mayer and } \\
\text { Ellersieck } 1986\end{array}$ \\
\hline growth & $\begin{array}{l}\begin{array}{l}\text { feeding (mortality from } \\
\text { stress) }\end{array} \\
\end{array}$ & Atlantic salmon & fenvalerate & 0.008 & Haya 1989 \\
\hline growth & size (length, weight) & $\begin{array}{l}\text { sheepshead } \\
\text { minnow }\end{array}$ & fenvalerate & 0.002 & $\begin{array}{l}\text { Hansen et al. } \\
1983\end{array}$ \\
\hline predation & swimming (tremors) & bluegill & esfenvalerate & 0.000025 & Little et al. 1993 \\
\hline predation & swimming (critical speed) & rainbow trout & permethrin & 0.00075 & $\begin{array}{l}\text { Kumaraguru et } \\
\text { al. } 1982\end{array}$ \\
\hline predation & $\begin{array}{l}\text { avoidance behavior (startle } \\
\text { response) }\end{array}$ & Japanese medaka & permethrin & 0.009 & Rice et al. 1997 \\
\hline predation & $\begin{array}{l}\text { behavior (equilibrium, } \\
\text { coughing) }\end{array}$ & rainbow trout & permethrin & 0.0013 & $\begin{array}{l}\text { Holcombe et al. } \\
1982\end{array}$ \\
\hline \multicolumn{6}{|l|}{ Migration } \\
\hline behavior & $\begin{array}{l}\text { schooling (location, } \\
\text { grouping pattern) }\end{array}$ & fathead minnow & permethrin & 0.007 & $\begin{array}{l}\text { Holcombe et al. } \\
1982\end{array}$ \\
\hline rearing & $\begin{array}{l}\text { territory defense } \\
\text { (aggression) }\end{array}$ & bluegill & esfenvalerate & 0.0001 & Little et al. 1993 \\
\hline \multicolumn{6}{|l|}{ Reproduction } \\
\hline mating & $\begin{array}{l}\text { detection of mate } \\
\text { (electrophysiology) }\end{array}$ & Atlantic salmon & cypermethrin $^{c}$ & 0.00001 & $\begin{array}{l}\text { Moore and } \\
\text { Waring } 2001\end{array}$ \\
\hline physiology & $\begin{array}{l}\text { biological stimulation } \\
\text { (hormone production, } \\
\text { expressible milt) }\end{array}$ & Atlantic salmon & cypermethrin ${ }^{c}$ & 0.000004 & $\begin{array}{l}\text { Moore and } \\
\text { Waring } 2001\end{array}$ \\
\hline success & $\begin{array}{l}\text { recruits (number per } \\
\text { female) }\end{array}$ & bluegill & esfenvalerate & 0.00067 & $\begin{array}{l}\text { Fairchild et al. } \\
1992\end{array}$ \\
\hline success & $\begin{array}{l}\text { egg hatch (number) } \\
\text { larvae survive (number) } \\
\text { larvae abnormality } \\
\text { (deformities ) }\end{array}$ & $\begin{array}{l}\text { Australian } \\
\text { crimson-spotted } \\
\text { rainbowfish }\end{array}$ & esfenvalerate & $\begin{array}{l}0.001 \\
0.032 \\
0.032\end{array}$ & Barry et al. 1995 \\
\hline
\end{tabular}

${ }^{a}$ Lowest-observed-effect concentration. Shaded values are used in the final risk evaluation.

${ }^{b}$ Adjusted 24-hour value.

' Not proposed for seed orchard use by BLM; data used for assessment purposes only. 
Pyrethroids have been documented to affect behavior and physiology in fish important for survival. Sublethal effects observed in fish include alterations in growth, metabolic processes, swimming, a reduced startle response, loss of equilibrium, body tremors, and depressed olfactory sensitivity.

Juvenile Atlantic salmon exposed to $0.008 \mathrm{mg} / \mathrm{L}$ fenvalerate were unable to survive the stress of hunger over a 70-hour period, with mortality resulting in over half of the test animals (Haya 1989). Growth was reduced in sheepshead minnow fry exposed to fenvalerate concentrations $\geq 0.002 \mathrm{mg} / \mathrm{L}$ over a period of 28 days (Hansen et al. 1983).

Primary toxicity involves disruption to the neuromuscular system, affecting swimming and other coordinated muscular movement. Gross body tremors of juvenile bluegill continually or pulse-exposed to esfenvalerate were sensitive indicators of toxicity at concentrations as low as $0.000025 \mathrm{mg} / \mathrm{L}$ (Little et al. 1993). Rainbow trout exposed to $0.00075 \mathrm{mg} / \mathrm{L}$ permethrin showed a substantial decrease in swimming performance that was related to exposure duration, from one to 43 days (Kumaraguru and Beamish 1986). This effect was attributed to an increased metabolic rate and a higher demand in oxygen consumption. After a 24-hour exposure to $>0.009 \mathrm{mg} / \mathrm{L}$ permethrin, Japanese medaka were hypoactive and underreactive to startle stimuli (Rice et al. 1997). Rainbow trout exposed for 48 hours to permethrin at $0.0013 \mathrm{mg} / \mathrm{L}$ caused rapid gill movements and a pattern of swimming at the water surface (Holcombe et al. 1982).

Juvenile selection of rearing habitat, smolt outward migration, and adult homing are behaviors related to successful migration. Aggression of bluegill, a response of the fish to defend rearing territory, was significantly lower among fish exposed to pulsed 11-hour concentrations of $0.0001 \mathrm{mg} / \mathrm{L}$ esfenvalerate (Little et al. 1993). Schooling behavior of fathead minnows was affected at $0.0072 \mathrm{mg} / \mathrm{L}$ permethrin (Holcombe et al. 1982).

Following a five-day exposure to $0.00001 \mathrm{mg} / \mathrm{L}$ cypermethrin (nominal concentration), male Atlantic salmon showed inhibited olfactory stimulation to a female reproductive pheromone (Moore and Waring 2001). The same study found that exposures $<0.000004$ $\mathrm{mg} / \mathrm{L}$ reduced biochemical responses to the pheromone and caused a reduction of viable sperm produced.

Barry et al. (1995) studied the effects of esfenvalerate exposure to the Australian crimsonspotted rainbowfish over a period of six days. At $0.001 \mathrm{mg} / \mathrm{L}$, there was a significant decrease in the number of larvae hatching per spawning day. Hatchability of eggs was affected and there was an increase in abnormalities in larvae at a concentration of 0.032 $\mathrm{mg} / \mathrm{L}$. In an aquatic mesocosm study of esfenvalerate on bluegill, reproductive success, as defined by the number of offspring per female, was decreased at a concentration of $0.00067 \mathrm{mg} / \mathrm{L}$ (Fairchild et al. 1992).

Environmental factors may also influence pyrethroid toxicity to aquatic species, altering effect estimates to fish (Table D-6). Pyrethroid insecticides readily bind to organic

\section{Table D-6. Environmental Factors Influencing Pyrethroid Toxicity to Fish}

\begin{tabular}{|c|c|c|c|c|}
\hline $\begin{array}{l}\text { Environmental } \\
\text { Factor }\end{array}$ & $\begin{array}{l}\text { Assessment } \\
\text { Measures }\end{array}$ & Species & Chemical & Reference \\
\hline turbidity & 96-hr LC $_{50}$ (suspended solids) & rainbow trout & cypermethrin $^{b}$ & Shires 1983 \\
\hline temperature & $96-h r \operatorname{LC}_{50}\left(5-25^{\circ} \mathrm{C}\right)$ & rainbow trout & permethrin & Kumaraguru et al. 1982 \\
\hline $\begin{array}{l}\text { hardness }{ }^{a} \\
\mathrm{pH}\end{array}$ & $\begin{array}{l}96-h r \operatorname{LC}_{50}(10-300) \\
96-h r \operatorname{LC}_{50}(6.5-9.5)\end{array}$ & $\begin{array}{l}\text { coho salmon } \\
\text { steelhead trout }\end{array}$ & $\begin{array}{l}\text { dimethrin }{ }^{\mathrm{b}} \\
\text { d-trans allethrin }^{\mathrm{b}} \\
\text { RU-11679 }^{\mathrm{b}} \\
\text { s-bioallethrin }\end{array}$ & Mauck and Olson 1976 \\
\hline
\end{tabular}

${ }^{a}$ As mg/L CaCO3.

${ }^{b}$ Not proposed for seed orchard use by BLM; data used for assessment purposes only.

$\mathrm{D}-8$ 
matter in the soil, have little mobility, and are practically insoluble in water. When caged rainbow trout were exposed to cypermethrin in a pond containing 14 to $22 \mathrm{mg} / \mathrm{L}$ suspended solids, the amount of pesticide necessary to result in mortality increased by nearly five times (from 0.001 to $0.005 \mathrm{mg} / \mathrm{L}$ ) (Shires 1983). Rainbow trout became more sensitive to permethrin with increasing water temperature (Kumaraguru and Beamish 1986). The 96 -hour $\mathrm{LC}_{50}$ values decreased by nearly an order of magnitude ( 0.0064 to $0.00069 \mathrm{mg} / \mathrm{L}$ ) between 10 and $20^{\circ} \mathrm{C}$, respectively. Toxicity of four pyrethroids to coho salmon and steelhead trout was not influenced by $\mathrm{pH}$ in the range of 6.5 to 9.5 , or by water hardness ranging from 10 to $300 \mathrm{mg} / \mathrm{L} \mathrm{CaCO}_{3}$ (Mauck and Olson 1976).

\section{D.2.2 Herbicides}

The herbicides evaluated are dicamba, glyphosate, hexazinone, picloram, and triclopyr.

Classification of herbicides by chemical structure for evaluating toxic effects in fish is not practical because the mechanism by which herbicides elicit toxicity in animals is nonspecific, with a broad overlapping of biological effects. Another method is to classify herbicides by their acute toxicity to fish as presented below. No proposed-use herbicides are classified as very highly or highly toxic to fish. Two herbicides are considered moderately or slightly toxic to fish. Three herbicides are considered practically non-toxic to fish.

- Very highly $(<0.1 \mathrm{mg} / \mathrm{L})$ and highly toxic $(0.1$ to $1.0 \mathrm{mg} / \mathrm{L})$ to fish: none.

- Moderately (1.0 to $10 \mathrm{mg} / \mathrm{L})$ and slightly toxic $(10$ to $100 \mathrm{mg} / \mathrm{L})$ to fish: picloram and dicamba.

- Practically non-toxic ( $>100 \mathrm{mg} / \mathrm{L}$ ) to fish: glyphosate, hexazinone, triclopyrtriethylamine salt.

Herbicides do not typically elicit a specific mechanism of toxicity to fish. Toxicity is often associated with skin and eye irritations, nausea, hemorrhages, and kidney and liver inflammation in mammals which can eventually lead to mortality. The gill, liver, and kidneys are often the target organs for herbicides in fish.

Table D-7 lists relevant assessment endpoints and effect concentrations of dicamba, glyphosate, hexazinone, picloram, and triclopyr to fish species as identified from the literature.

Based on available information, chronic picloram toxicity to fish is not cumulative in terms of lethality (Woodward 1976). However, long-term exposures have been shown to affect fish development and growth. It was observed that the NOEC of technical grade picloram for lake trout was apparently $<0.035 \mathrm{mg} / \mathrm{L}$, as this level of herbicide reduced fry survival and growth. Most abnormalities occurred during yolk absorption, which took four to five days longer in picloram-treated fish. Morgan and Kiceniuk (1992) observed no effects of glyphosate exposure on growth and weight, or foraging activities at concentrations up to $0.1 \mathrm{mg} / \mathrm{L}$ for 12 hours. In an early lifestage test for hexazinone using the fathead minnow, a NOEC of $17 \mathrm{mg} / \mathrm{L}$ was determined, with fish length affected at the LOEC of $35.5 \mathrm{mg} / \mathrm{L}$ (EPA 1994).

The toxicity of triclopyr (butoxyethyl ester) at a concentration lower than $0.56 \mathrm{mg} / \mathrm{L}$ reduced spontaneous swimming activity in coho salmon after 96 -hour exposures (Johansen and Geen 1990). At concentrations lower than $0.10 \mathrm{mg} / \mathrm{L}$, fish were very sensitive to stimuli. At slightly higher concentrations, they were initially sensitive prior to reaching a pronounced state of lethargy. It was suggested that the formulation affected the nervous system of the fish. 
Table D-7. Effects of Herbicides on Fish Species

\begin{tabular}{|c|c|c|c|c|c|}
\hline $\begin{array}{l}\text { Assessment } \\
\text { Endpoints }\end{array}$ & $\begin{array}{l}\text { Assessment } \\
\text { Measures }\end{array}$ & Species & Chemical & $\begin{array}{l}\mathrm{LOEC}^{\mathrm{a}} \\
(\mathrm{mg} / \mathrm{L})\end{array}$ & Reference \\
\hline \multicolumn{6}{|l|}{ Survival } \\
\hline mortality & $1 / 20 \mathrm{LC}_{50}{ }^{\mathrm{b}}$ & rainbow trout & dicamba & 1.8 & $\begin{array}{l}\text { Mayer and } \\
\text { Ellersieck } 1986\end{array}$ \\
\hline mortality & $1 / 20 \mathrm{LC}_{50}{ }^{\mathrm{b}}$ & cutthroat trout & dicamba & 10 & Caux et al. 1993 \\
\hline mortality & $1 / 20 \mathrm{LC}_{50}{ }^{\mathrm{b}}$ & coho salmon & dicamba & $\begin{array}{c}5.5 \\
(6-\text { day })\end{array}$ & Caux et al. 1993 \\
\hline mortality & $1 / 20 \mathrm{LC}_{50}{ }^{\mathrm{b}}$ & cutthroat trout & $\begin{array}{l}\text { dicamba/ picloram } \\
\text { mixture }\end{array}$ & 10 & Woodward 1982 \\
\hline mortality & $1 / 20 \mathrm{LC}_{50}{ }^{\mathrm{b}}$ & rainbow trout & glyphosate & 1.6 & EPA 1993a \\
\hline mortality & $1 / 20 \mathrm{LC}_{50}{ }^{\mathrm{b}}$ & chinook salmon & glyphosate & 1.9 & Mitchell et al. 1987 \\
\hline mortality & $1 / 20 \mathrm{LC}_{50}{ }^{\mathrm{b}}$ & coho salmon & glyphosate & 2.2 & Mitchell et al. 1987 \\
\hline mortality & $1 / 20 \mathrm{LC}_{50}{ }^{\mathrm{b}}$ & sockeye salmon & glyphosate & 5.3 & Servizi et al. 1987 \\
\hline mortality & $1 / 20 \mathrm{LC}_{50}{ }^{\mathrm{b}}$ & rainbow trout & hexazinone & 16 & Wan et al. 1988 \\
\hline mortality & $1 / 20 \mathrm{LC}_{50}{ }^{\mathrm{b}}$ & coho salmon & hexazinone & 14.5 & Wan et al. 1988 \\
\hline mortality & $1 / 20 \mathrm{LC}_{50}{ }^{\mathrm{b}}$ & chum salmon & hexazinone & 16.1 & Wan et al. 1988 \\
\hline mortality & $1 / 20 \mathrm{LC}_{50}{ }^{\mathrm{b}}$ & chinook salmon & hexazinone & 19.7 & Wan et al. 1988 \\
\hline mortality & $1 / 20 \mathrm{LC}_{50}{ }^{\mathrm{b}}$ & pink salmon & hexazinone & 15.5 & Wan et al. 1988 \\
\hline mortality & $1 / 20 \mathrm{LC}_{50}^{\mathrm{b}}$ & sockeye salmon & hexazinone & 18.2 & Wan et al. 1988 \\
\hline mortality & $1 / 20 \mathrm{LC}_{50}{ }^{\mathrm{b}}$ & rainbow trout & picloram & 0.16 & $\begin{array}{l}\text { Mayer and } \\
\text { Ellersieck } 1986\end{array}$ \\
\hline mortality & $1 / 20 \mathrm{LC}_{50}{ }^{\mathrm{b}}$ & cutthroat trout & picloram & 0.17 & $\begin{array}{l}\text { Mayer and } \\
\text { Ellersieck } 1986\end{array}$ \\
\hline mortality & $1 / 20 \mathrm{LC}_{50}^{\mathrm{b}}$ & lake trout & picloram & 0.09 & $\begin{array}{l}\text { Mayer and } \\
\text { Ellersieck } 1986\end{array}$ \\
\hline mortality & $1 / 20 \mathrm{LC}_{50}{ }^{\mathrm{b}}$ & cutthroat trout & $\begin{array}{l}\text { picloram/dicamba } \\
\text { mixture }\end{array}$ & 0.8 & Woodward 1982 \\
\hline mortality & $1 / 20 \mathrm{LC}_{50}{ }^{\mathrm{b}}$ & rainbow trout & \begin{tabular}{|l|} 
triclopyr \\
(triethylamine salt)
\end{tabular} & 47.4 & EPA 1998b \\
\hline mortality & $1 / 20 \mathrm{LC}_{50}{ }^{\mathrm{b}}$ & rainbow trout & $\begin{array}{l}\text { triclopyr } \\
(B E E)^{c}\end{array}$ & 0.033 & EPA 1998b \\
\hline mortality & $1 / 20 \mathrm{LC}_{50}{ }^{\mathrm{b}}$ & chinook salmon & $\begin{array}{l}\text { triclopyr } \\
(B E E)^{c}\end{array}$ & 0.088 & $\begin{array}{l}\text { Kreutzweiser et al. } \\
1994\end{array}$ \\
\hline mortality & $1 / 20 \mathrm{LC}_{50}^{\mathrm{b}}$ & coho salmon & $\begin{array}{l}\text { triclopyr } \\
(B E E)^{c}\end{array}$ & 0.052 & Mayes et al. 1986 \\
\hline
\end{tabular}


Table D-7. Effects of Herbicides on Fish Species (continued)

\begin{tabular}{|c|c|c|c|c|c|}
\hline $\begin{array}{l}\text { Assessment } \\
\text { Endpoints }\end{array}$ & $\begin{array}{l}\text { Assessment } \\
\text { Measures }\end{array}$ & Species & Chemical & $\begin{array}{l}\text { LOECa } \\
(\mathrm{mg} / \mathrm{L})\end{array}$ & Reference \\
\hline growth & size (length, weight) & cutthroat trout & picloram & 0.61 & Woodward 1979 \\
\hline growth & size (length, weight) & lake trout & picloram & 0.035 & Woodward 1976 \\
\hline growth & size (length, weight) & rainbow trout & glyphosate & $\begin{array}{c}0.046 \\
(\mathrm{NOEC})\end{array}$ & $\begin{array}{l}\text { Morgan and Kiceniuk } \\
1992\end{array}$ \\
\hline growth & $\begin{array}{l}\text { foraging (rearing } \\
\text { distance, attacks, } \\
\text { captures, ingestion) }\end{array}$ & rainbow trout & glyphosate & $\begin{array}{c}0.046 \\
(\mathrm{NOEC})\end{array}$ & $\begin{array}{l}\text { Morgan and Kiceniuk } \\
1992\end{array}$ \\
\hline growth & size (length) & fathead minnow & hexazinone & 35.5 & EPA 1994 \\
\hline fitness & $\begin{array}{l}\text { hypersensitivity to } \\
\text { stimuli }\end{array}$ & coho salmon & triclopyr $(\mathrm{BEE})^{\mathrm{c}}$ & 0.10 & $\begin{array}{l}\text { Johansen and Geen } \\
1990\end{array}$ \\
\hline fitness & $\begin{array}{l}\text { lethargic } \\
\text { (spontaneous } \\
\text { activity) }\end{array}$ & coho salmon & triclopyr $(\mathrm{BEE})^{\mathrm{c}}$ & 0.32 & $\begin{array}{l}\text { Johansen and Geen } \\
1990\end{array}$ \\
\hline \multicolumn{6}{|l|}{ Migration } \\
\hline rearing & $\begin{array}{l}\text { territory defense } \\
\text { (agonistic behaviors) }\end{array}$ & rainbow trout & glyphosate & $\begin{array}{c}0.046 \\
(\mathrm{NOEC})\end{array}$ & $\begin{array}{l}\text { Morgan and Kiceniuk } \\
1992\end{array}$ \\
\hline adaptation & $\begin{array}{l}\text { osmoregulation (gill } \\
\text { lesions) }\end{array}$ & rainbow trout & glyphosate & $\begin{array}{c}0.046 \\
(\mathrm{NOEC})\end{array}$ & $\begin{array}{l}\text { Morgan and Kiceniuk } \\
1992\end{array}$ \\
\hline adaptation & $\begin{array}{l}\text { sea water challenge } \\
\text { (mortality) }\end{array}$ & coho salmon & dicamba & 0.25 & Lorz et al. 1979 \\
\hline adaptation & $\begin{array}{l}\text { sea water challenge } \\
\text { (mortality) }\end{array}$ & coho salmon & picloram & 0.25 & Lorz et al. 1979 \\
\hline adaptation & $\begin{array}{l}\text { sea water challenge } \\
\text { (mortality) }\end{array}$ & coho salmon & glyphosate & $\begin{array}{c}2.8 \\
(\mathrm{NOEC}) \\
\end{array}$ & Mitchell et al. 1987 \\
\hline \multicolumn{6}{|c|}{ Reproduction } \\
\hline success & $\begin{array}{l}\text { fecundity } \\
\text { (egg number) } \\
\text { gonadosomatic index } \\
\text { (gonad/body) }\end{array}$ & rainbow trout & glyphosate & $\begin{array}{c}2.0 \\
(\mathrm{NOEC})\end{array}$ & Folmar et al. 1979 \\
\hline success & $\begin{array}{l}\text { larval survival } \\
\text { (number) }\end{array}$ & rainbow trout & picloram & 2.0 & Mayes et al. 1987 \\
\hline
\end{tabular}

a Lowest-observed-effect concentration. Shaded values are used in the final risk evaluation.

b Adjusted 24-hour value.

BEE - butoxyethyl ester

There was no effect of dicamba on gill ATPase activity of coho salmon exposed up to $100 \mathrm{mg} / \mathrm{L}$ for 144 hours (Lorz et al. 1979). (ATPase is an enzyme that is needed for energy-requiring cellular activities to take place.) Histological examination of gill, liver, and kidney tissue indicated no apparent effects. When challenged with seawater, fish previously exposed to the lowest level of $0.25 \mathrm{mg} / \mathrm{L}$ showed a $32 \%$ mortality during the 11 days of the test. When coho salmon were treated with picloram at $0.25 \mathrm{mg} / \mathrm{L}$ for 144 hours, $25 \%$ mortality occurred. Inexplicably, no deaths occurred at the higher exposure concentrations for both herbicides. There was no apparent effect of picloram on the ATPase activity of the gills. Histological examination of fish exposed to $5.0 \mathrm{mg} / \mathrm{L}$ 
revealed abnormal liver and gill tissues. Mitchell et al. (1987) exposed coho salmon to glyphosate for 10 days at concentrations up to $2.8 \mathrm{mg} / \mathrm{L}$, with no effect on successful seawater adaptation.

Rainbow trout exposed for two months to glyphosate had no significant increase in gill lesions, and fish did not show any change in agonistic activity that would be important for territorial defense (Morgan and Kiceniuk 1992).

Rainbow trout exposed up to $2.0 \mathrm{mg} / \mathrm{L}$ glyphosate for $12 \mathrm{hr}$ showed no effect on fecundity (eggs per female) and gonadosomatic index (gonad weight/total body weight) (Folmar et al. 1979). Tests with the early lifestages of rainbow trout showed that picloram concentrations of $2 \mathrm{mg} / \mathrm{L}$ reduced survival of the larvae (Mayes et al. 1987).

Environmental factors may influence herbicide toxicity to aquatic species, altering the effect estimates to fish (Table D-8). Glyphosate toxicity to rainbow trout increased with higher test temperatures (Folmar et al. 1979). Toxicity increased from $\mathrm{pH} 6.5$ to 7.5 , but did not change up to $\mathrm{pH}$ 9.5. Increasing temperature and $\mathrm{pH}$ with exposures to picloram resulted in greater toxicities to cutthroat trout and lake trout (Woodward 1976). The specific content of $\mathrm{CaCO}_{3}$ in the tested "soft", "hard", and "very hard" waters was not specified, but were reported not to alter toxicity. Eyed eggs were the least sensitive lifestage, with toxicity increasing markedly as the fish entered the sac fry and early swimup stages.

\section{D.2.3 Fungicides and Fumigants}

The fungicides and fumigants group include dazomet, chlorothalonil, and propiconazole.

Classification of fungicides and fumigants by chemical structure for evaluating toxic effects in fish is not practical because the mechanism by which they elicit toxicity in animals is non-specific, with a broad overlapping of biological effects. Unlike

\section{Table D-8. Environmental Factors Influencing Herbicide Toxicity to Fish}

\begin{tabular}{|c|c|c|c|c|}
\hline $\begin{array}{l}\text { Environmental } \\
\text { Factor }\end{array}$ & $\begin{array}{l}\text { Assessment } \\
\text { Measure }\end{array}$ & Species & Chemical & Reference \\
\hline temperature & $96-\mathrm{hr} \mathrm{LC} \mathrm{LC}_{50}\left(7-17^{\circ} \mathrm{C}\right)$ & rainbow trout & glyphosate & Folmar et al. 1979 \\
\hline temperature & $96-\mathrm{hr} \mathrm{LC} \mathrm{LC}_{50}\left(5-15^{\circ} \mathrm{C}\right)$ & cutthroat trout & picloram & Woodward 1976 \\
\hline temperature & 96-hr LC ${ }_{50}\left(5-15^{\circ} \mathrm{C}\right)$ & lake trout & picloram & Woodward 1976 \\
\hline $\mathrm{pH}$ & 96-hr LC ${ }_{50}(6.5-9.5)$ & rainbow trout & glyphosate & Folmar et al. 1979 \\
\hline $\mathrm{pH}$ & 96-hr $\mathrm{LC}_{50}(6.5-8.5)$ & cutthroat trout & picloram & Woodward 1976 \\
\hline $\mathrm{pH}$ & 96-hr LC ${ }_{50}(6.5-8.5)$ & lake trout & picloram & Woodward 1976 \\
\hline hardness $^{a}$ & $\begin{array}{l}\text { 96-hr } \text { LC }_{50} \text { ("soft", "hard", very } \\
\text { hard") }\end{array}$ & cutthroat trout & picloram & Woodward 1976 \\
\hline hardness $^{a}$ & $\begin{array}{l}\text { 96-hr LC } \text { ("soft", "hard", very }_{50} \\
\text { hard") }\end{array}$ & lake trout & picloram & Woodward 1976 \\
\hline lifestage & $\begin{array}{l}\text { 96-hr } \mathrm{LC}_{50} \text { (eyed eggs, sac fry, swim } \\
\text { up fry, fingerling } 1.0 \mathrm{~g} \text {, fingerling } \\
2.0 \mathrm{~g} \text { ) }\end{array}$ & rainbow trout & glyphosate & Folmar et al. 1979 \\
\hline
\end{tabular}

${ }^{a}$ Content of $\mathrm{CaCO} 3$ not specified.

$\mathrm{D}-12$ 
the herbicides, fumigants and fungicides can be highly toxic to animals. The same classification method used for the herbicides can be applied to fungicides and fumigants based on the acute toxicity to fish. Two of the proposed-use fungicides and fumigants are classified as very highly or highly toxic to fish. One is considered moderately or slightly toxic to fish.

- Very highly $(<0.1 \mathrm{mg} / \mathrm{L})$ and highly toxic $(0.1$ to $1.0 \mathrm{mg} / \mathrm{L})$ to fish: dazomet, chlorothalonil.

- Moderately (1.0 to $10 \mathrm{mg} / \mathrm{L}$ ) and slightly toxic (10 to $100 \mathrm{mg} / \mathrm{L}$ ) to fish: propiconazole.

- Practically non-toxic (>100 mg/L) to fish: none.

All fungicides and most fumigants produce positive results in the usual microbial mutagenicity test systems (Ecobichon 1996). The microorganisms (salmonella, coliforms, yeasts, and fungi) used in these test systems are similar to those cell systems that fungicides were designed to target. It is possible that the fungicides and fumigants are mutagenic to higher animals as well.

Table D-9 lists relevant assessment endpoints and effect concentrations of dazomet, chlorothalonil, and propiconazole to fish species as identified from the literature.

Caux et al. (1996) reported a chronic 21-day LOEC for chlorothalonil of $0.0049 \mathrm{mg} / \mathrm{L}$ for rainbow trout with mortality as the endpoint.

A full life-cycle aquatic toxicity test with chlorothalonil resulted in a NOEC of $0.003 \mathrm{mg} /$ $\mathrm{L}$ in fathead minnows, with hatching success and survivability affected at the LOEC of $0.0065 \mathrm{mg} / \mathrm{L}$ (EPA 1999a).

Table D-9. Effects of Fungicides and Fumigants on Fish Species

\begin{tabular}{|c|c|c|c|c|c|}
\hline $\begin{array}{l}\text { Assessment } \\
\text { Endpoints }\end{array}$ & $\begin{array}{l}\text { Assessment } \\
\text { Measures }\end{array}$ & Species & Chemical & $\begin{array}{l}\mathrm{LOEC}^{\mathrm{a}} \\
(\mathrm{mg} / \mathrm{L})\end{array}$ & Reference \\
\hline \multicolumn{6}{|l|}{ Survival } \\
\hline mortality & $1 / 20 \mathrm{LC}_{50}^{\mathrm{b}}$ & rainbow trout & chlorothalonil & 0.0085 & EPA 1999a \\
\hline mortality & $1 / 20 \mathrm{LC}_{50}{ }^{\mathrm{b}}$ & rainbow trout & dazomet & 0.032 & BASF 1999 \\
\hline mortality & $1 / 20 \mathrm{LC}_{50}{ }^{\mathrm{b}}$ & rainbow trout & dazomet & 0.48 & USDA 1998 \\
\hline mortality & $1 / 20 \mathrm{LC}_{50}{ }^{\mathrm{b}}$ & brook trout & dazomet & 2.0 & USDA 1998 \\
\hline mortality & $1 / 20 \mathrm{LC}_{50}^{\mathrm{b}}$ & rainbow trout & propiconazole & 1.0 & Novartis 2000 \\
\hline mortality & $1 / 20 \mathrm{LC}_{50}{ }^{\mathrm{b}}$ & brown trout & propiconazole & 0.24 & Grande et al. 1994 \\
\hline survival & 21-day mortality $\left(1 / 20 \mathrm{LC}_{50}\right)$ & rainbow trout & chlorothalonil & 0.0049 & Caux et al. 1996 \\
\hline \multicolumn{6}{|l|}{ Migration } \\
\hline \multicolumn{6}{|l|}{$\overline{N A^{c}}$} \\
\hline \multicolumn{6}{|l|}{ Reproduction } \\
\hline success & $\begin{array}{l}\text { hatching (number, } \\
\text { survivability) }\end{array}$ & $\begin{array}{l}\text { fathead } \\
\text { minnow }\end{array}$ & chlorothalonil & 0.0065 & EPA 1999a \\
\hline success & $\begin{array}{l}\text { hatching (number) } \\
\text { hatching (survivability) }\end{array}$ & brown trout & propiconazole & $\begin{array}{l}3.0 \\
1.0 \\
\end{array}$ & Grande et al. 1994 \\
\hline
\end{tabular}

${ }^{a}$ Lowest-observed-effect concentration. Shaded values are used in the final risk evaluation.

b Adjusted 24-hour value.

c NA = No data available. 
In a brown trout early lifestage test with propiconazole, a LOEC of 1.0 and $3.0 \mathrm{mg} / \mathrm{L}$ were determined for survival and hatching, respectively (Grande et al. 1994).

No data are currently available relevant to migratory effects or environmental influences on toxicity.

\section{D.2.4 Other Pesticides}

The pesticide horticultural oil does not fit within the previously assessed categories.

No mortality or indications of toxicity were observed in 96-hour studies in which rainbow trout, bluegill sunfish, and juvenile rainbow trout were exposed to horticultural oil at a concentration of $100 \mathrm{mg} / \mathrm{L}$ (Valent USA 1983, Wildlife International 1991). Although no $\mathrm{LC}_{50}$ values were determined, the value of $100 \mathrm{mg} / \mathrm{L}$ was used as the toxicity data point for fish species in the risk assessment, due to the lack of additional exposure-response information.

No data are currently available on migratory or reproductive endpoints, or environmental influences on toxicity.

\section{D.2.5 "Other" Ingredients}

In addition to active ingredients, pesticide products contain a certain percentage of "other" ingredients (previously termed "inert" ing redients), which enhance the action of the active ingredient. Other ingredients can include surfactants, carriers, or preservatives. Some of the formulations proposed for use contain one or more of the following other ingredients: cyclohexanone, ethylbenzene, light aromatic solvent naphtha, and xylene.

Cyclohexanone, ethylbenzene, naphthalene (as an example of a light aromatic solvent naphtha), and xylene are hydrocarbons with solvent properties, having broad toxicological effects in fish. However, the primary target for acute exposure appears to be the gills.

Xylene occurs in three isomers which vary in the site of attachment on the benzene ring of the two methyl groups. Technical xylene typically contains mixed proportions of $o-$, $m-$, and $p$-isomers, with varying toxicity to fish. For the purposes of this assessment, all xylene isomers will be regarded as xylene.

Table D-10 lists relevant assessment endpoints and effect concentrations of cyclohexanone, ethylbenzene, light aromatic solvent naphtha, and xylene to fish species as identified from the literature.

Morrow et al. (1975) found that $100 \mathrm{mg} / \mathrm{L}$ xylene killed $100 \%$ of young coho salmon, and that 1 to $10 \mathrm{mg} / \mathrm{L}$ caused no significant mortality. Toxic symptoms before death included rapid, violent and erratic swimming, "coughing", and loss of equilibrium. Rainbow trout exposed to 3.2 and $6.2 \mathrm{mg} / \mathrm{L}$ xylene for 2 hours showed symptoms similar to anesthesia (Walsh et al. 1977).

Rainbow trout significantly avoided xylene at a nominal concentration of $0.1 \mathrm{mg} / \mathrm{L}$ during a one-hour test (Folmar 1976). Fish exposed to $0.001 \mathrm{mg} / \mathrm{L}$ did not show significant avoidance and those exposed to $0.01 \mathrm{mg} / \mathrm{L}$ were significantly attracted to the xylene. Maynard and Weber (1981) found that juvenile coho salmon avoided $o$-xylene at concentrations greater than $0.2 \mathrm{mg} / \mathrm{L}$. 
Table D-10. Effects of Other Ingredients on Fish Species

\begin{tabular}{|c|c|c|c|c|c|}
\hline $\begin{array}{l}\text { Assessment } \\
\text { Endpoints }\end{array}$ & $\begin{array}{l}\text { Assessment } \\
\text { Measures }\end{array}$ & Species & Chemical & $\begin{array}{l}\text { LOEC }^{a} \\
(\mathrm{mg} / \mathrm{L})\end{array}$ & Reference \\
\hline \multicolumn{6}{|l|}{ Survival } \\
\hline mortality & $1 / 20 \mathrm{LC}_{50}^{\mathrm{b}}$ & fathead minnow & cyclohexanone & 96.2 & HSDB 2001 \\
\hline mortality & $1 / 20 \mathrm{LC}_{50}{ }^{\mathrm{b}}$ & rainbow trout & cyclohexanone & $30.3-75.7$ & EPA 2001 \\
\hline mortality & $1 / 20 \mathrm{LC}_{50}^{\mathrm{b}}$ & rainbow trout & ethylbenzene & 14 & $\begin{array}{l}\text { Mayer and } \\
\text { Ellersieck } 1986\end{array}$ \\
\hline mortality & $1 / 20 \mathrm{LC}_{50}^{\mathrm{b}}$ & rainbow trout & $\begin{array}{l}\text { naphtha (as } \\
\text { naphthalene) }\end{array}$ & $0.32-1.1$ & EPA 2001 \\
\hline mortality & $1 / 20 \mathrm{LC}_{50}^{\mathrm{b}}$ & coho salmon & $\begin{array}{l}\text { naphtha (as } \\
\text { naphthalene) }\end{array}$ & 0.64 & Eisler 1987 \\
\hline mortality & $1 / 20 \mathrm{LC}_{50}^{\mathrm{b}}$ & rainbow trout & xylene & $0.42-0.68$ & $\begin{array}{l}\text { Mayer and } \\
\text { Ellersieck } 1986\end{array}$ \\
\hline survival & $\begin{array}{l}\text { predation (erratic swimming, } \\
\text { equilibrium, breathing) }\end{array}$ & coho salmon & xylene & 100 & $\begin{array}{l}\text { Morrow et al. } \\
1975\end{array}$ \\
\hline survival & predation (equilibrium) & rainbow trout & xylene & 3.2 & Walsh et al. 1977 \\
\hline \multicolumn{6}{|l|}{ Migration } \\
\hline rearing & $\begin{array}{l}\text { olfaction (avoidance } \\
\text { behavior) }\end{array}$ & rainbow trout & xylene & 0.1 & Folmar 1976 \\
\hline rearing & $\begin{array}{l}\text { olfaction (avoidance } \\
\text { behavior) }\end{array}$ & coho salmon & xylene & 0.2 & $\begin{array}{l}\text { Maynard and } \\
\text { Weber } 1981\end{array}$ \\
\hline \multicolumn{6}{|l|}{ Reproduction } \\
\hline success & $\begin{array}{l}\text { fertilization (rate, cell } \\
\text { cleavage) }\end{array}$ & $\operatorname{cod}$ & xylene & $8.0-35$ & $\begin{array}{l}\text { Kjorsvic et al. } \\
1982\end{array}$ \\
\hline
\end{tabular}

${ }^{\mathrm{a}}$ Lowest-observed-effect-concentration. Shaded values are used in the final risk evaluation.

${ }^{\mathrm{b}}$ Adjusted 24-hour value.

Kjorsvic et al. (1982) exposed cod eggs to xylene isomers in covered glass dished and monitored the effects both during fertilization and during early cleavage of fertilized eggs. Both $m$-xylene and $p$-xylene induced significant decreases in the fertilization rate at concentrations above $10 \mathrm{mg} / \mathrm{L}$. Effects on the early cleavage pattern were significant for xylene concentrations between 2 and $7 \mathrm{mg} / \mathrm{L}$. Observed effects included inhibition of formulation of the cleavage furrow. Small cells or a total absence of cleavage occurred on exposure to all isomers at concentrations of 16 to $35 \mathrm{mg} / \mathrm{L}$, while incomplete or uneven cleavage was found at exposures of 8 to $15 \mathrm{mg} / \mathrm{L}$.

Because of rapid volatilization from water and soil to the atmosphere, chronic exposure to fish is unlikely. In the atmosphere, these compounds are readily degraded, primarily by photochemical processes (WHO 1996, WHO 1997).

\section{D.2.6 Fertilizers}

Fertilizers include ammonium phosphate-sulfate and calcium nitrate. The following paragraphs provide information of the toxicity of these fertilizers to fish species.

Table D-11 lists relevant assessment endpoints and effect concentrations of the proposed fertilizers to fish species, as identified from the literature. 
Table D-11. Effects of Fertilizers on Fish Species

\begin{tabular}{|c|c|c|c|c|c|}
\hline $\begin{array}{l}\text { Assessment } \\
\text { Endpoints }\end{array}$ & $\begin{array}{l}\text { Assessment } \\
\text { Measures }\end{array}$ & Species & $\begin{array}{l}\text { Fertilizer } \\
\text { Component }\end{array}$ & $\begin{array}{l}\text { LOEC }^{a} \\
(\mathrm{mg} / \mathrm{L})\end{array}$ & Reference \\
\hline \multicolumn{6}{|l|}{ Survival } \\
\hline mortality & $1 / 20 \mathrm{LC}_{50}{ }^{\mathrm{b}}$ & rainbow trout & ammonia (as $\mathrm{NH}_{3}$ ) & 0.11 & Arthur et al. 1987 \\
\hline mortality & $1 / 20 \mathrm{LC}_{50}{ }^{\mathrm{b}}$ & Atlantic salmon & ammonia (as $\mathrm{NH}_{3}$ ) & $\begin{array}{c}0.0074- \\
0.036\end{array}$ & Knoph 1992 \\
\hline mortality & $1 / 20 \mathrm{LC}_{50}{ }^{\mathrm{b}}$ & rainbow trout & nitrate $\left(\right.$ as $\left.\mathrm{NO}_{3}\right)$ & $2.0\left(\mathrm{LC}_{48}\right)$ & Rouse et al. 1999 \\
\hline mortality & $1 / 20 \mathrm{LC}_{50}{ }^{\mathrm{b}}$ & cutthroat trout & nitrate $\left(\right.$ as $\left.\mathrm{NO}_{3}\right)$ & $4.0\left(\mathrm{LC}_{41}\right)$ & Rouse et al. 1999 \\
\hline mortality & $1 / 20 \mathrm{LC}_{50}{ }^{\mathrm{b}}$ & rainbow trout & $\begin{array}{l}\text { diammonium } \\
\text { phosphate }\end{array}$ & 93 & $\begin{array}{l}\text { Blahm and Snyder } \\
1973\end{array}$ \\
\hline mortality & $1 / 20 \mathrm{LC}_{50}{ }^{\mathrm{b}}$ & coho salmon & $\begin{array}{l}\text { diammonium } \\
\text { phosphate }\end{array}$ & $49-64$ & HSDB 2001 \\
\hline mortality & $1 / 20 \mathrm{LC}_{50}{ }^{\mathrm{b}}$ & bluegill & calcium nitrate & 480 & HSDB 2001 \\
\hline \multicolumn{6}{|l|}{ Migration } \\
\hline \multicolumn{6}{|l|}{$\mathrm{NA}^{\mathrm{c}}$} \\
\hline \multicolumn{6}{|l|}{ Reproduction } \\
\hline $\mathrm{NA}^{\mathrm{c}}$ & & & & & \\
\hline
\end{tabular}

a Lowest-observed-effect concentration. Shaded values are used in the final risk evaluation.

Adjusted 24-hour value.

NA $=$ No data available.

Ammonia is oxidized to nitrate by algae and bacteria. In water, the ammonium ion can exist in its ionized form $\left(\mathrm{NH}_{4}^{+}\right)$, and in its un-ionized form as ammonia $\left(\mathrm{NH}_{3}\right)$. The equilibrium between these two forms depends largely on $\mathrm{pH}$ and temperature. Ammonia demonstrates greater toxicity to aquatic species than does the ammonium ion, and this toxicity increases with decreases in $\mathrm{pH}$ and temperature.

Schuytema and Nebeker (1999a) identified a 10-day NOEC and LOEC for ammonium sulfate in Pacific treefrog tadpoles of 116 and $232 \mathrm{mg} / \mathrm{L}$, respectively, based on decreased length; no adverse effects on length or weight were observed in the clawed toad at the highest concentration tested of $939 \mathrm{mg} / \mathrm{L}$. In a follow-up study, the same investigators (Schuytema and Nebeker 1999b) identified a 10-day NOEC and LOEC in Pacific treefrog embryos of 58 and $110 \mathrm{mg} / \mathrm{L}$, and a 5-day NOEC and LOEC in clawed toad embryos of 24 and $58 \mathrm{mg} / \mathrm{L}$.

\section{D.3 Effects Analysis}

Based on the stream concentrations estimated by the risk assessment runoff and drift modeling, and the most sensitive assessment endpoints determined from the literature reviewed (as summarized in Section D.2 above), a sublethal effects risk evaluation was made. Data from the literature were evaluated to determine potential effects on some aspects of survival, migration, and reproduction, with the LOECs listed. From the listed data, the lowest LOEC from each of these three assessment endpoints was selected for the risk evaluation. The selected LOECs are not intended to be definitive of all possible adverse effects at all life-stages related to survival, migration, or reproduction, but are intended to be the most conservative, representative estimates available. 
For each stream at Tyrrell, the highest typical and maximum pesticide concentrations modeled are identified, and are compared to the selected assessment endpoint LOECs. An effects ratio was determined, defined as the estimated pesticide concentration over the sublethal effect level. For example, if the stream concentration of a given chemical is estimated to be $0.003 \mathrm{mg} / \mathrm{L}$, and the concentration of that chemical that affects reproduction is $0.006 \mathrm{mg} / \mathrm{L}$, then the concentration-effect ratio would be 0.5 -a moderate risk to the fish. Risks to some aspects of survival, migratory, and reproductive endpoints were determined to be low if the effects ratio was 0.1 or below, moderate if 0.1 to 1.0 , and high if 1.0 or greater.

\section{D.3.1 Insecticides and Acaricides}

\section{Biological}

The risk assessment did not include fate and transport modeling for B.t.; therefore, expected concentrations in streams were not quantified. EPA has determined that risks from B.t. are minimal to non-existent for non-target aquatic organisms, including endangered species (EPA 1998c) (see Table D-1). The potential risks to the survival, migratory, and reproductive endpoints evaluated for special status species in all surface waters associated with Tyrrell are therefore expected to be low for typical and maximum application scenarios.

\section{Organophosphates}

The potential risks to the evaluated sublethal endpoints are expected to be low for typical and maximum applications of acephate, chlorpyrifos, diazinon, and dimethoate in all surface waters at Tyrrell. This risk comparison is presented in Table D-12.

These estimates of risk may be influenced by environmental factors as previously discussed and presented in Section D.2, such as temperature, $\mathrm{pH}$, hardness, and fish size. Organophosphate compounds tend to strongly bind to organic material. It is likely that spring and summer rain events will contain significant quantities of organic material, reducing bioavailability.

Table D-12. Risks of Organophosphates to Special Status Fish

\begin{tabular}{|c|c|c|c|c|}
\hline & Stream 8 & Douglas Creek & Siuslaw River \\
\hline & & \multicolumn{3}{|c|}{ Highest Estimated Surface Water Concentration $(\mathrm{mg} / \mathrm{L})^{\mathrm{b}}$} \\
\hline & $\begin{array}{l}\text { typ: } \\
\text { max: }\end{array}$ & $\begin{array}{c}0 \\
0.00000454 \\
\end{array}$ & $\begin{array}{c}0.0000000212 \\
0.00000143 \\
\end{array}$ & $\begin{array}{c}0.00000000147 \\
0.000000131 \\
\end{array}$ \\
\hline \multicolumn{2}{|c|}{$\begin{array}{l}\text { Assessment Endpoint } \\
\left(\mathrm{LOEC}-\mathrm{mg} / \mathrm{Lc}^{\mathrm{c}}\right)\end{array}$} & \multicolumn{3}{|c|}{ Concentration-Effect Ratio ${ }^{a}$} \\
\hline $\begin{array}{r}\text { Survival } \\
(0.001) \\
\end{array}$ & $\begin{array}{l}\text { typ: } \\
\text { max: }\end{array}$ & $\begin{array}{c}0 \\
0.0045 \\
\end{array}$ & $\begin{array}{c}0.000021 \\
0.0014 \\
\end{array}$ & $\begin{array}{c}0.0000015 \\
0.00013 \\
\end{array}$ \\
\hline $\begin{array}{c}\text { Migration } \\
(0.01)\end{array}$ & $\begin{array}{l}\text { typ: } \\
\text { max: }\end{array}$ & $\begin{array}{c}0 \\
0.00045 \\
\end{array}$ & $\begin{array}{c}0.0000021 \\
0.00014 \\
\end{array}$ & $\begin{array}{c}0.00000015 \\
0.000013\end{array}$ \\
\hline $\begin{array}{l}\text { Reproduction } \\
(0.0003)\end{array}$ & $\begin{array}{l}\text { typ: } \\
\text { max: }\end{array}$ & $\begin{array}{c}0 \\
0.015 \\
\end{array}$ & $\begin{array}{c}0.000071 \\
0.0048 \\
\end{array}$ & $\begin{array}{c}0.0000049 \\
0.00044 \\
\end{array}$ \\
\hline
\end{tabular}

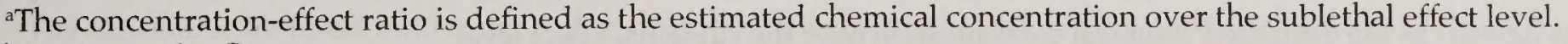

'See Appendix C.

'Lowest-observed effect concentration (LOEC) is the sublethal effect level from the laboratory study that reported the greatest sensitivity to the respective assessment endpoint (see Table D-2). 


\section{Organosulfites}

Potential risks from the organosulfite propargite to the survival and reproductive endpoints evaluated are expected to be extremely low. No information on migratory endpoints are currently available. The estimated effects ratios are summarized in Table D-13. Propargite is proposed for infrequent use at Tyrrell, with one application to individual trees between April and October, if needed at all. There is a very low risk to aquatic species under these conditions.

\section{Pyrethroids}

For typical applications of pyrethroid insecticides, potential risks of sublethal effects for the endpoints evaluated for special status species in all streams are low.

For maximum scenario applications of pyrethroid insecticides, potential risks to the survival endpoints evaluated are low in Douglas Creek and the Siuslaw River, and moderate in Stream 8. The potential risks to migration endpoints are low in all surface waters. Risks to reproductive endpoints are low in the Siuslaw River, moderate in Douglas Creek, and high in Stream 8. Table D-14 summarizes these risk estimates.

Table D-13. Risks of Organosulfites to Special Status Fish

\begin{tabular}{|c|c|c|c|c|}
\hline & Stream 8 & Douglas Creek & Siuslaw River \\
\hline & & \multicolumn{3}{|c|}{ Highest Estimated Surface Water Concentration $(\mathrm{mg} / \mathrm{L})^{\mathrm{b}}$} \\
\hline & $\begin{array}{r}\text { typ: } \\
\text { max: }\end{array}$ & $\begin{array}{c}0 \\
0.0000021\end{array}$ & $\begin{array}{c}0.0000000185 \\
0.000000689\end{array}$ & $\begin{array}{c}0.00000000132 \\
0.0000000625 \\
\end{array}$ \\
\hline \multicolumn{2}{|c|}{$\begin{array}{l}\text { Assessment Endpoint } \\
\text { (LOEC - mg/Lc) }\end{array}$} & \multicolumn{3}{|c|}{ Concentration-Effect Ratio } \\
\hline $\begin{array}{r}\text { Survival } \\
(0.008)\end{array}$ & $\begin{array}{r}\text { typ: } \\
\text { max: }\end{array}$ & $\begin{array}{c}0 \\
0.00026 \\
\end{array}$ & $\begin{array}{c}0.0000023 \\
0.000086\end{array}$ & $\begin{array}{c}0.00000017 \\
0.0000078 \\
\end{array}$ \\
\hline \begin{tabular}{|l}
$\begin{array}{c}\text { Migration } \\
\left(\mathrm{NA}^{\mathrm{d}}\right)\end{array}$ \\
\end{tabular} & $\begin{array}{r}\text { typ: } \\
\text { max: }\end{array}$ & $\mathrm{N} / \mathrm{A}$ & $\mathrm{N} / \mathrm{A}$ & $\mathrm{N} / \mathrm{A}$ \\
\hline $\begin{array}{l}\text { Reproduction } \\
(0.028)\end{array}$ & $\begin{array}{r}\text { typ: } \\
\text { max: }\end{array}$ & $\begin{array}{c}0 \\
0.000075\end{array}$ & $\begin{array}{c}0.00000066 \\
0.000025\end{array}$ & $\begin{array}{c}0.000000047 \\
0.0000022\end{array}$ \\
\hline
\end{tabular}

The concentration-effect ratio is defined as the estimated chemical concentration over the sublethal effect level.

bee Appendix C.

Lowest-observed effect concentration (LOEC) is the sublethal effect level from the laboratory study that reported the greatest sensitivity to the respective assessment endpoint (see Table D-4).

$\mathrm{NA}=$ No data available.

Table D-14. Risks of Pyrethroids to Special Status Fish

\begin{tabular}{|c|r|c|c|c|}
\hline \multicolumn{2}{|c|}{} & Stream 8 & Douglas Creek & Siuslaw River \\
\hline \multicolumn{2}{|c|}{} & Highest Estimated Surface Water Concentration (mg/L) \\
\hline & typ: & $\begin{array}{c}0.000000381 \\
0.00000565\end{array}$ & $\begin{array}{c}0.0000000617 \\
0.00000199\end{array}$ & $\begin{array}{c}0.00000000737 \\
0.000000205\end{array}$ \\
\hline $\begin{array}{c}\text { Assessment Endpoint } \\
(\text { LOEC - mg/Lc) }\end{array}$ & & \multicolumn{3}{|c|}{ Concentration-Effect Ratio } \\
\hline \begin{tabular}{l|c|c|c|} 
Survival \\
$(0.000025)$
\end{tabular} & typ: & 0.015 & 0.0025 & 0.00029 \\
\hline $\begin{array}{l}\text { Migration } \\
\text { max: }\end{array}$ & 0.23 & 0.080 & 0.0082 \\
\hline Reproduction & typ: & 0.0038 & 0.00062 & 0.000074 \\
$(0.0000040)$ & max: & 0.057 & 0.020 & 0.0021 \\
\hline
\end{tabular}

The concentration-effect ratio is defined as the estimated chemical concentration over the sublethal effect level.

See Appendix C.

${ }^{c}$ Lowest-observed effect concentration (LOEC) is the sublethal effect level from the laboratory study that reported the greatest sensitivity to the respective assessment endpoint (see Table D-5).

$\mathrm{D}-18$ 
These risk estimates may be influenced by environmental factors, as discussed in Section D.2, such as turbidity and temperature. It is likely that spring and summer runoff will contain significant quantities of organic material, reducing bioavailability of any pyrethroids, and therefore further reducing risk. Since warmer temperatures tend to reduce the toxicity of pyrethroids to salmonids, it is unlikely that toxic effects will exceed those described in the literature. Furthermore, actual risk to reproductive endpoints is unlikely, since pesticide applications would be conducted in spring and early summer months. It is unlikely that coho salmon will be spawning or emerging from eggs during the time of the proposed applications.

\section{D.3.2 Herbicides}

Risks to special status aquatic species from typical and maximum applications of dicamba, glyphosate, hexazinone, picloram and triclopyr are expected to be extremely low. The concentration-effects ratios are presented in Table D-15.

The influence of environmental factors on potential risks to aquatic species appears to be negligible, as discussed in Section D.2. Increasing temperature, $\mathrm{pH}$, hardness, or differences in multiple life stages of salmonids was shown to increase toxicity values up to two- to six-fold by Folmar et al. (1979) and Woodward (1976). Such increases are still not likely to result in any significant toxicity to the fish in Tyrrell's streams or downstream water bodies.

\section{D.3.3 Fungicides and Fumigants}

Typical and maximum applications of chlorothalonil, dazomet, and propiconazole are expected to be of extremely low risk to the survival and reproductive endpoints evaluated. No information on migratory endpoints is currently available. The concentration-effects ratios are summarized in Table D-16.

\section{D.3.4 Other Pesticides}

Extremely low risks to survival endpoints for special status aquatic species are predicted for horticultural oil. No information on migratory or reproductive endpoints is currently available. The concentration-effect ratios are presented in Table D-17.

Table D-15. Risks of Herbicides to Special Status Fish

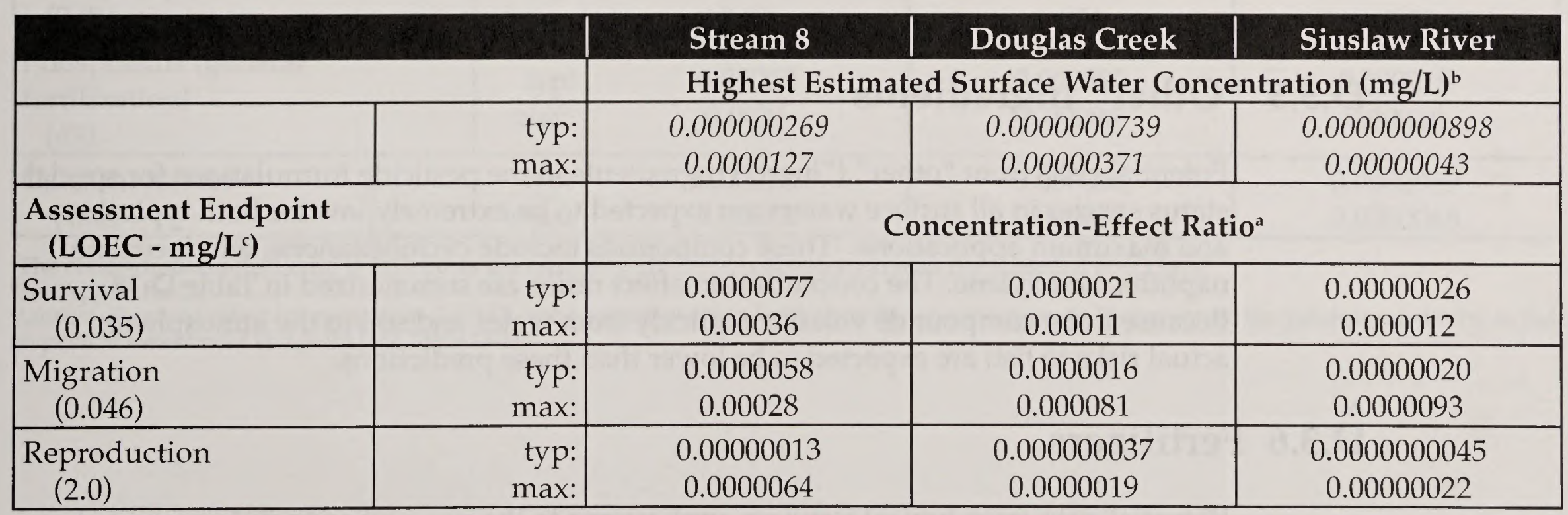

aThe concentration-effect ratio is defined as the estimated chemical concentration over the sublethal effect level.

bee Appendix C.

cLowest-observed effect concentration (LOEC) is the sublethal effect level from the laboratory study that reported the greatest sensitivity to the respective assessment endpoint (see Table D-7). 
Table D-16. Risks of Fungicides and Fumigants to Special Status Fish

\begin{tabular}{|c|c|c|c|c|}
\hline & Stream 8 & Douglas Creek & Siuslaw River \\
\hline & & \multicolumn{3}{|c|}{ Highest Estimated Surface Water Concentration $(\mathrm{mg} / \mathrm{L})^{\mathrm{b}}$} \\
\hline & $\begin{array}{l}\text { typ: } \\
\text { max: }\end{array}$ & $\begin{array}{c}0.0000000219 \\
0.0000057\end{array}$ & $\begin{array}{c}0.0000000161 \\
0.00000179 \\
\end{array}$ & $\begin{array}{c}0.00000000111 \\
0.000000165 \\
\end{array}$ \\
\hline \multicolumn{2}{|c|}{$\begin{array}{l}\text { Assessment Endpoint } \\
\left.\text { (LOEC - } \mathrm{mg} / \mathrm{Lc}^{\mathrm{c}}\right)\end{array}$} & \multicolumn{3}{|c|}{ Concentration-Effect Ratio } \\
\hline \begin{tabular}{|l} 
Survival \\
$(0.0049)$
\end{tabular} & $\begin{array}{r}\text { typ: } \\
\text { max: }\end{array}$ & $\begin{array}{c}0.000045 \\
0.0012 \\
\end{array}$ & $\begin{array}{c}0.0000033 \\
0.00037 \\
\end{array}$ & $\begin{array}{c}0.00000023 \\
0.000034 \\
\end{array}$ \\
\hline \begin{tabular}{|c|}
$\begin{array}{c}\text { Migration } \\
\left(\mathrm{NA}^{\mathrm{d}}\right)\end{array}$ \\
\end{tabular} & $\begin{aligned} \text { typ: } \\
\text { max: }\end{aligned}$ & $\mathrm{N} / \mathrm{A}$ & N/A & $\mathrm{N} / \mathrm{A}$ \\
\hline $\begin{array}{c}\text { Reproduction } \\
(0.0065)\end{array}$ & $\begin{aligned} \text { typ: } \\
\text { max: }\end{aligned}$ & $\begin{array}{c}0.0000034 \\
0.00088\end{array}$ & $\begin{array}{c}0.0000025 \\
0.00028\end{array}$ & $\begin{array}{c}0.00000017 \\
0.000025\end{array}$ \\
\hline
\end{tabular}

${ }^{a}$ The concentration-effect ratio is defined as the estimated chemical concentration over the sublethal effect level.

bSee Appendix C.

cLowest-observed effect concentration (LOEC) is the sublethal effect level from the laboratory study that reported the greatest sensitivity to the respective assessment endpoint (see Table D-10).

${ }^{\mathrm{d}} \mathrm{NA}=$ No data available.

Table D-17. Risks of Other Pesticides to Special Status Fish

\begin{tabular}{|c|c|c|c|c|}
\hline & Stream 8 & Douglas Creek & Siuslaw River \\
\hline & & \multicolumn{3}{|c|}{ Highest Estimated Surface Water Concentration $(\mathrm{mg} / \mathrm{L})^{\mathrm{b}}$} \\
\hline & $\begin{array}{l}\text { typ: } \\
\text { max: }\end{array}$ & $\begin{array}{c}0 \\
0.0000197\end{array}$ & $\begin{array}{c}0.000000202 \\
0.00000619\end{array}$ & $\begin{array}{c}0.0000000149 \\
0.00000057\end{array}$ \\
\hline \multicolumn{2}{|c|}{$\begin{array}{l}\text { Assessment Endpoint } \\
(\text { LOEC - mg/Lc) }\end{array}$} & \multicolumn{3}{|c|}{ Concentration-Effect Ratio ${ }^{a}$} \\
\hline $\begin{array}{c}\text { Survival } \\
(100)\end{array}$ & $\begin{aligned} \text { typ: } \\
\text { max: }\end{aligned}$ & $\begin{array}{c}0 \\
0.00000020 \\
\end{array}$ & $\begin{array}{c}0.0000000020 \\
0.000000062\end{array}$ & $\begin{array}{c}0.00000000015 \\
0.0000000057\end{array}$ \\
\hline $\begin{array}{c}\text { Migration } \\
\left(\mathrm{NA}^{\mathrm{d}}\right)\end{array}$ & $\begin{aligned} \text { typ: } \\
\text { max: }\end{aligned}$ & $\mathrm{N} / \mathrm{A}$ & $\mathrm{N} / \mathrm{A}$ & $\mathrm{N} / \mathrm{A}$ \\
\hline $\begin{array}{l}\text { Reproduction } \\
\left(\mathrm{NA}^{d}\right)\end{array}$ & $\begin{array}{r}\text { typ: } \\
\text { max: }\end{array}$ & $\mathrm{N} / \mathrm{A}$ & $\mathrm{N} / \mathrm{A}$ & $\mathrm{N} / \mathrm{A}$ \\
\hline
\end{tabular}

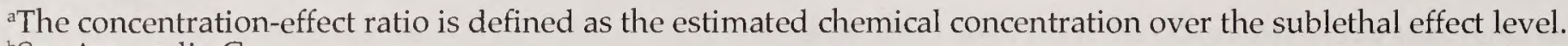

bSee Appendix C.

'Lowest-observed effect concentration (LOEC) is the sublethal effect level from the laboratory study that reported the greatest sensitivity to the respective assessment endpoint (see section D.2.4).

${ }^{\mathrm{d}} \mathrm{NA}=$ No data available.

\section{D.3.5 "Other" Ingredients}

Potential risks from "other" ("inert") ingredients in the pesticide formulations for special status species in all surface waters are expected to be extremely low for both typical and maximum applications. These compounds include cyclohexanone, ethylbenzene, naphtha, and xylene. The concentration-effect ratios are summarized in Table D-18. Because these compounds volatilize quickly from water and soil to the atmosphere, actual risks to fish are expected to be lower than these predictions.

\section{D.3.6 Fertilizers}

Potential risks from typical fertilizer applications to the survival endpoints evaluated are expected to be low. No information on migratory or reproductive endpoints is currently available. For maximum applications, potential risks are expected to be extremely 
low for nitrates and phosphates in all streams. The risk of ammonium or calcium nitrate toxicity to fish is moderate in Stream 8, a main tributary to the Siuslaw River.

Concentration-effects ratios are presented in Table D-19.

Table D-18. Risks of "Other" Ingredients to Special Status Fish

\begin{tabular}{|c|c|c|c|c|}
\hline & & Stream 8 & Douglas Creek & Siuslaw River \\
\hline & & \multicolumn{3}{|c|}{ Highest Estimated Surface Water Concentration $(\mathrm{mg} / \mathrm{L})^{\mathrm{b}}$} \\
\hline & $\begin{aligned} \text { typ: } \\
\text { max: }\end{aligned}$ & $\begin{array}{c}0.00000017 \\
0.0000198\end{array}$ & $\begin{array}{c}0.0000000508 \\
0.00000676\end{array}$ & $\begin{array}{c}0.00000000613 \\
0.00000070\end{array}$ \\
\hline \multicolumn{2}{|c|}{$\begin{array}{l}\text { Assessment Endpoint } \\
\text { (LOEC - } \mathrm{mg} / \mathrm{Lc} \text { ) }\end{array}$} & \multicolumn{3}{|c|}{ Concentration-Effect Ratio ${ }^{a}$} \\
\hline $\begin{array}{c}\text { Survival } \\
(0.32)\end{array}$ & $\begin{aligned} \text { typ: } \\
\text { max: }\end{aligned}$ & $\begin{array}{c}0.00000053 \\
0.00006\end{array}$ & $\begin{array}{c}0.00000016 \\
0.000021\end{array}$ & $\begin{array}{c}0.000000019 \\
0.0000022 \\
\end{array}$ \\
\hline $\begin{array}{c}\text { Migration } \\
(0.10)\end{array}$ & $\begin{aligned} \text { typ: } \\
\text { max: }\end{aligned}$ & $\begin{array}{c}0.0000017 \\
0.00020\end{array}$ & $\begin{array}{c}0.00000051 \\
0.000068\end{array}$ & $\begin{array}{c}0.000000061 \\
0.0000070\end{array}$ \\
\hline $\begin{array}{l}\text { Reproduction } \\
(8.0)\end{array}$ & $\begin{array}{l}\text { typ: } \\
\text { max: }\end{array}$ & $\begin{array}{c}0.000000021 \\
0.0000025\end{array}$ & $\begin{array}{c}0.0000000064 \\
0.00000085\end{array}$ & $\begin{array}{c}0.0000000008 \\
0.000000088\end{array}$ \\
\hline
\end{tabular}

aThe concentration-effect ratio is defined as the estimated chemical concentration over the sublethal effect level.

'See Appendix C.

Lowest-observed effect concentration (LOEC) is the sublethal effect level from the laboratory study that reported the greatest sensitivity to the respective assessment endpoint (see Table D-10).

Table D-19. Risks of Fertilizers to Special Status Fish

\begin{tabular}{|c|c|c|c|c|}
\hline & & Stream 8 & Douglas Creek & Siuslaw River \\
\hline & & \multicolumn{3}{|c|}{ Highest Estimated Surface Water Concentration $(\mathrm{mg} / \mathrm{L})^{\mathrm{b}}$} \\
\hline Nitrogen & $\begin{array}{l}\text { typ: } \\
\text { max: }\end{array}$ & $\begin{array}{c}0.0242 \\
0.631 \\
\end{array}$ & $\begin{array}{c}0.00608 \\
0.151 \\
\end{array}$ & $\begin{array}{c}0.000781 \\
0.0178 \\
\end{array}$ \\
\hline Phosphate & $\begin{array}{l}\text { typ: } \\
\text { max: }\end{array}$ & $\begin{array}{c}0.00145 \\
0.0177 \\
\end{array}$ & $\begin{array}{c}0.000443 \\
0.00422 \\
\end{array}$ & $\begin{array}{c}0.0000892 \\
0.000498 \\
\end{array}$ \\
\hline Calcium nitrate & $\begin{array}{l}\text { typ: } \\
\text { max: }\end{array}$ & $\begin{array}{c}0.00886 \\
0.0117 \\
\end{array}$ & $\begin{array}{l}0.00279 \\
0.00279 \\
\end{array}$ & $\begin{array}{l}0.000285 \\
0.000328 \\
\end{array}$ \\
\hline \multicolumn{2}{|l|}{$\begin{array}{l}\text { Survival Endpoint } \\
\left(\text { LOEC }-\mathrm{mg} / \mathrm{L}^{\mathrm{c}}\right)\end{array}$} & \multicolumn{3}{|c|}{ Concentration-Effect Ratio } \\
\hline $\begin{array}{l}\text { Nitrogen (general fertilization) } \\
(2.0)\end{array}$ & $\begin{array}{l}\text { typ: } \\
\text { max: }\end{array}$ & $\begin{array}{c}0.012 \\
0.32 \\
\end{array}$ & $\begin{array}{c}0.0030 \\
0.076 \\
\end{array}$ & $\begin{array}{c}0.00039 \\
0.0089 \\
\end{array}$ \\
\hline $\begin{array}{l}\text { Phosphorus (general } \\
\text { fertilization) } \\
\text { (49) }\end{array}$ & $\begin{array}{l}\text { typ: } \\
\text { max: }\end{array}$ & $\begin{array}{c}0.00030 \\
0.0036\end{array}$ & $\begin{array}{c}0.000090 \\
0.00086\end{array}$ & $\begin{array}{c}0.000018 \\
0.00010\end{array}$ \\
\hline $\begin{array}{l}\text { Calcium nitrate } \\
(480)\end{array}$ & $\begin{array}{l}\text { typ: } \\
\text { max: }\end{array}$ & $\begin{array}{l}0.00018 \\
0.00024 \\
\end{array}$ & $\begin{array}{l}0.000058 \\
0.000058 \\
\end{array}$ & $\begin{array}{l}0.0000059 \\
0.0000068 \\
\end{array}$ \\
\hline
\end{tabular}

${ }^{a}$ The concentration-effect ratio is defined as the estimated chemical concentration over the sublethal effect level.

bee Appendix C.

'Lowest-observed effect concentration (LOEC) is the sublethal effect level from the laboratory study that reported the greatest sensitivity to the respective assessment endpoint (see Table D-11). 


\section{D.4 References}

Abbott Laboratories. 1982. Toxicology profile: Dipel, Bacillus thuringiensis insecticide. Chemical and Agricultural Products Division. North Chicago, IL.

Allison, D.T., and R.O. Hermanutz. 1977. Toxicity of diazinon to brook trout and fathead minnows. EPA 600/3-77-060. National Environmental Research Center, Ecological Research Services, U.S. Environmental Protection Agency. Washington, DC.

Arthur, J.W., C.W. West, K.N. Allen, and S.F. Hedtke. 1987. Seasonal toxicity of ammonia to five fish and nine invertebrate species. Bulletin of Environmental Contamination and Toxicology 38:324-331.

Barry, M.J., K. O'Halloran, D.C. Logan, J.T. Ahokas, and D.A. Holdway. 1995. Sublethal effects of esfenvalerate pulse-exposure on spawning and non-spawning Australian crimson-spotted rainbowfish (Melanotaenia fluviatilis). Archives of Environmental Contamination and Toxicology 28:459-463.

BASF Corporation. 1999. Material safety data sheet: Basamid® Granular soil fumigant. Research Triangle Park, NC.

Beyers, D.W., J.J. Keefe, and C.A. Carlson. 1994. Toxicity of carbaryl and malathion to two federally listed endangered fishes, as estimated by regression and Anova. Environmental Toxicology and Chemistry 13:101-107.

Blahm, T.H., and G.R. Snyder. 1973. Effect of chemical fire retardants on the survival of juvenile salmonids. National Marine Fisheries Service, Environmental Facility. Prescott, OR.

Brewer, S.K., E.E. Little, A.J. DeLonay, S.L. Beauvais, S.B. Jones, and M.R. Ellersieck. 2001. Behavioral dysfunctions correlate to altered physiology in rainbow trout (Oncorhynchus mykiss) exposed to cholinesterase-inhibiting chemicals. Archives of Environmental Contamination and Toxicology 40:70-76.

Bull, C.J., and J.E. McInerney. 1974. Behavior of juvenile Coho salmon (Oncorhynchus kisutch) exposed to sumithion (fenitrothion), an organophosphate insecticide. Journal of the Fisheries Research Board of Canada 31:1867-1872.

Caux, P.-Y., R.A. Kent, M. Taché, C. Grande, G.T. Fan, and D.D. MacDonald. 1993. Environmental fate and effects of dicamba: A Canadian perspective. Reviews of Environmental Contamination and Toxicology 133:1-59.

Caux, P.Y., R.A. Kent, G.T. Fan, and G.L. Stephenson. 1996. Environmental fate and effects of chlorothalonil: A Canadian perspective. Critical Reviews in Environmental Science and Technology 26(1):45-93.

Curtis, L.R., W.K. Seim, and G.A. Chapman. 1985. Toxicity of fenvalerate to developing steelhead trout following continuous or intermittent exposure. Journal of Toxicology and Environmental Health 15:445-457.

Du Pont. 1999. Material safety data sheet: "Asana" XL insecticide. Wilmington, DE.

Dwyer, F.J., L.C. Sappington, D.R. Buckler, and S.B. Jones. 1995. Use of surrogate species in assessing contaminant risk to endangered and threatened species. Draft final report submitted to Foster L. Mayer, Project Officer, Gulf Breeze Environment Research Laboratory, EPA. U.S. EPA Project Number DW14935115-01-0. 
Ecobichon, D.J. 1996. Toxic effects of pesticides. In Casarrett and Doull's Toxicology: The Basic Science of Poisons. Klaassen, C.D., ed. McGraw-Hill. New York, NY. pp 643-689.

Eisler, R. 1987. Polycyclic aromatic hydrocarbon hazards to fish, wildlife, and invertebrates: A synoptic review. U.S. Fish and Wildlife Service, Patuxent Wildlife Research Center. Laurel, MD.

EPA. See U.S. Environmental Protection Agency.

Extoxnet. 1996. Bacillus thuringiensis. Pesticide Information Profiles. Extension Toxicology Network (database of pesticide information profiles). Cooperative Extension Offices of Cornell University, Oregon State University, University of Idaho, and University of California at Davis; and Institute for Environmental Toxicology, Michigan State University. Major funding by USDA Extension Service. http: / / ace.orst.edu/info/ extoxnet

Fairchild, J.F., T.W. La Point, J.L. Zajicek, M.K. Nelson, F.J. Dwyer, and P.A. Lovely. 1992. Population-, community- and ecosystem-level responses of aquatic mesocosms to pulsed doses of a pyrethroid insecticide. Environmental Toxicology and Chemistry 11(1):115129.

Ferrando, M.D., E. Sancho, and E. Andreu-Moliner. 1991. Comparative acute toxicities of selected pesticides to Anguilla anguilla. Journal of Environmental Science and Health, Part B: Pesticides, Food Contaminants, and Agricultural Wastes 26(5-6):491-498.

Folmar, L.C. 1976. Overt avoidance reaction of rainbow trout fry to nine herbicides. Bulletin of Environmental Contamination and Toxicology 15:509-514.

Folmar, L.C., H.O. Sanders, and A.M. Julin. 1979. Toxicity of the herbicide glyphosate and several of its formulations to fish and aquatic invertebrates. Archives of Environmental Contamination and Toxicology 8:269-278.

Grande, M., S. Andersen, and D. Berge. 1994. Effects of pesticides on fish: Experimental and field studies. Norwegian Journal of Agricultural Sciences, Supplement 13:195-209.

Hansen, D.J., L.R. Goodman, J.C. Moore, and P.K. Higdon. 1983. Effects of the synthetic pyrethroids AC 222,705, permethrin and fenvalerate on sheepshead minnows in early life stage toxicity tests. Environmental Toxicology and Chemistry 2:251-258.

Haya, H. 1989. Toxicity of pyrethroid insecticides to fish. Environmental Toxicology and Chemistry 8:381-391.

Hazardous Substances Databank. 2001. On-line database. National Library of Medicine. Bethesda, MD.

Holcombe, G.W., G.L. Phipps, and D.K. Tanner. 1982. The acute toxicity of kelthane, dursban, disulfoton, pydrin, and permethrin to fathead minnows Pimephales promelas and rainbow trout Salmo gairdneri. Environmental Pollution (Series A) 29:167-187.

Johansen, J.A, and G.H. Geen. 1990. Sublethal and acute toxicity of the ethylene glycol butyl ether ester formulation of triclopyr to juvenile coho salmon (Oncorhynchus mykiss). Archives of Environmental Contamination and Toxicology 19(4):610-616.

Johnson, W.W., and M.T. Finley. 1980. Handbook of acute toxicity of chemicals to fish and aquatic invertebrates. Summaries of toxicity tests conducted at Columbia National Fisheries Research Laboratory, 1965-1978. Resource Publication 137. U.S. Department of the Interior, Fish and Wildlife Service. Washington, DC. 
Kjorsvic E., L.J. Saethre, and S. Lonning. 1982. Effects of short-term exposure to xylenes on the early cleavage stages of cod eggs (Gadusmorhus L.). Sarsia 67: 299-308.

Knoph, M.B. 1992. Acute toxicity of ammonia to Atlantic salmon (Salmo salar) parr. Comparative Biochemistry and Physiology 101C(2):275-282.

Kreutzweiser, D.P., S.B. Holmes, and D.C. Eichenberg. 1994. Influence of exposure duration on the toxicity of triclopyr ester to fish and aquatic insects. Archives of Environmental Contamination and Toxicology 26:124-129.

Kumaraguru, A.K., F.W.H. Beamish, and H.W. Ferguson. 1982. Direct and circulatory paths of permethrin (NRDC-143) causing histopathological changes in the gills of rainbow trout, Salmo gairdneri Richardson. Journal of Fish Biology 20:87-91.

Kumaraguru, A.K., and F.W.H. Beamish. 1986. Effect of permethrin (NRCC-143) on the bioenergetics of rainbow trout, Salmo gairdneri. Aquatic Toxicology 9:47-58.

Little, E.E., R.D. Archeski, B.A. Flerov, and V.I. Kozlovskaya. 1990. Behavioral indicators of sublethal toxicity in rainbow trout. Archives of Environmental Contamination and Toxicology 19:380-385.

Little, E.E., F.J. Dwyer, and J.F. Fairchild. 1993. Survival of bluegill and their behavioral responses during continuous and pulsed exposures to esfenvalerate, a pyrethroid insecticide. Environmental Toxicology and Chemistry 12:871-878.

Lorz, H.W., S.W. Glenn, R.H. Williams, M. Clair, and L.A. Norris. 1979. Effects of selected herbicides on smolting of coho salmon. EPA/600/3-79/071. Research and Development Section, Oregon Department of Fisheries and Wildlife. Corvallis, OR.

Macek, K.J., C. Hutchinson, and O.B. Cope. 1969. The effects of temperature on the susceptibility of bluegills and rainbow trout to selected pesticides. Bulletin of Environmental Contamination and Toxicology 4(3):174-183.

Mauck, W.L., and L.E. Olson. 1976. Toxicity of natural pyrethrins and five pyrethroids to fish. Archives of Environmental Contamination and Toxicology 4:18-29.

Mayer, F.L., and M.R. Ellersieck. 1986. Manual of acute toxicity: Interpretation and data base for 410 chemicals and 66 species of freshwater animals. Resource Publication 160. U.S. Fish and Wildlife Service. Washington, DC.

Mayes, M.A., P.G. Murphy, D.L. Hopkins, F.M. Gersich, and F.A. Blanchard. 1986. The toxicity and metabolism of triclopyr butoxyethyl ester: Coho salmon. The Toxicologist 6(1):102.

Mayes, M.A., D.L. Hopkins, and D.C. Dill. 1987. Toxicity of picloram (4-amino-3,5,6trichloropicolinic acid) to life stages of the rainbow trout. Bulletin of Environmental Contamination and Toxicology 38:653-660.

Maynard, D.J., and D.D. Weber. 1981. Avoidance reactions of juvenile coho salmon (Oncorhynchus kisutch) to monocyclic aromatics. Canadian Journal of Fisheries and Aquatic Science 38:772-778.

Merritt, R. 1999. MSU Extension Entomology Bulletins - 61893002. Michigan State University Extension. East Lansing, MI. http:/ / www.msue.msu.edu/msue/imp/ modet/61893002.html 
Mitchell, D.G., P.M. Chapman, and T.J. Long. 1987. Acute toxicity of Roundup ${ }^{\circledR}$ and Rodeo ${ }^{\circledR}$ herbicides to rainbow trout, chinook and coho salmon. Bulletin of Environmental Contamination and Toxicology 39:1028-1035.

Moore, A., and C.P. Waring. 1996. Sublethal effects of the pesticide diazinon on olfactory function in mature male Atlantic salmon parr. Journal of Fish Biology 48:758-775.

Moore, A., and C.P. Waring. 2001. The effects of a synthetic pyrethroid pesticide on some aspects of reproduction in Atlantic salmon (Salmo salar L.). Aquatic Toxicology 52:1-12.

Morgan, M.J., and J.W. Kiceniuk. 1991. Recovery of foraging behavior of Atlantic salmon exposed to a simulated commercial application of fenitrothion. Environmental Toxicology and Chemistry 10(7):961-965.

Morgan, M.J., and J.W. Kiceniuk. 1992. Response of rainbow trout to a two month exposure to Vision ${ }^{\circledR}$, a glyphosate herbicide. Environmental Contamination and Toxicology 48:772-780.

Morrow, J.E., R.L. Gritz, and M.P. Kirton. 1975. Effects of some components of crude oil on young coho salmon. Copeia 2:326-331.

Novartis Crop Protection, Inc. 2000. Material safety data sheet: BANNER MAXX. Greensboro, NC.

Rice, P.J., C.D. Drewes, T.M. Klubertanz, S.P. Bradbury, and J.R. Coats. 1997. Acute toxicity and behavioral effects of chlorpyrifos, permethrin, phenol, strychnine, and 2,4dinitrophenol to 30-day-old Japanese medaka (Oryzias latipes). Environmental Toxicology and Chemistry 16(4):696-704.

Rouse, J.D., C.A. Bishop, and J. Struger. 1999. Nitrogen pollution: An assessment of its threat to amphibian survival. Environmental Health Perspectives 107(10):799-803.

Sancho, E., M. Ferrando, E. Andreu, and M. Gamon. 1992. Acute toxicity, uptake and clearance of diazinon by the European eel, Anguilla anguilla (L.). Journal of Environmental Science and Health, Part B: Pesticides, Food Contaminants, and Agricultural Wastes B27(2):209-221.

Scholz, N.L., N.K. Truelove, B.L. French, B.A. Berejikian, T.P. Quinn, E. Casillas, and T.K. Collier. 2000. Diazinon disrupts antipredator and homing behaviors in chinook salmon (Oncorhynchus tshawytscha). Canadian Journal of Fisheries and Aquatic Science 57(9): 1911-1918.

Schuytema, G.S., and A.V. Nebeker. 1999a. Comparative toxicity of ammonium and nitrate compounds to Pacific treefrog and African clawed frog tadpoles. Environmental Toxicology and Chemistry 18(10):2251-2257.

Schuytema, G.S., and A.V. Nebeker. 1999b. Comparative effects of ammonium and nitrate compounds on Pacific treefrog and African clawed frog embryos. Archives of Environmental Contamination and Toxicology 36:200-206.

Schuytema, G.S., and A.V. Nebeker. 1999c. Effects of ammonium and nitrate, sodium nitrate, and urea on red-legged frogs, Pacific treefrog, and African clawed frogs. Bulletin of Environmental Contamination and Toxicology 63:357-364.

Servizi, J.A., R..W. Gordon, and D.W. Martens. 1987. Acute toxicity of Garlon 4 and Roundup herbicides to salmon, daphnia, and trout. Bulletin of Environmental Contamination and Toxicology 39:15-22. 
Shires, S.W. 1983. The use of small enclosures to assess the toxic effects of cypermethrin on fish under field conditions. Pesticide Science 14:475-480.

Symons, P.E.K. 1973. Behavior of young Atlantic salmon (Salmo salar) exposed to or force-fed fenitrothion, an organophosphate insecticide. Journal of the Fisheries Research Board of Canada 30(5):651-655.

Uniroyal Chemical Company. 1998. Material safety data sheet: Omite ${ }^{\circledR}$ CR. Middlebury, CT.

USDA. See U.S. Department of Agriculture.

U.S. Department of Agriculture. 1998. Dazomet: Pesticide fact sheet. Prepared for U.S. Forest Service by Information Ventures, Inc. http:/ / www.fs.fed.us/foresthealth/ pesticide/dazomet.html

U.S. Environmental Protection Agency. 1984. Health and environmental effects profile for acephate. Office of Research and Development. Cincinnati, $\mathrm{OH}$.

U.S. Environmental Protection Agency. 1986. Hazard Evaluation Division, Standard Evaluation Procedure: Ecological risk assessment. EPA-540/9-85-001. Office of Pesticide Programs. Washington, DC.

U.S. Environmental Protection Agency. 1993a. Registration eligibility decision: Glyphosate. EPA 738-R-93-014. Office of Prevention, Pesticides and Toxic Substances. Washington, DC.

U.S. Environmental Protection Agency. 1994. Reregistration eligibility decision (RED): Hexazinone. EPA 738-R-94-022. Office of Prevention, Pesticides, and Toxic Substances. Washington, DC.

U.S. Environmental Protection Agency. 1998a. Guidelines for ecological risk assessment. Federal Register 63(93):26846-26924.

U.S. Environmental Protection Agency. 1998b. Reregistration eligibility decision (RED): Triclopyr. EPA 738-R-98-011. Office of Prevention, Pesticides, and Toxic Substances. Washington, DC.

U.S. Environmental Protection Agency. 1998c. Biopesticide fact sheet: Bacillus thuringiensis subspecies kurstaki strain M-200. Office of Pesticide Programs. Washington, DC.

U.S. Environmental Protection Agency. 1999a. Reregistration eligibility decision (RED): Chlorothalonil. EPA 738-R-99-004. Office of Prevention, Pesticides, and Toxic Substances. Washington, DC.

U.S. Environmental Protection Agency. 1999b. Environmental Fate and Effects Division's revised chapter for the dimethoate RED. Office of Pesticide Programs. Washington, DC.

U.S. Environmental Protection Agency. 2000a. Reregistration eligibility science chapter for chlorpyrifos: Fate and environmental risk assessment chapter. Office of Pesticide Programs. Washington, DC.

U.S. Environmental Protection Agency. 2000b. Environmental Fate and Effects Division science chapter for reregistration eligibility document for propargite. Office of Pesticide Programs. Washington, DC. 
U.S. Environmental Protection Agency. 2001. Ecotox: Ecotoxicology database. Office of Research and Development, National Health and Environmental Effects Research Laboratory, Mid-Continent Ecology Division. Duluth, MN.

Valent USA Corporation. 1983. 96-hour aquatic toxicity study in rainbow trout and bluegill sunfish with 70 Orchard Spray. Walnut Creek, CA. Performed by Gulf Life Sciences Center. Pittsburg, PA.

Walsh, D.F., J.G. Armstrong, T.R. Bartley, H.A. Salman, and P.A. Frank. 1977. Residues of emulsified xylene in aquatic weed control and their impact on rainbow trout. REC-ERC76-11. Engineering and Research Center, U.S. Bureau of Reclamation. Denver, CO.

Wan, M.T., R.G. Watts, and D.J. Moul. 1988. Evaluation of the acute toxicity to juvenile Pacific salmonids of hexazinone and its formulated products: Pronone 10G, Velpar L, and their carriers. Bulletin of Environmental Contamination and Toxicology 41(4):609-616.

Washington State Pesticide/ESA Task Force. 2001. A process for evaluating pesticides in Washington state surface waters for potential impacts to salmonids. March 2001. Publication No. 052.

WHO. See World Health Organization.

Wildlife International Ltd. 1991. 90 Neutral Oil: A 96-hour static acute toxicity test with the rainbow trout (Oncorhynchus mykiss). Easton, MD. Submitted to Unocal Corporation, Los Angeles, CA.

Woodward, D.F. 1976. Toxicity of the herbicides dinoseb and picloram to cutthroat (Salmo clarki) and lake trout (Salvelinus namaycush). Journal of the Fisheries Research Board of Canada 33(8):1671-1676.

Woodward, D.F. 1979. Assessing the hazard of picloram to cutthroat trout. Journal of Range Management 32(3):230-232.

Woodward, D.F. 1982. Acute toxicity of mixtures of range management herbicides to cutthroat trout. Journal of Range Management 35(4):539-540.

World Health Organization. 1996. Ethylbenzene. Environmental Health Criteria 186 (abstract). Geneva, Switzerland.

World Health Organization. 1997. Xylenes. Environmental Health Criteria 190 (abstract). Geneva, Switzerland. 
Final EIS - Tyrrell Seed Orchard IPM

$D-28$ 


\section{Appendix E: Public Comments on Draft EIS and BLM Responses}

\section{Introduction - NEPA Public Involvement in the Eugene District}

The Council on Environmental Quality's regulations for implementing the National Environmental Policy Act (NEPA) (40 CFR 1500-1508) mandate public participation in the environmental impact analysis process. BLM prepared the Draft EIS and made it available for public review and comment on June 27, 2003. The availability of the Draft EIS was announced as follows:

- A Notice of Availability was published in the Federal Register on June 13, 2003.

- Notices were placed in three local newspapers: Eugene Register-Guard (June 8, 2003); Cottage Grove Sentinel (June 11, 2003); and West Lane News (June 12, 2003).

- Copies of the Draft EIS were sent to four local libraries: the Eugene City Library, downtown branch; and the Springfield, Cottage Grove, and Fern Ridge (Veneta) public libraries in Lane County.

- Postcards offering to send a hard copy or CD of the Draft EIS upon request were sent to the 16 agencies and 74 members of the public on the Draft EIS mailing list.

- Electronic copies of the Draft EIS were placed on the Eugene District website for viewing or downloading, at http:/ / www.edo.or.blm.gov/planning/seed_orchard/ pest_mgmt_eis.htm

- Copies of the Draft EIS were available in hard copy and CD at the BLM Eugene District Office and the Tyrrell Seed Orchard office.

The public comment period ended on August 25, 2003.

BLM held meetings in an open house format to present the findings of the Draft EIS and invite public comments. The meetings were held at Tyrrell Seed Orchard on July 16, 2003 from 1:00 to 3:00 p.m. and 5:00 to 7:00 p.m. There was one attendee at the early session, and two attendees during the late session.

\section{Content Analysis}

BLM received very few comments on the Draft EIS. Two verbal comments were received during the public meetings and three written comments were received during the public comment period. The BLM EIS team reviewed all public comments. However, due to the small number of comments received, no statistical analysis of the commentors' demographics and nature of comments was performed.

The commentor at the first session was an individual who identified himself as a volunteer at Tyrrell, a BLM retiree, and a nearby landowner. The commentors at the second session were a couple who live near the orchard. Written comments were received from two Federal agencies and an individual representing herself and two organizations. Table E-1 lists the commentors and the overall focus of their comments. Of the three written comments, two were sent to BLM after the comment deadline of August 25, 2003, but have been considered in preparing the Final EIS. 


\section{Table E-1. Comment Summary}

\begin{tabular}{|c|c|c|c|}
\hline $\begin{array}{l}\text { Tracking } \\
\text { Number }\end{array}$ & Commentor & $\begin{array}{l}\text { Format and } \\
\text { Date }\end{array}$ & Focus \\
\hline $\mathrm{T} 1$ & $\begin{array}{l}\text { Albert Goins } \\
\text { Volunteer at Tyrrell Seed Orchard, BLM retiree, } \\
\text { and landowner } \\
\text { Lorane, OR }\end{array}$ & $\begin{array}{l}\text { Tyrrell Public } \\
\text { Meeting } \\
7 / 16 / 03\end{array}$ & $\begin{array}{l}\text { Requested information on } \\
\text { monitoring conducted for } \\
\text { the spring } 2003 \text { esfenvalerate } \\
\text { spray project }\end{array}$ \\
\hline $\mathrm{T} 2$ & $\begin{array}{l}\text { Mary Seereiter } \\
\text { Neighbor of seed orchard } \\
\text { Lorane, OR }\end{array}$ & $\begin{array}{l}\text { Tyrrell Public } \\
\text { Meeting } \\
7 / 16 / 03\end{array}$ & $\begin{array}{l}\text { Dislike for chemicals in } \\
\text { general; asked questions } \\
\text { about the details of the risk } \\
\text { assessment and impact } \\
\text { analysis. Support for the } \\
\text { research activities at Tyrrell. }\end{array}$ \\
\hline $\mathrm{T} 3$ & $\begin{array}{l}\text { Michael P. Tehan } \\
\text { National Marine Fisheries Service (NOAA } \\
\text { Fisheries) } \\
\text { National Oceanic and Atmospheric } \\
\text { Administration } \\
\text { Portland, OR }\end{array}$ & $\begin{array}{l}\text { Letter dated } \\
8 / 13 / 03 \\
\text { received } 8 / \\
20 / 03\end{array}$ & $\begin{array}{l}\text { Suggestions for additional } \\
\text { analysis, monitoring, and } \\
\text { protection measures for } \\
\text { anadromous fish species }\end{array}$ \\
\hline $\mathrm{T} 4$ & $\begin{array}{l}\text { Judith Leckrone Lee } \\
\text { Manager, Geographic Unit } \\
\text { Region 10, U.S. Environmental Protection Agency } \\
\text { Seattle, WA }\end{array}$ & $\begin{array}{l}\text { Faxed letter } \\
\text { dated } 9 / 10 / \\
03, \text { received } \\
9 / 10 / 03\end{array}$ & $\begin{array}{l}\text { Support for Alternative B, } \\
\text { pesticide safety, IPM for } \\
\text { specific diseases, additional } \\
\text { technologies, Port-Orford- } \\
\text { Cedar management, pesticides } \\
\text { listed in a recent Western } \\
\text { District Court decision }\end{array}$ \\
\hline T5 & $\begin{array}{l}\text { Jan Wroncy } \\
\text { Individually and representing Coast Range } \\
\text { Guardians and Canaries Who Sing } \\
\text { Eugene, OR }\end{array}$ & $\begin{array}{l}\text { Letter dated } \\
8 / 25 / 03 \\
\text { faxed } 8 / 27 / 03\end{array}$ & $\begin{array}{l}\text { Support for Alternative } D \text {, } \\
\text { opposition to use of pesticides, } \\
\text { request to exclude } B . t \text {. from } \\
\text { Alternative D, statement that } \\
\text { impacts from pesticides are } \\
\text { underestimated and would } \\
\text { affect salmon, recommended } \\
\text { no use of fertilizers to decrease } \\
\text { need for pesticides }\end{array}$ \\
\hline
\end{tabular}


Of the five commentors, one supported the selection of Alternative B (IPM with Environmental Protection Emphasis-the proposed action and preferred alternative), and one recommended that Alternative D (Non-Chemical Pest Management ${ }^{1}$ ) be selected. Three commentors did not express any preference for a selected alternative, and one of those limited comments to suggestions for changes to the details of Alternative B to further protect threatened salmonid species.

\section{Comments and Responses}

Copies of each comment on the Draft EIS are provided at the end of this appendix. Each item (transcript or comment letter) was assigned an identification number (T1 through T5) that appears in the upper right-hand corner of the first page of the comment letter or public meeting notes. Because some commentors made more than one comment, each comment was also assigned an identification number. Separate comments within the transcript or letter are numbered along the left margin of the item, and are identified using an alphanumerical code consisting of the item's identification number and the individual comment number. For example, the first separate comment in item T3 is labeled T3-1, the second separate comment is T3-2, and so on. The public meeting notes are presented first, followed by letters from Federal agencies and then by other comments.

Table E-2 presents BLM's responses to each comment, including references to sections of the EIS that were changed, as appropriate. Excerpts from written comment letters were copied verbatim from the letter and presented in Table E-2 to maintain proper context.

${ }^{1}$ Revised to be named Non-Pesticide Pest Management for Final EIS in response to comment T5-2. 


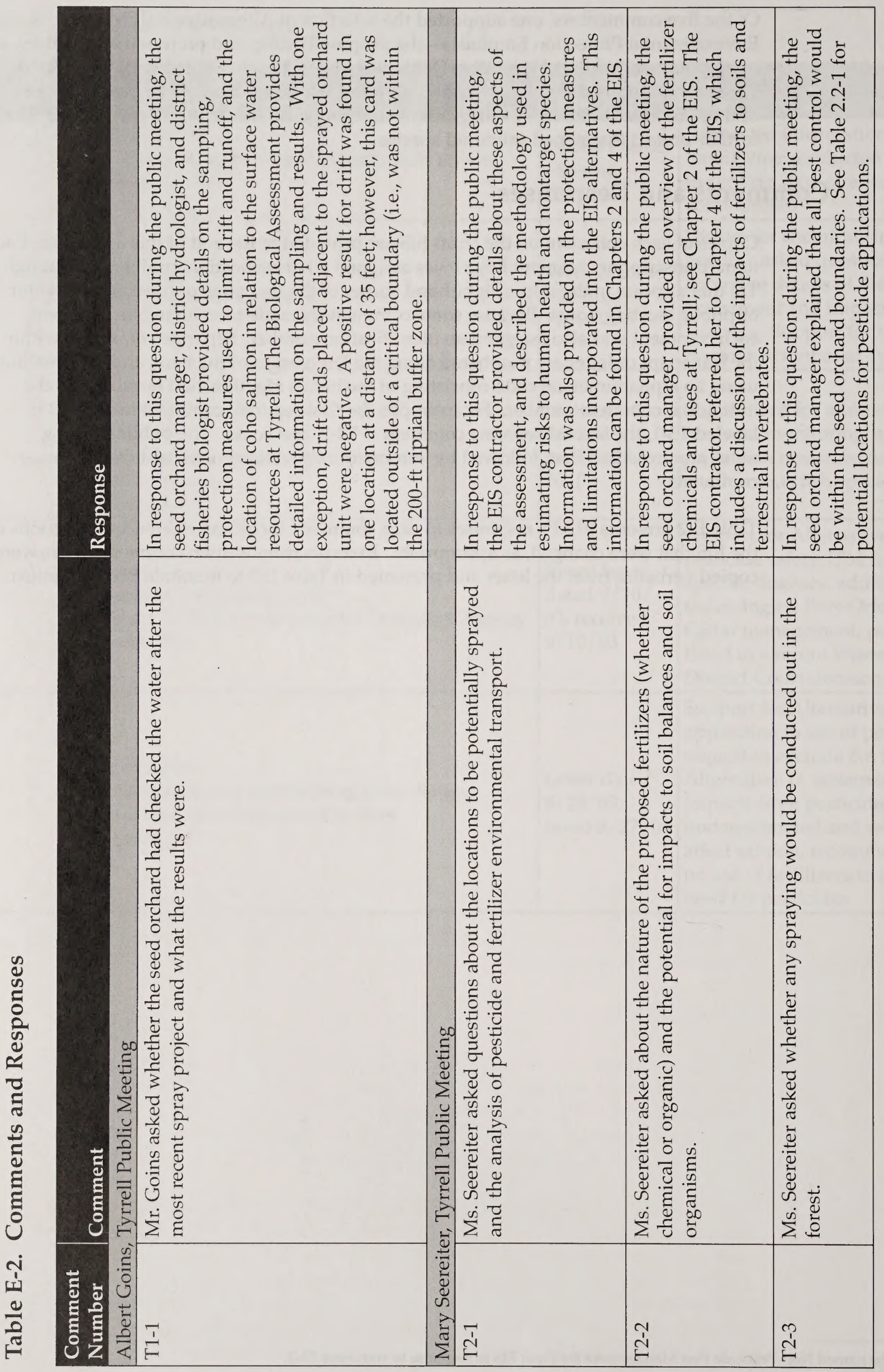




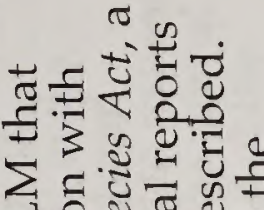

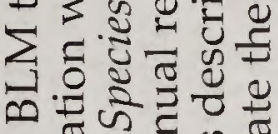

的舟

ठี के च

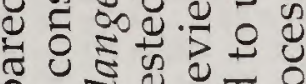

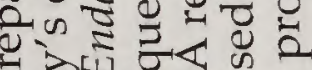

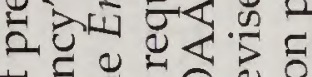

च

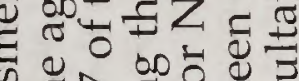

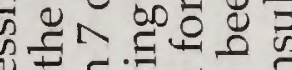

W

记

उु

कo टै है:

च व

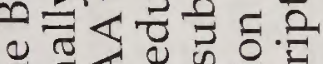

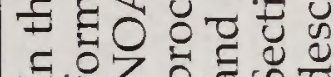

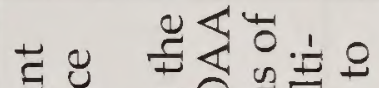

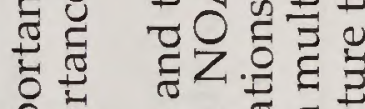

हैं

I. .2 क

สำ 원

.

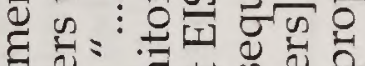

ป.

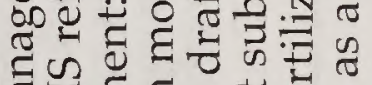

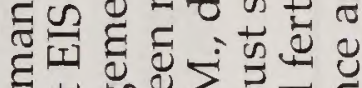

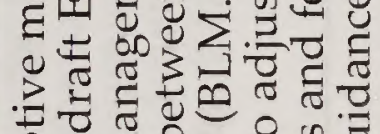

के है = \&

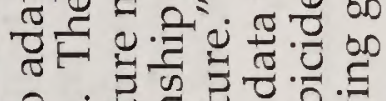

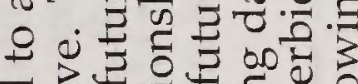

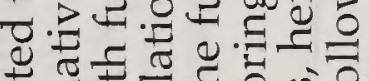

동

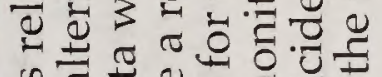

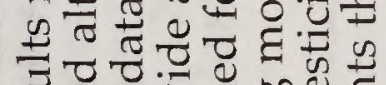

$\overline{0} 0.000000$

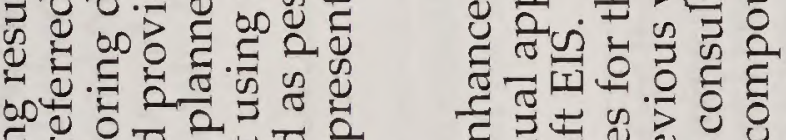

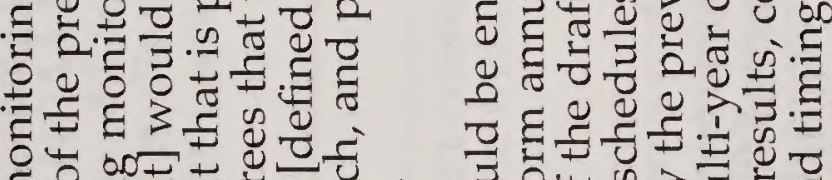

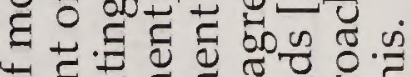

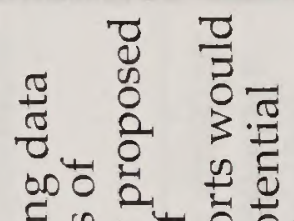

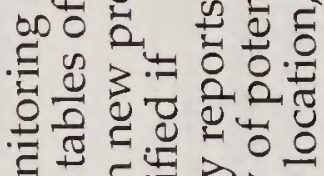

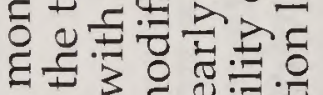

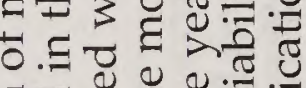

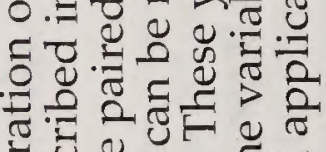
to

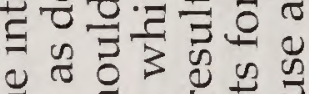
Е $0,0 \frac{0}{2}$ के .

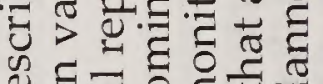

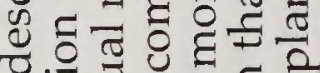

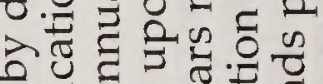
: है बิ:

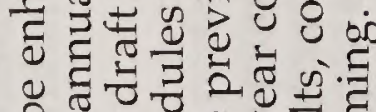

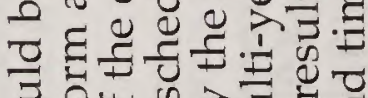
จ. w. $\backsim .2$. ڤ艹

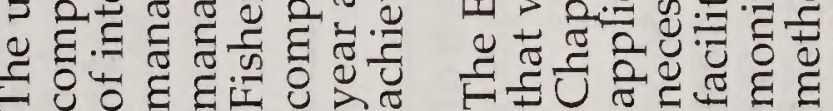

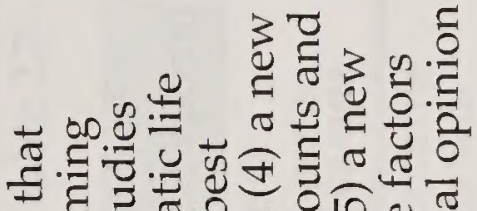

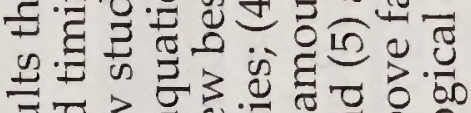

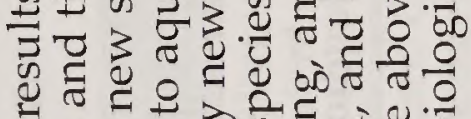

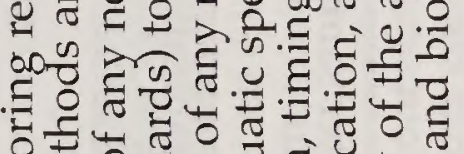

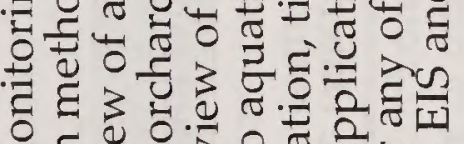

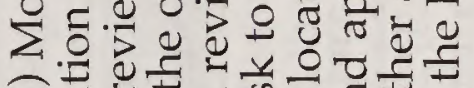
छ๘

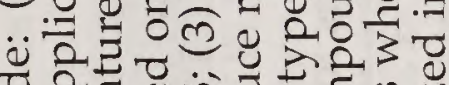

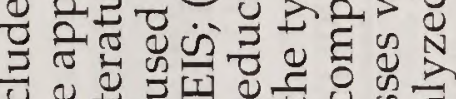
บ․ㄷㄹ

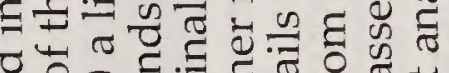
을

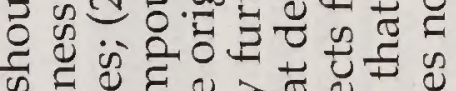
जे

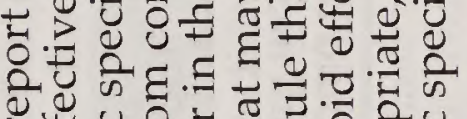

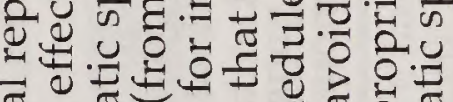

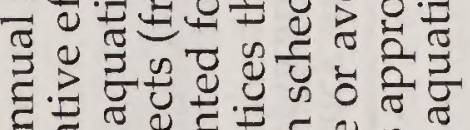

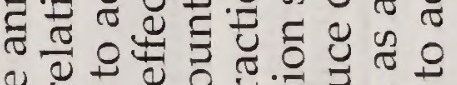

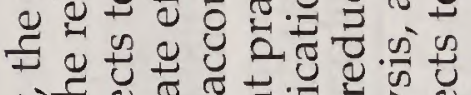

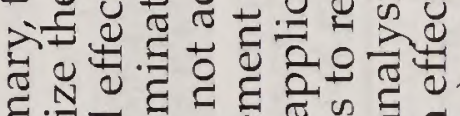

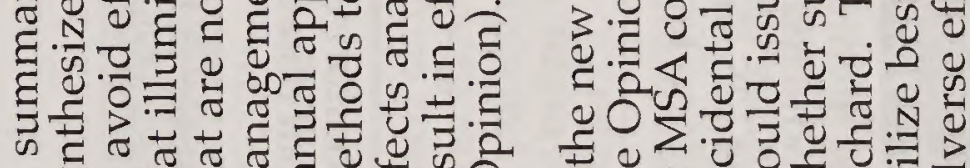

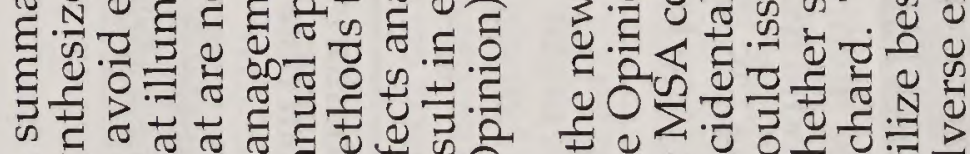

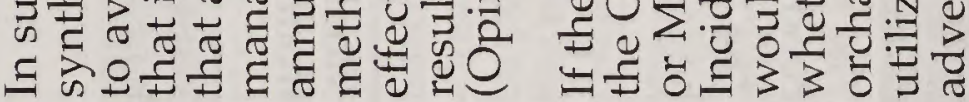

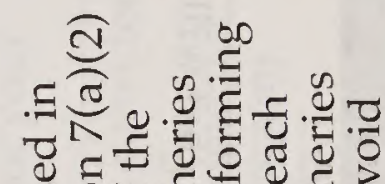
N. 릉 उ 5 文政 Uै

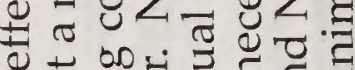

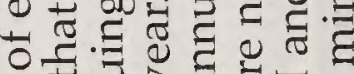
ob. छ.尹̃ -58 वे 3.0 \% Ð

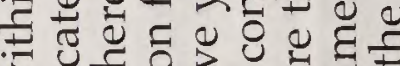
. . 충 2, उ

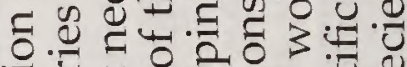
च :

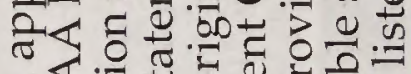

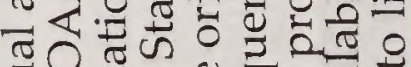

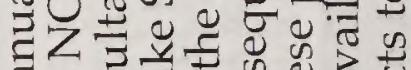
दे के क⿺

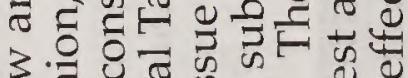

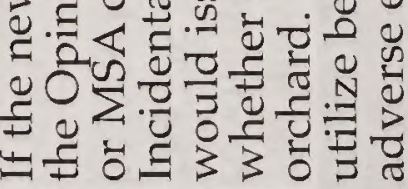

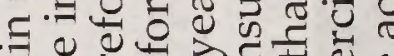
उ: 




$E-6$ 


\begin{tabular}{|c|c|c|c|c|c|c|c|c|}
\hline & 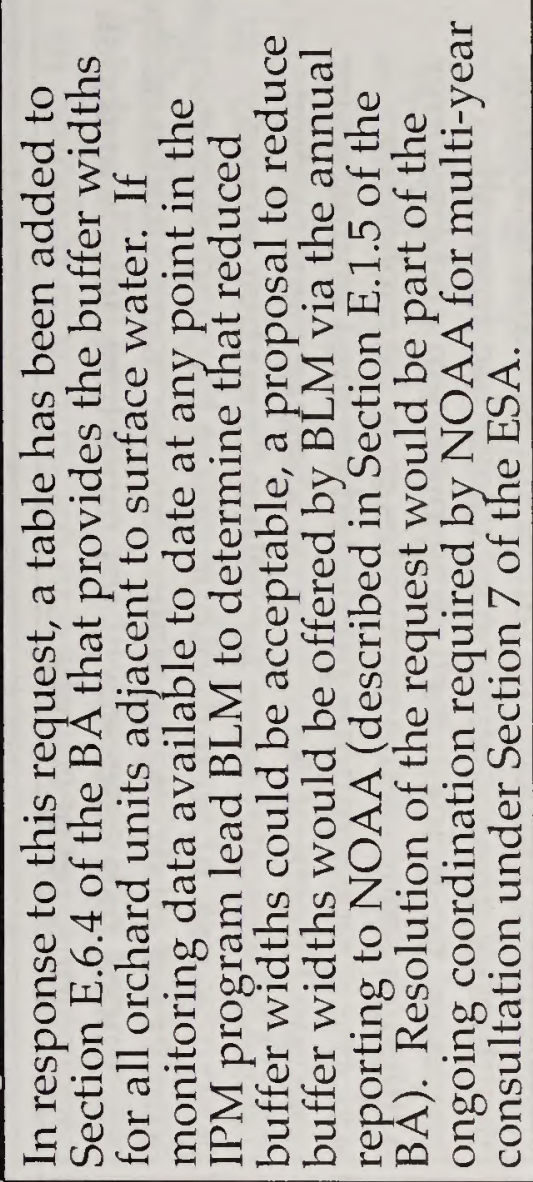 & 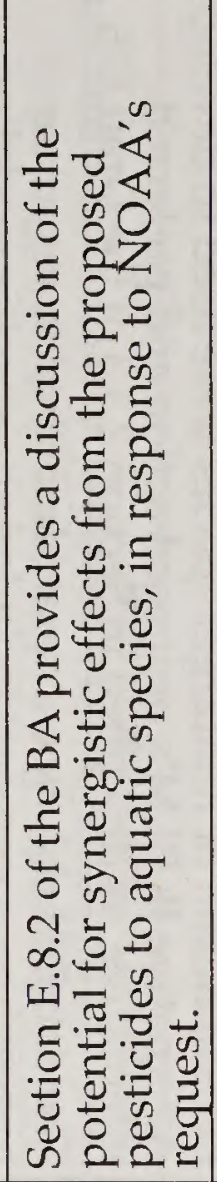 & 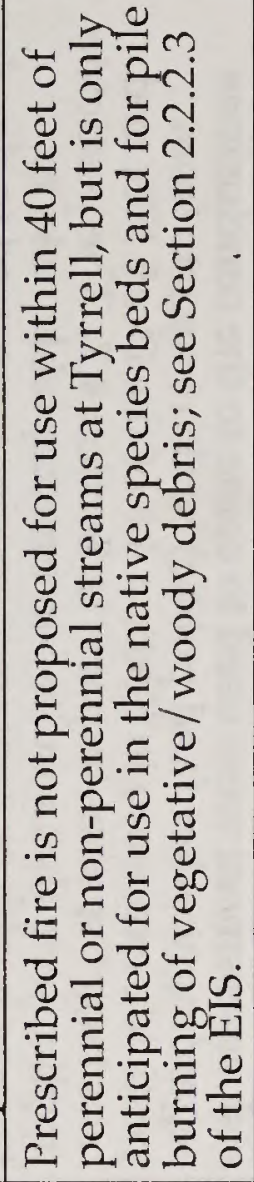 & 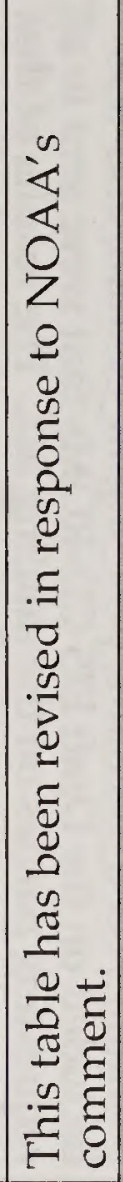 & & 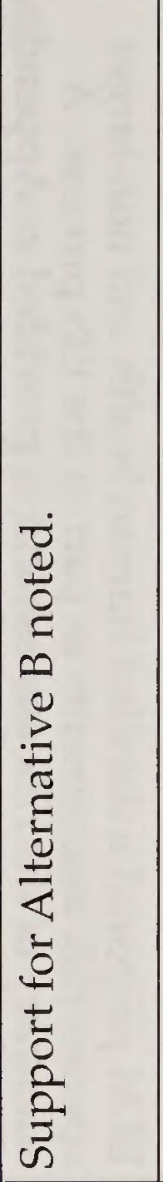 & 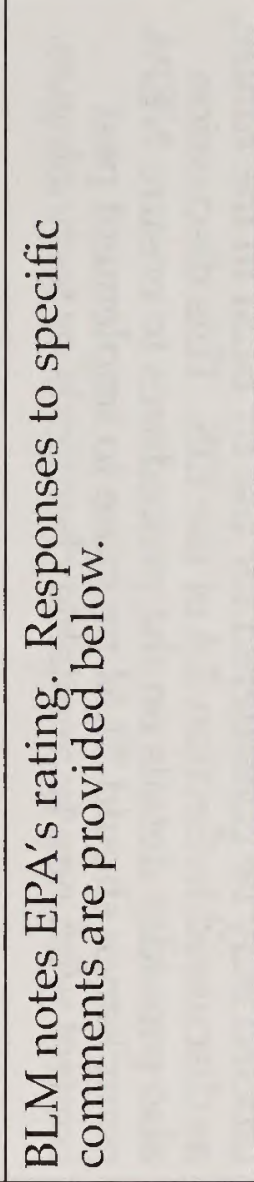 & 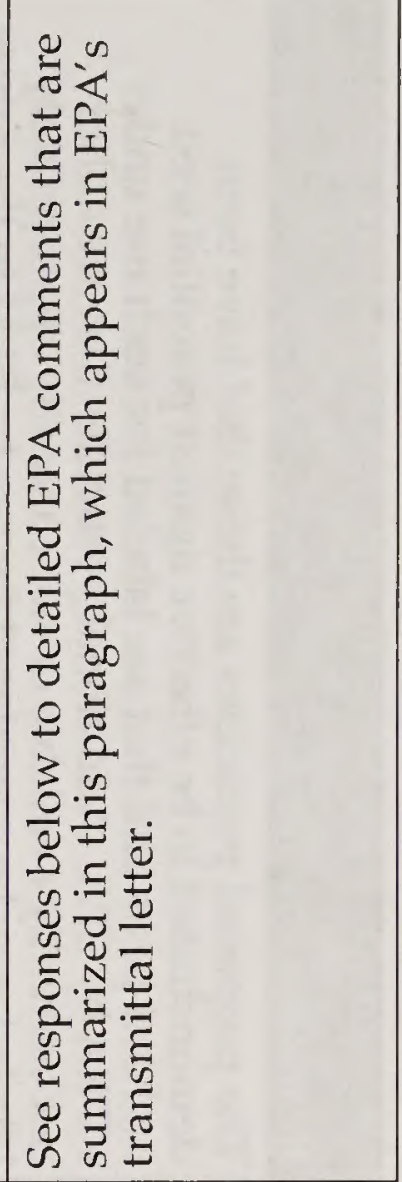 \\
\hline छ & 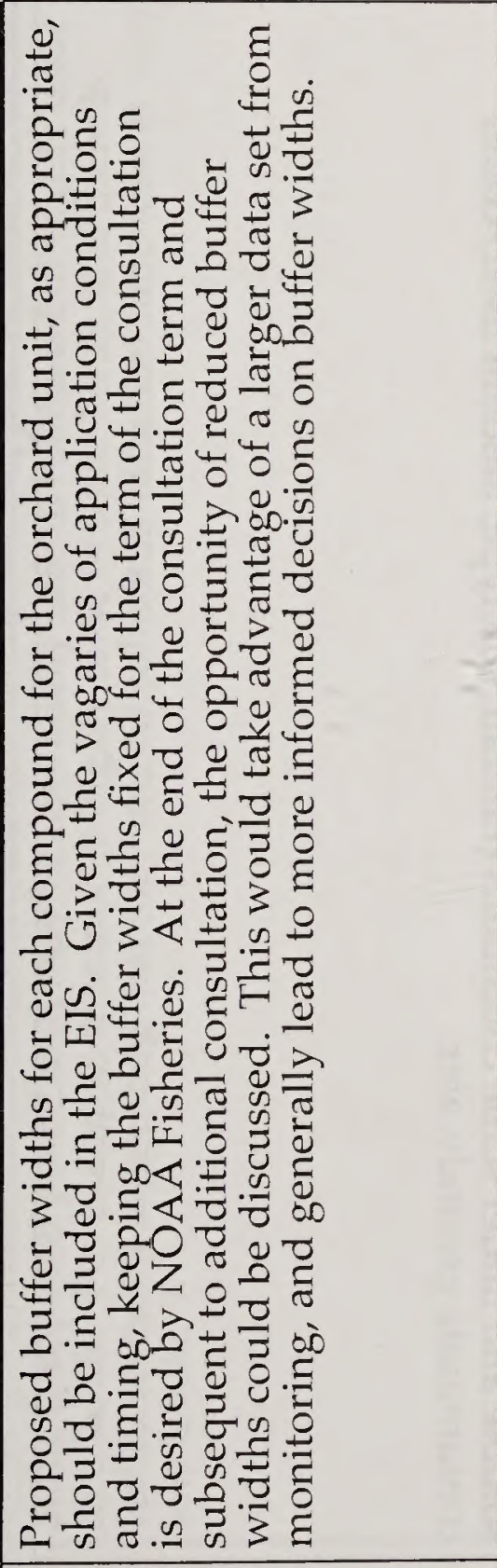 & 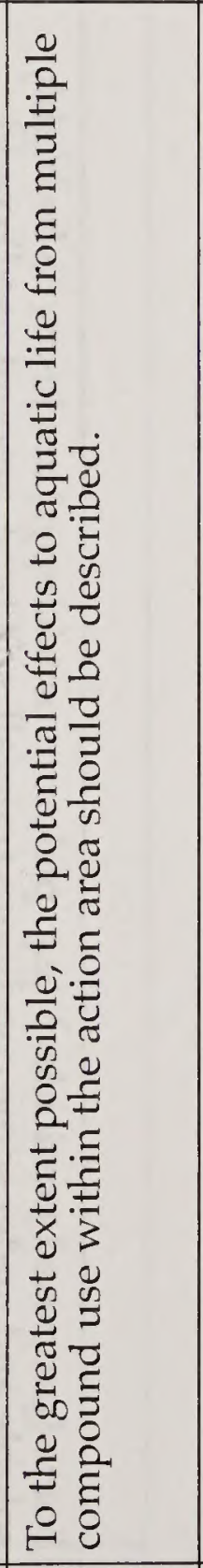 & 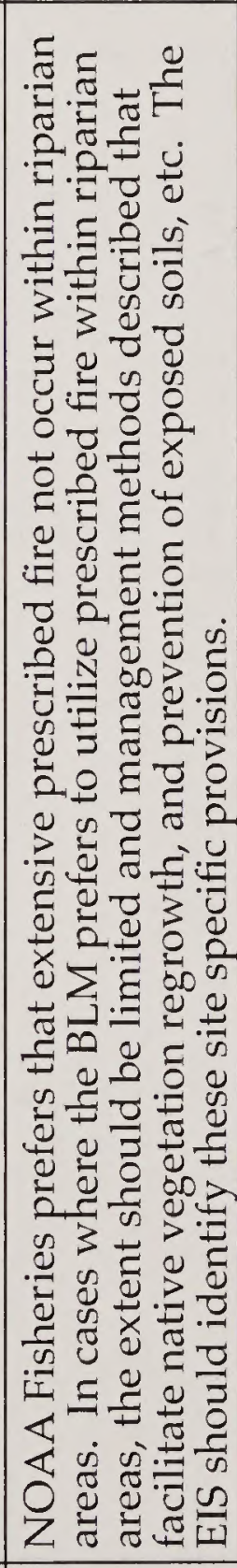 & 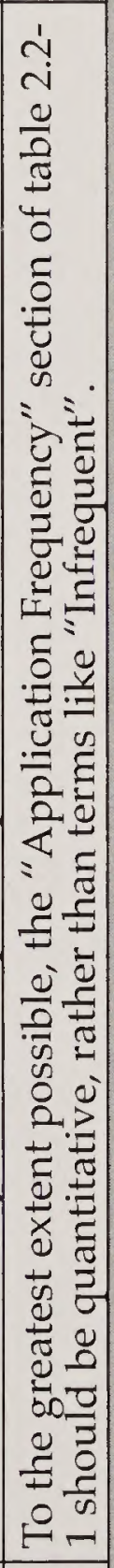 & 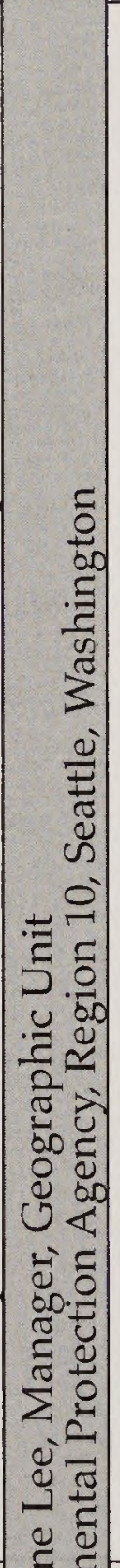 & 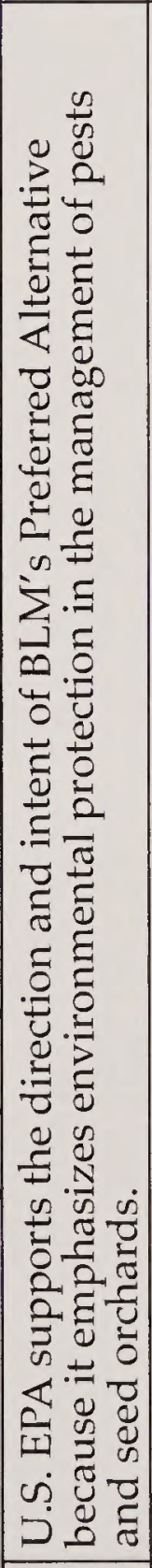 & 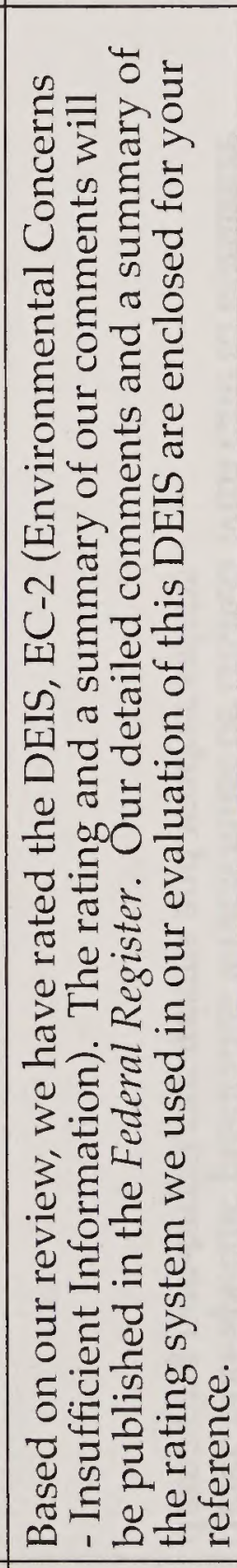 & 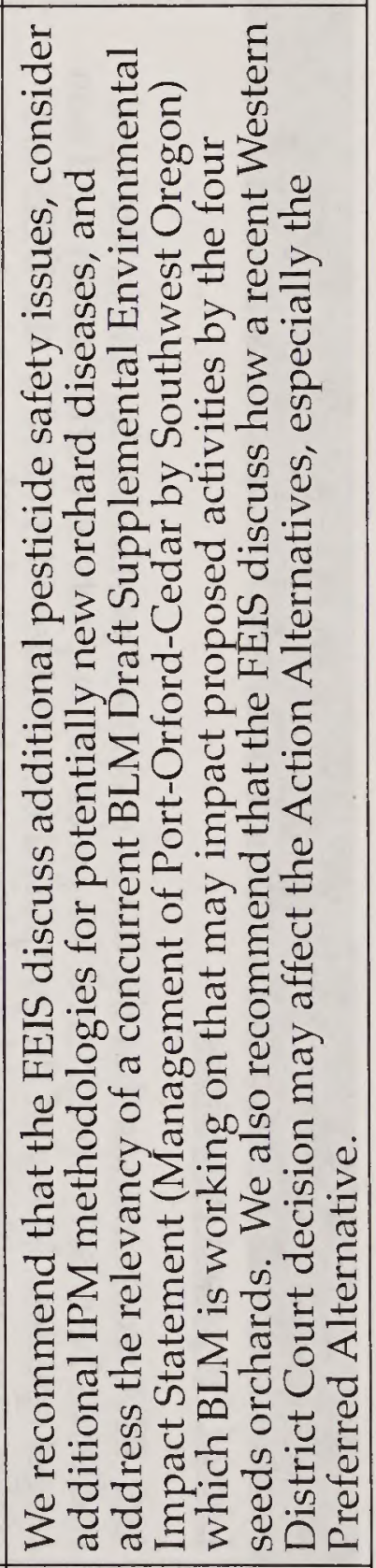 \\
\hline & & $\begin{array}{l}\infty \\
1 \\
0 \\
\hat{H}\end{array}$ & $\begin{array}{l}\hat{1} \\
\hat{n}\end{array}$ & & 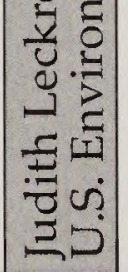 & & & $\frac{P}{4}$ \\
\hline
\end{tabular}



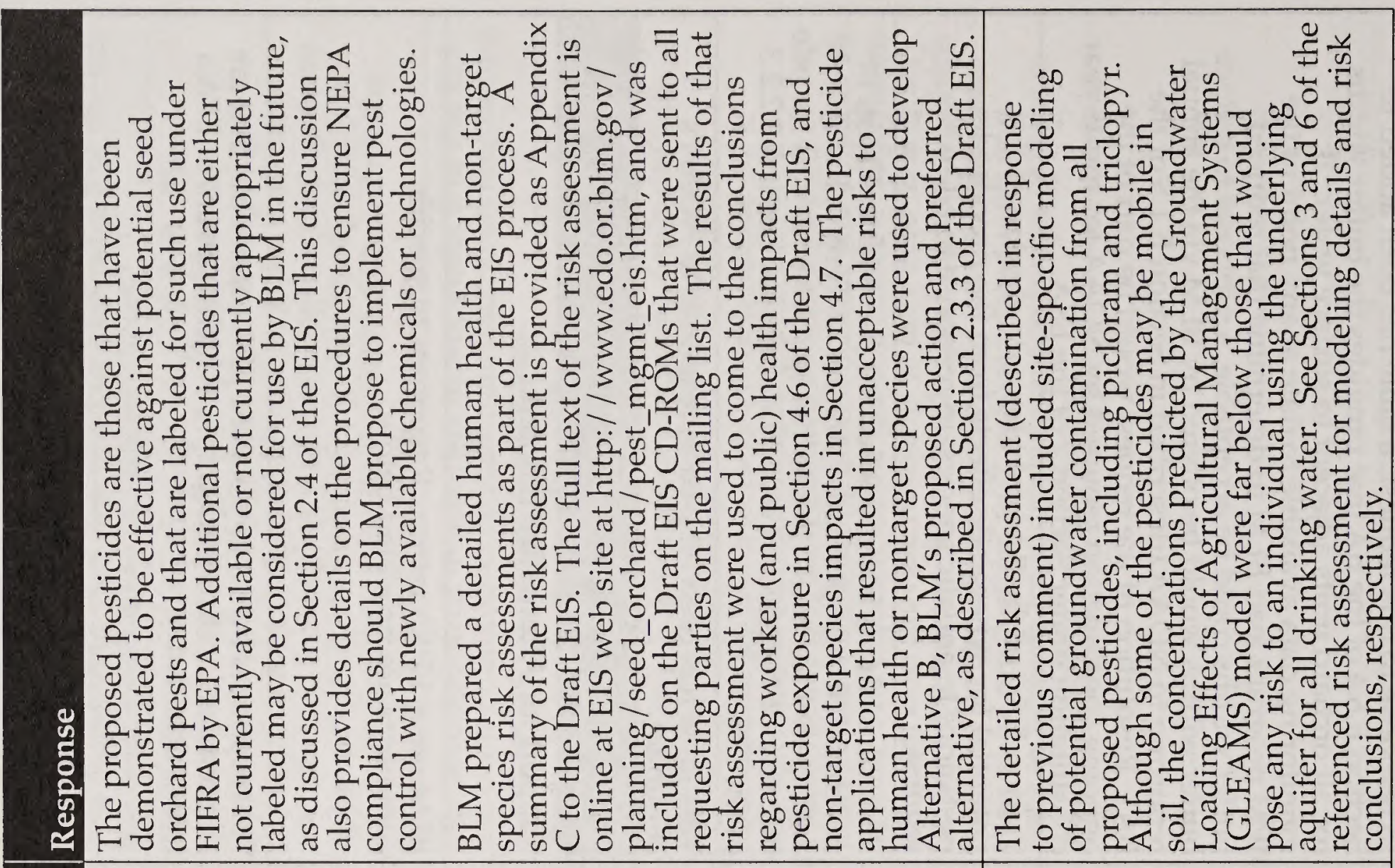

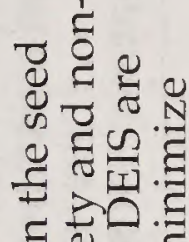

$\Xi \stackrel{0}{0}$

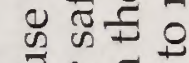

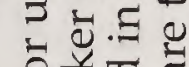

કั

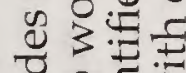

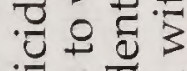

急

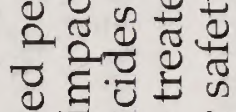

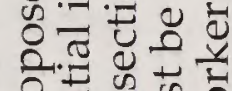

을

2.

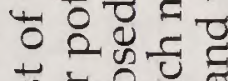

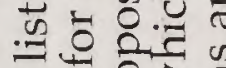

등 3

I

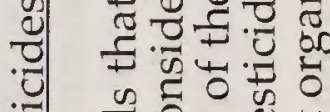

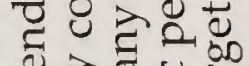

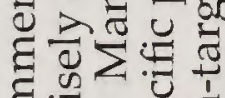

둥 के

ญ.

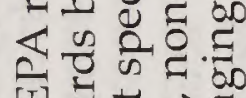

퍼

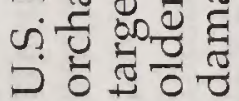

글

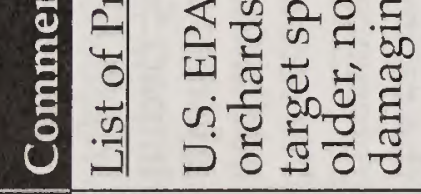

是 


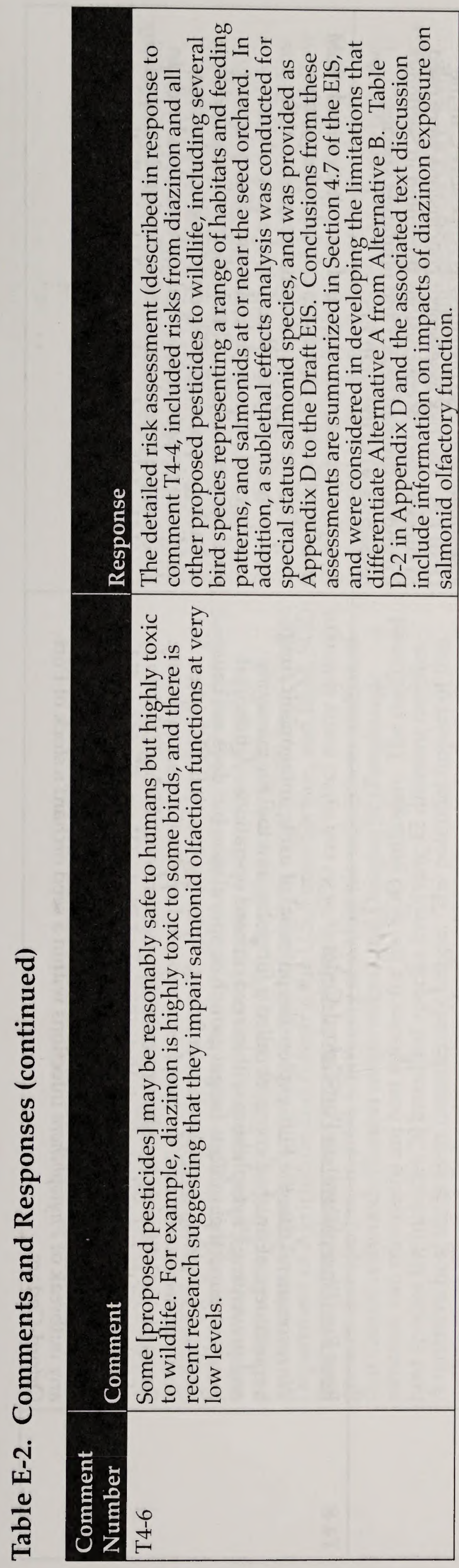


s.

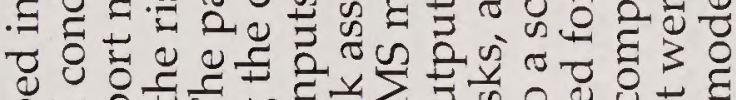

9 9.

눈 9.

Z

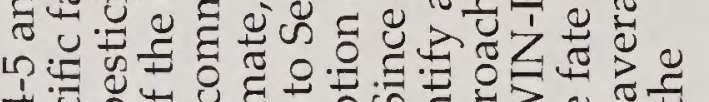

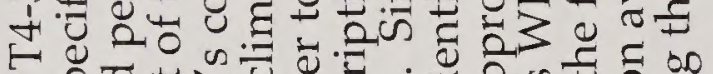
20

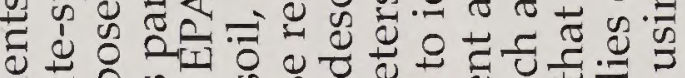

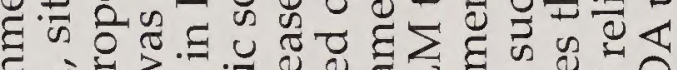

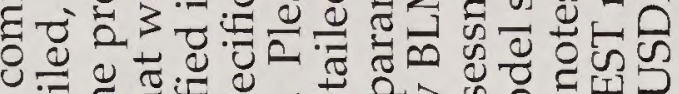

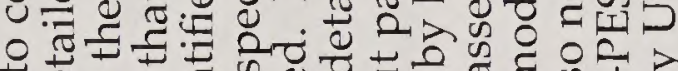

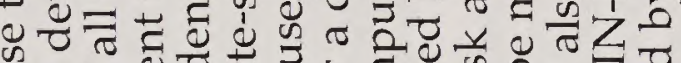

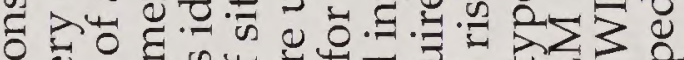
के 50 के す⿹丁口

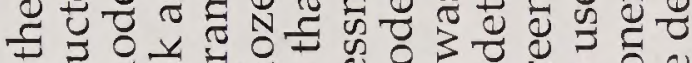

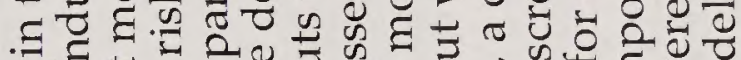

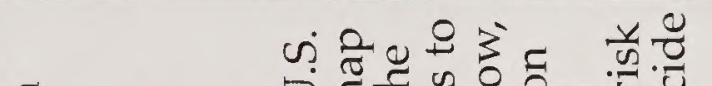
ำ

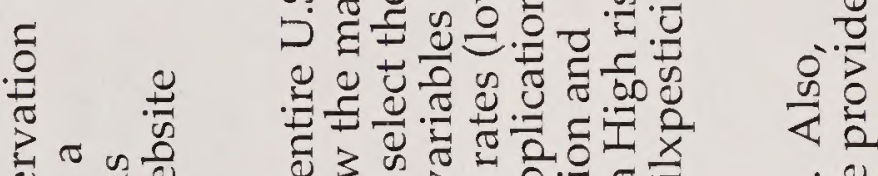

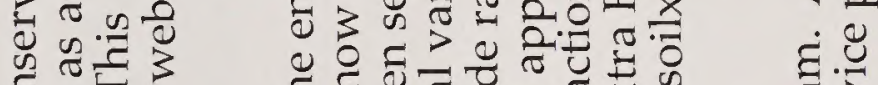

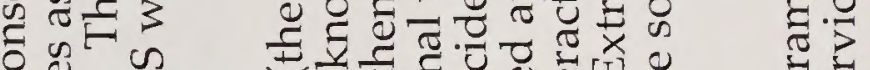
U.

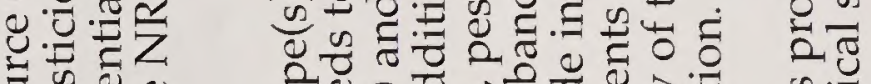

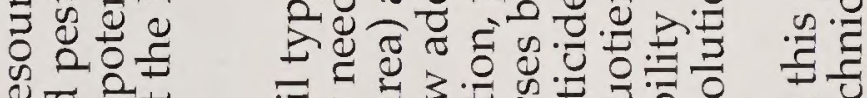

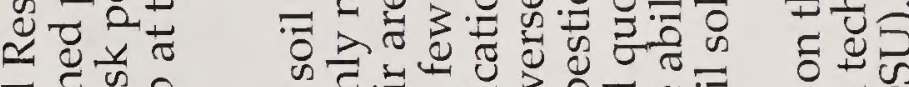

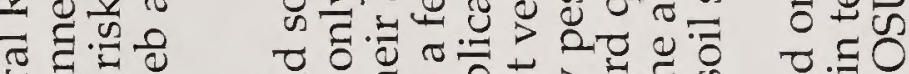
元宩

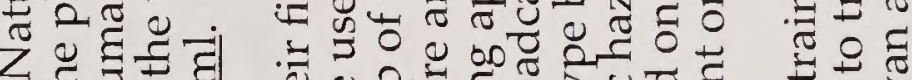

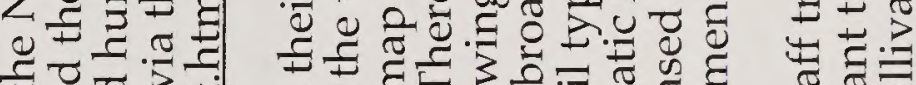

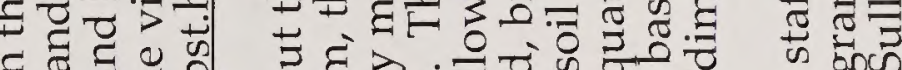

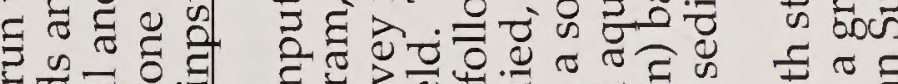

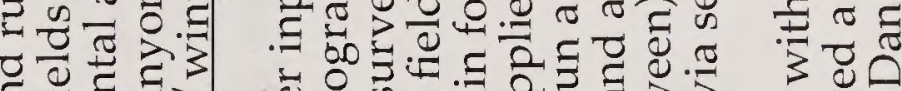

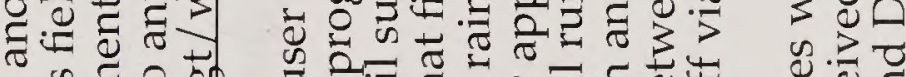

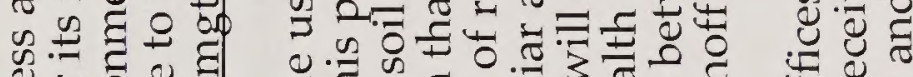

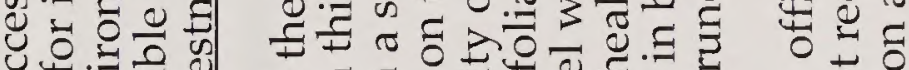

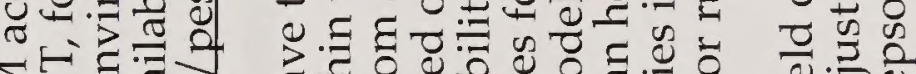

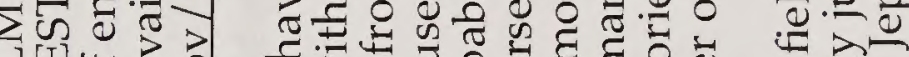

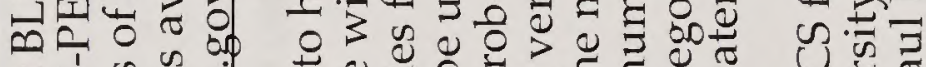

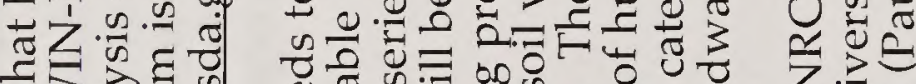

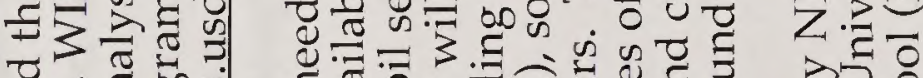
चี

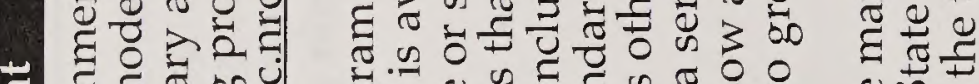

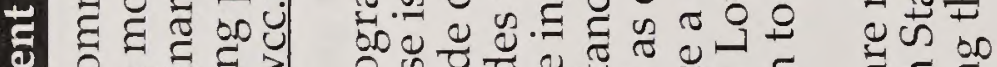

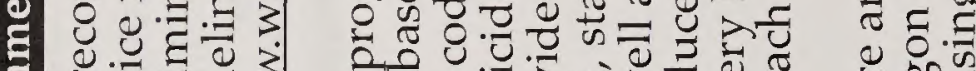
$3=03$ ग

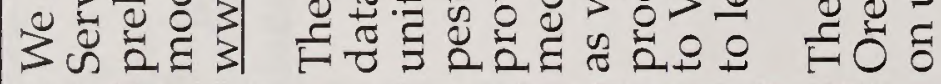

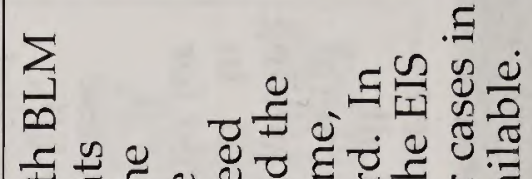

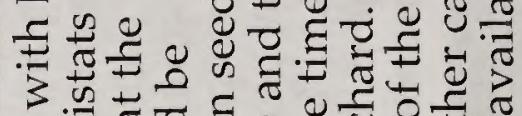

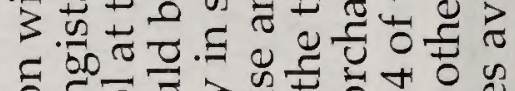

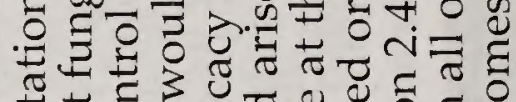

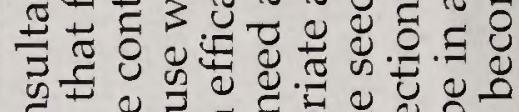
ป

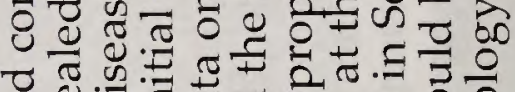

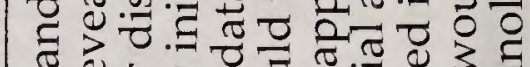

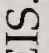
. 20. .

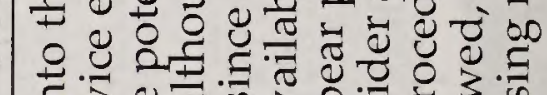

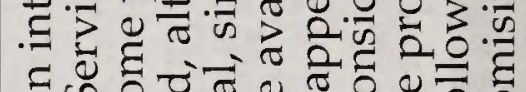

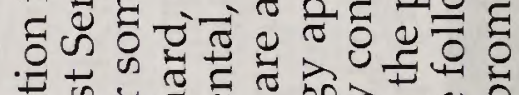

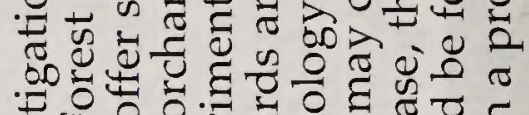

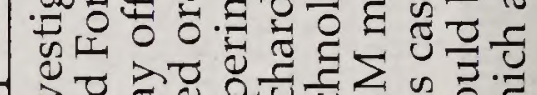

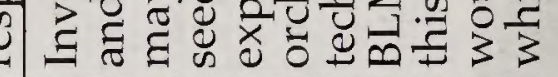

或 u.

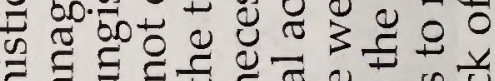

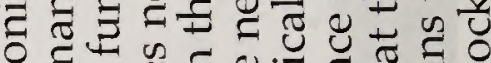

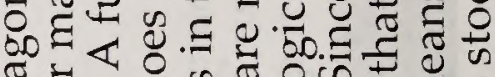

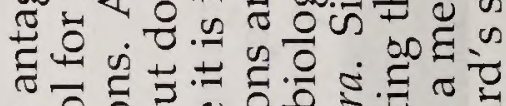
$008.0 \%$

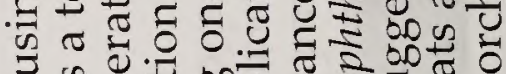

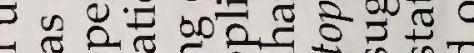

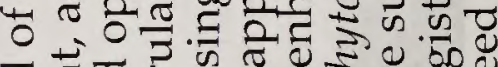

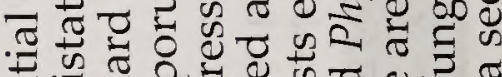

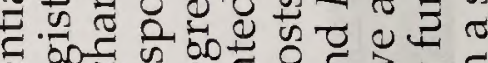

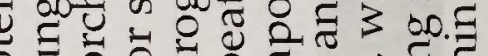

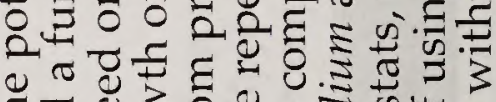
モ⿻ ๖.

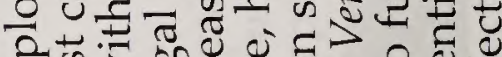

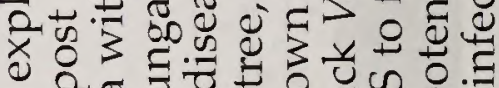
0

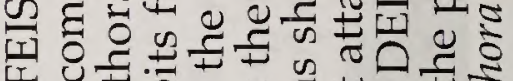
จ $\exists$ 응. \& $0 . \Xi \pm$ के 글

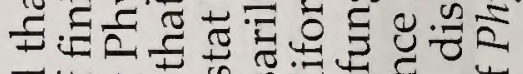

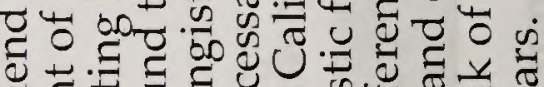

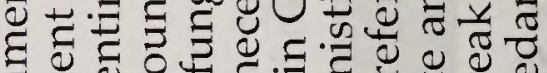
है ญ्.

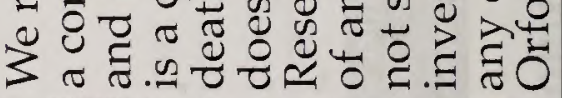




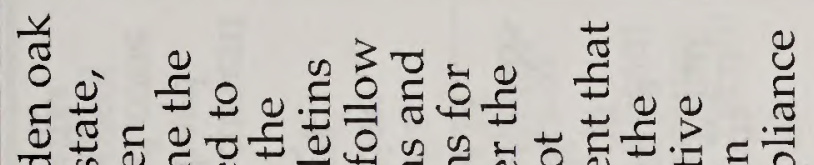

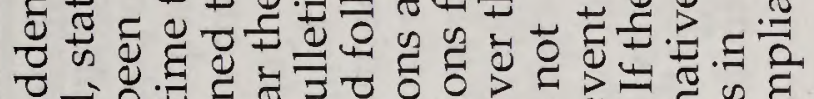

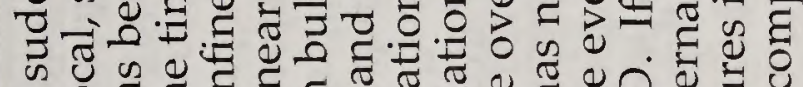
क⿺辶⿻ -

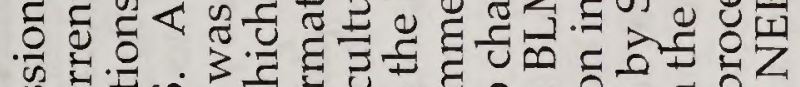

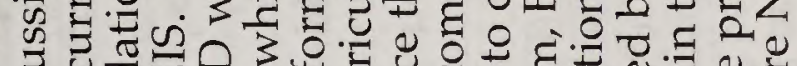

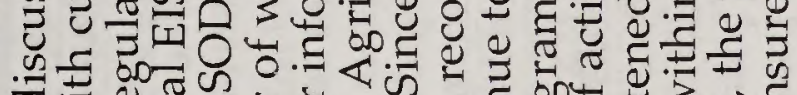
\%

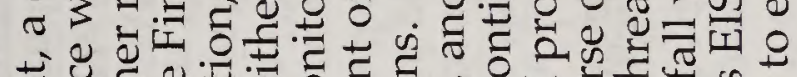

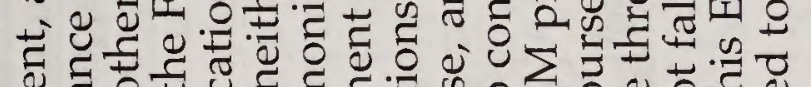

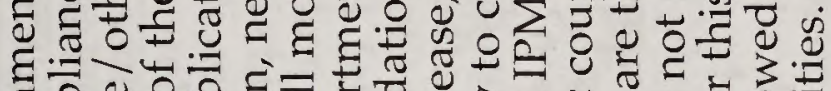
हों

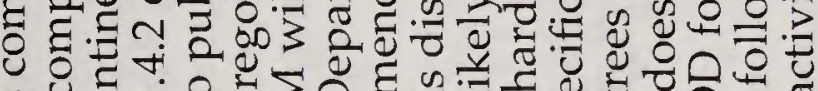
虽

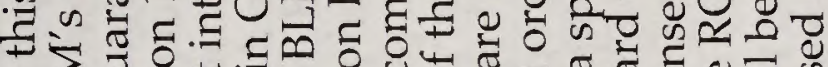

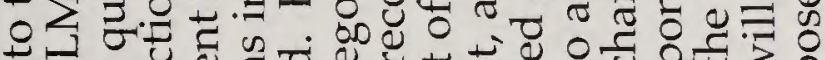

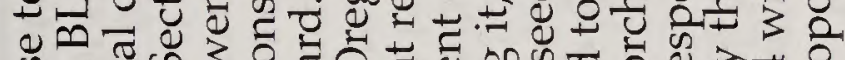

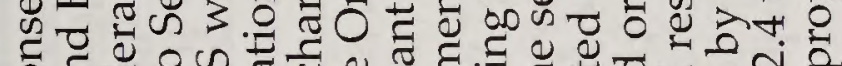

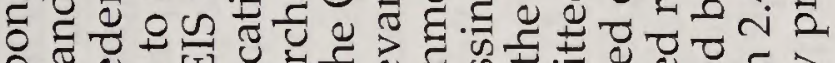

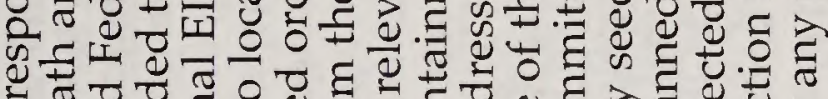

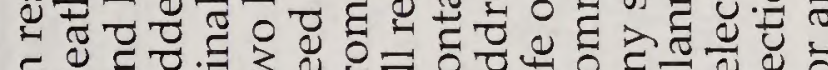

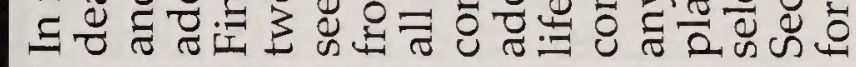

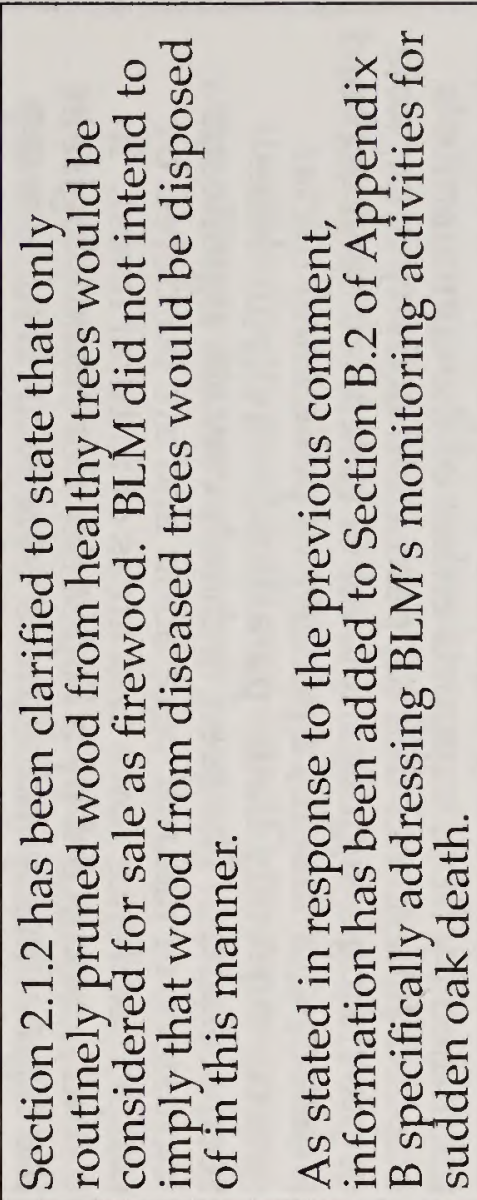

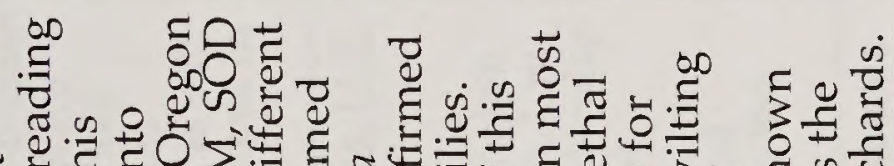

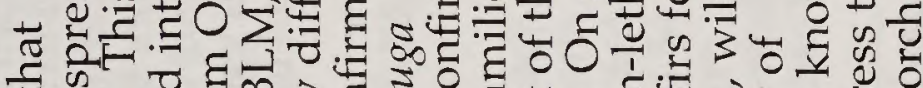

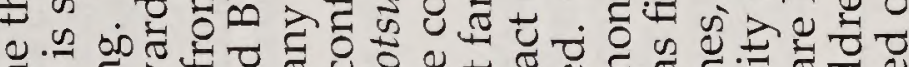
o.

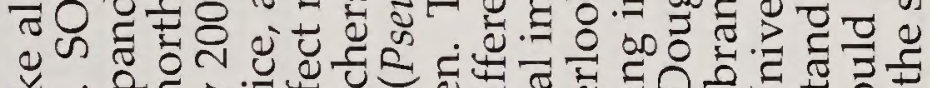

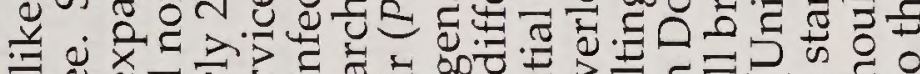

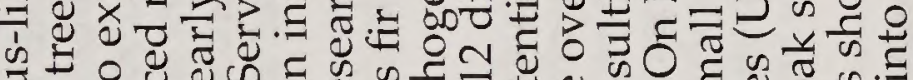

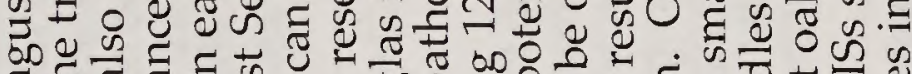

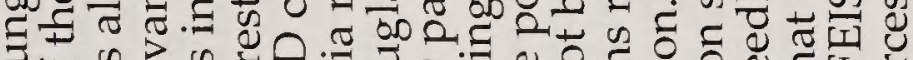

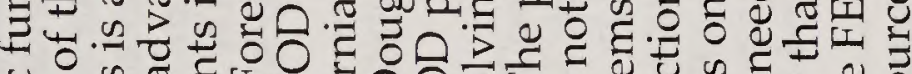
U.

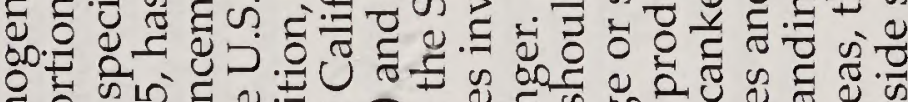
‡ 20. 503.00 o 50 50 E.

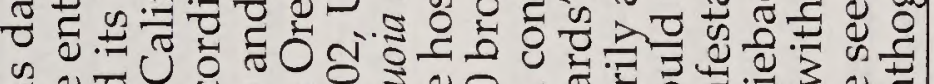

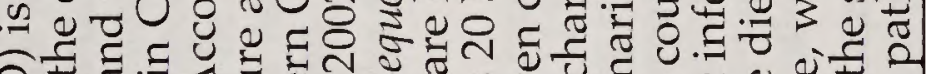
Oิ 00 \%

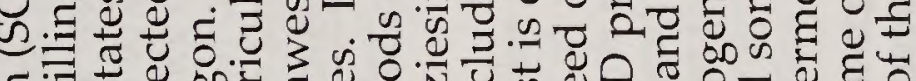
프 के के

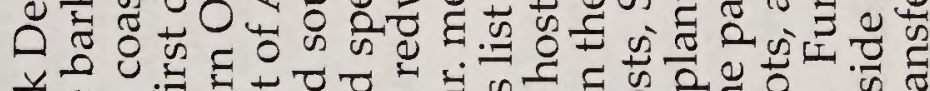

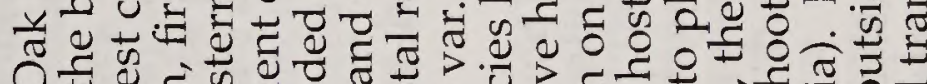
0 平 5

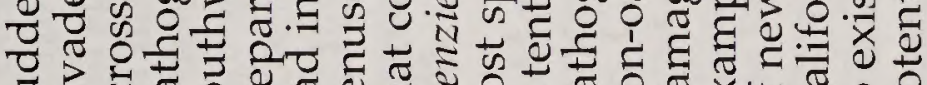

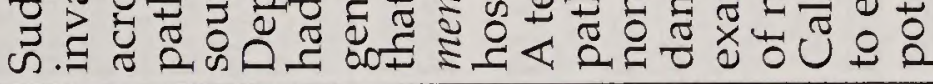

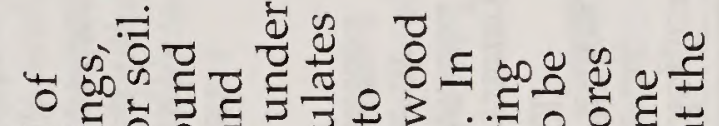
z

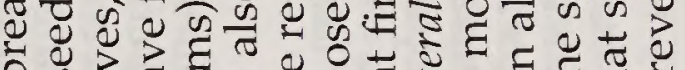
क人

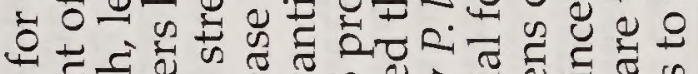
(ब)

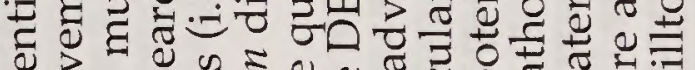

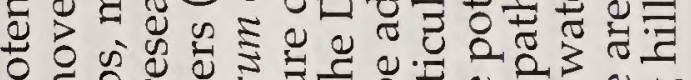
․․ㄹㄹ

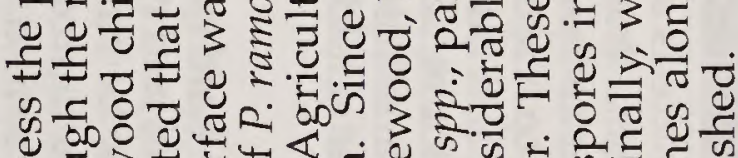

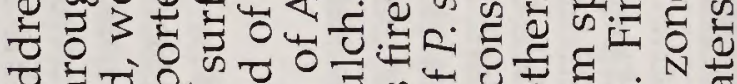

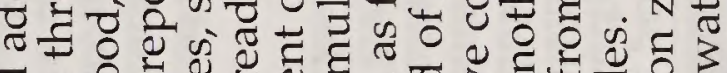
F.

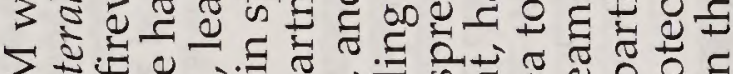

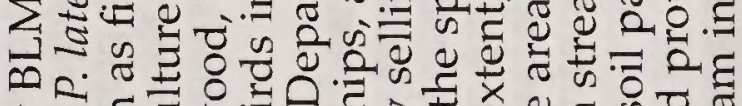

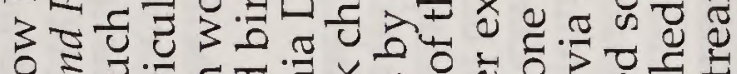

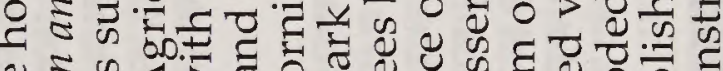

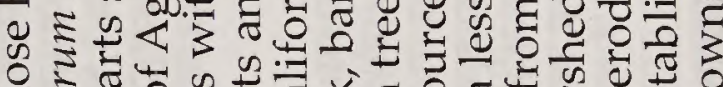

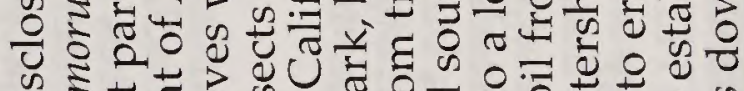

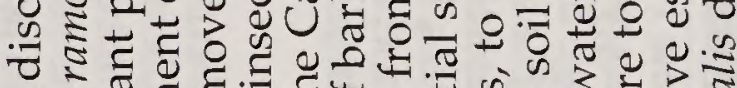

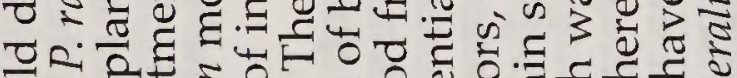
z 0 t जि

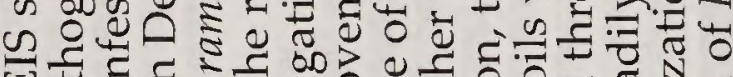

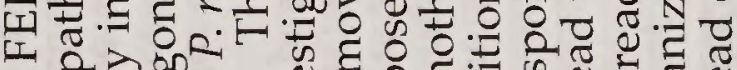
\% 年 


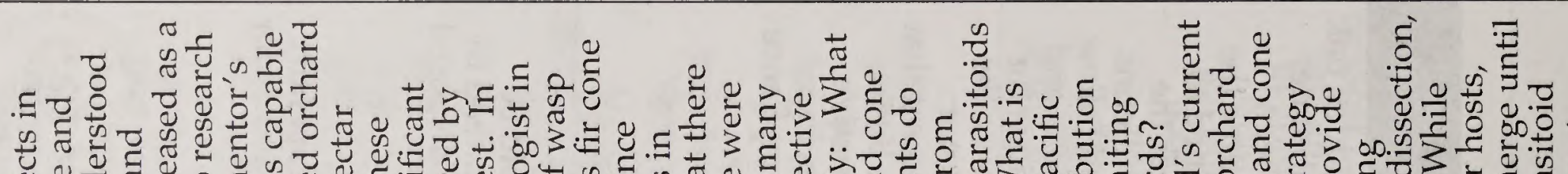

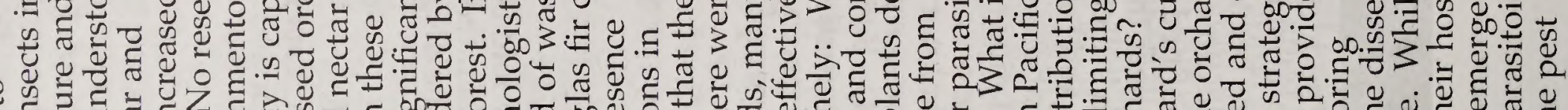
P.

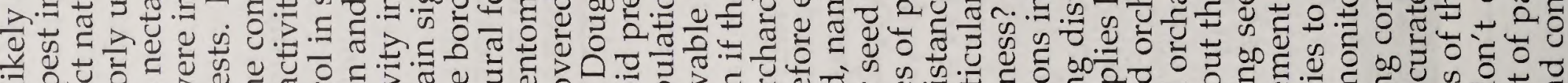
2.

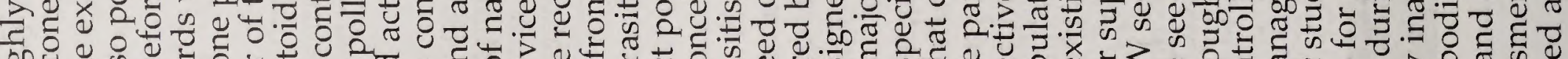
.0.

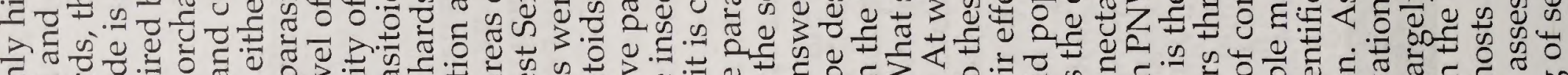

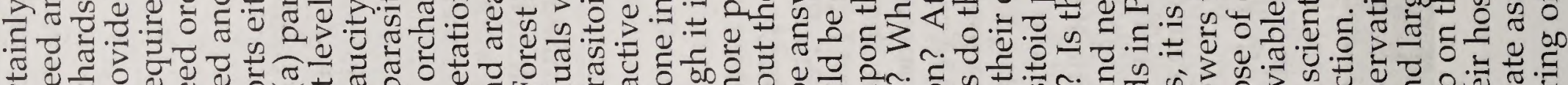

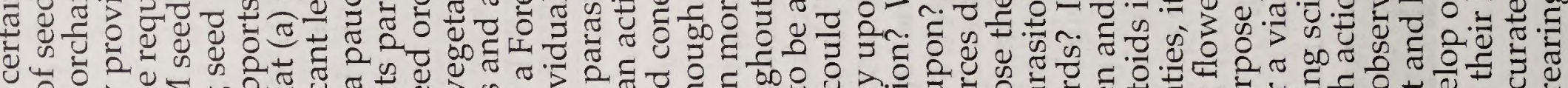

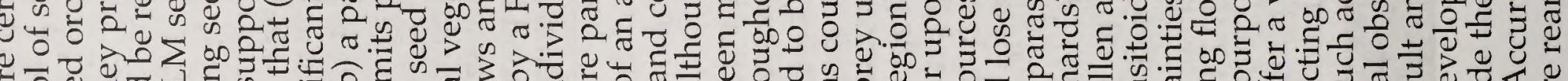

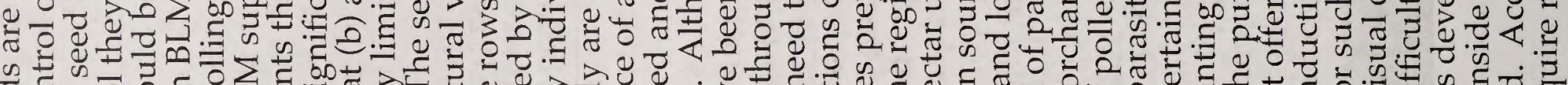
\%

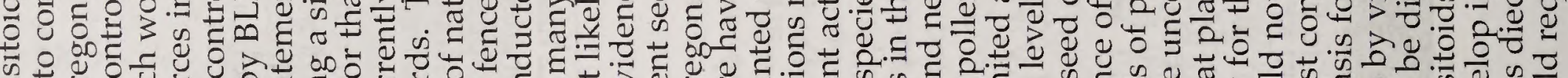

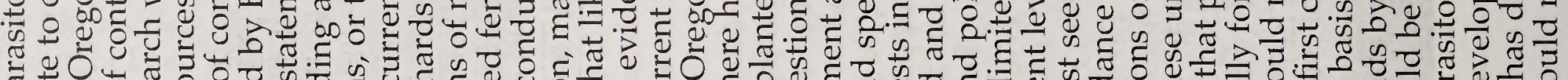

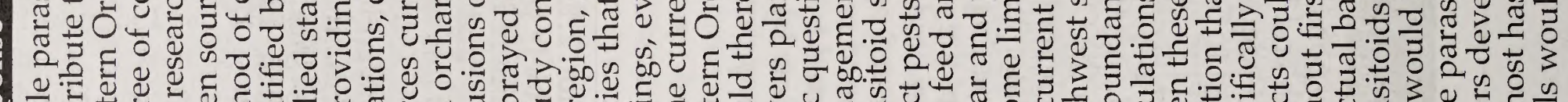

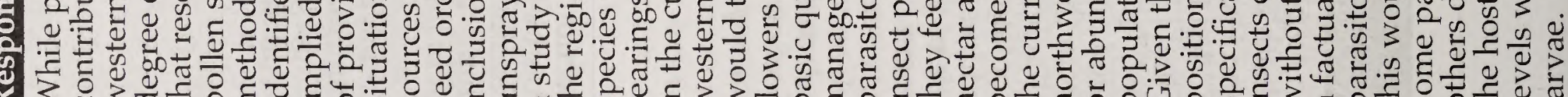

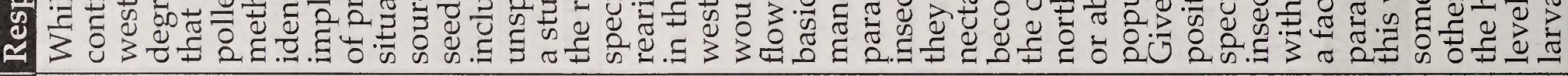

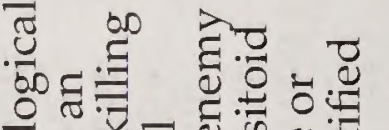

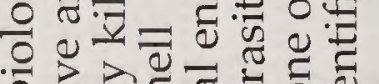

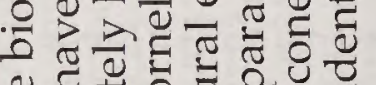

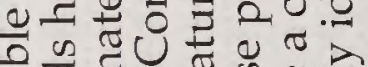

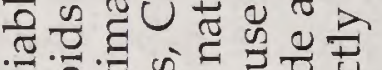
5 .

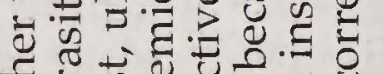

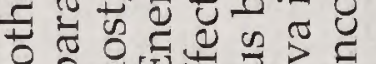

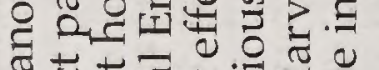

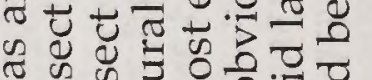

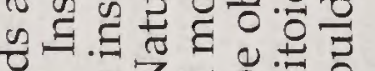
을

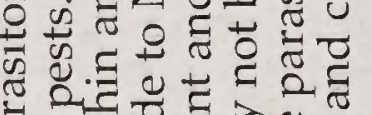

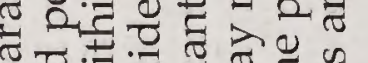

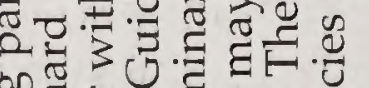
船

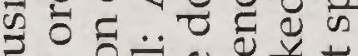
पै

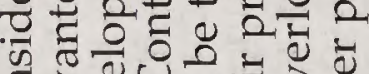
等

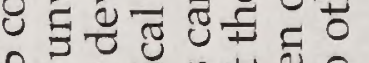

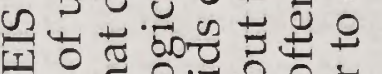
1 오을 응 600. 政造

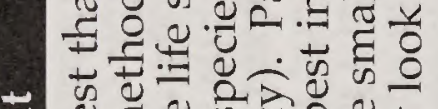

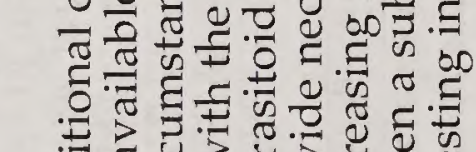

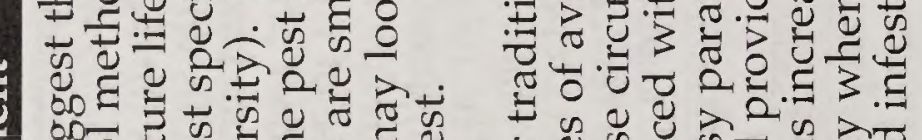
记

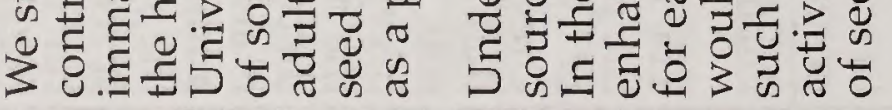

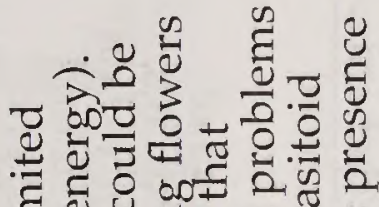

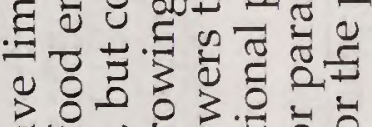

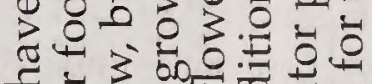

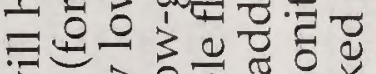

3 츠응 $\pi$

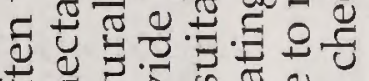

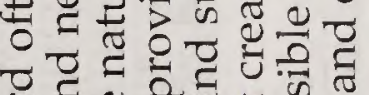

उٓ

들 음용

0 .

$\checkmark v$.

D. s. o

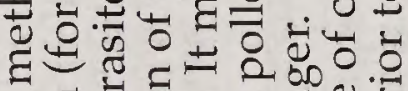

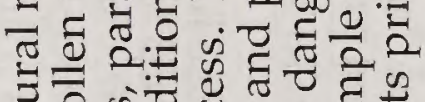
है w के

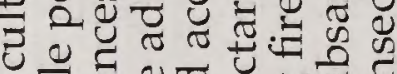

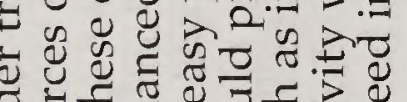




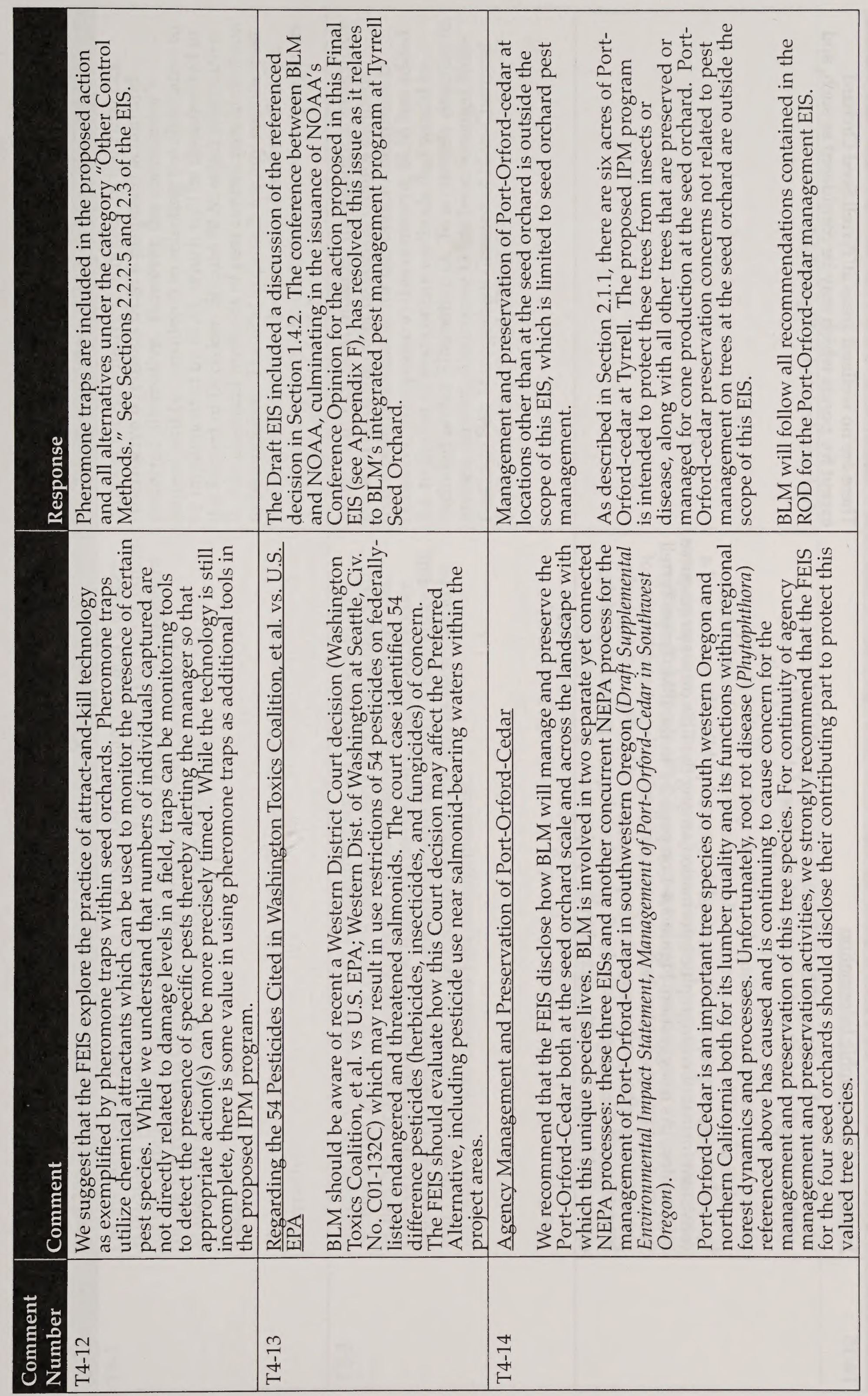




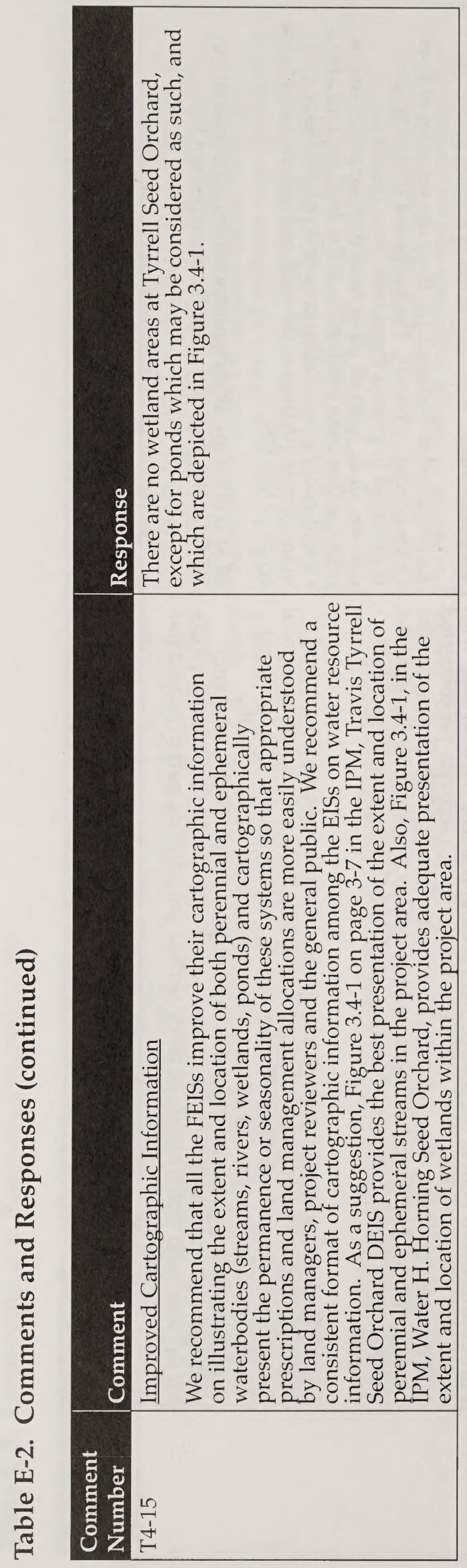



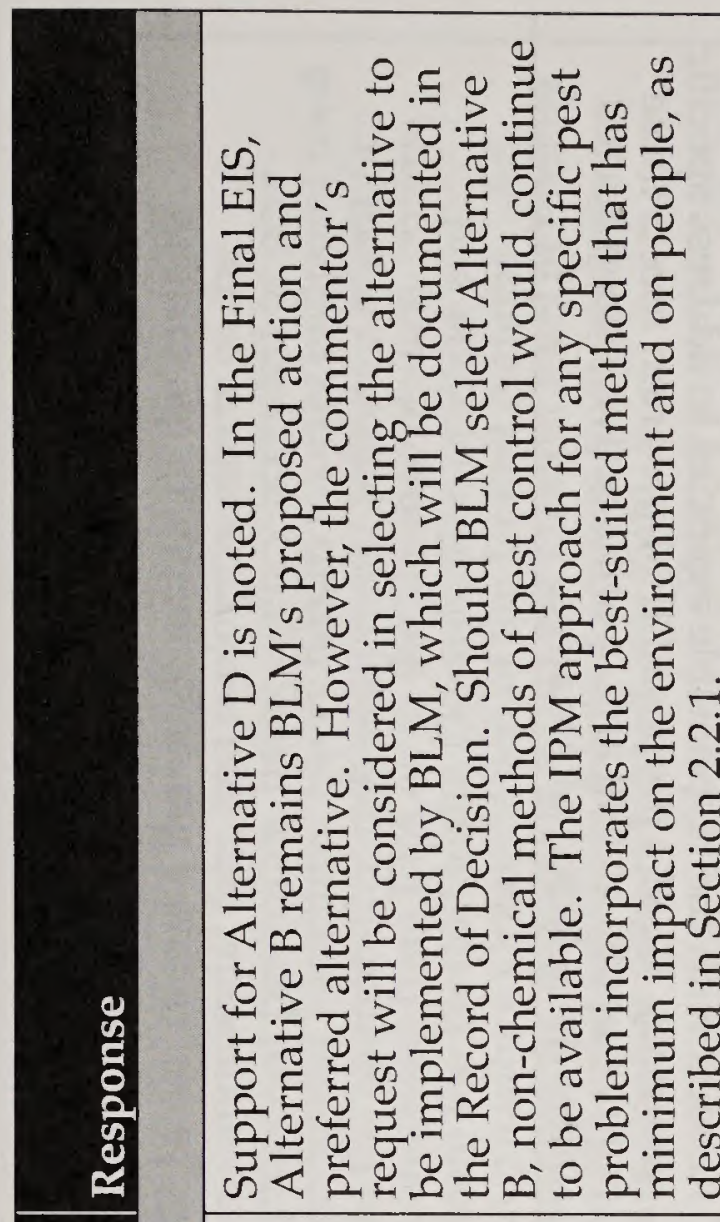

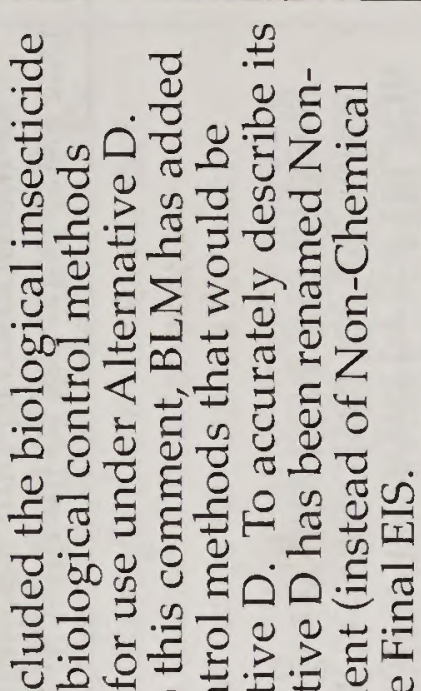

थ

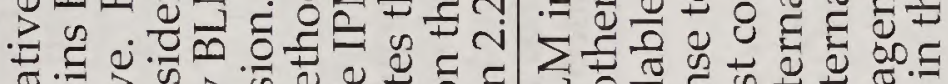

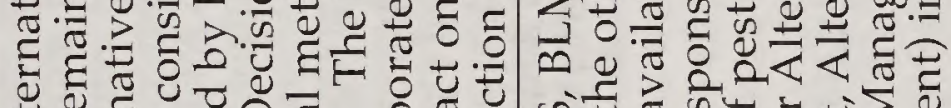

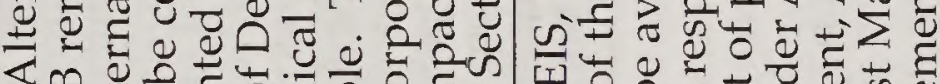

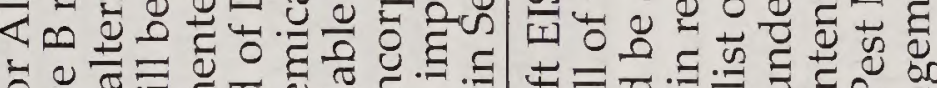

屯.

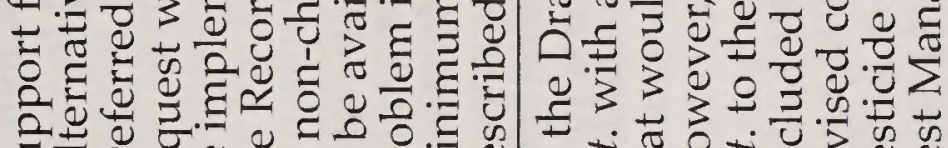

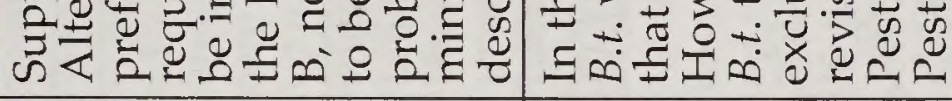

$\vec{\Xi}+$

की

0 政

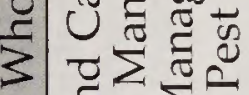

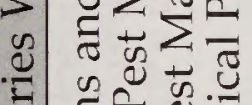

जै

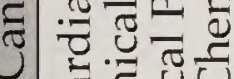

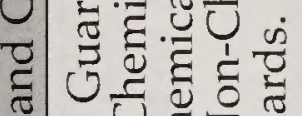

đ)

๘ี

$\simeq 30: 7$

(ี)

()

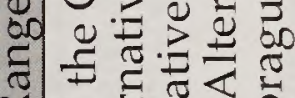

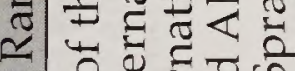

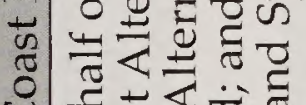

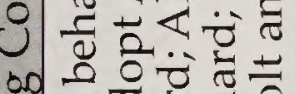

을

눙

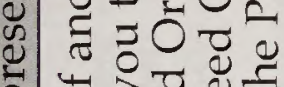

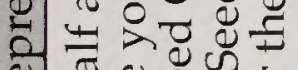

잉

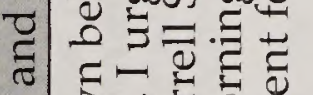

3. on

跣

ร象领

这

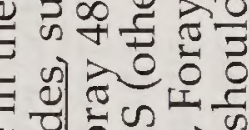

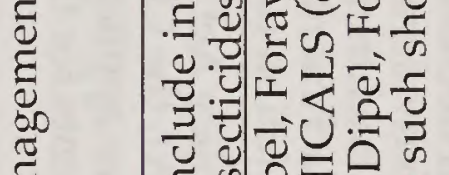

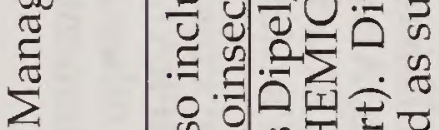

ष

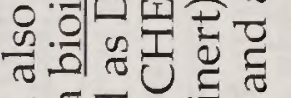

ฮู

है

뭉

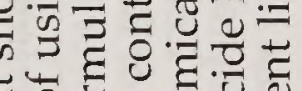

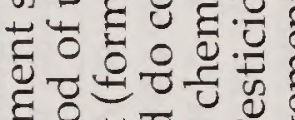

ì

$\cong$

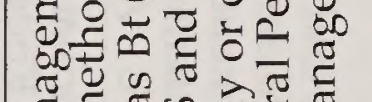

$\widetilde{\Xi}$ 絮光

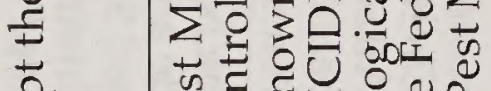

음

ए

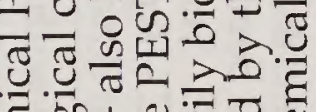

J

$\frac{2}{n}$

บ을

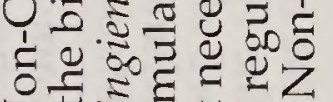

Z.

प.

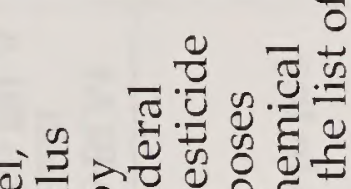

ô.

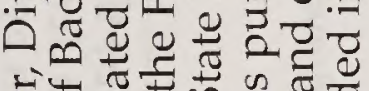

5

要

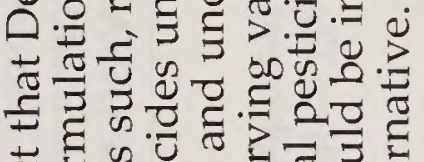

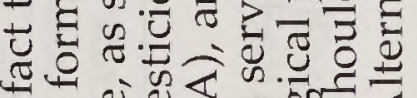

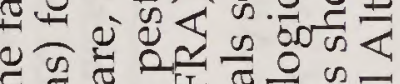

o

E

o워불

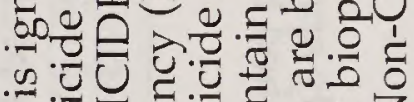

s.

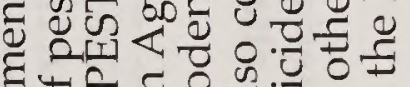

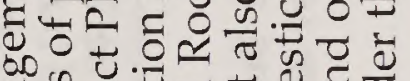

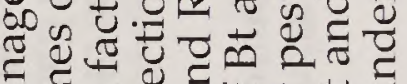

ब综.

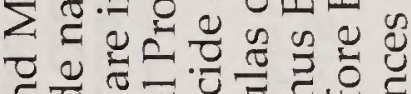

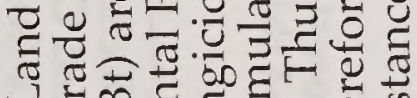

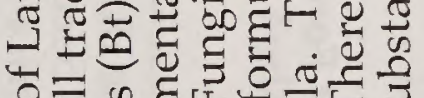

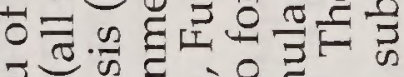

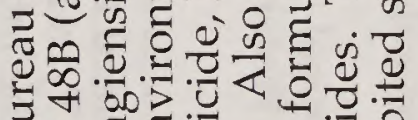

过司完:

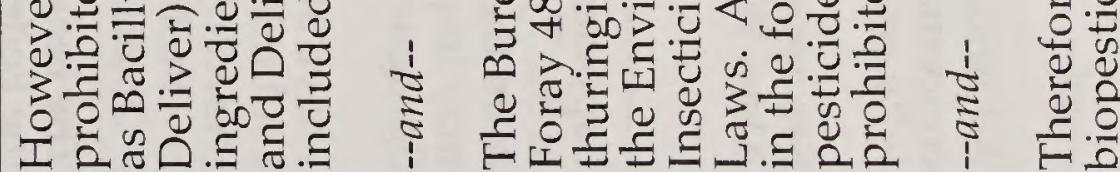




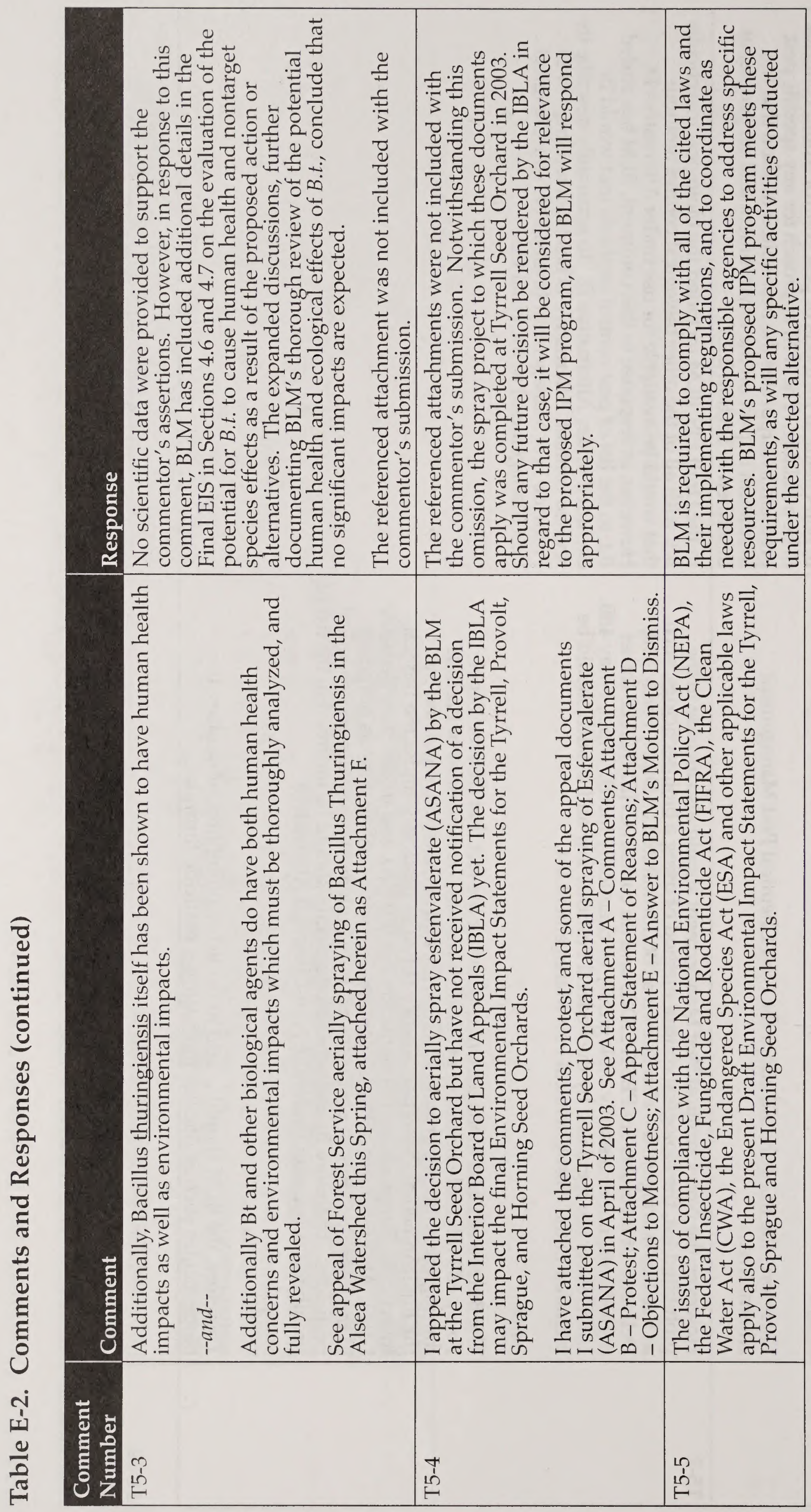



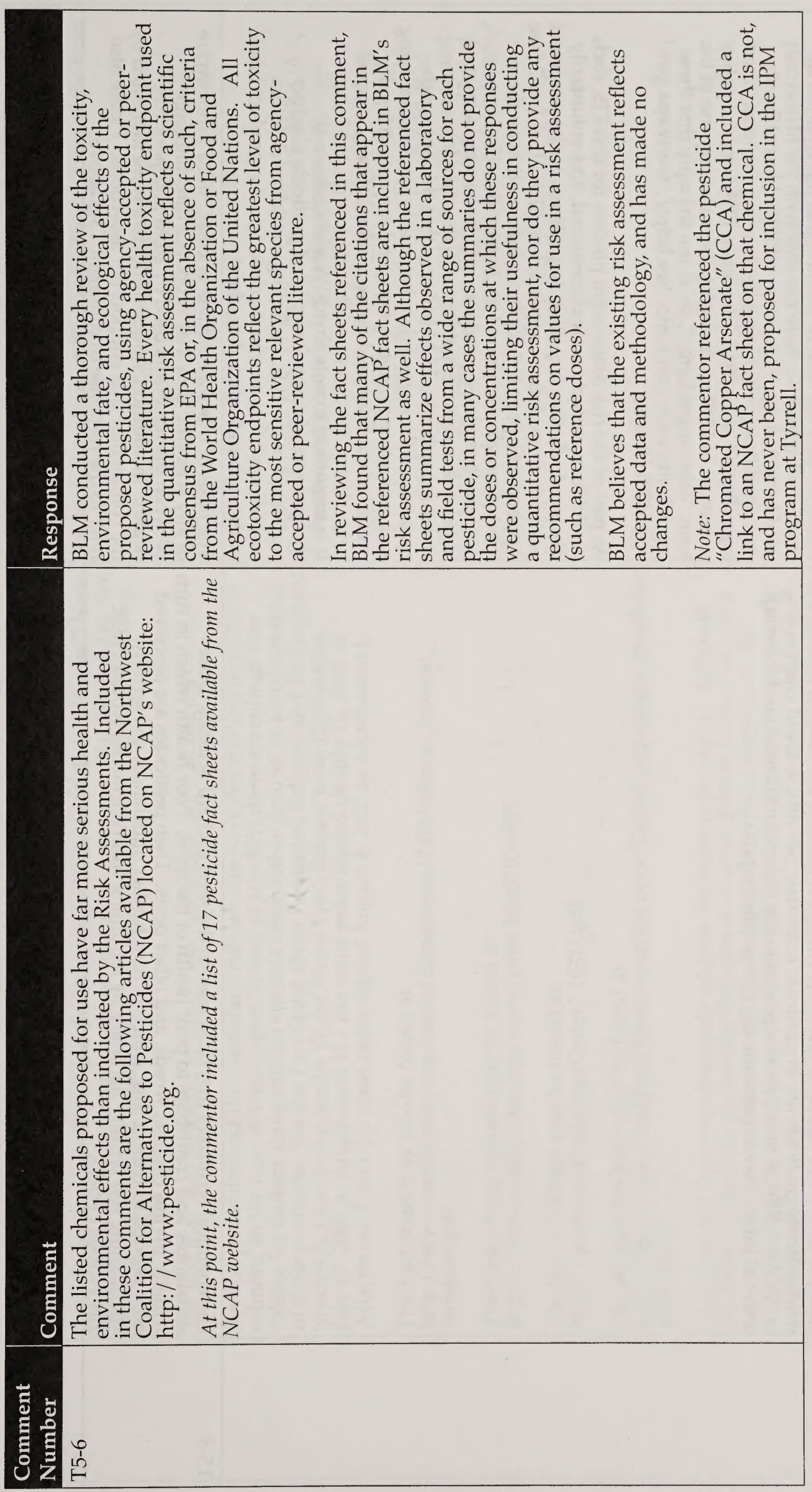


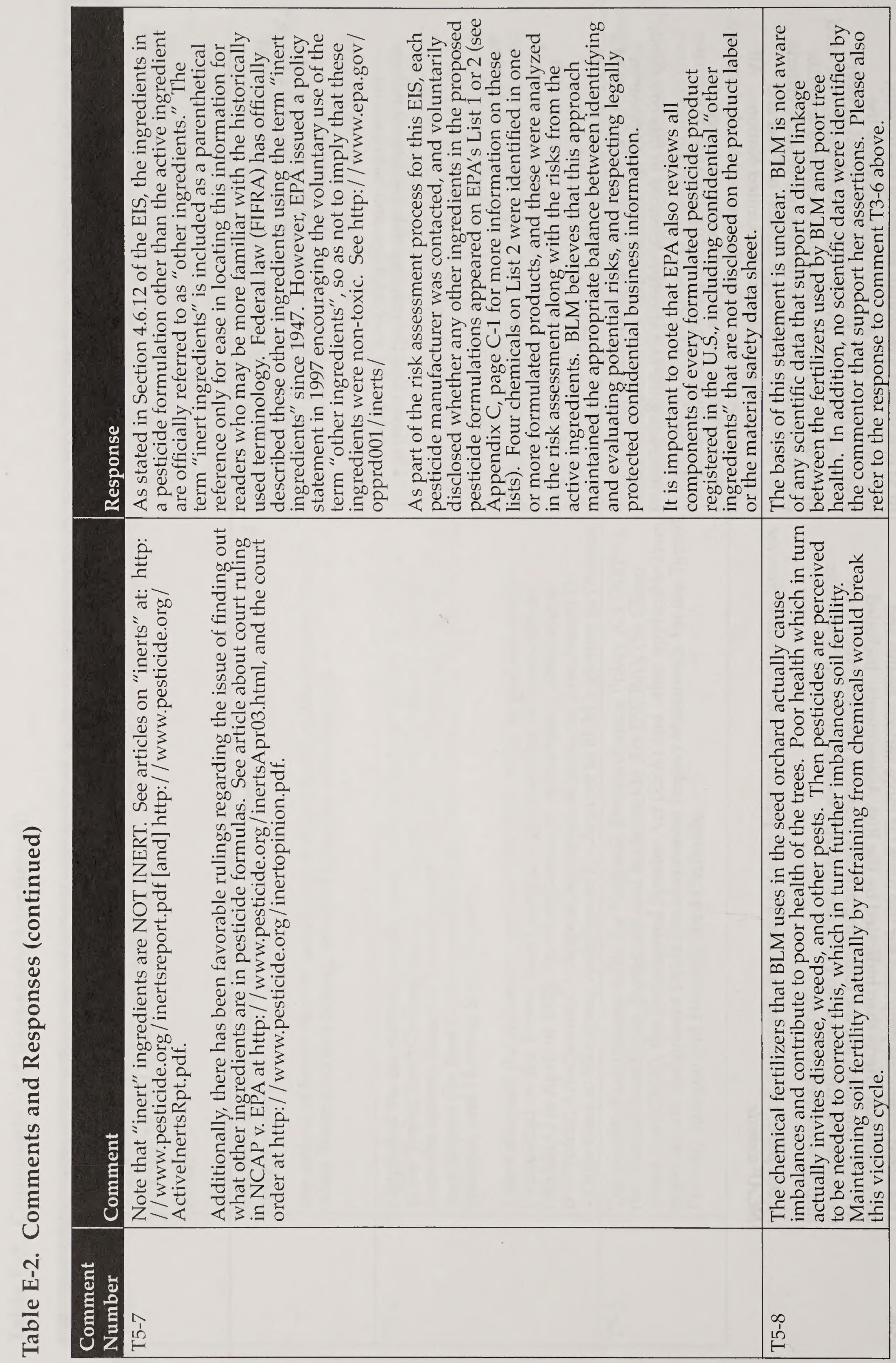




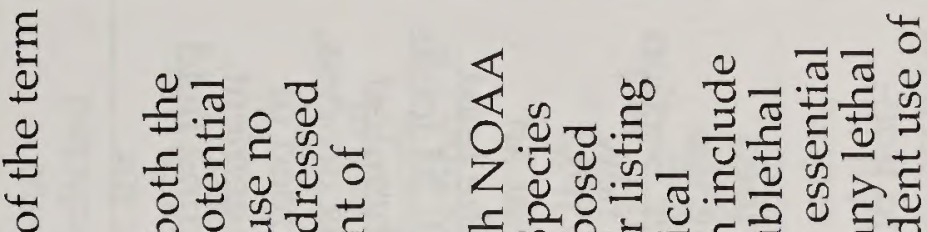

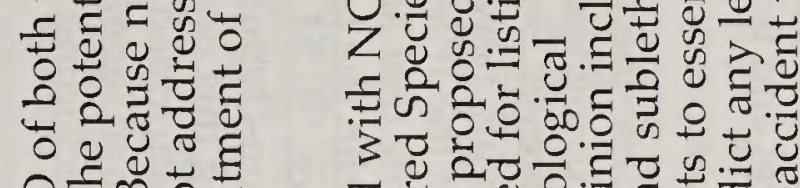

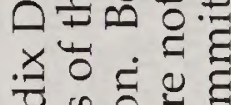

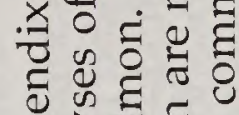

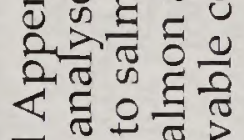

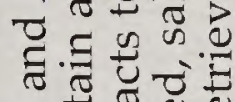
U 릉 $\times 0, \exists:=$ 药

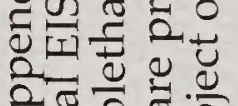

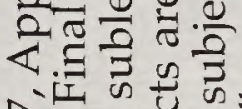

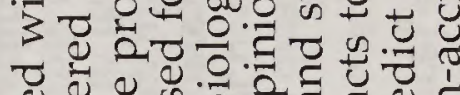

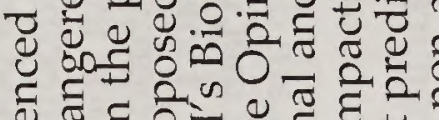

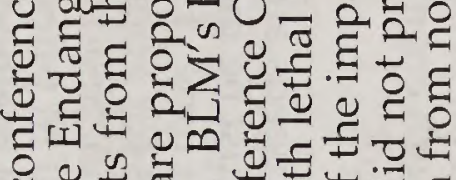

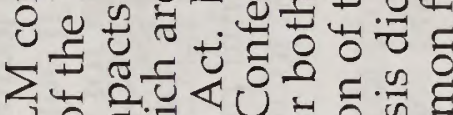
$\sum_{1}=\frac{\pi}{0} 0$ गे.

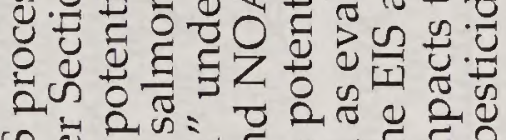
no 200 . 人的的.

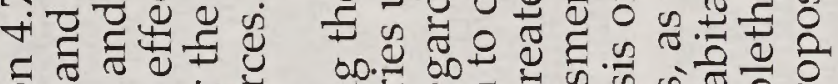

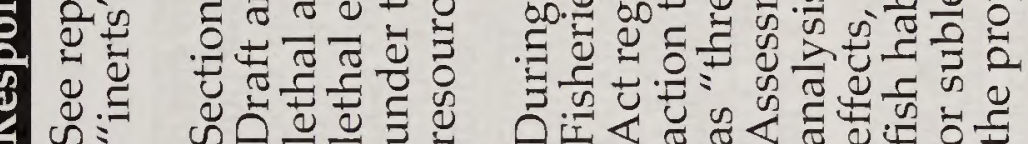

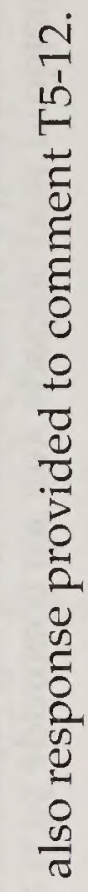
₹ 更 焉龺

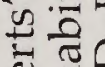

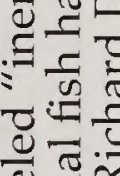
焉:

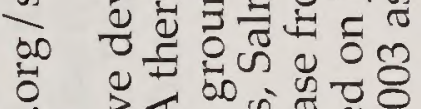

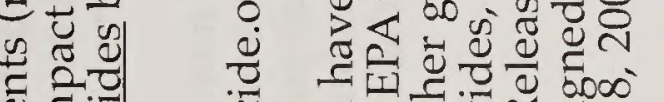
$\Rightarrow$

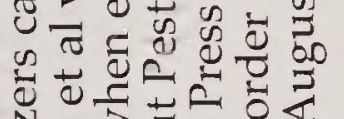

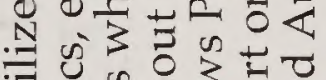
3 .

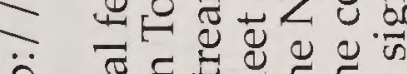

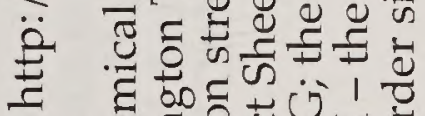

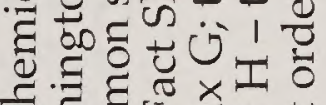
ชิ

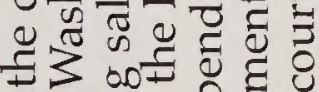
च ह

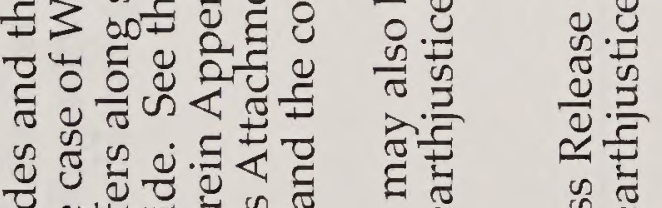

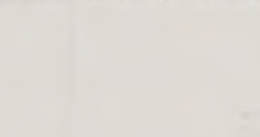

约

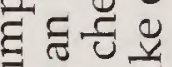
व 苞

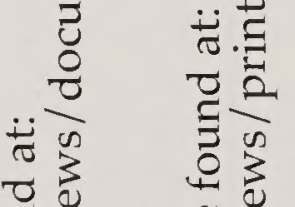

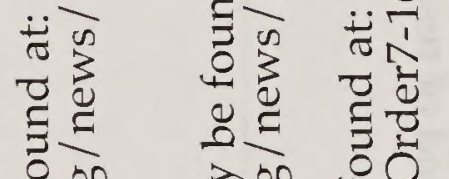
过

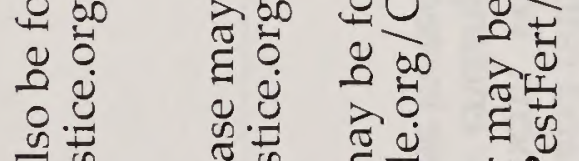

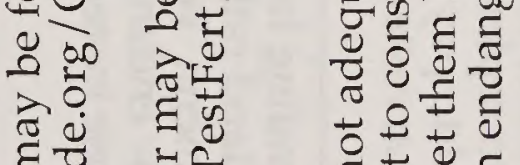

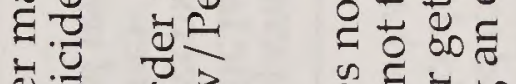

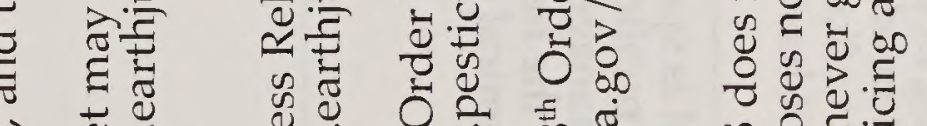

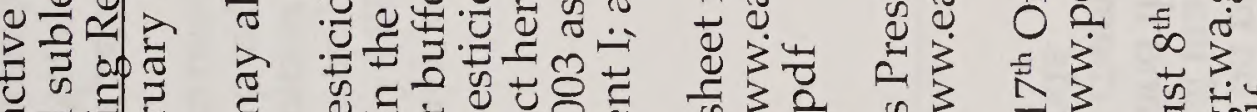

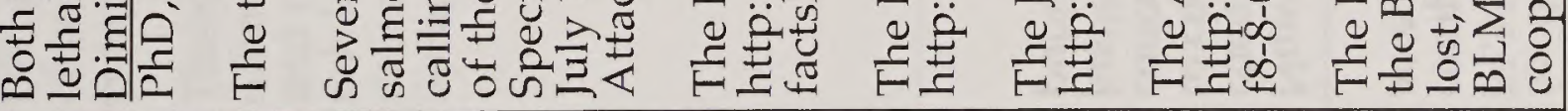




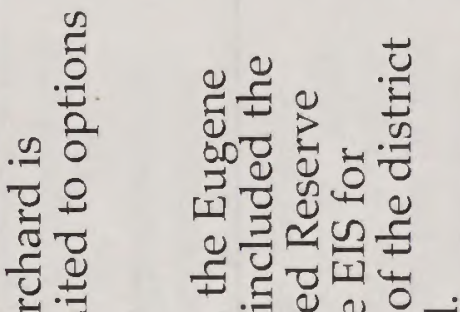

五.

을

फ้동

远芯

出

블

吉

ธี。

की

$\exists \stackrel{\Xi}{\Xi}$ \%

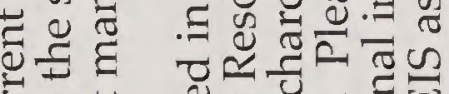

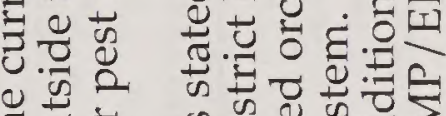

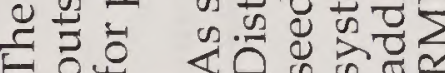

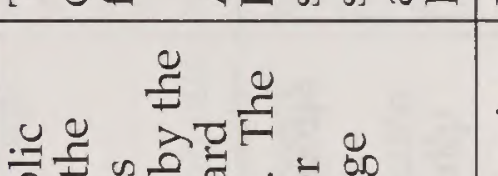

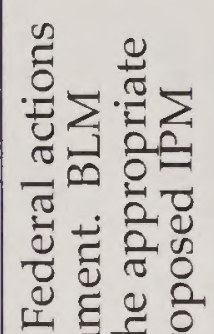

हृँ

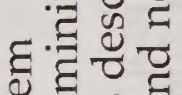

कृ

过范

हृ हु

올 동

पू

के

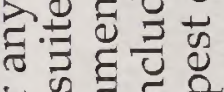

के की

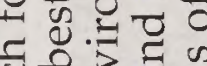

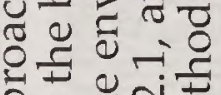

مै

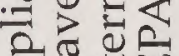

ह둰ㄷㄴ

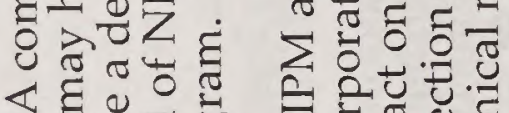

$4 \frac{1}{\pi} \overline{0}$

눙

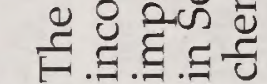

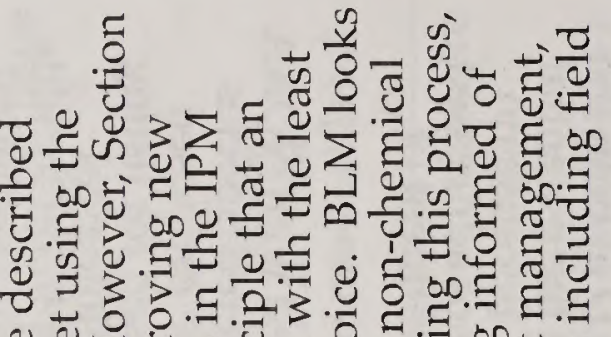

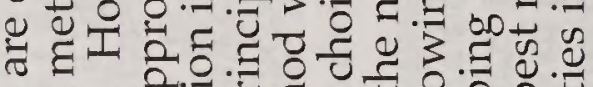

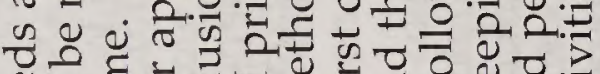

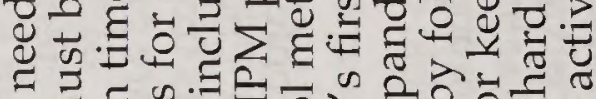

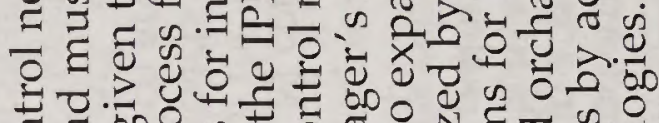
苛

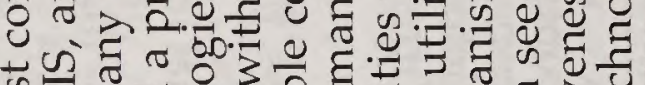

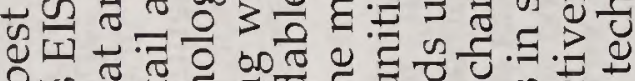

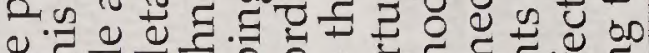

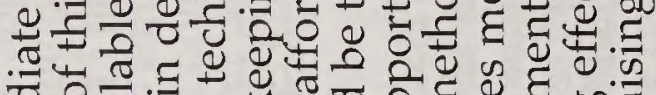

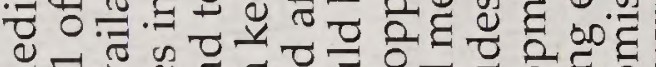

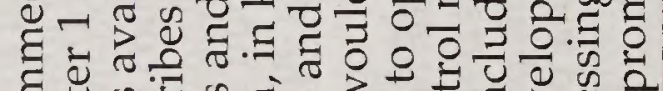
छั क वे क्ष

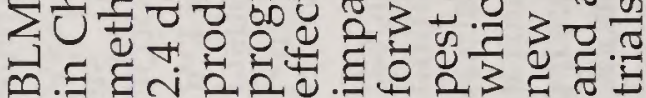

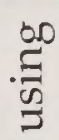

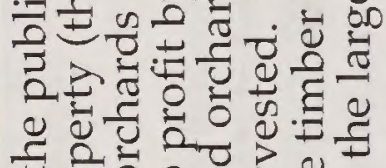

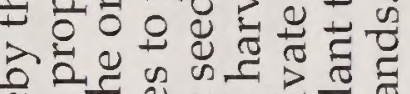

o

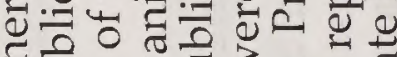

उ

केष

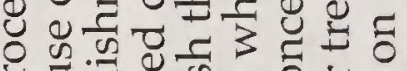

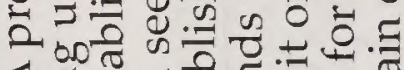

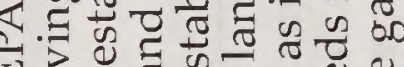

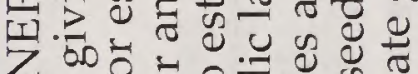

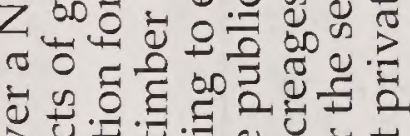

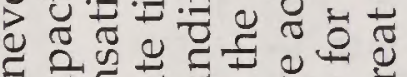

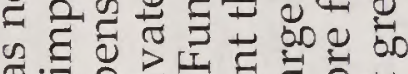

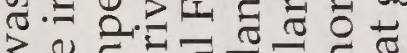

उ

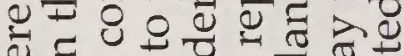

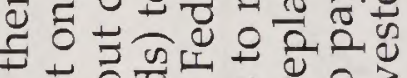

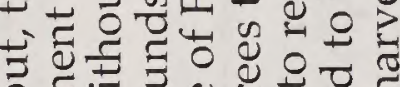

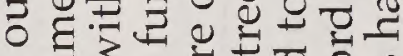

है

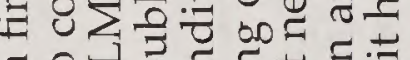

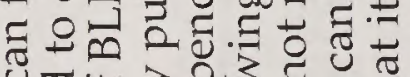

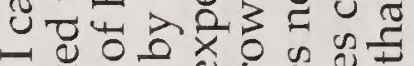

व.

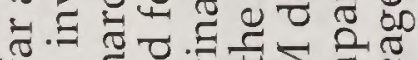

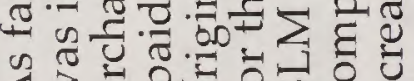

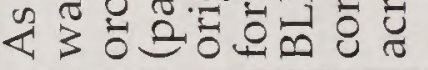

$\underbrace{\infty}_{0}$

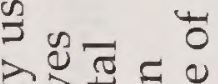

ज记

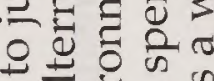

क

画导志㝴

응욜원

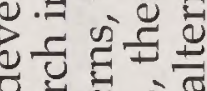

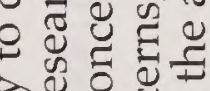

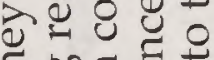

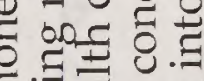

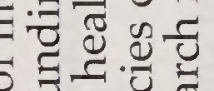

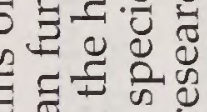

है चे के

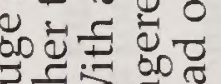

表宁造

$\Xi$ 물ㄷㄷㅇ

르 है

क.

क 을 월

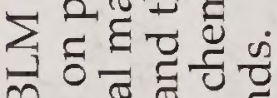

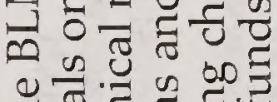

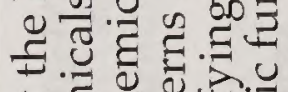

उद्ध है 


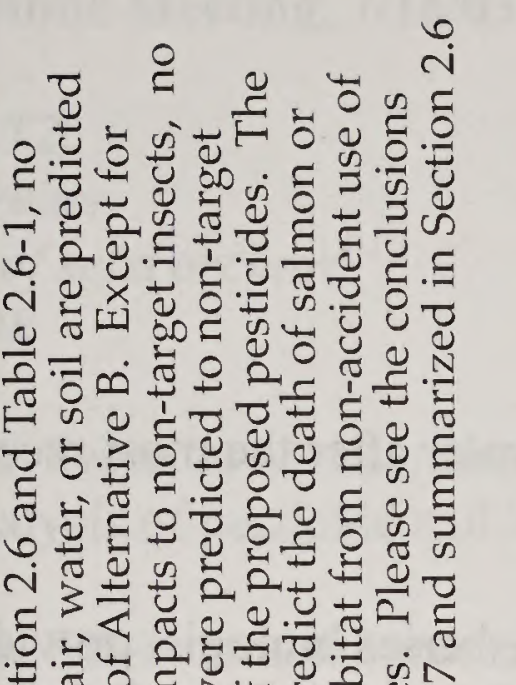

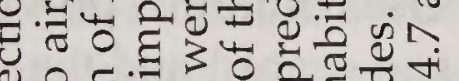

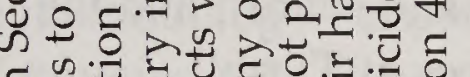

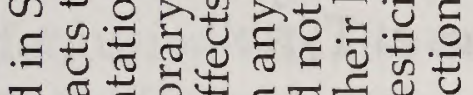

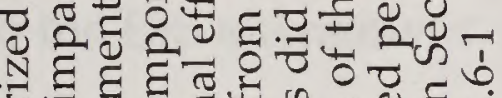

\% ब

ปี

क के हृत

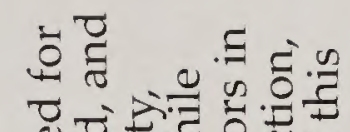

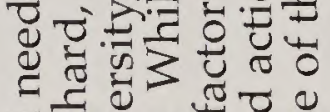

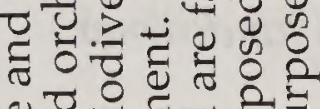

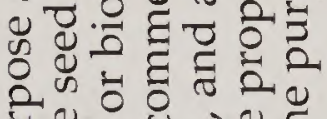
20 0 \%

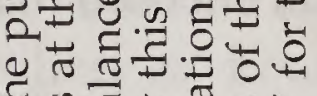

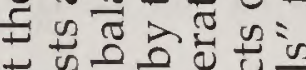

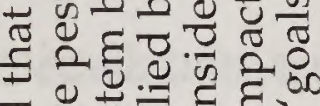
प so w

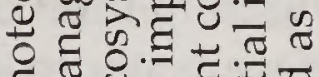

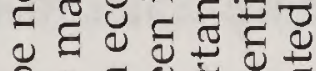

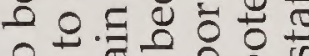
क.ज

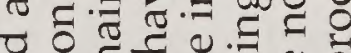

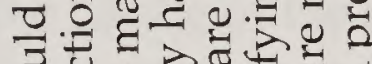

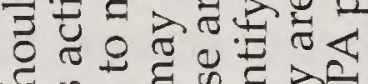

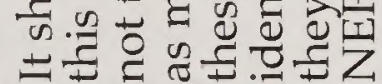

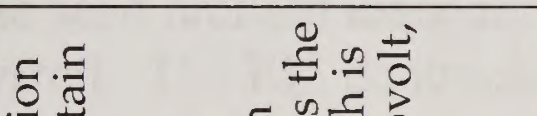

促

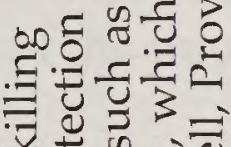

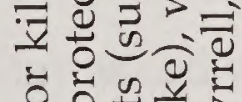

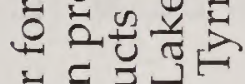

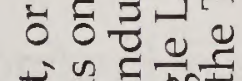

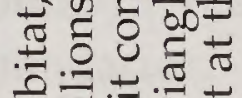
元: $\frac{\pi}{\pi} \frac{\pi}{\pi} \frac{\overrightarrow{0}}{\pi}$ 范

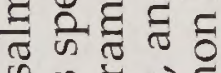
का 0 के 政起西 की.

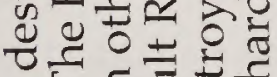

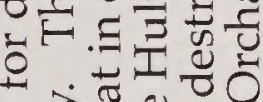

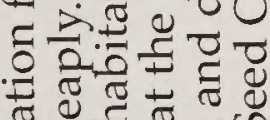

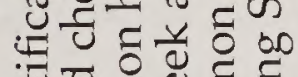

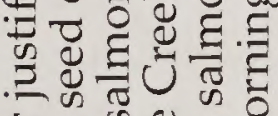
oิ \& w

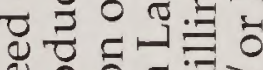

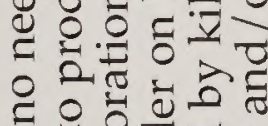

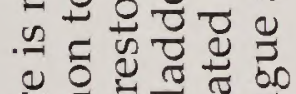

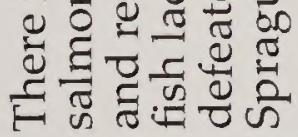




\section{Tyrrell Public Meeting, 7/16/03}

\section{Comment T1}

Albert Goins

Volunteer at Tyrrell Seed Orchard, BLM retiree, and landowner

Lorane, $O R$

T1-1 Mr. Goins asked whether the seed orchard had checked the water after the most recent spray project and what the results were.

The seed orchard manager, district hydrologist, and district fisheries biologist provided details on the sampling, protection measures used to limit drift and runoff, and the location of coho salmon in relation to the surface water resources at Tyrrell. 


\section{Tyrrell Public Meeting, 7/16/03}

\section{Comment T2}

Mary Seereiter

Neighbor of seed orchard

Lorane, OR

T2-1 Ms. Seereiter asked questions about the locations to be potentially sprayed and the analysis of pesticide and fertilizer environmental transport.

The EIS contractor provided details about these aspects of the assessment, and describec the methodology used in estimating risks to human health and nontarget species. Information was also provided on the protection measures and limitations incorporated into the EIS alternatives.

T2-2 Ms. Seereiter asked about the nature of the proposed fertilizers (whether chemical or organic) and the potential for impacts to soil balances and soil organisms.

The seed orchard manager provided an overview of the fertilizer chemicals and uses at Tyrrell. The EIS contractor referred her to Chapter 4 of the EIS, which includes a discussion of the impacts of fertilizers to soils and terrestrial invertebrates.

T2-3 Ms. Seereiter asked whether any spraying would be conducted out in the forest.

The seed orchard manager explained that all pest control would be within the seed orchard boundaries. 


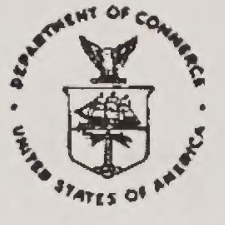

Refer to:

OHB2003-0192-GC
UNITED STATES DEPARTMENT OF COMMERCE National Oceanic and Atmospheric Administration NATIONAL MARINE FISHERIES SERVICE 525 NE Oregon Street

PORTLAND, OREGON $97232-2737$

Mr. Glenn Miller, Manager

Tyrrell Seed Orchard

P.O. Box 121

Lorane, OR 97451

Re: Draft Environmental Impact Statement for the Proposed Integrated Pest Management (IF'M) Program at the bureau or Land Management S (BLIVI) I yrrell seed urcnard

\section{Dear Mr. Miller:}

NOAA's National Marine Fisheries Service (NOAA Fisheries) staff have reviewed the above mentioned draft Environmental Impact Statement (EIS), and present these comments ${ }^{1}$ within the context of the National Environmental Policy Act (NEPA) and in anticipation of a section 7(a)(2) consultation under the Endangered Species Act and the Magnusan-Stevens Fishery Conservation and Management Act (MSA). In accordance with NEPA regulations at 40 CFR part 1503.2, "federal agencies with jurisdiction by law or special expertise with respect to any environmental impact involved and agencies which are authorized to develop and enforce environmental standards shall comment on statements within their jurisdiction, expertise, or authority". These comments are on the preferred alternative (Alternative B-IPM with Environmental Protection Emphasis) as described in the draft EIS.

The use of monitoring results related to adaptive management is an important component of the preferred alternative. The draft EIS refers to the importance of integrating monitoring data with future maragement: ".... [adaptive management] would provide a relationship between monitoring results and the management that is planned for the future." (BLM., draft EIS page b4). NOAA Fisheries agrees that using monitoring data to adjust subsequent applications of compounds ${ }^{2}$ is vital to a multi-year approach, and presents the following guidance as a proposed strunture en achieve thic.

The EIS should be enhanced by describing the integration of monitoring data that will inform annual application variables as described in the tables of Chapter 2 of the draft EIS. Annual

\footnotetext{
'As the proposed action is continued to be refined, additional comments will likely be delivered to the BLM within the context of ESA section 7(a)(2) and MSA consultation.

2 "Compounds" is defined as pesticides, herbicides and fertilizers.
} 
reports should be paired with new proposed application schedules for the upcoming year, which are modified if necessary by the previous years monitoring results. These yearly reports would facilitate multi-year consultation that accounts for the variability of potential monitoring results, compounds planned for use and application location, method, and timing.

In summary, the annual reports should include: (1) Monitoring results that synthesize the relative effectiveness of application methods and timing to avoid effects to aquatic species; (2) a literature review of any new studies that illuminate effects (from compounds used on the orchards) to aquatic life ${ }^{3}$ that are not accounted for in the original EIS; (3) a review of any new best management practices that may further reduce risk to aquatic species; (4) a new annual application schedule that details the type, location, timing, amounts and methods to reduce or avoid effects from compound application, and (5) a new effects analysis, as appropriate, that assesses whether any of the above factors result in effects to aquatic species not analyzed in the EIS and biological opinion (Opinion).

If the new annual application plan is within the range of effects analyzed in the Opinion, NOAA Fisheries will indicate in writing that a new section 7(a)(2) or MSA consultation is not necessary, therefore continuing coverage of the Incidental Take Statement of the Opinion for another year. NOAA Fisheries would issue the original Opinion for five years, with annual reports informing whether subsequent Opinions or MSA consultations are necessary for each orchard. These provisions would ensure that the BLM and NOAA Fisheries utilize best available scientific and commercial data to minimize and avoid adverse effects to listed species within the action area.

Additional comments on the draft EIS, are provided below:

\section{Monitoring}

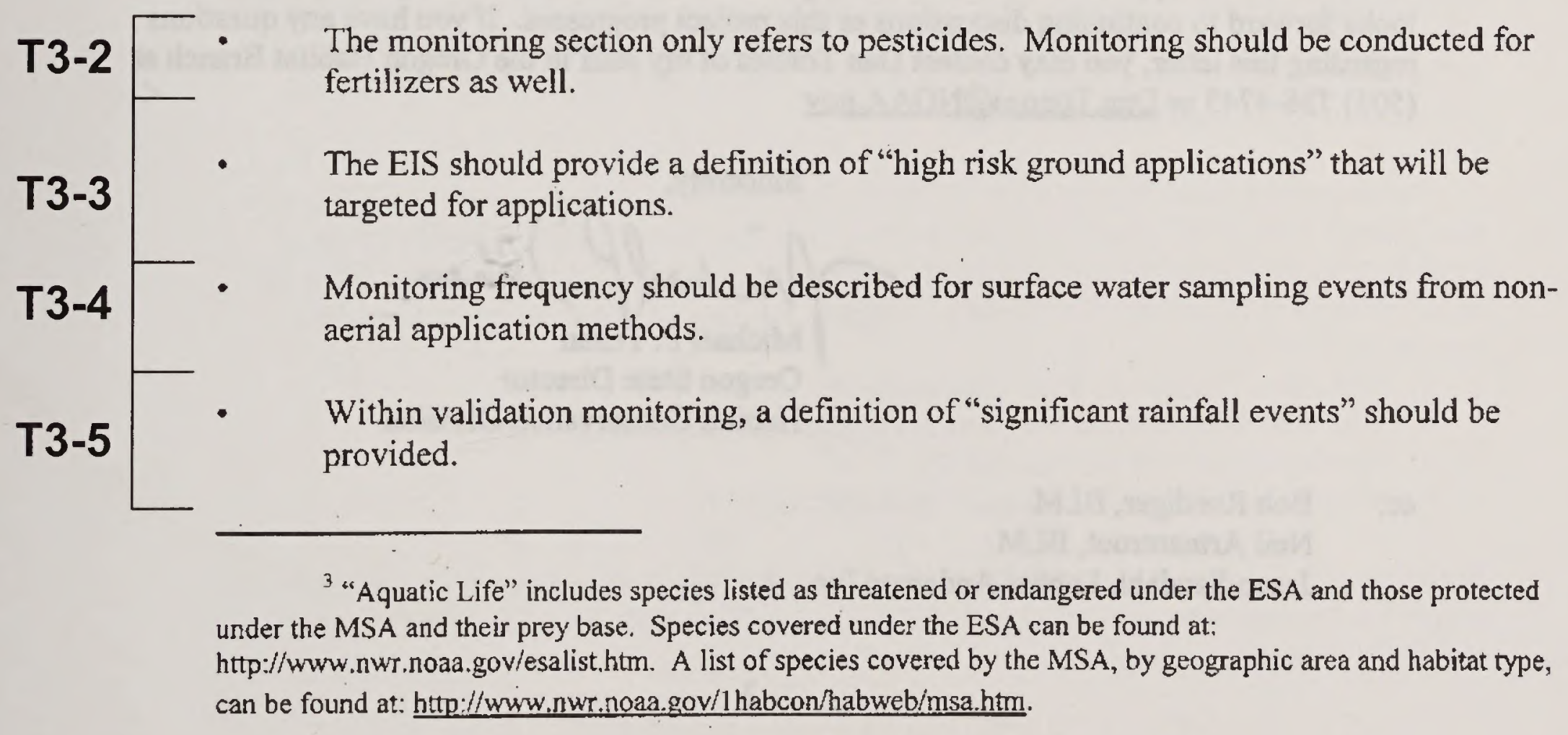




\section{Eertilizer Application}

ertilizers application should occur at agronomic rates, as defined the amount of nutrients tpplied to vegetation equal the anticipated biological uptake of the plants. 1This eliminates excess uutrients from polluting surface or ground waters.

\section{3uffer Widths}

'roposed buffer widths for each compound for the orchard unit, as appropriate, should be ncluded in the EIS. Given the vagaries of application conditions and timing, keeping the buffer widths fixed for the term of the consultation is desired by NOAA Fisheries. At the end of the :onsultation term and subsequent to additional consultation, the opportunity of reduced buffer widths could be discussed. This would take advantage of a larger data set from monitoring, and zenerally lead to more informed decisions on buffer widths.

T3-8

\section{Synergistic Effects}

To the greatest extent possible, the potential effects to aquatic life from multiple compound use within the action area should be described.

\section{Prescribed Fire}

T3-9

NOAA Fisheries prefers that extensive prescribed fire not occur within riparian areas. In cases where the BLM prefers to utilize prescribed fire within riparian areas, the extent should be limited and management methods described that facilitate native vegetation regrowth, and prevention of exposed soils, etc. The EIS should identify these site specific provisions.

Application Schedules

To the greatest extent possible, the "Application Frequency" section of table 2.2-1 should be quantitative, rather than terms like "Infrequent".

NOAA Fisheries appreciates the BLM's early coordination efforts for the proposed action, and looks forward to continuing discussions as this project progresses. If you have any questions regarding this letter, you may contact Dan Tonnes of my staff in the Oregon Habitat Branch at (503) 736-4743 or Dan.Tonnes@NOAA.gov

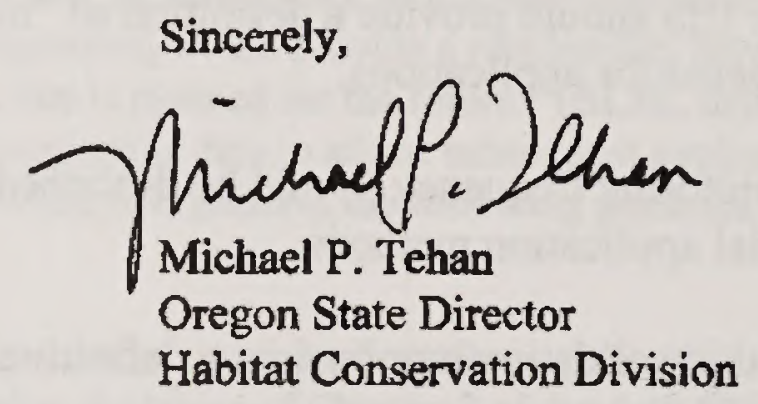

cc: Bob Ruediger, BLM

Neil Armantrout, BLM

Jason Sandahl, Labbat-Anderson Inc. 


\section{REFERENCES}

Lee, K. K. 1995. Stream velocity and dispersion characteristics determined by dye tracer studies on selected stream reaches in the Willamette River Basin, Oregon. U.S. Geological Survey Water Resources Investigations Report 95-4078. Available at: http://oregon.usgs.gov/pubs dir/pdf/95-4078.pdf. $48 \mathrm{p}$.

Heard, S. B. C. B. Gienapp, J. F. Lemire, and K. S. Heard. 2001. Transverse mixing of transported material in simple and complex stream reaches. Hydrobiologia 464:207-218 


\section{UNITED STATES ENVIRONMENTAL PROTECTION AGENCY \\ REGION 10 \\ 1200 Sixth Avenue \\ Seattle, Washington 98101 \\ SEP 102003}

Reply To

Attn Of: ECO-088

Mr. Harvey Koester, Manager

Bureau of Land Management

Provolt and Sprague Seed Orchards

3040 Biddle Road

Medford, OR 97504

Mr. Greg Tyler, Manager

Bureau of Land Management

Horning Seed Orchard

27004 Scheckly Road

Colton, OR 97017

\section{Ref: 01-016-BLM, 01-017-BLM, 01-018-BLM, \& 01-019-BLM}

Mr. Glenn Miller, Manager

Bureau of Land Management

Tyrrell Seed Orchard

P.O. Box 121

Lorane, OR 97451

Dear BLM Seed Orchard Managers:

The U.S. Environmental Protection Agency (EPA) has reviewed three Draft Environmental Impact Statements (DEIS) for the proposed Integrated Pest Management Programs, Provolt Seed Orchard and Sprague Seed Orchard, Walter H. Horning Seed Orchard, and Travis Tyrrell Seed Orchard pursuant to our responsibilities under Section 309 of the Clean Air Act and the National Environmental Policy Act (NEPA) as amended. Section 309, independent of NEPA, directs U.S. EPA to review and comment in writing on the environmental impacts associated with all major federal actions.

The Bureau of Land Management (BLM) is proposing to implement a common integrated pest management (IPM) program at four seed orchard operations in the Oregonian towns of Provolt, (Provolt Seed Orchard), Merlin (Sprague Seed Orchard), Colton (Walter H. Horning Seed Orchard), and Loraine (Travis Seed Orchard). All four DEISs propose the same four Action Alternatives:

- Maximum Production IPM (Alternative A)

- IPM with Environmental Protection Emphasis (Alternative B),

- Ground-Based IPM (Alternative C)

- Non-Chemical Pest Management (Alternative D)

For baseline purposes, all of the DEISs have proposed the No Action Alternative (Alternative E) which is the current management approach. Also, all of the DEISs have identified Alternative B as BLM's Proposed Alternative. 
U.S. EPA supports the direction and intent of BLM's Preferred Alternative because it emphasizes environmental protection int the management of pests and seed orchards.

Based on our review, we have rated the DEIS, EC-2 (Environmental Concerns - Insufficient Information). The rating and a summary of our comments will be published in the Federal

T4-2 Register. Our detailed comments and a summary of the rating system we used in our evaluation of this DEIS are enclosed for your reference.

We recommend that the FEIS discuss additional pesticide safety issues, consider additional IPM methodologies for potentially new orchard diseases, and address the relevancy of a concurrent BLM Draft Supplemental Environmental Impact Statement (Management of Port-

T4-3 Orford-Cedar by Southwest Oregon) which BLM is working on that may impact proposed activities for the four seeds orchards. We also recommend that the FEIS discuss how a recent Western District Court decision may affect the Action Alternatives, especially the Preferred Alternative.

I encourage you to contact Tom Connor at (206) 553-4423 or Sharon Collman, our Pesticides/IPM Outreach Coordinator, at (206) 553-2876 if you would like to discuss our comments. Thank you for the opportunity to review these four Draft EISs on the Integrated Pest Management Program for BLM's Provolt, Sprague, Horning, and Tyrrell Seed Orchards.

Sincerely,

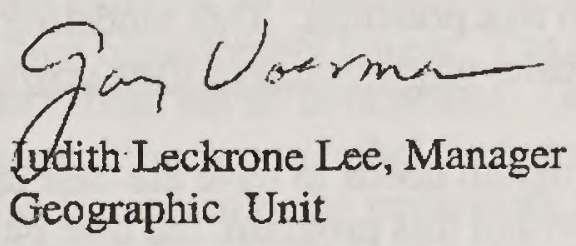

Enclosures 


\section{U.S. ENVIRonmental Protection Agency's DetaIled Comments on the Integrated Pest Management, Provolt, Charles A. Sprague, WALTER H. HoRNING, AND TRAVIS TYRRELL SEED ORCHARDS ENVIRONMENTAL IMPACT STATEMENTS}

\section{Environmental Issues}

\section{$\underline{\text { List of Proposed Pesticides }}$}

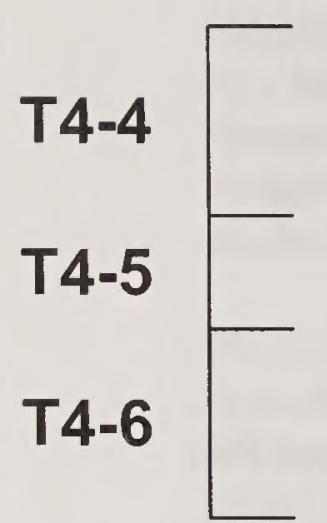

T4-7

U.S. EPA recommends that the list of proposed pesticides for use in the seed orchards be wisely considered for potential impacts to worker safety and non-target species. Many of the proposed insecticides identified in the DEIS are older, non-specific pesticides which must be treated with care to minimize damaging non-target organisms and worker safety. Some (e.g. picloram or triclopyr) are known to be highly soluble and under some conditions (rainfall, soil type, amount used) could contaminate groundwater. Some may be reasonably safe to humans but highly toxic to wildlife. For example, diazinon is highly toxic to some birds, and there is recent research suggesting that they impair salmonid olfaction functions at very low levels.

We recommend that BLM access and run the Natural Recource Conservation Service model, WIN-PEST, for its fields and the planned pesticides as a preliminary analysis of environmental and human risk potential. This modeling program is available to anyone via the web at the NRCS website www.wcc,nrcs. usda.gov/pestmgt/winpst.html.

The program needs to have the user input their field soil type(s) (the entire US database is available within this program, the user only needs to know the map unit code or soil series from a soil survey map of their area) and then select the pesticides that will be used on that field. There are a few additional variables to provide including probability of rain following application, pesticide rate (low, med, standard), soil verses foliar applied, broadcast verses banded application as well as others. The model will run a soil type by pesticide interaction and produce a series of human health and aquatic hazard quotients (Extra High risk to Very Low and categories in between) based on the ability of the soilxpesticide to leach to groundwater or runoff via sediment or soil solution.

There are many NRCS field offices with staff trained on this program. Also, Oregon State University just received a grant to train technical service providers on using the tool (Paul Jepson and Dan Sullivan at OSU). 


\section{Root.Rot (Phytophthora) on Port-Orford-Cedar}

We recommend that the FEIS explore the potential of using antagonistic fungi, a constituent of finished compost called a fungistat, as a tool for managing and preventing Phytophthora within seed orchard operations. A fungistat is a compound that inhibits fungal growth or sporulation but does not cause death. A fungistat keeps the disease from progressing once it is in

T4-8 the tree but does not necessarily cure the tree, hence repeated applications are necessary. Research in Califomia has shown some composts enhance biological activity of antagonistic fungi that attack Verticillium and Phytophthora. Since we did not see a reference in the DEIS to fungistats, we suggest that the FEIS investigate and disclose the potential of using fungistats as a means to mitigate any outbreak of Phytophthora infections within a seed orchard's stock of PortOrford-Cedars.

\section{Sudden Oak Death (Phytophthora ramorum)}

Sudden Oak Death (SOD) is damaging pathogenic fungus-like algae that invades the bark killing the entire tree or portions of the tree. SOD is spreading across west coast states and its known host species is also expanding. This pathogen, first detected in California in 1995, has advanced northward into southwestern Oregon. According to announcements in early 2001 from Oregon Department of Agriculture and Forestry, the U.S. Forest Service, and BLM, SOD had invaded southwestern Oregon. In addition, SOD can infect many different genuses and species. In 2002, University of California researchers confirmed that coastal redwoods (Sequoia T4-9 sempervirens) and Douglas fir (Pseudotsuga menziesii var. menziesii) are host species for the SOD pathogen. The confirmed host species list includes 20 broadleaf species involving 12 different families. A tentative host list is even considerably longer. The potential impact of this pathogen on the seed orchards' tree stocks should not be overlooked. On most non-oak hosts, SOD primarily attacks foliage or stems resulting in non-lethal damage to plants, and it could impact seed production. On Douglas firs for example, the pathogenic infestation causes cankers on small branches, wilting of new shoots, and some dieback of branches and needles (University of California). Furthermore, with the understanding that oak stands are known to exist outside some of the seed orchard areas, the FEISs should address the potential transfer of this pathogen from outside sources into the seed orchards

\section{Phytophthora ramorum and lateralis}

The FEIS should disclose how BLM will address the potential for spread of the pathogens $P$. ramorum and $P$. lateralis through the movement of seedlings, or by infested plant parts such as firewood, wood chips, mulch, leaves, or soil. Oregon Department of Agriculture has reported that researchers have found that $P$. ramorum moves with wood, leaves, surface waters

T4-10 (i.e., streams) and soil. The role of insects and birds in spread of $P$. ramorum disease is also under investigation. The California Department of Agriculture quarantine regulates the movement of bark, bark chips, and mulch. Since the DEIS proposes to dispose of wood from trees by selling it as firewood, be advised that firewood is another potential source of the spread of $P$. spp., particularly $P$. lateralis. In addition, tractors, to a lesser extent, have considerable

Page 2 of 4 
T4-10 $\begin{aligned} & \text { potential for moving the spores within soil from one area to another. These pathogens can also } \\ & \text { be spread through a watershed via streams from spores in water since the spores can readily } \\ & \text { adhere to eroded soil particles. Finally, we are aware that some organizations have established } \\ & \text { protection zones along hilltops to prevent the spread of } P \text {. lateralis downstream in the watershed. }\end{aligned}$

\section{Potential Improvements to the Proposed IPM Program}

(1) Parasitoids. We suggest that the FEIS consider using parasitoids as another viable biological control methodology of unwanted orchard pests. Insect parasitoids have an immature life stage that develops on or within an insect host, ultimately killing the host species (Biological Control: A Guide to Natural Enemies, Comell University). Parasitoids can be the dominant and most effective natural enemy of some pest insects, but their presence may not be obvious because parasitoid adults are small and often overlooked. The parasitoid larva inside a cone or seed may look similar to other pest species and could be incorrectly identified as a pest.

T4-11 Under traditional cultural methods, a seed orchard often will have limited sources of available pollen (for egg production) and nectar (for food energy). In these circumstances, parasitoid activity may be naturally low, but could be enhanced with the addition of plants that would provide low-growing flowers for easy parasitoid access. It may be possible to find suitable flowers that would provide nectar and pollen sources without creating additional problems such as increasing fire danger. It may also be possible to monitor parasitoid activity when a subsample of cones are dissected and checked for the presence of seed infesting insects prior to harvest.

(2) Pheromone Traps. We suggest that the FEIS explore the practice of attract-and-kill technology as exemplified by pheromone traps within seed orchards. Pheromone traps utilize chemical attractants which can be used to monitor the presence of certain pest species. While

T4-12 we understand that numbers of individuals captured are not directly related to damage levels in a field, traps can be monitoring tools to detect the presence of specific pests thereby alerting the manager so that appropriate action(s) can be more precisely timed. While the technology is still incomplete, there is some value in using pheromone traps as additional tools in the proposed IPM program.

\section{Pesticide Restrictions}

\section{Regarding the 54 Pesticides Cited in Washington Toxics Coalition, et al. vs U.S. EPA}

BLM should be aware of recent a Western District Court decision (Washington Toxics Coalition, et al. vs U.S. EPA; Westem Dist. of Washington at Seattle, Civ. No. C01-132C) which

T4-13 may result in use restrictions of 54 pesticides on federally-listed endangered and threatened salmonids. The court case identified 54 different pesticides (herbicides, insecticides, and fungicides) of concern. The FEIS should evaluate how this Court decision may affect the Preferred Alternative, including pesticide use near salmonid-bearing waters within the project areas.

\section{Page 3 of 4}




\section{Additional Concern}

\section{Agency Management and Preservation of Port-Orford-Cedar}

We recommend that the FEIS disclose how BLM will manage and preserve the Port-OrfordCedar both at the seed orchard scale and actoss the landscape within which this unique species lives. BLM is involved in two separate yet connected NEPA processes: these three EISs and another concurrent NEPA process for the management of Port-Orford-Cedar in southwestern Oregon (Draft Supplemental Environmental Impact Statement, Management of Port-OrfordCedar in Southwest Oregon).

Port-Orford-Cedar is an important tree species of south western Oregon and northern California both for its lumber quality and its functions within regional forest dynamics and processes. Unfortunately, the root rot disease (Phytophthora) referenced above has caused and is continuing to cause concern for the management and preservation of this tree species. For continuity of agency management and preservation activities, we strongly recommend that the FEIS for the four seed orchards should disclose their contributing part to protect this valued tree species.

\section{Improved Cartographic Information}

We recommend that all the FEISs improve their cartographic information on illustrating the extent and location of both perennial and ephemeral waterbodies (streams, rivers, wetlands, ponds) and cartographically present the permanence or seasonality of these systems so that appropriate prescriptions and land management allocations are more easily understood by land managers, project reviewers and the general public.

We recommend a consistent format of cartographic information among the EISs on water resource information. As a suggestion, Figure 3.4-1 on page 3-7 in the IPM, Travis Tyrrell Seed Orchard DEIS provides the best presentation of the extent and location of perennial and ephemeral streams in the project area. Also, Figure 3.4-1, in the IPM, Water H. Horning Seed Orchard, provides adequate presentation of the extent and location of wetlands within the project area. 


\section{U.S. Environmental Protection Agency Rating System for \\ Draft Environmental Impact Statements Definitions and Follow-Up Action*}

\section{Environmental Impact of the Action}

\section{LO - Lack of Objections}

The U.S. Environmental Protection Agency (EPA) review has not identified any potential environmental impacts requiring substantive changes to the proposal. The review may have disclosed opportunities for application of mitigation measures that could be accomplished with no more than minor changes to the proposal.

\section{EC - Environmental Concerns}

EPA review has identified environmental impacts that should be avoided in order to fully protect the environment. Corrective measures may require changes to the preferred alternative or application of mitigation measures that can reduce these impacts.

\section{EO - Environmental Objections}

EPA review has identified significant environmental impacts that should be avoided in order to provide adequate protection for the environment. Conrective measures may require substantial changes to the preferred alternative or consideration of some other project alternative (including the no-action alternative or a new alternative). EPA intends to work with the lead agency to reduce these impacts.

\section{EU - Environmentally Unsatisfactory}

EPA review has identified adverse environmental impacts that are of sufficient magnitude that they are unsatisfactory from the standpoint of public health or welfare or environmental quality. EPA intends to work with the lead agency to reduce these impacts. If the potential unsatisfactory impacts are not corrected at the final EIS stage, this proposal will be recommended for referral to the Council on Environmental Quality (CEQ).

\section{Adequacy of the Impact Statement}

\section{Category 1 - Adequate}

EPA believes the draft EIS adequately sets forth the environmental impact(s) of the preferred alternative and those of the alternatives reasonably available to the project or action. No further analysis of data collection is necessary, but the reviewer may suggest the addition of clarifying language or information.

\section{Category 2 - Insufficient Information}

The draft EIS does not contain sufficient information for EPA to fully assess environmental impacts that should be avoided in order to fully protect the environment, or the EPA reviewer has identified new reasonably available alternatives that are within the spectrum of alternatives analyzed in the draft EIS, which could reduce the environmental impacts of the action. The identified additional information, data, analyses or discussion should be included in the final EIS.

\section{Category 3 - Inadequate}

EPA does not believe that the draft EIS adequately assesses potentially significant environmental impacts of the action, or the EPA reviewer has identified new, reasonably available alternatives that are outside of the spectrum of alternatives analyzed in the draft EIS, which should be analyzed in order to reduce the potentially significant environmental impacts. EPA believes that the identified additional information, data, analyses, or discussions are of such a magnitude that they should have full public review at a draft stage. EPA does not believe that the draft EIS is adequate for the purposes of the National Environmental Policy Act and or Section 309 review, and thus should be formally revised and made available for public comment in a supplemental or revised draft EIS. On the basis of the potential significant impacts involved, this proposal could be a candidate for referral to the CEQ.

* From EPA Manual 1640 Policy and Procedures for the Review of Federal Actions Impacting the Environment February, 1987. 


\section{FAX - Comments Tyrrell EIS}

Date Aucust 75,2003

Number of pages includin ocover sheet $=7$

To: Glenr Miller
$\frac{\text { Rugene BLM }}{\text { Tyrell Seed Orchard }}$
$\frac{\text { Post Office } 121}{\text { Lorane OR } 97451}$
Phone $(54) 683-6445$
Eox Phome (541)683.6597

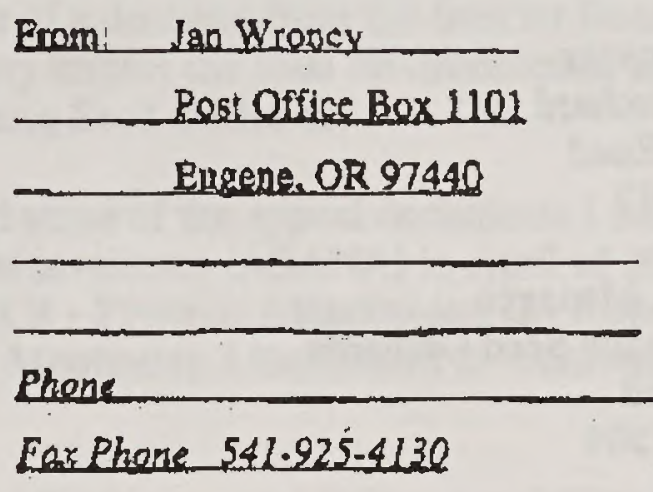

emial: OR,Eugene_TSOEIS@or,blm.gov

REMARKS: Comments on Draft Environmental Impact Statement -

Integrated Pest Management for the Travis Tyrrell Seed Orchard

As I indicated yesterday, I was sickened by diestl fumes. I was ill all afternoon, evening and through this morning. I had to put in the links for the various attachments, and could not finish thai yesterday because I was too sick. I just finished the printing of these comments to send to you. Please accept them for the EIS.

Respectfully submitted by,

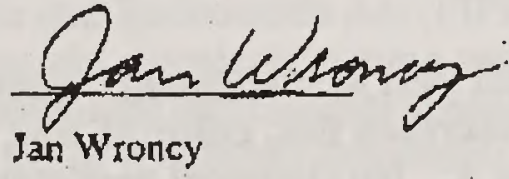


Glenn Miller, Manager

August 25, 2003

Travis Tyrrell Seed Orchard

Post Office Box 121

Lorane, Oregon 97451

Greg Tyler, Manager

Horning Seed Orchard

27004 Sheckly Road

Colton, OR 97017

Harvey Koester, Manager

Provolt and Sprague Seed Orchards

3040 Biddle Road

Medford, OR 97504

RE: Comments on the Draft Environmental Impact Statements for Integrated Pest Management for the Bureau of Land Management's Tyrrell, Provolt, Sprague, and Horning Seed Orchards, June 2003.

Dear Mr. Miller, Mr. Tyler and Mr. Koester:

On my own behalf and on behalf of the Coast Range Guardians, and Canaries Who Sing, $X$ urge you to adopt Alternative D - Non-Chemical Pest Management for the Tyrrell Seed Orchard; Alternative D - Non-Chemical Pest Management for the Horning Seed Orchard;
and Alternative C - Non-Chemical Pest Management for the Provolt and Sprague Seed Orchards.

The Non-Chemical Pest Management "would allow the seed orchard manager to use only the biological, prescribed fire, cultural, and other non-chemical-pesticide methods listed under Alternative A. No chemical pesticides would be permitted" at page 2-17, section 2.3.4 in the Tyrrell Draft EIS; page 2-19, section 2.3.5 in the Horning Draft EIS; and at page 2-21, section 2.3.4 in the Provolt and Sprague Draft EIS.

\footnotetext{
However the Non-Chemical Pest Management should also include in the prohibited list,
the biological control method of using a bioinsecticides, such as Bacillus thuringiensis - also
known as Bt (formulated as Dipel, Foray 48B, Deliver). Bt formulas are PESTICIDES and

However the Non-Chemical Pest Management should also include in the prohibited list,
the biological control method of using a bioinsecticides, such as Bacillus thuringiensis - also
known as Bt (formulated as Dipel, Foray 48B, Deliver). Bt formulas are PESTICIDES and do contain CHEMICALS (other ingredients, not necessarily biologically or chemically inert). Dipel, Foray 48B, and Deliver are regulated by the Federal Pesticide law and as such should be included in the Non-Chemical Pest Management prohibited list.

T5-3 Additionally Bacillus thuringiensis itself has been shown to have human health impacts as well as environmental impacts.
}

Wroncy/Coast Range Guardians/Canaries Who Sing - Comments on Seed Orchard LPM Draft

EIS August 25, 2003

Page - 1 


\section{APPEAL DECISION STILL PENDING FROM THE INTERIOR BOARD OF LAND} APPEALS

I appealed the decision to aerially spray Esfenvalerate (ASANA) by the BLM at the Tyrrell Seed Orchard but have not received notification of a decision from the Interior Board of Land Appeals (IBLA) yet. The decision by the IBLA may impact the final Environmental Impact Statements for the Tyrrell, Provolt, Spague, and Horning Seed Orchards.

T5-4 I have attached the comments, protest, and some of the appeal documents I submitted on the Tyrrell Seed Orchard aerial spraying of Esfenvalerate (ASANA) in April of 2003. See Attachment A - Comments; Attachment B - Protest; Attachment C - Appeal Statement of Reasons; Attachment D - Objections to Mootness; Attachment E - Answer to BLM's Motion to Dismiss.

The issues of compliance with the National Environmental Policy Act (NEPA), the Federal Insecticide, Fungicide and Rodenticide Act (FIFRA), the Clean Water Act (CWA), the Endangered Species Act (ESA) and other applicable laws apply also to the present Draft Environmental lmpact Statements for the Tyrrell, Provolt, Sprague and Horning Seed Orchards.

\section{BLM IS IGNORING IMPACTS OF BACILLUS THURINGIENSIS PESTICIDE FORMULAS}

The Bureau of Land Management is ignoring the fact that Deliver, Dipel, Foray 48B (all trade names of pesticide formulas) formulations of Bacillus thuringiensis $(\mathrm{Bt})$ are in fact

T5-2 PESTICIDES, and are, as such, regulated by the Environmental Protection Agency (EPA) as pesticides under the Federal Insecticide, Fungicide and Rodenticide Act (FIFRA), and under State Pesticide Laws. Also formulas of Bt also contain chemicals serving various purposes in the formula. Thus Bt pesticides are both biological pesticides and chemical pesticides. Therefore Bt and other biopesticides should be included in the list of prohibited substances under the Non-

- Chemical Alternative. Additionally Bt and other biological agents do have both human health concerns and environmental impacts which must be thoroughly analyzed, and fully revealed.

T5-3

See appeal of Forest Service aerially spraying of Bacillus Thuringiensis in the Alsea Watershed this Spring, attached herein as Attachment 5 .

\section{IMPACTS OF PESTICIDES UNDERESTIMATED}

The listed chemicals proposed for use have far more serious health and environmental effects than indicated by the Risk Assessments. Included in these comments are the following articles website: http:/lwwwpesticide.org

Wroncy/Coast Range Guardians/Canaries Who Sing - Comments on Seed Orchard IPM Draft EIS August 25, 2003 


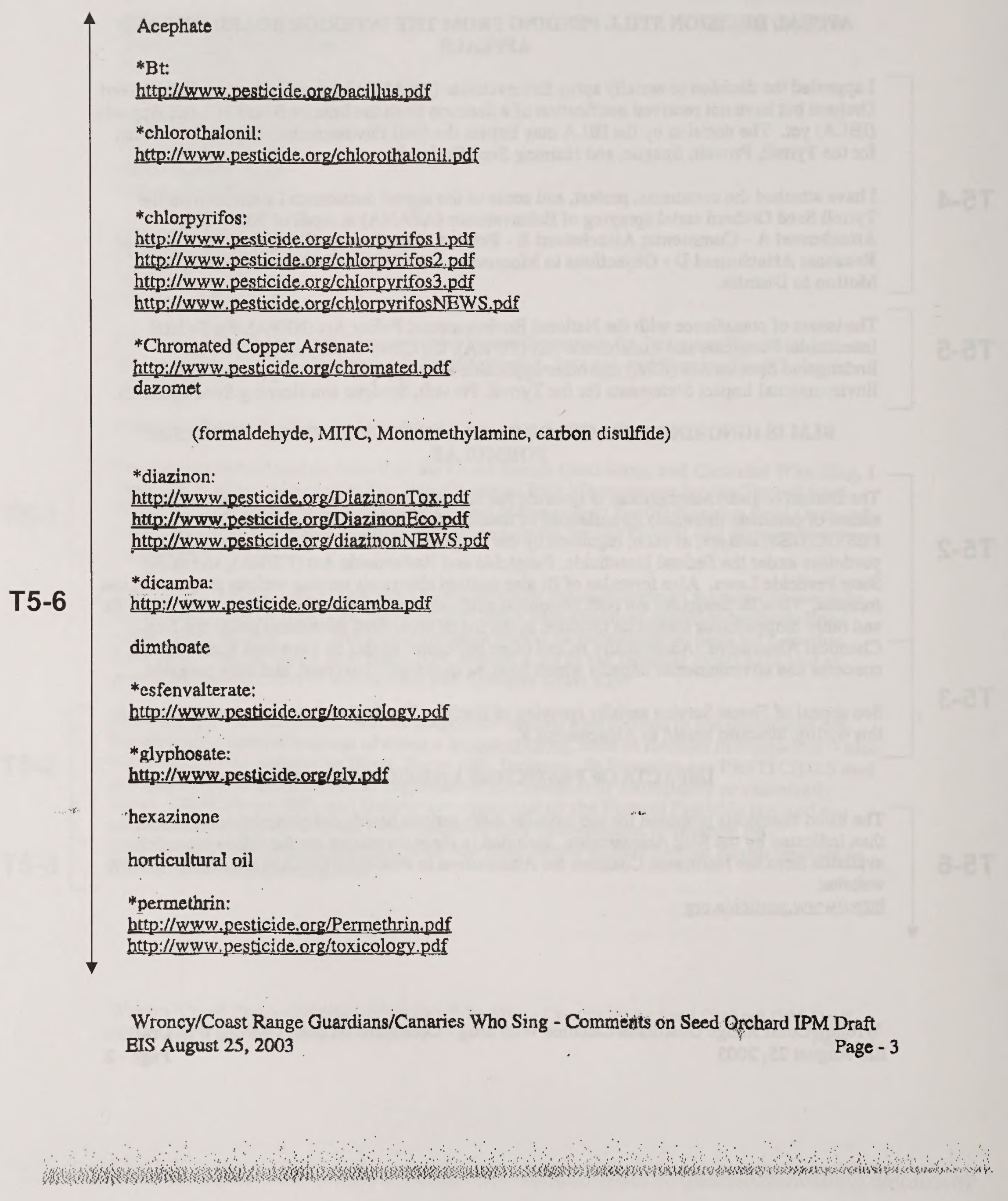


*picloram:

http://www.pesticide.org/picloram.pdf

(hexachlorobenzene)

propargite

propiconazole

T5-6

*triclopyr:

http://www.pesticide.org/triclopyr.pdf

**nitrate (note that nitrate is misleading, the chemical fertilizers that BLM uses are not pure nitrate)

***Inert ingredients:

(cyclohexanone, ethylbenene, light aromatic solvent naptha, xylene)

\section{“INERTS" NOT INERT}

***Note that "inert" ingredients are NOT INERT. See articles on "inerts" at: http://www.pesticide.org/inertsreport.pdf http://www,pesticide. org/ActiveInertsRpt.pdf

Additionally there has been favorable rulings regarding the issue of finding out what other ingredients are in pesticide formulas. See article about court ruling in NCAP v. EPA at: http://www.pesticide.org/InertsApr03.html and the court order at: http://www.pesticide.org/inertopinion.pdf

\section{CHEMICAL FERTULIZERS CAUSE IMBALANCES AND POOR HEALTH OF TREES}

The chemical fertilizers that BLM uses in the seed orchard actually cause soil fertility imbalances and contribute to poor health of the trees. Poor health which in turn actually invites disease, weeds and other pests. Then pesticides are perceived to be needed to correct this, which in turn further imbalances soil fertility. Maintaining soil fertility naturally by refraining from chemicals would break this vicious cycle.

\section{IMPACTS ON SALMON}

Both the active ingredients and the other ingredients (mislabeled "inerts") have lethal and sublethal effects on salmon and also impact essential fish habitat. See Diminishing Returns

T5-9 Returns: Salmon Decline and Pesticides by Dr. Richard D. Ewing, PhD, February 1999.

The text also may be found at: http://www.pesticide.org/salpest.pdf

Wroncy/Coast Range Guardians/Canaries Who Sing - Comments on Seed Orchard IPM Draft EIS August 25, 2003 
Several pesticides and the chemical fertilizers can have devastating impacts on salmon. In the case of Washington Toxics, et al v. EPA there are rulings now calling for buffers along salmon streams when either ground or aerial spraying of these pesticide. See the Fact Sheet about Pesticides, Salmon, and Endangered Species Act herein Attachment G ; the News Press Release from Earthjustice July 17, 2003 as Attachment $H$ - the court order signed on July 16, 2003 as Attachment I; and the court order signed August 8, 2003 as Attachment J.

The Fact Sheet may also be found at: http://www.enthjustice.org/news/documents/7-03/salmon lawsuit factsheet.pdf

The News Press Release may be found at: http://www. earthjustice.org/news/print,htmi?ID=635

The July $17^{\text {th }}$ Order may be found at: http://www.pesticide.org/Order7-16-03.pdf

The August $8^{\text {ti }}$ Order may be found at: http://agu,wa,gov/PestFert/BnyResources/docs/OrderFurtherInjunctiveRelief8-8-03.pdf

The Draft EIS does not adequately address the impacts to salmon. Although the BLM chooses not to consider the salmon an irretrievable resource, once lost, we will never get them back. By choosing chemical management, the BLM is sacrificing an endangered species for sake of saving money for private cooperators.

\section{BLM PUBLIC FUNDING OF SEED ORCHARDS NOW BENERITING PRIVATE TIMBER AND SEED COMPANIES AT PIJBLIC EXPENSE}

As far as I can find out, there was never a NEPA process whereby the public was invited to comment on the impacts of giving use of public property (the orchards of BLM) without compensation for establishment of the orchards (paid for by public funds) to private timber and

T5-10 seed companies to profit by the original expenditure of Federal Funding to establish the public seed orchard for the growing of trees to replant the public lands which were harvested. The BLM does not need to replant large acreages as it once did. Private timber companies can afford to pay more for the seeds for trees to replant the large acreages that it has harvested at great private gain on private lands.

Now the BLM is spending huge sums of money to develop EIS's to justify using chemicals on

T5-11 pablic land rather than funding research into the alternatives to chemical management. With all funds spent on justifying chemical use instead of research into the alternatives is a waste of public funds.

Wroncy/Coast Range Guardians/Canaries Who Sing - Comments on Seed Orchard IPM Draft EIS August 25, 2003 
Damage from contamination of water, air and soil is unjustifiable. Destruction of non-target organisms is unnecessary and inconsistent with goals to maintain ecosystem balance or biodiversity.

There is no need or justification for destroying salmon habitat, or for killing salmon to produce seed cheaply. The BLM has spent millions on protection and restoration of salmon habitat in other programs that it conducts (such as the fish ladder on Lake Creek at the Hult Reservoir, and at Triangle Lake), which is defeated by killing salmon and destroying salmon habitat at the Tyrrell, Provolt, Spague and/or Horning Seed Orchards.

\section{CONCLUSION}

\section{T5-1 Therefore, the BLM should adopt the Non-Chemical Pest Management Alternative, and add to the list of prohibited substances, the biopesticides such as Bacillus thuringiensis \\ T5-2 pesticide formulas.}

Respectfully submitted by,

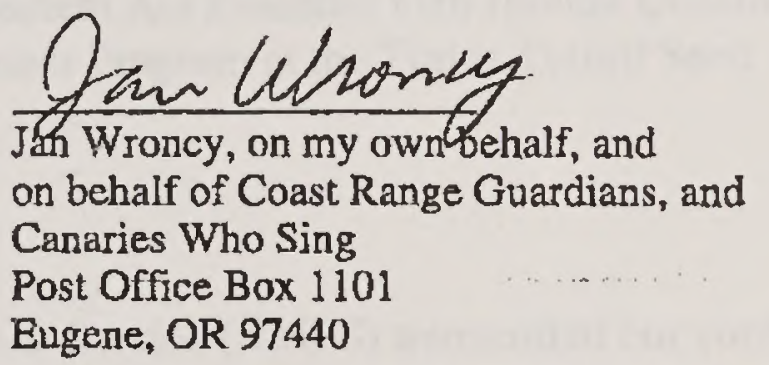

Wroncy/Coast Range Guardians/Canaries Who Sing - Comments on Seed Orchard IPM Draft EIS August 25, 2003 
Final EIS - Tyrrell Seed Orchard IPM

$E-42$ 


\section{Appendix F}

NOAA Fisheries Conference Opinion Transmittal Letter and Conference Opinion

Refer to NMFS No.:

2004/00213

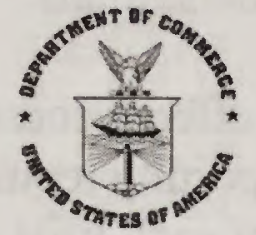

UNITED STATES DEPARTMENT OF COMMERCE

National Oceanic and Atmospheric Administration

NATIONAL MARINE FISHERIES SERVICE

Northwest Region

7600 Sand Point Way N.E., Bldg. 1

Seattle, WA 98115

February 9, 2005

Julia Dougan

Eugene District Manager

U.S. Bureau of Land Management

P.O. Box 10226

Eugene, Oregon 97440

Re: Amendment to the Endangered Species Act Interagency Consultation and Magnuson-

Stevens Fishery Conservation and Management Act Essential Fish Habitat Consultation for the Proposed Integrated Pest Management Program at the Travis Tyrrell Seed

Orchard in Lane County, Oregon

Dear Mr. Reuwsaat:

On January 18, 2005, the National Marine Fisheries Service (NMFS) transmitted our conference opinion and Magnuson-Stevens Fishery Conservation and Management Act (MSA) essential fish habitat (EFH) consultation on the effects of the Bureau of Land Management's (BLM) actions to carry out the Proposed Integrated Pest Management Program at the Travis Tyrrell Seed Orchard in Lane County, Oregon (Opinion) (refer to: NMFS No.: 2004/00213). That Opinion was one of four issued at approximately the same time as a result of concurrent consultations on different seed orchards in Oregon, all operated by the BLM. Since then, staff of NMFS and the BLM reviewed the results of those four consultations and found drafting errors were made such that some actions were attributed to the wrong orchard and, consequently, resulted in an improper effects analysis and incidental take statement. The enclosed document contains an amended Opinion intended to correct errors in the January 18, 2005 document, which is now withdrawn, and ensure that we have a common understanding of our consultation efforts.

In this new Opinion, NMFS concludes that the proposed action is not likely to jeopardize the continued existence of the Oregon Coast coho salmon (Oncorhynchus kisutch), proposed for listing under the ESA. This Opinion also includes an amended incidental take statement with terms and conditions necessary to minimize the impact of the taking that is reasonably certain to be caused by this action. Take from actions by the action agency and contractors, if any, that meet these terms and conditions will be exempt from the ESA take prohibition.

This document also includes the results of our amended consultation on the action's likely effects on essential fish habitats (EFH) for Chinook (O. tshawytscha) and coho salmon pursuant to section 305(b) of the Magnuson-Stevens Fishery Conservation and Management Act (MSA), 
and includes four conservation recommendations to avoid, minimize, or otherwise offset potential adverse effects to EFH. Section 305(b)(4)(B) of the MSA requires Federal agencies to provide a detailed written response to NMFS within 30 days after receiving these recommendations. If the response is inconsistent with the recommendations, the BLM must explain why the recommendations will not be followed, including the justification for any disagreements over the effects of the action and the recommendations.

In response to increased oversight of overall EFH program effectiveness by the Office of Management and Budget, NMFS established a quarterly reporting requirement to determine how many conservation recommendations are provided as part of each EFH consultation and how many are adopted by the action agency. Therefore, in your statutory reply to the EFH portion of this consultation, we ask that you clearly identify the number of conservation recommendations accepted.

I apologize for any inconvenience these errors may have caused and appreciate the interest you and your staff has in assuring that our consultations are based on the most accurate and up-todate information available. If you have further questions, please do not hesitate to contact Dan Gambetta, fisheries biologist, at 503.231.2243, or Cathy Tortorici, Oregon Coast/Lower Columbia Habitat Branch Chief, at 503.231.6268.

Sincerely,

for

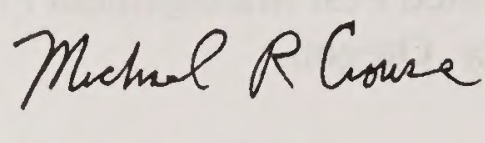

D. Robert Lohn
Regional Administrator

cc: Jeannette Griese, BLM

Bob Ruediger, BLM 


\title{
Amendment to the \\ Endangered Species Act - Section 7 Consultation Conference Opinion
}

\author{
$\&$
}

\section{Magnuson-Stevens Fishery Conservation and Management Act Essential Fish Habitat Consultation}

\author{
Proposed Integrated Pest Management Program, \\ Travis Tyrrell Seed Orchard, \\ Lane County, Oregon
}

Agency: Bureau of Land Management

Consultation

Conducted By: National Marine Fisheries Service, Northwest Region

Date Issued: $\quad$ February 9, 2005

Issued by:

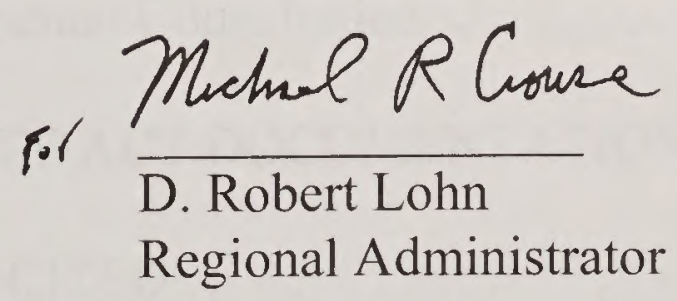

Refer to NMFS No.: $\quad 2004 / 00213$ 
Acronyms used in this document:

AgDrift - Agricultural Drift

BLM - Bureau of Land Management

BMPs - Best Management Practices

BRT - Biological Review Team

$\mathrm{Bt}$ - Bacillus thuringiensis

CFS - Cubic Feet Per Second

CPs - Conservation Practices

DOI - Department of Interior

EC - Effective Concentration

EIS - Environment Impact Statement

EFH - Essential Fish Habitat

EPA - Environmental Protection Agency

ESA - Endangered Species Act

ESUs - Evolutionarily Significant Units

EXAM - Exposure Analyis Modeling Systems

FMPs - Federal Fishery Management Plans

GLEAMS - Groundwater Loading Effects of Agricultural Management Systems

IPM - Integrated Pest Management

LC50 - Median Lethal Concentration

LOEC - Lowest Observed Effect Concentration

MSA - Magnuson-Stevens Fishery Conservation and Management Act

$\mathrm{mg} / \mathrm{L}$ - milligrams per litre

MPI - Matrix of Pathways and Indicators

MOC - Method of Characteristics

NOAA Fisheries - NOAA's National Marine Fisheries Service

NWFSC - Northwest Fisheries Science Center

ODEQ - Oregon Department of Environmental Quality

ODFW - Oregon Department of Fish and Wildlife

ODF - Oregon Department of Forestry

OSUES - Oregon State University Extension Service

PFMC - Pacific Fishery Management Council

PPM - Parts Per Million

PFC - Properly Function Condition

RA - Risk Assessment

RM - River Mile

ROD - Record of Decision

SERA - Syracuse Environmental Research Associates

SONC - Southern Oregon/Northern California

SPMDs - Semi-Permeable Membrane Devices

SWW - Southwest Washington

USDA - United States Department of Agriculture

USGS - United States Geological Survey

VSP - Viable Salmonid Population

WTC - Washington Toxics Coalition 


\section{TABLE OF CONTENTS}

INTRODUCTION $\ldots \ldots \ldots \ldots \ldots \ldots \ldots \ldots \ldots \ldots \ldots \ldots \ldots \ldots \ldots \ldots \ldots \ldots \ldots$

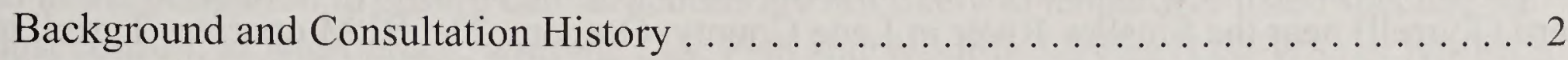

Description of the Proposed Actions . . . . . . . . . . . . . . . . . . . . 3

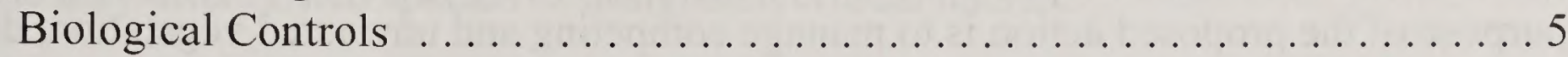

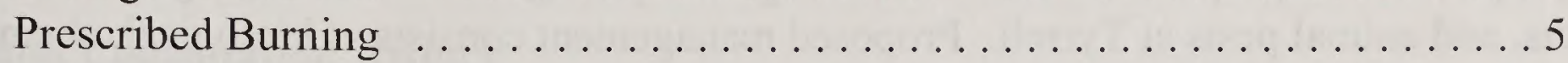

Cultural Methods . ............................ 5

Chemical Pesticides . . . . . . . . . . . . . . . . . . . . 6

Annual Monitoring and Reporting Requirements . . . . . . . . . . . . 15

Framework for Multi-Year Consultation . . . . . . . . . . . . . . . . 19

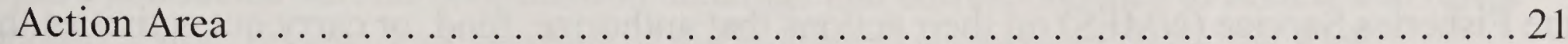

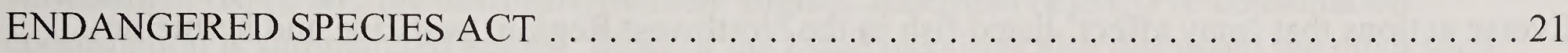

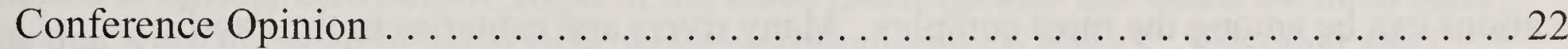

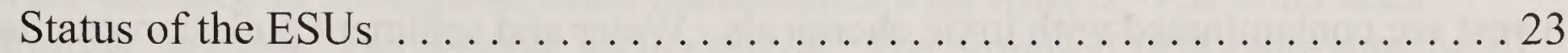

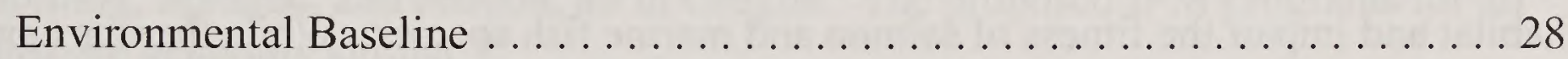

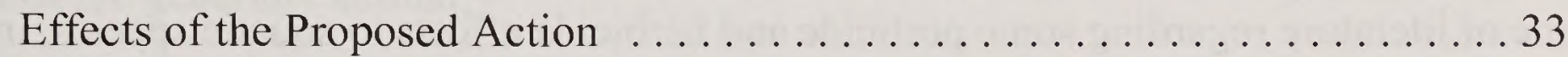

General Effects to Aquatic Species From Exposure to Proposed Compounds . . 35

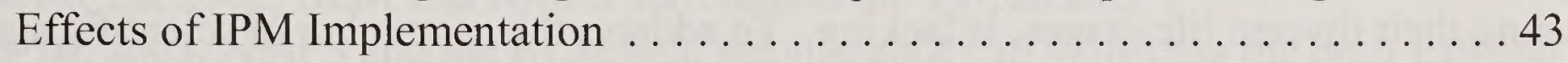

Cumulative Effects ............................ 76

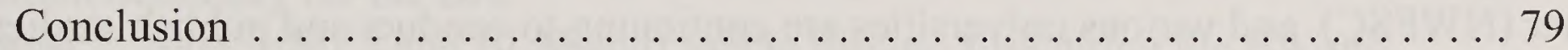

Conservation Recommendations . . . . . . . . . . . . . . . 79

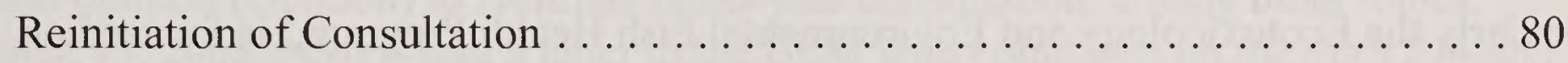

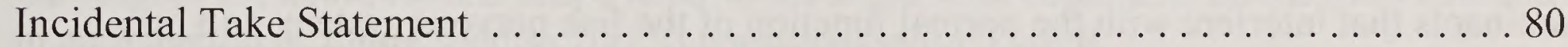

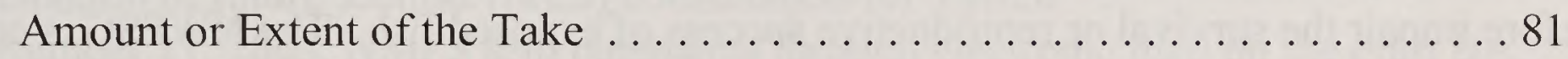

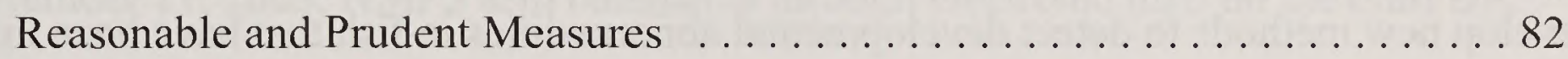

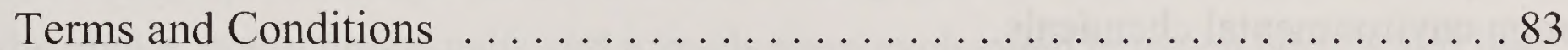

MAGNUSON-STEVENS FISHERY CONSERVATION AND MANAGEMENT ACT . . . 94

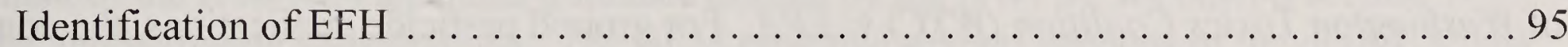

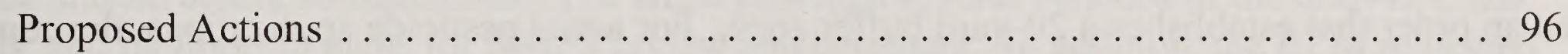

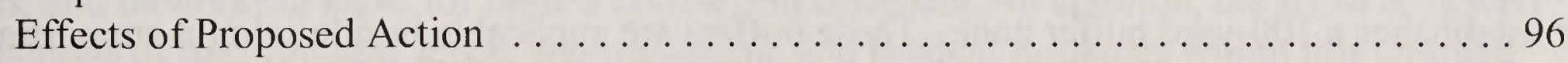

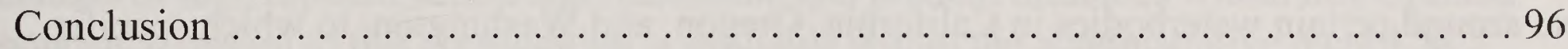

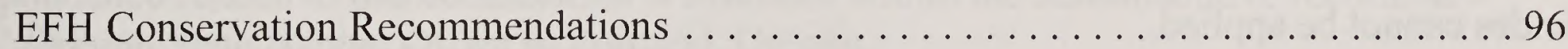

Statutory Response Requirement . . . . . . . . . . . . . . . . . . . 96

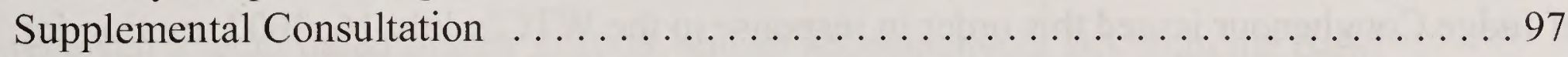

DATA QUALITY ACT DOCUMENTATION AND PRE-DISSEMINATION REVIEW . . . 97

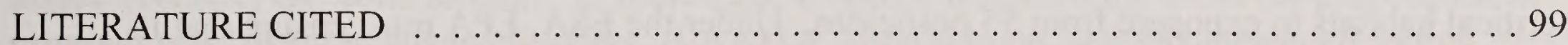




\section{INTRODUCTION}

The Bureau of Land Management (BLM) owns and operates the 361-acre Travis Tyrrell seed orchard (Tyrrell) near the Siuslaw River in Lane County, Oregon. The BLM operates Tyrrell to produce conifer seedlings, preserve individual conifer trees, and produce native species seed. The purpose of the proposed action is to manage competing and unwanted vegetation, diseases, insects, and animal pests at Tyrrell. Proposed management consists of biological, chemical, cultural, and other methods to preserve and enhance seed orchard production. Collectively, these actions are referred to as integrated pest management (IPM).

Federal agencies are required under section 7(a)(2) of the ESA to consult with the National Marine Fisheries Service (NMFS) on their actions that authorize, fund, or carry out activities that 'may affect' listed salmonids or designated critical habitat. From a scientific perspective, among the diverse actions that 'may affect' listed fish in the Northwest Region, pesticide and herbicide applications can be among the most complex. Many rivers and estuaries in the Pacific Northwest are contaminated with toxic chemicals. Water and sediment pollution can degrade fish habitat and impair the fitness of salmon and marine fish species. While there is a healthy volume of literature regarding some pesticide and herbicide effects to aquatic species, in some cases, data for a specific pesticide/herbicide on particular salmonid species and their prey, including their diverse life-stages, is lacking. To address this, a number of scientific agencies, including the Environmental Protection Agency (EPA), the NMFS Northwest Fisheries Science Center (NWFSC), and various universities are continuing to conduct and publish studies that further describe pesticide and herbicide effects to aquatic species. Research within the NWFSC, particularly the Ecotoxicology and Environmental Fish Health Program, ${ }^{1}$ is focused on contaminants that interfere with the normal function of the fish nervous system, and may therefore impair the survival or reproductive success of exposed fish. The NWFSC is continuing to develop new methods to detect developmental abnormalities in fish that have been exposed to common environmental chemicals.

On January 22, 2004, the U.S. District Court for the Western District of Washington ruled in the case of Washington Toxics Coalition (WTC) v. EPA. For ground pesticide applications, the court issued an order that establishes a 20 -yard buffer zone. For aerial pesticide applications, the court order establishes a 100-yard buffer zone. These buffers are applicable beside salmon-supporting waters around certain waterbodies in California, Oregon, and Washington, to which specific pesticides cannot be applied.

Chief Judge Coughenour issued this order in response to the WTC's July 16, 2003, motion for injunctive relief to establish buffer zones as an interim measure to reduce the likelihood of jeopardy to 26 species of salmon and steelhead. This order is in effect until the EPA and NMFS have completed an evaluation of threatened and endangered Pacific salmon and steelhead and their critical habitats to exposure from 55 pesticides. Under the ESA, EPA must ensure that its

http://www.nwfsc.noaa.gov/research/divisions/ec/ecotox/index.cfm 
registration of a pesticide is not likely to jeopardize the continued existence of species listed as endangered and threatened or adversely modify habitat critical to those species' survival. In addition to the obligation to ensure that its actions are not likely to jeopardize listed species, the EPA must consult, as appropriate, with the U.S. Fish and Wildlife Service (USFWS) or NMFS if a pesticide's use may affect listed species or designated critical habitat.

\section{Background and Consultation History}

This five-year consultation for Tyrrell was initiated by the BLM to help streamline the implementation of a comprehensive IPM program. For the past several years, the BLM and NMFS have conducted several coordination meetings and correspondence to review and refine the proposed action, review draft versions of the biological assessment (BA), the Risk Assessment (RA), and the draft Environment Impact Statement (EIS). Pre-consultation coordination is summarized below. Most of the listed meetings also discussed the other seed orchards that were intended to undergo separate consultation with NMFS. The other seed orchards are Horning, Sprague, and Provolt, all in Oregon. The proposed IPM programs for all the seed orchards are generally similar.

- $\quad$ On October 28, 2002, BLM and NMFS staff toured the Tyrrell site.

- On July 10, 2003, NMFS and the BLM held a conference call to discuss the draft EIS and information necessary for the BA.

- $\quad$ On August 5, 2003, NMFS and BLM staff met to discuss structuring the BA and biological opinion (Opinion) to facilitate multi-year consultation, among other topics.

- $\quad$ On August 13, 2003, NMFS sent a letter to the BLM with comments on the draft EIS and in anticipation of future section 7(a)(2) consultation for Tyrrell.

- On November 11, 2003, NMFS sent comments through electronic mail on the draft BA.

In addition to the above, many phone calls and e-mails were exchanged between NMFS and the BLM regarding the proposed action. The BLM, at the request of NMFS, tailored their assessment of the IPM with technical guidance drafted by the NWFSC for NMFS section 7 pesticide and herbicide consultations. The BLM provided several versions of the draft BA, risk analysis, and monitoring plans for NMFS review and comment. In addition, the BLM reviewed draft versions of the proposed action and reasonable and prudent measures within this Opinion. Correspondence related to this consultation is available within the administrative record, at NMFS' Oregon State Habitat Office in Portland, Oregon.

NMFS received a letter dated March 2, 2003, and an accompanying BA from the BLM requesting informal consultation on the proposed five-year IPM program for the Tyrrell orchard. In the letter and the BA, the BLM determined that the proposed action is "not likely to adversely affect' (NLAA) OC coho salmon. In March 2004, NMFS informed the BLM the proposed IPM program was 'likely to adversely affect' (LAA) OC coho salmon, and recommended formal consultation for the proposed action. 
This consultation also fulfills the essential fish habitat (EFH) consultation requirements under the Magnuson-Stevens Fishery Conservation and Management Act (MSA) 1996. The MSA, as amended by the Sustainable Fisheries Act of 1996 (Public Law 104-267), established procedures designed to identify, conserve, and enhance EFH for those species regulated under a Federal fisheries management plan. Federal agencies must consult with NMFS on all actions, or proposed actions, authorized, funded, or undertaken by the agency, that may adversely affect EFH $(\S 305(b)(2))$. The objective of the EFH consultation is to determine whether the proposed action will adversely affect designated EFH for Chinook (O. tshawytscha) and coho salmon, and to recommend conservation measures to avoid, minimize, or otherwise offset potential adverse effects to EFH resulting from the proposed action.

This Opinion was originally issued on January 13,2005 , and is currently being amended at the Agency's request in order to clarify the proposed action. This amendment shall supercede the previous Opinion in its entirety.

The action area for this consultation begins within the drainages (ephemeral and perennial) within, and downstream from, the Tyrrell orchard, including OC coho-bearing Douglas Creek, Stream 8, and Stream 1 as they drain into the Siuslaw River. The downstream portion of the action area extends into the Siuslaw River estuary.

\section{Description of the Proposed Actions}

Management of pests enables the seed orchard to produce improved seed for conifer seedling production, preserve valuable individual conifer trees, produce native species plants and plant species seed. This seed is supplied to BLM and other cooperators for reforestation and restoration projects.

The pest management objectives at Tyrrell include the following:

1. Minimize insect damage to orchard trees, cone crops and native plants.

2. Remove noxious weeds and control vegetation that favors animal pests and disease conditions, and reduce fire hazard conditions.

3. Reduce growth of vegetation to allow tree establishment and growth, and reduce the fire hazard.

4. Treat fungal and bacterial diseases to maintain the health and vigor of the orchard trees used for seed production and control plant pathogens in native seedling grow-out beds.

5. Minimize animal damage to orchard trees, native plant beds, orchard equipment and infrastructure.

The BA states that it is the policy of the Department of Interior (DOI) to use chemical pesticides only after considering all the alternatives, and to develop, support, and adopt IPM strategies wherever practicable (DOI 1981). The concept of IPM used in the BA is as follows: 
IPM is an approach to solving pest problems by applying our knowledge about pests to prevent them from damaging crops, harming animals, infesting buildings or otherwise interfering with our livelihood or enjoyment of life. IPM means responding to pest problems with the most effective, least-risk option. Under IPM, actions are taken to control pests only when their numbers are likely to exceed acceptable levels. Any action taken is designed to target the troublesome pest, and limit the impact on other organisms and the environment. Applying pesticides to crops, animals, buildings or landscapes on a routine basis, regardless of need, is not IPM (BLM 2004).

The BA further defines the context for the proposed Tyrrell IPM, emphasizing the holistic approach to pest management consistent with DOI policy, and the integration of a broad range of pest control methods:

IPM for seed orchards is the maintenance of seed orchard pests at tolerable levels by the planned use of a variety of preventive, suppressive, or regulatory methods (including no action) that are consistent with orchard management goals. Each pest management activity is the end result of a decision-making process where pest problems and their impact on hosts are considered, and control methods are analyzed for their effectiveness, as well as their impacts on economics, human health, and the environment. Deciding which particular method would be used depends on several factors. Initial questions at the seed orchard might include, "Is it really necessary to control this pest? Can we live with the damage and still have the trees survive and produce suitable amounts of seed?" If the answers are yes and no, respectively, then decisions must be made as to what method(s) of control to use.

The focus of IPM is on long-term prevention or suppression of pests. The integrated approach to pest management incorporates the best-suited biological, chemical, and cultural controls that have minimum impact on the environment and on people. IPM is not pesticide-free management; however, a successful IPM program should result in the most efficient use of pesticides if and when they are needed (BLM 2004).

The BLM has proposed a number of specific measures to address unwanted vegetation, insects, disease, and animal pests at Tyrrell. These measures generally fall into the following categories:

- Biological controls, such as bird or bat boxes to attract insect-eaters, or encouraging predators that can control animal pests.

- $\quad$ Prescribed burning to remove vegetation.

- Cultural methods, including mechanical (tractor mowing) and manual (pruning) methods, mulch mats, and fences.

- Chemical insecticides, herbicides, fungicides and fertilizers. 


\section{Biological Controls}

Biological pest control is the deliberate use of natural enemies such as parasites, predators, or disease organisms to reduce pest populations. Three types of biological control are in use, or proposed for use, to manage insect pests:

1. Bird boxes are placed on perimeter fences throughout the orchard. Birds are seen predating insects throughout the year, though their overall effect has not been quantified. Bat boxes are also used to attract insect-eating bats. Bat houses have also been used at Tyrrell to provide roosting and breeding habitat to encourage bats, such as the big brown bat and little brown myotis, to live in the vicinity and feed on insects in Tyrrell.

2. Bacillus thuringiensis (Bt), a biological insecticide, has been used in the greenhouses and is being considered to help reduce insect damage at the orchard.

3. Grazing using sheep, goats, or cattle could also be used to help control undesirable vegetation.

\section{Prescribed Burning}

The BLM proposed pile burning of insect-infested vegetation or cones to reduce insect populations by eliminating insect habitat, which would otherwise allow the pupae to emerge in spring as adult insects. Pile-burning of vegetation with disease infections is a sanitation method of control, which eliminates the infected material and reduces the risk of disease spread within Tyrrell.

Prescribed fire may be used for removing vegetation in native species beds before planting. High temperatures, created through the use of a propane-fueled flame wand, kill any existing herbaceous material, provide a weed-free bed for growing native plants, and quickly removes dead plant litter. Prescribed fire may also be used to remove native grass straw after seed harvest or diseased native grasses in native species beds. Prescribed fire is not proposed for use in riparian areas.

\section{Cultural Methods}

The following methods may be used for various applications:

1. Vegetation. Hand-pulling; pruning; thinning; hand tools to cut and grub; tractors with various blade attachments for mowing; gasoline-powered string trimmers; brush cutter machine mounted on tractor; chainsaw for cutting up thinned, rogued, dead/dying orchard trees; power pruner; wood chipper; chipping with large tub grinders and marketing the chips for energy development; and mulch mats.

2. Insects. Pruning, thinning, shaping, use of grafting wax or spray seal on tree wounds, sanitation of damaged branches and trees, sanitation of insect-damaged cones and cones not harvested for seed production, hand-picking large and noticeable insect pupae. 
3. Disease. Pruning, power saws to cut infected or dead trees, removal of diseased plants from the native plant gardens using a tractor and rototiller, mesh shade screens to protect seedlings from heat damage, hand-painting older trees with exposed and thin bark to reflect the sun's rays and insulate from extreme heat.

4. Animal pests. Trapping of gophers, walking (herding) stray deer and elk toward gates and out of the orchard, pruning tree limbs, removing unwanted vegetation, mowing cover crop vegetation that provides cover for small animals, live trapping, fencing to exclude deer and elk from the orchard, chicken wire to exclude rabbits from common garden study, tubes to protect seedlings from voles.

\section{Chemical Pesticides (insecticides, herbicides, fungicides and fertilizers)}

Table 1 lists the following chemical pesticides available for use at Tyrrell.

Table 1. Chemicals Proposed for Tyrrell

\begin{tabular}{|l|l|l|l|l|}
\hline Insecticides & Fungicides & Herbicides & Fumigant & Fertilizers \\
\hline $\begin{array}{l}\text {-acephate } \\
\text {-chlorpyrifos } \\
\text {-diazinon } \\
\text {-dimethoate } \\
\text {-esfenvalerate } \\
\text {-horticultural oil } \\
\text {-imidacloprid } \\
\text {-permethrin } \\
\text {-potassium salts of } \\
\text { fatty acids } \\
\text {-propargite }\end{array}$ & $\begin{array}{l}\text {-chlorothalonil } \\
\text {-propiconazole }\end{array}$ & $\begin{array}{l}\text {-dicamba } \\
\text {-glyphosate } \\
\text {-picloram }\end{array}$ & -dazomet & $\begin{array}{l}\text {-ammonium } \\
\text { phosphate - } \\
\text { sulfate } \\
\text {-calcium } \\
\text { nitrate }\end{array}$ \\
\hline
\end{tabular}

Table 2 provides the relative toxicity to salmonids and insects, and application data as proposed by the BLM. 
Table 2. Pesticide, Herbicide and Fertilizer Data

\begin{tabular}{|c|c|c|c|c|c|c|}
\hline Pesticide & Chemical Family & $\begin{array}{l}\text { Pest. } \\
\text { Use }\end{array}$ & $\begin{array}{l}\text { Fish Acute } \\
\text { Toxicity }\end{array}$ & $\begin{array}{l}\text { Application } \\
\text { Date Range }\end{array}$ & $\begin{array}{l}\text { Application } \\
\text { Frequency }\end{array}$ & $\begin{array}{l}\text { Application } \\
\text { Method }\end{array}$ \\
\hline \multirow[b]{2}{*}{ Acephate } & \multirow[b]{2}{*}{ Organo-phosphate } & \multirow[b]{2}{*}{ I } & \multirow[b]{2}{*}{ Slightly toxic } & Apr & \multirow[b]{2}{*}{$\begin{array}{c}\text { Once every } 3 \\
\text { years }\end{array}$} & Implants \\
\hline & & & & Apr-Sep & & HPHS \\
\hline \multirow[b]{2}{*}{ B.t. } & \multirow[b]{2}{*}{ Biological } & \multirow[b]{2}{*}{ I } & \multirow[b]{2}{*}{$\begin{array}{l}\text { No Data } \\
\text { Available }\end{array}$} & \multirow[b]{2}{*}{ Apr - Sept } & \multirow{2}{*}{$\begin{array}{c}\text { Once every } 3 \\
\text { years }\end{array}$} & Aerial \\
\hline & & & & & & $\begin{array}{l}\text { HPHS or } \\
\text { HSHHW }\end{array}$ \\
\hline Chlorpyrifos & Organo-phosphate & I & $\begin{array}{l}\text { Very highly } \\
\text { toxic }\end{array}$ & Apr - Sept & $\begin{array}{c}\text { Once every } 3 \\
\text { years }\end{array}$ & HPHS \\
\hline Diazinon & Organo-phosphate & I & $\begin{array}{l}\text { Very highly } \\
\text { toxic }\end{array}$ & Apr - Sept & $\begin{array}{c}\text { Once every } 3 \\
\text { years }\end{array}$ & HPHS \\
\hline Dimethoate & Organo-phosphate & I & $\begin{array}{l}\text { Slightly to } \\
\text { moderately } \\
\text { toxic }\end{array}$ & Apr - Jun & Every 3 years & HPHS \\
\hline \multirow{3}{*}{ Esfenvalerate } & \multirow{3}{*}{ Pyrethroid } & \multirow{3}{*}{ I } & \multirow{3}{*}{$\begin{array}{l}\text { Very highly } \\
\text { toxic }\end{array}$} & Mar-Aug & \multirow{3}{*}{ Annually } & Aerial \\
\hline & & & & Mar-Aug & & Airblast \\
\hline & & & & Mar-Aug & & $\begin{array}{c}\text { HPHS } \\
\text {-or- } \\
\text { HSHHW }\end{array}$ \\
\hline $\begin{array}{l}\text { Horticultural } \\
\text { Oil }\end{array}$ & Petro-Chem & I & $\begin{array}{l}\text { Moderate to } \\
\text { highly toxic }\end{array}$ & $\begin{array}{c}\text { Mar-Sep } \\
\text { (as additive) } \\
\text { Sep-Jul } \\
\text { (dormant oil) }\end{array}$ & $\begin{array}{c}\text { Once every } 3 \\
\text { years }\end{array}$ & HPHS \\
\hline Imidacloprid & nictinoid & I & $\begin{array}{l}\text { Not acutely } \\
\text { toxic }\end{array}$ & Jan-Mar & Annually & Implants \\
\hline Permethrin & Pyrethroid & I & $\begin{array}{l}\text { Very highly } \\
\text { toxic }\end{array}$ & May-Aug & $\begin{array}{c}\text { Every } 1 \text { to } 2 \\
\text { years }\end{array}$ & HPHS \\
\hline Propargite & Organosulfite & I & Highly Toxic & Apr-Oct & $\begin{array}{c}\text { Once every } 3 \\
\text { years }\end{array}$ & HPHS \\
\hline Chlorothalonil & $\begin{array}{c}\text { Chlorinated } \\
\text { benzene nitrile }\end{array}$ & $\mathrm{F}$ & $\begin{array}{c}\text { Very Highly } \\
\text { Toxic }\end{array}$ & Feb - Jun & $\begin{array}{c}\text { Once every } 3 \\
\text { years }\end{array}$ & HPHS \\
\hline
\end{tabular}




\begin{tabular}{|c|c|c|c|c|c|c|}
\hline Pesticide & Chemical Family & $\begin{array}{l}\text { Pest. } \\
\text { Use }\end{array}$ & $\begin{array}{c}\text { Fish Acute } \\
\text { Toxicity }\end{array}$ & $\begin{array}{l}\text { Application } \\
\text { Date Range }\end{array}$ & $\begin{array}{l}\text { Application } \\
\text { Frequency }\end{array}$ & $\begin{array}{l}\text { Application } \\
\text { Method }\end{array}$ \\
\hline Propiconazole & Triazole & $\mathrm{F}$ & $\begin{array}{l}\text { Moderately } \\
\text { toxic }\end{array}$ & Mar - Nov & $\begin{array}{c}\text { Once every } 2 \\
\text { years }\end{array}$ & $\begin{array}{c}\text { Tractor-pulled } \\
\text { spray rig w/ } \\
\text { boom } \\
\text {-or- } \\
\text { HSHHW }\end{array}$ \\
\hline Dicamba & $\begin{array}{c}\text { Benzoic acid } \\
\text { derivative }\end{array}$ & $\mathrm{H}$ & Slightly toxic & May - Sept & $\begin{array}{c}\text { Once every } 3 \\
\text { years }\end{array}$ & $\begin{array}{c}\text { HSHHW } \\
\text {-or- } \\
\text { BS }\end{array}$ \\
\hline \multirow[t]{3}{*}{$\begin{array}{l}\text { Glyphosate } \\
\text { (Roundup) }\end{array}$} & \multirow[t]{3}{*}{$\begin{array}{l}\text { Amino acid } \\
\text { derivative }\end{array}$} & \multirow[t]{3}{*}{$\mathrm{H}$} & \multirow[t]{3}{*}{$\begin{array}{l}\text { Moderately } \\
\text { toxic }\end{array}$} & Apr-Oct & \multirow{3}{*}{$\begin{array}{c}\text { Every } 1 \text { to } 2 \\
\text { years }\end{array}$} & $\begin{array}{c}\text { Tractor-pulled } \\
\text { spray rig w/ } \\
\text { boom } \\
\text {-or- } \\
\text { HSHHW }\end{array}$ \\
\hline & & & & & & $\begin{array}{c}\text { Tractor-pulled } \\
\text { spray rig w/ } \\
\text { boom }\end{array}$ \\
\hline & & & & Mar - Oct & & BS \\
\hline Picloram & $\begin{array}{l}\text { Picolinic acid } \\
\text { derivative }\end{array}$ & $\mathrm{H}$ & $\begin{array}{l}\text { Slightly to } \\
\text { moderately } \\
\text { toxic }\end{array}$ & May-Aug & $\begin{array}{c}\text { Every } 2 \text { to } 3 \\
\text { years }\end{array}$ & $\begin{array}{l}\text { Tractor-pulled } \\
\text { spray rig w/ } \\
\text { boom } \\
\text {-or- } \\
\text { HSHHW } \\
\text {-or- } \\
\text { BS }\end{array}$ \\
\hline Triclopyr & Amine salt & $\mathrm{H}$ & $\begin{array}{l}\text { Slightly to } \\
\text { moderately } \\
\text { toxic }\end{array}$ & May-Sep & $\begin{array}{c}\text { Every } 1 \text { to } 2 \\
\text { years }\end{array}$ & $\begin{array}{c}\text { HSHHW } \\
\text {-or- } \\
\text { Tractor-pulled } \\
\text { spray rig w/ } \\
\text { boom } \\
\text {-or- } \\
\text { BS }\end{array}$ \\
\hline Dazomet & Thiozine & $\mathrm{F}$ & $\begin{array}{l}\text { Moderate to } \\
\text { highly toxic }\end{array}$ & Jun & $\begin{array}{c}\text { Every } 2 \text { to } 3 \\
\text { years }\end{array}$ & $\begin{array}{l}\text { Ground-pull } \\
\text { spreader }\end{array}$ \\
\hline
\end{tabular}

Relative fish toxicity as determined by the Pesticide Action Network (PAN) ${ }^{2}$

\section{KEY:}

$\mathrm{I}=$ insecticide, $\mathrm{F}$ = fungicide, $\mathrm{H}=$ herbicide

HSHHW=Hydraulic Sprayer with Hand Held Wand, BS=Backpack Sprayer, HPHS=High Pressure Hydraulic Sprayer, HS=Hand Sprayer

2 PAN can be accessed at: http://www.pesticideinfo.org/Index.html 


\section{Proposed Conservation Practices (CPs)}

1. Application of general fertilization at maximum rates $(1,000 \mathrm{lb} / \mathrm{acre})$ will be preceded by soil aeration throughout the unit to encourage downward movement (as opposed to runoff) of fertilizer in the case of an unpredicted large storm event.

2. Fertilizer will not be applied within 40 feet of perennial streams or non-perennial streams that are flowing water at the time of application.

3. Fertilizer loading (pertaining to application equipment) areas will be at least 100 feet from perennial streams.

4. Pesticides will be applied within the parameters of prescribed environmental conditions stated on the label.

5. No spraying will occur if snow or ice covers the target foliage.

6. If possible, spraying will be conducted during the early morning or late evening, allowing foliage to dry before pollinators become active.

7. Orchard fields will be mowed prior to insecticide applications to remove floral components of the ground cover if significant amounts of flowers are present, and if pollinators are likely to be active on the day of the application.

8. No pesticides, other than implants and injections, will be used to control pests within 40 feet of any perennial or non-perennial streams. Implants and injections will only occur in established orchard units.

9. Chemical weed control within 20 feet of perennial or non-perennial streams with flowing water at the time of application will be limited to spot hand applications.

10. No carrier other than water will be used to mix (dilute) the pesticide products for application. In some cases, surfactants or adjuvants may be added to application mixtures of pesticides to improve their effectiveness or minimize handling and application problems. The seed orchard will only use surfactants or adjuvants that do not contain any ingredients on EPA's List 1 or 2, where listing indicates a chemical is of toxicological concern, or is potentially toxic with a high priority for testing (EPA 2000a). If a surfactant or adjuvant that contains any List 1 or 2 ingredients is considered, the risk associated with that chemical will be evaluated before a use determination is made.

11. Maintenance and calibration of spray equipment will occur at least annually to ensure proper application rates.

12. No more than one application of picloram will be made on an area in any given year to reduce the potential for picloram accumulation in the soil.

\section{Proposed Runoff CPs}

1. Pesticide and fertilizer applications will be timed, to the extent predictable by weather forecasts, to not coincide or closely precede a large storm event that could result in substantial runoff.

2. As weather and soil conditions permit, soil aeration will be done around the perimeter of orchard units prior to general orchard fertilizer applications, and aerial or airblast applications. 
3. To minimize the potential for chemical contamination of runoff to streams, pesticide and fertilizer application will not occur if soils are saturated. Saturation levels will be determined by a soil scientist.

4. Silt catchment barriers, such as bio-bags, will be installed across all ephemeral drainages beside or inside treatment units during periods when overland flow may occur following pesticide application. The function of these barriers will be to catch organics and sediment leaving the treatment area.

\section{Proposed Spill CPs}

1. Equipment used for pesticide transport, mixing, and application will be properly maintained to avoid leaking pesticides into water or soil.

2. To prevent contamination from a spill event, pesticides will be mixed and equipment cleaned in areas protected from the potential for runoff to surface waters or leaching to groundwater. Areas used for mixing insecticides will be at least 200 feet from streams with water.

3. A pesticide safety plan will be developed to identify project-specific safety procedures. In the event of a spill, spill containment procedures in the safety plan will be followed. A spill kit, filled with absorbent materials, will be near the insecticide mixing area for use in the event of an accidental spill.

\section{Proposed Drift CPs}

1. To limit the potential for drift, pesticides will not be applied through aerial, airblast, or high-pressure hydraulic sprayer methods within 200 feet of perennial streams or nonperennial streams that are flowing at the time of application. A 40-foot buffer will also be applied (when using these methods) on non-perennial streams that are dry at the time of application.

2. From the edge of the 200 -foot buffer to 40 feet from the flowing streams, pesticide applications will be limited to methods associated with little to no drift. These methods could include tractor-pulled spray rig with boom, backpack sprayers, hydraulic sprayer with hand-held wand, capsule implantation, or other no-drift technologies.

3. Factors such as relative humidity, wind speed, and air temperature will be considered to determine the timing of applications that will minimize the potential for off-target drift.

4. When spraying trees within two tree rows from the edge of treatment unit perimeters, spraying will be done by directing the nozzle towards the center of the treatment unit, minimizing the chance for drift outside the designated treatment areas.

\section{Proposed Aerial CPs}

1. When using aerial or airblast methods to apply insecticides in orchard units, spray will be discontinued over road or ditch surfaces.

2. To help prevent potential impacts to aquatic species associated with a spill, chemical pesticides will not be transported by air over perennial streams. 
3. Application unit boundaries will be clearly marked with highly visible traffic cones or flagging in a manner that will allow visual identification from the air or ground.

4. If necessary and feasible, smoke flares will be deployed in each orchard before application to provide for pilot/applicator recognition of wind speed and direction.

5. Flight patterns will occur parallel to streams and buffer areas when operationally feasible and will not cross water bodies (ponds, streams, live water).

6. Areas immediately beside buffers will be treated before the rest of the unit during an aerial spray project. The helicopter will operate around the buffer areas with the boom closest to the sensitive area turned off to provide maximum spray control.

7. Aerial applications will be designed to deliver a median droplet diameter of 200 to 800 microns to reduce drift.

8. Aerial Spray will be released at the lowest height consistent with pest control and flight safety.

Proposed Application Methods. Pesticides may be applied using several methods, including: (1) High-pressure hydraulic sprayer; (2) hydraulic sprayer with hand-held wand; (3) tractor-pulled spray rig with boom; (4) backpack sprayer; (4) capsule implantation; (5) aerial (helicopter); (6) airblast sprayer; (7) ground-pull granular spreaders; and (8) hand application. For some pesticides, different combinations of pesticide and application method are being proposed to give Tyrrell flexibility in addressing specific management needs that may occur.

Each method is described briefly in the following paragraphs.

High-Pressure Hydraulic Sprayer. High-pressure hydraulic sprayers consist of a powered pump and tank carried by truck or tractor, and hand-held nozzles for dispersing the solution upward into the tree. These sprayers could be used to treat individual mature trees with the insecticides acephate, b.t., dimethoate, potassium salts of fatty acids, chlorpyrifos, diazinon, esfenvalerate, permethrin, horticultural oil, or propargite, or with the fungicide chlorothalonil.

Hydraulic Sprayer with Hand-Held Wand. A spray tank is mounted on a truck, tractor, or all-terrain vehicle (ATV), and may be used to apply herbicides around trees in orchard units, along fence-lines, and as a spot treatment in fallow fields, orchard units, and administrative areas. The sprayer may be operated by one worker, who drives and stops to spray, or by two workers, with one driving and the other spraying. This method may be used to apply the insecticides, esfenvalerate, b.t., potassium salts of fatty acids, the fungicide proiconazole, or the herbicides dicamba, glyphosate, or picloram.

Tractor-Pulled Spray Rig with Boom. This method may be used to apply herbicides for control of weeds in orchard units, in roadways, or in fallow areas. Equipment consists of a hydraulic spray tank pulled by a tractor or heavy-duty pickup truck, with a spray boom attached to the tank to release the herbicide. At Tyrrell, this method may be used to apply the herbicides glyphosate or picloram, or fungicide propiconazole. 
Backpack Sprayer. A backpack sprayer consists of a plastic tank containing the pesticide that is strapped to the applicator's back. A hand-operated hydraulic pump forces the liquid from the tank through a nozzle in a hand-held wand. At Tyrrell, a backpack sprayer could be used to apply the insecticide potassium salts of fatty acids, and the herbicides dicamba, glyphosate, or picloram for treatment of unwanted vegetation in orchard units and along fencelines.

Capsule Implantation. The insecticides acephate and imidacloprid may be implanted into individual trees for long-term control of insect pests in the form of a capsule. One small hole is drilled into a tree for every 4 inches of circumference, and a capsule is inserted.

Aerial Application. A helicopter is equipped with a pesticide tank for aerial application of liquid mixtures. The size and type of helicopter may vary; however, a standard representation of its application equipment is used in the risk assessment, based on the local contractor's current equipment. Aerial methods may be used to apply the insecticides esfenvalerate and B.t. to active seed production units, or to apply fertilizer.

Airblast Sprayer. Airblast sprayers are pulled behind a tractor or a truck. Airblast sprayers use fans or blowers to propel spray mixtures into dense foliage or the tops of trees. The nozzles of airblast sprayers are positioned in the air stream to break up spray droplets and propel them into the tree tops. At Tyrrell, an airblast sprayer may be used to apply the insecticide esfenvalerate to orchard units.

Ground Pull Granular Spreaders. Fertilizers or the granular fumigant dazomet may be distributed over the ground using a spreader pulled by a truck or tractor. After application of the fumigant dazomet, the granules will be incorporated to a depth of 4 to 8 inches, depending on targets to be controlled (e.g., annual weeds, specific soil-borne pathogens).

Hand Application. The fertilizer calcium nitrate may be hand-applied, using a scoop or small hand-crank spreader, to the dripline of trees to stimulate flower production.

Rate/Frequency/Volume and Locations of Applications. The BLM provided application data for each chemical proposed for use at Tyrrell over the proposed five-year term of the consultation. Table 3 details the use data for diazinon, dimethoate, and esfenvalerate, and is included here as an example of data provided for all chemicals in the BA. All of the tables can be viewed within the BA. 
Table 3. Chemical Application Data - Tyrrell

\begin{tabular}{|c|c|c|c|c|c|}
\hline $\begin{array}{l}\text { Application } \\
\text { Method }\end{array}$ & Location & $\begin{array}{l}\text { Typical } \\
\text { Application } \\
\text { Rate and } \\
\text { Area }\end{array}$ & $\begin{array}{l}\text { Max. Label } \\
\text { Application Rate and } \\
\text { Max. Area }\end{array}$ & $\begin{array}{l}\text { Applicat } \\
\text { ion Date } \\
\text { Range }\end{array}$ & $\begin{array}{l}\text { Anticipated } \\
\text { Frequency }\end{array}$ \\
\hline \multicolumn{6}{|c|}{$\begin{array}{l}\text { Diazinon: Diazinon } 50 W(50 \% \text { a.i. as a wettable powder) } \\
\text { Target pests: ants, spiders, moths, aphids, mites, or other serious insect outbreaks in the administrative and landscaping } \\
\text { areas, or in isolated orchard locations when small but serious insect damage needs attention }\end{array}$} \\
\hline $\begin{array}{l}\text { High-pressure } \\
\text { hydraulic sprayer }\end{array}$ & $\begin{array}{l}\text { Individual trees in any } \\
\text { production orchard unit }\end{array}$ & $\begin{array}{l}0.015 \mathrm{lb} \\
\text { a.i./tree, in } \\
\text { water at } 3 \\
\text { gal/tree } \\
1 \text { application } \\
\text { to } 500 \text { trees } \\
\text { on } 10 \text { acres }\end{array}$ & $\begin{array}{l}0.075 \mathrm{lb} \text { a.i./tree, in } \\
\text { water at } 5 \mathrm{gal} / \text { tree } \\
2 \text { application to } 1,000 \\
\text { trees on } 20 \text { acres. }\end{array}$ & $\begin{array}{l}\text { Apr - } \\
\text { Sept }\end{array}$ & $\begin{array}{l}\text { Once every } 3 \\
\text { years }\end{array}$ \\
\hline \multicolumn{6}{|c|}{$\begin{array}{l}\text { Dimethoate: Digon } 400 \text { ( } 43.5 \% \text { a.i. as a liquid concentrate) } \\
\text { Target pests: Douglas-fire cone gall midge }\end{array}$} \\
\hline $\begin{array}{l}\text { High-pressure } \\
\text { hydraulic sprayer }\end{array}$ & $\begin{array}{l}\text { Individual trees in any } \\
\text { orchard unit }\end{array}$ & $\begin{array}{l}0.13 \mathrm{lb} \\
\text { a.i./tree, in } \\
\text { water at } 2 \\
\text { gal/tree } \\
1 \text { application } \\
\text { to } 80 \text { acres }\end{array}$ & $\begin{array}{l}0.34 \mathrm{lb} \text { a.i./tree, in } \\
\text { water at } 4 \mathrm{gal} / \text { tree } \\
2 \text { applications to } 135 \\
\text { acres }\end{array}$ & $\begin{array}{l}\text { Apr - } \\
\text { Jun }\end{array}$ & Every 3 years \\
\hline \multicolumn{6}{|c|}{$\begin{array}{l}\text { Esfenvalerate: Asana }{ }^{\circledR} \text { XL ( } 8.4 \% \text { a.i. as an emulsifiable concentrate) } \\
\text { Target pests: Douglas-fir cone worm, western conifer seed bug, Douglas-fir seed chalcid, Douglas-fir cone moth, Douglas- } \\
\text { fir cone gall midge }\end{array}$} \\
\hline Aerial (helicopter) & Seed production units & $\begin{array}{l}0.19 \mathrm{lb} \\
\text { a.i./tree, in } \\
\text { water at } 10 \\
\text { gal/acre } \\
1 \text { or } 2 \\
\text { applications } \\
\text { to } 80 \text { acres }\end{array}$ & $\begin{array}{l}0.19 \mathrm{lb} \text { a.i./tree, in } \\
\text { water at } 10 \mathrm{gal} / \text { acre } \\
2 \text { applications to } 80 \\
\text { acres }\end{array}$ & & \\
\hline Airblast sprayer & Seed production units & $\begin{array}{l}0.05 \mathrm{lb} \\
\text { a.i./acre, in } \\
\text { water at } 100 \\
\text { gal/acre } \\
1 \text { or } 2 \\
\text { applications } \\
\text { to } 80 \text { acres }\end{array}$ & $\begin{array}{l}0.088 \mathrm{lb} / \mathrm{a} . \mathrm{i} . / \mathrm{acre}, \text { in } \\
\text { water at } 175 \mathrm{gal} / \mathrm{acre} \\
3 \text { application to } 135 \\
\text { acres }\end{array}$ & $\begin{array}{l}\text { Mar - } \\
\text { Aug }\end{array}$ & $\begin{array}{l}\text { Annually, } \\
\text { rotating among } \\
\text { orchard units }\end{array}$ \\
\hline
\end{tabular}




\begin{tabular}{|l|l|l|l|l|l|}
\hline $\begin{array}{l}\text { Application } \\
\text { Method }\end{array}$ & Location & $\begin{array}{l}\text { Typical } \\
\text { Application } \\
\text { Rate and } \\
\text { Area }\end{array}$ & $\begin{array}{l}\text { Max. Label } \\
\text { Application Rate and } \\
\text { Max. Area }\end{array}$ & $\begin{array}{l}\text { Applicat } \\
\text { ion Date } \\
\text { Range }\end{array}$ & $\begin{array}{l}\text { Anticipated } \\
\text { Frequency }\end{array}$ \\
\hline $\begin{array}{l}\text { High Pressure } \\
\text { hydraulic sprayer - } \\
\text { or-hydraulic } \\
\text { sprayer with hand- } \\
\text { held wand }\end{array}$ & $\begin{array}{l}\text { individual trees in any } \\
\text { orchard }\end{array}$ & $\begin{array}{l}0.001 \mathrm{lb} \\
\text { a.i./tree, in } \\
\text { water at } 2 \\
\text { gal/tree } \\
\text { or 2 } \\
\text { application to } \\
2,000 \text { trees on } \\
40 \text { acres }\end{array}$ & $\begin{array}{l}\text { Cumulative maximum } \\
+1.6 \text { lb a.i./acre per } \\
\text { year } \\
\text { water at } 4 \text { gal/tree } \\
3 \text { application to } 5,000 \\
\text { trees on } 100 \text { acres }\end{array}$ & & \\
\hline
\end{tabular}

Table 4 lists the proposed no-application buffers at Tyrrell.

Table 4. BLM Tyrrell Proposed Minimum No-Application Buffers

\begin{tabular}{|c|c|c|}
\hline Chemical & Application Method & Minimum Stream Buffer ( $\mathrm{ft}$ ) \\
\hline $\begin{array}{l}\text { B.t. } \\
\text { Esfenvalerate }\end{array}$ & Aerial & 200 \\
\hline Esfenvalerate & Airblast Sprayer & 200 \\
\hline $\begin{array}{l}\text { Acephate } \\
\text { B.t. } \\
\text { Chlorothalonil } \\
\text { Chlorpyrifos } \\
\text { Diazinon } \\
\text { Dimethoate } \\
\text { Esfenvalerate } \\
\text { Horticultural oil } \\
\text { Permethrin } \\
\text { Potassium salts of fatty acids } \\
\text { Propargite }\end{array}$ & High-pressure hydraulic sprayer & 200 \\
\hline $\begin{array}{l}\text { Glyphosate } \\
\text { Propiconazole } \\
\text { Picloram }\end{array}$ & Tractor-pulled spray rig with boom & 40 \\
\hline $\begin{array}{l}\text { B.t. } \\
\text { Propiconazole } \\
\text { Dicamba } \\
\text { Esfenvalerate } \\
\text { Glyphosate } \\
\text { Picloram } \\
\text { Potassium salts of fatty acids }\end{array}$ & $\begin{array}{l}\text { Hydraulic sprayer with handheld } \\
\text { wand }\end{array}$ & 40 \\
\hline
\end{tabular}




\begin{tabular}{|l|l|l|}
\hline Chemical & Application Method & Minimum Stream Buffer (ft) \\
\hline $\begin{array}{l}\text { Dicamba } \\
\text { Glyphosate } \\
\text { Picloram } \\
\text { Potassium salts of fatty acids }\end{array}$ & Backpack sprayer & 40 \\
\hline $\begin{array}{l}\text { Acephate } \\
\text { Imidacloprid }\end{array}$ & Capsule implantation & 40 \\
\hline
\end{tabular}

The BLM has proposed that these buffer widths be adjusted over time in relation to monitoring results.

\section{Annual Monitoring and Reporting Requirements}

The BLM has proposed a methodology for water quality monitoring whenever a pesticide or fertilizer covered under the BA is proposed for use. The plan covers four types of monitoring: (1) Implementation monitoring, (2) effectiveness monitoring, (3) validation monitoring, and (4) compliance monitoring.

The overall objective of the monitoring program at Tyrrell is to document the impacts of IPM actions on water quality, and to use this information to continue or modify the protection measures needed to meet the requirements for a healthy aquatic ecosystem. A full assessment of protection measures used in Tyrrell requires monitoring both groundwater and surface water.

Implementation Monitoring. All pesticide and fertilizer applications would be documented by the orchard manager or designated representative. Items to be documented include type of chemical applied, date of application, method of application, area treated, amount applied, precipitation for the three days preceding and following application, location used for mixing and loading, wind direction and speed for aerial or airblast applications, relative humidity, air temperature, and notes regarding whether any leakage or spills occurred. A list of all protection measures and limitations for each unit applied would be provided in an Annual Tyrrell Seed Orchard Monitoring Report.

\section{Monitoring of Effectiveness of CPs.}

Drift Card Monitoring. All orchard units beside flowing streams and planned for aerial, airblast, high-pressure hydraulic sprayer applications, and select hand-held spray applications of chemicals would have spray cards placed, so that drift from the application can be captured and characterized. Where the application unit is in direct proximity to a flowing stream, cards would be placed at a maximum of 200-foot intervals along the edge of the unit before the application. Where open canopy occurs in the stream buffer, drift cards would be selectively placed to characterize potential intrusion of drift toward channels. Immediately after the application, the cards would be collected and reviewed to determine if a drift signature is present, the extent of the drift, and the potential for aquatic contamination. A copy of all the cards would be kept on file at Tyrrell along with a record of their location and all the compliance monitoring documentation. 
Surface Water Monitoring. For aerial, airblast, high-pressure hydraulic sprayer, and select hand-held spray applications of chemicals, water samples would be taken in streams before and after spray application as per ODF (1997) protocols and site-specific "time of concentration" measurements. Selection of sampling stations for surface water sampling would be based on the proximity to application areas. For aerial spray treatments, samples would also be collected above and below helicopter corridors in cases where the helicopter crosses a stream to access orchard spray units.

Per state protocols (ODF 1997), where applicable, samples would be taken within 24 hours before application and at 15 minutes, 2 hours, 4 hours, 8 hours, and 24 hours after the first swath has been sprayed parallel to the stream of concern. The time of collection would be based on the time of concentration measurements in the flowing channels associated with the treatment areas. A 24-hour concentration would be determined by either a series of composite samples taken through the use of a continuous pumping sampler or by a formula depicted in ODF (1997). These data would provide a 24-hour concentration to compare with the ODF calculation, water quality criteria, and literature studies.

All data would be used in conjunction with the spray cards to determine the effectiveness of the full suite of protective measures and limitations implemented to avoid drift. Samples would be analyzed at a state-certified laboratory that has detection limits of 0.02 parts per billion (ppb) for most of the potential pesticides. Samples would be collected in accordance with laboratory instructions. When sites are sampled, additional interpretive data, such as $\mathrm{pH}$, specific conductance, turbidity, temperature, or suspended sediment may also be collected. At the discretion of the fish biologist, stream reaches may be visually inspected after application.

Surface Runoff. Pesticide and fertilizer fate modeling from the risk assessment indicates that field runoff events within the first six months after spray application have the highest probability for carrying detectible concentrations of chemicals. One study (Rashin and Graber 1993) determined that runoff events within the first 72 hours of application were the most important in terms of increases in detectible chemical concentrations. Effectiveness monitoring of protection measures in the proposed action would target those periods of precipitation that could result in field surface runoff and increased stream flow. These periods are most likely to carry the greatest detectible concentrations of pesticides or fertilizers.

Previous rates of surface runoff and predicted concentrations at the Horning Seed Orchard have been shown to be significantly lower than the literature and model predictions for the soils and climate at the orchard (BLM 2002). Under this plan, similar investigations would be conducted at Tyrrell.

Perennially-flowing Streams $8,11,12,13$, and 25 would be equipped with continuous flow recording devices. Flow-weighted water and sediment samples would be collected with the intention of providing individual storm concentrations for multiple runoff events. Other sampling designs would be employed if and where appropriate. Operation of these stations would target streams affected by application. The data from these stations would be used to 
characterize runoff response and to represent water quality conditions as a result of the effectiveness of implemented protective measures and limitations in the higher-risk seed production orchards.

Semi-permeable membrane devices (SPMDs) may be used in addition to, or in lieu of, flowweighted sampling, particularly when there are concerns about sublethal concentrations below the laboratory detection limit. SPMDs could be used to 'accumulate' pesticides to detect levels that would otherwise be undetectable by traditional water sampling. Details regarding SPMDs are provided in the Cumulative Effects Runoff discussion below.

Stream 54 is an important non-perennial stream. Depending on the type of and location of application, it would either be monitored individually, like Streams 8, 11, 12, 13, and 25; or a site on Stream 8 would be used to characterize potential runoff from both Streams 8 and 54 .

All data would be used in conjunction with continuous recorded climate data to assess the effectiveness of protection measures and limitations in minimizing introduction of pesticides and fertilizers to the aquatic system. Samples would be analyzed at a state-certified laboratory that has detection limits of $0.02 \mathrm{ppb}$ for most of the potential pesticides. Samples would be collected in accordance with laboratory instructions.

Cumulative Concentrations Runoff. SPMDs would be deployed, as appropriate, in Streams $8,11,12,13$, and 25 to monitor the accumulation of pesticides in reaches containing aquatic species. The SPMD is an instream 'accumulator' which allows calculation of an average chemical concentration during the period of deployment. For this reason, the SPMDs would only be deployed during the initial winter storm and spring storm periods after pesticide application.

Streamflow measurement sites in Streams 8, 11, 12, 13, and 25 would provide flow data for deriving concentrations (chemical loading) over the period of time the SPMD is deployed. Operation of these stations and associated SPMD units would target streams affected by applications. Data from the SPMD concentrations would be used to compare and validate the storm flow concentration monitored during the deployment period. Since previous monitoring at the Horning Seed Orchard documented no detection of esfenvalerate at $0.02 \mathrm{ppb}$ for all storm flow monitoring, the SPMD would serve as a better indicator of a 'low concentration' presence of the pesticide and provide documentation of beneficial use exposure over time.

Depending on the type and location of application, Stream 54 would either be monitored individually, like Streams $8,11,12,13$, and 25, or the site on Stream 8 would be used to characterize potential runoff from both Streams 8 and 54 .

Monitoring Related to Modeled Concentrations. Validation monitoring is intended to verify the water quality modeling predictions presented in the EIS. Monitoring the stream systems will identify the effectiveness of protection measures, and to help to gauge the estimates in the RA. 
Collection chambers will be installed in areas where there are concerns regarding overland flow. During the first overland flow event following select chemical applications, these sites will be visited, and a water sample taken from the collection chamber. Once the first surface runoff event is captured and results become available, the need to sample later runoff events will be determined based on concentrations detected. In the short term, these data will be used to assess the mobility of chemicals with high aquatic toxicity. Additional validation utilizing field- and climate-specific data to validate risk assessment estimates will occur in selected cases, such as higher risk application areas, where validation findings could lead to improved protection measures, or if unusual weather conditions prevailed. Stream concentrations gathered from Streams $8,11,12,13$, and 25 will be compared to model results using actual application information, field-specific data, and continuous climate record. Concentrations will be compared with modeled results utilizing field- and climate-specific data to validate RA estimates.

Stream concentrations will also be compared to model results using actual application information, field-specific data, and continuous climate record. These data will provide a relationship between previous monitoring results and the management that is planned for the future. Once the yearly application period is complete, the climate record collected during that period will be used to model a predicted concentration using the Groundwater Loading Effects of Agricultural Management Systems (GLEAMS) ${ }^{3}$ and Method of Characteristics (MOC) ${ }^{4}$ models. These concentrations will be 'diluted' using the continuous flow data from the station. The resulting concentrations will be compared with the actual measured concentrations for each storm event sampled.

\section{Compliance Monitoring.}

Spill Monitoring. In the event of a chemical spill, the volume of spill, proximity to water, and chemical characteristics, such as toxicity and mobility, will be evaluated to determine if water sampling is desirable and necessary. If so, water samples may be collected in a sufficient number and at surface water and groundwater locations that will allow characterization of impacts and effective remediation methods. At a minimum, sampling will be conducted in the streams draining the spill area and the immediate groundwater table. The Tyrrell domestic well will be sampled if in proximity to spill.

A spill prevention plan will be developed before any pesticide applications, and be part of Tyrrell's Pesticide Safety Plan. The spill prevention plan will minimize or eliminate the risk of a pesticide spill for any pesticide operation. Tyrrell will develop a model or general pesticide spill

${ }^{3}$ The GLEAMS model, developed by the USDA Agricultural Research Service, is a computerized mathematical model developed for field-sized areas to evaluate the movement and degradation of chemicals within the plant root zone under various crop management systems. The model has been tested and validated using a variety of data on pesticide movement. A more detailed discussion of the GLEAMS model can be found in the Tyrrell RA Sec 3-13.

${ }^{4}$ MOC is a two-dimensional groundwater flow and chemical transport model, developed by the U.S. Geological Survey and is designed to account for the attenuating affect of buffer zones. 
plan which will address concerns and identify such factors as: (1) Critical sites where spills will likely occur, such as narrow road or stream/waterway crossings, soft soil or roadway areas, and rough roads; (2) mechanical or operational requirements, such as tire tread to reduce blowouts, speed limits at critical roadway curves or other areas, and quantity carrying capacity of tanks/vehicles at safe levels to prevent roll-overs and sloshing; (3) environmental restrictions, such as rainfall limits and standing water limits; and (4) approved mixing sites.

At the operational level, the plan will include specific routes of the equipment, load limits for equipment, allowable speeds on the routes, mixing site limits in quantities, chemical types, or spill potential.

Annual Reporting. All water quality monitoring information associated with application of the Tyrrell Seed Orchards IPM program will be compiled, analyzed, documented, and reviewed on a 'water year' basis. This 'water year' will include all monitoring performed during the October 1 to September 30 period. This information, along with any recommendation for adjustments to protection measures and adjustments to the monitoring plan, will be contained in an Annual Tyrrell Monitoring Report. This report will be available to the public and regulatory agencies on November 15 of each year and be on file at Tyrrell. BLM will request that NMFS' review of this Plan be completed by January 15 of the following year. This schedule will provide for timely inclusion of monitoring results in the Annual Operating Report and inclusion of the full period of runoff during the fall/winter period and planning for the upcoming budget year.

\section{Framework for Multi-Year Consultation}

In light of the dynamic nature of new scientific data, parallel section 7 consultations with EPA, and legal actions and decisions regarding pesticides summarized above, the BLM included within the proposed action a methodology to facilitate multi-year consultation on the proposed project, as necessary, using the following process:

1. The BLM will submit an Annual Operation Report to NMFS with the following information:

a. A description of pesticide applications conducted over the reporting period.

b. The results of the previous year monitoring program.

c. A literature review of the pesticides that are proposed for use at Tyrrell the following year. There may be a single review covering pesticides proposed at all four seed orchards. The review will include new scientific data regarding nontarget fish species effects or environmental fate, changes to EPA-approved labels, and legal findings relevant to the use of the pesticides. Any new data will be considered in terms of effects on seed orchard use as proposed in the BA and on the conclusions of the EIS RA.

d. A plan for proposed pesticide applications for the following year, including, units or acres to be treated, proposed pesticide, application rate and method, dates, and 
a proposed monitoring plan covering the locations and pesticides to be monitored. This plan will note that it may be possible for the seed orchard manager to schedule some applications, such as roadside vegetation management or insecticides for cone and seed insects in units that will be harvested to meet specific seed needs, in advance, and they will be fully described. However, the seed orchard manager will have the flexibility to use any of the applications as described in Table $3-1$ of the BA, to respond to unforeseen pest management needs (for example, detection of disease or an insect infestation).

e. Any proposed changes to the selected alternative as described in the EIS and Record of Decision (ROD), including new limitations, protection measures, or mitigation measures as part of an adaptive management approach; the use of pesticides in addition to those listed in Table 3-1; or other relevant information.

2. A new BA providing an updated effects analysis will be submitted to NMFS with the Annual Operation Report if the literature review:

a. Identifies new scientific data or labeling details indicating additional possible effects to listed species.

b. Identifies proposed changes to the selected alternative as described in the EIS and ROD.

c. Determines that monitoring data following pesticide applications indicate that effects are greater than anticipated.

\section{Approach to Finding New Information on Chemicals Proposed for Use at Tyrrell.}

Before the analysis phase begins, the BLM will identify the relevant technical literature for the pesticide or pesticides in question. The ESA requires that Federal agencies use the best scientific and commercial data available [50 C.F.R. 402. 14(d)]. This section provides an overview of search and acquisition strategies that will be used to identify peer-reviewed data and other forms of scientific evidence that are relevant to Pacific salmon and steelhead.

Online Scientific Databases. The literature search for each active ingredient, as well as inert ingredients, adjuvants, surfactants and degradates will include keyword-based queries of several scientific databases. In addition to EPA's ECOTOX database, the targeted databases will include Aquatic Sciences and Fisheries Abstracts, Medline, Web of Science, AGRICOLA, Chem Abstracts, and BIOSIS. The searches will also be supplemented with literature abstracting databases including Toxline, Toxnet, and Current Contents: Agriculture, Biology, and Environmental Sciences.

Keywords. Scientific databases will be searched with keywords that are specific to fish or known invertebrate prey species for salmon or steelhead. ${ }^{5}$

${ }^{5}$ For fish, all keywords, or an appropriate subset, will include salmonid, Chinook salmon, coho salmon, steelhead salmon, chum salmon, sockeye salmon, pink salmon, Atlantic salmon, cutthroat trout, bull trout, rainbow trout, char, Oncorhynchus mykiss, O. tshawytcha, O. kisutch, O. nerka, O. gorbuscha, O. clarkii, Salmo, Salvelinus, alevin, fry, parr, smolt, 
Paper-Based Searches. Paper-based searches of bibliographies, guidance documents, modeling studies, and review articles will be conducted to identify primary sources of relevant scientific information. In addition, data provided in support of pesticide registrations will be considered.

Other Actions Not Covered Under the BA. Herbicide use for competing vegetation (non-noxious applications) are not covered in this Opinion.

\section{Action Area}

'Action area' means all areas to be affected directly or indirectly by the Federal action and not merely the immediate area involved in the action (50 C.F.R. 402.02). For purposes of this consultation, the action area begins within the drainages (ephemeral and perennial) within, and downstream from, the orchard, including OC coho-bearing Douglas Creek, Stream 8, and Stream 1 as they drain into the Siuslaw River. The downstream portion of the action area extends into the Siuslaw River estuary.

The action area is used by OC coho salmon for all life history stages, and is designated as critical habitat. The project area is also designated as EFH for Pacific Coast salmon (PFMC 1999), or is in an area where environmental effects of the proposed project may adversely affect designated EFH for those species.

\section{ENDANGERED SPECIES ACT}

The ESA establishes a national program for conserving threatened and endangered species of fish, wildlife, plants, and the habitat on which they depend. Section 7(a)(2) of the ESA requires Federal agencies to consult with USFWS and NMFS, as appropriate, to ensure that their actions are not likely to jeopardize the continued existence of endangered or threatened species or adversely modify or destroy their designated critical habitats.

Section 9(a)(1) and protective regulations adopted pursuant to section 4(d) of the ESA prohibit the 'taking' of listed species without a specific permit or exemption. Among other things, an action that harasses, wounds, or kills an individual of a listed species or harms a species by altering habitat in a way that significantly impairs its essential behavioral patterns is a taking (50 C.F.R. 222.102). 'Incidental take' refers to takings that result from, but are not the purpose of, carrying out an otherwise lawful activity conducted by the Federal agency or

and fish. For potential impacts to invertebrate prey species, all keywords, or an appropriate subset, will include chironomid, mayfly, stonefly, copepod, amphipod, mysid, cladoceran, Chironimidae, Simuliidae, Ephemeroptera, Plecoptera, Neoptera, Trichoptera, Copepoda, Diptera, Gammaridae, Daphnia. For potential impacts on primary production in aquatic systems, all keywords, or an appropriate subset, will include algae, diatom, periphyton, Chlorella, and Selenastrum. Additional keywords may be used as appropriate. For each pesticide, the active ingredient, inert ingredient(s), adjuvant, surfactant, degradate(s), product name(s), and Chemical Abstract Registry Number (CAS RN) will be used in the database search. 
applicant (50 C.F.R. 402.02). Section 7(o)(2) exempts any taking that meets the terms and conditions of a written incidental take statement from the taking prohibition.

\section{Conference Opinion}

This Opinion presents NMFS' review of the status of each evolutionary significant unit (ESU) ${ }^{6}$ considered in this consultation and critical habitat, the environmental baseline for the action area, all the effects of the action as proposed, and cumulative effects. An analysis of those combined factors is used to conclude whether the proposed action is likely to appreciably reduce the likelihood of both the survival and recovery of the affected ESUs, or is likely to destroy or adversely modify designated critical habitat (50 C.F.R. 402.14(g)). If the action under consultation is likely to jeopardize an ESU, or destroy or adversely modify designated critical habitat, NMFS must identify any reasonable and prudent alternatives for the action that avoid jeopardy or destruction or adverse modification of critical habitat and meet other regulatory requirements (50 C.F.R. 402.02).

In September 2001, in the case Alsea Valley Alliance v. Evans, U.S. District Court Judge Michael Hogan struck down the 1998 ESA listing of Oregon Coast (OC) coho salmon and remanded the listing decision to NMFS for further consideration. In November 2001, the Oregon Natural Resources Council appealed the District Court's ruling. Pending resolution of the appeal, in December 2001, the Ninth Circuit Court of Appeals stayed the District Court's order that voided the OC coho listing. While the stay was in place, the OC coho ESU was again afforded the protections of the ESA.

On February 24, 2004, the Ninth Circuit dismissed the appeal in Alsea. On June 15, 2004, the Ninth Circuit returned the case to Judge Hogan and ended its stay. Judge Hogan's order invalidating the $\mathrm{OC}$ coho listing is back in force. Accordingly, OC coho are now not listed, and ESA provisions for listed species, such as the consultation requirement and take prohibitions, do not apply to OC coho.

In response to the Alsea ruling, NMFS released its revised policy for considering hatchery stocks when making listing decisions on June 3, 2004 (69 FR 31354). NMFS completed a new review of the biological status of OC coho salmon, and applying the new hatchery listing policy, proposed to list OC coho salmon as a threatened species on June 14, 2004 (69 FR 33102). NMFS must make a final decision on the proposed OC coho salmon listing by June 14, 2005.

Life history of OC coho salmon are represented in Table 6. Spawning, incubation, rearing, and migration occur throughout accessible reaches of the watershed.

6 'ESU' means an anadromous salmon or steelhead population that is either listed or being considered for listing under the ESA, is substantially isolated reproductively from conspecific populations, and represents an important component of the evolutionary legacy of the species (Waples 1991). An ESU may include portions or combinations of populations more commonly defined as stocks within or across regions. 


\section{Status of the ESUs}

This section defines range-wide biological requirements of each ESU, and reviews the status of the ESUs relative to those requirements. The present risk faced by each ESU informs NMFS' determination as to whether additional risk would 'appreciably reduce' the likelihood of both survival and recovery in the wild. The greater the present risk, the more likely any additional risk resulting from the proposed action's effects on the population size, trend (growth rate), distribution, and genetic diversity of the listed species would be an appreciable reduction (McElhaney et al. 2000).

Coho Salmon. Coho salmon is a widespread species of Pacific salmon, occurring in most major river basins around the Pacific Rim from Monterey Bay in California, north to Point Hope, Alaska, through the Aleutians, and from Anadyr River south to Korea and northern Hokkaido, Japan (Laufle et al. 1986). From central British Columbia south, the vast majority of coho salmon adults are 3-year-olds, having spent approximately 18 months in freshwater and 18 months in saltwater (Gilbert 1912, Pritchard 1940, Sandercock 1991). The primary exceptions to this pattern are "jacks," sexually mature males that return to freshwater to spawn after only 5 to 7 months in the ocean. However, in southeast and central Alaska, the majority of coho salmon adults are 4-year-olds, having spent an additional year in freshwater before going to sea (Godfrey et al. 1975, Crone and Bond 1976). The transition zone between predominantly 3year-old and 4-year-old adults occurs somewhere between central British Columbia and southeast Alaska.

With the exception of spawning habitat, which consists of small streams with stable gravels, summer and winter freshwater habitats most preferred by coho salmon consist of quiet areas with low flow, such as backwater pools, beaver ponds, dam pools, and side channels (Reeves et al. 1989). Habitats used during winter generally have greater water depth than those used in summer, and also have greater amounts of large woody debris. West Coast coho smolts typically leave freshwater in the spring (April to June) and re-enter freshwater when sexually mature from September to November and spawn from November to December and occasionally into January (Sandercock 1991). Stocks from British Columbia, Washington, and the Columbia River often have very early (entering rivers in July or August) or late (spawning into March) runs in addition to "normally" timed runs.

The status of coho salmon for purposes of ESA listings has been reviewed many times, beginning in 1990. The first two reviews occurred in response to petitions to list coho salmon in the Lower Columbia River and Scott and Waddell Creeks (central California) under the ESA. The conclusions of these reviews were that NMFS could not identify any populations that warranted protection under the ESA in the Lower Columbia River (Johnson et al. 1991), and that Scott and Waddell Creeks' populations were part of a larger, undescribed ESU (Bryant 1994).

A review of West Coast (Washington, Oregon, and California) coho salmon populations began in 1993 in response to several petitions to list numerous coho salmon populations and NMFS' own initiative to conduct a coastwide status review of the species. This coastwide review 
identified six coho salmon ESUs, of which the three southern-most were proposed for listing, two were candidates for listing, and one was deemed "not warranted" for listing (Weitkamp et al. 1995). In October 1996, the BRT updated the status review for the Central California (CC) ESU, and concluded that it was at risk of extinction (NMFS 1996a). In October 1996, NMFS listed this ESU as threatened on May 6, 1997 (62 FR 24588); protective regulations were applied on July 18, 1997 (62 FR 68479), and critical habitat was designated on May 5, 1999 (64 FR 24049).

In December 1996, the BRT updated the status review update for both proposed and candidate coho salmon ESUs (NMFS 1996b). However, because of the scale of the review, comanagers' requests for additional time to comment on the preliminary conclusions, and NMFS' legal obligations, the status review was finalized for proposed coho salmon ESUs in 1997 (NMFS 1997), but not for candidate ESUs. In May 1997, NMFS listed the Southern Oregon/Northern California coasts (SONC) coho ESU as threatened, while it announced that listing of the OC coho ESU was not warranted due to measures in the OCSRI plan. This finding for OC coho salmon was overturned in August 1998, and the ESU listed as threatened.

The process of updating the coho salmon status review was begun again in October 1998, for coho salmon in Washington and the Lower Columbia River. However, this effort was terminated before the BRT could meet, due to competing activities with higher priorities.

In response to a petition by Oregon Trout et al. (2000), the status of Lower Columbia River (LCR) coho salmon was revisited in 2000, with BRT meetings held in March and May 2001 (NMFS 2001a). The BRT concluded that splitting the LCR/Southwest Washington coast ESU to form separate LCR and Southwest Washington coast coho salmon ESUs was most consistent with available information and the LCR ESU was at risk of extinction. Like the 1996 status review update, these results were never finalized.

The coho salmon BRT met in January, March, and April 2003, to discuss new data received and to determine if the new information warranted any modification of the conclusions of the original BRTs.

Oregon Coast (OC) Coho Salmon. The status and relevant biological information concerning OC coho salmon are well described in the proposed and final rules from the Federal Register (60 FR 38011, July 25, 1995; and 63 FR 42587, August 10, 1998, respectively), and Weitkamp et al. (1995). Estimated escapement of coho salmon in coastal Oregon was about 1.4 million fish in the early 1900s, with harvest of nearly 400,000 fish (Weitkamp et al. 1995). Abundance of wild OC coho salmon declined during the period from about 1965 to 1975 (Nickelson et al. 1992). Lichatowich (1989) concluded that production potential for OC coho salmon in coastal Oregon rivers, based on stock recruit models, was only about 800,000 fish due to a decline with a reduction in habitat capacity of nearly $50 \%$. Recent estimates of wild spawner abundance in this evolutionarily significant unit (ESU) have ranged from 16,500 adults in 1990 , to 60,000 adults in 1996 , and nearly 238,700 adult coho in 2002 (ODFW 2003). 
Abundance of wild coho salmon spawners in Oregon coastal streams declined during the period from about 1965 to roughly 1975, and has fluctuated at a low level since that time (Nickelson et al. 1992). Despite better-observed spawning escapements in 2001, population trends remain low (Table 5). Contemporary production of coho salmon may be less than $10 \%$ of the historic production (Nickelson et al. 1992). Average spawner abundance has been relatively constant since the late 1970s, but preharvest abundance has declined. Average recruits-per-spawner may also be declining.

The bulk of production for the OC coho salmon ESU is skewed to its southern portion, where the coastal lake systems (e.g., Tenmile, Tahkenitch, and Siltcoos Basins) and the Coos and Coquille Rivers are more productive. Siuslaw River coho salmon populations have been characterized as depressed (e.g., spawning habitat underseeded, declining trends, or recent escapements below long-term average) and at moderate risk of extinction (Weitkamp et al. 1995).

The Siuslaw River Basin has approximately 514 miles of coho salmon spawning habitat (Hollen et al. 1998), and coho salmon abundance in the basin is approximately $2 \%$ of historic levels. A recent estimate of average annual wild coho salmon spawner abundance is 4,441 spawners $(n=12)$ with a range of 668 spawners (1997) to 11,024 spawners (2001) (ODFW 2001, ODFW 2002) (Table 5). Historic coho salmon runs were estimated to be approximately 209,000 adults (circa 1890) (EcoTrust 2002). Estimates of historic coho salmon production indicate that the Siuslaw River Basin $\left(562 \mathrm{coho} / \mathrm{mi}^{2}\right)$ was twice as productive as the nearby Yaquina (204 coho/mi ${ }^{2}$ ) and Alsea (261 coho/mi ${ }^{2}$ ) River Basins (EcoTrust 2002).

Based on survey data collected by ODFW, estimated densities of juvenile OC coho salmon in the Siuslaw River Basin range from 0.00 fish $\mathrm{m}^{2}$ to 1.76 fish $\mathrm{m}^{2}$. Juvenile $\mathrm{OC}$ coho salmon rear year-round and migrate in the mainstem and tributaries of the Siuslaw River. Estimated spawning populations for naturally-produced coho salmon in the Siuslaw River Basin averaged 8,533 adults from 1990 through 2002 . These results are summarized in Table 5. 
Table 5. Estimated Spawning Populations for Naturally-Produced Coho Salmon in the Siuslaw River Basin (population information source: ODFW 2001, 2002)

\begin{tabular}{|c|c|c|c|}
\hline \multirow[b]{3}{*}{ Year } & \multicolumn{3}{|c|}{ Estimated Wild Coho Population } \\
\hline & \multicolumn{2}{|c|}{ Siuslaw River Basin } & \multirow{2}{*}{$\frac{O C E S U}{\text { Number of fist }}$} \\
\hline & Number of fish & Calc. \% of ESU & \\
\hline 1990 & 2,685 & 16 & 16,510 \\
\hline 1991 & 3,740 & 13 & 29,078 \\
\hline 1992 & 3,440 & 9 & 38,604 \\
\hline 1993 & 4,428 & 10 & 44,266 \\
\hline 1994 & 3,205 & 9 & 37,477 \\
\hline 1995 & 6,089 & 15 & 41,303 \\
\hline 1996 & 7,625 & 13 & 59,453 \\
\hline 1997 & 668 & 5 & 14,068 \\
\hline 1998 & 1,089 & 5 & 19,816 \\
\hline 1999 & 2,724 & 8 & 34,646 \\
\hline $2000 *$ & 6,571 & 12 & 52,678 \\
\hline $2001^{*}$ & 11,024 & 7 & 149,058 \\
\hline Average & 4,441 & 10 & 44,746 \\
\hline
\end{tabular}

* Figures are preliminary.

Coho Salmon Habitat Use in the Action Area. In the project area, coho salmon are found in Douglas Creek and in two unnamed tributaries referred to as Stream 8 and Stream 1 in the $\mathrm{BA}$.

Coho salmon in Stream 8 are found approximately 500 feet below the proposed spray unit at the Road 20-5-16 culvert, which is a barrier to fish passage. The BLM has indicated that historically, coho salmon presence likely extended upstream from the culvert for approximately 700 feet to a waterfall that is a natural barrier to any upstream movement of fish.

In Stream 1 below the Siuslaw River Road, sculpin were the only fish found, although the BLM (2004) states that habitat appears suitable for coho salmon use.

Within the action area, the coho salmon population is depressed and habitat is underseeded. Coho salmon typically spawn in the streams associated with the Tyrrell Orchard in December, and fry will be expected to emerge before or about the time of some of the proposed chemical applications, depending on water temperatures.

Table 6 illustrates coho habitat use by life-stage in the action area. 
Table 6. OC coho Salmon Life History Timing in the Siuslaw River Basin (Weitkamp 1995, Steelquist 1992, ODFW 2002). Light Shading Represents Low-Level Abundance, Dark Shading Represents Peak Abundance.

\begin{tabular}{|c|c|c|c|c|c|c|c|c|c|c|c|c|}
\hline \multirow[b]{2}{*}{ Life History Event } & \multicolumn{12}{|c|}{ Calendar Year (month) } \\
\hline & $\mathrm{J}$ & $\mathrm{F}$ & M & A & M & $\mathrm{J}$ & $\mathrm{J}$ & A & $\mathrm{s}$ & o & $\mathrm{N}$ & $\mathrm{D}$ \\
\hline \multicolumn{13}{|l|}{ River Entry } \\
\hline \multicolumn{13}{|l|}{ Spawning } \\
\hline \multicolumn{13}{|l|}{ Intragravel Development } \\
\hline \multicolumn{13}{|l|}{ Juvenile Rearing } \\
\hline Juvenile Out-migration & & & & & & & & & & & & \\
\hline
\end{tabular}

A watershed assessment (EcoTrust 2002) describes coho salmon use in the Siuslaw Basin:

Coho are found in all but the smallest headwater tributaries within the basin. They are also absent from the mainstem Siuslaw river and mainstems of major tributaries during the hot summer months.

Coho salmon and steelhead trout are the two most depressed salmonids in the Siuslaw Basin. Both these species reside spatially in similar sized streams (however they differ in their preferred habitat). They both typically live for over a year in freshwater. The majority of Chinook salmon reside in freshwater for only a few months in the spring, then head to the estuary. This suggests that the existing freshwater habitat (below the headwater reaches inhabited by cutthroat) is likely not in good condition for summer and winter rearing. This thesis is corroborated by the fact that habitat surveys for these reaches note mostly poor quality.

Timing of adult coho salmon river entry is largely influenced by river flow. Coho salmon normally wait for freshets before entering rivers. In the Siuslaw River Watershed, adults are believed to typically enter the river between September and mid-January, ${ }^{7}$ with peak migration into the Siuslaw River occurring in October (Mullen 1981, as cited in Weitkamp et al. 1995). Spawning occurs from late October to late January, with peak spawning generally occurring in mid-December (Weitkamp et al. 1995). Intragravel residency (egg to fry) varies greatly between basins and reaches, and is largely dependent on substrate composition and water temperature (Groot and Margolis 1991). No specific information is available on intragravel residence timing in the Siuslaw River Watershed. However, a study done in Oregon coastal streams found an average incubation period of 110 days, with emergence typically occurring two to three weeks following hatch (Groot and Margolis 1991). This suggests a four- to five-month intragravel residency period. Seaward migration of juveniles occurs during the spring. Reports of

${ }^{7}$ Tami Wagner, ODFW, personal communication via telephone with R. Markle, February 6, 2001. 
outmigration timing vary from February through June (Rodgers et al. 1993, as cited in Weitkamp et al. 1995) to March into early July.?

\section{Environmental Baseline}

The 'environmental baseline' includes the past and present impacts of all Federal, state, or private actions and other human activities in the action area, the anticipated impacts of all proposed Federal projects in the action area that have already undergone formal or early section 7 consultation, and the impact of state or private actions which are contemporaneous with the consultation in process (50 C.F.R. 402.02). For projects that are ongoing actions, the effects of all past actions are part of the environmental baseline and the effects of future actions over which the Federal agency has discretionary involvement or control will be analyzed as 'effects of the action.'

Analysis of the environmental baseline is guided by the specific habitat components necessary to support $\mathrm{OC}$ coho in the action area. When the environmental baseline departs from conditions that support those biological requirements, it becomes more likely that additional risk to the ESU resulting from the effects of the proposed action on the ESU or its habitat will result in jeopardy (NMFS 1999). The biological requirements of OC coho in the action area vary depending on the life history stage present and the natural range of variation present within that system (Groot and Margolis 1991; NRC 1996; Spence et al. 1996).

Generally, during spawning migrations, adult salmon require clean water with cool temperatures or thermal refugia, dissolved oxygen near $100 \%$, low turbidity, adequate flows and depths to allow passage over barriers to reach spawning sites, and sufficient holding and resting sites. Spawning areas are selected based on species-specific requirements of flow, water quality, substrate size, and groundwater upwelling. Embryo survival and fry emergence depend on substrate conditions (i.e., gravel size, porosity, permeability, and oxygen levels), substrate stability during high flows, and, for most species, water temperatures of $13^{\circ} \mathrm{C}$ or less. Habitat requirements for juvenile rearing include seasonally suitable microhabitats for holding, feeding, and resting. Migration of juveniles to rearing areas, whether the ocean, lakes, or other stream reaches, requires unobstructed access to these habitats. Physical, chemical, and thermal conditions may all impede migrations of adult or juvenile fish.

Analysis of the environmental baseline is guided by the specific habitat components necessary to support OC coho in the action area. When the environmental baseline departs from conditions that support those biological requirements, it becomes more likely that additional risk to the ESU resulting from the effects of the proposed action on the ESU or its habitat will result in jeopardy (NMFS 1999). The biological requirements of OC coho in the action area vary depending on the life history stage present and the natural range of variation present within that system (Groot and Margolis 1991; Spence et al. 1996). 
The OC coho ESU considered in this Opinion resides in and migrates through the action area. Thus, for this action area, the biological requirements for $\mathrm{OC}$ coho are the habitat characteristics that would support successful migration, spawning, incubation, rearing and emigration.

The Tyrrell orchard is in the Mid-Coast Subbasin of the Siuslaw River Watershed. The Siuslaw River Watershed covers 104,683 acres (approximately 164 square miles) and is in Lane and Douglas Counties, southwest of the city of Eugene. Ecotrust and the Siuslaw Watershed Council conducted a recent watershed assessment of the Siuslaw Basin. As described in the text below, the watershed assessment identified general factors of habitat decline that are reminiscent of most of the basins in the OC coho ESU:

Over the period of 100 years - 1850 s to 1950 s - farming, logging, fishing, road and railroad construction progressively changed the landscape from the forested ridge tops to the valley bottoms within all of the Siuslaw subbasins. New technologies were applied to utilize the abundant resources; wetlands were drained and diked, streams were used as sluceways for log transport, gill nets were used to catch salmon, private logging roads, railroads and public roads were constructed across the landscape. Estuaries and streams were cut off from their floodplains, fish passage was blocked by culverts, streams were choked with logging debris, spawning beds were covered by sediments, gravel beds and large woody debris were lost, water temperatures increased as riparian forests were cut and, in general, riparian habitat became degraded in many areas. ${ }^{8}$

Using the NMFS matrix of pathways and indicators (MPI), the BLM evaluated several baseline conditions in the Upper Siuslaw River ( $6^{\text {th }}$ field watershed) (see Attachment D in the BA). The MPI method assesses the current condition of instream, riparian, and watershed factors that collectively provide for a properly functioning aquatic habitat, essential for maintaining salmonid populations. Environmental baselines are categorized as either "properly functioning," "at risk," or "not properly functioning." The BLM found that no factors in the Upper Siuslaw River are regarded as properly functioning. Factors at risk include chemical contamination/nutrients, high sedimentation/turbidity, the presence of some physical barriers to anadromous fish, maintenance of pool frequency, poor pool quality, limited off-channel habit, high peak/base flows, and increased drainage networks. All other factors were identified as not properly functioning (BLM 2004). Factors in the basin that continue to contribute to its degraded habitat include logging and road building, agricultural development, suburban development, and off-channel/estuarine habitat isolation from dike and levee installations, among other factors. These type of land uses have been demonstrated to result in increased finesediment inputs (which reduces spawning habitat quality), result in riparian vegetation loss (increases stream temperatures and reduced large wood inputs to streams) (Spence et al. 1996.). Channel sinuosity losses, in addition to off-channel/estuarine habitat isolation, have particularly acute impacts to rearing coho salmon. Given coho salmon's general life-history of freshwater rearing for up to 1.5 years, the reduction of slack water/beaver pond habitat, which provides

${ }^{8}$ http://www.inforain.org/siuslaw/siuslaw.pdf 
velocity refuge, predator shelter, and feeding areas, likely have reduced the necessary habitat to facilitate the recovery of coho in the Siuslaw to a viable population status. As discussed below, the water quality of remaining habitats have been degraded, which further reduces suitable coho habitat quality and quantity.

Factors Affecting Water Quality. While all of the factors discussed above contribute to coho habitat degradation within the Siuslaw Basin, the proposed IPM program has the most significant potential to alter water quality within the basin. Other habitat parameters, such as sediment regimes or riparian habitat conditions, are not anticipated to be affected by the proposed action. As such, factors which contribute to water quality problems in the basin are discussed in more detail here. The Siuslaw River is on the Oregon Department of Environmental Quality (ODEQ) 303(d) List of Water Quality Limited Water Bodies for temperature (ODEQ 2002). The temperature standard $\left(64^{0} \mathrm{~F}\right)$ is regularly exceeded $(63 \%)$ during summer flows from the mouth to the headwaters. Historic readings at Mapleton indicate temperature exceedences occurred in 1980,1982 , and 1984 to 1992 with a maximum of $75.2^{\circ} \mathrm{F}$.

The Ecotrust and the Siuslaw Watershed Council watershed assessment identified water quality problems including elevated temperatures, and some contaminants, due to natural basin factors and habitat degradation.

Nearly the entire mainstem river and some tributaries, typically have elevated temperatures during summer months. The watershed assessment attributed increased temperatures to three factors:

1. The basin is roughly split between the central and southern Oregon coast regions. Ambient temperatures increase significantly from north to south, and the eastern portion of the basin (including Douglas Creek and the project area) is unaffected by the cooler coastal fog belt, and thus has higher summer temperatures.

2. Riparian cover has been lost within significant portions of the mainstem Siuslaw and tributaries, particularly wider valleys where agricultural land use is common. Douglas Creek drains to the portion of the Siuslaw in the Lorane Valley, which has less than $40 \%$ shade cover.

3. The amount of exposed bedrock aside and in stream channels may absorb heat which is transferred to water through long wave radiation. In some areas, the lack of riparian cover exposes more bedrock relative to the pre-disturbed state.

At the Mapleton water quality station (15 miles east of the City of Florence), documented chemical water quality issues include dissolved lead levels that have exceeded chronic toxicity levels, and three detections of lead above the acute toxicity level. The watershed assessment states: "Limited data and analysis indicate that lead levels appear to exceed acute toxicity levels on a regular basis. This problem may be limited to the lower mainstem." The natural 'soft' water chemistry of the Siuslaw make dissolved metals, including chromium, copper, lead, nickel, silver, and zinc more toxic to organisms. 
The BA summarizes water quality conditions in the Siuslaw as follows:

The 1988 State Water Quality Assessment cited a moderate nutrient problem in the Siuslaw River. This problem was identified by observation and has not been confirmed by any measurements. Currently, turbidity does not meet aesthetically pleasing water quality criteria and low dissolved oxygen concentrations have been measured for the Siuslaw River, although it is expected to be a problem only in the larger slow-moving stream reaches that have high water temperatures. The greatest concern is for impacts to fish habitat and other aquatic life. Studies and monitoring reports from adjacent watersheds, such as Wolf Creek, show that summer water temperatures are probably too high to support salmonids and some other aquatic organisms (BLM 2002). However, no excessive temperatures have been recorded to date in the seed orchard tributaries.

The 2002 ODEQ 303(d) list includes the Siuslaw River from river mile (RM) 20 to 105.9 as water quality-limited for summer temperatures, and from RM 5 to 105.9 for dissolved oxygen (ODEQ 2003). The list also includes impaired biological criteria for the lower segment of the South Fork Siuslaw, whose confluence is two miles upstream from Tyrrell.

Tyrrell Orchard Drainages. The 361-acre seed orchard has three main streams that originate or flow through the Orchard. Douglas Creek is the largest of the drainages at 2,965 acres and the Stream 8 watershed is approximately 450 acres. The BA did not include an estimate of watershed size for Stream 1.

According to the recent Siuslaw River Watershed assessment, the Douglas Creek Watershed has a total of 4.3 miles of stream available for anadromous species. Close to three miles of spawning surveys conducted in the 1990's revealed 'relatively high numbers' of adult coho spawners, conversely, snorkel surveys revealed 'relatively low numbers of juvenile coho.' Because large portions $(69 \%)$ of the watershed have degraded riparian cover, stream temperatures may be elevated, and only $10 \%$ of the basin has the potential to contribute wood to aquatic habitat. There are 71 road crossings over fish bearing streams (which includes resident cutthroat trout) in the subbasin. ${ }^{9}$

There are five ephemeral channels which drain section 9 of the seed production orchard treatment units and flow into Douglas Creek. A BLM access road crosses many of these drainages. The riparian vegetation along each of the drainages is generally limited to small shrubs and trees, and varies in width, with some orchard production units within or near the ephemeral channels.

The entire perennial portion of Stream 8 is in the lower section 15 of the orchard seed production units. The perennial section of the stream has relatively mature riparian vegetation for its whole

${ }^{9}$ http://www.inforain.org/siuslaw/siuslaw.pdf 
length to the Siuslaw River. An BLM access road and culvert blocks anadromous access to a small portion of the creek. Most of the upland intermittent and ephemeral origins of Stream 8 are within several seed production units and fallow grass land owned by the BLM.

Soils. Three types of soil are present at Tyrrell: Bellpine C, bellpine D, bellpine E, bellpine F, dupee, and jory (SCS 1983, 1993). The cation exchange capacity of each of these soils is in the range of 10 to 25 milliequivalents per 100 grams (meq/100 g), indicating that they contain smectite clay and low to moderate amounts of organic matter, which adsorbs pesticides and fertilizers and retards their movement through the soil. Table 7 presents soil characteristics relevant to the environmental mobility of fertilizers and pesticides.

Table 7. Soil Characteristics at Tyrrell

\begin{tabular}{|c|c|c|c|c|c|c|c|c|}
\hline Soil Series & $\begin{array}{l}\text { Depth } \\
\text { (inches) }\end{array}$ & $\begin{array}{l}\text { Permeabilit } \\
\text { y (in/hr) }\end{array}$ & $\begin{array}{l}\text { Depth to } \\
\text { Water } \\
\text { Table (feet) }\end{array}$ & Runoff & $\begin{array}{l}\text { Slope } \\
(\%)\end{array}$ & $\begin{array}{l}\text { Organic } \\
\text { Matter } \\
(\%)\end{array}$ & $\begin{array}{l}\text { Clay } \\
(\%)\end{array}$ & $\begin{array}{l}\text { Soil } \\
\text { Sensitivity }\end{array}$ \\
\hline \multirow[t]{2}{*}{ Bellpine C } & $0-13$ & $0.6-2.0$ & \multirow[t]{2}{*}{$>6$} & \multirow[t]{2}{*}{ slow } & \multirow[t]{2}{*}{$3-12$} & $3-6$ & $27-35$ & \multirow[t]{2}{*}{ low } \\
\hline & $13-34$ & $0.2-0.6$ & & & & $1-4$ & $40-55$ & \\
\hline \multirow[t]{2}{*}{ Bellpine D } & $0-13$ & $0.6-2.0$ & \multirow[t]{2}{*}{$>6$} & \multirow[t]{2}{*}{ medium } & \multirow[t]{2}{*}{$12-20$} & $3-6$ & $27-35$ & \multirow[t]{2}{*}{ low } \\
\hline & $13-34$ & $0.2-0.6$ & & & & $1-4$ & $40-55$ & \\
\hline \multirow[t]{2}{*}{ Bellpine $\mathbf{E}$} & $0-13$ & $0.6-2.0$ & \multirow{2}{*}{$>6$} & \multirow[t]{2}{*}{ rapid } & \multirow[t]{2}{*}{$20-30$} & $3-6$ & $27-35$ & \multirow[t]{2}{*}{ very low } \\
\hline & $13-34$ & $0.2-0.6$ & & & & $1-4$ & $40-55$ & \\
\hline \multirow[t]{2}{*}{ Bellpine F } & $0-13$ & $0.6-2.0$ & \multirow[t]{2}{*}{$>6$} & \multirow[t]{2}{*}{ rapid } & \multirow[t]{2}{*}{$30-50$} & $3-6$ & $27-55$ & \multirow[t]{2}{*}{ very low } \\
\hline & $15-24$ & $0.2-0.6$ & & & & $1-4$ & $40-55$ & \\
\hline \multirow[t]{2}{*}{ Dupee } & $0-12$ & $0.6-2$ & \multirow{2}{*}{$\begin{array}{l}1.5-3.3 \\
\text { (winter), >6 } \\
\text { (Summer) }\end{array}$} & \multirow{2}{*}{$\begin{array}{l}\text { medium } \\
\text { to rapid }\end{array}$} & \multirow[t]{2}{*}{$3-20$} & $2-3$ & $15-27$ & \multirow[t]{2}{*}{ high } \\
\hline & $12-55$ & $0.2-0.6$ & & & & $1-2$ & $35-50$ & \\
\hline \multirow[t]{2}{*}{ Jory } & $0-9$ & $0.6-2$ & \multirow[t]{2}{*}{$>6$} & \multirow[t]{2}{*}{ slow } & \multirow[t]{2}{*}{$2-12$} & $3-6$ & $27-40$ & \multirow[t]{2}{*}{ very low } \\
\hline & $9-60$ & $0.2-0.6$ & & & & $0.5-2$ & $45-60$ & \\
\hline
\end{tabular}

Sources: SCS 1983, SCS 1993, OSUES 1998.

Weather. In the BA, the BLM provided data regarding annual precipitation in the area based on Cottage Grove values and runoff patterns for the Siuslaw River near Mapleton, Oregon. As depicted in Table 8, this information indicates that the high-precipitation period occurs from November through March, with approximately $69 \%$ of the annual precipitation occurring during those five months. For that same five-month period, approximately $81 \%$ of the annual runoff takes place. April/May is a transition period with approximately $13 \%$ of the annual total precipitation and $12 \%$ of the annual runoff. The mean monthly precipitation amounts for April and May are 3.5 and 2.5 inches, respectively. 
Table 8. Tyrrell Orchard Precipitation Statistical Summaries of Precipitation at Cottage Grove and Runoff Patterns from the Siuslaw River near Mapleton, Oregon (BLM 2002a).

\begin{tabular}{|c|c|c|c|}
\hline Month & $\begin{array}{l}\text { Mean Monthly } \\
\text { Precipitation } \\
\text { (inches) }\end{array}$ & $\begin{array}{c}\text { Annual Runoff } \\
(\%)\end{array}$ & $\begin{array}{c}\text { Mean Runoff Per } \\
\text { Sq. Mile* } \\
\text { (cfs/sq. mile) }\end{array}$ \\
\hline October & 3.60 & 1.8 & 0.76 \\
\hline November & 7.46 & 9.7 & 4.29 \\
\hline December & 7.20 & 20.9 & 8.95 \\
\hline January & 6.53 & 19.8 & 8.50 \\
\hline February & 5.20 & 17.0 & 8.01 \\
\hline March & 5.38 & 14.0 & 6.00 \\
\hline April & 3.53 & 8.1 & 3.60 \\
\hline May & 2.53 & 4.1 & 1.76 \\
\hline June & 1.39 & 2.2 & 0.96 \\
\hline July & 0.53 & 1.1 & 0.46 \\
\hline August & 0.95 & 0.6 & 0.27 \\
\hline September & 1.65 & 0.7 & 0.34 \\
\hline
\end{tabular}

\section{Effects of the Proposed Action}

'Effects of the action' means the direct and indirect effects of an action on the species or critical habitat, together with the effects of other activities that are interrelated or interdependent with that action, that will be added to the environmental baseline (50 C.F.R. 402.02). If the proposed action includes offsite measures to reduce net adverse impacts by improving habitat conditions and survival, NMFS will evaluate the net combined effects of the proposed action and the offsite measures.

'Indirect effects' are those that are caused by the proposed action and are later in time, but still are reasonably certain to occur (50 C.F.R. 402.02). Indirect effects may occur outside the area directly affected by the action, and may include other Federal actions that have not undergone section 7 consultation but will result from the action under consideration. To be considered indirect effects, such actions must be reasonably certain to occur, as evidenced by appropriations, work plans, permits issued, or budgeting; follow a pattern of activity undertaken by the agency in the action area; or be a logical extension of the proposed action.

'Interrelated actions' are those that are part of a larger action and depend on the larger action for their justification; 'interdependent actions' are those that have no independent utility apart from the action under consideration (50 C.F.R. 402.02). Future Federal actions that are not a direct 
effect of the action under consideration, and not included in the environmental baseline or treated as indirect effects, are not considered in this Opinion.

The application of pesticides, herbicides and fertilizers in proximity to lakes and river systems can result in the transport of potentially toxic chemicals (active ingredients and/or adjuvants) to surface waters (USGS 1999) that may harm ESA-listed species. Pesticides, herbicides and fertilizers can impair the essential biological requirements of salmon if they undermine the physical, chemical, or biological processes that collectively support a productive aquatic ecosystem (Preston 2002) or affect the physiological or behavioral performance of salmonids in ways that will reduce growth and survival, migratory success, or reproduction.

The degree, or likelihood, of effects to listed salmonids from the discharge of pesticides to surface waters vary spatially and temporally, according to factors that have been simplified into the following categories:

1. Likelihood of Exposure. If listed fish do not occupy habitat that has been chemically modified, the likelihood of adverse effects could be limited to loss of prey base. ${ }^{10}$

2. Water Quality Conditions. Dissolved oxygen levels and temperature affect salmonids susceptibility to pesticide exposure.

3. Lifestage of the Salmonid. Salmonids occupy freshwater as incubating eggs/alevins, newly-emerged fry, and rearing parr and smolts and as returning adults. Each lifestage has a different susceptibility or tolerance of exposure to pesticides.

4. Levels of other Contaminants. Concurrent discharge and/or background levels of other contaminants ${ }^{11}$ can magnify adverse effects through mixture toxicity resulting from discharges associated with the IPM program.

5. Concentration and relative toxicity of the chemical.

Within the BA, the BLM evaluated expected effects from the pesticide portion of their IPM using models that assess potential delivery to aquatic systems from drift, surface runoff, and groundwater runoff. While these models are a viable analysis method to evaluate potential water concentrations, they generally do not account for many of environmental variables that can change the effects of pesticide applications. As applied, the models also did not account for the multitude of possible exposures that are proposed over the five-year implementation period. Background or concurrent delivery of pollutants from other sources, and degraded water quality within receiving waterways will add to the risk caused by pesticide delivery from BLM applications.

10 'Prey base' refers to macroinvertebrates and aquatic plants that serve a food sources for juvenile salmonids. A loss of prey base upstream from areas occupied by listed salmon could result in decreased feeding opportunities downstream.

${ }^{11}$ Contaminants range from pesticides, herbicides and nutrients (phosphates and nitrates), to those associated primarily with road and urban runoff including heavy metals, and organics (i.e. oil and grease). 
Most adverse effects to listed salmonids in the action area from the proposed IPM are likely to be sublethal. As stated in Rand (1995), sublethal effects to listed salmonids take the form of behavioral, physiological, biochemical, or histological changes in the exposed fish. These changes may not be immediately lethal, but can cause fish to exhibit impaired behaviors (i.e., narcosis) or eventually develop a lower level of physical health, thus reducing their chances of survival as compared to unexposed fish. Possible consequences include loss of equilibrium, reduced swimming ability, and impaired predator avoidance behavior, which lead to increased predation risk and reduced foraging ability. Increased mixture toxicity between the pesticides and other contaminants in receiving waterways is likely to occur and exacerbate these effects.

\section{General Effects to Aquatic Species From Exposure to Proposed Compounds}

The following is a general discussion of effects from the proposed pesticides that are likely to adversely effect ESA-listed species and/or their prey base within the action area. Effects are presented by 'families' of pesticides, that have similar modes of action to aquatic species, and are based on literature reviews and published studies.

Organophosphates. Organophosphates are a group of closely-related pesticides that share a common mechanism of toxicity. The insecticides acephate, chlorpyrifos, diazinon, and dimethoate fall within this organophosphate category and are being proposed for use at Tyrrell. The central and peripheral nervous system is the primary target by disrupting the enzyme that hydrolyzes the nuerotransmitter acetylcholine. Inhibition of this enzyme, acetylcholinesterase, results in an accumulation of acetylcholine which has the effect of continuous stimulation of cholinergic and muscarinic receptors. Organophosphates are highly toxic to fish.

Acetylcholinesterase inhibition can result in impairment of biological functioning such as growth, maturation, sensory systems and reproduction. Sublethal behavioral effects can include swimming, foraging, predator avoidance, and disruption of migratory behavior.

Acephate. Acephate is a contact insecticide that is applied to leaf surfaces of plants where it is eaten or comes in contact with pests. Acephate acts by inhibiting the enzyme acetylcholinesterase which is necessary for control of nerve transmission (USDA 1995). Acephate is very water soluble, very mobile in soils, and degrades rapidly in soils under aerobic conditions (EPA 2001). Acephate is considered slightly toxic to aquatic invertebrates and freshwater fish. A summary of toxicity values for aquatic life published in the literature for acephate is found in section 8.3.1 in the Tyrrell RA.

Methamidophos. Methamidophos, a degradate of acephate, is considered very highly toxic to aquatic invertebrates and slightly toxic to fish on an acute basis (EPA 2001). Acephate degrades to methamidophos in less than two days. This degradate has a slightly longer half-life ( $<10$ days) (EPA 2001) and shares the high mobility of its parent chemical. The BA predicted that acephate will reach water surface waters in negligible concentrations. This is probably due to its short anaerobic half-life, however, nothing is mentioned of its degradate. Methamidphos is significantly more toxic to the prey base of salmonids, more persistent, highly mobile, and carries with it a greater potential for adversely affecting salmonid habitat. 
Chlorpyrifos. Chlorpyrifos is very highly toxic to fish and aquatic invertebrates (USDA 1995b). A summary of toxicity values for aquatic life published in the literature for chlorpyrifos is found in section 8.3.2 in the Tyrrell RA. When released into the environment, the half-life of chlorpyrifos ranged from 11 to 141 days in a variety of different soil types; it is thus considered to be moderately persistent (USDA 1995b). The potential for run-off into surface water could occur via erosion up to several months after application. It's degradate, TCP (3,5,6-trichloro-2pyridinol), is a much more persistent chemical ( $>365$ days) that exhibits much lower soil/water partitioning than chlorpyrifos and is highly water soluble. Within an area of continuous application, accumulated amounts of chlorypyrifos in the soil will eventually degrade into TCP. A storm event could mobilize TCP through dissolution in runoff water and be transported to surface water in a persistent amount. However, TCP was found to be much less toxic than chlorpyrifos to aquatic organisms (EPA 2000a).

Diazinon. Diazinon is very toxic to freshwater aquatic organisms and very highly toxic to aquatic invertebrates on an acute basis. A summary of toxicity values for aquatic life published in the literature for diazinon is found in section 8.3.5 in the Tyrrell RA. Exposure to low concentrations ( $1 \mathrm{ppm}$ or less) has been determined to cause genetic damage and disrupts behaviors that are crucial for reproduction and protection from predators (Cox 2000). Diazinon is moderately mobile in soils and persistent in the environment ( 37 to 39 days) (EPA 2001b) Diazinon is potentially of the most concern of the organophosphate group. There is a higher exposure risk and probability with more soluble chemicals with longer half-lives than less soluble chemicals with a shorter half-lives. Reduced populations of macro-invertebrates that may result from acute concentrations of diazinon, although temporary, may indirectly effect the health of juvenile salmonids that prey on them.

Dimethoate. Dimethoate is highly toxic to fish and to aquatic invertebrates. LC50 and EC50 values for aquatic macroinvertebrates range from 0.043 t0 $0.2 \mathrm{ppm}$ (EPA 1999). A summary of toxicity values for aquatic life published in the literature for dimethoate is found in section 8.3 .7 in the Tyrrell RA. Dimethoate is highly soluble and highly mobile in soil, the potential of leaching and runoff to water is high. Dimethoate can be rapidly broken down by most soil microorganisms with soil half-lives ranging generally from 4 to 16 days, but as high as 122 days, have been reported; a representative value would be 20 days (Extoxnet 2000).

Environmental factors may also influence organophosphate toxicity to aquatic species, altering effect estimates to fish (Table C-3 in Tyrrell BA). In general, acute toxicity of chlorpyrifos and azinphos-methyl were found to increase with temperature, $\mathrm{pH}$, and body size of the fish. The Siuslaw River Watershed is water quality limited with respect to temperature in the summer months which may aggravate the toxicity of organophosphates.

Table C-2 in the Tyrrell BA lists relevant assessment endpoints and effect concentrations of acephate, chlorpyrifos, diazinon, and dimethoate and other relevant organophosphates to salmonid species.

Organosulfites. Propargite is an organosulfur miticide/acaricide that is highly toxic to fish, is moderately persistent ( 38 to 168 days) but is immobile in soils, and not very soluble in 
water. A summary of toxicity values for aquatic life published in the literature for propargite is found in section 8.3.14 in the Tyrrell RA. Having a high affinity for soil and sediment, propargite has the potential to move off the site of application during rainfall/irrigation by erosion/runoff on soil particles and by drift. Given the moderate to slow degradation rates for metabolism and photolysis, and the high $\mathrm{Koc}^{12}$ values, propargite will probably partition to sediments and organic material if transported to surface waters (EPA 2000b). No data is available on environmental influences to toxicity.

Propargite does not share a common mechanism of toxicity with other pesticides (EPA 2000b), and would not elicit a cumulative risk with other pesticides from a purely mechanistic perspective. However, it is a contributor to the overall pesticide burden that an aquatic organism may experience and could, in combination with other stressors, pose a significant risk in small amounts.

Pyrethroids. Pyrethroids, including esfenvalerate and permethrin, are highly toxic to aquatic invertebrates and fish. The pyrethroid group share similar mechanisms of toxicity, resembling that of Dichlorodiphenyltrichloroethane (known more commonly as 'DDT'), targeting the central and peripheral nervous system, resulting in greatly altered ionic currents and disrupted nerve function through membrane depolarization (Eisler 1992). Disruption to the neuromuscular system, through neurotoxic modes of action, can affect foraging behavior, predator avoidance, swimming performance and other coordinated muscular movement. Toxicity has been known to increase with higher water temperatures and acidity.

Esfenvalerate. Esfenvalerate is very highly toxic to aquatic species. A summary of toxicity values for aquatic life published in the literature for esfenvalerate is found in section 8.3.8 in the Tyrrell RA. The persistence of esfenvalerate varies upon environmental conditions with half-lives in direct sunlight, soil, and water being 7.5 days, up to 90 days, and 10 to 220 days, respectively. Sublethal effects of inhibited olfactory response to a female reproductive pheromone were found at concentrations of less than $0.004 \mathrm{mu} g / \mathrm{L}$ or 4 parts per trillion in Atlantic Salmon (Moore and Waring 2001). The same study found exposure of milt and eggs to a concentration of $0.1 \mathrm{mu} \mathrm{g} / \mathrm{L}$ reduced egg fertilization. Pyrethroids have been documented to affect behavior and physiology in fish important for survival. Sublethal effects observed in fish include alterations in growth and metabolic processes. These sublethal effects occur at low concentrations that would precede any effects realized at the individual level but could potentially have consequences at the population level.

Permethrin. Permethrin is highly toxic to fish and especially aquatic macroinvertebrates. A summary of toxicity values for aquatic life published in the literature for permethrin is found in section 8.3.14 in the Tyrrell RA. Permethrin's water solubility is low and exhibits a strong tendency to bind to soil particles. Runoff and erosion are not expected to contribute to elevated concentrations in surface water, however, drift from permethrin airblast applications was

${ }^{12} \mathrm{Koc}$ is a sorption coefficient that is often used to compare the relative mobility of different pesiticides. The higher the Koc value the more strongly the pesiticide is sorbed, and therefore the less mobile it is. 
predicted to exceed the 21-day maximum acceptable toxicant concentration for aquatic invertebrates in onsite streams. The Tyrrell BA states that this exposure concentration would persist for less than 24 hours, compared to the three-week exposures used to calculate this criterion and therefore, is not expected to indicate a potential risk. The greatest effect of insecticides on fish probably arises from effects on terrestrial and aquatic insects that form the salmonids' food base (Spence et al. 1996). The consideration of an individual exposure scenario when multiple pathways of exposures to similar acting chemicals exist does not make a conservative estimate. The drift of permethrin as well as drift and runoff from a potentially persistent application of esfenvalerate to a potentially degraded baseline could elevate the risk to the prey base of steelhead.

Nicotinoids. These insecticides include imidacloprid, a relatively new insecticide that acts on the central nervous system of insects, causing irreversible blockage of post-synaptic nicotingergic acetylcholine receptors. Imidacloprid is proposed for use only in the form of the

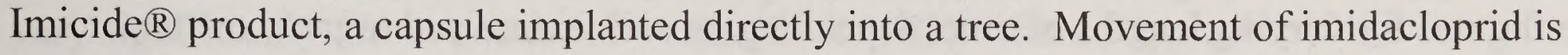
restricted to the vascular system of the tree and kills insects when they feed. The potential for imidacloprid to enter air, soil, or water is negligible when using Imicide $\AA$ capsules

Herbicides. Herbicides can impair the essential biological requirements of salmon if they undermine the physical, chemical, or biological processes that collectively support a productive aquatic ecosystem (Preston 2002). The alteration of watershed characteristics by herbicides can include: Disruption of the growth of riparian deciduous vegetation, reduction of delivery of leaves and intermediate-sized wood, and alteration of hydrologic and sediment delivery processes (Spence et al. 1996). Moreover, aquatic plants and macroinvertebrates are generally more sensitive than fish to the toxic effects of herbicides. The application of herbicides can affect the productivity of the stream by altering the composition of benthic algal communities; the food source of macro-invertebrates. Benthic algae are important primary producers in aquatic habitats, and are thought to be the principal source of energy in many mid-sized streams (Minshall, 1978; Vannote et al. 1980; Murphy, 1998). Herbicides can directly kill algal populations at acute levels or indirectly promote algal production by increasing solar radiation reaching streams by disruption of riparian vegetative growth. The disruption of riparian vegetative growth carries with it other adverse consequences for salmonid habitat, such as loss of shade, bank destabilization, and sediment control. Therefore, herbicides can potentially impact the structure of aquatic communities at concentrations that fall below the threshold for direct impairment in salmonids. The integrity of the aquatic food chain is an essential biological requirement for salmonids, and the possibility that herbicide applications will alter the productivity and watershed characteristics of streams and rivers exist.

Herbicides can cause significant shifts in the composition of benthic algal communities at concentrations in the low parts per billion (Hoagland et al. 1996). Moreover, based on the data available, herbicides have a high potential to elicit significant effects on aquatic microorganisms at environmentally relevant concentrations (DeLorenzo et al. 2001). In many cases, however, the acute sensitivities of algal species to herbicides are not known. In addition, Hoagland et al. (1996) identify key uncertainties in the following areas: (1) The importance of environmental 
modifying factors such as light, temperature, $\mathrm{pH}$, and nutrients; (2) interactive effects of herbicides where they occur as mixtures; (3) indirect community-level effects; (4) specific modes of action; (5) mechanisms of community and species recovery; and (6) mechanisms of tolerance by some taxa to some chemicals. Herbicide applications have the potential to impair autochthonous production and, by extension, undermine the trophic support for stream ecosystems.

Glyphosate. Glyphosate, an amino acid derivative, is a broad-spectrum, non-selective systemic herbicide. It is absorbed by leaves, moves rapidly through the plant, and acts to prevent production of an essential amino acid that inhibits plant growth. Glyphosate is slightly toxic to fish, and practically non-toxic to aquatic invertebrate animals (USDA 2001). However, the presence of inert ingredients may exacerbate its toxicity. A summary of toxicity values for aquatic life published in the literature for glyphosate is found in section 8.3.9 in the Tyrrell RA. Glyphosate is strongly adsorbed to most soils, and dissolves easily in water. Glyphosate remains unchanged in the soil for varying lengths of time, depending on soil texture and organic matter content. The half-life of glyphosate can range from 3 to 130 days (USDA 2001). Soil microorganisms eventually break down glyphosate and the potential for leaching is low due to the soil adsorption. Although glyphosate has a low propensity for leaching, it can enter waterbodies by other means, such as overspray, drift, or erosion of contaminated soil (EPA 1993). Once in water, glyphosate is strongly adsorbed to any suspended organic or mineral matter and is then broken down primarily by microbes.

The toxicity of glyphosate to aquatic species increases with increasing temperature and $\mathrm{pH}$ (SERA 2003a). In the aquatic environment with freshwater fish, toxicity appears to increase with increasing temperature and $\mathrm{pH}$. As reported in the Handbook of Acute Toxicity of Chemicals to Fish and Aquatic Invertebrates (USFWS 1980), glyphosate was twice as toxic to rainbow trout at $17 \mathrm{c}$ at $7^{\circ} \mathrm{Celsius}$. With bluegills, toxicity was twice as toxic at $27 \mathrm{c}$ compared to 17c. Toxicity was also two to four times greater to bluegills and rainbow trout at a $\mathrm{pH}$ level of 7.5 to 9.5 than at $\mathrm{pH} 6.5$ (PH of 7.0 is considered "neutral water"). However, the EPA states (1993) that glyphosate is stable at pH 3, 6, 9 at 5 and 35 Environmental Concentration.

Glyphosate acid and its salts are classified as 'moderately toxic' chemicals by the EPA. Technical glyphosate acid (parent chemical) is 'practically nontoxic' to fish and may be 'slightly toxic' to aquatic invertebrates. The 96 -hour LC50 is $86-140$ milligrams per litre $(\mathrm{mg} / \mathrm{L})$ in rainbow trout and $120 \mathrm{mg} / \mathrm{L}$ in bluegill sunfish. The 48-hour LC50 for glyphosate in daphnia (water flea), an important food source for freshwater fish, is $780 \mathrm{mg} / \mathrm{L}$. The results of a rainbow trout yolk-sac 96-hour LC50 static bioassay yielded results at the $3.4 \mathrm{mg} / \mathrm{L} \mathrm{level}^{13}$.

${ }^{13}$ USGS acute toxicity website: http://www.cerc.usgs.gov/data/acute/acute.htm 
There is a very low potential for the chemical to build up in the tissues of aquatic invertebrates or other aquatic organisms. ${ }^{14}$ In one study of bioaccumulation and persistence, glyphosate was applied to two hardwood communities in Oregon coastal forest and none of the 10 coho salmon fingerlings analyzed had detectable levels of the herbicide or its metabolite aminomethylphosphonic acid, although levels were detectable in stream water for three days and in sediment throughout the 55-day monitoring period. ${ }^{15}$

Dicamba. Dicamba is a member of the benzoic acid chemical family. Benzoic acid herbicides are similar in mode of action and structure to the phenoxy herbicides, such as 2,4-D. Like phenoxy herbicides, dicamba mimics a plant growth hormone, affecting cell division (Cox 1994). Study results in aquatic organism toxicity have yielded varying results. Dicamba is slightly toxic to fish and may be toxic to aquatic macroinvertebrates (SERA 1999). A summary of toxicity values for aquatic life published in the literature for dicamba is found in section 8.3.6 in the Tyrrell RA. Dicamba is moderately persistent in soil and highly mobile in soil. Half-lives vary significantly, from one to six weeks (EPA 1983), with the typical half-life being four weeks (Weed Sci Soc Amer 1983). Exposure to non-target species may be difficult to control due to its high volatility (SERA 1999).

Dicamba is categorized by the EPA as 'slightly toxic' to fish, and 'practically non-toxic' to aquatic organisms. The LC50 (96-hour) for technical dicamba is $135 \mathrm{mg} / \mathrm{L}$ in rainbow trout (O. mykiss) and bluegill sunfish (Lepomis microchirus). The LC50 (48-hour) for dicamba is 35 $\mathrm{mg} / \mathrm{L}$ in rainbow trout (USDA 2001). It is important to note that although dicamba is 'slightly toxic' to fish, there are variations in study results with reference to salmonids. One study found that there were no effects on yearling coho salmon at concentrations up to 100 parts per million (ppm). However, yearling coho were killed by much smaller doses $(0.25 \mathrm{ppm})$ during a seawater challenge test that simulated their migration from river to ocean (Cox 1994). Little is known about sublethal effects on fish.

Dicamba does not bind to soil particles. Microbes appear to be the primary source of chemical breakdown the soil. In sterilized soil, over $90 \%$ of applied dicamba was recovered after four weeks, suggesting that microbes were responsible for the decomposition. ${ }^{16}$ Sunlight does not appear to play a major role in breakdown, as with many other herbicides. Volatilization (vaporization) of dicamba from soil surfaces may not be an important process, although some volatilization can occur from plant surfaces. The principal soil metabolite appears to be 3,6-dichlorosalicylic acid.

Picloram. Picloram is a pyridine carboxylic acid herbicide that acts as a plant growth regulator (SERA 2003c). It is absorbed by the plant roots, leaves, and barks. It moves both up

\footnotetext{
${ }^{14}$ Extoxnet website: http://extoxnet.orst.edu/

15 Toxnet website: http://toxnet.nlm.nih.gov

${ }^{16}$ Toxnet website: http://toxnet.nlm.nih.gov
} 
and down within the plant, and accumulates in new growth, interfering with the plant's ability to make proteins and nucleic acids. It is moderately toxic to fish and slightly toxic to aquatic invertebrates. Refer to table 8-26 in the Tyrrell RA. Picloram is highly soluble in water, resistant to biotic and abiotic degradation processes, and degrades very slowly with half-lives ranging from 167 to 513 days (EPA 1995). Its major route of dissipation appears to be leaching. Given its high persistence, it appears unlikely that picloram will degrade once it reaches groundwater, even over a period of several years (EPA 1995). While not as toxic as other the chemicals examined in this consultation, the environmental fate characteristics of picloram may ensure introduction into steelhead habitat and subsequent exposure.

Chlorothanonil. Chlorothalonil is a member of the polychlorinated benzene carbonitrile fungicide class of pesticides. This chemical is toxicologically dissimilar to existing chemical substances currently used in Tyrrell and is not expected to share a common mechanism of activity. The results of the 96-hour acute toxicity studies indicate that chlorothalonil is very highly toxic to fish and aquatic macroinvertebrates (EPA 1999). A summary of toxicity values for aquatic life published in the literature for chlorothalonil is found in section 8.3.2 in the Tyrrell RA. There is a lack of data on the effects upon early life stages, sublethal behavioral effects or environmental influences on toxicity.

Chlorothalonil is almost non-soluble in water, has not generally been considered a highly mobile pesticide, and is more likely to be found in runoff from treated areas. Refer to section 3.1.2 in the Tyrrell RA. The persistence of chlorothalonil varies with environmental conditions and is resistant to hydrolysis, photolysis, and volatilization, and only moderately susceptible to degradation in soil under aerobic conditions (EPA 1999). Chlorothalonil can contaminate surface water via spray drift or through runoff and erosion. Chlorothalonil in the soil under aerobic conditions degrades to SDS-3701. SDS-3701 appears to be more persistent, mobile, and available for runoff for longer periods than chlorothalonil. However, studies have shown that SDS-3701 is significantly less toxic than parent chlorothalonil (EPA 1999).

Adjuvants. Numerous adjuvants, solvents, and other 'inert' ingredients are also contained in pesticide formulations, many of which are toxic to aquatic species (Stark \& Walthall, 2003), and consequently are also applied in the watersheds. Frequently used adjuvants include surfactants such as nonylphenol polyethoxylates, alkylbenzene sulfonate, polyethoxylated alkyl amines, and others. Toxic solvents include kerosene, naphthalene, cyclohexanone, ethylbenzene, xylene, a variety of oils, and other chemicals. Inert ingredients are generally inclusive of adjuvants and solvents, but may include other additives as well. The proprietary nature of many pesticide formulations can make analyzing pesticide formulation toxicity mechanisms difficult due to undisclosed ingredients.

Adjuvants include the following:

1. Surfactants (surface-active ingredients). These are substances that improve the emulsifying, dispersing, spreading, wetting, or other surface-modifying properties of liquids. Surfactants include emulsifying agents, crop oils, concentrates, and stickers. 
2. Emulsifying Agents. An emulsion is a mixture of two incompletely mixed liquids, one which is dispersed in the other. Emulsifying agents work to promote the suspension of one liquid in the other. In herbicides, there are two types of emulsions: "Oil-in-water" emulsion, in which the spray mixture is similar to water; and "water-in-oil" emulsion, a rather viscous spray, also called "invert" emulsions. The "oil-in-water" emulsions are widely used in the formulation of herbicides to aid in getting an oil-soluble herbicide dispersed in a water mixture so that the active ingredient may be applied as a water spray. Inert emulsions are used to aid in drift control, to improve resistance of the herbicide treatment to the effects of weather (rain), to improve accuracy of delivery of the herbicide, and to enhance herbicide activity.

3. Wetting Agents (spreaders). Spreaders are added to decrease surface tension in a mixture and cause a larger portion of each spray droplet to come in contact with surface of the vegetation. The goal is to increase coverage and effectiveness, although it may also alter herbicide selectivity. There are four spreader types: (1) Anionic, which has an electrical charge in water; (2) cationic, which has an electrical charge in water; (3) nonionic, which does not have an overall electrical charge; and (4) amphoteric, which has positive or negative charges, depending on the $\mathrm{pH}$ of the solution.

4. Drift Control Agents. Drift of herbicide sprays can be a problem in some environments. One way to reduce herbicide drift is to increase the droplet size of the spray. Adjuvants that are used to control drift do so, in part, by reducing the number of fine spray droplets. Thickeners may be used as drift control agents.

5. Crop Oil Concentrates. These are products that contain $80-85 \%$ petroleum or vegetable oil and 14-20\% surfactant and emulsifiers. An "emulsifiable oil," on the other hand, is a product that contains $98 \%$ oil and $1-2 \%$ emulsifiers. This group is also called "nonphytotoxic oils" and "phytobland oils."

6. Stickers. These are adjuvants that cause herbicide to stick to foliage and prevent runoff from target vegetation. The desired result is increased effectiveness.

7. Compatibility Agents. These are adjuvants that aid in the suspension of herbicides when they are combined with other pesticides or fertilizers. Used primarily when the carrier solution is a liquid fertilizer.

8. Acidifiers and Buffers. Acidifiers are acids that neutralize alkaline solutions and lower $\mathrm{pH}$ when added to herbicide, while buffers can change the $\mathrm{pH}$ to a certain level and maintain it, even if the alkalinity changes.

9. Antifoaming Agents and Spray Colorants. Defoaming agents and dyes.

\section{Specific Inert Ingredients Known to be Present in Products Proposed for Use.}

Cyclohexanone. Cyclohexanone is present in the Digon ${ }^{\circledR} 400$ formulation of dimethoate.

Ethylbenzene. Present in the Asana ${ }^{\circledR}$ XL formulation of esfenvalerate and the Pounce ${ }^{\circledR}$ 3.2 EC formulation of permethrin. This inert ingredient is most commonly found in vapor form since it moves easily into the air from water and soil. In the air, ethylbenzene is broken down by sunlight in approximately three days. In surface water, it breaks down by reacting with other pesticides. In soils, ethylbenzene is broken down by bacteria. 
Light aromatic solvent naphtha. Present in the Pounce ${ }^{\circledR} 3.2$ EC formulation of permethrin. Light aromatic solvent naphtha is slightly toxic to terrestrial species, as illustrated by the data summarized in the RA.

Petroleum distillates. Present in the Digon ${ }^{\circledR} 400$ formulation of dimethoate.

Xylene. Present in the Asana ${ }^{\circledR}$ XL formulation of esfenvalerate and the Pounce ${ }^{\circledR} 3.2 \mathrm{EC}$ formulation of permethrin. The inert ingredient xylene very quickly evaporates into the air from surface water and soil where it may remain for several days until it is broken down by sunlight. Because xylene is applied as a liquid, it does have the potential to infiltrate into the soil. Most xylene insurance water evaporates into the air in less than a day. Xylene is more persistent in groundwater where evaporation is impaired.

In some cases, the pesticide active ingredient may be less toxic to aquatic species than the 'inert' ingredients. The herbicide glyphosate provides a classic example. The LC50 values for rainbow trout range for technical grade glyphosate range from $86 \mathrm{mg} / \mathrm{L}$ to $140 \mathrm{mg} / \mathrm{L}$ (EPA, 1993). However, LC50 values for rainbow trout to glyposate formulations range from $8.2 \mathrm{mg} / \mathrm{L}$ to $>1000 \mathrm{mg} / \mathrm{L}$ (EPA 1993), depending on the adjuvants and surfactants added.

Herbicide mobility in soil can be increased by the use of surfactants, but effects to mobility are unlikely due to the relatively low concentration of surfactants in the soil/water matrix at Forest Service application rates (Bakke 2002) which are comparable to BLM application rates. In general, it appears that aquatic species are more susceptible to adverse effects from surfactants than terrestrial species. At least some of the aquatic sensitivity to surfactants is due to irritation of gill membranes and alteration of their permeability and molecular exchange properties.

Impurities may also pose risks for aquatic species. Hexachlorobenzene, classified as a human carcinogen, is an impurity in picloram (SERA 2003). Hexaclorobenzene is ubiquitous and persistent in the environment. Under typical application scenarios, it volatilizes from the soil or vegetation surface, but can bioconcentrate in fish if it reaches aquatic habitats.

Hexachlorobenzene can contaminate water by runoff or volatilization and deposition in rainwater. Because hexachlorobenzene binds tightly to soil, it is not likely to percolate through soil to contaminate groundwater.

\section{Effects of IPM Implementation}

Chemical use within the proposed IPM program is reasonably likely to result in sublethal adverse effects to listed salmonids within the action area. Within the past several years, the following studies documented that significant sublethal effects to salmonids can result from exposure to pesticides and other toxic pesticides. Sandahl et al. (2004) documented that chlorpyrifos (an organophosphate insecticide) and copper (a metal) both caused loss of olfactory sensory function in juvenile coho salmon at environmentally relevant concentrations. A $20 \%$ reduction in olfactory sensory function occurred at $4.4 \mu \mathrm{g} / \mathrm{l}$ for copper and $0.72 \mu \mathrm{g} / \mathrm{l}$ for chlorpyrifos. In addition, Sandahl et al. (2004) demonstrated that a concentration of $0.2 \mu \mathrm{g} / \mathrm{l}$ of 
the insecticide esfenvalerate evoked distinct and irregular bursts of postsynaptic activity in the olfactory bulb of juvenile coho salmon. These effects could interfere with olfactory mediated behaviors that are important for the survival and migration of salmonids.

Scholz et al. (2000) documented sublethal behavioral effects in Chinook salmon from the insecticide diazinon at concentrations as low as $1.0 \mu \mathrm{g} / \mathrm{l}$. Since the behavioral effects observed by Scholz et al. included inhibition of predator avoidance, the 'sublethal' exposure could ultimately result in death.

Accurate assessment and understanding of sublethal effect thresholds are further complicated by allostatic loading, as described by McEwen and Wingfield (2003). Briefly, allostatic loading results when organisms are exposed to multiple stressors during their life cycle that reduce the chance of reproductive stress. Given the emerging understanding of the risks of allostatic loading, the pesticides in the proposed action (including other organophosphates and pyrethroids) have the potential for low-dose sublethal effects.

Further, in a study of environmental contaminants on behavior, Weis et al. (2001) stated: "It is assumed that effects at the molecular and cellular levels precede detectable effects at the individual organism level, which precede effects at the population and community level." As evidence, Weis (2001) found that neurotoxic effects at the biochemical level altered the predatorprey behavior of the mummichog, (Fundulus heteroclitus) which then had consequences that were in clear connection on the population and community structure such as reduced growth and condition. Pollution exposure, whether it be from elevated pesticide concentrations or more conventional impacts such as anoxia or high temperature, may also lead to reduced growth rates and infection for juvenile salmonids but even these responses are preceded in time by effects at the molecular level and can have connections to the population and community level.

Most adverse effects from the chemical portion of the IPM plan are likely to be sublethal, which can be further divided into narcosis and rheotropism. Sublethal or nonlethal endpoints do not require that mortality be absent, rather, they indicate that death is not the primary toxic endpoint being examined. Rand (1995) states that the most common sublethal endpoints in aquatic organisms are behavioral (e.g., swimming, feeding, attraction-avoidance, and predator-prey interactions), physiological (e.g., growth, reproduction, and development), biochemical (e.g., blood enzyme and ion levels), and histological changes (e.g., degenerative necrosis of the liver, kidneys, and gill lamellae; Lorz et al. 1979). Some sublethal effects may indirectly result in mortality. Changes in certain behaviors, such as swimming or olfactory responses, may diminish the ability of the salmonids to find food or escape from predators and may ultimately result in death. Some sublethal effects may have little or no long-term consequences to the fish because they are rapidly reversible or diminish and cease with time. Individual fish may exhibit different responses to the same concentration of toxicant. The individual condition of the fish can significantly influence the outcome of the toxicant exposure. Fish with greater energy stores will be better able to survive a temporary decline in foraging ability, or have sufficient metabolic stores to swim to areas with better environmental conditions. Fish that are already stressed are 
more susceptible to the deleterious effects of contaminants, and may succumb to toxicant levels that are considered sublethal to a healthy fish.

Narcosis and rheotropism, discussed further below, are two types of sublethal effects that compromise salmonids ability to migrate, feed, and seek refuge from predators. In some instances, sublethal effects such as reduced predator avoidance, may indirectly result in injury or mortality to ESA-listed salmonids, through increased predation.

Sublethal Effect - Narcosis. When exposed to elevated concentrations of polar and nonpolar organic pesticides, fish can become narcotized. Narcosis is a generalized, nonselective toxicity response that is the result of a general disruption of cell membrane function. The process of narcosis is poorly understood, but is thought to involve either a 'critical volume' change in cellular membranes due to the toxicant dissolving into the lipid membrane and altering its function, or by the 'protein binding' process in which hydrophobic portions of receptor proteins in the lipid membrane are bound by the toxicant molecules, thus changing the receptor protein's function (Rand 1995). A fish with narcosis is more susceptible to predation as a result of a loss of equilibrium, a reduction in swimming ability or a lack of predator avoidance behavior. Furthermore, a fish with narcosis also has difficulty maintaining its position in the water column, and can be carried by water currents into areas of sub-optimal water quality.

Sublethal Effect - Rheotropism. Rheotropism refers to fish behavior in a current of water, either directly as a response to water flowing over the body surface or indirectly as a response to the visual, tactile or inertial stimuli resulting from the displacement of fish in space (Dodson and Mayfield 1979). Several studies involving the herbicide 2, 4-D (which is not proposed for use in the IPM) provide example's of rheotropism. Folmar (1976) used rainbow trout fry in an investigation to determine whether fish avoided water contaminated by 2, 4 D. At concentrations of 1.0 or $10.0 \mathrm{mg} / \mathrm{L}$ of $2,4-\mathrm{D}$, there was significant avoidance of the chemical. Similarly, Dodson and Mayfield (1979) assessed the effect of 2,4-D on the reotaxic response (the tendency to swim upstream to compensate for flowing water) of rainbow trout. The report stated that, at 'realistic concentrations' of 2,4-D in water, there would be a tendency for fish to be moved downstream because of a reduced reotaxic response.

Chemical Interactions and Mixture Toxicity. Rand (1995) states that in 'assessing chemically induced effects (responses), it is important to consider that in the natural aquatic environment organisms may be exposed not to a single chemical but rather to a myriad or mixture of different substances at the same or nearly the same time. Exposures to mixtures may result in toxicological interactions.' A toxicological interaction is one in which exposure to two or more chemical residues results in a biological response quantitatively or qualitatively different from that expected from the action of each chemical alone. Exposure to two or more chemicals simultaneously may produce a response that is simply additive of the individual responses or one that is greater (synergistic) or less (antagonistic) than expected from the addition of their individual responses. Application of pesticides within the IPM is likely to contribute to elevated toxicological responses caused by other sources of chemical pesticides within the action area. 
As discussed within the cumulative effects section, at least 27 different herbicides/pesticides are applied within the Siuslaw Watershed (USGS 2003).

The temporal and spatial variability of the composition of mixtures, along with local water quality parameters, makes understanding and predicting relative effects a complex and challenging task. Furthermore, sub-lethal effects, which by nature are less apparent than lethality, have rarely been studied in conjunction with exposure to chemical mixtures (Kraak et al. 1994 as cited in Forget et al., 1999).

Given the proposed five-year implementation of the IPM plan and the number of herbicides and pesticides and application events, many discreet variables will influence relative effects (i.e., exposure) to listed salmonids. Variables range from weather (wind/rain/temperature/humidity), the fate characteristics of the pesticide, herbicide or fertilizers, implementation of CPs, the particular application area's topography and composition of the nearest waterway buffer, the lifestage of the salmonid, relative water quality, and background concentrations from non-BLM applications. The pathways of potential exposure to listed salmonids and their prey base can be from waterborne delivery, either through overland flow or subsurface flow, or through airborne drift soon after application.

To explore the likelihood/magnitude of exposure from individual applications, the BLM addressed predicted effects from the standpoint of the lowest observable effects level from individual pesticides, herbicides and fertilizers. The BLM incorporated several models to conduct this analysis. Drift was modeled through the Agricultural Drift (AgDRIFT) model and runoff was predicted using the GLEAMS and MOC models. The use of models to predict environmental concentrations resulting from pesticide, herbicide and fertilizer use is complicated by the wide range variables described above. To simplify the task, the BLM incorporated a limited number of application scenarios based on anticipated operations and circumstances. While the scenarios chosen in the RA are intended for use in predicting expected conditions, a conservative bias or worst possible case scenario was incorporated when assumptions were required. General model assumptions are discussed below, and discussed in more detail further within this analysis:

The GLEAMS model was used to predict runoff of chemicals and water as they might be measured at the edge of each orchard unit. However, the Tyrrell units generally have significant areas of untreated field edges and well-vegetated buffers between treated acreage and receiving streams. These untreated intervening areas, collectively termed 'buffer zones,' are expected to have a significant effect in reducing the amount of chemicals that actually reach streamwater. To account for the attenuating effect of buffer zones, the MOC model was set up to represent steady saturated shallow subsurface flow across a minimum 30 -foot buffer zone. The fate and transport modeling assumptions used in the RA correspond to the pesticide application details of (Maximum Production IPM), and that the proposed action (Alternative B, IPM with Environmental Protection Emphasis) actually contains additional limitations on certain aspects of chemical pesticide and fertilizer use to provide added protection to human health and the environment. 
The proposed action was developed based on the results of the RA. These limitations, such as the use of wider buffers for certain pesticide application methods, provide additional protection against the possibility of adverse effects to listed fish species.

The BLM used the Quotient Method (EPA 1986) in their BA to evaluate risk to aquatic organisms and threatened salmonids. However, the method is based on lethal response and assumes that the dose/response curve resembles a typical curve produced from a toxicological model presented in the 1975 Regulations for the Enforcement of the Federal Insecticide, Fungicide, and Rodenticide Act (40 C.F.R. 154). Furthermore, the EPA (1986) states that the procedure does not indicate the 'probability of adverse effects,' and that they 'view the risk of criteria with their safety factors as 'rough' estimates of potential risk to non-target species.' Similarly, NMFS does not currently recognize this method as being sufficiently protective of ESA-listed species. In the context of this consultation and given the lack of more specific information to the contrary, NMFS considers the $1 / 20^{\text {th }}$ value procedure as a conservation measure that attempts to minimize, though not avoid, lethal or sublethal effects in coho salmon. NMFS has used the $1 / 20^{\text {th }}$ value in conjunction with the LC50 value and the most conservative sublethal effect concentration available in the literature to assist in evaluating the effects of the proposed action.

For sublethal effects, the lowest observed effect concentration (LOEC) from each of the three assessment endpoints was selected for the risk evaluation. The selected LOECs are intended to be the most conservative, representative estimates available for adverse effects at all life-stages related to survival, migration, or reproduction. The estimated pesticide concentration over the sublethal effect level was defined as an effects ratio. Risks to survival, migratory, and reproductive endpoints were determined to be low if the effects ratio was 0.1 or below, moderate if 0.1 to 1.0 , and high if 1.0 or greater.

While the modeling assumptions are conservative, it is important to note model results just express output concentrations from applications that do not account for potential multiple exposures to listed fish and to their supporting ecosystems. Multiple exposures to single or combined pesticides, herbicides and fertilizers from the proposed multi-year, multi-location BLM applications may be delivered to non-target aquatic habitats, particularly during fall and spring runoff events. Potential non-target runoff areas support each of the listed salmonid life history stages. Repeated exposure to the same pesticides, herbicides or fertilizers or from exposure to mixtures are likely to result in adverse effects to listed salmonids. Moreover, the risk of adverse effects increase when BLM produced pesticide herbicide or fertilizer runoff is added to waterways that are already contaminated. The BA indicates that receiving waterways with listed fish have elevated temperatures during certain periods of the year. Studies have demonstrated that elevated temperatures may increase the susceptibility of listed fish or their prey base to small concentrations of pesticides, herbicides or fertilizers (Folmar et al. 1979; Woodward 1976; Kumaraguru and Beamish 1986).

NMFS is unaware of a comprehensive data set for chemical contamination/nutrients within the receiving waterways bearing ESA-listed OC coho salmon: The Siuslaw River, Douglas Creek, 
and Stream 8. However, given some of the land uses that are known to occur in the watershed, it can be assumed that some level of fertilizer, pesticide, and herbicide contamination has likely occurred, and will likely occur within the five-year implementation of the IPM. The risk of adverse effects increase when BLM chemical runoff is added to waterways that may have chemical concentrations from concurrent runoff or drift.

The volumes, timing and types of substances that may be delivered to aquatic systems from nonBLM applications in the action area are likely to be highly variable. It is generally understood that mixtures of some types of pesticides are likely to produce cumulative toxicity and lethal and sublethal effects in salmonids (EPA 1999). In addition, the Siuslaw River exceeds summer water temperature optimum, while studies have demonstrated that elevated temperatures may increase the susceptibility of listed fish or their prey base to small concentrations of chemicals (Folmar et al. 1979; Woodward 1976; Kumaraguru and Beamish 1986).

For the purpose of this analysis, the calendar year has been divided into three general zones of exposure risk to listed coho from the proposed action, as depicted in Figure 1. The three zones correlate with differing levels of precipitation, levels of chemical use, and lifestages of OC coho salmon likely to be occupying the Siuslaw River and Stream 8, Stream 1, and Douglas Creek. Through these three zones, the precipitation and number and type of chemical applications determine the relative risk $\mathrm{OC}$ coho salmon and their prey species. 
Figure 1. Timing of Listed Species by Lifestage and Annual Precipitation - Tyrrell

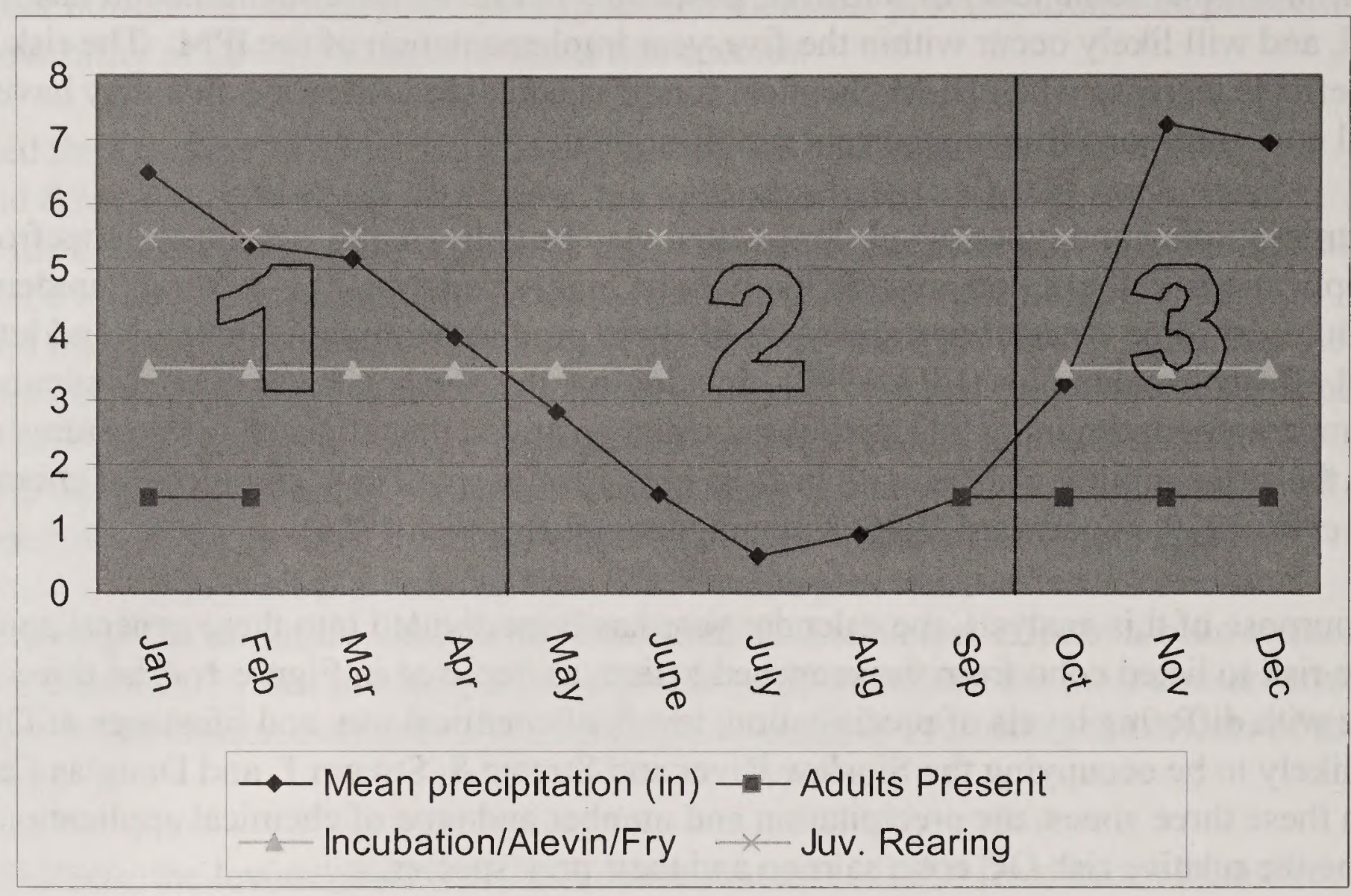

Corresponding to Figure 1, the precipitation and lifestages and relative risk of exposure has been summarized in Table 9. 
Table 9. Precipitation, Lifestage, and Application/Delivery Risk to OC coho salmon.

\begin{tabular}{|c|c|}
\hline $\begin{array}{l}\text { Zone One } \\
\text { (January } \\
\text { through April) }\end{array}$ & $\begin{array}{l}\text { Precipitation ranges from } 3.5 \text { to } 6.5 \text { inches per month. Approximately } 55 \% \text { of annual } \\
\text { precipitation occurs in this period. }\end{array}$ \\
\hline $\begin{array}{l}\text { Coho } \\
\text { Lifestage(s) }\end{array}$ & Adults, incubating eggs (alevins) and newly-emerged fry, as well as juveniles up to 1.5 years old. \\
\hline $\begin{array}{l}\text { Applications and } \\
\text { delivery risk: }\end{array}$ & $\begin{array}{l}\text { Most BLM applications would occur during the latter stages (March and April) of zone one as the } \\
\text { growing season arrives. }\end{array}$ \\
\hline $\begin{array}{l}\text { Zone Two (May } \\
\text { through } \\
\text { September) }\end{array}$ & $\begin{array}{l}\text { Precipitation ranges from less than one to over three inches per month. Approximately } 13 \% \text { of } \\
\text { the annual precipitation occurs in this period. }\end{array}$ \\
\hline $\begin{array}{l}\text { Coho } \\
\text { Lifestage(s) }\end{array}$ & $\begin{array}{l}\text { Alevin/fry in May, June, and rearing juveniles throughout. Adults are present in the latter stages of } \\
\text { zone. }\end{array}$ \\
\hline $\begin{array}{l}\text { Applications and } \\
\text { delivery risk: }\end{array}$ & $\begin{array}{l}\text { Zone two generally encompasses the most risk from insect pest as well as the vegetation growing } \\
\text { season, thus the majority of BLM applications are proposed to occur within zone two. Since most BLM } \\
\text { chemical applications will occur within this time-frame, the greatest potential for accumulation of } \\
\text { chemicals on orchard grounds exist. Esfenvalerate is scheduled to undergo a majority of its applications } \\
\text { during this time frame. This chemical has been identified by NMFS to carry a high risk to aquatic } \\
\text { species due to the frequency of applications and its relative toxicity to salmonids and their preybase. }\end{array}$ \\
\hline $\begin{array}{l}\text { Zone Three } \\
\text { (October } \\
\text { through } \\
\text { December): }\end{array}$ & Precipitation rises dramatically from almost three inches in October to over seven in November. \\
\hline $\begin{array}{l}\text { Coho } \\
\text { Lifestage(s) }\end{array}$ & Rearing juveniles are fully present during this zone as well as adults. \\
\hline $\begin{array}{l}\text { Applications and } \\
\text { delivery risk: }\end{array}$ & $\begin{array}{l}\text { Within this zone, most BLM applications would occur during the beginning of this zone, though there } \\
\text { may be several applications (over the five year term) in each month. The increase in precipitation } \\
\text { during this zone could deliver chemicals that have accumulated (but not yet delivered to aquatic } \\
\text { systems) on orchard grounds from zone one, and particularly zone two through runoff and subsurface } \\
\text { flow pathways. A sudden spike in the hydrograph can potentially lead to a pulse of contaminants to the } \\
\text { waterbodies. This scenario holds particular relevance for esfenvalerate. As previously mentioned, a } \\
\text { majority of its applications will occur in the preceding time zone, resulting in accumulation followed by } \\
\text { transport. }\end{array}$ \\
\hline
\end{tabular}

Factors of Uncertainty. Predicting exposure levels or effects from specific exposure levels is difficult because of the uncertainty inherent in the tools used to conduct effects analyses. Sources of analytical tool uncertainty are lack of information regarding laboratory to field extrapolation, mixture effects, toxicity and behavior of degradation/metabolic products, use of physiologically/ecologically relevant endpoints based on the pesticide mechanism of action, and reliance on short-term toxicity tests. All of these sources of uncertainty fall into one or more of three basic categories: (1) Parameter uncertainty (measurement, sampling, and systematic errors); (2) modeling uncertainty (simplification of real world processes, model misuse, use of 
inappropriate surrogates); and (3) scenario uncertainty (descriptive, aggregation, and professional judgement errors).

Examples of sources of uncertainty associated with the proposed project are: (1) The fate of herbicides in streams; (2) modeling uncertainty; (3) the site-specific foraging habits of salmonids and the vulnerability of key prey taxa; (4) the toxicity of pesticide mixtures; and (5) the mitigating or exacerbating effects of local environmental conditions. Where appropriate, these and other uncertainties will be identified, and where uncertainties cannot be resolved using the best available scientific literature, the benefit of the doubt will be given to the threatened or endangered species in question.

\section{Vectors of Exposure.}

Waterborne Delivery. The BA indicated that there are three primary scenarios of pesticides reaching the stream channel due to the proposed action:

1. Drift from chemical spray. This period of concern lasts on the order of hours, usually until the chemical has been allowed to dry on foliar surfaces.

2. Runoff from the fields to which spray is applied. This period also lasts on the scale of several hours, during which time the rain flowing over foliar and soil surfaces collects the most available chemical residues (either dissolved or associated with fine particulate).

3. Potential spills in and near stream channels. Spills are instantaneous loads of pesticide delivery directly into the water.

These scenarios have the potential to transport chemicals to adjacent drainages and waterways which listed salmonids occupy for migration, rearing, and spawning. Large amounts of precipitation which expands the ephemeral stream system can result in flowing water coming into contact with pesticide deposits (Norris 1980, as cited in Dent and Robben 2000). The adsorption potential, stability, solubility, and toxicity of a chemical determines the extent to which it will migrate and adversely effect surface waters and groundwater (Spence et al. 1996).

Chemical Drift. Drift occurring immediately after application is one way that exposure to non-target species may occur outside the application area. In evaluating drift effects to nontarget species, the BLM modeled off-target pesticide drift from aerial applications, airblast applications, and applications using a tractor-pulled rig with a boom using AgDRIFT, a cooperative model developed by the EPA Office of Research, the United States Department of Agriculture (USDA) Agricultural Research Service, the Forest Service, and the Spray Drift Task Force.

Aerial applications, ground vehicle, and hand methods of pesticide applications could result in spray drift and volatilized chemicals. Data from field studies were used to characterize drift from applications using high-pressure hydraulic sprayers, hand-held wands, and backpack sprayers. For all applications, the highest of the deposition values predicted for all potentially treated orchards was used as the input to the quantitative risk calculations. The AgDRIFT model 
was used to estimate off-target drift deposition from ground boom applications of the herbicides dicamba and glyphosate.

Drift is dependent on gravity, air movement, and droplet size. ${ }^{14}$ Smaller droplets stay aloft longer and the longer a droplet is suspended the greater the potential for it to be translocated by air currents. A droplet size of 100 microns (mist) takes 11 seconds to fall 10 feet in still air. The same size droplet would travel 13.4 feet in a one mph wind while dropping that same 10 feet, and 77 feet at $5 \mathrm{mph}$. Application pressure, nozzle size, nozzle type, spray angle, and spray volume are all factors in determining droplet size. Droplet sizes increase with decreasing pressure and larger nozzle sizes. An indicated droplet size (i.e., 300 microns) actually represents a median diameter of all droplets. Actual droplet sizes will range from considerably smaller as well as larger than the indicated droplet size. During temperature inversions little vertical air mixing occurs and drift can translocate contaminates several miles. In addition, low relative humidity and/or high temperature conditions will increase evaporation and the potential for drift. Proposed buffers, application criteria, and concurrent drift monitoring reduce this risk. Application during calm conditions reduce spray drift. Modeling was completed using the following scenarios:

\section{Parameter}

Boom height above canopy

Swath width

Wind speed

Temperature (April 15)

Temperature (May 31-June 1)

Temperature (July 1)

Relative humidity (April 15)

Relative humidity (May 31-June 1)

Relative humidity (July 1)

\section{Typical Scenario}

15 feet

45 feet

$3 \mathrm{mph}$

$40^{\circ} \mathrm{F}$

$60^{\circ} \mathrm{F}$

$75 \%$

$75 \%$

\section{Maximum Scenario}

15 feet

45 feet

$6 \mathrm{mph}$

$40^{\circ} \mathrm{F}$

$60^{\circ} \mathrm{F}$

$70^{\circ} \mathrm{F}$

$75 \%$

$65 \%$

$50 \%$

Predicting environmental concentrations resulting from pesticide and fertilizer use at Tyrrell is complicated by the wide range of chemical, environmental, and operational assumptions. The modelers dealt with this uncertainty by choosing a limited number of scenarios based on anticipated operations and circumstances.

For example, the GLEAMS model was used to predict runoff of chemicals and water as they might be measured at the edge of each orchard unit. However, Tyrrell's orchard units have areas of well-vegetated buffers between treated acreage and receiving streams, typically be in the range of 50 to 100 feet or more. To account for the attenuating effect of buffer zones, the MOC model was set up to represent steady saturated shallow subsurface flow across a minimum 30 foot buffer zone. However, as previously mentioned, the spray buffers at Tyrrell are generally wider than the 30-foot buffer zone used in the model.

${ }^{14}$ NebGuide website at $<$ http://www.ianr.unl.edu/pubs/pesticides/g1001.htm 
In addition, fate and transport modeling assumptions used in the risk assessment correspond to the pesticide application details of (Maximum Production IPM) that do not contain the additional limitations on certain aspects of chemical pesticide and fertilizer use to provide added protection to human health and the environment. These additional limitations are currently in place under the proposed action.

For both aerial and ground applications, the highest of the deposition values predicted for all potentially treated orchards was used as the input to the quantitative risk calculations. No drift beyond buffer areas is expected from other ground application methods, based on the results of field studies summarized in the RA report.

Table 10 shows a comparison of the exposure profile data (estimated water concentrations from spray drift) specific to Stream 8, Douglas Creek, and the Siuslaw River to stressor-response profile data (referenced LOEC's ) taken from attachment C of the BA to estimate the risk of adverse effects. The estimated surface water concentrations are extremely low, several orders of magnitude below the levels of concern. The levels of concern are determined following the quotient methodology used by EPA's Office of Pesticide Programs (Sec 9.1 in Tyrrell RA).

Table 10. RA-Modeled Stream Concentrations of Pesticides Under the Proposed Action Resulting from Application Drift, and Salmonid Effect Concentrations Selected by NMFS for Effects Evaluation.

\begin{tabular}{|c|c|c|c|c|c|c|c|c|c|}
\hline \multirow[b]{2}{*}{ Pesticide } & \multicolumn{2}{|c|}{ Stream 8} & \multicolumn{2}{|c|}{ Douglas Creek } & \multicolumn{2}{|c|}{ Siuslaw River } & \multicolumn{3}{|c|}{ Effect Concentration } \\
\hline & Тур & $\operatorname{Max}$ & Тур & $\operatorname{Max}$ & Typ & $\operatorname{Max}$ & $\begin{array}{c}\text { LOEC } \\
(\mathrm{mg} / \mathrm{L})^{*}\end{array}$ & End-point & REF \\
\hline \multicolumn{10}{|c|}{ Aerial (helicopter) } \\
\hline Esfenvalerate & $3.26 \mathrm{E}-010$ & na & $9.83 \mathrm{E}-011$ & na & $1.18 \mathrm{E}-011$ & na & $2.50 \mathrm{E}-005$ & predation & $\begin{array}{l}\text { Little et al. } \\
\qquad 1993\end{array}$ \\
\hline -Ethylbenzene & $1.17 \mathrm{E}-011$ & na & $4.20 \mathrm{E}-012$ & na & $7.89 \mathrm{E}-013$ & na & 14 & mortality & $\begin{array}{l}\text { Mayer \& } \\
\text { Ellersieck }\end{array}$ \\
\hline - Xylene & $3.05 \mathrm{E}-011$ & na & $1.26 \mathrm{E}-011$ & na & $2.37 \mathrm{E}-012$ & na & 0.1 & rearing & $\begin{array}{c}1986 \\
\text { Folmar } 1976\end{array}$ \\
\hline \multicolumn{10}{|l|}{ Airblast sprayer } \\
\hline Esfenvalerate & $2.27 \mathrm{E}-007$ & $3.50 \mathrm{E}-007$ & $6.48 \mathrm{E}-008$ & $1.23 \mathrm{E}-007$ & $8.18 \mathrm{E}-009$ & $1.27 \mathrm{E}-008$ & $2.50 \mathrm{E}-005$ & predation & $\begin{array}{l}\text { Little et al. } \\
\qquad 1993\end{array}$ \\
\hline -Ethylbenzene & $8.11 \mathrm{E}-009$ & $4.28 \mathrm{E}-008$ & 2.92E-009 & $1.67 \mathrm{E}-008$ & $9.74 \mathrm{E}-010$ & $1.79 \mathrm{E}-009$ & 14 & mortality & $\begin{array}{l}\text { Mayer \& } \\
\text { Ellersieck }\end{array}$ \\
\hline - Xylene & $2.43 \mathrm{E}-008$ & $1.45 \mathrm{E}-007$ & 8.77E-009 & $5.00 \mathrm{E}-008$ & $2.92 \mathrm{E}-009$ & $5.36 \mathrm{E}-009$ & 0.1 & rearing & $\begin{array}{c}1986 \\
\text { Folmar } 1976\end{array}$ \\
\hline
\end{tabular}




\begin{tabular}{|c|c|c|c|c|c|c|c|c|c|}
\hline \multirow[b]{2}{*}{ Pesticide } & \multicolumn{2}{|c|}{ Stream 8} & \multicolumn{2}{|c|}{ Douglas Creek } & \multicolumn{2}{|c|}{ Siuslaw River } & \multicolumn{3}{|c|}{ Effect Concentration } \\
\hline & Typ & $\operatorname{Max}$ & Typ & Max & Typ & Max & $\begin{array}{c}\text { LOEC } \\
(\mathrm{mg} / \mathrm{L})^{*}\end{array}$ & End-point & REF \\
\hline \multicolumn{10}{|c|}{ Tractor-pulled spray rig with boom } \\
\hline Propiconazole & $4.35 \mathrm{E}-009$ & $7.24 \mathrm{E}-007$ & $1.98 \mathrm{E}-013$ & $3.09 \mathrm{E}-013$ & $6.46 \mathrm{E}-011$ & $9.53 \mathrm{E}-009$ & 0.24 & mortality & $\begin{array}{c}\text { Grande et al } \\
1994\end{array}$ \\
\hline $\begin{array}{l}\text { Glyphosate } \\
\text {-circles around } \\
\text { trees }\end{array}$ & $9.00 \mathrm{E}-007$ & $1.10 \mathrm{E}-007$ & $2.23 \mathrm{E}-007$ & $3.45 \mathrm{E}-007$ & $2.73 \mathrm{E}-008$ & $3.89 \mathrm{E}-008$ & & & \\
\hline $\begin{array}{l}\text { Glyphosate } \\
\text {-strips between } \\
\text { rows }\end{array}$ & $2.02 \mathrm{E}-005$ & $2.37 \mathrm{E}-005$ & 8.27 E-007 & $1.17 \mathrm{E}-006$ & $9.28 \mathrm{E}-008$ & $1.24 \mathrm{E}-007$ & $\begin{array}{c}0.046 \\
(\mathrm{NOEC})\end{array}$ & $\begin{array}{l}\text { migration \& } \\
\text { growth }\end{array}$ & $\begin{array}{c}\text { Morgan \& } \\
\text { Kiceniuk } \\
1992\end{array}$ \\
\hline $\begin{array}{l}\text { Glyphosate } \\
\text {-Rd/Fal } \\
\end{array}$ & $3.21 \mathrm{E}-006$ & $3.95 \mathrm{E}-006$ & $1.32 \mathrm{E}-007$ & $1.94 \mathrm{E}-007$ & $1.48 \mathrm{E} 008$ & $2.07 \mathrm{E} 008$ & & & \\
\hline $\begin{array}{l}\text { Hexazinone } \\
\text {-Boom-circles }\end{array}$ & $8.10 \mathrm{E}-007$ & $1.05 \mathrm{E}-006$ & $3.32 \mathrm{E}-008$ & $3.05 \mathrm{E}-007$ & $2.46 \mathrm{E}-008$ & $3.88 \mathrm{E}-008$ & & & \\
\hline $\begin{array}{l}\text { Hexazinone } \\
\text {-strips }\end{array}$ & $1.19 \mathrm{E}-005$ & $1.57 \mathrm{E}-005$ & 4.89E-007 & $8.07 \mathrm{E}-007$ & $3.62 \mathrm{E}-007$ & $8.60 \mathrm{E}-008$ & 14.5 & mortality & $\begin{array}{c}\text { Wan et al. } \\
1988\end{array}$ \\
\hline $\begin{array}{l}\text { Hexaninone } \\
\text {-Boom } \\
\text { Rd/Fence }\end{array}$ & $1.93 \mathrm{E}-006$ & $7.10 \mathrm{E}-006$ & $7.89 \mathrm{E}-008$ & $3.50 \mathrm{E}-007$ & $8.85 \mathrm{E}-009$ & $3.73 \mathrm{E}-008$ & & & \\
\hline $\begin{array}{l}\text { Picloram } \\
\text {-Boom }\end{array}$ & $2.70 \mathrm{E}-006$ & $9.96 \mathrm{E}-006$ & 7.89E-009 & $3.42 \mathrm{E}-009$ & $5.86 \mathrm{E}-008$ & $2.02 \mathrm{E}-007$ & 0.035 & growth & $\begin{array}{c}\text { Woodward } \\
1976\end{array}$ \\
\hline $\begin{array}{l}\text { Triclopyr TEA } \\
\text {-Boom }\end{array}$ & $1.48 \mathrm{E}-006$ & $9.25 \mathrm{E} 006$ & $6.28 \mathrm{E} 007$ & $2.73 \mathrm{E}-006$ & $8.29 \mathrm{E}-008$ & $3.16 \mathrm{E}-007$ & 47.4 & Mortality & EPA 1998a \\
\hline $\begin{array}{l}\text { Triclopyr BEE } \\
\text {-Boom }\end{array}$ & $\begin{array}{l}1.48 \mathrm{EE}- \\
006\end{array}$ & $8.32 \mathrm{E}-006$ & 4.05E-007 & $2.43 \mathrm{E}-006$ & 4.93E-008 & $2.81 \mathrm{E}-007$ & 0.033 & mortality & EPA $1998 a$ \\
\hline
\end{tabular}

* Selected LOEC's are for various species of fish and might be less for aquatic macroinvertebrates (relevant to all tables)

** Numerical values represent scientific notation.

From the perspective of viewing each application as a stand-alone event, the likelihood of direct adverse effects to OC coho salmon from drift are remote. The attenuating effects of vegetative buffer zones, the conservative nature of the analysis, the ecological protection measures in place (as described within the proposed action), and the individual modeled concentrations lead to this conclusion.

However, this judgement is academic in nature; it is solely from the perspective of an individual pesticide application, with no contributing factors such as a degraded baseline or additive and synergistic effects from other chemicals. Further, though the use of models represent the best available technology for predicting drift concentrations, the variables that can determine 
exposure risk (i.e., weather) are likely to be highly variable over the five-year term of the proposed action. Given these factors, there is a reasonable likelihood that runoff concentrations will differ from those predicted and are reasonably likely to lead to adverse effects.

Runoff. The chemical and physical properties of the pesticide such as solubility in water and affinity to soil particles help determine the rate and method of transport. Chemicals that adsorb well to the soil will tend to be immobilized and be broken down in place as opposed to highly soluble chemicals that could be washed away via soil surface or subsurface movement with irrigation or rainwater, and would more likely be a potential contaminant.

The soils at Tyrrell vary from poorly-drained to well-drained soils. A relatively high amount of organic material is returned to the soil each year from leaves and the annual dieback of vegetation. This organic material can adsorb pesticides and retard their movement. However, the BA stated that a high degree of soil compaction from heavy equipment use has occurred. Excessive compaction in cultivated soils results in poor internal drainage, the potential for increased runoff.

Chemical residues can be carried off-site by surface water runoff following the first rain event. Significant rain events can increase erosion of soils with absorbed pesticides or flush of the more soluble chemicals. This period also lasts on the scale of several hours, during which time the rain flowing over foliar and soil surfaces collects the most available chemical residues (either dissolved or associated with fine particulates). Thus, the initial pulse of runoff entering the streams is most likely to carry the highest concentration of bioavailable pesticide residues.

In addition, elevated concentrations of pesticides in Stream 1, Stream 8, Douglas Creek, and the Siuslaw River have the potential to occur during the seasonal rise in precipitation during the months of October through April.

The BLM-assessed runoff and leaching from the proposed action using the GLEAMS and the MOC models. GLEAMS will model the concentration of chemicals that will leave a target field, in this case an orchard block, that is transported by overland flow or that is adsorbed to soil particles transported in the flow by estimation of soil chemical concentrations, initial maximum runoff loadings, and long-term chemical loss in runoff, sediment, and soil below the root zone. The GLEAMS analysis included two scenarios: (1) Typical environmental characteristics and pesticide/fertilizer use; and (2) wet conditions and maximum pesticide/fertilizer use.

The model is not able to predict chemical concentrations reaching streams separated from the target fields by buffer areas. As previously mentioned, the Tyrrell units generally have areas of untreated field edges and well-vegetated buffers between treated acreage and receiving streams. Buffer widths between treated acreage and receiving streams at Tyrrell will typically be in the range of 50 to 100 feet or more. These untreated intervening areas are expected to reduce the amount of chemicals that actually reach streamwater. To account for the attenuating affect of buffer zones, the MOC model developed by the USGS was used. This is a two-dimensional 
groundwater flow and chemical transport model that computes changes in concentration over time, accounting for the processes of dispersion, adsorption, and degradation.

The uncertainty in the GLEAMS model can be attributed to the model's sensitivity to input parameters that were not directly measured and had to be estimated based on available literature. These parameters include pesticide decay rates, foliar washoff, Koc, and soil curve numbers. The decay rates and foliar washoff factors govern the quantity of the contaminant available for movement, whereas the sorption coefficients and the runoff curve numbers govern the actual movement of the contaminants. The aerial coverage influences the mass of pesticide that reaches the ground from application. Uncertainty in these parameters causes the majority of model uncertainty and exacerbates the risk from exposure.

Table 11 shows a comparison of the exposure profile data (estimated water concentrations from runoff and erosion) specific to Stream 8, Douglas Creek, and the Siuslaw River to stressorresponse profile data from attachment $\mathrm{C}$ of the $\mathrm{BA}$ to estimate the risk of adverse effects. With the exception of esfenvalerate, the estimated surface water concentrations are low, several orders of magnitude below the levels of concern. The levels of concern are determined following the quotient methodology used by EPA's Office of Pesticide Programs (Sec 9.1 in Tyrrell RA).

The individually-reported concentrations appear to conclude that direct adverse effects to OC coho salmon from runoff and erosion are remote. From the perspective of viewing each application as a stand alone event, the likelihood of direct adverse effects to coho salmon from runoff and erosion are small. The attenuating effects of vegetative buffer zones, the conservative nature of the analysis, the ecological protection measures in place (as described in the proposed action), and the individual modeled concentrations lead to this conclusion.

However, as for spray drift, this judgement is academic in nature; it is solely from the perspective of an individual pesticide application, with no contributing factors such as a degraded baseline or additive and synergistic effects from other chemicals. Further, though the use of models represent the best available technology for predicting runoff concentrations, the variables that can determine exposure risk (i.e. weather) are likely to be highly variable over the five-year term of the proposed action. Given these factors, there is a reasonable likelihood that concentrations will differ from those predicted and potentially lead to adverse effects. 
Table 11. RA-Modeled Stream Concentrations of Pesticides Under the Proposed Action Resulting from Runoff and Erosion, Effect Concentrations Selected by NMFS for Effects Evaluation.

\begin{tabular}{|c|c|c|c|c|c|c|c|c|c|}
\hline \multirow[b]{2}{*}{ Pesticides } & \multicolumn{2}{|c|}{ Stream 8} & \multicolumn{2}{|c|}{ Douglas Creek } & \multicolumn{2}{|c|}{ Siuslaw River } & \multicolumn{3}{|c|}{ Effect Concentration } \\
\hline & Typ & $\operatorname{Max}$ & Тур & $\operatorname{Max}$ & Тур & Max & $\begin{array}{c}\text { LOEC } \\
(\mathrm{mg} / \mathrm{L})^{*}\end{array}$ & End-point & REF \\
\hline \multicolumn{10}{|c|}{ High Pressure Hydraulic Sprayer } \\
\hline Acephate & $-0-$ & $-0-$ & $-0-$ & $-0-$ & $-0-$ & $-0-$ & $>20.0$ & mortality & EPA 1984 \\
\hline Chloropyrifos & $-0-$ & $2.26 \mathrm{E}-006$ & $62.12 \mathrm{E}-008$ & $7.31 \mathrm{E}-007$ & $1.47 \mathrm{E}-009$ & $6.67 \mathrm{E}-008$ & 0.003 & mortality & EPA 2000 \\
\hline Diazinon & $-0-$ & 4.54E-006 & $68.89 \mathrm{E}-010$ & $1.43 \mathrm{E}-006$ & $7.64 \mathrm{E}-011$ & $1.13 \mathrm{E}-007$ & 0.001 & predation & $\begin{array}{c}\text { Scholz et al } \\
2000\end{array}$ \\
\hline Dimethoate & $-0-$ & $0-$ & $-0-$ & $-0-$ & $-0-$ & $-0-$ & 1.24 & mortality & $\begin{array}{c}\text { Scholz et al } \\
2000\end{array}$ \\
\hline Cyclohexanone & $-0-$ & $-0-$ & $-0-$ & $-0-$ & $-0-$ & $-0-$ & $30.3-75.7$ & mortality & EPA 2001 \\
\hline $\begin{array}{l}\text { Petroleum } \\
\text { distillate }\end{array}$ & $\begin{array}{c}1.70 \mathrm{E}- \\
007\end{array}$ & $1.98 \mathrm{E}-005$ & $5.08 \mathrm{E}-008$ & $6.76 \mathrm{E}-006$ & $6.13 \mathrm{E}-009$ & $7.00 \mathrm{E}-007$ & 100 & mortality & $\begin{array}{c}\text { Valent USA } \\
1983\end{array}$ \\
\hline Horticultural Oil & $-0-$ & $1.97 \mathrm{E}-005$ & $52.02 \mathrm{E}-007$ & $6.19 \mathrm{E}-006$ & $1.49 \mathrm{E}-006$ & $5.70 \mathrm{E}-007$ & 100 & mortality & $\begin{array}{c}\text { Valent USA } \\
1983\end{array}$ \\
\hline $\begin{array}{l}\text { Permethrin } \\
\text { Ethylbenzene }\end{array}$ & $-0-$ & $-0-$ & $5.72 \mathrm{E}-010$ & $5.12 \mathrm{E}-008$ & $3.98 \mathrm{E}-011$ & $3.38 \mathrm{E}-009$ & $7.5 \mathrm{E}-004$ & predation & $\begin{array}{c}\text { Kumaraguru } \\
\text { et al. } \\
198 ?\end{array}$ \\
\hline -Light & $-0-$ & $-0-$ & $-0-$ & $7.05 \mathrm{E}-008$ & $-0-$ & $4.81 \mathrm{E}-009$ & 0.32 & mortality & $\begin{array}{l}\text { Mayer \& } \\
\text { Ellersieck }\end{array}$ \\
\hline $\begin{array}{l}\text { Aromatic } \\
\text { solvent naptha }\end{array}$ & $-0-$ & $-0-$ & $2.28 \mathrm{E}-008$ & $1.14 \mathrm{E}-006$ & $1.58 \mathrm{E}-009$ & $9.57 \mathrm{E}-008$ & 0.1 & rearing & $\begin{array}{c}1986 \\
\text { EPA } 2001\end{array}$ \\
\hline -xylene & $-0-$ & $-0-$ & $-0-$ & $-0-$ & $-0-$ & $-0-$ & & & Folmar 1976 \\
\hline Propargite & $-0-$ & $2.10 \mathrm{E}-006$ & $61.85 \mathrm{E}-008$ & $6.89 \mathrm{E}-007$ & $1.32 \mathrm{E}-009$ & $6.25 \mathrm{E}-008$ & 0.008 & mortality & $\begin{array}{c}\text { Uniroyal } \\
1998\end{array}$ \\
\hline Chlorothanonil & $-0-$ & $5.70 \mathrm{E}-006$ & $61.61 \mathrm{E}-008$ & $1.79 \mathrm{E}-006$ & $1.11 \mathrm{E}-009$ & $1.65 \mathrm{E}-007$ & 0.0049 & mortality & $\begin{array}{c}\text { Caux et al. } \\
1996\end{array}$ \\
\hline
\end{tabular}




\begin{tabular}{|c|c|c|c|c|c|c|c|c|c|}
\hline \multirow[b]{2}{*}{ Pesticides } & \multicolumn{2}{|c|}{ Stream 8} & \multicolumn{2}{|c|}{ Douglas Creek } & \multicolumn{2}{|c|}{ Siuslaw River } & \multicolumn{3}{|c|}{ Effect Concentration } \\
\hline & Тyp & $\operatorname{Max}$ & Тур & Max & Typ & Max & $\begin{array}{c}\text { LOEC } \\
(\mathrm{mg} / \mathrm{L})^{*}\end{array}$ & End-point & REF \\
\hline \multicolumn{10}{|c|}{ Ground Application } \\
\hline Propiconazole & $\begin{array}{c}2.19 \mathrm{E}- \\
008\end{array}$ & $2.43 \mathrm{E}-006$ & $-0-$ & $-0-$ & $3.25 \mathrm{E}-010$ & $3.08 \mathrm{E}-008$ & 0.24 & mortality & $\begin{array}{c}\text { Grande et al } \\
1994\end{array}$ \\
\hline Dicamba & $-0-$ & $-0-$ & $-0-$ & $-0-$ & $-0-$ & $-0-$ & 1.8 & mortality & $\begin{array}{c}\text { Mayer \& } \\
\text { Ellersieck } \\
1986\end{array}$ \\
\hline Glyphosate & 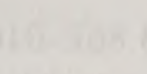 & $\sqrt{1+12}$ & 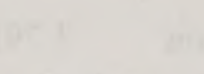 & & 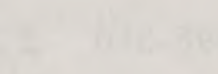 & 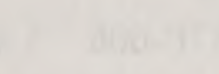 & & & $x_{1}$ \\
\hline Ground Circles & $\begin{array}{c}1.04 \mathrm{E}- \\
007\end{array}$ & 5.09E-006 & $\begin{array}{c}2 . .57 \mathrm{E}- \\
008\end{array}$ & $1.60 \mathrm{E}-006$ & $3.16 \mathrm{E}-009$ & $1.81 \mathrm{E}-007$ & $\begin{array}{c}0.046 \\
(\mathrm{NOEC})\end{array}$ & $\begin{array}{l}\text { migration \& } \\
\text { growth }\end{array}$ & $\begin{array}{c}\text { Morgan \& } \\
\text { Kiceniuk } \\
1992\end{array}$ \\
\hline Ground Strips & $-0-$ & $-0-$ & $7 . .94 \mathrm{E}-00$ & $1.51 \mathrm{E}-006$ & $8.91 \mathrm{E}-010$ & $1.61 \mathrm{E}-007$ & & & \\
\hline \multicolumn{10}{|l|}{ Hexazinone } \\
\hline Ground Circles & $-0-$ & 2.63E-007 & $-0-$ & $8.80 \mathrm{E}-008$ & $-0-$ & $9.75 \mathrm{E}-009$ & 14.5 & Mortality & Wan et al. \\
\hline Ground Strips & $-0-$ & $-0-$ & $-0-$ & $7.56 \mathrm{E}-008$ & $-0-$ & $8.07 \mathrm{E}-009$ & & & 1988 \\
\hline Picloram & $-0-$ & 7.23E-009 & $-0-$ & -0 & $-0-$ & $5.90 \mathrm{E}-011$ & 0.033 & growth & $\begin{array}{c}\text { Woodward } \\
1979\end{array}$ \\
\hline Triclopyr TEA & $-0-$ & 3.89E-009 & $-0-$ & $1.15 \mathrm{E}-009$ & $-0-$ & $1.33 \mathrm{E}-010$ & 47.4 & mortality & EPA $1998 a$ \\
\hline Triclopyr BEE & $\begin{array}{c}2.96 \mathrm{E}- \\
007\end{array}$ & $1.27 \mathrm{E}-005$ & $7.39 \mathrm{E}-008$ & $3.71 \mathrm{E}-006$ & $8.98 \mathrm{E}-009$ & $4.30 \mathrm{E}-007$ & 0.033 & mortality & EPA 1998a \\
\hline Dazomet & $-0-$ & $-0-$ & $-0-$ & $-0-$ & -0 & -0 & 0.032 & mortality & BASF 1999 \\
\hline
\end{tabular}

\footnotetext{
* Selected LOEC's are for various species of fish and might be less for aquatic macroinvertebrates (relevant to all tables)

** Numerical values represent scientific notation.
}

While runoff from typical and maximum applications of all proposed pesticides and other ('inert') ingredients are predicted to have a low potential for sublethal effects to OC coho, this is not the case for the insecticide esfenvalerate. As stated in the BA, under maximum conditions (saturated soils plus a large storm), runoff following esfenvalerate applications was predicted to pose a moderate risk of survival and reproduction to OC coho salmon in Stream 8 as well as Douglas Creek. Refer to Table 12 for modeled concentrations reported by the BA. 
Table 12. Risk Assessment Modeled Stream Concentrations of Esfenvalerate Under the Proposed Action Resulting from Runoff and Erosion.

\begin{tabular}{|c|c|c|c|c|c|c|c|c|c|}
\hline \multirow[b]{2}{*}{ Pesticide } & \multicolumn{3}{|c|}{ Stream 8} & \multicolumn{3}{|c|}{ Douglas Creek } & \multicolumn{3}{|c|}{ Siuslaw River } \\
\hline & $\begin{array}{c}\text { Typ } \\
1 \text { App }\end{array}$ & $\begin{array}{c}\text { Typ } \\
2 \text { Apps }\end{array}$ & Max & $\begin{array}{c}\text { Typ } \\
1 \text { App }\end{array}$ & $\begin{array}{c}\text { Typ } \\
2 \text { Apps }\end{array}$ & $\operatorname{Max}$ & $\begin{array}{c}\text { Typ } \\
1 \text { App }\end{array}$ & Typ 2 Apps & Max \\
\hline \multicolumn{10}{|c|}{ Aerial (both sections) } \\
\hline Esfenvalerate & $8.02 \mathrm{E}-008$ & $2.05 \mathrm{E}-007$ & $5.65 \mathrm{E}-006$ & $2.42 \mathrm{E}-008$ & $6.17 \mathrm{E}-008$ & na & $2.89 \mathrm{E}-009$ & $7.37 \mathrm{E}-009$ & na \\
\hline $\begin{array}{l}\text {-Ethyl } \\
\text { benzene }\end{array}$ & $4.13 \mathrm{E}-010$ & $6.39 \mathrm{E}-009$ & $1.37 \mathrm{E}-006$ & $1.49 \mathrm{E}-010$ & 2.24E-009 & na & $2.79 \mathrm{E}-011$ & $3.86 \mathrm{E}-010$ & na \\
\hline - Xylene & $-0-$ & $-0-$ & $-0-$ & -0 & $-0-$ & na & $-0-$ & $-0-$ & $11 \mathrm{a}$ \\
\hline \multicolumn{10}{|c|}{ Aerial (section 15) } \\
\hline Esfenvalerate & $1.49 \mathrm{E}-007$ & $3.81 \mathrm{E}-007$ & na & $-0-$ & $-0-$ & na & $2.06 \mathrm{E}-009$ & $5.25 \mathrm{E}-009$ & na \\
\hline $\begin{array}{l}\text {-Ethyl } \\
\text { benzene }\end{array}$ & $7.66 \mathrm{E}-010$ & $1.19 \mathrm{E}-008$ & na & $-0-$ & $-0-$ & na & $2.00 \mathrm{E}-011$ & $2.76 \mathrm{E}-010$ & na \\
\hline - Xylene & $-0-$ & $-0-$ & na & $-0-$ & $-0-$ & na & -0 & $-0-$ & na \\
\hline \multicolumn{10}{|c|}{ Airblast (both sections) } \\
\hline Esfenvalerate & $2.11 \mathrm{E}-008$ & $5.36 \mathrm{E}-008$ & $2.45 \mathrm{E}-006$ & $6.35 \mathrm{E}-009$ & $1.62 \mathrm{E}-008$ & $\begin{array}{c}8.95 \mathrm{E}- \\
007\end{array}$ & $7.60 \mathrm{E}-010$ & $1.93 \mathrm{E}-009$ & $\begin{array}{c}9.22 \mathrm{E}- \\
008\end{array}$ \\
\hline $\begin{array}{l}\text {-Ethyl } \\
\text { benzene }\end{array}$ & $-0-$ & $9.41 \mathrm{E}-010$ & $5.93 \mathrm{E}-007$ & $-0-$ & $3.46 \mathrm{E}-010$ & $\begin{array}{c}2.05 \mathrm{E}- \\
007\end{array}$ & $-0-$ & $6.93 \mathrm{E}-011$ & $\begin{array}{c}2.20 \mathrm{E}- \\
008\end{array}$ \\
\hline - Xylene & $-0-$ & $-0-$ & $-0-$ & $-0-$ & $-0-$ & $-0-$ & $-0-$ & $-0-$ & $-0-$ \\
\hline \multicolumn{10}{|c|}{ HPHS \& HHW (both sections) } \\
\hline Esfenvalerate & $3.91 \mathrm{E}-008$ & $9.97 \mathrm{E}-008$ & na & $-0-$ & $-0-$ & na & $5.41 \mathrm{E}-010$ & $1.37 \mathrm{E}-009$ & na \\
\hline $\begin{array}{l}\text {-Ethyl } \\
\text { benzene }\end{array}$ & $-0-$ & $1.75 \mathrm{E}-009$ & na & $-0-$ & $-0-$ & na & $-0-$ & $4.96 \mathrm{E}-011$ & na \\
\hline - Xylene & $-0-$ & $-0-$ & na & $-0-$ & $-0-$ & na & $-0-$ & $-0-$ & na \\
\hline
\end{tabular}




\begin{tabular}{|c|c|c|c|c|c|c|c|c|c|}
\hline \multirow[b]{2}{*}{ Pesticide } & \multicolumn{3}{|c|}{ Stream 8} & \multicolumn{3}{|c|}{ Douglas Creek } & \multicolumn{3}{|c|}{ Siuslaw River } \\
\hline & $\begin{array}{c}\text { Typ } \\
1 \text { App }\end{array}$ & $\begin{array}{c}\text { Typ } \\
2 \text { Apps }\end{array}$ & Max & $\begin{array}{c}\text { Typ } \\
1 \text { App }\end{array}$ & $\begin{array}{c}\text { Typ } \\
2 \text { Apps }\end{array}$ & Max & $\begin{array}{c}\text { Typ } \\
1 \text { App }\end{array}$ & Typ 2 Apps & Max \\
\hline \multicolumn{10}{|c|}{ HPHS \& HHW (section 15) } \\
\hline Esfenvalerate & $1.31 \mathrm{E}-008$ & $3.34 \mathrm{E}-008$ & $3.03 \mathrm{E}-006$ & $2.63 \mathrm{E}-009$ & $6.71 \mathrm{E}-009$ & $\begin{array}{c}\text { 7.19E- } \\
007\end{array}$ & $3.74 \mathrm{E}-010$ & $9.52 \mathrm{E}-010$ & $\begin{array}{c}7.67 \mathrm{E}- \\
008\end{array}$ \\
\hline $\begin{array}{l}\text {-Ethyl } \\
\text { benzene }\end{array}$ & $-0-$ & $5.16 \mathrm{E}-010$ & $6.23 \mathrm{E}-007$ & $-0-$ & $1.32 \mathrm{E}-010$ & $\begin{array}{c}1.45 \mathrm{E}- \\
007\end{array}$ & $-0-$ & $3.59 \mathrm{E}-011$ & $\begin{array}{c}3.25 \mathrm{E}- \\
007\end{array}$ \\
\hline - Xylene & $-0-$ & $-0-$ & $-0-$ & $-0-$ & $-0-$ & $-0-$ & $-0-$ & $-0-$ & $-0-$ \\
\hline Esfenvalerate & $3.91 \mathrm{E}-008$ & $9.97 \mathrm{E}-008$ & na & $-0-$ & $-0-$ & na & $5.41 \mathrm{E}-010$ & $1.37 \mathrm{E}-009$ & na \\
\hline $\begin{array}{c}\text {-Ethyl } \\
\text { benzene }\end{array}$ & $-0-$ & $1.40 \mathrm{E}-009$ & na & $-0-$ & $-0-$ & na & $-0-$ & $3.97 \mathrm{E}-011$ & na \\
\hline - Xylene & $-0-$ & $-0-$ & na & $-0-$ & $-0-$ & na & $-0-$ & $-0-$ & na \\
\hline
\end{tabular}

For the insecticide esfenvalerate, the proposed action will contain numerous applications with varied methodologies (Table 11). Individually predicted exposure concentrations have failed to look at the realistic pesticide burden to OC coho. A more accurate depiction is the total summation of esfenvalerate applications from all sources of exposure. Table 13 provides this information as the sum-total of all esfenvalerate concentrations predicted from modeling.

Table 13. Total Summation of Esvenvalerate Burden Under the Proposed Action

\begin{tabular}{lcccccccccc}
\hline & & Stream 8 & \multicolumn{3}{c}{ Douglas Creek } & \multicolumn{3}{c}{ Siuslaw River } \\
\cline { 2 - 10 } Pesticide & $\begin{array}{c}\text { Typ } \\
\text { 1 App }\end{array}$ & $\begin{array}{c}\text { Typ } \\
\text { 2 Apps }\end{array}$ & Max & $\begin{array}{c}\text { Typ } \\
\text { 1 App }\end{array}$ & $\begin{array}{c}\text { Typ } \\
\text { 2 Apps }\end{array}$ & Max & $\begin{array}{c}\text { Typ } \\
1 \text { App }\end{array}$ & $\begin{array}{c}\text { Typ 2 } \\
\text { Apps }\end{array}$ & Max \\
\hline & & & & & & & & & & \\
\hline
\end{tabular}

From the BLM data used to develop Table 11, alternative A, which represents maximum seed production strategy, would adversely affect OC coho salmon at Stream 8 and Douglas Creek. In addition, the very likely, but unquantified, presence of pesticides from upstream applications, as well as water quality stressors (e.g., high summer water temperatures) would further exacerbate the adverse reaction to any toxic chemicals. Toxicity of pyrethroids has been known to increase 
with higher water temperatures. Furthermore, there is a direct risk to aquatic invertebrates from these predicted concentrations from maximum application.

Accidental Spills. The RA addressed spills through the Exposure Analysis Modeling System (EXAMS) model. EXAMS was developed at EPA's Center for Exposure Assessment Modeling at Athens, Georgia (Burns 2000). Model inputs of half-lives and adsorption coefficients determined the rate and extent of transport of organic chemicals throughout potential spill sites.

Concentrations in streams and the Siuslaw River that could occur from accidental spills of pesticides or fertilizers were estimated using a separate EXAMS simulation for each chemical and spill site.

There are five potential sites where accidental spill of pesticide concentrate, tank mix, or fertilizer load might occur and are modeled. They include: (1) Siuslaw River Road, at the point where it crosses Douglas Creek; (2) Road 20-5-16 in Section 15, where it crosses a tributary to the Siuslaw River; (3) the orchard road in Section 9 that crosses a tributary to Douglas Creek; (4) the orchard road in Section 15 that crosses a tributary to the Siuslaw River; and (5) an aerial spill of 10 gallons of esfenvalerate mix into a third order stream draining to Douglas Creek.

Results of the modeling show that maximum residues from spills into the larger perennial streams would reach the Siuslaw within an hour. Spills into the smaller tributaries, especially in Section 9, which drains into Douglas Creek through a small pond, would take 15 hours or longer to reach maximum concentrations in the Siuslaw River. The likelihood of contaminant exposure from spills will be minimized through siting the mixing and loading zones in a designated chemical area away from water. These CPs should avoid the scenario of spill delivery of pesticides to surface waters.

Aquatic species are at risk from spills of concentrate containing chlorpyrifos, diazinon, dimethoate, esfenvalerate, horticultural oil, permethrin, propargite, chlorothalonil, glyphosate, triclopyr butoxyethyl ester, dazomet, and ammonium phosphate-sulfate. They are at risk from tank mix spills containing chlorpyrifos, diazinon, dimethoate, esfenvalerate, permethrin; propargite, chlorothalonil, glyphosate, picloram, triclopyr, dazomet, and ammonium phosphatesulfate. All species in Douglas Creek would be at risk from an aerial spill of esfenvalerate into one of its tributaries. Spill mixtures may elicit synergistic or additive effects from the chemicals present in mixture themselves or from combinations of spill chemicals and baseline concentrations.

Summary of Vectors of Exposure. After the application of chemicals in the field, there are two time periods in which exposure to non-target species may occur outside the application area. The first immediately follows the application event, and is the result of spray drifting or volatilizing from the field. This period of concern lasts on the order of hours, usually until the chemical has been allowed to dry on foliar surfaces. The second period occurs after the first rain event when chemical residues are carried offsite by surface water runoff. This period also lasts 
on the scale of several hours, during which time the rain flowing over foliar and soil surfaces collects the most available chemical residues (either dissolved or associated with fine particulates). Thus, the initial pulse of runoff entering the streams is most likely to carry the highest concentration of bioavailable pesticide residues.

Site conditions at Tyrrell include multiple possible pathways of exposure to coho salmon; namely drift and runoff through seasonal, ephemeral, and perennial drainages within or near the orchard. Coho salmon, often at multiple lifestages, are expected to be beside and downstream from Tyrrell throughout the year. In the event of a discharge into Stream 1, Stream 8, Douglas Creek (and the Siuslaw River, via these tributaries) it is highly probable that coho salmon will be in the vicinity of the exposure. As such, discharges, via subsurface runoff, drift, or overland runoff to Stream 1, Stream 8, and Douglas Creek may have little time to become diluted or attenuate in concentrations.

Given the likelihood of salmonid presence year-round in receiving waterways, in the event of a discharge to Stream 8, Douglas Creek, and the Siuslaw River, it is highly probable that OC coho salmon will be exposed to chemical contaminants. In particular, there is a high-risk scenario to OC coho salmon in Stream 8. Under potential conditions (saturated soils plus a large storm) and maximum application schedules, runoff and drift following esfenvalerate applications was predicted to pose a significant risk to OC coho salmon in Stream 8 of sublethal effects to survival and reproductive endpoints. In drawing conclusions about the potential for risk, both the lethal and sublethal effects analyses utilized the most sensitive toxicity data points (including data for the most sensitive life stage), and assumed that fish species would be present at the time of pesticide application.

Accumulation of Pesticides, Herbicides, and Fertilizers in Soil. Impacts from the application of pesticides to soil can be divided into two groups - those occurring from chemicals which are highly mobile in soils and have a high water solubility, and impacts from chemicals with a low mobility in soil (high adsorption rate) and are only slightly soluble in water. High lipophilicity (fat solubility) of the chemical is the primary driver for non-specific partitioning (sorption) into soil organics. True adsorption (binding to a specific site) also occurs, and positively charged chemicals tend to adsorb to clay particles (clays tend to have negative surface charges). Therefore, some chemicals with high water solubility can be adsorbed by soils with significant clay content.

Most chemicals proposed for application have a low mobility in soil due to a higher rate of adsorption. These chemicals would likely remain near the surface of the soil and degrade over time. Most degradation occurs by microbial metabolism. Other methods of degradation include hydrolysis (the splitting of a molecule by the addition of the elements of water), photolysis (degradation by radiant energy), and chemical degradation. Except the herbicide picloram which has a soil half-life in the 5- to 6-month range, the soil half-life of most of these chemicals is less than three months. 
Three of the pesticides proposed for application at Tyrrell are highly mobile in soil: Dimethoate, dicamba, and picloram. The RA predicted that none of these would leach into the groundwater in at Tyrrell. The application of the pesticides would not use a sufficient amount of water to move chemicals past the surface of the soil and the timing of the proposed pesticide considers forecasts for precipitation (an application rate of 50 to 150 gallons per acre of water mixed with the chemical would be equivalent to about 0.02 to 0.05 inches of water applied to the area). Any applied pesticides would likely remain near the surface and begin degrading, until subsequent rainfall or irrigation moves any remaining residues into the soil horizon. Mobile pesticides leaching through the soil column would migrate into groundwater. Photodegradation and metabolism by soil microbes would no longer be viable degradation pathways, and half-lives in groundwater could become substantially longer.

The GLEAMS modeling conducted for the RA indicates that negligible accumulation was expected. The long period of simulation (10 years with application assumed to occur annually) allowed an evaluation of the tendency for a chemical's environmental persistence, if residues remain after one year, to contribute to an increased concentration in runoff or leachate in later years. This conservative assumption is inherent in the stream concentrations estimated to result from any pesticide loss in runoff from treated areas.

Fertilizers. Fertilizers are used to optimize production at Tyrrell. Fertilizers are to be distributed over the ground using a broadcast spreader pulled by a truck or mounted on a tractor or ATV. Several types of fertilizers are proposed for use at Tyrrell: Ammonium nitrate, ammonium sulfate monoammonium and diammonium phosphate, calcium nitrate, potassium nitrate, potassium chloride, and potassium sulfate. Most of these fertilizers are very soluble in water and can contribute ammonia and nitrates in runoff to surface waters.

Modeled concentrations of nitrogen and phosphorous are reported in Table 14 from the various application rates. 
Table 14. Risk Assessment Modeled Stream Concentrations of Fertilizers Under the Proposed Action.

\begin{tabular}{|c|c|c|c|c|c|c|c|c|c|}
\hline \multirow[b]{2}{*}{ Fertilizer } & \multicolumn{3}{|c|}{ Stream 8} & \multicolumn{3}{|c|}{ Douglas Creek } & \multicolumn{3}{|c|}{ Siuslaw River } \\
\hline & $700 \mathrm{lb} /$ acre & $1,000 \mathrm{lb} / \mathrm{acre}$ & $\operatorname{Max}$ & $700 \mathrm{lb} / \mathrm{acre}$ & $1,000 \mathrm{lb} / \mathrm{acre}$ & Max & $700 \mathrm{lb} / \mathrm{acre}$ & $1,000 \mathrm{lb} / \mathrm{acre}$ & $\operatorname{Max}$ \\
\hline \multicolumn{10}{|l|}{ Spreader } \\
\hline Nitrogen & $1.26 \mathrm{E}-002$ & $2.42 \mathrm{E}-002$ & $6.31 \mathrm{E}-001$ & $3.23 \mathrm{E}-003$ & $6.08 \mathrm{E}-003$ & $1.51 \mathrm{E}-001$ & $4.11 \mathrm{E}-004$ & $7.81 \mathrm{E}-004$ & $1.78 \mathrm{E}-002$ \\
\hline Phosphorous & $9.42 \mathrm{E}-004$ & $1.45 \mathrm{E}-003$ & $1.77 \mathrm{E}-0002$ & $4.43 \mathrm{E}-004$ & $4.43 \mathrm{E}-004$ & $4.22 \mathrm{E}-003$ & $5.79 \mathrm{E}-005$ & $8.92 \mathrm{E}-005$ & $4.98 \mathrm{E}-004$ \\
\hline $\begin{array}{l}\text { Calcium } \\
\text { Nitrate } \\
\text { hand } \\
\text { application }\end{array}$ & $8.86 \mathrm{E}-003$ & na & $1.17 \mathrm{E}-002$ & $2.79 \mathrm{E}-003$ & na & $2.85 \mathrm{E}-004$ & na & na & $3.28 \mathrm{E}-004$ \\
\hline
\end{tabular}

Ammonia in the runoff can exist in its ionized form (NH4+), and in its un-ionized form as ammonia (NH3). The equilibrium between these two forms is largely dependent on $\mathrm{pH}$ and temperature. Un-ionized ammonia is the more toxic form, because it is a neutral molecule and thus is able to diffuse across the epithelial membranes of aquatic organisms much more readily than the charged ammonium ion (EPA 1999). However, the ammonium ion is generally present in much greater concentrations and can also contribute to ammonia toxicity under some conditions. The RA modeling analysis assumed the most conservative situation and considered all of the ammonium in the runoff to be in the more toxic unionized form (NH3).

Ammonia is of much concern due to its relatively toxic nature and its ubiquity in water bodies. Ammonia occurs in natural waters secreted by aquatic plants and animals, and generated by heterotrophic bacteria as the primary end product of decomposition of organic matter (Randall \& Tsui 2002). As aquatic plants and animals die, bacteria break down large protein molecules containing nitrogen into ammonia. Ammonia is then oxidized by specialized bacteria to form nitrites and nitrates.

Concentrations of ammonia acutely toxic to fishes may cause loss of equilibrium, hyperexcitability, increased breathing, cardiac output and oxygen uptake (EPA 1986). In extreme cases, damage to the central nervous system from acute levels can lead to convulsions, coma, and death (Randal \& Tsui 2002). Other mechanisms of ammonia toxicity were outlined by Ruffier et al. (1981) to include gill damage leading to suffocation, osmoregulation dysfunction (bloating) causing kidney failure, and inhibition of ammonia excretion leading to neurological and cytological failure. 
At lower concentrations, ammonia has many sublethal effects on fishes, including a reduction in hatching success, increased respiratory distress, hormonal dysfunction, reduction in growth rate and morphological development (Rice \& Bailey 1980, Soderberg et al. 1983, USEPA 1986, USEPA 1999). The literature also contains some information concerning the effects that chronic exposure to low levels of ammonia can have on the structure and function of select tissues and organs such as gills, livers, and kidneys and their increased susceptibility to disease (Soderberg et al. 1983, USEPA 1986, USEPA 1999). Behavioral effects to chronic levels of ammonia are reduced swimming stamina and performance which would affect predator avoidance and foraging behaviors (EPA 1999).

The proposed action would preclude fertilizers within 50 feet of waterways as a measure to reduce delivery to aquatic systems. This distance would act as a preventative measure to reduce runoff to surface water as the additional ground will sorb fertilizer compounds.

\section{Water Quality Factors Which Alter Susceptibility to Toxic Pesticides and}

Fertilizers. The combination of heat and other stress factors can compromise salmonid immune system function (Hardie et al., 1994; Kollner and Kotterba 2002; McCullough 1999), putting them at an increased susceptibility to disease. Likewise, exposure to environmental pollutants can decrease tolerance to temperature extremes (Paladino et al., 1980). Sub-cellular and molecular changes such as enzyme induction are known to precede observable individual or population level effects (Boon et al., 1992).

As previously discussed, factors in the Siuslaw Watershed contribute to elevated stream temperatures in waterways that host listed salmonids in the action area. Glyphosate toxicity to rainbow trout increases with higher test temperatures (Folmar et al., 1979). Toxicity also increased from $\mathrm{pH} 6.5$ to 7.5 , but did not change up to $\mathrm{pH} 9.5$. Increasing temperature and $\mathrm{pH}$ with exposures to picloram resulted in greater toxicities to cutthroat trout and lake trout (Woodward 1976). Rainbow trout became more sensitive to permethrin with increasing water temperature (Kumaraguru and Beamish 1986). The 96-hour LC50 values decreased by nearly an order of magnitude $(0.0064$ to $0.00069 \mathrm{mg} / \mathrm{L})$ between 10 and $20^{\circ} \mathrm{C}$, respectively.

Higher temperatures can also shift the equilibrium of ammonia species to its more toxic unionized form. The concentration of un-ionized ammonia present in an ammonia solution has been calculated to double in a $10^{\circ} \mathrm{C}$ rise in temperature (Ruffier et al., 1981). While the effects of temperature on the mechanism of ammonia toxicity is not well understood, the increased bioavailability to the more toxic unionized ammonia can increase the risk of fertilizers to salmonids.

Mixture Toxicity. Aquatic organisms can be exposed to complex mixtures of contaminants resulting from pollution that originates from industrial, agricultural, and domestic land use. Eco-toxicological studies that assess the effects of contaminants to aquatic communities typically have been limited to assessing the impacts of individual toxicants only. However, discrete assessments of individual toxicants do not capture the true exposure routes and effects to species which occupy habitat that is subject to multiple temporal and spatial chemical discharge. For salmonids, who occupy diverse habitat types throughout each life 
history stage, exposure to chemical mixtures can occur within the water column, and from contaminated sediments and food. Given these complexities, consideration must be given to the potential that a wide variety of chemicals might be simultaneously present in complex mixtures. Furthermore, these mixtures of chemicals likely contribute to reduced productivity of some aquatic ecosystems. For instance, Arkoosh et al., (1991) found that juvenile Chinook salmon that migrated through waters contaminated with PCBs and PAHs, and heavily influenced by an urban landscape, bioaccumulated the pollutants, and showed signs of suppressed immune responses compared to uncontaminated fish. Casillas et al., (1993) found that juvenile Chinook in urban waters showed suppressed immune function, reduced survival, and impaired growth as they migrated to the oceanic environment. More recently, a pilot study by the NWFSC revealed significant pre-spawn mortality of coho salmon within a highly urbanized watershed within the City of Seattle, as compared to a relatively non-urbanized stream within the Stillaguamish River Watershed. It is thought that pollutant mixtures delivered to the urbanized watershed through contaminated stormwater contributed to the high level of pre-spawn mortality, though the exact causes of mortality have not been fully determined to date.

Multiple chemicals that co-occur in aquatic systems may alter their toxicity by additive, antagonistic, or greater than additive (synergistic) effects (Denton et al. 2002). An additive effect occurs when the combined effect of several chemicals is equal to the sum of individual effects of each chemical as if they were alone (Klassen 1986). Antagonistic effect occurs when a mixture contains chemicals that interfere with each other's actions, or with the action of the other chemical. A greater than additive (synergistic) effect occurs when the combined effect of two chemicals is much greater than the sum of the effect of each agent individually (Klassen 1986). A special form of synergism is potentiation, which occurs when one substance has no toxic effect in and of itself, but when added to another chemical it enhances the toxicity of the toxic component (Klassen 1986).

Predicting Mixture Toxicity. It is necessary to examine the interactions or noninteractions of toxicants when characterizing and predicting the risk of chemical mixtures to listed salmonids. Predictive assessments of the aquatic toxicity of chemical mixtures are represented by numerous methods and models that are presented in several fields of pharmacology and toxicology (Faust 2003). In essence, however, there are two different fundamental hypotheses on the functional relationship between the toxicity of single substances and those of combined toxicants (Faust 2003). Commonly, those hypotheses are called concentration addition and response addition.

The concentration addition model best describes the scenario of non-interactive, joint-action and is generally applied to chemicals that exhibit a similar mode of action. The individual components of a mixture act independently but produce the same or similar effects and can be expressed in terms of the other (Broderius et al. 1995). For example, the joint toxicity of diazinon and chlorpyrifos on Ceriodaphnia dubia was examined in a study by Bailey et al. (1997). The toxic interaction was evaluated by a Toxic Unit approach that compared the LC50 estimates associated with the mixtures with the LC50s of the individual pesticides when tested alone. The results suggested that diazinon and chloryprifos exert additive toxicity to 
Ceriodaphnia dubia. This is entirely reasonable given that both are metabolically activated organophosphorus pesticides and act similarly with respect to the inhibition of acetlycholinesterase (Bailey et al. 1997). The toxicity of s-triazine mixtures, herbicides that commonly interfere with photosynthetic electron transport, are found to also be accurately predicted by the concept of concentration addition (Faust et al. 2001). The study further demonstrated that low concentrations of individual triazines, that alone did not cause a statistically significant response, contribute predictably to the overall effects of multi-component mixtures. For an assessment of mixtures which have a common specific mechanism of action, these studies show that an assessment of mixtures solely by independent components can tend to underestimate its overall toxicity.

As an alternative concept to concentration addition, mixtures of chemicals composed of dissimilar toxicants with varying modes of action, can be analyzed via the response-addition model, for predicting toxicity (Faust 2001). These models are based on the assumption that each toxicant neither enhances or interferes with the other and contributes to a common response only if the concentrations of both substances exceed their respective thresholds (Broderius et al. 1995). In this case, the toxicity of a mixture is equal to the that of its most toxic component (Sharma et al. 1999) and that the relative effect of a toxicant remains unchanged in the presence of another chemical (Faust et al. 2001). This approach has been demonstrated to provide accurate predictions of single species toxicity when all underlying assumptions are fulfilled.

Faust et al. (2003) studied the situation of multiple exposures to biocides with strictly different specific mechanisms of action to freshwater algae. Both concepts of concentration addition and response addition was applied to predict mixture toxicity. The concentration addition approach tended to overestimate mixture toxicity showing that the response addition approach proved to be superior when mixture components are well known to interact specifically with different molecular target sites.

However, developing scientific research indicates that simple concentration addition and response addition models are not always good predictors of the toxicity of mixtures. In many cases the effects of mixtures cannot be predicted from single components. Pape-Lindstrom and Lydy (1997) demonstrated that the response addition model does not always accurately predict the mixture toxicity of chemicals with dissimilar modes of action. In their experimental design, larvae of the aquatic midge (Chironomus tendons) were exposed to binary combinations of atrazine and various organophosphate insecticides. Their results conclusively show a greater than additive response for several combinations of chemicals that have dissimilar modes of action. Mixtures that result in greater than additive (synergistic) toxicity are of much concern due to unpredictability based on the effect of individual components (Woods et al. 2002).

The complex interactions that result from a mixture are generally between the chemicals and the physiological systems within the body, rather than between the chemicals themselves (Marking 1985). Examples of such interactions are the alteration of the absorption, distribution, biotransformation, or excretion of one chemical by another. There are two currently recognized 
mechanisms of greater than additive (synergistic) toxicity that involve such interactions, the increase in enzymatic activation of the other chemical and the inhibition of enzymes responsible for detoxification (Woods et al. 2002).

In the metabolism of an organic chemical, enzymatic activity induces a series of chemical alterations, in a process called biotransformation. The process of biotransformation can be divided into 'phase I' and 'phase II' metabolism. The first involves a change in the molecular structure of a chemical by involving either hydrolysis, oxidation, or reduction (Sipes and Gandolfi 1986). Phase II biotransformation involves the conjugation of a substrate to endogenous chemicals (Boon et al. 1992). The end result of these reactions is that the metabolites are chemically distinct from their parent chemical. Metabolites are usually more hydrophilic than their parent chemical which restricts the partitioning of metabolites into cellular membranes, decreases reabsorption and facilitates eventual elimination (Sipes and Gandolfi 1986). The ease of which chemicals are eliminated depends on their water solubility. This explains why lipophilic chemicals, like dioxins, are readily absorbed, poorly excreted, and have a tendency to accumulate.

However, it is important to note that biotransformation can result in higher toxicity (Boon et al. 1992). For example, several organophosphorus insecticides such as chlorpyrifos, methylparathion, and malathion are in of themselves poor inhibitors of acetylcholinesterase. However, upon phase I metabolic conversion, their corresponding oxygen analogs are highly potent acetylcholinesterase inhibitors. The rate of metabolic activation to a chemical of higher toxicity can be increased by the presence of other chemicals in a mixture (Woods et al. 2002). This can help explain the greater than additive toxicity noted for combinations of organophosphorus insecticides and other chemicals.

Inhibition of enzymes that are responsible for detoxification will result in increased levels of active chemical to interact with target sites (Woods et al. 2002). Carboxylesterases are an important class of serine hydrolases that cleave esters into the corresponding alcohol and acid. They can serve an important function by detoxifying pyrethroids and other ester containing chemicals such as herbicides (Denton et al. 2002). However, carboxylesterases can be inhibited by organophosphates and carbamates. Mixtures of organophosphates and pyrethroids could potentially exhibit a synergistic toxicity. Denton et al. (2002) examined joint mixture toxicity of diazinon and esfenvalerate to fathead minnows. The observed greater than additive (synergistic) toxicity was attributed to inhibition of carboxylesterase activity by diazinon, a potent organophosphate.

Tyrrell Mixture Analysis. The concept of concentration addition has been used to quantitatively analyze the effect of simultaneous exposure of pesticides to salmonids from pesticide applications at Tyrrell. Additive action is the most common form of mixture toxicity (Marking 1985), and would be very relevant considering the type of pesticides used at Tyrrell. Greater than additive or less than additive interactions would be exceptions and are difficult to predict. 
Concentration addition is expressed mathematically as: $\quad \sum_{i=1}^{n} \frac{C_{i}}{E C X_{i}}=1$

For a multi-component mixture of $n$ substances: $c_{i}$ is the concentration of the individual substances present in a mixture or dose, $E C x_{i}$ is the equivalent effect concentrations of the individual substance. The equivalent effect concentrations must be similar in the respect of the assessment endpoint for this approach to hold scientific relevance. The quotients resulting from $c_{i} / E C x_{i}$ would then represent the concentrations of individual mixture components as fractions of equitoxic concentrations scaled for its relative potency, TU (toxic unit). By summing the toxic units, the toxic strength of a mixture of chemicals may be determined.

For example, assume a chemical mixture of chemical A and B with similar modes of toxic action occurs. The known environmental concentration or dose of $\mathrm{A}$, is divided by the toxicity of $\mathrm{A}$ (LC50 or other relevant endpoint), which will result in a unitless fractional toxic unit for A. The same procedure is followed for each component in the mixture. The summation of toxic units A and $\mathrm{B}$ carries a result that approaches 1 . If 1 is reached, then it can be assumed that there is additive toxicity on the acute level. ${ }^{15}$

Concentration addition implies that every toxicant in any concentration contributes, more or less, to the overall toxicity of a mixture, and holds the assumption that the chemicals in a mixture exhibit a similar mode of action. There are two major pesticide groups proposed for use in Tyrrell that fulfill these requirements. The organophosphate insecticide group: Acephate, diazinon, chlorpyrifos, and dimethoate, all act similarly in the inhibition of acetylcholinesterase, and the pyrethroid insecticide group: Esfenvalerate and permethrin, which act similarly in the blocking of neural voltage activated sodium/calcium channels. For the purpose of this analysis it is assumed that these groups of pesticides would be simultaneously present in salmonid habitat at modeled concentrations from erosion, runoff, and drift. ${ }^{16}$ Traditionally, each pesticide group would undergo a separate analysis. In the BLM BA, these pesticides were analyzed individually without consideration to the overall toxicity of a mixture.

Within this analysis, the toxic unit approach described above was used to assess the groups of similarly acting chemicals (organophosphates and pyrethroids) in a specific waterbody using the maximum BLM-modeled concentrations due to drift, runoff, and erosion. For instance, as seen in Table 2, esfenvalerate is proposed to be applied within the March through August period annually, using aerial, airblast, and a high-pressure hydraulic sprayer/hydraulic sprayer with hand-held wand.

15 Acute mortality data (LC50s) were used as the equivalent effect concentrations of the individual substances Sublethal or LOEC data can also be used if available.

${ }^{16}$ The highest concentrations in these streams were identified (Table 8-1 in the BA), and can be considered to represent 24-hour average concentrations. 
The BLM-modeled estimates of water concentrations from each application type from drift and runoff were then summed. This summation is not unrealistic, because during most of the application window precipitation levels are low relative to other periods, and generally continue to decrease per month, thus reducing the likelihood of runoff delivery facilitated by individual rain events, and individual applications. As such, most delivery to the drainages of Tyrrell of esfenvalerate applied from March through August could occur in zone three (mid-September through December) when precipitation increases and overland flow is more likely. Summation of these individual model results is logical and represents a hypothesis of plausible exposure concentrations to $\mathrm{OC}$ coho salmon within the listed waterways. ${ }^{17}$

The equivalent effect concentrations of the individual substances were taken from the scientific literature pertaining to the assessment endpoint in question. As depicted in Table 15, after a toxic unit was calculated for each model concentration, they were summed up to give a final toxic unit. As mentioned before, as the final toxic unit approaches 1, we can expect there to be effects on the acute level.

\footnotetext{
${ }^{17}$ Note that chemical degradation, or binding to soils, may dilute concentrations or delay delivery to surface
} waters. 
Table 15. Mixture Toxicity for Fish Species Within Receiving Waterways

\begin{tabular}{|c|c|c|c|c|}
\hline Chemical & App Method & $\begin{array}{c}\text { Main Trib } \\
\text { Sec } 15 \\
(\mathrm{mg} / \mathrm{L}) \\
\end{array}$ & $\begin{array}{c}\text { Douglas } \\
\text { Creek } \\
(\mathrm{mg} / \mathrm{L}) \\
\end{array}$ & $\begin{array}{c}\text { Siuslaw } \\
\text { River } \\
(\mathrm{mg} / \mathrm{L}) \\
\end{array}$ \\
\hline \multicolumn{5}{|l|}{$\begin{array}{l}\text { Organophosphate } \\
\text { group }\end{array}$} \\
\hline Acephate & HPHS \& HHW runoff\&erosion & 0 & 0 & 0 \\
\hline Chlorpyrifos & HPHS runoff\&erosion & 0 & $7.07 e-06$ & $4.90 \mathrm{e}-07$ \\
\hline Diazinon & HPHS runoff\&erosion & 0 & $9.88 \mathrm{e}-09$ & $8.49 \mathrm{e}-10$ \\
\hline Dimethoate & HPHS runoff\&erosion & 0 & 0 & 0 \\
\hline & TU summation & $\mathbf{0}$ & $7.08 \mathrm{e}-06$ & $4.91 \mathrm{e}-07$ \\
\hline \multicolumn{5}{|l|}{$\begin{array}{l}\text { Pyrethroid } \\
\text { group }\end{array}$} \\
\hline \multirow[t]{8}{*}{ Esfenvalerate } & $\begin{array}{l}\text { AERIAL runoff\&erosion(both } \\
\text { sections) }\end{array}$ & $2.33 \mathrm{e}-03$ & $7.01 \mathrm{e}-04$ & $8.38 \mathrm{e}-05$ \\
\hline & AERIAL runoff\&erosion(section 15) & $4.33 \mathrm{e}-03$ & 0 & $5.97 \mathrm{e}-05$ \\
\hline & AERIAL drift & $3.70 \mathrm{e}-06$ & $1.07 \mathrm{e}-06$ & $1.34 \mathrm{e}-07$ \\
\hline & $\begin{array}{l}\text { AIRBLAST runoff\&erosion(both } \\
\text { sections) }\end{array}$ & $6.09 \mathrm{e}-04$ & $1.84 \mathrm{e}-04$ & $2.19 \mathrm{e}-05$ \\
\hline & $\begin{array}{l}\text { AIRBLAST runoff\&erosion(section } \\
\text { 15) }\end{array}$ & $1.13 \mathrm{e}-03$ & 0 & $1.56 \mathrm{e}-05$ \\
\hline & AIRBLAST drift & $2.58 \mathrm{e}-03$ & $7.77 \mathrm{e}-04$ & $9.30 \mathrm{e}-05$ \\
\hline & $\begin{array}{l}\text { HPHS \& HHW runoff\&erosion(both } \\
\text { sections) }\end{array}$ & $3.80 \mathrm{e}-04$ & $7.63 \mathrm{e}-05$ & $1.08 \mathrm{e}-05$ \\
\hline & $\begin{array}{l}\text { HPHS \& HHW } \\
\text { runoff\&erosion(section 15) }\end{array}$ & $1.13 \mathrm{e}-03$ & 0 & $1.56 \mathrm{e}-05$ \\
\hline \multirow[t]{2}{*}{ Permethrin } & HPHS runoff\&erosion & 0 & $1.97 \mathrm{e}-07$ & $1.37 \mathrm{e}-08$ \\
\hline & TU summation & $1.25 \mathrm{e}-02$ & $1.74 \mathrm{e}-03$ & $3.00 \mathrm{e}-04$ \\
\hline
\end{tabular}

* Numerical values are in scientific notation.

Referring to Table 15, the final toxic units for organophosphates and pyrethroids within the main tributary of Section 15, Douglas Creek, and the Siuslaw River are extremely low, several orders of magnitude below where we expect there to be an acute effect. Using similar methods as those discussed above, Table 16 shows the hypothetical mixture toxicity for macroinvertebrates within the same waterways. 
Table 16. Mixture Toxicity for Macroinvertebrates Within Receiving Waterways

\begin{tabular}{|c|c|c|c|c|}
\hline Chemical & App Method & $\begin{array}{c}\text { Main Trib } \\
\text { Sec } 15 \\
(\mathrm{mg} / \mathrm{L})\end{array}$ & $\begin{array}{c}\text { Douglas } \\
\text { Creek } \\
(\mathrm{mg} / \mathrm{L})\end{array}$ & $\begin{array}{c}\text { Siuslaw } \\
\text { River } \\
(\mathrm{mg} / \mathrm{L})\end{array}$ \\
\hline \multicolumn{5}{|l|}{$\begin{array}{l}\text { Organophosphate } \\
\text { group }\end{array}$} \\
\hline Acephate & HPHS \& HHW runoff\&erosion & 0 & 0 & 0 \\
\hline Chlorpyrifos & HPHS runoff\&erosion & 0 & $2.12 \mathrm{e}-04$ & $1.47 \mathrm{e}-05$ \\
\hline Diazinon & HPHS runoff\&erosion & 0 & $1.07 \mathrm{e}-06$ & $9.20 \mathrm{e}-08$ \\
\hline \multirow[t]{2}{*}{ Dimethoate } & HPHS runoff\&erosion & 0 & 0 & 0 \\
\hline & TU summation & $\mathbf{0}$ & $2.13 e-04$ & $1.48 \mathrm{e}-05$ \\
\hline \multicolumn{5}{|l|}{$\begin{array}{l}\text { Pyrethroid } \\
\text { group }\end{array}$} \\
\hline \multirow[t]{8}{*}{ Esfenvalerate } & $\begin{array}{l}\text { AERIAL runoff\&erosion(both } \\
\text { sections) }\end{array}$ & $6.83 e-03$ & $2.06 \mathrm{e}-03$ & $2.46 \mathrm{e}-04$ \\
\hline & AERIAL runoff\&erosion(section 15) & $1.27 \mathrm{e}-02$ & 0 & $1.75 \mathrm{e}-04$ \\
\hline & AERIAL drift & $1.09 \mathrm{e}-05$ & $3.13 e-06$ & $3.93 \mathrm{e}-07$ \\
\hline & $\begin{array}{l}\text { AIRBLAST runoff\&erosion(both } \\
\text { sections) }\end{array}$ & $1.79 \mathrm{e}-03$ & $5.40 \mathrm{e}-04$ & $6.43 \mathrm{e}-05$ \\
\hline & $\begin{array}{l}\text { AIRBLAST runoff\&erosion(section } \\
\text { 15) }\end{array}$ & $3.32 \mathrm{e}-03$ & 0 & $4.57 \mathrm{e}-05$ \\
\hline & AIRBLAST drift & $7.57 \mathrm{e}-03$ & $2.28 \mathrm{e}-03$ & $2.73 \mathrm{e}-04$ \\
\hline & $\begin{array}{l}\text { HPHS \& HHW runoff\&erosion(both } \\
\text { sections) }\end{array}$ & $1.11 \mathrm{e}-03$ & $2.24 \mathrm{e}-04$ & $3.17 \mathrm{e}-05$ \\
\hline & $\begin{array}{l}\text { HPHS \& HHW } \\
\text { runoff\&erosion(section 15) }\end{array}$ & $3.32 \mathrm{e}-03$ & 0 & $4.57 e-05$ \\
\hline \multirow[t]{2}{*}{ Permethrin } & HPHS runoff\&erosion & 0 & $1.47 \mathrm{e}-06$ & $1.02 \mathrm{e}-07$ \\
\hline & TU summation & $3.67 \mathrm{e}-02$ & $5.10 \mathrm{e}-03$ & $8.81 \mathrm{e}-04$ \\
\hline
\end{tabular}

* Numerical values are in scientific notation.

Macroinvertebrates are generally more sensitive than salmonids to pesticides. We would expect to see similar trends as before but magnified effects. Referring to Table 16, for macroinvertebrates, the final toxic units for organophosphates within the main tributary of Section 15, Douglas Creek, and the Siuslaw River are still low.

Prey Base Effects and Bioaccumulation. It is becoming increasingly evident that the indirect effects of contaminants on ecosystem structure and function are a key factor in determining a toxicant's cumulative risk to aquatic organisms (Preston, 2002). As mentioned within the analysis of the family of pesticide above (as applicable), adverse effect to salmonid prey base can occur from exposure to some substances. Moreover, aquatic plants and macroinvertebrates are generally more sensitive than fish to the acutely toxic effects of herbicides. Therefore, chemicals can potentially impact the structure of aquatic communities at concentrations that fall below the threshold for direct biological impairment in salmon. The integrity of the aquatic food chain is an essential biological requirement for salmon and 
steelhead, and the reasonable likelihood herbicide applications will reduce the productivity of streams and rivers is a significant adverse effect.

Pesticide, herbicide and fertilizer effects to salmonid prey base typically occur through two primary mechanisms: (1) Effects to the amount and/or type of food supply; or (2) by pesticide exposure via food organisms. Depending on the exposure scenario, effects to aquatic invertebrate communities can be very short-term, or take months or years to fully recover. Pesticide exposure via food organisms is likely to be much more episodic and short-term. Norris et al. (1991) provide a summary and literature review of pesticide and fertilizer effects to salmonids. The amount and/or type of food supply can be altered by pesticides and fertilizers in complex and subtle ways, particularly if the aquatic system is exposed to a combination of insecticides, herbicides, and fertilizers.

Insecticides can alter the prey base by direct mortality of aquatic invertebrates. Insecticides are typically more toxic to fish and other aquatic organisms than herbicides, but are generally applied at lower rates (Beschta et al., 1995). Insecticides can cause direct mortality of aquatic invertebrates, or trigger extensive drift of aquatic invertebrates out of the affected area (Spence et al. 1996). If grazing invertebrates are reduced or eliminated from a stream reach, primary production release may occur (such as algal blooms), altering trophic structure.

Herbicides are often not highly toxic to salmonids, as they are generally designed to interfere with physiological systems unique to plants. However, low concentrations of herbicides may exert significant effects on salmonid prey items by affecting algal or aquatic plant communities (Pratt et al., 1997), or directly on salmonids through sub-lethal effects of the herbicide (Spence et al., 1996). In addition, some herbicides are moderate to highly toxic to aquatic invertebrates, such as triclopyr ester (SERA 2003b), and adjuvants and surfactants present in herbicide commercial formulations can greatly enhance toxicity (Stark and Walthall, 2003, SERA, 1997). Fertilizers can also affect salmonid food supply by increasing algal and other aquatic plant growth, altering the aquatic invertebrate community.

Salmonid pesticide exposure through food organisms can occur through incidental exposure of terrestrial insects which subsequently become prey items for fish (Norris et al., 1991), or indirectly through invertebrate ingestion of organic material delivered to the aquatic system (Urban and Cook, 1986). Chemicals which are more lipophilic (fat soluble) will tend to partition into organic material in or on soil. Runoff can mobilize organic material into streams where it is consumed by insects and crustaceans. Little data is available on the risk of exposure via this pathway, but risk is likely to be highly variable depending on conditions at the time of application, such as seasonal timing.

Bioaccumulation in fish is partially mediated by the presence of insecticides and herbicides in food items and sediment residues, but also includes bioconcentration, defined as passive uptake from the water column (Klaassen et al., 1986). The lipophilicity of the chemical and fat content of the organism are the primary factors determining the extent of bioaccumulation. Chemicals with high lipophilicity tend to partition out of the water column and into food items, with the 
degree of partitioning proportional to the organism fat content. Concentration up the food chain (biomagnification) occurs when repeated exposure through consumption of contaminated prey items results in high concentrations of chemical in predators, such as salmonids. In order for bioaccumulation to occur, a chemical must have sufficient lipophilicity and persistence, and relatively low acute toxicity. Within the BA, the potential for bioaccumulation of degradates and metabolites is not addressed.

The possibility of adverse effects from additive, antagonistic or synergistic effects from multiple applications exists. The relative risk of these type of adverse effects depends upon the volume and timing of their delivery, and background water quality conditions. Within the zones of possible exposure periods described above, the greatest likelihood of additive/synergistic effects from applications would occur anytime precipitation events cause significant subsurface or overland flow delivery to aquatic systems. The volume and types of chemicals delivered would depend upon the relative success of CPs to inhibit off-target delivery of chemicals. At Tyrrell, it is thought that the greatest potential for this pathway of adverse effects would occur in zone three (mid-September through December). As precipitation levels rise, subsurface and overland flow off Tyrrell will increase, thus chemical delivery to Streams 1 and 8, Douglas Creek, and the Siuslaw River could occur. Likely delivery pathways to these drainages (with the exception of the Siuslaw River) are the ephemeral/intermittent waterways that border, or originate from many of the treatment units. Similarly, zone two delivery is plausible, but unlikely in most circumstances because of infrequent surface water flows in most of the ephemeral and intermittent waterways during this low precipitation period, in combination with the proposed buffers and additional CPs designed to reduce off-target delivery. As previously mentioned, model results are derived from a number of conservative assumptions, and NMFS utilized the maximum application rate scenario, and assumed that the application frequency listed in Table 2 would actually occur.

Cultural, Biological, and Physical Methods. The cultural, biological, and physical pest treatments are unlikely to have measurable effects, due to the small amount of area where these treatments would be applied, and the very limited amount of disturbance to riparian soils and native vegetation communities the treatments are expected to create. Cultural and biological controls have very little potential to effect salmonids or their habitat. Cultural controls are preventive measures to reduce the risk of introduction or dissemination of weeds. They do not involve ground disturbing activities. Biological controls use insects and pathogens determined to be host-specific, highly damaging to targeted species, able to survive in the host's habitat, free of natural parasites, and not likely to be parasitized in the host plant's habitat. Biological controls pose no foreseeable risk to salmonids or their habitat. Physical controls involve ground disturbing activities (pulling or cutting of weeds). However, the scope and magnitude of this action is so limited that any effect to salmonids or their habitat is considered negligible. The use of prescribed burns is limited to non-riparian areas. Provided that proper treatment methods (i.e., burn containment and timing) are used, there would be very little potential for adverse effects.

Establishment of Monitoring Criteria. The following pesticides proposed for use at Tyrrell (Table 16) posed the largest threat to aquatic organisms and habitat. The close 
monitoring of these contaminants is necessary in order monitor the effectiveness of CPs and the Terms and Conditions of this Opinion.

Low and high triggers for reinitiation were established by considering LC50 values taken from the scientific literature, and dividing by 20 to create a 'low trigger, 'and 2 to create a 'high trigger.'

The low trigger reflects a conservation measure that attempts to reduce, though not avoid, sublethal effects in coho salmon. A high trigger reflects a concentration in which direct mortalities may occur which is not authorized in this Opinion. The low trigger levels are those estimated dissolved contaminant concentrations in water, which can be surpassed a single time, for one compound, during each of the three annual precipitation and application zones as displayed within the Opinion (Figure 1 and Table 11). Thus, a total of three annual exceedences of the low trigger are allowed per year, one during each period.

A high trigger reflects a concentration in which direct mortalities may occur which is not authorized in this Opinion. The high trigger values are those dissolved contaminant concentrations in flowing water at which acute lethality may occur. Meeting or exceeding these concentrations would require re-initiation of consultation.

The literature sources were agreed upon by NOAA and BLM and previously used by the BLM in an extensive effects analysis section of the BA. Detection limits of pesticides are also given if known. The low trigger and high trigger values may be revisited (and potentially revised) annually to incorporate new data regarding baseline conditions, and newly-published sublethal effects.

Table 17. Monitoring Triggers

\begin{tabular}{|c|c|c|c|c|c|c|}
\hline Compound & $\begin{array}{l}\text { Chemical } \\
\text { Family }\end{array}$ & $\begin{array}{l}\text { LC50 } \\
\text { (PPB) }\end{array}$ & 'low trigger' & 'high trigger' & $\begin{array}{c}\text { Detection } \\
\text { Limit }\end{array}$ & LC50 Source \\
\hline Chlorpyrifos & \multirow{3}{*}{$\begin{array}{l}\text { Organo- } \\
\text { phosphate }\end{array}$} & 3 & 0.15 & 1.5 & 0.04 & EPA 1984 \\
\hline Dimethoate & & 6200 & 310 & 3100 & 0.8 & EPA 1999 \\
\hline Diazinon & & 90 & 4.5 & 45 & 0.2 & $\begin{array}{l}\text { Johnson \& } \\
\text { Finley } 1980\end{array}$ \\
\hline Permethrin & \multirow[t]{2}{*}{ Pyrethroids } & 7 & 0.4 & 3.5 & 0.4 & $\begin{array}{l}\text { Holcombe et al. } \\
1982\end{array}$ \\
\hline Esfenvalerate & & 0.09 & 0.0005 & 0.045 & 0.02 & $\begin{array}{l}\text { Curtis et al., } \\
1985\end{array}$ \\
\hline Propargite & Organo-sulfite & 118 & 5.9 & 59 & 0.4 & EPA 2000 \\
\hline
\end{tabular}




\begin{tabular}{|l|l|c|c|c|c|c|}
\hline Compound & $\begin{array}{l}\text { Chemical } \\
\text { Family }\end{array}$ & $\begin{array}{c}\text { LC50 } \\
\text { (PPB) }\end{array}$ & 'low trigger' & 'high trigger' & $\begin{array}{c}\text { Detection } \\
\text { Limit }\end{array}$ & LC50 Source \\
\hline $\begin{array}{l}\text { Trichloropyridnol } \\
\text { (Triclopyr and } \\
\text { chlorpyrifos } \\
\text { degradate) } \\
\text { picloram }\end{array}$ & $\begin{array}{l}\text { Pyridine } \\
\text { derivatives }\end{array}$ & 1500 & 75 & 750 & NA & Wan 1988 \\
\hline $\begin{array}{l}\text { Chlorothanil } \\
\text { Chlorinated- } \\
\text { benzene nitrile }\end{array}$ & 42 & 2.1 & 21 & 0.04 & EPA 1999 \\
\hline
\end{tabular}

Semi-Permeable Membrane Devices (SPMDs). SPMDs will be deployed to monitor instream waterborne concentrations of pesticide contaminants. The SPMD is an instream 'accumulator' which allows calculation of an average chemical concentration during the period of deployment.

SPMDs provide a time-weighted average concentration for the chemicals of interest and only measure the dissolved and, therefore, the readily bioavailable fraction. The contaminants of highest concern (pyrethroids and organophosphates) are highly hydrophobic and exhibit high Koc-binding affinities. These contaminants are likely to bind to available particulate organic carbon and ultimately move as particles in marine, freshwater, and estuarine ecosystems. Thus, the SPMD data will capture only a small fraction of these contaminants that actually enters the waterbody. Contaminants sequestered by particulate organic carbon are not sampled and are still available to enter food webs, or play significant roles in habitat forming processes. However, SPMDs successfully monitor the dissolved waterborne concentrations of contaminants that are immediately bioavailable to ESA-listed species. Thus, they are a reliable source of information on the effectiveness of conservation practices to reduce exposure and eliminate any chance of acute mortalities.

\section{Cumulative Effects}

Cumulative effects are defined in 50 C.F.R. 402.02 as 'those effects of future state or private activities, not involving Federal activities, that are reasonably certain to occur within the action area of the Federal action subject to consultation.' Other activities within the watershed have the potential to impact fish and habitat within the action area. Future Federal actions, including the ongoing operation of hydropower systems, hatcheries, fisheries, and certain land management activities are being (or have been) reviewed through separate section 7 consultation processes with a variety of Federal action agencies.

${ }^{18}$ Trichloropyridnol (TCP) is a degradate of both chlorpyrifos and Triclopyr, that is classified as moderately toxic to fish. As a moderately toxic, common degradate of two of the pesticides applied, with a half-life ranging from 12 - 229 days, TCP poses a risk to listed salmonids greater than or equal to some of the pesticides applied. Therefore, TCP was added to the list of compounds to be monitored. 
Within this Opinion, cumulative effects have been analyzed from the context of future chemical use and pollutant discharge (and other water quality degradation) to surface waters from nonFederal land use. Such land uses include urban and suburban, commercial forestry and agriculture.

While general land use is known upstream and downstream from the project area, specific pesticide and fertilizer application amounts and acres treated are not well documented. However, pesticide application rates for various crops grown in Oregon have been documented (Jenkins 1999). In addition, the USDA Farm Service Agency provided NMFS the numbers of acres dedicated to agricultural production within the Upper Siuslaw Watershed, which are listed in Table 18. Also within Table 18, NMFS provides an estimate of the pounds of pesticides used for the number of acres that produce alfalfa, Christmas trees, and vineyards. While the application pound estimates for alfalfa and christmas trees are for the North Coast of Oregon, they represent the best available information to estimate the volume of chemicals utilized consistent with these types of land uses in the Siuslaw River Watershed. Similarly, the vineyards application pounds are from estimates derived by Jenkins in the Rogue River Basin.

Based on the estimates in Table 18 (below), predicting the volume of drift or runoff into receiving waterways, and ultimate delivery to the action area is possible, but not likely to be within a range of significant accuracy. To conduct a specific cumulative delivery estimate, the location of the treatment units relative to surface water, and the application timing and method would need to be understood. Despite these difficulties, there is a logical assumption that delivery and exposure to $\mathrm{OC}$ coho salmon from these, and other unknown or unquantified applications elsewhere in the basin, will occur within the five-year implementation period of the proposed IPM. Similarly, water quality degradation from nonagricultural land use, including roads and urban/suburban areas, are likely to deliver similar and dissimilar pollutants, such as PAHs, to portions of the action area. The BLM chemical input to occupied habitat could exacerbate effects through additive, antagonistic, or greater than additive (synergistic) effects. These effects (mostly sublethal) may be already manifest in OC coho from other pollutants within the action area. The pathways of effects from these water quality pollutants would be similar to those discussed the Mixture Toxicity Section, above. 
Table 18. Estimates of Pounds Applied for Alfalfa, Christmas Trees, and Vineyards on Annual Basis Within the Upper Siuslaw Watershed.

\begin{tabular}{|c|c|c|c|}
\hline \multicolumn{4}{|l|}{ Alfalfa } \\
\hline Treatment & $\begin{array}{l}\text { lbs a.i. } / 2000 \mathrm{ac} \text { (as } \\
\text { reported for N. OR } \\
\text { coast by Jenkins) }\end{array}$ & $\begin{array}{c}\text { normalized to lbs } \\
\text { a.i./1000 ac }\end{array}$ & $\begin{array}{l}\text { a.i./595 acres (\# acres for } \\
\text { upper Siuslaw, as reported } \\
\text { by USDA Farm Service) }\end{array}$ \\
\hline $2,4-\mathrm{DB}$ & 100 & 50 & 30 \\
\hline Bromoxynil & 13 & 6.5 & 4 \\
\hline Carbaryl & 40 & 20 & 12 \\
\hline Diuron & 1100 & 550 & 327 \\
\hline EPTC & 700 & 350 & 208 \\
\hline Glyphosate & 30 & 15 & 9 \\
\hline Hexazinone & 140 & 70 & 42 \\
\hline Methyl bromide & 400 & 200 & 119 \\
\hline Metribuzin & 300 & 150 & 89 \\
\hline Paraquat & 650 & 325 & 193 \\
\hline Pronamide & 140 & 70 & 42 \\
\hline Sethoxydim & 60 & 30 & 18 \\
\hline Sulfur & 45 & 22.5 & 13 \\
\hline \multicolumn{4}{|l|}{ Christmas Trees } \\
\hline Treatment & $\begin{array}{l}\text { lbs a.i. } / 236 \text { ac (as } \\
\text { reported for N. OR } \\
\text { coast by Jenkins) }\end{array}$ & $\begin{array}{c}\text { normalized to lbs } \\
\text { a.i./1000 ac }\end{array}$ & $\begin{array}{c}\text { a.i./47 acres (\# acres for } \\
\text { upper Siuslaw, as reported } \\
\text { by USDA Farm Service) }\end{array}$ \\
\hline Atrazine & 64 & 271 & 13 \\
\hline Chlorothalonil & 158 & 669 & 31 \\
\hline Chlorpyrifos & 15 & 64 & 3 \\
\hline Endosulfan & 30 & 127 & 6 \\
\hline Glyphosate & 50 & 212 & 10 \\
\hline Hexazinone & 80 & 339 & 16 \\
\hline Oxyfluorfen & 80 & 339 & 16 \\
\hline \multicolumn{4}{|l|}{ Vineyards (grapes) } \\
\hline Treatment & $\begin{array}{l}\text { lbs a.i./500 ac (as } \\
\text { reported for the } \\
\text { Rogue River by } \\
\text { Jenkins) }\end{array}$ & $\begin{array}{c}\text { normalized to lbs } \\
\text { a.i./1000 ac }\end{array}$ & $\begin{array}{c}\text { a.i./505 acres (\# acres for } \\
\text { upper Siuslaw, as reported } \\
\text { by USDA Farm Service) }\end{array}$ \\
\hline Carbaryl & 20 & 40 & 20 \\
\hline Carbofuran & 29 & 58 & 29 \\
\hline Diuron & 50 & 100 & 51 \\
\hline Glyphosate & 219 & 438 & 221 \\
\hline Iprodione & 300 & 600 & 303 \\
\hline Malathion & 51 & 102 & 52 \\
\hline Napropamide & 37 & 74 & 37 \\
\hline Simazine & 221 & 442 & 223 \\
\hline Sulfur & 2797 & 5594 & 2825 \\
\hline Triadimefon & 15 & 30 & 15 \\
\hline
\end{tabular}


Given the known water quality stressors (high summer water temperatures and low dissolved oxygen) facing rearing juvenile coho salmon in the Siuslaw River, and the very likely but unquantified, presence of pesticides from concurrent applications, any additional exposure to toxic chemicals from is very likely to adversely affect fish rearing within the area influenced by the proposed project. Confounding this assessment are the above described sources of uncertainty, particularly the future non-BLM discharges of various chemicals.

NMFS believes that baseline conditions within much of the action area will be subject to local changes in the short and long term. NMFS assumes that future private and state actions will continue at similar intensities as in recent years.

\section{Conclusion}

After reviewing the best available scientific and commercial information regarding the biological requirements and the status of the OC coho salmon ESU considered in this Opinion, the environmental baseline for the action area, the effects of the proposed action, and the cumulative effects, NMFS' concludes that the action, as proposed, is not likely to jeopardize the continued existence of these species.

These conclusions are based on the following considerations: (1) The BLM will use integrated pest management to ensure that a combination of all available pest control strategies, including pesticide alternatives, are applied to keep pests below treatment thresholds while reducing the need for pesticide applications; (2) when pesticide use is required, BLM will select the pesticide formula that is least toxic for fish and aquatic life while achieving management needs; (3) the application of pesticides will be timed to coincide with weather conditions that are least likely to result in riparian and aquatic contamination; (4) broad non-spray buffers will be observed to reduce the likelihood of significant quantities of pesticide will be transported to riparian and aquatic systems through aerial drift, surface runoff, and groundwater runoff; (5) pesticides will be applied using precise methods designed to reduce the amount of pesticide loss; (6) a comprehensive sampling, monitoring, and analysis protocol will be used to ensure that the behavior and transport of pesticides in the environment are as predicted; (7) the proposed action includes an explicit process to quickly modify the proposed action based on any significant new information that may be developed through consultations now underway with the EPA regarding the effects of pesticides proposed for use during management of Tyrrell; and (8) all fertilizer applications will be applied at environmentally optimum rates designed to reduce the presence of fertilizer products in drainage water delivered to surface and groundwater systems.

\section{Conservation Recommendations}

Section 7 (a)(1) of the ESA directs Federal agencies to use their authorities to further the purposes of the ESA by carrying out conservation programs for the benefit of threatened and endangered species. Conservation recommendations are discretionary measures suggested to minimize or avoid adverse effects of a proposed action on listed species, to minimize or avoid adverse modification of habitats, or to develop additional information. NMFS believes the 
following conservation recommendations are consistent with these obligations, and therefore should be carried out by the BLM. Information from the proposed recommendations will help to reduce uncertainty about the effects of past and ongoing human and natural factors leading to the status of listed salmon, their habitats, and the aquatic ecosystem within the action area.

1. The BLM should conduct or fund a study of non-pesticide use IPM methods relative to pesticide use effectiveness. The study should be tailored to determine the various production implications of these two approaches.

2. The BLM should conduct or fund additional monitoring of Stream 1, 8, and Douglas Creek Watersheds for toxic compounds. Sampling of sediment for pyrethroids should occur. Pyrethroids tend to bind to soil particles rather than stay suspended in the water column. This sampling should occur within the orchard as well as within receiving waterways that have listed fish. This data would assist in future ESA effect calls for similar proposed IPM actions, inform relative background conditions in this watershed, as well as provide meaningful data for adaptive management of the proposed IPM.

To be kept informed of actions minimizing or avoiding adverse effects, or those that benefit listed salmon and steelhead or their habitats, NMFS requests notification of the achievement of any conservation recommendations.

\section{Reinitiation of Consultation}

Consultation must be reinitiated if: (1) The amount or extent of taking specified in the incidental take statement is exceeded, or is expected to be exceeded; (2) new information reveals effects of the action may affect listed species in a way not previously considered; (3) the action is modified in a way that causes an effect on listed species that was not previously considered; or (4) a new species is listed or critical habitat is designated that may be affected by the action (50 C.F.R. 402.16).

Monitoring data showing that pesticide residues exceed thresholds within the terms and conditions of this Opinion, are an example of new information that would require reinitiation.

If the BLM fails to provide specified monitoring information by November 15 of each year (excluding 2004), NMFS may consider that a modification of the action that causes an effect on listed species not previously considered and causes the incidental take statement of the Opinion to expire. Consultation also must be reinitiated five years after the date this Opinion is signed. To reinitiate consultation, contact the Oregon State Habitat Office of the Habitat Conservation Division of NMFS, and refer to NMFS No.: 2004/00213.

\section{Incidental Take Statement}

Section 9(a)(1) and protective regulations adopted pursuant to section 4(d) of the ESA prohibit the taking of listed species without a specific permit or exemption. Among other things, an action that harasses, wounds, or kills an individual of a listed species or harms a species by 
altering habitat in a way that significantly impairs its essential behavioral patterns is a taking ( 50 C.F.R. 222.102). Incidental take refers to takings that result from, but are not the purpose of, carrying out an otherwise lawful activity conducted by the Federal agency or applicant ( 50 C.F.R. 402.02). Section 7(o)(2) exempts any taking that meets the terms and conditions of a written incidental take statement from the taking prohibition.

An incidental take statement specifies the impact of any incidental taking of endangered or threatened species. It also provides reasonable and prudent measures that are necessary to minimize impacts and sets forth terms and conditions with which the action agency must comply to implement the reasonable and prudent measures. However, the incidental take statement included in this conference opinion does not become effective until NMFS adopts this conference opinion as a biological opinion, after the listing is final. Until the time that the species is listed, the prohibitions of the ESA do not apply.

\section{Amount or Extent of the Take}

Individuals of $\mathrm{OC}$ coho salmon will be present in the action area during part of the year when actions necessary to carry out the Tyrrell Seed Orchard IPM are likely to release pesticides that will travel into streams and rivers occupied by this ESA-listed species and their prey. As discussed in this Opinion, pesticides released into those streams are reasonably likely to injure or kill some juvenile salmonids and their prey through a combination lethal and sublethal effects that will continue while the Tyrrell Seed Orchard IPM is in effect and pesticide use is part of that program.

Because such pesticide releases are likely to injure or kill individuals of these ESA-listed species, incidental take is reasonably certain to occur. However, the relationship between habitat conditions and the distribution and abundance of salmonids in the action area is imprecise, as is the exact type, amount and timing of the pesticides that are likely to be released, such that a specific number of individuals likely to be taken cannot be practically obtained. In these circumstances, NMFS uses the causal link established between the activity and a change in habitat conditions affecting the species to describe the extent of take as a numerical level of habitat disturbance.

In this case, the extent of take for this incidental take statement is limited to that which will result from detection of any pesticide concentration in the water column shown by the 'low trigger' and 'high trigger' values presented in Table 19 (below). These indicators and their estimated values were selected using the best available scientific information on the effects of acute toxicity on ESA-listed salmon.

The 'low trigger' values refer to concentrations in flowing water that may be exceeded for one compound, one time, during each of the three annual precipitation and application 'zones' as described in this Opinion. Thus, a total of three annual exceedences of the 'low triggers' are allowed, one during each period. The 'high trigger' values are concentrations at which acute lethal take is likely to occur and are the maximum extent of take authorized by this opinion. Any 
observed concentration of a compound named here that is greater than a 'high trigger' will exceed the extent of take authorized by this opinion. These 'low trigger' and 'high trigger' values may be revisited annually to incorporate any significant new information regarding baseline conditions and the lethal or sublethal effects of pesticides on salmonids.

Table 19. Extent of incidental take anticipated to result from completion of the Tyrrell Seed Orchard IPM quantified as pesticide concentrations in the water column.

\begin{tabular}{|c|c|c|c|}
\hline Compound & Chemical Family & $\begin{array}{l}\text { Low Trigger } \\
\quad(\mathrm{PPB})\end{array}$ & $\begin{array}{l}\text { High Trigger } \\
\text { (PPB) }\end{array}$ \\
\hline Chlorpyrifos & \multirow[t]{3}{*}{ Organo-phosphate } & 0.15 & 1.5 \\
\hline Dimethoate & & 310 & 3100 \\
\hline Diazinon & & 4.5 & 45 \\
\hline Permethrin & \multirow[t]{2}{*}{ Pyrethroids } & 0.4 & 3.5 \\
\hline Esfenvalerate & & 0.0005 & 0.045 \\
\hline Propargite & Organo-sulfite & 5.9 & 59 \\
\hline $\begin{array}{l}\text { Trichloropyridnol (Triclopyr and } \\
\text { chlorpyrifos degradate) picloram }\end{array}$ & $\begin{array}{l}\text { Pyridine } \\
\text { derivatives }\end{array}$ & 75 & 750 \\
\hline Chlorothanil & Chlorinated-benzene nitrile & 2.1 & 21 \\
\hline
\end{tabular}

In this Opinion, NMFS determined that this level of anticipated take is not likely to result in jeopardy to the species. Moreover, the habitat that will be affected is not unique and does not appear to be limited on a watershed scale or site-specific basis. The extent of habitat affected by the action is the threshold for reinitiating consultation. Should any of these limits be exceeded during project activities, the reinitiation provisions of this Opinion apply.

\section{Reasonable and Prudent Measures}

Reasonable and Prudent Measures are non-discretionary measures to avoid or minimize take that must be carried out by cooperators for the exemption in section 7(o)(2) to apply. The BLM has the continuing duty to regulate the activities covered in this incidental take statement where discretionary Federal involvement or control over the action has been retained or is authorized by law. The protective coverage of section 7(o)(2) may lapse if the BLM fails to exercise its discretion to require adherence to terms and conditions of the incidental take statement, or to exercise that discretion as necessary to retain the oversight to ensure compliance with these terms and conditions. 
The NMFS believes that the following reasonable and prudent measures are necessary and appropriate to minimize take of listed species resulting from completion of the proposed action.

\section{The BLM shall:}

1. Minimize incidental take by ensuring that orchard pests are managed using integrated pest management techniques that use treatment thresholds and minimize the need for pesticide application.

2. Minimize incidental take from pesticide applications by choosing pesticide formulas, timing, place, and manner of pesticide use to minimize the likelihood of delivery to riparian and aquatic systems.

3. Minimize incidental take from fertilizer application by ensuring that fertilizer is applied in a time, place and manner that minimizes the likelihood of delivery to surface and groundwater.

4. Minimize incidental take from aerial applications by implementing practices that preclude and/or limit non-target delivery of chemicals.

5. Ensure completion of a annual comprehensive monitoring and operations reporting program to confirm this Opinion is meeting its objective of minimizing take from permitted activities.

\section{Terms and Conditions}

To be exempt from the prohibitions of section 9 of the ESA, the BLM must comply with the following terms and conditions, which implement the reasonable and prudent measures described above. These terms and conditions are non-discretionary and, in relevant part, apply equally to proposed actions in all categories of activity.

1. To implement Reasonable and Prudent Measure \#1 (integrated pest management) the BLM shall:

a. Treatment thresholds. Ensure that no action to suppress insect pests will be taken unless pest monitoring show that one or more pests have reached a threshold at which losses in seed yield and quality exceed the economic and environmental cost of treatment. No pesticide will be applied on a routine basis, without regard for treatment thresholds based on pest populations.

b. $\quad$ Prescribed burning. When prescribed burning will be used as a pest control, the following conditions will apply.

i. Design the prescribed burn to minimize disturbance of riparian ground cover and vegetation, and any other habitat characteristic that could be damaging to long-term ecosystem function.

ii. Ensure that all vehicles, including emergency equipment, are not operated, maintained, or stored next to any stream, water body or wetland. Equipment shall not disturb native riparian vegetation. 
iii. Ensure that all vehicles, including emergency equipment, are not fueled within 150 feet of any waterbody.

iv. If riparian areas are inadvertently damaged during a prescribed burn, immediately prepare and implement a rehabilitation plan designed to restore riparian ground cover and vegetation.

v. Appropriate fire suppression equipment shall always be at the project site during a prescribed burn.

c. Each supervisor engaged in IPM activities must be informed of the following requirement:

NOTICE: If a sick, injured or dead specimen of a threatened or endangered species is found, the finder must notify the Vancouver Field Office of NMFS Law Enforcement at 360.418.4246. The finder must take care in handling of sick or injured specimens to ensure effective treatment, and in handling dead specimens to preserve biological material in the best possible condition for later analysis of cause of death. The finder also has the responsibility to carry out instructions provided by Law Enforcement to ensure that evidence intrinsic to the specimen is not disturbed unnecessarily.

2. To implement Reasonable and Prudent Measure \#2 (use of pesticides), the BLM shall ensure that:

a. These terms and conditions do not authorize any pesticide use that is inconsistent with the EPA pesticide product label.

b. Pesticides will be mixed and equipment cleaned in areas where spills cannot runoff to surface waters or leach to groundwater, such as a paved and bermed mixing pad capable of containing the volume of any potential spill.

c. Spill Prevention Plan. Prepare and carry out a spill prevention plan to prevent contamination from spill of pesticides and other hazardous materials. The plan will contain the pertinent elements listed below, meet requirements of all applicable laws and regulations, and must be available for inspection on request by NMFS.

i. The name and address of the party(s) responsible for accomplishment of the spill prevention plan.

ii. A description of any regulated pesticide and other hazardous materials that will be used as part of the IPM Plan.

iii. Training and certification for those who will be involved with pesticide transportation, storage, use, disposal, record keeping, monitoring, and emergency response

iv. Practices to prevent spills associated with mixing sites (i.e. containment), critical areas where spills are likely to occur, and environmental restrictions. 
v. Spill containment and notification procedures, specific cleanup and disposal instructions for different products, quick response containment and cleanup measures that will be available on the site, proposed methods for disposal of spilled materials.

vi. Identify specific routes of the equipment, load limits for equipment, allowable speeds on the routes, mixing site limits in quantities, chemical types, or spill potential.

d. Choice of pesticide. Choose pesticides and additives as follows.

i. When pesticides are required, the BLM will choose the pesticide that is least toxic to fish while meeting IPM pest control objectives, and accounting for human health concerns.

ii. No carrier other than water will be used to mix (dilute) the pesticide products for application.

iii. No surfactant or adjuvant that contains ingredients included on EPA's List 1 or 2 for toxicological concern or that has a high priority for testing (EPA 2000a) may be used, unless otherwise approved in writing by NMFS.

iv. Only one application of picloram may be made on an area in any given year to reduce the potential for picloram accumulation in the soil.

v. No additional adjuvants may be added to Roundup ${ }^{\circledR}$, including but not limited to ' $\mathrm{x}-77$.'

e. $\quad$ Timing of pesticide application.

i. Prioritize applications for mornings or evenings when pollinators are not active (as seasonally applicable) in accordance with the best overall weather period.

ii. Weather. Pesticides will not be applied under the following weather and soil conditions unless the product label specifically recommends otherwise.

(1) Within 72 hours of predicted precipitation that would result in runoff and measurable increases in streamflow. To predict this, use a combination of precipitation forecasting, antecedent soil moisture conditions and current streamflows. These methods shall be documented and included in the annual monitoring report.

(2) In areas with standing water (unless covered by plastic in isolated areas away from aquatic systems), saturated soils, snow or ice.

(3) In unstable air situations that may affect spray pattern or lead to offsite movement of spray, such as high air temperatures, during temperature inversions.

(4) In wind that exceeds 6 miles per hour or blows toward flowing streams.

f. Areas of pesticide application.

i. Application buffers. Application methods will be restricted by zones as follows. Zone widths refer distances from any non-perennial or perennial stream or water body with flowing water, measured horizontally from, and 
perpendicular to, the bankfull elevation, the edge of the channel migration zone, or the edge of any associated wetland, whichever is greater.

(1) $\leq 40$ Feet. Cultural methods.

(2) $\quad \mathbf{4 0}$ Feet. Capsule implantation, backpack prayer, hydraulic sprayer with handheld wand, tractor-pulled spray rig with boom, cultural methods, although hand-held wicks and backpack sprayers may be used to control plants designated as noxious weeds in Oregon, as defined in ORS 603-52-1200, that cannot be effectively controlled using cultural methods.

$\mathbf{2 0 0}$ Feet - All of the above, and high-pressure hydraulic sprayer, airblast sprayer, and aerial applications. Beside non-perennial streams dry during the time of application, a 40-foot buffer will also be applied (when using these methods).

ii. Do not apply pesticides to road or ditch surfaces that directly contribute to stream channel flow, nor to fence-lines within 50 feet on either side of stream channels.

g. Method of pesticide application.

i. Mow or graze orchard fields before insecticide applications to remove floral components or ground cover that attract pollinators (as seasonally applicable and practicable).

ii. No pesticide may be applied on a routine basis, without regard for treatment thresholds based on pest populations.

3. To implement Reasonable and Prudent Measure \#3 (use of fertilizers), the BLM shall ensure that:
a. Fertilizer will not be applied within 50 feet of any stream, wetland or other waterbody.
b. $\quad$ Fertilizer will be applied at agronomic rates. ${ }^{19}$
c. Fertilizer loading (pertaining to application equipment) areas shall be at least 100 feet from perennial streams.

4. To implement reasonable and prudent measure \#4 (aerial chemical application), the BLM shall ensure that:

a. Aerial Application CPs. In addition to the drift CPs listed above, the following actions shall be implemented during aerial applications:

i. Smoke flares shall be deployed beside surface water before application to provide for pilot/applicator recognition of wind speed and direction.

\footnotetext{
19 'Agronomic rate' means a quantity and timing of total nutrient application that does not exceed the requirements of the crop production and harvest or grazing system, as opposed to a nutrient application rate based on production goals that are difficult to define and variable. Calculation of the agronomic rate should take into account the total nitrogen or phosphorus resources for plant nutrition, and any retention of phosphorus in the soil and losses of nitrogen through denitrification and ammonia volatilization.
} 
ii. Chemicals shall not be transported by air over perennial streams.

5. To implement Reasonable and Prudent Measure \#5 (monitoring and reporting), the BLM shall ensure that:

a. Annual monitoring report. All water quality monitoring information associated with application of the Tyrrell Seed Orchard IPM program shall be compiled, analyzed, documented, and reviewed on a 'water year' basis. This 'water year' shall include all monitoring performed during the October 1 to September 30 period. This information, along with any recommendation for adjustments to protection measures and adjustments to the monitoring plan, shall be contained in an Annual Tyrrell Seed Orchard Monitoring Report. This report shall be available to the public and regulatory agencies on November 15 of each year and be on file at the Tyrrell seed orchard.

i. $\quad$ Project identification.

(1) BLM contact person.

(2) Pesticide project manager

(3) Starting and ending dates for work completed.

ii. $\quad$ IPM documentation.

(1) Description of how treatment was based on weather and pest monitoring.

(2) A description of the biological and cultural pest controls used before pesticides were applied, or the reasons that biological and cultural controls were not used. Note that this provision is applicable to the overall orchard IPM, not individual applications, and shall be documented within the annual monitoring report.

(3) Pesticide use history.

(a) Type of chemical applied

(b) Date of application

(c) Buffers present

(d) Method of pesticide application

(e) Total area treated

(f) Amount of pesticide applied

(g) Precipitation for the three days preceding and following application

(h) Wind direction and speed, relative humidity, air temperature at time of application

(i) Location used for mixing and loading and notes regarding whether any leakage or spills occurred

iii. Effectiveness Monitoring.

(1) Orchard units or treatment areas directly beside open water (within 200 feet) shall require drift cards be placed at a maximum of 100foot intervals along the edge of Tyrrell's unit before the 
application (for aerial, airblast and high pressure hydraulic sprayer applications).

(2) If open canopy occurs in the waterway buffer, drift cards shall be selectively placed along the waterway edge to characterize potential intrusion of drift toward waterways. Any applications shall cease if there is any indication that there is off-target delivery occurring.

(3) Immediately after the application, the cards shall be collected and reviewed to determine if a drift signature is present, the extent of the drift, and the potential for aquatic contamination. A copy of all the cards shall be kept on file at Tyrrell, along with a record of their location and all the compliance monitoring documentation.

vi. Surface Water Monitoring to Detect Drift.

(1) Aerial, airblast, and high-pressure hydraulic sprayer applications of chemicals, water samples shall be collected before and after spray application that include representative "15 minute" and "24hour (composite)" post-treatment water samples.

(2) Section of sampling stations for surface water sampling shall be based on the proximity to application areas and characteristics of nearby surface water.

(3) All data shall be used in conjunction with the spray cards to determine the effectiveness of the full "suite" of protective measures implemented to avoid drift.

(4) Samples shall be analyzed at a state-certified laboratory that has detection limits at the lowest certified detection levels.

(5) Samples shall be collected in accordance with laboratory instructions.

(6) When sites are sampled, additional interpretive data shall be collected for $\mathrm{pH}$, specific conductance, turbidity, suspended sediment, temperature, or other relevant parameters. ${ }^{20}$

(7) Surface water samples are collected within the project area, also collect water samples concurrently where flowing water enters the project area to facilitate a baseline/cumulative concentration analysis. $^{21}$

iii. Surface Runoff.

(1) Effectiveness monitoring of protective measures and limitations in the proposed action shall target those periods of precipitation that could result in field surface runoff and increased streamflow.

${ }^{20}$ Temperature shall always be collected, but other parameters collected will depend upon the applicability to the particular 'targeted' chemical.

${ }^{21}$ It is anticipated that most, if not all, sampling locations at Tyrrell will not require 'upstream' sampling, because drainages sampled will originate solely from the orchard boundaries. 
These periods are most likely to carry the greatest detectible concentrations of chemicals.

(2) Continuous flow recording stations shall be established during runoff events with the intention of providing individual storm concentrations.

(3) The data from recording stations shall be interpreted to be representative of water quality conditions as a result of the effectiveness of implemented protection measures and limitations in the higher-risk seed production areas.

(4) All data shall be used in conjunction with continuous recorded climate data to evaluate the effectiveness of protection measures and limitations in minimizing introduction of pesticides and fertilizers to the aquatic system.

(5) Samples shall be analyzed at a state-certified laboratory that has the lowest certified detection levels.

iv. Cumulative Concentrations Runoff.

(1) Stormflow with the highest potential for chemical presence shall be sampled and, during these flow events, samples shall be composited according to the rise and fall of the hydrograph.

(2) Semi-permeable membrane devices (SPMDs) shall be deployed, to monitor the accumulation of chemicals in waters containing aquatic species.

(3) SPMDs shall be deployed before initial winter storms and spring storm periods after compound application.

(4) Streamflow gauges (USGS and BLM) shall be maintained to provide flow data for deriving concentrations (chemical loading) over the period of time the SPMD is deployed.

(5) Data from the SPMD concentrations shall be used to compare and validate the storm flow concentration monitored during the deployment period.

(6) The SPMDs shall be tested for those compounds that were applied and can be sequestered.

v. Monitoring of Best Management Actions. For select sites, monitoring shall be used to validate the water quality modeling predictions presented in the EIS and BA.

(1) Monitoring the stream systems shall identify the effectiveness of protection measures, and to help to gauge the estimates in the RA.

(2) Collection chambers shall be installed in selected areas where there is concern regarding overland flow. During the first overland flow event following select chemical applications, these sites shall be visited, and a water sample taken from the collection chamber. This data shall be used to assess the mobility of chemicals that have been used onsite within the past year. 
(3) Concentrations shall be compared with modeled results utilizing field- and climate-specific data to validate RA estimates.

(4) If detectable concentrations are found, stream concentrations shall also be compared to model results using actual application information, field-specific data, and continuous climate record. These data shall provide a relationship between previous monitoring results and the management that is planned for the future.

(5) For select sites and once the yearly application period is complete, the climate record collected during that period shall be used to model a predicted concentration using the GLEAMS and MOC models. These concentrations shall be "diluted" using the continuous flow data from the station. The resulting concentrations shall be compared with the actual measured concentrations for each storm event sampled.

vi. Spill Monitoring. In the event of a chemical spill, the volume of spill, proximity to water, and chemical characteristics, such as toxicity and mobility, shall be immediately evaluated to determine if water sampling is desirable and necessary. If the spill occurs in an area that is reasonably certain to deliver to surface waters, either immediately, or on the next precipitation event, sampling shall occur, as appropriate.

(1) Water samples shall be collected in a sufficient number and at surface water and groundwater locations that shall allow characterization of impacts and effective remediation methods. Depending on ODEQ Monitoring Hazardous Substances Remediation Rules (OAR 340-122), monitoring could include surface water, groundwater, air, and soil.

(2) At a minimum, sampling shall be conducted in the streams draining the spill area and the immediate groundwater table. Tyrrell's domestic well shall be sampled if in proximity to spill.

vii. Notification of Discharge. If a surface water discharge occurs, the BLM shall notify NMFS within 10 business days of detection. Notification will include the type, location, and concentration of the discharge.

viii. Implement monitoring at Tyrrell as follows: 
The concentrations of the following pesticides shall not exceed the following trigger values in flowing water. ${ }^{22}$

\begin{tabular}{|c|c|c|c|}
\hline Compound & Chemical Family & Low Trigger & High Trigger \\
\hline Chlorpyrifos & \multirow{3}{*}{ Organo-phosphate } & 0.15 & 1.5 \\
\hline Dimethoate & & 310 & 3100 \\
\hline Diazinon & & 4.5 & 45 \\
\hline Permethrin & \multirow[t]{2}{*}{ Pyrethroids } & 0.4 & 3.5 \\
\hline Esfenvalerate & & 0.0005 & 0.045 \\
\hline Propargite & Organo-sulfite & 5.9 & 59 \\
\hline $\begin{array}{l}\text { Trichloropyridnol (Triclopyr and } \\
\text { chlorpyrifos degradate) picloram }\end{array}$ & $\begin{array}{l}\text { Pyridine } \\
\text { derivatives }\end{array}$ & 75 & 750 \\
\hline Chlorothanil & Chlorinated-benzene nitrile & 2.1 & 21 \\
\hline
\end{tabular}

(1) The low trigger and high trigger values may be revisited (and potentially revised) annually to incorporate new data regarding baseline conditions, and newly-published sublethal effects.

(2) The 'low trigger' levels are those estimated flowing water concentrations, which can be surpassed a single time, for a total of one compound, during each of the three annual precipitation and application 'zones' as displayed within the Opinion. Thus, a total of three annual exceedences of the 'low triggers' are allowed, one during each period.

(3) The 'high trigger' values are those concentrations at which acute lethal take may occur in flowing water concentrations at the confluence with listed salmonids. Meeting or exceeding these concentrations would require re-initiation of consultation.

\footnotetext{
${ }^{22}$ For the Rodeo formulation of glyphosate, if additives and their concentrations in tank mixes are
} identified, along with the total volume and locations of application, are included in the annual monitoring report, no testing of water samples for glyphosate will be required, unless NOAA-Fisheries identifies additives of concern in the future.

${ }^{23}$ Trichloropyridnol (TCP) is a degradate of both chlorpyrifos, that is classified as moderately toxic to fish. As a moderately toxic, common degradate of two of the pesticides applied, with a half-life ranging from $12-229$ days, TCP poses a risk to listed salmonids greater than or equal to some of the pesticides applied. Therefore, TCP was added to the list of compounds to be monitored. 
Surface drift monitoring shall occur for the following compounds that are applied using the specific methodologies.

\begin{tabular}{|c|c|c|c|}
\hline Application Method & Compound & $\begin{array}{l}\text { Surface Water } \\
\text { Drift } \\
\text { Monitoring }\end{array}$ & $\begin{array}{l}\text { Sites for Surface Water Drift Sampling and sites } \\
\text { for SPMD Placement }\end{array}$ \\
\hline Aerial & Esfenvalerate & $\begin{array}{l}\text { A representative } \\
\text { stream }^{24} \text { or } \\
\text { streams will be } \\
\text { sampled and } \\
\text { tested for each } \\
\text { application }\end{array}$ & \multirow[t]{2}{*}{$\begin{array}{l}\text { Stream } 8 \text { and stream } 54 \text { will be monitored at one of } \\
\text { four established sites downstream from potentially } \\
\text { affected tributaries. Streams } 11,12,13,25 \text { and } 17 \\
\text { would be monitored where they cross the fenced } \\
\text { orchard boundary*. }\end{array}$} \\
\hline $\begin{array}{l}\text { Airblast sprayer } \\
\text { Hydraulic sprayer w/ } \\
\text { handheld wand } \\
\text { Backpack Sprayer - } \\
\text { Hand-held wand }\end{array}$ & $\begin{array}{l}\text { Esfenvalerate } \\
\text { Chlorpyrifos } \\
\text { Permethrin } \\
\text { Diazinon } \\
\text { Dimethoate } \\
\text { Propargite } \\
\text { Chlorothalonil }\end{array}$ & $\begin{array}{l}\text { Surface water } \\
\text { sampling and } \\
\text { testing for each } \\
\text { application } \\
\text { within } 300 \text { feet } \\
\text { of surface water }\end{array}$ & \\
\hline
\end{tabular}

* Additional upstream sites in section 9 may be added to substituted upstream in specific instances where it is thought that capture of potentially contaminated runoff is more effective.

xiv. Circumstances that would trigger reinitiation

(1) More than one discharge per zone, as defined in this Opinion, between the 'low trigger' and high trigger; values (within any one year). Note that discharges below the low trigger value are not applicable to this total.

(2) A discharge within any one year above the 'high trigger' value.

(3) For compounds with a common mode of action (i.e. pyrethroids and organophosphates), if the sum total of the toxic units is $>0.05$ (equivalent to $1 / 20$ th of the standardized LC50's) it will be counted as a 'low trigger' exceedence. If the sum total of the toxic units is $>0.5$ (equivalent to $1 / 2$ of the standardized LC50's) it will be counted as a 'high trigger' exceedence. This applies only when both detections occur in the same location, and at the same time (the compounds co-occur in the water column). The toxic units for each class, pyrethroids, and organophosphates, will be calculated as outlined within this Opinion. Only one 'low trigger' exceedence will be counted if there is a toxic unit 'low trigger'

${ }^{24}$ A representative stream is any stream beside a spray unit, downwind of a spray unit, or otherwise liekly to be affected if drift outisde the treatment units occurs. 
exceedence and if the same chemical family already contains a 'low trigger' exceedence of an individual compound.

To account for the synergistic action of pyrethroids and organophosphates, as described within this Opinion, an exceedence of a 'low trigger' of both a pyrethroid and an organophosphate (either individually or as a sum total of family toxic units) will be considered the equivalent of exceeding a high trigger. This applies only when both detections occur in the same location, and at the same time (the compounds co-occur in the water column), and includes SPMD data.

(5) Upon any SPMD detection, the data shall be used to provide a 24-hour average waterborne contaminant concentration for the chemicals that were applied and can be sequestered. To reflect the margin of error within the SPMD methodology, a 2-fold safety factor (Huckins 2004) shall be applied to the back calculated 24-hour average concentration (multiply the value by two). The corrected 24-hour concentration shall then be treated as a discharge within the final monitoring plan and the same circumstances (Table 18) apply for reinitiation.

(6) An annual review of SPMD data collection, data use, and sampling methodology may occur. In the event of a detection, factors leading to the resultant discharge concentration shall be reviewed.

b. Annual Operation Report ${ }^{25}$. The Annual Operation Report will be submitted to NMFS by December 1st, and include the following information (NMFS will review the Annual Operation Report within 30 business days of its receipt):

i. A description and list of pesticide applications conducted over the reporting period.

ii. The results of the previous year monitoring program. If a discharge occurred during the previous year, possible causes of the discharge shall be explored, as well as future mitigation steps to prevent like discharges in the future.

iii. A data review of the pesticides that are proposed for use, or may be used, at Tyrrell in the following year. The review will include:

(1) New scientific data regarding non-target fish species effects or environmental fate.

(2) Changes to EPA-approved labels (ESA-approved and other).

(3) A review of legal findings relevant to the use of compounds.

(4) Any new scientific data will be reviewed and summarized, as stated in the proposed action, considered in terms of effects on orchard operations and compound use. Literature will include

25 Note that the annual operations plan for 2005 only needs to include data specified within letter (e). 
peer-reviewed data and other forms of scientific evidence that may be relevant to Pacific salmon and steelhead

(5) A plan for proposed pesticide applications for the following year, including, to the extent possible, units or acres to be treated, proposed pesticide, application rate and method, dates, and a proposed monitoring plan. ${ }^{26}$

(6) Any proposed changes to the IPM, including new limitations, protection measures, or mitigation measures as part of an adaptive management approach; the use of pesticides in addition to those proposed; or other relevant information. The annual report shall be sent to:

\section{Director, Oregon State Habitat Office NMFS}

Attn: 2004/00213

525 NE Oregon Street

Portland, OR 97232

c. Submital of a New BA and Request for Reinitiation. Throughout the implementation of the proposed action(s), the BLM shall assess situations that might trigger a new consultation, including but not limited to:

i. $\quad$ New pesticides are proposed for use at Tyrrell.

ii. A proposal is made to increase application rates.

iii. New toxicity information becomes available that indicates additional possible effects that were not identified in the BA or considered in the original Opinion.

iv. Monitoring results show significant changes in expected results concurrent with science review.

v. A proposal is made to increase the application acreage.

vi. New information on persistence, delivery or movement of chemicals within Tyrrell and/or new literature.

d. Annual coordination. Meet with NMFS by January 15, each year as necessary, to discuss the annual monitoring report and any action necessary to make the program more effective.

\section{MAGNUSON-STEVENS FISHERY CONSERVATION AND MANAGEMENT ACT}

The MSA, as amended by the Sustainable Fisheries Act of 1996 (Public Law 104-267), established procedures designed to identify, conserve, and enhance EFH for those species regulated under a Federal fisheries management plan. Pursuant to the MSA:

${ }^{26}$ The draft monitoring plan shall include proposed sampling locations, frequencies, and methods in relation to the application plan. The 2005 monitoring plan will also include a map with the proposed SPMD placement site. 
- $\quad$ Federal agencies must consult with NMFS on all actions, or proposed actions, authorized, funded, or undertaken by the agency, that may adversely affect EFH ( $\$ 305(b)(2))$.

- $\quad$ NMFS must provide conservation recommendations for any Federal or state action that would adversely affect EFH $(\S 305(\mathrm{~b})(4)(\mathrm{A}))$.

- $\quad$ Federal agencies must provide a detailed response in writing to NMFS within 30 days after receiving EFH conservation recommendations. The response must include a description of measures proposed by the agency for avoiding, mitigating, or offsetting the impact of the activity on EFH. In the case of a response that is inconsistent with NMFS EFH conservation recommendations, the Federal agency must explain its reasons for not following the recommendations $(\$ 305(\mathrm{~b})(4)(\mathrm{B}))$.

EFH means those waters and substrate necessary to fish for spawning, breeding, feeding, or growth to maturity (MSA $\S 3$ ). For the purpose of interpreting this definition of EFH: "Waters" include aquatic areas and their associated physical, chemical, and biological properties that are used by fish and may include aquatic areas historically used by fish where appropriate; "substrate" includes sediment, hard bottom, structures underlying the waters, and associated biological communities; "necessary" means the habitat required to support a sustainable fishery and the managed species' contribution to a healthy ecosystem; and "spawning, breeding, feeding, or growth to maturity" covers a species" full life cycle (50 C.F.R. 600.10). "Adverse effect" means any impact which reduces quality and/or quantity of EFH, and may include direct (e.g., contamination or physical disruption), indirect (e.g., loss of prey or reduction in species fecundity), site-specific or habitat-wide impacts, including individual, cumulative, or synergistic consequences of actions (50 C.F.R. 600.810).

EFH consultation with NMFS is required regarding any Federal agency action that may adversely affect EFH, including actions that occur outside EFH, such as certain upstream and upslope activities.

The objectives of this EFH consultation are to determine whether the proposed action would adversely affect designated EFH and to recommend conservation measures to avoid, minimize, or otherwise offset potential adverse effects to EFH.

\section{Identification of EFH}

Pursuant to the MSA, the Pacific Fisheries Management Council (PFMC) has designated EFH for three species of Federally-managed Pacific salmon: Chinook and coho salmon (PFMC 1999). Freshwater EFH for Pacific salmon includes all those streams, lakes, ponds, wetlands, and other waterbodies currently, or historically accessible to salmon in Washington, Oregon, Idaho, and California, except areas upstream from certain impassable man-made barriers (as identified by the PFMC 1999), and longstanding, naturally-impassable barriers (i.e., natural waterfalls in existence for several hundred years). Detailed descriptions and identifications of EFH for salmon are found in Appendix A to Amendment 14 to the Pacific Coast Salmon Plan (PFMC 1999). Assessment of potential adverse effects to these species' EFH from the proposed action is based, in part, on this information. 


\section{Proposed Actions}

The proposed action and action area are detailed above this Opinion. The action area includes habitats that have been designated as EFH for various life-history stages of Chinook and coho salmon.

\section{Effects of Proposed Action}

As described in detail above, the proposed action may result in short- and long-term adverse effects to habitat due to adverse alteration of water quality.

\section{Conclusion}

NMFS concludes that the proposed action may adversely affect designated EFH for Chinook and coho salmon.

\section{EFH Conservation Recommendations}

Pursuant to section 305(b)(4)(A) of the MSA, NMFS is required to provide EFH conservation recommendations to Federal agencies regarding actions which may adversely affect EFH. The terms and conditions outlined in this Opinion are generally applicable to designated EFH for Chinook and coho salmon and address these adverse effects with the exception of monitoring requirements (RPM 5). Consequently, NMFS adopts Terms and Conditions 1 through 4 as EFH conservation recommendations.

\section{Statutory Response Requirement}

Federal agencies are required to provide a detailed written response to NMFS' EFH conservation recommendations within 30 days of receipt of these recommendations. The response must include a description of measures proposed to avoid, mitigate, or offset the adverse affects that the activity has on EFH. In the response is inconsistent with the EFH conservation recommendations, the response must explain the reasons for not following the recommendations, including the scientific justification for any disagreements over the anticipated effects of the proposed action and the measures needed to avoid, minimize, mitigate, or offset such effects.

In response to increased oversight of overall EFH program effectiveness by the Office of Management and Budget, NMFS established a quarterly reporting requirement to determine how many conservation recommendations are provided as part of each EFH consultation and how many are adopted by the action agency. Therefore, in your statutory reply to the EFH portion of this consultation, we ask that you clearly identify the number of conservation recommendations accepted. 


\section{Supplemental Consultation}

The BLM must reinitiate EFH consultation with NMFS if the proposed action is substantially revised in a manner that may adversely affect $\mathrm{EFH}$, or if new information becomes available that affects the basis for NMFS' EFH conservation recommendations (50 C.F.R. 600.920(k)).

\section{DATA QUALITY ACT DOCUMENTATION AND PRE-DISSEMINATION REVIEW}

Section 515 of the Treasury and General Government Appropriations Act of 2001 (Public Law 106-554) ("Data Quality Act") specifies three components contributing to the quality of a document. They are utility, integrity, and objectivity. This section of the Opinion addresses these Data Quality Act (DQA) components, documents compliance with the DQA, and certifies that this Opinion has undergone pre-dissemination review.

Utility: This ESA section 7 consultation on the proposed programmatic Integrated Pest Management program at the Travis Tyrrell Seed Orchard in Lane County, Oregon concluded that the action will not jeopardize the continued existence of OC coho salmon. Pursuant to the MSA, NMFS provided the BLM with conservation recommendations to conserve EFH. The intended user of this consultation is the BLM. The American public will benefit from the consultation.

This consultation will be posted on the NMFS Northwest Region web site (http://www.nwr.noaa.gov). The format and naming adheres to conventional standards for style.

Integrity: This consultation was completed on a computer system managed by NMFS in accordance with relevant information technology security policies and standards set out in Appendix III, "Security of Automated Information Resources," Office of Management and Budget Circular A-130; the Computer Security Act; and the Government Information Security Reform Act.

\section{Objectivity:}

\section{Information Product Category: Natural Resource Plan.}

Standards: This consultation and supporting documents are clear, concise, complete, and unbiased; and were developed using commonly accepted scientific research methods. They adhere to published standards including the NMFS ESA Consultation Handbook, ESA Regulations, 50 C.F.R. 402.01 et seq., and the MSA implementing regulations regarding EFH, 50 C.F.R. $600.920(j)$.

Best Available Information: This consultation and supporting documents use the best available information, as referenced in the literature cited section. The analyses in this conference opinion/EFH consultation contain more background on information sources and quality. 
Referencing: All supporting materials, information, data and analyses are properly referenced, consistent with standard scientific referencing style.

Review Process: This consultation was drafted by NMFS staff with training in ESA and MSA implementation, and reviewed in accordance with Northwest Region ESA quality control and assurance processes. 


\section{LITERATURE CITED}

Altenburger R., Backhaus T., Boedeker W., Faust M., Scholze M., and L. H. Grimme. 2000. Predictability of the Toxicity of Multiple Chemical Mixtures to Vibrio fischeri: Mixtures composed of Similarily Acting Chemicals. Environmental Toxicology and Chemistry. Vol. 19 pp. 2341-2347.

Arkoosh, M. R., E. Casillas, E. Clemons, B. B. McDain, and U. Varanasi. 1991. Suppression of immunological memory in juvenile Chinook salmon (Oncoryynchus tshawytscha) from an urban estuary. Fish and Shellfish Immunology 1:262-277.

Bailey H. C., Miller J. L., Miller M. J., Wiborg L. C., Deanovic L., and T Shed. 1997. Joint Acute Toxicity of Diazinon and Chlorpyrifos to Ceriodaphnia dubia. Environmental Toxicology and Chemistry. Vol. 16, No. 11, pp. 2304-2308.

BLM 2003. Draft Environmental Impact Statement for the Integrated Pest Management at the Tyrrell Seed Orchard.

BLM. 2004. Tyrrell Seed Orchard Biological Assessment.

Boon, J.P., Everaarts, J.M., Hillebrand, M.T.J., Eggens, M.L., Pijnenburg, J., and A Goksoyr. 1992. Changes in levels of hepatic biotransformation enzymes and haemoglobin levels in female plaice (Pleuronectes platessa) after oral administration of a technical polychlorinated biphenyl mixture (Clophen A40). The Science of the Total Environment. 114:113-133.

Broderius S.J., Kahl M.D., and M.D. Hoglund. 1995. Use of Joint Response to Define the Primary Mode of Toxic Action for Diverse Industrial Organic Chemicals. Environmental Toxicology and Chemistry. Vol. 14, No. 9, pp. 1591-1605.

Busby, P., S. Grabowski, R. Iwamoto, C. Mahnken, G. Matthews, M. Schiewe, T. Wainwright, R. Waples, J. Williams, C. Wingert, and R. Reisenbichler. 1995. Review of the status of steelhead (Oncorhynchus mykiss) from Washington, Idaho, Oregon, and California under the U.S. Endangered Species Act.

Busby, P. J., T. C. Wainwright, G. J. Bryant, L. J. Lierheimer, R. S. Waples, F. W. Waknitz, and I. V. Lagomarsino. 1996. Status review of west coast steelhead from Washington, Idaho, Oregon, and California. U.S. Department of Commerce, NOAA Technical Memo. NMFS-NWFSC

Casillas, E., J. E. Stein, M. R. Arkoosh, D. W. Brown, D. A. Misitano, S. L. Chan, and U Varanasi. 1993. Effects of estuarine habitat quality on juvenile salmon: I. Chemical Contaminant exposure and II. Altered growth and immune function. 
Caux, P.Y., R.A. Kent, G.T. Fan, and G.L. Stephenson. 1996. Environmental fate and effects of chlorothalonil: A Canadian perspective. Critical Reviews in Environmental Science and Technology 26(1):45-93.

Cox, Caroline. 1994. Dicamba. Herbicide fact sheet: Journal of Pesticide Reform. Vol 14, 1.6p.

DeLorenzo, M.E., Scott, G.I., and Ross, P.E. 2001. Toxicity of pesticides to aquatic microorganisms: A review. Environ. Toxicol. Chem. 20:84-98.

Denton D. L., Wheelock C. E., Murray S. A., Deanovic L. A., Hammock B. D., and D. E. Hinton. 2002. Joint Acute Toxicity of Esfenvalerate and Diazinon to Larval Fathead Minnows (Pimephales promelas) Environmental Toxicology and Chemistry. Vol. 22, No. 2, pp. 336-341.

Dodson, J.J. and Mayfield, C.I. 1979. The dynamics and behavioral toxicology of AquaKleen (2,4-D butoxyethanol ester) as revealed by the modification of rheotropism in rainbow trout. Trans. Am. Fish. Soc., 108: 632-640. Available at:

http://www.inchem.org/documents/ehc/ehc/ehc84.htm\#SubSectionNumber:6.2.6

EcoTrust. 2002. A watershed assessment for the Siuslaw Basin. Portland, Oregon. Available at http://www.inforain.org/siuslaw/index.htm. Accessed on April 25, 2002.

Faust, M., Altenburger, R., Backhaus, T., Blanck, H., Boedeker, ., Gramatica, P., Hamer, V., Scholze, M., Vighi, M., rimme, L.H., 2001. Predicting the joint algal toxicity of ulticomponent s -triazine mixtures at low-effect concentrations of individual toxicants. Aquatic Toxicology Vol. 56, pp.13-/32.

Faust, M., Altenburger, R., Backhaus, T., Blanck, H., Boedeker, W., Gramatica, P., Hamer, V., Scholze, M., Vighi, M.,Grimme, L.H., 2003. Joint algal toxicity of 16 dissimilarly acting chemicals is predictable by the concept of independent action. Aquatic Toxicology Vol. 63, pp.43-63.

Folmar, L.C. 1976. Overt avoidance reaction of rainbow trout fry to nine herbicides. Bulletin of Environmental Contamination and Toxicology 15:509-514.

Forget J., Pavillon J.F., Menasria M.R., Bocquene' G. 1998. Mortality and LC50 values for several stages of the marine copepod Tigriopus brevicornis (Mu“ller) exposed to the metals arsenic and cadmium and the pesticides atrazine, carbofuran, dichlorvos and malathion. Ecotoxicology and Environmental Safety vol.40 pp. 239-244.

Forget J., Pavillon J.F., Beliaeff B., and G. Bocquene. 1999. Joint Action of Pollutant Combinations (Pesticides and Metals) on Survival (LC50 values) and Acetylcholinesterase Activity of Tigriopus brevicornis (Copepoda, Harpacticoida). Environmental Toxicology and Chemistry. Vol. 18 pp. 912-918. 
Grande, M., S. Andersen, and D. Berge. 1994. Effects of pesticides on fish: Experimental and field studies. Norwegian Journal of Agricultural Sciences, Supplement 13:195-209.

Groot, C. And L. Margolis. 1991. Pacific Salmon Life Histories. University of British Columbia, Vancouver, BC, Canada. pp. 564.

Hardie, L.J., Fletcher, T.C., and C.J. Secombes. 1994. Effect of temperature on macrophage activation and the production of macrophage activating factor by rainbow trout (Oncorhynchus mykiss) leucocytes. Developmental and Comparative Immunology. 18: 57-66.

Heard, S. B. C. B. Gienapp, J. F. Lemire, and K. S. Heard. 2001. Transverse mixing of transported material in simple and complex stream reaches. Hydrobiologia 464:207-218

Hoagland, K.D., Carder, J.P., Spawn, R.L. 1996. Effects of organic toxic substances. Pages 469-496 In R.J. Stevenson, M.L. Bothwell and R.L. Lowe, editors. Algal ecology: freshwater benthic ecosystems. Academic Press, New York, N.Y. US.

Jacobs, S., J. Firman, and G. Susac. 2001. Status of Oregon coastal stocks of anadromous salmonids, 1999-2000: Monitoring Program Report Number OPSW-ODFW-2001-3, Oregon Depart of Fish and Wildlife, Portland, Oregon.

Jacobsen, K. C., M.R. Arkoosh, A.N. Kagley, and E.R. Clemons. Cumulative Effects of Natural and Anthropogenic Stress on Immune Function and Disease Resistance in Juvenile Chinook Salmon. Northwest Fisheries Science Center. Journal of Aquatic Animal Health: Vol. 15, No 1, pp 1-12.

Jenkins, J. J., P. Thomson, and D. Buchwalther. 1999. Pesticides and Groundwater Quality in Oregon. Report to the Oregon Department of Agriculture.

Klassen C.D. 1986. Principles of Toxicology. In: Klaassen C. D., Amdur M. O., and M. D. O'Doul, editors. Casarett and Doull's Toxicology, the Basic Science of Poisons. 3rd edition. New York: Macmillian Publishing Company.

Kraak M.H.S., Lavy D., Schoon H., Toussaint M., Peeters W.H.M.,Van Straalen N.M. 1994. Ecotoxicity of Mixtures of Metals to the Zebra Mussel (Dreissena polymorpha). Environmental Toxicology and Chemistry. 13:109-114.

Knoph, M.B. 1992. Acute toxicity of ammonia to Atlantic salmon (Salmo salar) parr. Comparative Biochemistry and Physiology 101C(2):275-282.

Kumaraguru, A.K., and F.W.H. Beamish. 1986. Effect of permethrin (NRCC-143) on the bioenergetics of rainbow trout, Salmo gairdneri. Aquatic Toxicology 9:47-58. 
Lee, K. K. 1995. Stream velocity and dispersion characteristics determined by dye tracer studies on selected stream reaches in the Willamette River Basin, Oregon. U.S. Geological Survey Water Resources Investigations Report 95-4078. Available at: http://oregon.usgs.gov/pubs_dir/pdf/95-4078.pdf. 48 p.

Lichatowich, J. A. 1989. Habitat alteration and changes in abundance of coho (Oncorhynchus kisutch) and Chinook (Oncorhynchus tshawyscha) salmon in Oregon's coastal streams, p. 92-99. In C. D. Levings, L. B. Holtby, and M. A. Henderson (editors), Proceedings of the National Workshop on Effects of Habitat Alteration on Salmonid Stocks, May 6-8, 1987, Nanaimo, B.C. Can. Spec. Publ. Fish. Aquat. Sci. 105.

Little EE, Archeski RD, Flerov BA, Kozlovskaya VI. 1990. Behavioral indicators of sublethal toxicity in rainbow trout. Arch. Environ. Contam. Toxicol. 19(3):380-385.

Little, E.E., F.J. Dwyer, and J.F. Fairchild. 1993. Survival of bluegill and their behavioral responses during continuous and pulsed exposures to esfenvalerate, a pyrethroid insecticide. Environmental Toxicology and Chemistry 12:871-878.

Lorz, H.W., S.W. Glenn, R.H. Williams, M. Clair, and L.A. Norris. 1979. Effects of selected herbicides on smolting of coho salmon. EPA/600/3-79/071. Research and Development Section, Oregon Department of Fisheries and Wildlife. Corvallis, OR.

Marking LL. 1985. Toxicity of Chemical Mixtures. In Rand GM, Petrocelli SR (eds), Fundamentals of Aquatic Toxicology. Mcgraw-Hill, New York, New York. 164-176.

Mayer, F.L., and M.R. Ellersieck. 1986. Manual of acute toxicity: Interpretation and data base for 410 chemicals and 66 species of freshwater animals. Resource Publication 160. U.S. Fish and Wildlife Service. Washington, DC.

McClure, M., B. Sanderson, E. Holmes, C. Jordan, P. Kareiva, and P. Levin. 2000. A standardized quantitative analysis of the risks faced by salmonids in the Columbia River basin. Draft Report dated April 7, 2000. National Marine Fisheries Service, Northwest Fisheries Science Center, Cumulative Risk Initiative, Seattle, Washington. 125 pp. + appendices.

McCullough, D.A. 1999. A review and synthesis of effects of alterations to the water temperature regime on freshwater life stages of salmonids, with special reference to Chinook salmon. U.S. EPA. Seattle, WA.

McElhany, P., M. Ruckleshaus, M. J. Ford, T. Wainwright, and E. Bjorkstedt. 2000. Viable Salmon Populations and the Recovery of Evolutionarily Significant Units. U. S. Department of Commerce, National Marine Fisheries Service, Northwest Fisheries Science Center, NOAA Technical Memorandum NMFS-NWFSC-42. 156 p. http://www.nwfsc.noaa.gov/publications/techmemos/tm42/tm42.pdf 
Minshall, G.W. 1978. Autotrophy in stream ecosystems. BioScience 28:767-771.

Moore, A., and C.P. Waring. 2001. The effects of a synthetic pyrethroid pesticide on some aspects of reproduction in Atlantic salmon (Salmo salar L.). Aquatic Toxicology 52:112.

Morgan, M.J., and J.W. Kiceniuk. 1992. Response of rainbow trout to a two month exposure to Vision ${ }^{\circledR}$, a glyphosate herbicide. Environmental Contamination and Toxicology 48:772780.

Murphy, M.L. 1998. Primary production. Pages 144-168 In R. J. Naiman and R. E. Bilby, editors. River ecology and management: lessons from the Pacific coastal ecoregion. Springer-Verlag, New York, N.Y., USA.

Myers, J. M., R. G. Kope, G. J. Bryant, D. Teel, L. J. Lierheimer, T. C. Wainwright, W. S. Grant, F. W. Waknitz, K. Neely, S. T. Lindley, and R. S. Waples. 1998. Status review of Chinook salmon from Washington, Idaho, Oregon, and California. U.S. Department of Commerce, NOAA Technical Memo. NMFS-NWFSC.

Nickelson, T.E., J.W. Nicholas, A.M. McGie, R.B. Lindsay, D.L. Bottom, R.J. Kaiser, and S.E. Jacobs. 1992. Status of anadromous salmonids in Oregon coastal basins. Oregon Department of Fish and Wildlife, Research Development Section and Ocean Salmon Management, 83 p. Oregon Department of Fish and Wildlife, P.O. Box 59, Portland.

NMFS (National Marine Fisheries Service). 1996. Factors for Decline: A Supplement to the notice of determination for West Coast steelhead. Habitat Conservation Program, Portland, Oregon.

NMFS (National Marine Fisheries Service). 2003. Preliminary conclusions regarding the updated status of ESUs of West Coast salmon and steelhead (draft). http://www.nwr.noaa.gov/BRTdraftreport/BRTdraftreport.html

NMFS. 1999. The Habitat Approach: Implementation of Section 7 of the endangered Species Act for Actions Affecting the Habitat of Pacific Anadromous Salmonids.

NMFS. 1996. Making Endangered Species Act Determinations of Effect for Individual or Grouped Actions at the Watershed Scale. Environmental and Technical Service Division. Habitat Conservation Branch.

NRC (National Research Council). 1996. Upstream-Salmon and Society in the Pacific Northwest. National Academy Press, Washington, D.C. 452 p.36

Norris, L.A., Lorz, H.W., and S.V. Gregory. 1991. Forest Chemicals. American Fisheries Society Special Publication 19:207-295. 
Oregon Department of Forestry. 1997. Forest chemical monitoring program. November 1997. Salem, OR.

ODFW (Oregon Department of Fish and Wildlife). 2001. Annual estimate of wild coho spawner abundance in coastal river basins within the Oregon Coastal ESU, 1990-2000. Found at <http://osu.orst.edu/Dept/ODFW/spawn/coho.htm> under Stratified Random Sampling Estimates for Coastal River Basins 1990-2000. Accessed on December 27 , 2001.

ODFW (Oregon Department of Fish and Wildlife). 2002. Preliminary estimated coho spawner abundance 2001 spawning season. Found at $<$ http://osu.orst.edu/Dept/ODFW/spawn/coho.htm> under Estimates of 2001 Spawner abundance in Coastal Rivers Preliminary. Accessed on April 24, 2002.

ODFW (Oregon Department of Fish and Wildlife). 2003. Estimated coho spawner abundance. 2002 spawning season. ODFW website.

Pape-Lindstrom P. A., and M. J. Lydy, 1997. Synergistic Toxicity of Atrazine and Organophospate Insecticides Contravenes the Response Addition Mixture Model. Environmental Toxicology and Chemistry. Vol. 16, No. 11, pp. 2415-2420.

PFMC (Pacific Fishery Management Council). 1999. Amendment 14 to the Pacific Coast Salmon Plan. Appendix A: Description and Identification of Essential Fish Habitat, Adverse Impacts and Recommended Conservation Measures for Salmon. Portland, Oregon.

Pratt, J.R., Melendez, A.E., Barreiro, R., and N.J. Bowers. 1997. Predicting the ecological effects of herbicides. Ecological Applications. 7:1117-1124.

Preston, B.L. 2002. Indirect effects in aquatic ecotoxicology: implications for ecological risk assessment. Environmental Management 29:311-323.

Randall, D.J. and T.K.N. Tsui. 2002. Ammonia Toxicity in fish. Marine pollution bulletin. Vol. 45 , no. $1-12$, pp. 17-23.

Rashin, E., and C. Graber. 1993. Effectiveness of Conservation Practices for Aerial Application of Forest Practices. Prepared for the Timber/Fish/Wildlife Cooperative Monitoring Evaluation and Research Committee. Olympia, WA. Ecology Publication No. 93-81.

Rice, S.D., and J.E. Bailey. 1980. Survival, Size, and Emergence of Pink Salmon, Oncorhynchus gorbuscha, Alevins after Short- and Long-term Exposures to Ammonia. Natl. Mar. Fish. Serv., Northwest and Alaska Fish. Cent., Fish. Bull. 78:641-648. 
Renz, J. 2004 - pers. com. 4/14/04. OR Dept. Of Land Conservation and Development.

Rouse, J.D., C.A. Bishop, and J. Struger. 1999. Nitrogen pollution: An assessment of its threat to amphibian survival. Environmental Health Perspectives 107(10):799-803.

Ruffier, P.J., W.C. Boyle, and J. Kleinschmidt. 1981. Short-term acute bioassays to evaluate ammonia toxicity and effluent standards. Journal of the Wastewater Pollution Control Federation 53: 367-377.

Sharma SS, Schat H, Vooijs R, Van Heerwaarden LM. 1999. Combination toxicology of copper, zinc and cadmium in binary mixtures: Concentration-dependent antagonistic, nonadditive, and synergistic effects on root growth in Silene vulgaris. Environmental Toxicology and Chemistry 18:348-355.

Shires, S.W. 1983. The use of small enclosures to assess the toxic effects of cypermethrin on fish under field conditions. Pesticide Science 14:475-480.

Sipes I. G. and A. J. Gandolfi. 1986. Biotransformation of Toxicants. In: Klaassen C. D., Amdur M. O., and M. D. O’Doul, editors. Casarett and Doull's Toxicology, the Basic Science of Poisons. 3rd edition. New York: Macmillian Publishing Company.

Spence, B C. , G.A. Lomnicky, R.M. Hughes, and R.P. Novitzki, 1996. An ecosystem approach to salmonid conservation. TR-4501-96-6057. ManTech Environmental Research Services Corp., Corvallis, OR.

Soderberg, R.W., J.B. Flynn, and H.R. Schmittou. 1983. Effects of ammonia on growth and survival of rainbow trout in intensive static-water culture. Transactions of the American Fisheries Society 112: 448-451.

Scholz, N.L., N.K. Truelove, B.L. French, B.A. Berejikian, T.P. Quinn, E. Casillas, and T.K. Collier. 2000. Diazinon disrupts antipredator and homing behaviors in Chinook salmon (Oncorhynchus tshawytscha). Canadian Journal of Fisheries and Aquatic Science 57(9):1911-1918.

SERA (Syracuse Environmental Research Associates, Inc.). 1997. Effects of surfactants on the toxicity of glyphosate, with specific reference to Rodeo. Prepared for USDA Forest Service under Contract No. 53-3187-5-12. USDA Animal and Plant Health Inspection Service, Riverdale, MD.

SERA (Syracuse Environmental Research Associates, Inc.). 2003. Triclopyr - revised human health and ecological risk assessments final report. Prepared for USDA Forest Service under Contract No. GS-10F-0082F. USDA Forest Service, Arlington, VA. 
Stark, J.D. and W.K. Walthall. 2003. Agricultural adjuvants: Acute mortality and effects on population growth rate of Daphnia pulex after chronic exposure. Environmental Toxicology and Chemistry. 22: 3056-3061.

Steelquist, R. 1992. Field guide to the Pacific salmon. Sasquatch Books. Seattle, WA.

Urban, D. J. and N.J. Cook. 1986. Hazard evaluation division, standard evaluation procedure, ecological risk assessment. U.S. Environmental Protection Agency, Washington, D.C. Publication \#PB86-247657.

Uniroyal Chemical Company. 1998. Material safety data sheet: Omite ${ }^{\circledR}$ CR. Middlebury, CT.

U. S. Bureau of Land Management. 2004. Biological Assessment for Integrated Pest Management at the Travis Tyrrell Seed Orchard.

U. S. Bureau of Land Management. 2003. Draft Environmental Impact Statement for the Integrated Pest Management at Travis Tyrrell Seed Orchard.

U. S. Bureau of Land Management. 2002. Risk Assessment of Pesticides and Fertilizers Proposed for Use at Tyrrell Seed Orchard. Lorane, OR Eugene District.

U. S. Environmental Protection Agency. 1986. Quality criteria for water 1986. (EPA 440/5-86001). Washington, DC.

U. S. Environmental Protection Agency. 1993. Registration Eligibility Decision (RED): Glyphosate. Office of Prevention, Pesticides, and Toxic Substances. Publication: 738-R93-014. 109p.

U. S. Environmental Protection Agency. 1999. Update of Ambient Water Quality Criteria for Ammonia (EPA-822-R-99-014). Washington, DC.

U.S. Environmental Protection Agency. 2000. Reregistration eligibility science chapter for chlorpyrifos: Fate and environmental risk assessment chapter. Office of Pesticide Programs. Washington, DC.

U.S. Environmental Protection Agency. 2001. Ecotox: Ecotoxicology database. Office of Research and Development, National Health and Environmental Effects Research Laboratory, Mid-Continent Ecology Division. Duluth, MN.

U.S. Environmental Protection Agency. 1999. Environmental Fate and Effects Division's revised chapter for the dimethoate RED. Office of Pesticide Programs. Washington, DC. 
U.S. Geological Survey. 1999. The quality of our nation's waters - nutrients and pesticides.

U.S. Geological Survey Circular 1225, 82 p. Available at:

http://pubs.usgs.gov/publications/1999/

USFWS. 1980. Johnson, W.W. and Finley, M. T. Handbook of acute toxicity of chemicals to fish and aquatic invertebrates. Resource Publication 137. $106 \mathrm{pp}$.

USDA Forest Service. 2001. Pesticide Fact Sheets. 2,4-D. At:

http://www.infoventures.com/e-hlth/pestcide/pest-fac.html. Accessed November, 2001.

Valent USA Corporation. 1983. 96-hour aquatic toxicity study in rainbow trout and bluegill sunfish with 70 Orchard Spray. Walnut Creek, CA. Performed by Gulf Life Sciences Center. Pittsburg, PA.

Vannote, R.L., Minshall, G.W., Cummins, K.W., Sedell, J.R., and C.E. Cushing. 1980. The river continuum concept. Can. J. Fish. Aquat. Sci. 37:130-137.

Weed Science Society of America. 1983. Herbicide Handbook. 5th ed. Champaign IL.

Weis, J. S., G. Smith, T. Zhou, C. Santiago-Bass, and P. Weis. 2001. Effects of contaminants on behavior: biochemical mechanisms and ecological consequences. BioScience 51

(3):209-217.

Weitkamp, L.A., T.C. Wainwright, G.J. Bryant, G.B. Milner, D.J. Teel, R.G. Kope, and R.S. Waples. 1995. Status review of coho salmon from Washington, Oregon, and California. U.S. Dep. Commer., NOAA Tech. Memo. NMFS-NWFSC-24, 258 p.

Woods M., Kumar. A, and R. Correll. 2002. Acute Toxicity of Mixtures of Chlorpyrifos, Profenofos, and Endosulfan to Ceriodaphnia dubia. Bulletin of Environmental Contamination and Toxicology. Vol. 68 pp. 801-808

Woodward D.F. 1976. Toxicity of the herbicides dinoseb and picloram to cutthroat (Salmo clarki) and lake trout (Salvelinus namaycush). J Fish Res Board Can 33(8): 1671-1676. Abstract available at: http://link.springer.de/forum.htm.

Woodward, D.F. 1982. Acute toxicity of mixtures of range management herbicides to cutthroat trout. Journal of Range Management 35(4):539-540. 




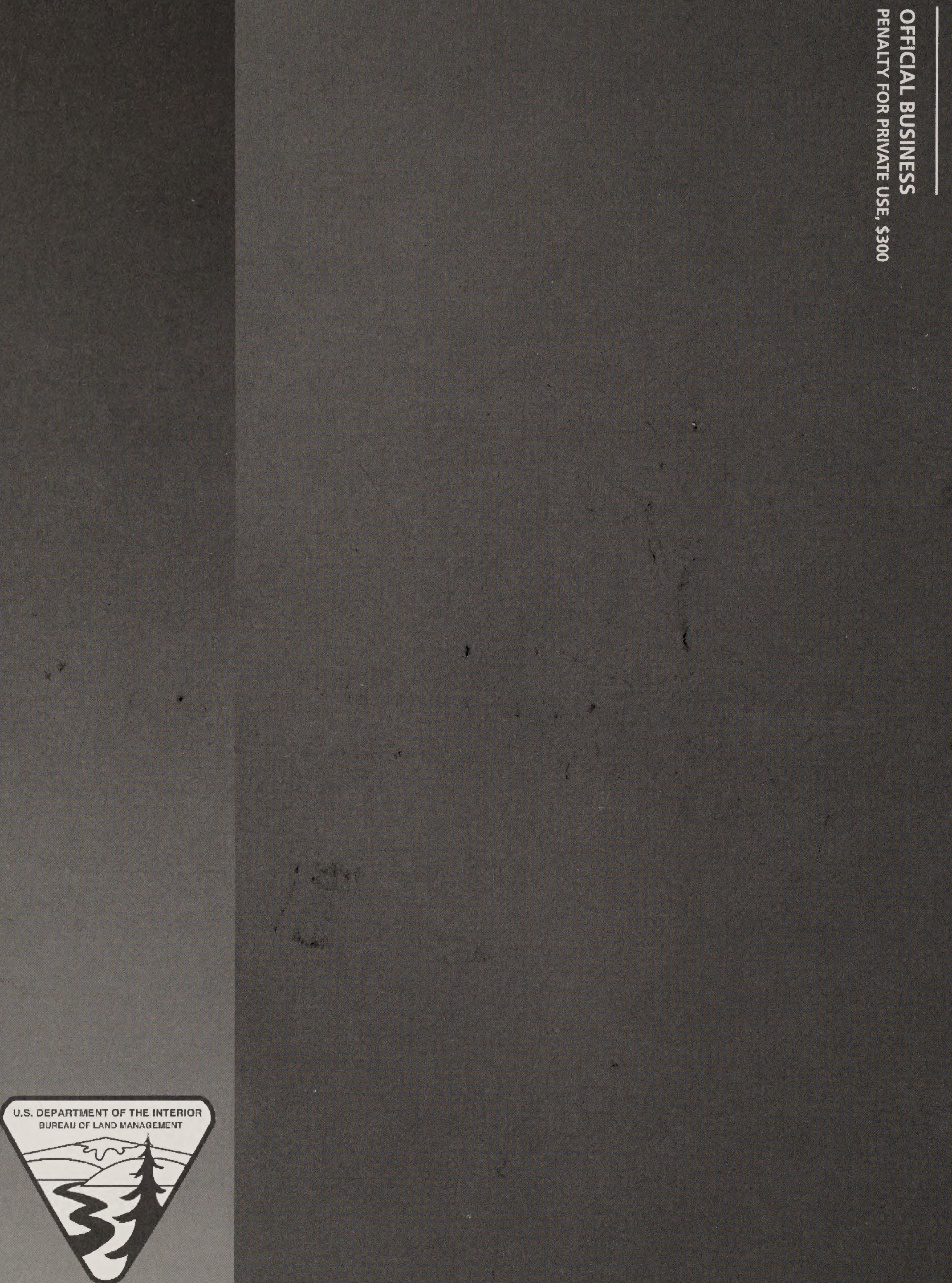

\section{UNITED STATES}

DEPARTMENT OF THE INTERIOR

BUREAU OF LAND

MANAGEMENT

Eugene District Office

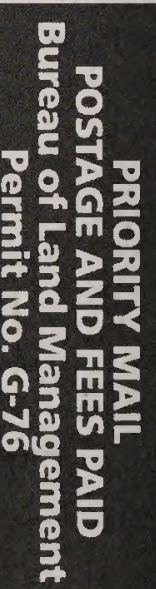

